\author{
A Dissertation \\ Presented to the Faculty of the Graduate School \\ of Cornell University \\ In Partial Fulfillment of the Requirements for the Degree of \\ Doctor of Philosophy
}

by

Gregg Thomas Lightfoot

May 2015 
(C) 2015 Gregg Thomas Lightfoot 


\title{
MANIFESTING DESTINY ON CUBAN SHORES: NARCISO LÓPEZ, CUBAN ANNEXATION AND THE PATH OF AMERICAN EMPIRE, 1800-1859
}

\author{
Gregg Thomas Lightfoot Ph.D.
}

Cornell University 2015

\begin{abstract}
Manifesting Destiny tells the story of the Narciso López's filibustering attempts in Cuba (18481851) set against the backdrop of long-term American interest in the island and discusses the fluid economic and social contexts in early nineteenth century Cuba and the United States. The study focuses on the importance given Cuba by the collective American consciousness and highlights the various arguments made for the necessity and permissibility of annexation of the island. Beyond just a sectional Southern concern as traditionally posited by many analysts of the period, the annexation of Cuba was an abiding and obsessive national American concern that reflected deeply-held beliefs about the nature and magnanimity of American democracy as well as the nation's destinarian exceptionalism. Incorporation of Cuba and Cubans, set apart in the American imagination from the rest of South America and the Caribbean, promised a conservative transfer of power and fulfillment of the reserved revolution that many believed was the hallmark of American exceptionalism. Americans took a paternalistic view of the Cuban people - reduced to political dependence by the Spanish - and offered political and moral guidance to the island's population. The Northern and Southern American business class along with elite Cuban creoles saw in their annexation plans a means to strengthen the longstanding and lucrative economic ties between the two societies. The presence of an aggressive British abolitionary influence in the Caribbean coupled with attendant fears of racialized revolution in
\end{abstract}


Cuba energized the annexation movement and encouraged filibustering activities as expedient alternatives to lethargic official negotiations for purchase of the island. Despite filibustering's seemingly chaotic planning and destabilizing repercussions, those intellectually and economically guiding the effort saw in their efforts an easily controllable leader in Narciso López, a willing and receptive Cuban population, and an agreeable American public bolstered by a robust business class' encouragement. All of these attributes augured well for a quick, limited, and manageable annexation with no disruption to either Cuba's slavery system or the domestic society built upon it. This study explores these themes and their implications by examining the literary, economic, and political landscapes of both the United States and Cuba contained within the pages of diplomatic and popular literary sources of the period. 


\section{BIOGRAPHICAL SKETCH}

Gregg Lightfoot earned his B.A. in History and Secondary Education from the University of Miami, Florida in 1995. Mr. Lightfoot completed his M.A. in United States History from the University of Miami, Florida in 2002 under thesis director Edward Baptist. Apart from various lapses into the academic world, he has spent most of his professional life teaching inside high school classrooms. His longtime interest in relations between Cuba and the United States comes from spending much of his life in the vibrant, arresting, and at times perplexing Miami milieu. Ithaca, New York was quite a change. 
To Elizabeth and Ann 


\section{ACKNOWLEDGMENTS}

Many thanks are due the various people who collectively and individually offered advice, guidance, and support throughout my thinking and writing process. First to my committee Edward Baptist, Derek Chang, Ray Craib, and Mary Roldán - I offer my thanks for your insights, your encouragement, and your patience. Each of you, with your own style, offered the perfect mixture of independence and expectation throughout the process. To my friends and colleagues who offered sympathetic ears and shoulders throughout my time in Ithaca and beyond, your support meant the world to me and was the foundation upon which I built my hopes of finishing this project. Each of you, through your own endeavors, challenges, and successes demonstrated for me the worth of determined effort and focus. As you all have shared my frustrations with kindness, compassion, and encouragement, I too share the joy of my success with all of you. And finally, my family, those of blood and those of commitment, whose constant dedication to my success carried me through the roughest angst-ridden moments, I thank you with a depth and debt of gratitude that I will never be able repay. 


\section{TABLE OF CONTENTS}

Introduction - Annexation as National Progress 1

1. The Pillars of Policy 23

2. Early Cuban Political Economy 100

3. The Intellectual Framework and Popular Contours of Annexation 181

4. The Great Imagining $\quad 245$

5. American Vistas on the Failure of Annexation 336 


\section{Introduction: Annexation as National Progress}

...Such scenes that Eastern plant awakes;

But we have one ordained to beat it,

The Haschish of the West, which makes

Or fools or knaves of all who eat it.

The preacher eats, and straight appears

His Bible in a new translation;

Its angels negro overseers,

And Heaven itself a snug plantation!

The man of peace, about whose dreams

The sweet millennial angels cluster,

Tastes the mad weed, and plots and schemes,

A raving Cuban filibuster!

The noisiest Democrat, with ease,

It turns to Slavery's parish beadle;

The shrewdest statesman eats and sees

Due southward point the polar needle.

The Judge partakes, and sits erelong

Upon his bench a railing blackguard;

Decides off-hand that right is wrong, And reads the Ten Commandments backward.

O potent plant! So rare a taste

Has never Turk or Gentoo gotten;

The hempen Haschish of the East

Is powerless to our Western Cotton!

"The Haschish" - From Anti-Slavery Poems: Songs of Labor and Reform by John Greenleaf Whittier

Narciso López died on September 1, 1851 at half past one in the middle of Havana's sundrenched town square. The death sentence by garroting, ordered by Spanish officials, was in response to López's attempted overthrow of the Spanish government in Cuba. General López's death brought to an end the meteoric rise of one of the most extravagant, popular, and since forgotten personas of the early American republic. López's final expedition of 1851 marked the high point in the United States of popular support for cohesive efforts to annex Spain's mosttreasured possession. Cuba's incorporation into the United States, beyond the event's immediate 
geopolitical effects, promised the fulfillment of a perceived American national duty driven to leadership of democracy's expansion throughout the Western Hemisphere. The obvious economic self-interest present in the pursuit of Cuba, while acknowledged by many involved in the efforts, received secondary emphasis in deference to the mighty narrative of benign intent and benevolent consequences. The immediate societal dividends of Cuban annexation held allure for Americans who believed that the island promised a way out of sectional issues engulfing the antebellum political landscape. Many American observers believed that Southern planters and politicians - a budding Caribbean empire within their grasp - might be in a more amenable mood regarding compromise on the slavery question if they were successful in preserving and profiting from Cuban slavery. Ambrosio Gonzales, one of López's lieutenants, asserted the peacemaking potential of Cuban annexation in a lyrically reminiscing article published in the New Orleans

\section{Times-Democrat.}

As I consider you the recognized friend and advocate of the Latin-American race, I am more than willing to pay, through you, this tribute of gratitude to the noble spirits who have, in this section of the country, sacrificed their fortunes and their lives for the cause of the Union, of the South and of civil liberty, giving you what I can remember of the incidents connected with the inception and development of this episode of our American history: one imperfectly understood and greatly misinterpreted. The effort on behalf of Cuban annexation was the natural outcome of two political forces. On the one hand, the South, frustrated in its expectation of obtaining additional States out of the territory acquired from Mexico, needed the annexation of Cuba in order to maintain an equilibrium with the North in the Senate; and, on the other hand, the Cubans, oppressed with taxation, thirsting for political freedom and fearing for the preservation of their property, sighed for independence and consequent annexation. Had success attended the effort of American statesmanship and Cuban patriotism, the Union would have been strengthened and our civil war would have been averted. No wonder, then, that so many of the best and most farseeing men in the country, in every section, some reflectively, others instinctively, were the friends of Cuban annexation. ${ }^{1}$

\footnotetext{
${ }^{1}$ Ambrosio Gonzalez, "Liberation of The Gem Of The Antilles: An Interesting Account of This Initial Movement from Gen. Ambrosio Jose Gonzalez, Second in Command to Gen. Lopez," New Orleans Times Democrat, March $10,1884$.
} 
Defeat of the various Cuban annexationary schemes, bringing with it the disappearance of hopeful compromise on the slavery question, invited a pessimism that became pervasive in the United States after 1854.

While this work does not simply retell the age-old narrative of the United States' magnificent expansionism, the always imprecise concept of America's self-perceived mission in the world underlies much of the period's action and debate. Manifest destiny, a widely held but vaguely defined belief system, embraced several core beliefs that many Americans used, in varying ways, as shorthand for their understood responsibilities in leading the budding democratic family of the Western Hemisphere. First, many Americans believed that the strength of their values and institutions justified moral claims to leadership. Second, the lands on the North American continent west of the Mississippi River and in the Caribbean were destined for political and agricultural improvement helmed by the United States. Third, Americans who supported expansion believed that God and the Constitution ordained an irrepressible destiny to redeem and democratize the world. Chief among the practitioners of the confidence shown in the democratic experience was a group of up-and-coming politicians, editors, and businessmen. The Young America movement, strongest among members of the Democratic Party but spanning the political spectrum, downplayed divisions over slavery and ethnicity by embracing national unity and emphasizing American exceptionalism, territorial expansion, democratic participation, and economic interdependence. Ralph Waldo Emerson captured the political outlook of this new generation in a speech he delivered in 1844 entitled "The Young American."

In every age of the world, there has been a leading nation, one of a more generous sentiment, whose eminent citizens were willing to stand for the interests of general justice and humanity, at the risk of being called, by the men of the moment, chimerical and 
fantastic. Which should be that nation but these States? Which should lead that movement, if not New England? Who should lead the leaders, but the Young American? ${ }^{2}$

However, the confidence displayed by Emerson and others in the abilities of this cadre of young leaders was not necessarily shared by all. Many Americans disapproved of aggressive expansion. For opponents of manifest destiny, the lofty rhetoric of the Young Americans was nothing other than a kind of American imperial policies that the American Revolution supposedly repudiated. Many members of the Whig Party (and later the Republican Party) argued that the United States' mission was to lead by example, not by conquest. Abraham Lincoln summed up this criticism with a fair amount of sarcasm during a speech in 1859 .

He (the Young American) owns a large part of the world, by right of possessing it; and all the rest by right of wanting it, and intending to have it...Young America had "a pleasing hope - a fond desire - a longing after" territory. He has a great passion - a perfect rage - for the "new"; particularly new men for office, and the new earth mentioned in the revelations, in which, being no more sea, there must be about three times as much land as in the present. He is a great friend of humanity; and his desire for land is not selfish, but merely an impulse to extend the area of freedom. He is very anxious to fight for the liberation of enslaved nations and colonies, provided, always, they have land... As to those who have no land, and would be glad of help from any quarter, he considers they can afford to wait a few hundred years longer. In knowledge he is particularly rich. He knows all that can possibly be known; inclines to believe in spiritual trappings, and is the unquestioned inventor of "Manifest Destiny."3

Despite the biting critique, Lincoln and other anti-expansionists struggled against the tide of popular opinion. The excitement of democratic territorial expansion in the wake of the contentious Mexican-American War consumed the press and the public. However, lost in the

\footnotetext{
${ }^{2}$ Ralph Waldo Emerson, “The Young American,” accessed March 12, 2011, http://www.emersoncentral.com/ youngam.htm. Brady Harrison "The Young Americans: Emerson, Walker and the Early Literature of American Empire," American Studies 40, no.3 (Fall 1999), 75-97, reviews the importance of Emerson and the Young America movement to William Walker's efforts at filibustering to Nicaragua. The Cuba Joven movement allied with many Young Americans in their efforts at annexation of Cuba.

${ }^{3}$ Abraham Lincoln, "Second Lecture on Discoveries and Inventions before the Phil Alpha Society at Illinois College, Jacksonville, Illinois, February 11, 1859," accessed February 15, 2012, http://www.abrahamlincolnonline .org/lincoln/speeches/ discoveries.htm. Robert May discusses a variety of Lincoln's speeches in reference to direct critiques of Stephen Douglas' positions and veiled references to his own views on U.S. Caribbean policy in May, Slavery, Race, and Conquest in the Tropics: Lincoln, Douglas, and the Future of Latin America (Cambridge: Cambridge University Press, 2013), 160-190.
} 
debates over adding the western lands to the growing United States, and the historical retelling of this tale, was the near fanatical enthusiasm for adding Cuba to the American nation. Many Northern businessmen and Southern slaveowners supported the idea of expansion of American power and slavery into the Caribbean as a useful alternative to continental expansion. Since slavery already existed in Cuba, as did weighty American influence, a public relations juggernaut sought to explain away charges from critics of Cuban annexation as simple imperialism coupled with abrogation of American diplomatic responsibilities.

Regardless of the great antebellum interest in acquiring Cuba, annexation's impact on the era's decision-making remains largely outside the national narrative. The avoidance of Cuba's inclusion in the antebellum discussion exists largely because the fanciful attempts at Cuban annexation, all exhibiting a decided lack of operational success, seem only an amusing sidelight among weightier political maneuvering. Further complicating the issue is the strong belief that López's attempts to secure the island's freedom were but further examples of the robust antebellum ideology of territorial plunder coupled with the expansion of slavery that exhibited an American society beholden to slave-power conspiracy. ${ }^{4}$ These perspectives push many historians toward viewing López, his supporters, and support for Cuban annexation at the beginning of the 1850s as a similarly Southern-guided exercise in hopes of securing slavery’s spread. However, this dissertation asserts that López and his American supporters represented a significant break

\footnotetext{
${ }^{4}$ Cuban freedom as opposed to annexation is a purposeful choice. While many Americans clearly advocated annexation to the U.S. as Cuba's only pathway to freedom, López and some prominent Cubans were less direct in what freedom meant. López's American supporters often used this ambiguity to their advantage in sidestepping the issue of what came next after López's victory in deference to language extolling the role the United States should play in expanding democracy throughout the Caribbean. Herminio Portell-Vilá's, López's most comprehensive biographer, asserts that López was not an annexationist but rather sought independence for the island. Tom Chaffin, the most thorough English language discussant of López's actions and intentions rejects this assertion. "Even if López had privately nursed dreams of independent Cuba, if he had been victorious, it still seems unlikely that he would have been able to arrest the trajectory of the movement away from annexation... His campaign lived and died as an annexationist movement" Chaffin, Fatal Glory: Narciso López and the First Clandestine U.S. War Against Cuba (Charlottesville: UVA Press, 1996), 223-224, n. 4.
} 
with the prevailing notions of manifest destiny on display during the Mexican-American War. López and his supporters harnessed an ideological approach toward expansion that connected their efforts to those of the lauded American revolutionists of the early national period. The break represented by the $1848-1851$ period is one in which many hopeful annexationists and their political supporters saw Cuban annexation as the key to an alternative path away from sectionalism and war. This brief period - wedged between two rancorous decades, each culminating with massive military undertakings - saw the confluence of literary and political streams of thought that envisioned a union buoyed by the expansion of democracy throughout the hemisphere coupled with the refusal to discuss the issue of slavery in relation to that expansion. Cubans stood similarly motivated by the hope of annexation and the selfdeterminative political future promised by freedom from Spain and kinship with the American family.

This dissertation urges a reevaluation of Cuban annexation as a moment of shared political and economic ambition between elements of the North and South as well as a geopolitical and socio-economic amalgamation of Cuban and American boosterism. This work argues for an expansive view of López's intentions and his base of support. Furthermore, the subsequent failure of Cuban annexation represented a significant historical rupture resultant from the immense expectations placed on annexation's presumed success. The psychosocial toll taken by annexation's failure weighed most-heavily upon American shoulders since this failure represented irreconcilable ideological contradictions inherent in the ideas of manifest destiny and, more profoundly, United States national foundation. Many Americans - long-believing themselves both honorable in their intentions and disinterested in aggrandizement - saw expansion as naturally assumed, mutually beneficial, and providentially ordained. American 
citizens of numerous political stripes and their representative policymakers alike, felt United States foreign policy to be both magnanimous and devoid of self-interest. However, failure to spread this religion of democracy to Cuba represented a failure of the American national self to reckon with the original Constitutional paradox of liberty and slavery. Cuban annexation was a last ditch effort to avoid conflict and soothe anxiety by extolling the abilities of white men of all social classes in crafting their own places in the rapidly expanding capitalism of the Atlantic world. However, in contrast to the maniacal importance Americans invested in the cause, many Cubans supportive of annexation embraced the failure of these efforts as an important pivot point rather than a crisis moment. The spectacular failure of American guidance demonstrated for many Cubans both the necessity to unify internally in the face of Spanish colonialism and to redouble their efforts toward freedom with focus aimed toward internal sources of support rather than toward external redemption. Cubans saw annexation as but one of numerous pathways toward self-determination and satisfaction of their demands for participation in the Caribbean's geopolitical democratization.

The developing Cuban struggle against the Spanish - one based upon a perceived lack of protection for slavery and rationalized commercial exchange on the island - was, in the minds of American and Cuban capitalists, an encumbrance to the practice of economic and political liberty. These capitalists argued Cuba, in its Spanish-dominated condition and despite massive American investment, was moribund in the face of more generalized Atlantic agricultural modernization. They further lamented that the island, while benefitting from an imposed social stability, lacked an infrastructure of rational economic exchange and struggled with a tight market supply of commodifiable labor. Beyond economics, annexationists believed the Spanish presence in Cuba rendered the island impotent thanks to imperial prevention of political freedom 
- a belief bolstered by a fair amount of American anti-Catholic sentiment. To address these concerns, Cuban and American annexationists held forth a relatively consistent approach toward a solution - a solution that at all moments demanded Spanish exit from the island.

Supporters of annexation chose filibustering as the preferred means to take Cuba. Filibustering was privately financed schemes of varying degrees of operational reality directed at capturing and occupying foreign territory without the approval of the United States government. This extralegal approach toward expansion was a robust phenomenon of the antebellum period that offered Americans of all socio-economic classes the opportunity to experience an everdeveloping sense of United States nationalism. This expansion merged rhetorical ideas of race, gender, religion, and economics into dynamic action while simultaneously locating the foundation of United States national strength in foreign locales. Filibustering adventures took greatest hold in the imagination of those Americans who looked toward Cuba with particular interest. Fears of racialized revolution in Cuba (as in Haiti before it) as well as the presence of an aggressive British abolitionary influence in the Caribbean energized the movement to annex Cuba and encouraged filibustering activities as expedient alternatives to lethargic official negotiations. Despite filibustering's seemingly chaotic planning and destabilizing repercussions, those intellectually and economically guiding the effort saw in their efforts a willing and receptive Cuban population and an agreeable American business class.

Filibustering encouraged Americans to put their intellectual, social, and cultural mantras into practice. These private adventures offered lower-class men avenues of direct participation in the implementation of a political and cultural design that simultaneously offered a rising bourgeoisie the opportunity to gain and use their own economic and political influence. These combined efforts placed political and economic pressure on national policymakers through 
popular action and private cajoling. Filibustering expeditions offered a doubly compelling vision for supporters and participants alike. First, these expeditions fed an aggressive vision of white masculinity imbued with a martial strength for men struggling with shifting societal gender roles. Second, the aggrandizement of the United States offered a potent tonic to many who saw the nation under threat from atomizing sectionalism. The filibustering swashbuckler captured the imagination of men from all walks of life. The duel between militaristic manliness and a more restrained model of masculinity contributed to the continuing viability of the idea of manifest destiny and its redefinition in the wake of the Mexican-American war.

This work considers a confluence rather than a divergence of these manhood styles. While Southern and Northern political, social, and cultural ideologies became increasingly exclusionary and combative, I look at the 1848-1851 period as one in which the restrained and the martial merged in a particularly powerful and strangely settling attempt toward navigating sectional dispute. Detractors saw a disingenuous attempt to disguise Southern ambitions. However, practitioners of the pro-annexation media assault argued that Cuban freedom would play a large role in restoring male autonomy and virility lost in the wake of modernizing and feminizing American society. ${ }^{5}$ Filibustering, while illegal, nevertheless allowed men to assert their virility by claiming their own piratical independence from the emasculating forces of

\footnotetext{
${ }^{5}$ Amy S. Greenberg, Manifest Manhood and the Antebellum American Empire (Cambridge: Cambridge University Press, 2005). Greenberg foregrounds gender in her review of the actions of travelers, adventurers, gold seekers, and particularly filibusters. Men and a few women expressed an enthusiasm for the precepts of a personal and national manifest destiny, which remained strong into the 1850s. She argues that her characterization of restrained manhood - responsible, temperate, religious, and inviting of a feminine domestic influence - and martial manhood dominant, aggressive, violent, and extolling of strong masculine physicality - does not neatly fit within a simple Northern/Southern or Whig/Democratic binary. She does much good work in investigating how competing claims of different manhoods drove the desire for or refusal of filibustering adventures and the territory these actions promised. Her analysis focuses on a reading of the promise and appeal of filibustering after 1848 at a point when the traditional goals of manifest destiny (continental expansion) seemed to have been fulfilled. Men sought new regions where they could now gather across class and political lines in a celebration of their bravery and its application toward expanding American power. In this realm the annexation of the Caribbean and Central America became particularly appealing due to the sexualized assumptions made about the lands and their populations. So began a potent mixing of sexual, marital, and national ambitions.
} 
modernizing American. This embrace promised reinvigoration of the nation's might despite a tepid national government that prohibited such adventures. Individual men of action hoped to come together to shape the destiny of the nation in ways that stood at odds with dithering politicians and moralizing busybodies. This was not to be mere nostalgia but rather the recapturing of autonomy long since believed extinct. Cuban annexation offered Americans the opportunity to seize their own dreams while simultaneously strengthening the national project through the expansion of democracy.

Filibustering found its greater rhetorical success in the late 1840s due to a fortuitous confluence of events resultant from Texas annexation and the larger Mexican-American War. The process of independence, annexation, and statehood in Texas and the addition of the Mexican Cession produced three important precedents for the developing private/government partnership in the business enterprise of expansion. First, the United States government showed itself amenable to extra-legal means of delivering territory to the United States. Second, the federal government was supportive of efforts by private citizens on the battlefield and offered military support for the cause. Last, the debate over the addition of Texas as a slave state set into motion a series of debates that continued throughout the 1850s. Texas was the laboratory that created and confirmed manifest destiny's rhetorical and physical success while also establishing the moral and legal debate over slavery's expansion as the most important conversation in the United States. Manifest destiny blessed the entire enterprise with the triad of government assistance, armed citizens, and divine providence - a blessing supporters of intervention into Cuba hoped might reemerge to their benefit. However, the United States government responded quite differently toward filibustering in Cuba. The government's vacillation between lukewarm 
blind-eye and outright prohibition against Cuban filibustering was a source of continual

frustration for annexationists throughout the 1850 s.

The linkage of the gains made as a result of war with Mexico and potential filibustering expeditions in Cuba should not be surprising, coming as they did in such close temporal proximity and sharing many of the same supporters. As a result, opponents of López sought to paint his efforts, akin to those in Mexico, into the broad panorama of the slave power conspiracy. Unfortunately, historians largely followed this perspective in their discussions of López and his supporters' motivations and intentions. Until recently, many narrators of the nation's antebellum history saw López and support for his efforts as nefarious creations of Southern nationalists bent on the consistent, aggressive, and unbroken lineage of slavery's expansion. Historical attention given specifically to Narciso López has been scant and those works that mention his efforts specifically include him in the larger pro-slavery narrative. ${ }^{6}$ Robert May, a robust discussant of filibustering, takes a slightly broader approach to López arguing that by the 1850s filibustering and support for slavery, while fairly unique threads, became hopelessly intertwined. He asserts that the largest of the Cuba filibustering projects, the abortive John Quitman-led expedition of

\footnotetext{
${ }^{6}$ The works that focus more specifically on López offer more rounded discussions of his efforts. Robert Granville Caldwell analyzed López's personal motivations and effect on domestic politics. He argued that López was a disgraced noble looking to re-secure his fortune and political clout. His inability to ascend the military hierarchy in Cuba left him frustrated and desperate. Caldwell saw him as an ambitious man willing to take any means necessary to reverse his fortunes and chose to focus more on the diplomatic negotiations between the U.S. and Spanish authorities in Cuba. Robert Granville Caldwell, The López Expeditions to Cuba, 1848-51 (Princeton: Princeton University Press, 1915). Herminio Portell-Vilá's work is very intriguing and warrants more discussion later in this work. Suffice to say here, he argues that López was a prudent and passionate revolutionary who allied himself with Southern planters only temporarily. López's greatest achievement, therefore, was the molding of Americans and Cubans into an impressively unified annexationist movement. Herminio Portell-Vilá, Narciso López y Su Época (Havana: Cultural, 1930). Tom Chaffin is a standout in the historical record as he does much to downplay the assumed Southernness of López's expeditions arguing that López must be better contextualized in his moment to understand his motivations and influence. Tom Chaffin, Fatal Glory: Narciso López and the First Clandestine U.S. War Against Cuba (Charlottesville: University Press of Virginia, 1996). Most authors, even recent ones such as Walter Nugent, Habits of Empire (New York: Knopf, 2008) however follow the line of David Potter, The Impending Crisis (New York: Harper, 1976) and offer a few cursory remarks on López before sinking their teeth into the Quitman expeditions of 1854 linking the two men's intentions and bases of support together under the banner of Southern conspiracy.
} 
1854, in its appeal to Southern financial support "conceptualized their project in sectional terms." May asserts that the chaos filibusters generated actually impeded the expansion of United States commercial interests and may have hastened war. "Had Americans never filibustered, the Union might have weathered the storm." While he rightfully attributes the filibustering experience of the late 1850s to a Southern vision of Caribbean empire, he has a tendency to include López's attempts in that same category. ${ }^{7}$

Generally, the view of López as pawn of Southern interests rests on work of scholars focusing on boarder narratives of Southern history into which all filibustering neatly fits. Samuel Flagg Bemis described López as "a tool of the slavery expansionists in the United States," with his expeditions arising from, "the ambitions of the Southern imperialists to acquire Cuba as another slave state in the Union." Allan Nevins acknowledged the existence of some Northern support, but he viewed efforts at expansion as more a matter of Southern necessity and perhaps even desperation. Northern support, he argued, came from a limited collection of those who stood to gain economically from the undertakings. "The South found that its Mexican conquests had done little if anything to increase its slave area and augment its strength in Congress. Many of its leaders turned covetous eyes upon Cuba and Central America. Various Northerners put in an oar to aid this agricultural imperialism." John Hope Franklin saw the entire López undertaking as driven by a unique Southern masculinity which invented territorial need simply to satisfy its appetite rather than for sound geopolitical reasons. "The South's martial spirit forced an enthusiastic participation in every expansionist scheme and supported sectional programs of expansion when there were none on the national agenda." This unique Southern spirit he saw as

\footnotetext{
${ }^{7}$ Robert E. May, The Southern Dream of a Caribbean Empire, 1854-1861 (Baton Rouge: Louisiana State University Press, 1973). Quotation in May, Manifest Destiny's Underworld: Filibustering in Antebellum America (Chapel Hill: University of North Carolina Press, 2002), 279.
} 
separate from the larger ideology of manifest destiny. Fredrick Merk argued for separation between an earlier manifest destiny and the one that undergirded Southern attempts in the 1850s. "Cuban annexation was a goal more prosaic, sectional and Southern than the more national and poetic Manifest Destiny of the previous decade...The doctrine of Manifest Destiny, which in the 1840s had seemed Heaven-sent, proved to have been a bomb wrapped up in idealism."

Eugene Genovese argued that Cuban filibustering was a defensive action on the part of Southern planters aware of the need to defend their unique way of life. These men sought Cuba for geographic as much as economic reasons. Foremost in their minds was the fear that Spain, under pressure from the British, might abolish slavery with an attendant repeat of the horrors of Saint Domingue. "Many far-sighted Southerners understood the danger of permitting the isolation of Southern slavery. They desired Cuba in order to secure political control of the Caribbean, as well as for economic reasons." John McCardell found a simultaneous sectional destiny and Southern nationalism in his review of the Cuba affair. For McCardell, after Texas statehood, filibustering and manifest destiny became a strictly Southern affair. "The growth of Southern nationalism in the United States after 1850 operated at cross-purposes with Northern definitions of American nationalism." Charles Brown took an even more nefarious view of López's intentions claiming that the talk of freedom and independence was in part "camouflage to divert attention from the slave-economy character of Caribbean expansion." Recently, Robert Kagan remarked on the same old story. "Between 1849-1852 Southern planters placed their

\footnotetext{
${ }^{8}$ Samuel Flagg Bemis, A Diplomatic History of the United States (New York: Holt, 1942), 11; Allan Nevins, Ordeal of the Union, Vol. 1: Fruits of Manifest Destiny, 1847-1852 (New York: Scribners, 1947), 556; John Hope Franklin, The Militant South, 1800-1861 (Cambridge, MA.: Belknap Press, 1956), 98; Frederick Merk, Manifest Destiny and Mission in American History: A Reinterpretation (New York: Alfred A. Knopf, 1963) 202, 214.
} 
hopes in the Cuban filibuster Narciso López, who like other Creoles favored Cuba's annexation to the United States to prevent emancipation of its slave population." 9

This dissertation's injection of a differentiated path in this historiography is an effort to assert the agency of both Cuban and American actors in decision-making that existed outside of the slavery extension nexus. Certainly, there were those who supported annexation as an effort to expand slavery. However, López and his supporters doggedly crafted an approach to Cuban annexation that stressed shared national goals and seduced the collectivity of both American and Cuban audiences with those messages. López sought to dissipate rather than encourage sectional rancor, all in effort toward growing his base of support to its largest extent. The failure of this consensus attempt came as a result of López's death after his fourth attempt at Cuban insurrection in 1851. Planning attempts to take the island continued after his death as they also expanded in their scope. However, these efforts increasingly took on the predictably Southern veneer of dogmatic support for slavery that held supporters up to suspicion and ridicule on the part of an increasingly boisterous union of abolitionists and free-soil proponents. After the Kansas-Nebraska act and the attendant violence in Kansas, the desire or even possibility of overlooking the slavery question became obvious folly. Attempts at Cuban annexation after López's death also suffered from increased governmental intransigence as the Pierce and Buchanan administrations, fearing support would seem too open an endorsement of slavery and might scuttle both administrations' diplomatic pursuits aimed at the island's purchase, continued

\footnotetext{
${ }^{9}$ Eugene Genovese, The Political Economy of Slavery: Studies in the Economy and Society of the Slave South (New York: Pantheon, 1965), 248; John McCardell, The Idea of a Southern Nation: Southern Nationalists and Southern Nationalism, 1830-1860 (New York: W.W. Norton, 1979), 235-36; Charles Brown, Agents of Manifest Destiny: The Lives and Times of the Filibusters (Chapel Hill: UNC Press, 1980), 41; Robert Kagan, Dangerous Nation: America's Place in the World, from Its Earliest Days to the Dawn of the 20 ${ }^{\text {th }}$ Century (New York: Knopf, 1996), 239.
} 
long-standing presidential admonition of filibustering attempts. Yet all of these post-1851 efforts should not be read so easily and retroactively onto López's efforts. ${ }^{10}$

The following work focuses on both halves of the annexation story. Chapter One traces the production of American annexationary desire emanating from United States appreciation for its economic and cultural interests in the Caribbean. Rather than seeking a negation of the entire Caribbean based on the experience of the Haitian revolution and the perceived threat that republic's presence offered the United States, Cuba was hyper-present in Americans' conversations throughout the nineteenth century. The effusive public embrace of Cuba was as formative of American political culture as was the similarly strong silence on Haiti. Americans, as exemplified in the popular diplomacy of the Monroe administration, extolled Cuba as different from the rest of the Caribbean, an artificially segregated part of the American family destined for reunification. Beyond these geographic influences lay much more profound impulses of

\footnotetext{
${ }^{10}$ Both the Pierce and Buchanan administrations continued to pursue the possibility of purchasing Cuba but did so in private. Federal officials, and particularly presidents, found themselves excoriated by the public and the press when these impotent attempts became known. U.S. governmental interference with annexation, across four presidential administrations, focused on preventing filibustering activities like those of López from complicating the administrations' efforts at purchase. The Knights of the Golden Circle were probably the best known and longest existing pro-annexation/pro-slavery group in the United States. They were among the earliest groups to propose an elaborate secessionist plan that included annexing a wide arc of territory throughout much of the Caribbean, Central America, and South America in order to form a new nation built upon the foundation of slavery. The group reorganized itself in 1859 in Kentucky after George Bickley organized the first cell in Cincinnati (1854). Bickley, although run out of Cincinnati due to bad debts, demonstrates the broad reach of the group particularly in the Midwest. The group was active, if mainly in talk, throughout the Civil War, although during the war the organization's goal shifted from filibustering new slave territories and toward supporting secession and the Confederate war effort. Although mentioned in numerous sources, the best full-length treatment of the group is David C. Keehn, Knights of The Golden Circle: Secret Empire, Southern Secession, Civil War, (Baton Rouge: Louisiana State University Press, 2013). Keehn argues that after 1860, and the failure of filibustering efforts, “...the Knights became the strong arm of secession in many areas by promoting disunion through public meetings and political action and by intimidating countervailing voices into silence," (3). The relatively secrecy of the organization, while drawing members from all rungs of society, hurt its general influence and recruitment efforts. While Keehn finds the existence and relative strength of the Knights convincing, Frank Klement argues that secret societies during the Civil War were never much more than "on paper" organizations with vague goals and limited abilities, Dark Lanterns: Secret Political Societies, Conspiracies, and Treason Trials in the Civil War (Baton Rouge: LSU press, 1984). Jennifer Weber, although focusing on Lincoln's opponents more broadly, agrees more with Keehn's treatment of the organizational abilities, although varied among opposition groups, of the federal government's critics, Copperheads: The Rise and Fall of Lincoln's Opponents in the North (New York: Oxford University Press, 2008).
} 
emotional warmth toward Cubans. While Haiti demonstrated the deepest fears of many Americans of racial revolution and the South American republicans represented a lost opportunity in the application of republicanism perceived as too dangerously embracing of mixed-race populations, Americans perceived Cuba as a predominately white population in need of rescue from both their slaves and from Spanish degeneracy. The fact that Cuba was a dominated colony and not a failed state, as Americans perceived Haiti and Gran Colombia to be, further strengthened American empathy. Cubans, exhibiting a fierce desire for freedom, better exemplified the conservative social approached coupled with adherence to limited republicanism that marked the self-perceived United States example of liberation. The South American republicans, already free and given to egalitarian talk, embraced too broad a citizenry, through the halting inclusion (or at least tolerance) of African blood into their national characters, to be seen as direct descendants of United States magnanimity.

Chapter Two focuses on the unique positionality of the emergent Cuban elite in the shadow of the Haitian revolution. While annexation was an obsession for many Americans, it remained one of many pursuable avenues to independence-minded Cubans in the nineteenth century. Early Cuban political economy focused on developing a social-political response to the quick and profound economic changes in the Caribbean basin. Yet, the structural changes that the Cuban elite sought placed them squarely within an imperial framework of negotiation and accommodation. Cubans, much less than their American counterparts, were not convinced of their inherent Americanness and showed a reluctance to depart the Spanish family. This ambivalence kept Cuban vision centered squarely on social and economic development of the island within the Spanish Empire, to the frustration of Americans hungry for an effusive partner in annexation. Those Cubans supportive of union between Cuba and the United States argued 
that the result was obvious and natural. The issues, the landscapes, the geography, the economics, and the social systems all seemed as complementary as to be contiguous. For American business interests, economic investment in Cuba and trade with the island made union all but inevitable. Certainly slavery presented an obstacle in the public relations, but supporters argued that statehood might be delayed or annexation of the island used as a bargaining chip in negotiations with the Southern congressional delegation. For the annexationists within Havana elite, elimination of the onerous burden of Spanish taxation, ineptitude, and obstructionism would hasten the political reality of an already-existing economic union.

Chapter Three draws attention to the fusing of Cuban filibustering with the European revolutions of 1848. This desire to perfect democracy abroad played itself out in domestic politics as well with Young American activists pushing the government toward land reform, appropriations for technological improvements, anti-corruption, and increasing civil servant competence. Cuban filibustering's popularity in this moment should come as no surprise as it accompanied the explosion of cheap, sensational, and easily available press of all types. Tales from the battlefields of Mexico and the Southwest, peppered with the adventuring spirit of men seeking their fortune, captured the imagination and support of a vast new readership. This hagiography combined with López's mustachioed charisma were the factors necessary for the creation of a public relations juggernaut. A generational divide emerged as well, with many younger Americans across the political spectrum seeking the reinvigoration of a republicanism built on the bedrock of territorial expansion, democratic participation, economic interdependency, and the avoidance of the slavery issue. Stephen Douglas summed up this perspective in 1852 as he sought the Democratic nomination for President. "We must come together upon the basis of entire silence on the slavery question." He mixed this silence with a 
genuine belief in the need for the continuance of that great American expansionary tradition.

"The more degrees of latitude and longitude embraced beneath our Constitution the better."11

This loose faction of journalists, politicians, businessmen, and ordinary citizens alike sought to unite the nation together though an aggressive, romantic nationalism that harkened back to an earlier design of American patriotism and expansion. To this potent combination of nationalism and free trade, López and his supporters used the language of the republican revolutions budding throughout Europe in 1848 to bind their efforts to those of their fellow European revolutionaries and to curry favor with the American public that roundly supported the movement.

Chapter Four identifies sources of support for annexation in Cuba and their attempts at unifying with Cuban and American supporters in the United States. While the optimism of annexation pervaded a certain strata of the Cuban elite, support on the island among the masses was always muted as it was among an important plurality of conservative Cuban planters. The Cuban debate over annexation was short-lived and had much less effect on the Cuban geopolitical and domestic outlook than it did on the American introspection concerning republicanism, freedom, and slavery. Many elite Cubans, struggling with their concerns over slave rebellion and social destabilization, stood ready and willing for United States entry into Cuban affairs, if only to prevent "Africanization" of the island coming as a result of British abolitionism. However, the majority of Cubans, mainly as a result of the loosening of burdensome Spanish imperial policies, remained skeptical of American intentions and their elite brethren's machinations. Likewise, while the war with Mexico loomed large in the definition of American character and the aggressiveness of its foreign policy, this expansion was too arrogantly clear in its intentions, for many Americans, to offer service as the prototypical

\footnotetext{
${ }^{11}$ Stephen Douglas, "Foreign Policy - Expansion the Law of Our Existence," (1852) in The Life and Speeches of Stephen A. Douglas, ed. Henry Martyn Flint (New York: Derby and Jackson, 1860), 186.
} 
example of American magnanimity. These aggressive American hostilities of the mid-1840s

needed some rehabilitation and Cuban annexation offered a more pleasing, self-congratulatory

opportunity. Supporters perceived a multi-dimensionality to the effort at Cuban annexation that

they hoped might insulate the effort from critiques similar to those that befell the bald grab for

territory represented by southwestern continental expansion.

Chapter Five concludes the presentation with a discussion of the failure of annexation

and its effect on United States society. The overwhelming success of this print publicity machine

might have worked too well in the end. With the death of López, a transcendental if flawed

figurehead, the widespread knowledge of Cuban annexationists and the continuance of their

plans, encouraged by the press onslaught, began to seem entirely too Southern of a conspiracy

for many readers. The wash of abolitionist literature and sentiment after 1854 was too forcefully

confrontational in its refusal to yield to an effort with no charismatic figurehead. This end largely

obscured the earlier popularity and cross-sectional support López and his efforts enjoyed. ${ }^{12}$

López represented a combination of a martial but restrained man who hovered above rancorous

\footnotetext{
12 Trish Loughran, The Republic in Print: Print Culture in the Age of U.S. Nation Building, 1770-1870 (New York: Columbia University Press, 2007). My thoughts on the sudden unpopularity of Cuban annexation follow Loughran's broader thesis. She argues that the development of steam presses, entrepreneurial publishers, and improving transportation methods revolutionized the production and dissemination of printed matter in the $1830 \mathrm{~s}$ and $1840 \mathrm{~s}$. She claims there was no 'national' print culture in the period but was developed by the Civil War through a combination of technological improvements and national issues of prominence widely read about and debated. Her study seeks to answer two interrelated questions. First, if we accept Benedict Anderson's "imagined communities" thesis, how then can national formation be accounted for in the material absence of a national print culture? Second, once print networks bound the United States together in the mid-nineteenth century, how do we account for the profound cultural fragmentation that ultimately led to the Civil War? Loughran argues, paradoxically, that while the absence of a national print culture enabled revolutionaries and federalists to succeed in gaining independence and Constitutional ratification, Americans came to know one another better through shared print. This knowledge of virtual nationhood developed a rising awareness of what divided them, particularly the issue of slavery. I add to this by arguing that once the shared print culture was effectively built by 1848-1851, thanks largely to the Mexican war, and arguments for Cuban annexation made in certain and specific ways, annexation's supporters had particular difficulty spinning issues of slavery and democracy in the absence of López's charismatic voice. Craig Miner also discusses the impact of technological developments in printing as it specifically relates to the press's coverage of the Kansas-Nebraska debates. Although some voices of moderation existed, the vitriolic press on both sides of the debate served up stories that deeply touched emotions anchored in readers' particular geographic locales thereby hastening the advance of war. Cuban annexation was one of these stories. Craig Miner, Seeding Civil War: Kansas in the National News, 1845-1858 (Lawrence: University Press of Kansas, 2008).
} 
displays of sectionalism primarily because he was not American. His person - a Venezuelanborn, former Spanish military officer, regional official in Cuba, and finally Cuban independence fighter - allowed the public to invest in this transnational freedom fighter and wanderer in a way they were unable to with other Americans who carried with them the taint of party or region. López allowed Americans to envision a truncated American empire that ended with Cuban annexation, siphoned off concerns over slavery, and fed conceptualization of engagement with the island devoid of purely expansionistic steps toward areas farther south.

The great support of Americans for Narciso López and attempts at Cuban annexation were the last gasps of a holistic nationalism and individualistic masculinity that sought to downplay sectional divisions and stave off challenges from an ascendant manhood which stripped decision-making from individuals and gave it to waffling fearful politicians. The failure of annexation was, for Americans, the failure of robust benevolence in foreign affairs. This failure, according to critics, was a result of the abandonment of the political arena to negotiation, diplomacy, and dissembling accompanied by high-minded rhetoric that demonstrated American duplication of European effeminacy. Increasingly, Americans, some of whom never having shown much previous interest in politics, saw little result from diplomacy abroad, particularly in an area - the Caribbean - where many Americans were told and assumed dominance was the nation's birthright. These failures of international diplomacy infected the perceptions of domestic sectional diplomacy even if observers weren't all that interested in Cuba per se. Increasingly, the American public, beyond just the issue of Cuba, held little interest for the wastrels in Congress that pursued negotiation as the means of virtue and political 'action' on the pressing issues of the day. Conversely, annexation's failure, for Cubans, simply encouraged embrace of other more robust independence-minded strategies. 
Filibustering enjoyed its greatest popularity into the late 1850 s, at which point slavery and concerns over secession came to the fore. By the opening of the Civil War, most saw these attempts as simply territorial theft and muscular articulations of individual desires toward profit and dominance. Caribbean expansion, now predicated on the reinvigoration of slavery through filibustering, seemed anathema to the American democratic disposition. Throughout the antebellum period slavery continuously expanded onto new ground and, in the process, embraced new crops and new machinery. The planter class throughout the United States, the Caribbean, and South America exerted a political and economic dominance in rising world markets and their national political cultures that made the continued existence of slavery the foundation of their power. Yet, profits gained in the sugar, coffee, and cotton areas also depended on a complex economic and industrial partnership between non-slave owning business/production entities and slaveholding agriculturalists. The entire undertaking of the Atlantic economy fueled American growth and drove the confidence and economic funding required for the completion of manifest destiny's expansion. Workers and financiers, slaves and settlers, planters and industrialists all produced, willingly or forced, the economic juggernaut that, while encouraging American expansion, also became a part of its undoing.

One of the last pieces of manifest destiny's collapse was the economic fracturing of the regions of the United States. The national economic market steadily weakened as a unifying entity after 1857 when the South finally received some tangible demonstration of the superiority of their economic project. They emerged from the Panic of 1857 with the sense that the North needed Southern commerce more than the South needed Northern industry. The South embraced this evidence and the resultant increase in its confidence as a tonic to their presumption that Northern dominance might never relent. The confidence gained through lucrative business 
relations with world markets, the diversification of the Southern manufacturing base, the relatively light toll taken by the Panic of 1857, the possibility of Cuban annexation, the dominance of presidential elections in the 1850s, and the political capitulation of Northern interests in the tariff debate of 1858, all led the South toward a belief in the political and economic possibility of secession and the likelihood of success

The debates over expansion, economics, diplomacy, and manifest destiny in the antebellum decades exposed the many weaknesses of the American system. Despite a perceived American chauvinism in policies of Native American removal, the Mexican War, and filibustering, the bombast of the period belied a growing malaise among citizens in a society struggling to understand its past and deal with its present concerns. Proponents of manifest destiny attempted to make a virtue of the United States' lack of history and sought to turn the concept into the very a basis of nationhood. To locate such origins, champions of manifest destiny grafted biological and territorial imperatives -common among European definitions of nationalism - onto American political culture. The United States was the embodiment of a democratic ideal that had to be timeless, boundless, and portable. New methods of transportation and communication, the rapidity of the railroad and the telegraph, the rise of the international market economy, and the growth of the American frontier provided shared platforms to help Americans think across local identities and reaffirm a national character. Filibustering's naïveté saw American history as an unceasing and unencumbered destiny made manifest in every moment by individuals fighting for their personal existence and gain all while men of prominence imbued their actions with national importance and priority. However, filibustering failed at brokering a settlement between completing entrepreneurial classes and failed at using territorial gains as a template for bourgeois class unity. 


\section{Chapter One: The Pillars of Policy}

I thought the greatest danger of this union was in the overgrown extent of its territory, combining with the slavery question.

John Quincy Adams to Congressman David Trimble (April 13, 1820)

...But she [the United States of America] goes not abroad, in search of monsters to destroy. She is the well-wisher to the freedom and independence of all. She is the champion and vindicator only of her own...

John Quincy Adams (July 4, 1821)

The United States enjoyed a direct and hearty link with Cuba since at least the Revolutionary period. Many in the country looked upon the strength and longevity of these economic and geographic ties as the surest evidence of the inevitability of Cuba's absorption into the country. Most notable in the discussions, among American statesmen, concerning Cuba was the total lack of urgency shown by politicians toward action. Prior to 1824 , the belief that time was on the side of the new republic prevailed and with that belief came a lethargic imprecision of intent toward Cuba. However, this lack of urgency should not be taken for lack of interest. Rather, American policymakers did not feel the weight of the imperial Spanish yoke on their backs, as did Cubans, so movement toward the island was an issue of rhetorical import in larger discussions of domestic and commercial policy with no particularly impetus toward movement. An important co-determinant of this lackadaisical approach toward absorption of Cuba was the entirely one-sided participation in the discussion. Apart from a few Cuban expatriates, focused on philosophizing the liminality of forced exile or burnishing their educational mantles for business leadership, the 'Cuba' discussion was one held largely among elite American policymakers and businessmen. This developing Cuban dialogue in the United States focused on two prominent issues. First, most Americans with direct interest or stake in Cuba believed in the necessity of slavery's continuance. Second, to further protect against a repeat of the events in 
Saint Domingue, the continued presence of Spanish governance was a necessary hedge against other European powers interfering in the island's domestic activities and perhaps encouraging wider revolt. United States policymakers focused on quieting these two intertwined issues, thereby nurturing the budding relationship in America's pond. In order to accomplish this task, American policymakers' focus fell naturally and directly on British involvement in the Caribbean geopolitical sphere.

Early interactions between Americans and Cubans centered most influentially on the city of Philadelphia prior to the American Revolution and gradually opened to other American ports, notably Baltimore and New York City, in the decades after American victory. The Spanish government's weakening of trade restrictions in the 1770s allowed American merchants to establish branch houses in Havana and a few other Cuban ports of call, thereby strengthening the economic ties between the island and the United States. This unofficial and quiet assistance along with military supplying of the American war effort helped the Spanish government downplay its support lest this rebellious example be followed in Spain's own colonies. ${ }^{13}$ These

\footnotetext{
${ }^{13}$ The women of Havana, "Damas de la Habana" as they called themselves, answered George Washington's plea for financial support and raised about \$28 million to fund the U.S. Revolutionary army. Gen. Jean Baptiste de Rochambeau wrote "The joy was enormous when it was received, the money from Havana: The contribution of 800,000 silver pounds which helped stop the financial bankruptcy (of the Revolutionary Army) and raised up the moral spirit of the Army that had begun to dissolve." The success of the mission was not always assured. A dispirited French Admiral, Francois De Grasse, sent by Washington to secure additional funds, in turn sent General St. Simon to Havana, after a deciding to forgo the trip, personally feeling it a waste of time. De Grasse instead traveled to Cadiz and Saint Domingue in unsuccessful attempts at raising money there. Francisco de Miranda, an enthusiastic supporter of the American Revolution himself, used his closeness to the Captain General of Cuba to push the popular cause amongst his Cuban friends. The reaction was extremely favorable, especially among Cuban women who donated their money and their jewelry and convinced their relatives and friends to contribute to the fund-raising. "So the American mothers' sons are not born as slaves," as the inscription accompanying their gift read. When De Grasse and St. Simon set sail from Cuba in September 1781, his previously empty frigate L'Aigrette arrived in Virginia with 1,200,000 pounds of gold, silver, and diamonds. These private donations were in addition to the huge governmental loans that came from the Spanish Crown along with the support of an international trading company set up by the Spanish to facilitate war materiel moving to the Continental Army (to say nothing of the military actions taken by the Spanish against the British in Louisiana). Stephan Bonsal, When the French Were Here (New York: Kennikat Press, 1968), 119-120; Herminio Portell Vilá, Los Otros Extranjeros en la Revolucion Norteamericana (Havana: Ediciones Universal, 1978), 126-128; Charles Lee Lewis, Admiral de Grasse and American Independence (Boston: Ayers \& co, 1945), 17-25; Jean Jules Jusserand, With Americans of Past and Present Days (New York: Scribner's \& Sons, 1915), 81-100; James Allen Lewis, "New Spain During the American
} 
early ties between Cuba and the United States became even more profound as the United States became the chief trading partner of Cuba by the early 1800 s. $^{14}$

Building on the interactions of the Revolutionary period, Thomas Jefferson led the way in prophesizing that the social and economic gravitational pull of the United States would be enough to bring Cuba under American control. Jefferson, although reluctant in taking an active role toward gaining the island, set the frame of debate over Cuba for a generation. Jefferson and his successor James Madison sensed British interest in growing closer ties with Spanish authorities in Cuba. Both men feared a resultant loss of United States influence in the internal affairs of the island. However, American policymakers were content to watch developments with a wary eye, remaining unsure of American military abilities and uncertain if the island, destined to be Americanized, was worth fighting over. Patience became official United States policy, since even greater British influence in Cuba could not refute the inevitable laws of nature. During this period and on into the Monroe administration, John Quincy Adams played a monumental role in expressing the most fully developed conceptualization of the gravitational theory of United States diplomatic affairs regarding Cuba. His views, built solidly on a Jeffersonian foundation, looked upon possession of the island and the diplomacy required for completion of this project as a decided, yet delicate, affair.

Revolution, 1779-1783: A Viceroyalty at War" (PhD diss., Duke University, 1975); Francisco Ferrer Lull and J. Hefter, "The Spanish Louisiana Regiment in the Floridas 1779-1781," Military Collector and Historian 16 (Fall 1964), 79-80; John Francis McDermott, ed., The Spanish in the Mississippi Valley 1762-1784 (Urbana: University of Illinois Press, 1974).

${ }^{14}$ Linda Salvucci, "Supply and Demand and the Making of a Market: Philadelphia and Havana, 1780-1830," in Atlantic Port Cities: Economy, Culture and Society in the Atlantic World, 1650-1850, eds. Franklin W. Knight and Peggy K. Liss (University of Tennessee Press, 1991), 40-57 and "Atlantic Intersections: Early American Commerce and the Rise of the Spanish West Indies (Cuba)," Business History Review 79, no. 4 (Winter 2005), 781-809; Carmelo Richard Arena, "Philadelphia-Spanish New Orleans Trade: 1789- 1805," (PhD diss., University of Pennsylvania, 1959). Baltimore was also an early port of trade with Cuba and Latin American more broadly: Frank Rutter, The South American Trade of Baltimore (Baltimore: Johns Hopkins University 1897); Laura Bornholdt, Baltimore and Early Pan-Americanism: A Study in the Background of the Monroe Doctrine (Northhampton, MA: Smith College, 1949) and "Baltimore as a Port of Propaganda for Latin American Independence," (PhD diss., Yale University, 1945). 
Thomas Jefferson courted the idea of annexation of Cuba as a solution to the commercial and strategic security concerns presented by the island's geographical and political presence. Most pressing among those concerns for the Jefferson administration was the presence of a hostile Spanish government repeatedly frustrated by the perceived military and diplomatic machinations of the United States government. Chief among the accusations levied by the Spanish Crown was their suspicion that the Jefferson administration gave Francisco de Miranda material support for his 1806 military campaign against Spanish authorities in Venezuela. ${ }^{15}$

Although Miranda failed, the anger on the part of the Spanish drove Jefferson to embrace war as a possible means of closure. Jefferson was in no mood to be threatened by the diversions of the Spanish as he prepared for possible war against the British and French in the spring of 1807.

Dear Sir, - If anything Transonic \& foolish from Spain could add to my contempt of that government, it would be the demand of satisfaction now made by (Spanish Consul-General Valentin) Foronda. However, respect to ourselves requires that the answer should be decent, and I think it fortunate that this opportunity is given to make a strong declaration of facts, to wit, how far our knowledge of (Francisco de) Miranda's objects went, what measures we took to prevent anything further, the negligence of the Spanish agents to give us earlier notice, the measures we took for punishing those guilty, \& our quiet abandonment of those taken by the Spaniards. But I would not say a word in recrimination as to the western intrigues of Spain. I think that is the snare intended by this protest, to make it a set-off for the other. As soon as we have all the proofs of the western intrigues, let us make a remonstrance $\&$ demand of satisfaction, and, if Congress approves, we may in the same instant make reprisals on the Floridas, until satisfaction for that $\&$ for spoliations, and until a settlement of boundary. I had rather have war against Spain than not, if we go to war against England. Our southern defensive force can take the Floridas, volunteers for a Mexican army will flock to our standard, and rich pabulum will be offered to our privateers in the plunder of their commerce \& coasts. Probably Cuba would add itself to our confederation. The paper in answer to Foronda should, I think, be drawn with a view to its being laid before Congress, \& published to the world as our justification against the imputation of participation in Miranda's projects. ${ }^{16}$

\footnotetext{
${ }^{15}$ James Morton Callahan goes into great and unfootnoted depth on the purported support Spain claimed the United States provided Miranda. Callahan's judgment is that, while there was a great deal of moral support, the U.S. pursued a generally hesitant policy toward the Miranda uprising; a hesitance they continued throughout the Bolívarian revolutionary period in South America. Callahan, Cuba and International Relations (Baltimore: Johns Hopkins University Press, 1899), 69-119. Also see William Spence Robertson, Francisco de Miranda and the Revolutionizing of Spanish America (Washington: Government Printing Office, 1909), 341-400.

${ }^{16}$ Thomas Jefferson to James Madison, (August 16, 1807) in The Works of Thomas Jefferson, Federal Edition (New York and London: G.P. Putnam \& Sons, 1904-5), accessed on September 9, 2010, http://oll.libertyfund.org/title/ 806/87618.
} 
Jefferson's administration found itself in a very difficult position regarding these "western intrigues," which placed the president in an interestingly aggressive stance toward the Spanish (a stance largely dependent on extralegal volunteer support). The Spanish crown pressed their claims against American expansion into the Louisiana Purchase territory, specifically in Western Florida, while also pursuing vindication for their Venezuelan claims. Jefferson, for his part, struggled to keep a raucous Congressional voice at bay. His loudest Congressional critics saw the Louisiana Purchase as only the first step toward full realization of American commercial security in the Caribbean. A handful of lawmakers, among them Senators James Jackson of Georgia and Gouverneur Morris of New York, urged the Jefferson administration to lead the country to war in response to the Spanish closure of New Orleans to American shipping in 1802. Senator Jackson summed up the organic nature of the land and water of the Caribbean and perhaps unwittingly gave voice to the underlying basis of American foreign policy in the Western Hemisphere.

God and Nature have destined both New Orleans and the Floridas to belong to this great and rising empire. Natural bounds to the south are the Atlantic, the Gulf of Mexico and the Mississippi, and the world at some future day cannot hold them from us. To secure the great object said to be aimed at by this resolution, and to establish, beyond the reach of annoyance, a free communication between the Atlantic and the Western states, we must seize not only New Orleans but the Floridas and Cuba; and we must immediately create a formidable navy. ${ }^{17}$

Despite Jefferson's aggressiveness in negotiation and the liberal calls for military action against Spain, the President envisioned potential annexation of Cuba as a limited undertaking focused not on empire building but rather as a strike against the Spanish threat. Jefferson, while he hoped to eventually dispatch Spain from Cuba, also feared that if military action against the Spanish didn't go as planned the resulting chaos threatened loss of internal control of the island

\footnotetext{
17 Thomas Hart Benton, Abridgment of the Debates of Congress from 1789 to 1856: From Gales And Seaton's Annals Of Congress, Vol. II (New York: D. Appleton and Company, 1858), 679.
} 
and brought the possibility of generalized racial revolution to United States shores. Therefore, despite his disposition and pockets of military support, Jefferson held a restrained view of Cuba as the last necessary block in the economic and security apparatus of the American Caribbean and one that should not be threatened until absolutely necessary. ${ }^{18}$ Many in Jefferson's confidence, including the President himself, lacked confidence in United States military power and feared a social vacuum in Cuba more than the annoyance of Spain's continued presence there.

Jefferson decided against war with Spain in 1802 and again in 1807. Cuba remained under the Spanish flag and the vague strategic interest the United States held for the island slid into a period of dormancy as politicians, the press, and the public diverted their attention to domestic issues and eventually war with Britain in 1812. In the peace that followed the war and the relative political stability ushered in its wake, Americans were happy to shrink a bit from world affairs. This focus did not however prevent external forces from acting upon the country, necessitating response and a clearer articulation of American foreign policy aims. Jefferson's interest in Cuba as the cornerstone of Caribbean security never waned. In the run up to war with Britain late in James Madison's first administration, Jefferson spoke again of Cuba in strategic terms as potential payment from Spain in return for United States silence in the Bolívarian wars threatening to engulf Spain's South American colonies.

I would immediately erect a column on the southernmost limit of Cuba and inscribe on it a ne plus ultra as to us in that direction. We should only to include the north in our confederacy, which would be of course in the first war and we should have such an empire

\footnotetext{
${ }^{18}$ War with Spain never materialized. However in the turbulent atmosphere surrounding western relations and the Spanish presence, Aaron Burr sought advantage there for his plans to plunder New Orleans, proclaim himself king of a new southwestern nation and perhaps cleave off a portion of the Louisiana Purchase for himself. His plans, along with his sanity, faltered. Thomas Freeman, Southern Counterpart to Lewis And Clark: The Freeman and Custis Expedition of 1806 (Norman: University of Oklahoma Press, 1984) 40-60; David Robertson, The Trial of Aaron Burr for Treason (New York: James Cockcroft \& Co., 1875); Buckner Melton, Aaron Burr: Conspiracy to Treason (New York: Wiley \& Sons., 2002).
} 
for liberty as she has never surveyed since creation; and I am persuaded no Constitution was ever before so well calculated as ours for extensive empire and self-government. ${ }^{19}$

However, despite Jefferson's continuing interest in American policy in the Caribbean, his exit from the political stage opened the door for a new generation of policymakers to leave their imprint on the proceedings.

Secretary of State John Quincy Adams, not surprisingly given the position's preeminence in American history, casts a particularly impressive umbra in the first half century of the American republic. A practicing lawyer until his death on February 23, 1848, he also held ambassadorial posts, in the Netherlands, England, Prussia, and Russia, throughout his career. He was a member of the United States Senate and House of Representatives and later in his life, after a significant recanting of many of his philosophical and legal positions, an ardent abolitionist. While his one-term presidency is often seen as a failure of partisan politics, his vision for the United States put forward in his inaugural address, hopeful of a post-partisanism built upon public works in the wake of the acrid 1824 election, was as forward-looking as perhaps that of any other president.

The great object of the institution of civil government is the improvement of the condition of those who are parties to the social compact, and no government, in whatever form constituted, can accomplish the lawful ends of its institution but in proportion as it improves the condition of those over whom it is established... The magnificence and splendor of their public works are among the imperishable glories of the ancient republics... I cannot but hope that by the same process of friendly, patient, and persevering deliberation all constitutional objections will ultimately be removed. The extent and limitation of the powers of the General Government in relation to this transcendently important interest will be settled and acknowledged to the common satisfaction of all, and every speculative scruple will be solved by a practical public blessing. ${ }^{20}$

\footnotetext{
19 Thomas Jefferson to James Madison, (April 27, 1809), Library of Congress, accessed September 15, 2010, http://www.loc.gov/exhibits/jefferson/jeffwest.html\#149.

${ }^{20}$ John Quincy Adams, Inaugural Address March 4, 1825, accessed March 14, 2011, http://avalon.law.yale edu/19th_century/qadams.asp.
} 
He pushed for a new and robust role for the federal government and, as President, sought funding for an ambitious program of internal improvements (canals, navigable river improvements, national university, national observatory, new naval academy, strict patent laws) centered on a vast national road network. However, his call on Congress to rise above the mediocrity he accorded the body stymied any hopes for action on his agenda and did much to antagonize his defeated foe Andrew Jackson along with the general's new reactionary Congressional Democratic supporters. ${ }^{21}$ The pettiness of the Jacksonians in the wake of defeat in 1824 and their resultant insufferability after electoral victory in 1828 guided many historians to see Jackson's larger than life personality and the enlarged citizenry, whose suffrage ushered in his era, as the invigorating spirit of the age. However, this obscures the lasting effects that a robust modernizing capitalism had in counterbalancing Jackson's retrograde populism. The revisionist perspective of the era looks upon Jackson and Democrats as supportive of a racist laissez-faire expansionism that ultimately lost out to a more positive program of governmentally guided development combined with an equalizing ethos ascendant in Adams perspective. ${ }^{22}$

\footnotetext{
${ }^{21}$ Sean Patrick Adams offers an overview of new directions in the study of American political development through the study of "institutionalism... a formal set of rules within a prescribed boundary of authority. For historians, formal institutions like legislatures, corporations, banks, or political parties are visible remnants of political and economic tussles, cultural assumptions, and both formal and informal power arrangements." He argues that Adams' thinking represents an important American tradition of governmental institutions existing as agents of change and improvement and he credits Adams' thinking as foundational. Sean Patrick Adams, "The Tao of John Quincy Adams," Common-Place 9, no. 1 (October 2008), accessed on January 21, 2011, http://www.common-place.org/vol09/no-01/adams/.

${ }^{22}$ As Daniel Walker Howe says of the period: "The most bloody conflicts . . . derived from the domination and exploitation of the North American continent by the white people of the United States and their government. If a primary driving force can be identified in American history for this period, this was it. As its most ardent exponents, the Jacksonian Democrats, conceived it, this imperialist program included the preservation and extension of African American slavery as well as the expropriation of Native Americans and Mexicans. The remarkable changes in transportation and communications facilitated it. Determination to seize more land provoked harsh expulsions of populations, wars both large and small, and argument between pro- and anti-imperialists. Above all, westward expansion rendered inescapable the issue that would tear the country asunder a dozen years later: whether to expand slavery...Adams stood for a vision of coherent economic progress, of improvement both personal and national, directed by deliberate planning. Instead of pursuing improvement, Jacksonians accepted America the way it was, including the institution of slavery." Howe, What Hath God Wrought: The Transformation of America, 1815-1848 (Oxford University Press, 2007), 852 and 279. Interestingly, As Secretary of State for President James Monroe, Adams was responsible for the satisfactory resolution of ongoing border disputes between the United States,
} 
John Quincy Adams' thinking and actions from 1820-1823 had a profound effect on the political and legal scope of American policy. His approach established a foundation of singular American diplomacy that shunned joint action and centered American foreign policy on South America. His vision, articulated through his crafting of the Monroe Doctrine, locked in place the contours of the United States' coordinated hemispheric approach to commercial, political, and foreign affairs. The simplicity of the approach and the ease of its defense elevated American ambitions to such a naturalized state that the resultant ideology became almost completely immune from attack. Despite their political differences, Adams held similar beliefs about American exceptionalism and benevolent expansionism as the Jacksonians. Adams, as many Americans more generally, recognized that expansion, particularly in Cuba, was integral to the Union. He summed up this view in one of the most profound meditations on the interplay between the principles of American self-government and the obligation to enhance the worldwide prospects of freedom and liberty in a speech before the United States House of Representatives on July 4, 1821.

America, in the assembly of nations, since her admission among them, has invariably, though often fruitlessly, held forth to them the hand of honest friendship, of equal freedom, of generous reciprocity. She has uniformly spoken among them, though often to heedless and often to disdainful ears, the language of equal liberty, of equal justice, and of equal rights. She has, in the lapse of nearly half a century, without a single exception, respected the independence of other nations while asserting and maintaining her own. She has abstained from interference in the concerns of others, even when conflict has been for principles to which she clings, as to the last vital drop that visits the heart. She has seen that probably for centuries to come, all the contests of that Aceldama, the European world, will be contests of inveterate power, and emerging right. Wherever the standard of freedom and Independence has been or shall be unfurled, there will her heart, her benedictions and her prayers be. But she goes not abroad, in search of monsters to destroy. She is the wellwisher to the freedom and independence of all. She is the champion and vindicator only of

England, Spain, and Russia in different areas of North America. One of his greatest successes came through his tacit approval of Andrew Jackson's raids into Florida in 1817-1818, which strengthened the position of the United States in negotiations with the Spanish over transfer of the colony to the United States. While many contemporaries and historians alike attribute the Adams-Onís Treaty that codified that transfer, among settling other border disputes, as his greatest professional success, Adams role in the production of the Monroe Doctrine, both its philosophical underpinnings and public expression, remains, for this author, the most impressive and important of his numerous accomplishments. 
her own. She will commend the general cause by the countenance of her voice, and the benignant sympathy of her example. She well knows that by once enlisting under other banners than her own, were they even the banners of foreign independence; she would involve herself beyond the power of extrication, in all the wars of interest and intrigue, of individual avarice, envy, and ambition, which assume the colors and usurp the standard of freedom. The fundamental maxims of her policy would insensibly change from liberty to force. The frontlet on her brows would no longer beam with the ineffable splendor of freedom and independence; but in its stead would soon be substituted an imperial diadem, flashing in false and tarnished luster the murky radiance of dominion and power. She might become the dictatress of the world; she would be no longer the ruler of her own spirit. ... Her glory is not dominion, but liberty. Her march is the march of the mind. She has a spear and a shield: but the motto upon her shield is, Freedom, Independence, and Peace. This has been her Declaration: this has been, as far as her necessary intercourse with the rest of mankind would permit, her practice. ${ }^{23}$

Adams did not stand alone in his expansive view of foreign policy nor did he alone covet territory off of the continent. Many of the most prominent politicians of the day all sought a covert United States expansionism that promised territory and limited military exposure throughout the hemisphere. The United States followed a fairly consistent approach toward international disputes over territory well into the nineteenth century. The template called for diplomatic negotiation backed with the threat of unfettered and uncontrollable underground activities. One of the most successful techniques in this expansionary effort was the United States government's recognition of Americans in foreign territory. This technique allowed the conduct of the messy business of expansion without marshaling the military and, more importantly, the political will of the American people. This was the prevailing method of expansion used in the eastern Florida provinces, with quick success in 1817 and, with deferred but ultimate success, in Texas beginning in $1836 .^{24}$

\footnotetext{
${ }^{23}$ John Quincy Adams, Speech to the U.S. House of Representatives on Foreign Policy, accessed on March 1, 2011, http://millercenter.org/scripps/archive/speeches/detail/3484.

${ }^{24}$ Historiographically speaking, Adams receives far less attention and certainly less detail than many of the other antebellum presidents. Most of the studies of his life and work center on his time as Secretary of State and his later career as U.S. Representative from Massachusetts and abolitionist. Of course his defeat of Andrew Jackson and subsequent loss to him four years later in the Presidential elections of 1824 and 1828 are quite well discussed. However, these discussions most-often center on Jackson and his Democrats' personal and professional attacks on Adams, the tawdry nature of the two campaigns, and the meanings of Jackson's ultimate victory for the United States rather than on Adams or his presidency. His oratorical and authorial gifts should not be surprising as he
} 
However, the relative slap-dash nature of the process of continental expansion needed a more concerted philosophy and robust policy since the intended territories became too large for such impromptu shenanigans and the foreign policy intrigues became too dangerous and demanding for such sophomoric sleight of hand. The Monroe administration's necessity for foreign policy articulation responded to increasingly aggressive incursions from the Russians in the Northwest, ongoing border disputes with the British in Canada, the remote possibility of Spanish reconquest of South America, and British abolitionism in their Caribbean colonies.

studied deeply and taught rhetoric at Harvard. Lyon Rathbun, "The Ciceronian Rhetoric of John Quincy Adams" Rhetoric 18, no. 2 (Spring 2000), 175-231, details his approach to oratory and gives an overview of his professorial career. Adams also thought widely about issues of science and technology and a republic's obligation to fund those undertakings. He was influential in the foundation of the U.S. Naval Observatory of the Smithsonian Institution, Marlana Portolano, “John Quincy Adams’s Rhetorical Crusade for Astronomy” Isis 91, no. 3 (September, 2000), 480-503. The most positive view of Adams' effect on American history is Daniel Walker Howe's What Hath God Wrought: The Transformation of America, 1815-1848. Howe sees the transformations of the antebellum period as built upon a communication revolution rather than on an economic shift that practitioners of the "Market Revolution" school of Charles Seller's read in the period. Howe rejects the market-driven perspective as he sees it occurring earlier than the antebellum period with less disruptions and less profundity than the shift in mass communication, most graphically represented by the telegraph. Rather than the imposition of order on a downtrodden working class (as represented by larger religious congregations of more sober workers) that capitalism demands, Howe sees the embrace of religion and temperance (taking just two examples) as an eager embrace of the egalitarian impulses of personal responsibility that social and religious reform elicited from respondents. Politically, this tug of war plays out in the struggles between Whigs and Democrats and specifically in the persons of Andrew Jackson and John Quincy Adams. For Howe, Adams - principled, smart, and ultimately on the right side of history, especially on the question of slavery - plays a decided modern hero to the backward-looking, petty, power-hungry rogue Jackson. While many historians celebrate the rise of popular sovereignty under Jackson, Howe lauds Adams' Whiggish notion that law and principle must restrain populism. While Jackson won the numerous battles of the 1830s, Adams and his fellow Whigs, of which Howe counts Abraham Lincoln (who might have actually met Adams during Lincoln's one term in Congress), won the larger contest. "America's future lay predominately with the Whig vision of economic development and a stronger central government," (835). Both Adams and Lincoln, among countless others, valued capitalism as a moral as well as material benefit. Howe argues that the people who encouraged economic diversification and development in many cases also supported more humane laws, wider access to education, and a halt to the expansion of slavery, with some even demanding greater equality for women. The economic development that these Whigs wanted to promote empowered the average person in all kinds of ways. It brought wider vocational choices and opportunities for personal independence. Unlike Jacksonian democracy, which demanded governmental recession as necessary for personal independence, institutional capitalists like Adams and Lincoln saw government involvement as essential in supporting greater individual liberty. Picking up where his 1979 work The Political Culture of the American Whigs left off, Howe argues for a reinterpretation of the guiding ethos of the Jacksonian period. He argues that continued emphasis on Jackson as the prime spirit of the period obscures the important work done by the Whig modernists. "As economic modernizers, as supporters of strong national government, and as humanitarians more receptive than their (Democratic) rivals to talent regardless of race or gender, the Whigs deserve to be remembered. They facilitated the transformation of the United States from a collection of parochial agricultural communities into a cosmopolitan nation integrated by commerce, industry, information, and voluntary associations as well as by political ties. From the vantage point of the twentyfirst century, we can see that the Whigs, though not the dominant party of their own time, were the party of America's future," (612). 
However, the reality remained that the United States lacked the military power to back up their lofty ambitions. Nowhere was this realization made clearer than in Cuba where the United States, remained a spectator for the next two decades as British machination took center stage throughout the Caribbean. Yet, Britain's chief rival was not to be the Spanish, whom they, like the United States, viewed as an intractable annoyance in Cuba, but rather the Americans, whose imperial and economic ambitions eventually mirrored and challenged their own.

The British, certainly driven to some degree by imperial economic considerations in the immediate post-revolutionary period in Spain's former South American colonies, turned to a more open-market/free trade policy by 1820 . Moving in tandem with their market liberalization was the corresponding interest in abolition. Americans bristled at this active abolitionist force at work in the hemisphere and feared its ascendency due to British economic preponderance in the region. Many Americans eventually advocated Texas annexation as a hedge again British control in the area and creeping abolitionism along the southwest frontier. Americans worried most that in Cuba British abolitionism encouraged Cuban independence and a repeat of the events in Saint Domingue at the close of the eighteenth century. Americans long-harbored doubts about the true intentions of the British, particularly in light of the latter's ardent abolitionism and the concept's attempted export throughout the Western hemisphere beginning in the mid-1820s. While British actions were more directly hostile (particularly to slavery) in other areas in the Americas (notably Brazil) it was in Cuba that suspicions of British motivation held the most interest for Americans. That the British would have a much harder time encouraging abolition in Cuba, operating there under the close guise and active hostility of Spanish authorities, made little difference to Americans who saw in British actions the simple continuance of an uninterrupted string of hostile actions on their part. American mistrust of the British had its roots in the debates 
over the Monroe Doctrine in light of the still fresh wounds of the War of 1812. This mistrust continued most notably in the deep concerns over British intentions regarding their own possible Texas annexation in the early 1840 s. $^{25}$

James Monroe's declaration of American intent in the Western Hemisphere issued on December 2, 1823 ushered in a new era of American foreign relations and did much to center Cuba and the Caribbean in the articulation of American power in the hemisphere. Monroe's proclamation and the debate surrounding it guided the development of United States foreign and military policy for decades. Yet, the Monroe Doctrine did not emerge in a geopolitical vacuum. The year following the public announcement of the doctrine four other important events in Cuba's history took place. First, with the help of the French, the constitutional freedoms guaranteed by the liberal Spanish Constitution of 1812 - which came about as a result of upheaval in the Spanish political system during the Napoleonic wars - disappeared with the imposition of conservative rule by Ferdinand VII over the Spanish court. Second, a political uprising led by influential Cuban creoles, Los Soles y Rayos de Bolívar, spent itself as Spanish officials in Cuba moved quickly to repress the leadership who found themselves wanting of American support but disappointed by the Monroe administration. Third, a yearlong debate within Monroe's cabinet as to the prospect of Cuban annexation culminated with great political fervor. And finally, Mexico and Colombia contemplated invading Cuba because they felt threatened by Spain's aggressive military buildup there in anticipation of a potential reconquest of the crown's lost colonies. With its declaration of sovereignty in the diplomatic negotiation of

\footnotetext{
${ }^{25}$ Arthur Corwin, Spain and the Abolition of Slavery in Cuba, 1817-1886 (Austin: The University of Texas Press, 1968); Scott Silverstone, Divided Union: The Politics of War in the Early American Republic (Ithaca: Cornell University Press, 2004), ch. 3; Sam Haynes, Unfinished Revolution: The Early American Republic in a British World (Charlottesville: University of Virginia Press, 2010) and "Anglophobia and the Annexation of Texas: The Quest for National Security," in Manifest Destiny and Empire: American Antebellum Expansion, ed. Thomas Johannsen (Austin: University of Texas Press), 115-135; Jay Sexton, Debtor Diplomacy: Finance and American Foreign Relations in the Civil War (Oxford: Oxford University Press, 2005), ch. 1.
} 
these dangerous straits, the United States sought to chart a path that minimized European involvement in Cuba and kept the island part of the negotiating process. Chief in these negotiations was then Secretary of State John Quincy Adams.

The American need for a robust foreign policy that simultaneously protected and encouraged the growing and increasingly dynamic capitalist orientation of the country was obvious to Adams. He correctly recognized that this dynamic largely existed along the east-west access of the continent and benefited little, as of yet, from the federal government apparatus. However, his great fear was not territorial loss; he had no doubt that Russian and British interests in North America could be arrested and he had great confidence in the ability of American settlers to plant the flag of American self-government in their new communities in the West. Rather, he worried gravely about the ability of the United States to compete commercially with the British in South America and the Caribbean. ${ }^{26}$ This belief deepened with the valid concern that America's chief Latin American trading partner, Cuba, dangled perilously close to

\footnotetext{
${ }^{26}$ The centrality of Russia in the formulation of the Monroe Doctrine has always been over-emphasized. The lucrative nature of the New England/Caribbean/Baltic trade was something the Russians would never endanger by arguing too strenuously over their Northwestern interests. As David McFadden argues, "Although historians have focused on competing Russian and American territorial claims as central to the development of the Monroe Doctrine, the heart of the dispute, and its amicable settlement, can more accurately be traced to trade." While the Russians enjoyed closer relations with their trading partners among the indigenous populations of the Northwest, their aggressive paper-based move to expand their claims in the Northwest in the early 1820 s was more in response to illicit trade being conducted between the few American settlers in the region and the Aleut fur-traders. The Russians hoped bombast might force the Americans to the bargaining table and elicit important trade concessions. Secretary of State Adams, having a long relationship with the Russians starting with his ministerial post there in 1808, realized this tactic and gave U.S. ambassador Middleton full negotiating powers with Alexander I's government. Adams' experience with the Russians and his confidence in Middleton paid dividends. Russian claims were almost entirely rescinded by 1824 through these negotiations and freedom of trade was established on the Northwest Coast. Adams, fully aware of the negotiations and informing others in the Cabinet as well as the public in a series of articles in the National Intelligencer of their progress, had no reason to antagonize the Russians with grand pronouncements nor was he generally called upon to do so. He enjoyed a good relationship with Russian Ambassador Tuyll and stewarded through Congress most-favored trade status for the Russians in 1824. As Martin Van Buren, no fan of Adams, said in 1830 of the previous decade of Russian diplomacy, "Our commercial intercourse with Russia has been more free from personal vexation to our citizens or undue exactions upon their property engaged in it, than that with almost any other country." David W. McFadden, "John Quincy Adams, American Commercial Diplomacy, and Russia, 1809-1825," The New England Quarterly 66, no. 4 (December, 1993), 613-629; and Howard Kushner, Conflict on the Northwest Coast: American-Russian Rivalry in the Pacific Northwest, 1790-1867 (Westport, Connecticut: Greenwood Press, 1975).
} 
outstretched British claws. The Cabinet debates surrounding establishment of the Monroe Doctrine, the international diplomacy undertaken by the United States Department of State, and the geopolitical events in Europe focused attention on the Caribbean as key to the future defense of United States military and commercial interests from, primarily, the British. Adams was prescient enough to realize that the federal government's seizing and controlling of new territory, even if only a temporary stage preparing these lands for cultivation and speculation by private interests, had to be bolstered by a legitimizing force of spirit and proclamation of will that unified disparate American voices. ${ }^{27}$

While the nation continued to remain a series of temporary networks coalescing around government/private capital endeavors well into the 1840s, the projection of the animating spirit of attribution toward a higher purpose, which American expansion demanded, became the government's central purpose. Adams hoped that this projection of spirit, resting as it did on national military power should this doctrine be challenged, might help legitimize the role he and others saw for the federal government in the construction of the tangible and rhetorical infrastructure necessary for expansion. Unfortunately, this expansion built on federal auspices stood at odds with the Jeffersonian view of expansion controlled by semi-autonomous settler communities of small farmers lurching forward with mitochondrial democratic impulses unencumbered by federal bureaucracy. Therefore, the Monroe Doctrine represented a preview of the philosophical disagreement underlying the bitter partisan debates of the 1830s. That the lofty pronouncements of the Monroe Doctrine could not be guaranteed by military prowess, while a source of concern for Adams and other federalists, remained largely immaterial to the undertaking. The Doctrine was there, waiting for future inflation, when temporal possibilities

\footnotetext{
${ }^{27}$ Jay Sexton, The Monroe Doctrine: Empire and Nation in the Nineteenth Century America (New York: Hill and Wang, 2010), chs. 1-2.
} 
and military capabilities augured for more fortuitous results. Ultimately, and luckily for Adams and the United States, the British were uninterested in fighting over Cuba, seeing as they did the enormity of their commercial advantage in South America as unaffected by American posturing in the Caribbean.

However, Cuba was not the first moment of southerly-focused United States expansion. On January 11, 1811, Congress, in an effort to deal with the fast moving issues surrounding the West Florida territories adopted a "No-Transfer" resolution clearly stating American intentions. "Considering the influence which the destiny of the territory adjoining the southern border of the United States may have upon their security, tranquility, and commerce...the United States cannot, without serious inquietude, see any part of the said territory pass into the hands of any foreign power." 28 The Spanish grew increasingly uneasy as the reality of United States interest in acquiring all of Florida became baldly apparent. ${ }^{29}$ The Spanish hope remained that if the western Florida provinces might stay in their possession long enough that the Spanish court might then

\footnotetext{
${ }^{28}$ U.S. Congress, A Century of Lawmaking for a New Nation: U.S. Congressional Documents and Debates, 17741875, Annals of Congress, Eleventh Congress, Third Session: Journal of the Executive Proceedings of the Senate of the United States of America, Volume 2, (January 11, 1811), accessed on March 10, 2011, http://memory.loc.gov /cgi-bin/query/D?hlaw:1:./temp/ ammem_qDBX, 183.

${ }^{29}$ Views on the rebelliousness of the Anglo-American population in Spanish Florida have long been domain of intense debate and discussion. Andrew McMichael offers an overview and challenge to the prevailing thesis of Spanish failure of leadership in the area in "The Kemper Rebellion: Filibustering and Resident Anglo American Loyalty in Spanish West Florida," The Journal of the Louisiana Historical Association 43, no. 2 (Spring, 2002), 133-165. "A closer examination of the Kempers' filibustering within the context of other filibustering in the Spanish borderlands between 1785 and 1810 reveals that the West Florida raids were part of a larger pattern of frontier criminal activity endemic along the U.S./Spanish colonial frontier. These raids were not then a reaction to widespread dissatisfaction. Furthermore, Spanish administration in West Florida engendered a high degree of loyalty on the part of Anglo-Americans that only broke down after the Kemper raids," (135). For other views on the involvement of the U.S. government as well as international effects of the competition over Florida see: James G. Cusick, The Other War Of 1812: The Patriot War and the American Invasion of Spanish East Florida (Athens: University of Georgia Press, 2003); Isaac J. Cox, "The Border Missions of General George Mathews," The Mississippi Valley Historical Review 12, no. 3 (December, 1925), 309-333; J. Leitch Wright Jr, "British Designs on the Old Southwest: Foreign Intrigue on the Florida Frontier, 1783-1803," The Florida Historical Quarterly 44, no. 4 (April, 1966), 265-284; Phillip Matthew Smith, Persistent Borderland: Freedom and Citizenship in Territorial Florida (PhD diss., University of Texas, 2007); and J. C. A. Stagg, "George Mathews and John McKee: Revolutionizing East Florida, Mobile, and Pensacola in 1812," The Florida Historical Quarterly 85, no. 3 (Winter, 2007), 269-296.
} 
enjoy a quid pro quo with the United States - the Americans tempering their support of the

South American rebels in exchange for Spain's eventual ceding of the Florida territory. Coming

with these negotiations, they hoped, would be a clarification of the United States' southern

boundary and a validation of Spanish ownership of the rest of the Floridian peninsula. The unrest

within the Spanish royal court of Ferdinand VII, newly reestablished with French assistance in

1814, and the American acquisition of Amelia Island in 1817, ostensibly in response to Spanish

failure at reducing raiding expeditions launched from the island against United States shipping,

did little to mollify the mood and hastened Spanish calls for negotiation on the matter. However,

the success of Andrew Jackson's post-war forays into Florida strengthened Secretary of State

Adams' hand and eventually led to the forced sale of all of Florida by the Spanish through the

Transcontinental Treaty of $1819 .{ }^{30}$ Chief Justice John Marshall spoke of the victory and of the

new economic nation Adam's treaty set about crafting: "Throughout this vast republic, from the

St. Croix to the Gulf of Mexico, from the Atlantic to the Pacific, revenue is to be collected and

\footnotetext{
${ }^{30}$ William Earl Weeks, John Quincy Adams \& American Global Empire (Lexington: University Press of Kentucky, 1992), argues that while Adams' accomplishments in 1818-1819 earned him the title of "Greatest Secretary of State the U.S. has ever had," he over-emphasized the strength of his hand in the Florida negotiations both publicly and privately. The knowledge of this diplomatic legerdemain caused Adams to fear "that his success as a statesman ... was being attained at the cost of his personal integrity" (170). Weeks sees Adams as a tragic figure caught in the transition from the Revolutionary era conceptualization of statesmanship, emphasizing republican virtue and duty in service to the country, to a time when blatant political ambition and its attendant partisan intrigue became the norm. The exigencies of domestic and foreign affairs forced him to repeatedly repudiate his republican values and did much to shape his rejection of his early-career expediency as an outspoken member of Congress later in his career. Weeks' work answers Daniel Lang and Greg Russell who argue for a more ethical upright Adams who did not diverge as much as develop his morality built during the Revolution era. "Recourse to political ethics afforded Adams a vantage point from which to evaluate the volatile problem of intervention viewed in terms of the moral responsibilities and limits of American power at a crucial turning point in the diplomatic history of the young republic. Important in this connection is how Adams attempted to reconcile the blessings of liberty with the methods and purposes of American diplomacy within and beyond the Western Hemisphere. An attempt is made to evaluate the sources and meaning of statesmanship for Adams who, as perhaps the nation's most experienced diplomat and accomplished Secretary of State, judged the limits and opportunities of American power from a perspective that considered moral precepts and international law as compatible with the prudent pursuit of American national interest in world affairs." Lang and Russell, "The Ethics of Power in American Diplomacy: The Statecraft of John Quincy Adams," The Review of Politics 52, no. 1 (Winter, 1990), 3-31.
} 
expended, armies are to be marched and supported." ${ }^{31}$ Yet in the victory, Adams saw American vulnerability in the Caribbean, for if the Spanish could be forced into capitulation with an advance guard of American settlers and dubious military adventurers, American interests might be equally as easily subverted in a place like Cuba by the machinations of more-powerful European foes. ${ }^{32}$ Further complicating this possibility was the profound domestic malaise brought on by the twin crises of the Panic of 1819 and the Missouri Compromise. This was the ambivalent setting into which Adams cast American policymaking in $1820 .{ }^{33}$

President James Monroe felt optimistic on the issue of the nation's strength in the wake of his almost unanimous reelection in 1820 . He saw that unanimity as a sign that perhaps the nation had risen to a post-partisan plateau. On the issue of reduced receipts for the federal government in the wake of the economic downturn beginning in 1819, Monroe was more sanguine but still hit a note of confidence.

Under the present depression of prices affecting all the production of the country and every branch of industry the revenue has considerably diminished, the effect of which had been to compel Congress either to abandon these great measures of defense [extinction of the

\footnotetext{
${ }^{31}$ John Marshall, McCulloch v. Maryland, March 6, 1819, accessed March 14, 2011, http://law2.umkc.edu/ faculty/projects/ftrials/conlaw/mcculloch.html.

${ }^{32}$ Discussions of the annexation of the West Florida provinces and negotiation of the Transcontinental or AdamsOnís treaty are further developed by: George Dangerfield, The Awakening of American Nationalism: 1815-1828 (Prospect Heights, IL: Waveland Press, 1965), ch. 2; William Earl Weeks, “John Quincy Adams's 'Great Gun' and the Rhetoric of American Empire," Diplomatic History 14, no. 1 (January 1990), 25-42; Phillip Coolidge Brooks, Diplomacy and the Borderlands: The Adams-Onis Treaty of 1819 (Berkeley, CA: University of California Press, 1939); Gary Lawson and Guy Seidman, The Constitution of Empire: Territorial Expansion and American Legal History (New Haven: Yale University Press, 2008), chs. 2-3; The Birth of Modern Politics: Andrew Jackson, John Quincy Adams, and the Election of 1828: Lynn Hudson Parsons, Andrew Jackson, John Quincy Adams, and the Election of 1828 (Oxford: Oxford University Press, 2009), 45-80.

${ }^{33}$ The mood of the public was not uniformly positive, as some voiced concern about the lengthy delay in Spanish ratification of the Transcontinental Treaty. Many historians indicate this but do not assert reasoning for the Spanish delay. Ed Bradley does argue that it was an early filibustering activity led by American James Long into Texas in early 1819, similar to the one the Spanish government accused the Jefferson government of supporting in Venezuela, which delayed ratification. "Spain used its suspicion of the Monroe administration's involvement in the Long venture as partial justification for delaying ratification of the agreement." Although Bradley rejects Spain's claims, he does indicate that the Monroe administration was indeterminate in regards to Texas once negotiations began to wane. While the American were probably interested in Texas, Bradley finds responsibility for the filibustering and failure to stop it resting on the Louisianan and not federal authorities. Ed Bradley, "Fighting for Texas: Filibuster James Long, the Adams-Onís Treaty, and the Monroe Administration," The Southwestern Historical Quarterly 102, no. 3 (January 1999), 322-342.
} 
debt and costal fortification] or to resort to loans or internal taxes to supply the deficiency...I am satisfied equally well satisfied, as a general rule, that the demands of the current year, especially in time of peace, should be provided for by the revenue of that year. I have never dreaded, nor have I ever shunned, in any situation in which I have been placed making appeals to the virtue and patriotism of my fellow citizens well knowing that they could never be made in vain, especially in times of great emergency or for purposes of high national importance. Independently of the exigency of the case, many considerations of great weight urge a policy having in view a provision of revenue to meet to a certain extent the demands of the nation, without relying altogether on the precarious resource of foreign commerce. I am satisfied that internal duties and excises, with corresponding imposts on foreign articles of the same kind, would, without imposing any serious burdens on the people, enhance the price of produce, promote our manufactures, and augment the revenue, at the same time that they made it more secure and permanent...In our whole system, national and State, we have shunned all the defects which unceasingly preyed on the vitals and destroyed the ancient Republics. ${ }^{34}$

Only in one area, relations with the British in the Caribbean, did Monroe sound some alarm. "No agreement has yet been entered into respecting the commerce between the United States and the British dominions in the West Indies and on this continent. The restraints imposed on that commerce by Great Britain, and reciprocated by the United States on a principle of defense, continue still in force." ${ }^{35}$ Naturally, the concern of the President and Secretary Adams' was the issue of commerce and negotiation with the British. The larger backdrop of this issue and the situation that animated its importance was the wars of independence raging through South America. As Spain's breakaway colonies slowly established themselves as independent nations, with the full complement of trade and consumption needs, British shipping and manufacturing swept in to fill the Spanish void. The United States looked upon these developments with great concern and feared an expansion of British dominance into the Caribbean at-large anchored by South American trade. South American relations, as holding the key to the Caribbean's economic, then became the prevailing issue of the second Monroe administration.

\footnotetext{
${ }^{34}$ James Monroe, Second Inaugural Address, March 5, 1820, accessed on January 21, 2011, http://www.vlib.us /amdocs/texts/09monr2.htm.

${ }^{35}$ Ibid.
} 
Previous attempts at forcing the British toward compromise on Caribbean trade were somewhat successful. In response to British moves designed to monopolize West Indian trade by excluding American shipping, Congress passed a bill in 1818 closing United States ports to all British ships arriving from a port closed to United States shipping. In 1820, Congress again antagonized the British declaring non-intercourse between Britain's Western Hemisphere colonies and United States ports. United States policy stipulated that colonial products moved first to England were also off limits to American ports. The acts had great effect as British tonnage entering United States ports dropped from 174,935 in 1817 to 36,333 in 1820 . The British government relented after much prodding by the British Board of Trade, liberal Parliamentarians, and influential businessmen. The crown reopened ports to United States shipping again in 1822. However, in response, Adams continued to pressure Congress and wrote a bill for consideration that demanded parity for United States shipping in British ports throughout the Americas, a proposal the British roundly rejected. As a result the issue of open trade remained unresolved and the British took on a new appreciation for the overly aggressive stand taken by the United States over the matter. However, Caribbean trade was but one front in the larger offensive the Monroe administration set to launch in $1823 .{ }^{36}$

Europe was in a state of disarray at the onset of that year. In response to the upheavals of the Napoleonic wars, Prussia, Russia, and Austria moved to reestablish monarchical dominance. Conversely, the British moved decidedly toward a greater commercial nationalism, sensing correctly that the markets of the Western Hemisphere lay to their advantage as long as the independence of the new established republics held. France joined the former tripartite camp and successfully invaded Spain in 1823. The French reestablished Ferdinand VII in Spain for the

\footnotetext{
${ }^{36}$ F. Lee Benns, The American Struggle for the British West Indian Carrying Trade, 1815-1830 (Bloomington, IN: University of Indian Press), 60-69.
} 
second time in a decade and revived the Bourbon Empire on the Spanish throne. Many in United States policymaking circles began to fear French-guided Spanish designs - ably assisted by the Holy Alliance of Russia, Prussia and Austria - on its former South American colonies. Thomas Jefferson, presaging Monroe's doctrine by three years, called for recognition of the new Bolívarian republics as a hedge against European aggression there. He hoped the United States might enjoy,

...the advantages of a cordial fraternization among all the American nations and the important of their coalescing in an American system of policy, totally independent of and unconnected with that of Europe. The day is not distant when we may formally require a meridian of partition through the ocean which separates the two hemispheres, on the hither side of which no European gun shall ever be heard, nor an American on the other; and when during the rage of the eternal warns of Europe, the lion and the lamb, within our regions, shall lie together in peace...I wish to see the coalition begun. I am earnest for an agreement with the maritime powers of Europe, assigning them the task of keeping down the pirates of their seas and the cannibalism of the African coast and to us the suppression of the same enormities with our seas; and for this purpose I should rejoice to see the fleets of Brazil and the United States riding together as brethren of the same family and pursuing the same object. ${ }^{37}$

Speaker of the House Henry Clay, sensing an opening in the domestic political landscape, fearing Spanish aggression, and determined to steer the United States away from European conflict, pushed the Monroe administration harder and earlier on the subject of South American recognition than any other politician. In 1817, Clay, responding to an appropriations request made of Congress by President Monroe for a fact-finding mission to determine how sure revolutionary success in South America might be, rebuked that the mission was an insult. He insisted instead that a minister should be sent offering full support and recognition for the rebels. In Congress he spoke of the need for a more robust answer to the cause of Latin American independence.

We are the natural head of the great American family. I would not intermeddle in the affairs of Europe. We wisely keep aloof from their broils. I would not even intermeddle in those

\footnotetext{
37 Thomas Jefferson to William Short (1820) in The Jeffersonian Cyclopedia ed. John Foley (New York: Funk and Wagnall, 1900), 697-698.
} 
of other parts of America farther than to exert the incontestable rights appertaining to us as a free, sovereign, and independent power; and I contend that accrediting of a Minister from the new (La Plata) Republic is such a right. We are bound to receive their Minister, if we mean to be really neutral. If the Royal belligerent were represented and heard at our Government, the Republican belligerent ought also to be heard...For my part, I wish their (the Spanish colonies') independence. Let them have free government, if they be capable of enjoying it; but let them have, at all events, independence...I may be accused of an imprudent utterance... on this occasion. I care not; when the independence, the happiness, the liberty of a whole people is at stake, and that people our neighbors, and brethren, occupying a portion of the same continent imitating our example, and participating of the same sympathies of ourselves, I will boldly avow my feelings and my wishes in their behalf, even at the hazard of such an imputation. ${ }^{38}$

Again in 1820, Clay repeated his argument in language of great similarity to Jefferson's and in a challenging tone aimed at pushing the Monroe administration toward South American recognition.

I deprecate this deference for foreign power. A single expression of the British Minister to our Secretary of State, I am ashamed to say, has molded the policy of our Government towards South American. Our institutions now make us free; but how long shall we continue so, if we mold our opinions on those of Europe? Let us break these commercial and political fetters; let us no longer watch the nod of any European politician; let us become real and true Americans and place ourselves at the head of the American system. There can be no doubt that Spanish America, whatever the form or government established in its various parts, will be animated by an American feeling, and guided by an American policy. They will obey the laws of the system of the new world, in contradistinction to that of Europe. ${ }^{39}$

Clay linked recognition with diplomatic freedom in hopes of strengthening American

political morality while striking a populist tone. For Clay and many of his political generation the spread of democracy was directly proportional to United States strength. Beyond his presidential ambitions, Clay had consistently advocated for liberalization of relations with South America for more ideologically pure reasons as well. ${ }^{40}$ His vision was a multifaceted one based on the

\footnotetext{
${ }^{38}$ Henry Clay Speech in Congress January 24, 1817 in The Life, Correspondence, and Speeches of Henry Clay, Vol. $V$, Speeches ed. Calvin Colton (New York: A.S. Barnes, 1857), 102.

${ }^{39}$ Henry Clay Speech in Congress May 10, 1820 in The Life, Correspondence, and Speeches of Henry Clay, Vol. V, Speeches, ed. Calvin Colton (New York: A.S. Barnes, 1857), 243.

${ }^{40}$ This expedient but counseled combination of motives is a point most of the important biographers of Clay agree upon. Carl Schurz, Henry Clay (Boston: Houghton, 1887), says "there is no doubt that those appeals were on his part not a mere manoeuver of opposition, but came straight from his generous impulses. The idea of the whole American continent being occupied by a great family of republics would naturally set his imagination on fire...This tendency was reinforced by his general aptness to take a somewhat superficial view of things" (168). Robert Remini, Henry
} 
economic and moral advantages gained, particularly over the British, from an active and moral United States foreign policy toward the new republics. This activist view, which Clay demonstrated throughout the late 1810 s and early 1820 s, did not moderate until he moved into the position of Secretary of State under President Adams in $1825 .{ }^{41}$ Clay believed that swift recognition and engagement would help secure American gains in North America and the Caribbean while forestalling any attempt by the Spanish of rekindling imperial aspirations in the hemisphere.

The immense country, watered by the Mississippi and its branches, had a peculiar interest...Having but the single vent of New Orleans, for all the surplus produce of their industry, it was quite evident that they would have a greater security for enjoying the advantages of that outlet, if the dependence of Mexico upon any European power were effected. Such a power, owning at the same time Cuba, the key to the Gulf of Mexico, and all the shores of that Gulf, with the exception of the portion between the Perdido and the Rio Grande del Nord, must have a powerful command over our interests. Spain, it was true, was not a dangerous neighbor at present; but in the vicissitudes of states, she might be again resuscitated. ${ }^{42}$

Clay enjoyed great support from his Kentuckian constituents and realized in the matter that he

had a political stump to preach from with unparalleled success and volume. ${ }^{43}$ He envisioned an

Clay: Statesman for the Union (New York: Norton, 1991), argues that, "Latin America continued to be Clay's best line of attack. Not only did he honestly favor the independence of the provinces in revolt in Central and South American and believe the administration should recognize them as independent nations, but he also believed that Americans generally supported all efforts of subjugated people to free themselves from the tyranny of European monarchies" (170). David S. Heidler and Jeanne T. Heidler, Henry Clay: The Essential American (New York: Random House, 2010), laud Clay's motivations. "Many suspected that Clay's fixation on recognizing Latin American republics was just another way for him to embarrass Monroe and Adams. Yet his disgust over the administration's reluctance to support Latin American revolutionaries was quite sincere...Clay had early expressed sympathy for Latin American revolutionaries because he saw them as comparable to American's patriots of 1776," (136).

${ }^{41}$ While Clay and Adams were often at loggerheads on these issues, the Kentuckian, rightfully seeing Adams as the driver of foreign policy decisions for the Monroe administration and his chief rival in that field, often mended fences in the wake of the foreign policy decisions of the late Monroe presidency. Clay's advocacy toward Latin America moderated greatly after his promotion to Secretary of State most likely due to needs of practical statesmanship. He, like many other Americans, also began looking at the new republics as failing states rife with violence, fraud, and poor governance. These perspectives were greatly shaped by the racial stereotypes many Americans had of the inhabitants of these new states.

${ }^{42}$ Daniel Mallory, ed., The Life and Speeches of the Honorable Henry Clay, Vol. 1 (New York: Robert Bixby \& Co., 1843), 333-334.

${ }^{43}$ The three most-direct works focusing on Clay's views of Latin American independence are: Halford L. Hoskins, "The Hispanic American Policy of Henry Clay, 1816-1828," The Hispanic American Historical Review 7, no. 4 (November 1927), 460-478; J. B. Moore, "Henry Clay and Pan-Americanism," Columbia University Quarterly 7 , 
alliance structure in the Americas based on liberty and independence that might counterbalance the Holy Alliance and negate the danger of European aggression in the Western hemisphere. ${ }^{44}$ Clay's dogged public shaming of the Monroe administration pushed the president's cabinet to fully reckon with South American recognition. Adams expressed his uncertainty with hasty diplomatic moves, couching his conservative response as concern for the new republics' ability for self-government.

That it was our true policy and duty to take no part in the contest was equally clear. The principle of neutrality to all foreign wars was, in my opinion, fundamental to the continuance of our liberties and of our Union. So far as they were contending for independence, I wished well to their cause; but I see not prospect that they would establish free or liberal institutions of government ... Arbitrary power, military and ecclesiastical, was stamped upon their habits, and upon all their institutions ... I had little expectation of any beneficial result to this country from any future connection with them, political or commercial. $^{45}$

The President and his secretary remained contentedly on the sidelines, despite Clay's

belligerence, as European powers showed no initial aggression toward the South American republics. However, Monroe and Adams grew concerned as events in Europe threatened a new configuration of power. Adams, while never doubting the implausibility of reconquest, set about convincing his cabinet colleagues and President Monroe, that the Caribbean and South America were the new centers of United States foreign policy. This reality, Adams argued, necessitated a clearly articulated and visionary policy that promised the United States a dominant position in the hemisphere. Many Americans agreed with Adams' perspective that viewed anything short of

(September, 1915); and Randolph Bluford Campbell, "Henry Clay and the Emerging Nations of Spanish America, 1815-1829," (PhD diss., University of Virginia, 1966). While dated, these sources establish what is an oft-repeated truism of Clay's "Pan-Americanism," namely that he deftly mixed belief with politics in his calls for a forwardlooking policy of recognition and engagement.

${ }^{44}$ Joseph Byrne Lockey, Pan-Americanism-Its Beginnings (New York: Macmillan, 1920), 378-420. Roger Bullen, "The Great Powers and the Iberian Peninsula, 1815-48," in ed. Alan Sked Europe's Balance of Power, 1815-1848, (New York: Harper and Row, 1979), 54-78.

${ }^{45}$ Charles Francis Adams, ed., Memoirs of John Quincy Adams Comprising Portions of his Diary from 1795 to 1848, Vol. 5 (Philadelphia: J. B. Lippincott, 1874-77), 324-325. 
acceptance of the hemisphere's leadership position was an abrogation of the nation's republican mission.

The effects of this accretion toward a stronger American perspective on South America pushed Monroe and his cabinet toward action. In March 1822, the President sent Congress a draft motion that summarized United States government opinion on South American revolution and outlined ways toward recognition of the new republics. This action also offered response to increasingly clear British intentions to separate itself from the rest of Europe and move, albeit slowly, toward recognition. British participation in the Verona Conference of 1822 codified their singular perspective, with decisions during that conference placing the British in open breach of the wishes of the other members of the Quintuple Alliance (Russia, Austria, Prussia, and France). The British voiced opposition to French conquest of Spain and any attempt at reconquest in the Western Hemisphere. The upheaval in Spain held many domestic political effects, the most notable of which was Ferdinand's return to the throne, a turn toward strict Royal oversight of the affairs of state, and a corresponding purge of liberals in the Spanish Cortes by 1823. However, one of the positive results of the war was the distraction it caused in efforts at reconquest of Spain's South American colonies. In this vacuum, the Bolívarian independentistas took the upper hand and consolidated gains throughout South America. The British, correctly sensing the inevitability of this success, charted an independent path that put them in the best position to enjoy commercial success through trade with the new republics. The United States charted an independent path as well, one that focused on keeping access to these new markets while furthering the American cause in Cuba. ${ }^{46}$

\footnotetext{
${ }^{46}$ The Quintuple Alliance formed when France joined Russia, Prussia, Austria and Britain in 1818. The Verona conference focused almost exclusively on the Spanish Question. From the onset, British representative Lord Wellington's instructions were to express the uncompromising British opposition to the whole principle of intervention in Spain and Latin America. Wellington sat at the conference as British Foreign Secretary George
} 
Canning's representative. Canning having stepped into the Foreign Secretary's office as a result of the former Secretary Castlereagh's untimely suicide. The Russians offered assistance to France but were rebuffed by French desires to keep any intervention into Spain wholly French. Other representatives also opposed this audacious movement of Russian troops through central Europe. However, within the opposition clear dividing lines emerged with Wellington expressing Britain's opposition based firmly on the principle of non-intervention and not on the matter of troop movements and other superficial issues others found with the Russian plan. The governments supportive of French action agreed to send separate letters to the Spanish expressing support for French intervention but Wellington, in accordance with his instructions not to countenance any intervention in Spanish affairs, took no part in the conferences that followed. In waxing poetically, and in somewhat macabre prose, French Representative Chateaubriand said of Verona after recounting the deaths of his fellow representatives "If so many men whose names were inscribed with mine upon the register of the Congress, are now entered in the obituary; if not only individuals, but royal dynasties, have perished; if Poland has fallen; if Spain is revolutionized anew; if I have been to Prague, seeking the fugitive asylum of that illustrious race of whom I was the representative at Verona - what is all this but the common course of earthly things? Oh, the magic of genius! Who now remembers the speeches that circulated round the board of Prince de Metternich? Each of us, on raking into the profound depths of me mory, will discover a bed of death." M. De Chateaubriand, The Congress of Verona Comprising a Portion of Memoirs of His Own Time (London: Richard Bentley, 1838), 421. The only other full-length work on the Congress is the extremely detailed and largely British and French diplomatic-based work Irby C. Nichols Jr., The European Pentarchy and the Congress of Verona, 1822 (The Hague: Martinus Nijhoff, 1971). Nichols sees the Congress as an important turning point in Europe/British diplomatic relations, one that moved the British focus toward non-European affairs as its domain of greater interest. This stance was driven greatly by the personality and commercial/diplomatic inclination of George Canning. The members of the alliance called the conference in response to the military revolt in Spain that began in 1820. Led by influential members of the military ruling elite, the Trienio Liberal began when Spain's King Ferdinand VII provoked widespread unrest, particularly in the army, by refusing to accept the liberal constitution of 1812. Further damaging the King's reputation with liberals and military leaders alike was his desire to reclaim Spain's American colonies. Critics of the King rightfully saw the colonies as a source of riches for the court but not for Spain more generally and bristled at the idea of expending life and treasure at reconquest to enrich the throne. In January 1820, soldiers assembled at Cadiz for an expedition to South America, angered over infrequent pay, bad food, and poor quarters, mutinied under the leadership of Colonel Rafael del Riego y Nunez. Offering their allegiance to the 1812 Constitution, they began preparations to march on Madrid in effort to forcibly depose Ferdinand VII. On March 9, 1820 Ferdinand accepted the imposition of liberal rule under the 1812 Constitution and the Spanish governmental body, the Cortes, stocked with newly elected supporters of Colonel Riego, imprisoned the King until the French invasion of 1823 restored his rule. The military strength of the rebels, however, did not match their political audacity and during this three-year intersession Spain lapsed into a series of regional civil wars. Throughout the period, Ferdinand appealed to the Holy Alliance (Russia, Prussia and Austria) in hopes that they would intervene on his behalf to restore his rule but he received no satisfaction. Although decisions at the Verona conference concerning military strategy were ambiguous, France imposed its will upon the Holy Alliance in a secret agreement struck in 1823 and invaded Spain with a large force whose loyalty, training, and desire for combat made the undertaking an exercise in great ambivalence. Many of the French invading force's soldiers, veterans of the Napoleonic wars, harbored sympathies with the Spanish liberals. However, the Spanish liberal armies fell quickly (although French troops lingered until 1828) and when the fighting ended in September 1823, a restored Ferdinand revoked his accession to the 1812 Constitution on October 1st 1823, in the process invalidating all acts and measures decided in his stead by the liberal Cortes. Charles Fehrenback, "Moderados and Exaltados: The Liberal Opposition to Ferdinand VII: 1814-1823," The Hispanic American Historical Review 50, no. 1 (February, 1970), 52-69. Fehrenback offers a discussion of the failures of the liberal rebels to establish a viable government that enjoyed the popular support of the Spanish people. This dissatisfaction and the welcoming of French troops in 1823 rested more on the decade of economic destitution the Spanish economy and people suffered from rather than any deeply felt support for Ferdinand VII. "Exhausted by war and weary of innovations, the Spanish people in the early years of the Restoration wanted only peace and prosperity. In 1814 they believed that these could be achieved. Their confidence in Ferdinand's government waned, as depression conditions continued. The loss of American markets was a severe blow to Catalan textile industries; according to Castalanios, many factories were forced to close. Virtually all of the coastal cities suffered from a decline in commerce. The depression decreased governmental tax collections, and in January 1817 the government once more suspended payments. The only recourse was the printing press, but in 1817 value reales sold at a discount of 80 percent. The immediate result was that opposition increased rapidly. Although in 1817 Alcala Galiano noted little concerted revolutionary activity, 
On March 8, 1822 President James Monroe declared the United States’ open appreciation

for the victorious republics of South America and extended official recognition to those that had organized their governments. Monroe informed the Congress that, regarding liberated Spanish America, "we are compelled to conclude that its fate is settled, and that the Provinces, which have declared their independence and are in the enjoyment of it, ought to be recognized."47 However, this recognition did little to placate concerns that attempts at Spanish/French reconquest of the new republics might still unfold. Adams, long since having written off these concerns, now set about convincing Monroe and John C. Calhoun, the most reluctant member of the cabinet, that the danger was overblown and that the United States was free to pursue its strategy in the hemisphere without regards to European machination. ${ }^{48}$

One of the key areas of concern in the articulation of this new American policy was Cuba. On September 26, 1822, John Quincy Adams noted in his diary that former President Madison sent him a letter from P.S. Duponceau, a Philadelphian lawyer, addressed to General Mason. The letter tells of the presence and contact of a "Mr. Sanchez" traveling from Cuba and

two years later disgruntled liberals had converted the Masonic organization into a vast revolutionary network and had attracted such prominent businessmen as Tomas Isturiz and Beltran de Lis. In fact, the revolutionary junta, which planned the pronunciamiento, had not agreed on the type of government to be created, should the revolution be successful. It was Riego, apparently without the knowledge or consent of his fellow conspirators, who decided in favor of the Constitution of 1812. Because of this, the revolution almost collapsed at the outset. During January there was no apparent enthusiasm for its program...In retrospect, it is apparent that this failure was inevitable. The public wanted economic recovery and financial stability in 1820 . No ministry was capable of providing this. What is more, the constitutional image was damaged by the revolutionaries' greed. Many of these seemed less concerned with fiscal responsibility than Ferdinand, a fact which the royalist opposition never ceased to point out. Although Martinez de la Rosa may have attempted to create an efficient ministry between March and August 1822, most of the cabinets simply resorted to deficit spending, and during the constitutional trienio the liberals floated more than 3 billion reales in foreign loans. The treasury was usually destitute, yet government officials regularly rewarded themselves and their friends."

47 Thomas Hart Benton, ed., Abridgment of the Debates of Congress 1789-1856, Vol. VII (New York: Appleton, 1856), 172

${ }^{48}$ Calhoun followed Adams' belief that Cuba was the center of American concern but was greatly concerned about the ability of the United States to protect its interests there. "There is no portion of Spanish America that bears so immediately on our interest, as Mexico and Cuba and which will probably become the theater of British management and intrigue." Calhoun to Monroe, September 24, 1823, in ed. W. Edwin Hemphill The Papers of John C. Calhoun, Vol. VIII (Columbia, SC.: University of South Carolina Press, 1975), 284. 
presently in Philadelphia. Sanchez identified himself as a secret agent of a clandestine group in Havana that sought admission as a state into the United States. The space in which this Havana group operated existed only because of the general unrest gripping Spain, which had left a momentary political vacuum in Cuba. Mr. Sanchez implored the Americans to take advantage of this pregnant opportunity and relayed this general state of unrest on the island. The political debate, as his group saw it, existed most notably between competing interests of the peninsulares (those traditionally holding power in Havana and loyal to the deposed conservative government of Ferdinand VII) and criollos (Cuban Spaniards born on the island, frustrated in their meager claims to power), all of which feared a generalized slave revolt in this state of chaos. Monroe, intrigued by the Sanchez offer, called a meeting of his cabinet to discuss potentialities.

On September 27, just prior to entering a Cabinet meeting with only himself, John C. Calhoun, and the President in attendance, Adams learned that the British Foreign Secretary, Lord Castlereagh, had killed himself, thereby throwing into chaos the years of careful diplomacy between the British and American secretaries. Yet, Adams sensed an opening for the American side in the inevitably bumpy transition in the Foreign Secretary's office. The debate that ensued in the meeting was one that outlined the positions of the various actors and the main lines of argumentation regarding the Cuba question that unfolded over the next few months. Calhoun, eager for Cuba, relayed a conversation that he and Thomas Jefferson had concerning Cuba two years previous. In it, Jefferson indicated that Cuba was a desirable goal even if seizing it threatened war with Britain. Calhoun suggested that the President present Mr. Sanchez's offer to Congress and determine the warmth of the response. Adams rejected this course, correctly presuming that any discussion with Congress would be made public almost immediately. The subsequent publicity offered the British time to prepare a defensive political and military 
response. Adams also had a sense of unease with the messenger, not knowing who Sanchez worked for or the degree to which sentiment on the island as a whole was inclined toward the United States. While Adams hungered for Cuba he urged caution as he feared, "in the present state of our maritime forces, we could not maintain a war against Great Britain for Cuba. I held it for certain that a war with Great Britain for Cuba would result in her possession of that island." 49 Secretary of War Calhoun agreed with this evaluation of American military capacity, although he was more apt to gamble. Adams and Calhoun also shared a deep-seated fear of a race rebellion that might bring the island's slaves to power. Therefore, the Cabinet decided that the United States position would be to gain time and wait for a more opportune moment for amalgamation of the island into the American family. Adams suggested that the Cubans be told that the President lacked the authority to promise statehood to the island. Furthermore, he wrote, I doubted the authority of not only the Executive, but of Congress, to perform this. Mr. Jefferson through the case of Louisiana had settled the Constitutional question. But a transaction which should make an island separated from this continent by the ocean at once a member of the Union, with a representation in both houses of Congress, would certainly be an act of more transcendent power that a mere purchase of a territory contiguous to our own. ${ }^{50}$

The Monroe administration therefore encouraged the Havana group to keep their ties with Spain, although those relations should be kept cool. This approach was a risky proposition, particularly as it encouraged the Cubans to perhaps look toward the British for assistance. Adams correctly figured, however, that the British government might find itself in much the same international position as the United States; therefore they too would be unlikely to help the Cubans. The ultimate decision, although not without much prevarication by the President and

\footnotetext{
${ }^{49}$ Charles Francis Adams, ed., Memoirs of John Quincy Adams Comprising Portions of His Diary 1795-1848, Vol. 6 (Philadelphia: J. Lippincott \& Co., 1923), 71.

${ }^{50}$ Ibid., 72.
} 
revisited once again in the early months of 1823, was a victory for Adams and kept Cuba in the weakest hands until such time as the United States found itself in a more promising position.

Adams was correct on a very important point in the Cabinet negotiations. Even without word of Sanchez's offer going to Congress, the British caught wind of the Havana group's overture to the Americans. The new Foreign Secretary, George Canning, quickly caught up to speed on the situation after receiving information from his representative in Havana. In a letter to his representative at the Verona conference, Lord Wellington, Canning displayed his sensibilities, which were quite at odds with the Continental focus of his predecessor Castlereagh.

Every day convinces me more and more, that in the present state of the World, in the present state of the Spanish peninsula, and in the present state of the country, the American questions are out of all proportion more important to us than the European, and that, if we do not seize and turn them to our advantage in time, we shall rue the loss of an opportunity never, never to be recovered. ${ }^{51}$

Canning went on to outline what the policy of the United States looked like from his vantage point. His main concern, even as Verona unfolded, was the aggression that he sensed in the stance of the United States toward Cuba. Despite promises from Adams to British Ambassador Stanford Canning that the United States had no interest in taking Cuba, George Canning feared that transfer of the island might be forced by the United States as repayment for Spanish depredations on American shipping in the Caribbean. He told his ambassadorial staff in a circular letter of December 10, 1822 that the occupation of Cuba by the United States would be the harshest blow to the interest of Britain and that all measures must be taken to prevent the island's transfer. One of these measures was the approval for an armada to the Caribbean that would serve an important double purpose. Canning hoped a more robust naval presence might address Britain's own issues with Cuban piracy and simultaneously block United States

\footnotetext{
${ }^{51}$ Edward Stapleton ed., Some Official Correspondence of George Canning 1821-1827, Vol. 1 (London: Longman, Green, \& Co., 1887), 49.
} 
ambitions on the island with a foreboding show of British power. Canning also informed the French Prime Minister of his naval intentions. The aggressive British stance, which threatened to quickly militarize the Caribbean, in turn prompted the French Foreign Minister in Washington, on orders from the French Prime Minister, to inform Adams of his government's concerns in the Caribbean. The French, distracted with their forays on the Spanish peninsula, adamantly opposed British intentions in the Western Hemisphere, particularly as they entertained a fanciful joint Spanish/French undertaking designed to reestablish Ferdinand's control over South America. Cuba would be a natural repository for troops and armaments in the buildup for such and invasion and the island, the French self-interestingly argued, must remain under Spanish control. $^{52}$

While seemingly a settled issue, the Monroe administration again confronted the threat of transfer in Cuba following the invasion and reconquest of Spain by France beginning in 1823. Adams's attention turned toward the possible reconquest of the Spanish Empire under the auspices of the Holy Alliance. A war in Europe pitting Britain against the Holy Alliance, with Spain the prize, raised the possibility that Cuba might become payment to Britain by a thankful Spanish liberal government. At a cabinet meeting on March 17, 1823, President Monroe proposed to offer Canning a mutual promise not to take Cuba that Adams and Calhoun both recommended against. In a letter of instruction to the United States minister to Spain, Hugh Nelson, Adams condensed the position and importance of Cuba down to its most basic form while demonstrating his confidence that reoccupation of the South American republics was beyond the ability of the Holy Alliance.

\footnotetext{
${ }^{52}$ Harold W.V. Temperley, The Foreign Policy of Canning 1822-1827 (Hamden, CT.: The Shoe String Press, 1925), 76-108. Norihito Yamada "George Canning and the Spanish Questions, September 1822 to March 1823," The Historical Journal 52, no. 2 (2009) 343-362, also deals with Canning's diplomacy but focuses more on his efforts in Europe.
} 
Whatever may be the issue of this war, as between those two European powers, it may be taken for granted that the dominion of Spain upon the American continents, North and South, is irrecoverably gone. But the islands of Cuba and Porto Rico still remain nominally and so far really dependent upon her, that she yet possesses the power of transferring her own dominion over them, together with the possession of them to others. These islands, from their local position, are natural appendages to the North American continent' and one of them, Cuba, almost in sight of our shores, from a multitude of considerations has become an object of transcendent importance to the political and commercial interests of our Union. Its commanding position with reference to the Gulf of Mexico and the West India seas; the character of its population; its situation midway between our southern coast and the island of San Domingo; its safe and capacious harbor of Havana, fronting a long line of our shores destitute of the same advantage; the nature of its productions and of its wants, furnishing the supplies and needing the returns of commerce immensely profitable and mutually beneficial; give it an importance in the sum of our national interests, with which that of no other foreign territory can be compared and little inferior to that which binds the different members of this Union together. Such indeed are, between the interests of that island and of this country, the geographical, commercial, moral, and political relations, formed by nature, gathering in the process of time, and even now verging to maturity, that in looking forward to the probably course of events for the short period of half a century, it is scarcely possible to resist the conviction that the annexation of Cube to our federal republic will be indispensable to the continuance and integrity of the Union itself. It is obvious however that for this event we are not yet prepared...But there are laws of political as well of physical gravitation; and if an apple severed by the tempest from its native tree cannot but fall to the ground, Cuba, forcible disjoined from its own unnatural connection with Spain, and incapable of self-support, can gravitate only towards the North American Union, which by the same law of nature cannot cast her off from its bosom... They [these reasons] are now touched upon to illustrate the position that, in the war opening in Europe, the United States have deep and important interests involved. The condition of Cuba cannot but depend upon the issue of this war. As an integral part of the Spanish territories, Cuba had been formally and solemnly invested with the liberties of the Spanish Constitution [of 1812]. To destroy those liberties, and to restore in the stead of this Constitution the dominion of the Bourbon race, is the avowed object of this new invasion of the [Spanish] Peninsula...To confine ourselves to that which immediately concerns us, the condition of the island of Cuba, we know that the republican spirit of freedom prevails among its inhabitants... Hitherto the wishes of this government have been that the connection between Cuba and Spain should continue, as it has existed for several years. These wishes are known...These wishes continue...The transfer of Cuba to Great Britain would be an event unpropitious to the interests of this Union... The question both of our right and our power to prevent it, if necessary, by force, already obtrudes itself upon our councils, and the administration is called upon, in the performance of its duties to the nation, at least to use all the means within its competency to guard against and forefend it. ${ }^{53}$

The British, realizing that they were now on the defensive after Adams clear statement of purpose, made a startling offer on August 16, 1823. British Foreign Secretary George Canning

\footnotetext{
${ }^{53}$ Worthington Chauncey Ford, ed., Writings of John Quincy Adams, Vol. 7 (New York: Macmillan, 1917), 378382 .
} 
put to Richard Rush, United States minister at London, a request that both nations issue a joint declaration opposing any attempt by France or other European nation to take possession of Spain's colonies. However broad the proposal, Canning's interest focused on Cuba and the motives behind it were less well-intentioned than they at first appeared. The Foreign Secretary, fighting a war on two fronts - moving against the continental European powers and their league against Spain while simultaneously moving to check United States power in the Caribbean sought an ally in the United States for his own policy reasons. His proposal was a deft move that hoped to entice the Americans into a pledge that prevented, through a self-denying agreement, future American expansion into the Caribbean. Canning also hoped to enlist an ally in league with him to counteract any potential hostilities by the Holy Alliance against the South American republics. ${ }^{54}$

Canning's offer did much in reaffirming the philosophical positions Adams developed in the three years previous, vis-à-vis the British. The ensuing cabinet debates also solidified Adams' position within the Monroe cabinet as both the chief opinion maker and diplomatic influence on the President. He argued that the time was propitious to take a stand against the Holy Alliance while declining the overture from Britain. "It would be more candid, as well as more dignified, to avow our own principles explicitly to Russia and France, than to come in as a

\footnotetext{
${ }^{54}$ Canning's offer included five key points. "Is not the moment come when our Governments might understand each other as to the Spanish American Colonies? And if we can arrive at such an understanding, would it not be expedient for ourselves, and beneficial for all the world, that the principles of it should be clearly settled and plainly avowed? For ourselves we have no disguise. 1. We conceive the recovery of the Colonies by Spain to be hopeless. 2. We conceive the question of the recognition of them, as Independent States, to be one of time and circumstances. 3. We are, however, by no means disposed to throw any impediment in the way of an arrangement between them, and the mother country by amicable negotiation. 4 . We aim not at the possession of any portion of them ourselves. 5 . We could not see any portion of them transferred to any other Power, with indifference. If these opinions and feelings are as I firmly believe them to be, common to your Government with ours, why should we hesitate mutually to confide them to each other; and to declare them in the face of the world? It would at the same time put an end to all the jealousies of Spain with respect to her remaining Colonies-and to the agitation which prevails in those Colonies, an agitation which it would be but humane to allay; being determined (as we are) not to profit by encouraging it." "British Foreign Secretary George Canning's Overture for a Joint Declaration with the United States on the Spanish Colonies in America, 1823," accessed March 21, 2011, http://www.mtholyoke.edu /acad/intrel/canning.htm.
} 
cock-boat in the wake of the British man-of-war." ${ }^{\text {55 }}$ Adams, seizing upon Canning's pressure point of South American recognition, pushed for the rejection of the offer by counter offering a proposal that Adams knew Canning could not accept - the immediate recognition of the South American republics. Canning, if he was too supportive of recognition, threatened to alienate the liberal Spanish government struggling for sources of revenue along with its very existence. If the liberal del Riego government could hold out against a French/Holy Alliance invasion and turn the corner with the Spanish economy, they might offer themselves as a strong counter-balanced ally for the British in Europe. Conversely, delaying recognition allowed the United States to gain ground, particularly in economic terms, with the South American republics. Adams, not as concerned with European geopolitics as was Canning, had a much freer in choosing the paths available to him. This freedom allowed the issue of recognition to be a pivot-point for the articulation of a new policy from the United States. The issue of recognition was clear-cut for the United States - the nation was desirous of Texas and Cuba and, after the power shown by Adams against feeble Spanish protests during negotiations of Transcontinental Treaty, there was little to stand in the way. Recognition of the South American republics and championing republicanism throughout the hemisphere placed the United States in an extremely strong material and moral position and with it a directorial post at the head of the American republican community. If the British rejected the offer of joint recognition, the United States could go to their republican brethren and stand with them in solidarity, alone among the nations of the world on the highest of moral ground.

The rumor that the Holy Alliance might take action against the Western hemisphere, after dealing with the mainland Spanish situation, was one that Adams never took seriously. He was

\footnotetext{
${ }^{55}$ Adams, Memoirs, 179.
} 
more interested in the status of Cuba in a Bourbon controlled Spain, fearing as he did that the French might compel Ferdinand VII to transfer control of the island as repayment for their help in repositioning him on the Spanish throne. Adams also feared that the British might move against Cuba in the resulting vacuum created by French invasion of Spain. Yet, Canning was in a conciliatory mood on the issue of Cuba and sought to ease American concerns. His offer of jointdeclaration, while not completely altruistic, sought to ensure a 'hands-off' policy in regards to Cuba. Canning also feared losing the Americans as allies, thus making his economic policies in the hemisphere more difficult and possibly more combative against an emboldened and hostile United States merchant marine. Canning, having ostracized the European continental powers, sought to "prevent the drawing of a line of demarcation which I most dread - (hemispheric) America versus Europe. ${ }^{, 56}$ However, his position was not one of panic but rather one of pivot as well. He realized that if the United States rejected his joint declaration, the British government might gain the upper hand with the new republics. Canning could use United States rejection as a demonstrative signal to the South Americans that the British were more supportive of their cause as well as simultaneously unmasking American expansionist desire in the Caribbean. Added to Canning's geopolitical concerns was his need to solidify his position in the Foreign Office. He was uncertain of British military footing in regards to potential hostilities unfolding simultaneously in Europe and the Americas and therefore could ill-afford a misstep if he was to retain his position. Given all these reasons and wishing not to disrupt the lucrative South American trade that British companies enjoyed, the British Foreign Secretary was in a dodgy mood as to his real intentions, a mood Ambassador Rush recounted to Adams in an official communiqué.

\footnotetext{
${ }^{56}$ Quoted in David M. Pletcher, The Diplomacy of Annexation: Texas, Oregon and the Mexican War (Columbia, MO.: University of Missouri Press, 1973), 39.
} 
Having perceived, since we had last been together, the publication in the newspapers of correspondence between a portion of merchants of London and the foreign office, respecting the appointment of consuls, or commercial agents, for the South American States, I asked Mr. Canning whether I was to infer that this government was speedily about to adopt such a measure, to which he replied in the affirmative, saying that commercial agents would certainly be soon appointed and sent out to the proper ports in those quarters. As to the proposals he had submitted to me, I said that I was sure that he would appreciate the delicacy of the ground upon which I stood. The United States, it was true, would view any attempt on the part of France and the Continental Alliance to re-subjugate those new States, as a transcendent act of national injustice and indicative of a progressive and most alarming ambition. Yet to join Great Britain in a declaration to this effect might lay them open in some respects to consequences upon the character and extent of which it became my duty to reflect with great caution before I made up my mind to meet the responsibilities of them. The value of the declaration, it was agreed, would depend on its being formally made known to Europe? Would not such a step wear the appearance of the United States implicating themselves in the politics connections of Europe? Would it not be acceding, in this instance at least in the relative position of one of its leading powers in opposition to the projects avowed by other powers? This heretofore had been no part of the system of the United States. Their foreign policy had been essentially bottomed on the maxim of keeping peace and harmony with all powers, without offending any. In this broad principle lay one of my difficulties under his proposals...He replied, that however just such a policy might have been formerly or might continue to be as a general policy, he apprehended that powerful and controlling circumstances made it inapplicable on the present occasion. It connected the United States under interests as immediate and commanding, as it did or could any states of Europe. The United States was the first power established on that continent and now confessedly the leading power. They were connected with Spanish American by their position, as with Europe by their relations. Was it possible that they could see with indifference their fate decided upon by Europe? Had not a new epoch arrived in the relative positions of the United States toward Europe, which Europe must acknowledge? Were the great political and commercial interests that hung upon the destinies of the new continent, to be canvassed and adjusted without some proper understanding between the United States and Great Britain as the two chief commercial and maritime states of both worlds ? $^{57}$

\footnotetext{
${ }^{57}$ Richard Rush to Adams, London (September 19, 1823 - Rec'd November 3) in The Writings of James Monroe, Vol. 1, ed. Stan Hamilton (New York: Putnam, 1902), 378-379. Holding him in his confidence, Adams gave Rush wide-ranging powers in dealing with Canning. The Ambassador used this power forcefully but judiciously in his dealings with Canning. In their next meeting of October 2, Rush rejected "a promise by Great Britain of future acknowledgement. To this intimation I gave an immediate and unequivocal refusal." That letter was not received in Washington until November 19. In the same diplomatic pouch was Rush's letter from his mid-October meetings with Canning. For October 10, Rush recounted that Canning "said nothing of Spanish American affairs, except barely to remark at parting, that he should send off consuls to the new states very soon." Two days later Rush indicated, "He (Canning) said not one single word relative to South America, although the occasion was altogether favorable for resuming the topic, had he been disposed to resume it. I therefore consider that all further discussion between us in relations to it is now at an end." Rush goes on to recount his precise knowledge of world events and their results on British policy, thereby validating Adams' confidence while providing the Secretary of State with supporting evidence for his belief that the South American republics were now safe from the Holy Alliance. "I had myself regarded the questions involved in the discussion as essentially changed by the arrival of the news of the convention of the $4^{\text {th }}$ of July between Buenos Aires and the Commissioners from Spain; and of the complete annihilation of the remnant of the royal forces in Colombia under Morales on the third of August, both pieces of intelligence have reached England since the twenty-sixth of September, the date of my last conference with Mr. Canning on the South American subject...Mr. Canning not having acceded to my proposal, or I to his, we stand as
} 
Secretary Adams, while convinced of the need for the United States to go it alone in defense of hemispheric republicanism and in the defense of Cuban non-interference, was only Secretary of State and therefore set about convincing the President in Cabinet meetings toward an ultimate decision on the issue. Adams also felt the impingement of time, as it was clear from Rush's memo that the British mood, even by late September, cooled considerably as Canning gave signals of a change in British policy toward both recognition and joint declaration. Although Canning never officially rescinded the offer, his change of heart was more a repudiation of spirit rather than words; his mood fully-changed by late August. Ironically, while Canning soured on the joint declaration relatively quickly, understanding correctly that Rush's immediate rebuff was indicative of his boss's positioning and that the United States was uninterested in being pulled into European matters of power, indications of Canning's change of heart did not officially arrive in Washington until December 1823. Therefore, the issue captivated the President and his Cabinet throughout the early Fall.

Monroe sought his own counsel apart from his cabinet and wrote to former Presidents Jefferson and Madison for their opinion on the British offer. The former Presidents were in agreement for acceptance of the now-rescinded offer. Jefferson offered his support based upon the precept that our best interests lie in keeping Britain out of the European theater.

By acceding to her proposition, we detach her from the bands of despotism bringing her mighty weight into the scale of free government and emancipate a whole continent at one stroke, which might otherwise linger long in doubt and difficulty. Great Britain is the nation that can do us the most harm of any one, or all on earth; and with her on our side we need not fear the whole world. Cuba alone seems at present to hold up a speck of war connection with Spain, and incapable of self-support to us. Its possession by Great Britain would, indeed, be a great calamity to us. Could we induce her to join us in guaranteeing its independence against all the world, except Spain, it would be nearly as valuable to us as if

\footnotetext{
we were before his first advance to me, with the exception only of the light which the intervening discussion may be supposed to have shed upon the dispositions and policy of England in this important matter," (378-389). Canning, in his abruptness and as the unfortunate victim of the slow speed of information travel, had indeed overplayed his hand.
} 
it were our own. But should she take it, I would not immediate go to war for it; because the first war on other accounts will give it to us; or the island will give itself to us, when able to do so. ${ }^{58}$

Madison, less convinced, also urged acceptance.

The professions we have made to these neighbors, our sympathies with their liberties and independence, the deep interest we have, and the consequences threatened by a command of their resources by the great powers confederated against the rights and reforms, of which we have given so conspicuous and persuasive an example, all unite in calling for our efforts to defeat the meditated crusade. It is particularly fortunate the policy of Great Britain, though guided by calculations different from ours, has presented cooperation for an object the same with ours. With that cooperation we have nothing to fear from the rest of Europe and with it the best assurance of success to our laudable views. There ought not therefore to be any backwardness, I think, in meeting her in the way she has proposed, keeping in view, of course, the spirit and forms of the road to war, which must be the last stop if those short of war should be without avail. ${ }^{59}$

Monroe remained unconvinced, despite the Virginians' considerable gravitas in such concerns.

Secretary of State Adams recounted Monroe's unsettled disposition on the issue in early

November and told of Calhoun's overriding fear of reconquest of South America in

condescending, almost comedic terms.

P.U.S. altogether unsettled in his own mind as to the answer to be given Mr. Canning's proposals and alarmed far beyond anything I could have conceived possible, with the fear that the Holy Alliance are about to restore immediately all of South American to Spain, Calhoun stimulates the panic and the news that Cadiz has surrendered to the French has so affected the President that he appeared entirely to despair of the cause of South America...Calhoun is perfectly moon-struck by the surrender of Cadiz and says the holy allies, with ten thousand men, will restore all Mexico and all South American to the Spanish dominion. I did not deny that they might make a temporary impression for three, four, or five years, but I no more believe that the holy allies will restore dominion upon the American continent than that Chimborazo will sink beneath the ocean. ${ }^{60}$

Adams also recounted the argument made by Calhoun, the Secretary of War's confidence now bolstered by Jefferson and Madison's approval of acceptance, and offered his own rejoinder against the acceptance position.

\footnotetext{
${ }^{58}$ Thomas Jefferson to James Monroe (October 7, 1823), in The Jeffersonian Cyclopedia (New York: Funk and Wagnall, 1900), 585.

59 "Madison's Letters to Monroe: A Vigorous Endorsement of the Monroe Doctrine, December 6, 1823," New York Times, January 17, 1896.

${ }^{60}$ Adams, Memoirs, VI, 185-186.
} 
Mr. Calhoun inclined to giving a discretionary power to Mr. Rush to join in a declaration against the interference of the Holy Allies, if necessary, even if it should pledge us not to take Cuba or the province of Texas, because the power of Great Britain being greater than ours to seize upon them, we should get the advantage of obtaining from her the same declaration we should make ourselves. I thought the cases not parallel. We have no intention of seizing either Texas or Cuba. But the inhabitants of either or both may exercise their primitive rights and solicit a union with us. They will certainly do no such thing to Great Britain. By joining with her, therefore, in her proposed declaration, we give her a substantial and perhaps inconvenient pledge against ourselves, and really obtain nothing in return. Without entering now into the inquiry of the expediency of our annexing Texas or Cuba to our Union, we should at the least keep ourselves free to act as emergencies may arise, and not tie ourselves down to any principle which might immediately afterwards be brought to bear against ourselves. ${ }^{61}$

Adams was at the forefront in recognizing that the joint declaration was in fact an attempt by

Canning to limit United States expansion throughout the hemisphere, and particularly in Cuba. In

fact, Canning had previously offered the liberal government in Spain a guarantee of Cuban

protection in exchange for their recognition of the new republics (an agreement rejected by the

soon to be deposed liberals and one he would later offer to Ferdinand VII). Canning's words,

unknown at the time to the Americans, supported Adams perspective.

The other and perhaps still more powerful motive is my apprehension of the ambition and ascendancy of the US. It is obviously the policy of that Govt to connect itself with all the powers of America in a general Transatlantic League, of which it would have the sole direction. I need only say how inconvenient such an ascendancy may be in time of peace, and how formidable in case of war. I believe we now have the opportunity (but it may not last long) of opposing a powerful barrier to the influence of the US by an amicable connection with Mexico,' which from its position must be either subservient to or jealous of the US In point of population and resources it is at least equal to all the rest of the Spanish colonies; and may naturally expect to take the lead in its connections with the powers of Europe. I by no means think it at present necessary to go beyond the mere relations of amity and commercial intercourse, but if we hesitate much longer, and especially if our commercial treaty [July 23, 1824] with Buenos Ayres should not take effect, all the new states will be led to conclude that we regret their friendship upon principle, as of a dangerous and revolutionary character, and will be driven to throw themselves under the protection of the US, as the only means of security. ${ }^{62}$

\footnotetext{
${ }^{61}$ Adams, Memoirs, VI, 177-178.

${ }^{62}$ Canning to Greenville (December 17, 1823), in George Canning, ed. Charles Petrie (London: Eyre \& Spottiswoode, 1946), 188.
} 
Canning meanwhile, recognizing that joint declaration was a moot point, moved on to other diplomatic pursuits. In October, he met with French Minster Prince de Polignac. Beginning on October 3 and ending with the memorandum of October 9-12, 1823, Canning extracted from the French a widely disseminated guarantee of non-interference in South America and gained protection for British commercial rights with former Spanish colonies. Canning garnered these guarantees by effectively threatening war to prevent reconquest and reasserted a commercial foundation to his government's interest in South American. "Great Britain," he said, "would recognize the independence of the South American colonies in case France should employ force in aid of their subjugation or if Spain herself, reverting to her old colonial system, should attempt to put a stop to the trade of Britain with those colonies." ${ }^{\text {"63 }}$ Polignac responded magnanimously.

France disclaims on her part any intention or desire to avail herself of the present state of the colonies, or of the present situation of France toward Spain, to appropriate to herself any part of the Spanish possessions in American, or to obtain for herself any exclusive advantages; and that like England, she would willingly see the mother country in possession of superior commercial advantages by amicable arrangements and would be contented, like her, to rank, after the mother country, among the most favored nations; Lastly, that she abjured in any case any design of acting against the colonies by force of arms. ${ }^{64}$

With the French threat contained, all that remained for Canning's concern was the ambition of the United States. Canning by this point, much like Adams, accepted the success of the South American independence movement and turned his attention to the certainty of Cuba

\footnotetext{
${ }^{63}$ Quoted in French Ensor Chadwick, The Relations of the United States and Spain: Diplomacy (New York: Scribner's \& Sons, 1909), 197-198.

${ }^{64}$ Ibid. Polignac went on to say "As soon as the King of Spain should be at liberty, he will enter into the question of the best arrangement between Spain and her colonies in concert with their allies and with Great Britain among the number. We could not conceive the meaning of an acknowledgement of simple independence so long as there exists no government offering any appearance of solidity and that such acknowledgement in such a state of things appeared nothing less than a real sanction of anarchy. It would be worth of the European governments to concert together the means of calming in those distant and scarcely civilized regions passions blinded by party spirit and to endeavor to bring back to a principle of union in government, whether monarchial or aristocratic, people among whom absurd and dangerous theories are now keeping up agitation and disunion." The ambiguity of the French statement, largely ignored by Canning, left a sense of incompletion to the debate, a sense that flared again regarding Cuba in 1825.
} 
staying in Spain's hands, thereby denying United States intrusion under the aegis of 'emergency' in the wake of a French invasion. Cuba in American hands, standing as it did between Britain's lucrative South American trade and Europe, was a thought that greatly concerned Canning and prevention of it consumed his policies.

Monroe and his Cabinet continued to debate the issues, as they were not informed of the French guarantee until December 13. This time lapse allowed Calhoun's concerns of the Holy Alliance and reconquest to continue to weigh on Monroe who remained indecisive. The time lapse also makes the decisions to issue the Monroe Doctrine and the Doctrine itself bolder still. November was a flurry of discussions, decisions, and much hand-wringing. On the $7^{\text {th }}$ of the month, news reached Washington of the fall of Cadiz to French troops, thereby completing the defeat of the liberal government in Spain. Monroe, shaken, received some good news from Rush via diplomatic pouch on the $16^{\text {th }}$. The Ambassador's recounting of Canning's coolness toward his own proposal gave credence to Adam's position - that rather than a good faith effort to counter the Holy Alliance, the proposal was in fact a ruse designed to check American power. Adams recounted the slight feeling of relief and the contours of continuing concern in his diary entry of November 18.

The President thinks from the tenor of the dispatch received yesterday from R. Rush that Canning has changed his purpose; that he was less alarmed; that probably some inducements had been presented, after the triumph of the French in Spain, to quiet his apprehensions. My own opinion is confirmed that the alarm was affected; that the object was to obtain by a sudden movement a premature commitment of the American government against any transfer of the Island of Cuba to France or against the acquisition of it by ourselves; and failing in that point he has returned to the old standard of belligerent policy... ${ }^{65}$

Monroe's decision cleared its last hurdle with the official United States rejection of Canning's joint declaration on November 29, a full two weeks prior to the Polignac declaration

${ }^{65}$ Adams, Memoirs, VI, 188. 
coming to light. The Monroe Doctrine, announced before Congress on December 2 also beat news of the French declaration to the American public. The quick declaration of the Doctrine certainly came before the official rejection of joint declaration reached London and offered Adams a certain degree of security against Monroe changing his mind in the face of an aggressive British reaction. Furthermore, Adams knew that whatever reaction the British might offer would be minimized, regardless of its tenor, with the quick arrival in London of news of the Monroe Doctrine on the heels of the rejection note.

The Doctrine, as the diplomacy, had Adams' fingerprints all over it. The Secretary of State long-advocated many of its core principles and wrote often of these tenets in his official communications. However, while Adams' presence and influence was dominant, it represented a fairly unified strategy of Monroe's chief advisors. The Doctrine concerned itself with two primary principles: noncolonialization, which forbade European countries from establishing new colonies in the Western Hemisphere; and nonintervention, which precluded the United States from participating in the military affairs of Europe. Added to these was the pervading spirit of nontransfer, developed in a letter from Adams to Russian minister de Tuyll and echoed in the summary of these discussions given by Monroe at the beginning of his speech presenting the Doctrine to Congress. Nontransfer argued against the transfer, by one European power to another, of any possession in the Western Hemisphere. ${ }^{66}$ This last issue clearly pertained to Cuba and was the most important of all American concerns. With the issue of South American recognition largely tabled and the traditional willingness of the United States to avoid European affairs outside of the hemisphere, the Monroe Doctrine introduced nothing that 'new' to

\footnotetext{
${ }^{66}$ This nontransfer idea had long been circulated by Adams dating back officially to April 1823, when the Secretary of State warned the Spanish directly against selling Cuba to Britain. Of course, this expectation unofficially guided United States policy throughout the nineteenth century.
} 
American foreign policy. However, in the area of nontransfer, the Doctrine codified a bold new

initiative that sought to guarantee that Cuba would continue to rest in the weakest hands of

Europe. Monroe outlined the interest and sympathies Americans had toward the populations of

South America, while highlighting all that separated the polity and political system of Europe

and America. He argued for continued good relations between the continents but warned

European governments away from interference with the Western Hemisphere.

We owe it, therefore, to candor and to the amicable relations existing between the United States and those powers to declare that we should consider any attempt on their part to extend their system to any portion of this hemisphere as dangerous to our peace and safety. With the existing colonies or dependencies of any European power we have not interfered and shall not interfere. But with the Governments who have declared their independence and maintained it, and whose independence we have, on great consideration and on just principles, acknowledged, we could not view any interposition for the purpose of oppressing them, or controlling in any other manner their destiny, by any European power in any other light than as the manifestation of an unfriendly disposition toward the United States. In the war between those new Governments and Spain we declared our neutrality at the time of their recognition, and to this we have adhered, and shall continue to adhere, provided no change shall occur which, in the judgment of the competent authorities of this Government, shall make a corresponding change on the part of the United States indispensable to their security. The late events in Spain and Portugal show that Europe is still unsettled. Of this important fact no stronger proof can be adduced than that the allied powers should have thought it proper, on any principle satisfactory to themselves, to have interposed by force in the internal concerns of Spain. To what extent such interposition may be carried, on the same principle, is a question in which all independent powers whose governments differ from theirs are interested, even those most remote, and surely none more so than the United States. Our policy in regard to Europe, which was adopted at an early stage of the wars which have so long agitated that quarter of the globe, nevertheless remains the same, which is, not to interfere in the internal concerns of any of its powers; to consider the government de facto as the legitimate government for us; to cultivate friendly relations with it, and to preserve those relations by a frank, firm, and manly policy, meeting in all instances the just claims of every power, submitting to injuries from none. But in regard to those continents circumstances are eminently and conspicuously different. It is impossible that the allied powers should extend their political system to any portion of either continent without endangering our peace and happiness; nor can anyone believe that our southern brethren, if left to themselves, would adopt it of their own accord. It is equally impossible, therefore, that we should behold such interposition in any form with indifference. If we look to the comparative strength and resources of Spain and those new Governments, and their distance from each other, it must be obvious that she can never subdue them. It is still the true policy of the United States to leave the parties to themselves, in the hope that other powers will pursue the same course. ${ }^{67}$

\footnotetext{
${ }^{67}$ James Monroe, “Address to a Joint Session of Congress - December 2, 1823," accessed March 21, 2011, http://www.ourdocuments.gov/doc.php?flash=true \&doc=23.
} 
While the Doctrine had no force of law or significant military power behind, George Canning well understood its importance - the United States sought its position at the head of the American table and, with it, influence over affairs throughout the hemisphere. For Canning, this influence threatened British commercial dominance and had to be attended to through a variety of policy pressures. Free from his moral commitment to the defeated liberal rebels in Spain, Canning recognized the South American republics in closing months of 1824. However, it was the Cuba question that burned hottest between the issuance of the Monroe Doctrine and Simón Bolívar's Panama Conference of 1826. These intervening two years were a tumultuous time for the diplomacy concerning Cuba.

Diplomats and various heads of state centered the island as the prize in international affairs. The four main competitors, with some defensive interest shown by Colombia and Mexico, were: 1. The United States - still fearing itself too weak to take the island and defend itself from the inevitable British backlash, and not wanting to push the French and British toward each other - sought to protect the island as a colony of Spain; 2. Great Britain - not wishing to instigate war with the United States and fearing a wider European war with the Holy Alliance over Cuba - sought to keep the island in Spain's hands; 3. France - still reeling from the loss of Saint Domingue and emboldened by its recent successes in Spain - was happy to protect Spain's claim to the island which they saw as a de facto French claim; 4. Spain - seeking to retain some revenue from and dignity in their colonial lands - was happy to retain claim and use Cuba's possession as an important chip in their foreign policy gambling. Two important events occurred in this two-year period that shaped perceptions going into the Panama Conference. First, the French sent a robust fleet to the Caribbean that threatened the delicate balance of power there. 
Second, Mexico and Colombia, fearing their still-solidifying sovereignty, threatened military intervention into Cuba.

With the last remnants of Spanish troops losing their fight against South American republican armies in the spring of 1825, the foreign ministers of Mexico and Colombia sought interviews with the new United States Secretary of State, Henry Clay, to further discuss the fate of Puerto Rico and Cuba. The representatives made the Secretary aware of the two states' desire to invade Cuba, not only to free the colony but also to prevent the Spanish or French from using the island as a base for reconquest operations against their new republics. For Clay and the newly elected President, John Quincy Adams, the Mexican and Colombian concerns were plausible and well-received, even if they placed the United States government in a difficult position. The nontransfer principle of the Monroe Doctrine only applied to European transfer of colonies and, since Mexico and Colombia were not European countries and since they desired the freedom of Cuban territory for perfectly legitimate ends, the United States had little ground on which to protest. The Colombia/Mexico desire contrasted starkly with the American hopes of keeping Cuba in the weakest European hands. However, the Adams administration would find itself in a most indefensible position with its South American brethren if the United States stood in the way of the final expulsion of Spanish power from the hemisphere. Furthermore, Adams and Clay worried that even a combined force of Mexican and Colombian soldiers couldn't hold the island in the face of Spanish and perhaps French resistance. Even if the new republics were successful and after such time as the liberation forces might turn over governance to the Cubans, the concern for United States policymakers remained as to whether the island's new leaders could effectively police, protect, and govern themselves. Social conditions on the island were very different from the pre-independence situations in South America and for the United States, the 
overriding fear of chaos in Cuba promoting a racialized uprising, caused grave concern among

the President's cabinet. Adams confined to his diary his concerns.

It was apparent that the Spanish domination was annihilated on the American continent...But Cuba still remained in her possession and was a post of annoyance, both against Mexico and Colombia. However, from its situation, and the character of its population, it could only prove a useless and unsupportable burden to them. Neither were the United States desirous of making it part of their confederation. But the island was at their doors: they could not suffer it to be transferred from Spain to any European power, nor could they willingly see it conquered, either by Mexico or Colombia. Cuba was to the United States an object of paramount commercial importance. The capital employed in the trade was greater than that with all the dominions of France, the tonnage employed in it nearly equal to that with Great Britain. Therefore, we are content that it should remain in its present condition under the dominion of Spain but enjoying free trade with us. ${ }^{68}$

Adams spoke to Russian Ambassador de Tuyll in hopes of having Russia intervene with Ferdinand VII and encourage the king toward recognition of the republics. This recognition would cool the concerns of Mexico and Colombia as to Spanish intentions and prevent a slave uprising in Cuba and Puerto Rico that might make Spain's continued control of the islands more difficult. The specter of a slave uprising concerned Adams and Clay the most. They feared that if the Cubans, in the resulting independence arising from a joint Mexican/Colombian intervention, failed to keep internal discipline on their plantations or if they moved, as had Bolívar, toward emancipation, the American South might not be able to weather the storm as well as the region did after the Haitian uprising. Clay wrote a note to the Russia Ambassador, delivered by the latter's American counterpart, Henry Middleton, outlining American concerns.

But, if the United States have seen with satisfaction in the efforts of the nations of the American continent to withdraw themselves from the yoke of Spanish domination, it is not so with regard to the islands of Cuba and Porto Rico. The character of the population of these islands renders extremely problematical their capacity to maintain independence. A premature declaration would probably result only in the afflicting repetition of the disastrous scenes of St. Domingo ${ }^{69}$

\footnotetext{
${ }^{68}$ Adams, Memoirs, VII, 9-10.

${ }^{69}$ Henry Clay to Count Nesselrode, July 14, 1825 quoted in Niles National Register, Vol. 30 (Baltimore: Franklin Press, 1826), 114.
} 
Clay, echoing similar concerns to the American Minister in Spain, Alexander Everett, feared that

the United States might soon become embroiled in a war over Cuba.

True wisdom dictates that Spain, without indulging in unavailing regrets on account of what she has irretrievably lost, should employ the means of retaining what she may yet preserve from the wreck of her former possessions...not a solitary foot of land from the western limits of the United States to Cape Horn owns her sway; not a bayonet in all that vast extent remains to sustain her cause. And the Peninsula is utterly incompetent to replace those armies which have been vanquished and annihilated by the victorious forces of the new Republics. What possible object, then, can remain to Spain to protract a war which she can no longer maintain and to the conclusion of which there is only wanting the recognition of the new Governments by treaties of peace? If she can entertain no rational hope to recover what has been forced from her grasp, is there not great danger of her losing what she yet but feebly holds. The armies of the new states, flushed with victory, have no longer employment on the continent, and yet while the war continues, if be only in name, they cannot be disbanded without a disregard of all the maxims of just precaution. To what object will the new Republics direct their powerful and victorious armies? Will they not strike wherever they can reach? And from the proximity and great value of Cuba and Puerto Rico, is it not to be anticipated that they will aim, and aim a successful blow, too, at those Spanish islands? It is not, then, for the new republics that the President wishes you to urge upon Spain the expedience of closing the war...the maritime force of the Republics of Mexico and Colombia is not now nor is it likely to be adequate to the protection of the islands. The United States would entertain constant apprehensions of their passing from their possession to that of some less friendly sovereignty. And of all the European Powers, this Country prefers that Cuba and Porto Rico should remain dependent on Spain. If the war should continue and those islands become the theater of it, their fortunes have such connection with the prosperity of the United States that they could not be indifferent spectators' and the possible contingencies of such protracted war might bring upon the government of the United States, duties and obligation, the performance of which, however painful it should be, they might not be at liberty to decline. ${ }^{70}$

The Russians accepted the diplomatic task. Ferdinand VII, however, was unmoved and rejected the offer. This left the bulk of the diplomacy to Clay, Adams, and Canning.

Conditions in Cuba dictated great concern as well. Taking their inspiration from Simón

Bolívar, encouraged by his victory, and perhaps meeting with the Liberator personally, a group of Cuban creoles, El Soles y Rayos de Bolívar, presented their secret plans to a wider circle of supporters in Havana in early 1825. They called for annexation to Colombia, not the United States and sought South American support for their undertaking. Ultimately, the Spanish

\footnotetext{
${ }^{70}$ Clay to Everett (April 20, 1825), in The Papers of Henry Clay, Vol. 4, ed. James Hopkins (Lexington, KT.: University of Kentucky, 1972), 298.
} 
authorities had little trouble in putting the conspiracy down since post-1800 demographic changes on the island mitigated the dangers of generalized unrest on the island. Pro-Spanish French immigrants fleeing Haiti and the arrival of thousands of peninsulares from South American republics after independence buoyed Cuba's political and domestic stability. Regardless, the attempts to link up with Colombian and Mexican efforts frightened all diplomats involved. Conservative Cubans on the island also expressed their concerns through a United States representative there.

The situation on the Island then is considered as extremely critical - that is the remark of everyone who speaks on the subjects - Americans, Europeans and Creoles all say that the present state of tings cannot last long. That their commercial and agricultural prosperity is not only destroyed, but their personal safety endangered. Now that Bolívar is successful and released from further exertion in favor of Peru, they look forward, some with joy, some with fear, to invasion of the Island. ${ }^{71}$

Another menacing event took place in the summer of 1825 . The French sent orders to their governor, Count Donzelot, in Martinique encouraging him to not fear sending troops to Cuba should the need to restore order arise in the wake of any aggression taken against the island. Toward the end of May, Donzelot happily authorized French ships to give passage to Spanish soldiers leaving Peru for Cuba. ${ }^{72}$ American and British suspicions toward these actions grew when 28 additional ships reinforced the French squadron in the Caribbean. Furthermore, Ambassador Everett reported to Secretary Clay that Ferdinand VII had recently asked 35,000 French troops to stay on in Spain as the larger French force began their retreat from the peninsula. The Mexican government, fearing French intrigue and rejecting that nation's arguments that the bolstering of French naval power was simply an effort to assist new

\footnotetext{
${ }^{71}$ T.B. Robertson to Henry Clay (April 20, 1825), in Papers of Henry Clay, 272.

${ }^{72}$ On the situation in Martinique see Rebecca Schloss, Sweet Liberty: The Final Days of Slavery in Martinique (Philadelphia: University of Pennsylvania, 2009), chs. 1-3; John Savage, "Between Colonial Fact and French Law: Slave Poisoners and the Provostial Court in Restoration-Era Martinique," French Historical Studies 29, no. 4 (Fall 2006), 565-594; and Marco Fioravanti, "Domestic Enemy: Poisoning and Resistance to the Slave Order in the $19^{\text {th }}$ Century French Antilles," Historia Constitucional 14 (2013), 503-524.
} 
commercial relationships with South American republics, called upon the United States to live up the precepts of the Monroe Doctrine. The failure to robustly counter French aggression would force the Mexicans and Colombians to take on the mantle of such protection themselves. The Mexican government reminded the United States that just as the French launched their invasion of Spain in 1823 under the auspices of preventing the spread of yellow fever there, they could again easily launch aggression against Cuba under the plea of collecting debt from Haiti or Spain.

George Canning seized upon the chaos once again, suggesting a British, French, American tripartite pact guaranteeing the neutrality of all parties and the sanctity of Spanish possession of Cuba. The French rebuffed the offer, with United States Ambassador to Britain Rufus King following suit on November 20, 1825. Canning, once again out maneuvered in the Caribbean by the United States, smartly stayed out of the Mexico/Colombia negotiations and bided his time as diplomatic events continued to unfold with the United States now taking the lead. French disavowal of designs on Cuba, passed diplomatically to the United States in September, satisfied American policymakers and Secretary Clay moved quickly to smooth over the issues. On December 20, Clay sent letters to Mexican and Colombian diplomats asking them to divert their aggressive course toward Cuba. These letters found Mexico and Colombia in amendable moods as each had lost interest in pursuing the course against Cuba that had so concerned Canning, Clay, and Adams. Both nations became much more interested in beginning the process of commercial negotiations with Britain and Canning undoubtedly pressured both countries' governments to drop their interests in Cuba as a prerequisite. Mexico and Colombia decided to wait until the upcoming Panama Congress in order to put the issue of Spain's continued presence in Cuba to a wider chorus of interested parties. Ultimately, the Mexican and 
Colombian threats most likely aimed to prompt the exact diplomatic exchange over Spanish recognition that ensued between the United States and Spain. Regardless, the Mexican and Colombian governments shifted their focus away from aggression and toward commercial agreements. The French threat evaporated as well, then driving the attentions of both the Americans and British toward the Panama Congress. ${ }^{73}$

Concurrent to the diplomacy of 1825 was the issue of the upcoming Panama Congress set for the summer of 1826. First envisioned by Bolívar in 1824, the preparations for the PanAmerican gathering proceeded throughout 1825 and became an important point of negotiation even as the threats from Mexico, Colombia, and France unfolded in the Caribbean. Mexico and Colombia made their interest in United States attendance known as early as November 1825 with the delivery of diplomatic letters inviting an American delegation to the Congress. The two countries hoped to entice attendance using laudatory language focused on the unique perspective the United States offered the Congress on issues such as, the clarification of international law, the possibilities of an inter-American alliance based on the Monroe Doctrine, and the abolition of the slave trade. ${ }^{74}$ These offers prompted the United States to send its cease and desist in Cuba request to the governments of Mexico and Colombia in a not too subtle quid pro quo for attendance at the conference. All parties involved hoped the conference would also become the terrain of commercial rationalization in the new era of independence, with the new republics hoping to maneuver themselves among the shoals of British and American interests. Therefore, both Adams and Canning rightfully saw the Congress of paramount importance as the geo-

\footnotetext{
${ }^{73}$ William Manning, Early Diplomatic Relations Between the United States and Mexico (Baltimore: Johns Hopkins Press, 1916), 60-75; Josef Opatrny, U.S. Expansionism and Cuban Annexationism in the 1850s (Prague: Charles University, 1990), 40-60.

${ }^{74}$ Bolívar outlined a nine-point plan in February 1825. Among other issues were the continuing issue of freeing Cuba and Puerto Rico, recognition of Haiti, the condition of slavery throughout the hemisphere, taking a naval war to the shores of Spain, and considering freeing other Spanish possession such as the Philippines.
} 
political and commercial landscape was in great flux, or so the Americans hoped. In reality, the Congress was a debacle for the Americans who failed to gain any significant trade opportunities and saw their opportunities instead taken up by British commercial concerns through the diplomatic efforts of a gleeful Canning.

Adams, despite his considerable political acumen and perhaps because of his considerable social priggishness, overshot the mark concerning the Panama Congress and grossly overestimated the political will on the part of American Congress to engage the new South American republics. He declared his willingness to send American delegates to Colombia for the Congress in his first Annual Message without having laid the proper political groundwork. Adams, compounding his mistake, called on the Congress to move past the bitterness of the campaign and their lack of progress on key issues during the first year of his Presidency. Not in the mood for such prodding, Adams' Congressional opponents seized upon the Panama Congress to make trouble for the President. Clearly attendance at the Congress was in the best interest of the United States and if taken only on that measure, Adams was well within his rights to assume attendance. However, he overlooked the political flashpoint that the Panama Congress' agenda might become with the Southern Congressional contingent. The opposition, led by Martin van Buren and a revived Virginia/New York faction, saw nothing to be gained for the United States in binding itself to the new Republics who sought discussion of emancipation at the Panama Congress. ${ }^{75}$ There was not much for the supporters of attendance and the President to offer in

\footnotetext{
${ }^{75}$ Representative of many comments in the Congressional debates, as well as their wide-ranging field of criticism and an overarching sense of paranoia, were those of Tennessee Senator Hugh Lawson White. On the issue of discussing slavery at the Panama Congress he said, "Mr. President, I object to sending Ministers for the discussion of any such subject [slavery]. This is a dilemma from which we cannot escape without disgrace. It is impossible now to foresee what may besot comport with the interests of the United States at and subsequent period; and ought to be left free to act, unfettered by any agreement whatever...of all subjects that could be thought of, none would be found more unfortunate that this. It was hoped, that, after rejecting the convention with Colombia upon this subject, the Senate would have no more of it from foreigners. If slavery is an affliction, all of our southern and western states have it...is it then fit that the United States should disturb the quiet of these states by the discussion and argument
} 
defense, as it was clear that the new Republics did indeed view slavery as a key issue to be

discussed at the Congress. Adams went in a different direction, downplaying the slavery issue,

and focused on the camaraderie and good will toward the United States that attendance might

produce. He also tried to dispel the notion that mere attendance violated the spirit and letter of

Washington's, still influential, Farewell Address. He cast doubt on the opposition's idea that the

South American republics sought United States attendance simply to raise the Monroe Doctrine

to the level of binding law.

Had not Washington predicted that by our union and rapid growth, with an efficient Government, the period was not far distance when we might defy material injury from external annoyance; when we may take such an attitude as will cause our neutrality to be respected, and, with reference to belligerent nations, might choose peace or war, as our

with the new Republics, upon any subject connected with slavery? I think not! Let us cease to talk of slavery in this house, let us cease to negotiate upon any subject connected with it." On the issue of the status of Cuba and Puerto Rico and the threat of Spanish/French reconquest he was adamant. "There colonies are convenient to the new [South American] States; which having expelled their enemies from their own territory, will probably stimulate a portion of the inhabitants of those Islands to rebel, to declare themselves independent of Spain and by united their forces with those revolted subjects, endeavor to put down the Spanish authorities in those Islands. What consequences are likely to flow from such a measure? Russia probably, and France almost certainly, would them immediately take part with Spain in the war... These new states have told us, they suspect that France is secretly furnishing Spain the means of continuing war...Suppose you sanction this mission [Panama Congress], your ministers discuss this subject, come to an agreement upon it, stipulate that if any neutral power interferes on the part of Spain and that the United States will take part with the new States. The United States will thus become one party in the war." On the issue of commercial relations in South America, White was skeptical Britain's intentions. "In this state of things what is to become of our own important interests, our commerce for example, to secure which we seem so anxious? Great Britain is ever attentive to her own interest, watching the course of events, and turning them to the advantage of her own subjects. Even now some fear she is at this Congress, not as a party but as a listener, and will gain some advantage by our delay: how will she act? She would take no part in the war. She would be neutral, the United States belligerent; and what then becomes of your commerce. It will be engrossed by your neighbor, who has been attending to her own interests, while you have been seeking distinction by neglecting your own concerns, and attending to those of other nations. But sir, if in this I mistake the course of Great Britain, and she should elect to take part in the war, it would probably be on the side of Spain" Finally on the issue of forming some type of Western Hemispheric alliance he cast great doubt on whether South Americans had the potential for such matters. "Ours is the best plan of government which has yet been devised, but if it is the best for the people of the United States, does it thence follow that it would be the best for every nation? Ours is the best for an intelligent and virtuous people; but it does not thence follow, that it would be best for an ignorant and vicious people... The whole project then is wrong in principle and therefore ought not to meet our sanction." White also spent a great deal of time attacking the right and legality of the President to even send ministers to Panama using a very detailed discussion of Senatorial powers under the Constitution. "The President has the power, with the advice and consent of the Senate, to appoint an ambassador; but as to all other offices they must be created by some statute of the United States. This [Panama] Congress is created by treaties among the Spanish American States. It has no sovereignty attached to it - then you cannon by the law of nations send any ministers to transact business with such a body... There is no office as yet created, and until one is created, neither the President along, nor he, with the advice of the Senate, can, consistently with the Constitution, proceed to fill it," quoted in Nancy N. Scott, ed., A Memoir of Hugh Lawson White (Philadelphia: J. B. Lippincott \& Co., 1856), 46-49. 
interests guided by justice should counsel. We were then the only independent nation of this hemisphere and we were surrounded by European colonies...these colonies have now been transformed into eight independent states, with whom we have an immensely growing commercial and must have and have already important political connections... The rapidity of our growth and the consequent increase of our strength, has more than realized the anticipations of this admirable political legacy...The acceptance of this invitation (to Panama) therefore, far from conflicting with the counsel of the wise policy of Washington, is directly deducible from and comfortable with it. Nor is it less conformable to the views of my immediate predecessor as declared in his annual message to Congress of $2 \mathrm{~d}$. December $1823 .^{76}$

Adams attempted to place his decision to attend the Panama Congress in a direct line to Washington's Farewell Address. However, his attempts to use the Monroe Doctrine in his defense and to elevate it to the lofty heights of the Farewell Address, imbuing it with the veneer of public law, fell short. Many in Congress refused to expand the Doctrine's precepts beyond the immediate circumstances that it confronted in 1823-24. Adams' opponents set about attacking his visionary domestic policy, with the Panama Congress becoming a casualty of their broadside against the President. Adams implored the Congress to allow United States representation in Panama, claiming it was in line with the best impulses of the nation's heritage. However, the intractability of the Southern perspective on slavery and the growing obstructionism shown by the President's opponents doomed any compromise. ${ }^{77}$ Georgia Senator John Berrien, a

\footnotetext{
76 Thomas Hart Benton, ed., Abridgment of the Debates of Congress 1789-1856, Vol. IX (New York: D. Appleton \& Co., 1856), 112. For Adams' possible influence on the Farewell Address see S.F. Bemis "John Quincy Adams and George Washington” Massachusetts Historical Society Proceedings 67 (1945), 365-384.

77 The press in the North was supportive of Adams but for different reasons than he hoped. Editorials throughout the North supported the President, aware of the commercial advantages that might be gained from the Congress. Their main hope for American attendance at the Congress was the elimination of competition from other trading partners, namely the British, angling for advantage in South America. These papers also strongly urged the continuation of American neutrality. While many of them wondered if the President had the Constitutional right to send delegates, they had little doubt that the U.S. should be in attendance to safeguard commercial interests. The press verdict was that while the U.S. should observe from the sidelines, unofficially lest the country be dragged into war, the papers had no particularly qualms with the South American states forming an alliance to push for their own interests. Northern editorialists were incensed at Southern refusal of participation based on the slavery issue and made their feeling clearly known. Southern papers predictably felt the opposite. This difference of opinion between the Northern and Southern press mirrored the debate in Congress between Southern and Northern legislators. The best treatment of press opinions during the debate and the debate's importance (and general lack of treatment) in the historiographical record is Frances L. Reinhold, "New Research on the First Pan-American Congress Held at Panama in 1826," The Hispanic American Historical Review 18, no. 3 (August 1938), 342-363. He holds that most
} 
Jacksonian Democrat who later became Jackson's first Attorney General, summed up the

objections of the Southerners in Congress to the agenda items of the Panama Congress dealing

with the status of Cuba and Puerto Rico as well as the issue of slavery.

When we look to the situation of those islands to the commanding position they occupy with reference to the commerce of the West India, we cannot be indifferent to a change in their condition. But when we reflect that they are in juxtaposition to a portion of the Union where slavery exists; then the proposed change is to be effected by a people whose fundamental maxim it is that he who would tolerate slavery is unworthy to be free; that the principle of universal emancipation much march in the van of the invading force; and that all the horrors or a servile war will too surely follow in its train - these merely commercial consideration sink into insignificance - they are swallowed up in the magnitude of the dangers with which we are menaced. With a due regard to the safety of the Southern states, can you suffer these islands to pass into the hand of buccaneers drunk with their new-born liberty? Cuba and Puerto Rico must remain as they are. To Europe, the President had distinctly said 'we cannot allow a transfer of Cuba to any European power.' We must hold a language equally decisive to the South American States. We cannot allow their principle of universal emancipation to be called into activity in a situation where its contagion from our neighborhood would be dangerous to our quiet and safety. The relations of Hayti with the American States and the rights of Africans in this hemisphere are two other questions to be 'determined.' Our policy toward Hayti has been fixed for three and thirty years. We trade with her, but no diplomatic relations have been established between us. We receive no mulatto consuls or black ambassadors from her. And why? Because the peace of eleven states in this Union will not permit the fruits of a successful negro insurrection to be exhibited among them. It will not permit the fact to be seen and told that for the murder of their masters and mistresses they are to find friend among the white people of the United States. No, this is a question which had been determined here for three and thirty year, it is one which cannot be discussed in this chamber this day' and shall we go to Panama to discuss it? ${ }^{78}$

Adams agreed that Cuba and Puerto Rico needed to remain in Spain's hand but he

responded valiantly in asserting that representation at the Congress was essential to American

security.

The purpose of this government is to concur to nothing which would import hostility to Europe or justly excite resentment in any of her states...the invasion of both Cuba and Puerto Rico by the united forces of Mexico and Colombia is avowedly among the objects to be matured by the belligerent states at Panama. The convulsions to which, from the peculiar composition of the population, they would be liable in the event of such an invasion, and the danger there from resulting of their falling ultimately in the hands of some European power other than Spain, will not admit of our looking at the consequences to which the congress at Panama may lead with indifference. It is unnecessary to enlarge upon

of the American public and Northern press supported attendance but that Congress, beholden to slavery interests, could not break the grip in time to send meaning representation, costing the country a great deal of economic gain.

${ }^{78}$ Benton, Abridgment of Debates, VIII, 421. 
this topic or to say more than that all our efforts in references to this interest will be to preserve the existing state of things, the tranquility of the island and the peace and security of its inhabitant. And lastly, the congress at Panama is believed to present a fair occasion for urging upon all the new nations of the South the just and liberal principles of religious liberty. ${ }^{79}$

After an immense expenditure of political capital, Adams finally got his way and Congress approved funding for the American representatives to the Panama Congress. Yet, the fight left Adams mortally wounded in domestic politics since attendance at the Panama Congress never paid a domestic dividend large enough for him to counter the political firestorm the ordeal created. Even worse, the Panama Congress was doomed from the beginning. Only four republics in addition to the United States sent delegates and, adding to that insult, the delegates of the United States, while sent, never arrived. John Sergeant, accused by Southerners in Congress of being an abolitionist, refused to travel to and endure Panama in June (although he did arrive after the Congress was over). Richard Anderson, coming from Bogotá, died en route on his grounded steamship outside of Cartagena. The only two men who derived any satisfaction from the Congress were George Canning and his representative Edward Dawkins. After four years of being out-maneuvered by the Americans, Canning had his revenge at Panama.

In honesty, however, Canning laid the groundwork for his success early on after the collapse of his joint declaration offer. He moved quickly against the United States in establishing trade relations and treaties with the new republics, paying particular attention to the Mexican government in early 1825 - the geographic location of the new Mexican State and the potential for isolating the United States from Central and South American notably focused Canning's attention. He declared victory almost immediately in a January 8 letter.

The thing is done...the Yankees will shout in triumph; but it is they who lose most by our decision. The great danger of the time - a danger which the policy of the European system

\footnotetext{
79 “John Quincy Adams Message to Congress March 15, 1826," quoted in Edward McPherson, The Political History of the United States, During the Great Rebellion (Washington, DC: James Chapman, 1882), 353.
} 
would have fostered, was a division of the World into European and American, Republican and Monarchical; a league of worn-out governments, on the one hand and of youthful and stirring nations, with the United States at their head, on the other. We slip in between; and plant ourselves in Mexico. The United States have gotten the start on us in vain; and we link once more American to Europe. Six months more - and the mischief would have been done. $^{80}$

However, Canning's opposition to United States policy was not just exhibited in his earlier commercial treaty-making but also at the Congress of Panama. He realized, without much initial knowledge of the United States Congressional headwinds hampering Adams' agenda, that if United States participation in the Panama Congress went unchecked, the British might find themselves in a disadvantageous commercial position in regards to the new Republics. He relayed these concerns and included dispatches between France and the United States in the directions he gave his representative at the Panama Congress, Edward Dawkins.

You will see how earnestly it is desired by the US, by France and by this country that Cuba should remain a Colony of Spain. The British Government indeed, so far from denying the right of the new States of America to make a hostile attack upon Cuba, whether considered simply as a possession of a power with whom they are at war, or as an arsenal from which expeditions are fitted out against them, that We have uniformly refused to join with the US in remonstrating with Mexico and Colombia against the supposed intention, or intimating that we should feel displeasure at the execution of it. We should indeed regret it but we arrogate to ourselves no right to control the operations of one belligerent against another. The Government of the US however professes itself of a different opinion. It conceives that the interests of the US would be so directly affected by either the occupation of Havana by an invading force, or by the consequences which any attack upon Cuba, even if unsuccessful, might produce in the interior of the island, that the Cabinet of Washington hardly disguises Its intention to interfere directly, and by force, to prevent or repress such an operation. Neither England nor France could see with indifference the US in occupation of Cuba. Observe, therefore, the complicated consequences to which an expedition to Cuba by Mexico or Columbia might lead, and let the States assembled at Panama consider whether it is worthwhile to continue a war, the only remaining operation of which, (that is likely to be sensibly felt by their adversary) is thus morally interdicted to them by the consequences to which it would lead. You will understand that to a league among the states, lately colonies of Spain, limited to objects growing out of their common relations to Spain, His Majesty's Government would not object. But any project for putting the US of North America at the head of an American Confederacy, as against Europe, would be highly displeasing to your Government. It would be felt as an ill return for the service which has been rendered to those states, and the dangers which have been averted from them, by the

\footnotetext{
${ }^{80}$ George Canning to Hookham Frere quoted in E.M. Lloyd "Canning and Spanish America" Transactions of the
} Royal Historical Society 18 (1904), 77. 
countenance and friendship, and public declarations of Great Britain; and it would too probably at no very distant period endanger the peace of American and Europe. ${ }^{81}$

With those instructions, which Dawkins did not shy away from repeating to the assembled dignitaries, he became the extension of Canning's aggressive stance in relation to gaining privilege with the new Republics. These Republics well-understood the commercial and military benefits to be gained as well as the generous loans and expanded European markets they would enjoy through the invitation of British commerce. Dawkins summed up the success of Canning's commercial vision for England in a dispatch from Panama.

The United States, he says, had failed to get any commercial treaties in its favor, owing to the opposition of Mexico and Peru. The general influence of the United States is not, in my opinion, to be feared. It certainly exists in Columbia, but it has been very much weakened even there by their protests against an attack on Cuba, and by the indiscretions they have committed at Madrid. ${ }^{82}$

The British Foreign Secretary, unlike Adams, not only did not fear the eastern and western hemispheres interacting but he actively encouraged that interaction as essential to British economic dominance. Canning realized, as Adams began to, that the Monroe Doctrine was a momentary answer to a temporary problem. Britain, enjoying the commercial advantages that it did in the Americas, did not need new territory just commercial influence in order to continue that dominance. Canning's refusal to concern himself with the Monroe Doctrine and his outright disdain for its precepts, exampled by his concerted efforts at tying the South American republics closer commercially to Britain, formed the core of his foreign policy. His vision, centered on South America, was both good for the economic health of his nation and was one that freed him from the entanglements of European continental politics. Canning, in his customary succinct way, blithely summarized the hubris of the Americans.

\footnotetext{
${ }^{81}$ Canning to Dawkins, March 18, 1826 quoted in Joseph Byrne Lockey, Pan-Americanism: Its Beginnings (New York: Macmillan Company, 1920), 366.

82 Dawkins to Canning, October 15, 1826 quoted in A.W. Ward ed., The Cambridge History of British Foreign

Policy (New York: Macmillan, 1922), 76.
} 
The avowed pretensions of the United States to put themselves at the head of the confederacy of all the Americans, and to sway that Confederacy against Europe (Great Britain included) is not a pretension identified with our interests, or one that we can countenance or tolerate. It is however a pretension which there is no use in contesting in the abstract, but we must not say anything that seems to admit the principle. ${ }^{83}$

He then sang the praises of his own decisions that had in once decisive stoke nullified the

Monroe Doctrine and eliminated the moral suasion the Holy Alliance and intervention by Europe might have enjoyed in the Western Hemisphere.

I looked to America to redress the inequalities of Europe. Contemplating Spain, such as our ancestors had known her; I resolved that, if France had Spain, it should not be Spain with 'the Indies.' I called the New World into existence to redress the Balance of the Old. ${ }^{84}$

Canning, while perhaps a bit high-handed with his language, had successfully turned the new

Republics away from the United States and toward Britain as their protector and benefactor. The

legalistic sentiment the United States mustered in a retaliatory effort designed to convince the

new Republics toward their camp, compared to Canning's holistic efforts, was somewhat less

soaring and certainly less convincing.

The declaration of the late President was that of the head of the Executive Government of the United States. Although there is every reason to believe that the policy, which it announced, was in conformity with the opinion both of the nation and of Congress, the declaration must be regarded as having been voluntarily made, and not as conveying any pledge or obligation, the performance of which foreign nations have a right to demand. ${ }^{85}$

After its failure at the Congress of Panama, the United States lost interest in and realized

the impossibility of establishing its hegemony over the hemisphere. ${ }^{86}$ Successive presidential

\footnotetext{
${ }^{83}$ Canning to Vaughan, February 18, 1826 quoted in The Cambridge History of British Foreign Policy, 75.

${ }^{84}$ George Canning, December 12, 1826 quoted in The Cambridge History of British Foreign Policy, 77.

${ }^{85}$ Clay to Forbes, January 3, 1828 quoted in Watt Stewart, "Argentina and the Monroe Doctrine, 1824-1828," The American Historical Review 10, no. 1 (February 1930), 30.

${ }^{86}$ This was not an entirely one-sided decision. Latin Americans looked skeptically on American participation. For example, although Simón Bolívar might have seen the Panama Congress as a place for regional nationalism in Latin America to take hold and expand onto a hemispheric plateau, he certainly envisioned no need for U.S. participation. The Liberator succinctly stated his position in words that encouraged the anger of Adams' Congressional opponents. "I do not believe the [North] Americans should be admitted to the Congress of the Isthmus. Such a step would cause us trouble with Albion [England] even though the entire American administration favored us, which, I do not doubt, would be the case in view of its composition." Bolívar's successful trade negotiations with the British undoubtedly weighed on his fears of U.S. participation and British offense. Harold Bierck ed., Selected Writings of Simon Bolivar (New York: Banco de Venezuela, Colonial Press, 1951), 543. Although historians have traditionally seen the
} 
administrations realized the desirability of reciprocity trade treaties that the United States began

signing in the late 1810s. However, while these treaties did much to establish American

commercial dominance in the Caribbean and Central America, the British retained a near-

monopolistic upper hand in South America. In this precarious economic and political

environment, the idea that Cuba would fall into the hands of another power other than Spain, almost inevitably the British, haunted United States policymakers. The heavy financial

Panama Congress as a general waste of time for all involved and the debates surrounding it in the U.S. as, in Andrew Cayton's words, "either a diplomatic anti-climax to the Monroe Doctrine or one of the many political harbingers of the Jacksonian period," recent scholarship casts this view into question. Most notably, the U.S. Congressional debates over the Congress offered Jacksonians a potent political platform from which to attack Adams and was a seminal event in the minds of these latent Democrats in their party's formation. The best treatment of the debates is found in Jeffrey Malanson, "The Congressional Debate over U.S. Participation in the Congress of Panama, 1825-1826: Washington's Farewell Address, Monroe's Doctrine and the Fundamental Principles of U.S. Foreign Policy" Diplomatic History 30, no. 5 (Winter 2006), 813-838. He argues “The debate over U.S. participation at the Congress of Panama provides a vital and rare insight into political thought on questions of foreign policy principle a quarter of the way through the nineteenth century, and it defined the legacies of Washington's farewell address and the Monroe Doctrine to such an extent that they were not questioned again in any important way until the 1840s." Led by Bolívar, many in the new Republics looked at the United States with a mixture of mistrust and fear. The goal, as defined by the South American delegates, of the Panama Congress was a codification of a shared resistance against the future expansion of the United States and a disruption of its pretensions to a leadership position in the western hemisphere. This rejection sounded to Americans like an inability on the part of their southern brothers to accept and operate under the burdens of republican governance. The repudiation of American leadership was seen as a failure of both intellect and a racialized ignorance on the part of South Americans. While Bolívar was much more interested in a positive development and positioning of the Panama Congress and although he did not solely seek to counterbalance every action of the United States, he hoped a leadership position for the Congress would be a de facto weakening of the hemispheric power of the United States. Gil Fortoul, Historia Constitucional de Venezuela (Berlin: C. Heyman, 1907), sums up the profound disappointment felt by Bolívar amongst the ruins of the Congress. "Thus was frustrated the double purpose of Bolívar: that of saving from the domination of Spain - and of the United States - the islands of Cuba and Puerto Rico, and that of establishing a permanent balance between the great republics of English origin and the republics of Spanish origin. This probably would have made impossible the hegemony of the United States and would have prevented that power from exercising a protectorate over the other countries of this hemisphere. In any case the accomplishment of Bolivar's purpose would have been the means of developing among the Latin American people the positions of influence in the world which they lack today," (386). The change in Bolívar's tone was profound. His excitement, in his invitation, prior to the conference was enormous. "To initiate that system and to concentrate the power of this great political body calls for the exercise of a sublime authority, one capable of directing the policy of our governments, whose influence should maintain a uniformity of principles and whose very name alone should put an end to our quarrels...A hundred centuries hence, posterity, searching for the origin of our public law and recalling the compacts that solidified its destiny, will finger with respect the protocols of the Isthmus. In them will be found the plan of the first alliances that will have marked the beginning of our relations with the universe. What, then, will be the Isthmus of Corinth compared with that of Panama? (December 7, 1824 - Circular of Invitation to Congress of Panama). Yet after the Congress, Bolívar's words betrayed his devastation. "The Congress of Panama, an organization that might have been magnificent if only it had been effective, is no different from that crazy Greek who sought to direct sailing vessels from a rock. Its power will be a shadow, and its decrees mere advice, no more than this" (August 8, 1826 - letter to Gen. José Antonio Páez,). Quotes in Bierck, Selected Writings of Bolívar, 458, 628. 
obligations Spain had to the British and French along with the abiding nightmares of their plots to take the island, kept American fears at fever pitch.

The articulation and existence of the Monroe Doctrine makes it easy for historians and critics alike to be skeptical toward and insinuating of a nefarious reasoning behind the policy. They see a general disingenuousness in the foreign policy of the United States exemplified by the long-standing gulf between word and action. However, this incredulity is instructed by the 150-year history of the doctrine in practice, thereby encouraging a reading of the resultant skepticism from the moment of inception. Representative of this perspective is the following:

The Monroe Doctrine as articulated before the U.S. Congress in 1823 established a rhetorical style associated many years later with similar pronouncements during the Cold War and after. Typically couched in the language of idealism and high principle, such affirmations of presidential purpose often purported to advance the cause of humankind, or at least a substantial portion thereof, by upholding values such as freedom, democracy, and peace. Such language sometimes served as a cover for less ennobling purposes connected with the defense of strategic and economic interests and usually contained some kind of threat to take countermeasures if other nations went beyond what the United States regarded as the appropriate bounds. The Monroe Doctrine also instituted a pattern by affirming defensive objectives. ${ }^{87}$

Connecting the Doctrine to the moment of production allows a different and more appreciative understanding of the intricacies of policymaking and the importance of the Doctrine's articulation for the domestic and foreign political life of the United States. This contextualization also helps toward a deeper understanding of the Doctrine's abiding influence in the social affairs of the nation. While Monroe's words largely fell on deaf and contemptuous European ears, the underlying philosophy guiding Adams' foreign policy ideas grew from and nourished unique American identification with divine duty manifested in his realpolitik. Far from being uncounseled and immoral, Adams saw the existence of the Monroe Doctrine and American

\footnotetext{
${ }^{87}$ Mark T. Gilderhaus, “The Monroe Doctrine: Meanings and Implications” Presidential Studies Quarterly 36, no. 1 (March 2006), 5-16.
} 
leadership in hemispheric affairs as both righteous and necessary. He, like many Americans,

looked upon America's sister republics with concern and pity.

That the final issue of their present struggle would be their entire independence of Spain I had never doubted. That it was our true policy and duty to take no part in the contest was equally clear. The principle of neutrality in all foreign wars was, in my opinion, fundamental to the continuance of our liberties and our Union. So far as they were contending for independence I wished well to their cause but I had seen and yet see no prospect that they would establish free or liberal institutions of government. They are not likely to promote the spirit of freedom or order by their example. They have not the first elements of free or good government. Arbitrary power, military and ecclesiastical, was stamped upon their education, upon their habits, and upon all their institutions. Civil dissension was infused into all their seminal principles. War and mutual destruction was in every member of their organization, moral, political and physical. ${ }^{88}$

Adams understood the potential commercial and ongoing geopolitical importance of South

American recognition while also realizing the personal political importance that his imprimatur upon a guiding United States doctrine held for his electoral chances. His doctrine manifested itself on fertile domestic ideological ground.

Adams became a true convert to the idea of hemispheric relations particularly after he became President. While Secretary of State, he looked skeptically upon the South American republics and disavowed any common relationships, most likely as a result of the close commercial ties the republics had with Britain. Adams rightfully perceived a sense of trepidation on behalf of the new republics toward the growing colossus to the north. However, he also understood that these republics feared offending British sensibilities to a similar degree. A diplomatic and economic window, if delicately opened, allowed the possibility of warming of relations and hemispheric common cause. Adams spoke gingerly to Monroe on the potential of a hemispheric 'American system.' "We have it; we constitute the whole of it, there is no community of different interests or of principles between North and South America." 89

\footnotetext{
${ }^{88}$ John Quincy Adams, Memoirs, 325.

${ }^{89}$ Quoted in Samuel Flagg Bemis, John Quincy Adams and the Foundations of American Foreign Policy (New York: W.W. Norton, 1949), 366.
} 
This perspective gradually strengthened and culminated with his election in 1824 .

Adams had a close watch on the upcoming 1824 presidential election when he set about crafting and convincing others of his foreign policy intentions. With few overriding political issues in the upcoming election but with the promise of a bitterly fought race, Adams desperately sought an issue that might help him gain some electoral separation. ${ }^{90}$ He could not overlook the fact that Clay had made much political hay out of the South American situation and he looked toward the Monroe Doctrine as a response to these assaults. There was no question that Adams sought to follow Monroe into the Oval Office and that this ambition guided many of his policy decisions. In this perspective can be seen Adams cagey use of fears that Calhoun and Clay held of reconquest. The world wise Secretary took advantage of two men who were far less experienced diplomats and not privy to the wealth of diplomatic information at his disposal. He expertly sought not to convince Clay and Calhoun of the lack of a threat - he let them both base their formulations on their faulty premise of reconquest's reality - but rather to persuade Monroe that in the face of this threat the United States could stand tall. Adams knew his influence on the President's policy would be clear and demonstrative of a certain rigidity of backbone that would play well with the independent-spirited voting public. Bolstered by a perceived freedom from the delicate issues of diplomacy and augured by the Monroe Doctrine's proclamation of American

\footnotetext{
${ }^{90}$ Historian Ernest May develops this perspective. "In the instance of the Monroe Doctrine, the positions adopted by American policymakers seem to me to be best explained as functions of their domestic ambitions-Monroe's, to leave the presidency without being followed by recrimination and to be succeeded by someone who would not repudiate his policies; Adams's, Calhoun's, and Clay's, to become President; Jefferson's, Gallatin's, and perhaps Madison's, to see Crawford succeed. Consistently with their fundamental beliefs, any of these men could have taken different positions. Adams, for example, could have reasoned just as easily as Jefferson that concert with England would guarantee America's independence, security, and peace. He actually said as much not long before the specific issues materialized. The processes producing the actual foreign policy decisions are better understood as bargaining encounters among men with differing perspectives and ambitions than as debates about the merits of different policies. And the outcomes are most explicable as ones that equilibrated the competing or conflicting interests of men with differing political assets." The Making of the Monroe Doctrine (Cambridge: Harvard University Press, 1975), 255.
} 
dominance at the head of just such a hemispheric American diplomatic system, Adams embraced the friendship between North and South America with zeal.

The new Chief Executive's views on Latin America came to fruition under the tutelage of Henry Clay, whom he appointed Secretary of State. Adams and Clay represented a singular combination to guide the United States into an era during which attempts would be made to nurture nationalism in Latin America. Clay seemed content to demur to the President's long-standing expertise in diplomacy while Adams made full use of his Secretary's grasp of Latin American affairs. Their consolidated stance towards Latin America brought forth a calculated attempt to blend diplomatic policy begun during Monroe's administration with Henry Clay's 'American System' into an early form of pan-Americanism. Adams' efforts were based upon his perception of great similarity between the nationalistic feelings then prevalent in the United States and the forces of nationalism current in Spanish America. ${ }^{91}$

He also embraced a new paradigm in north/south political relations.

Those nations have now been transformed into eight independent nations, extending to our borders, seven of them republics like ourselves; with whom we have an immensely growing commercial, and must have, and have, already important political connections; with reference to whom our situation is neither distant nor detached; whose political principles and systems of government, congenial with our own, must and will have an action and counteraction upon us and ours to which we cannot be indifferent if we would... ${ }^{92}$

However, once the 1824 election was over and the political deal making ended, and with

the failure of the Panama Congress, the South American question along with the Monroe

Doctrine faded into obsolescence. Although there was general agreement with and support for

the Doctrine when it was first articulated, Jacksonian Democrats' condemnations of the President

on the domestic front weakened this support. Many politicians called the Doctrine a threat to the

received wisdom of Washington's Farewell Address. The political wrangling over United States

representation at the Panama Congress opened the door to a reinterpretation of the Monroe

Doctrine, forcing Adams to defend the policy and his role in its formulation to a public much less

fearful of the issues that had captivated them only three years earlier. Adams' role in a perceived

\footnotetext{
${ }^{91}$ Light T. Cummins, "John Quincy Adams and Latin American Nationalism” Revista de Historia de América 86 (July-December 1978), 224.

92 John Quincy Adams, A Compilation of the Messages and Papers of the Presidents, Vol. 2, accessed on March 10 , 2011, http://onlinebooks.library.upenn.edu/webbin/metabook?id=mppresidents, 904.
} 
assault on Washington's legacy, his visionary domestic program modeled upon Clay's American

System threatening to expand government's reach, and his desire to participate in Pan-American

alliances was a political call to arms for his opponents and became political fodder for the partisan papers proliferating throughout the country. ${ }^{93}$ The debates over the Panama Congress

and the Monroe Doctrine as much as the election of 1824 ended the relative domestic political

peace and foreign affairs consensus that existed during the Madison and Monroe administrations.

Adams rightfully tacked toward a belief that expanded commercial relationships with

South America and the economic benefits enjoyed from them could cement his position as the

domestically inclined, foreign policy guru. Commercial expansionism, he reasoned, functioned

as both ideological imperative and economic necessity. Robust economic growth was a necessity

if Adams was to realize the ambitious domestic agenda he envisioned as Secretary of State and

\footnotetext{
${ }^{93}$ James L. Lewis' work is interesting in that rather than a strictly diplomatic view of the entire Latin American issue, he emphasizes the evolutionary views of American policymakers within the context of the Founders' conceptualization of "union" and "neighborhood." The Founding generation, he argues, recognized the tenuous nature of the new union and believed it could be stabilized through the promotion of national independence, republican government, commercial prosperity, and territorial empire. The Constitutional scheme of states eliminated the problem of "neighborhood" as exampled by the Articles of Confederation - competing states that might engage in various rivalries. The Union provided for combination while guarding against intervention and influence of the European powers. The major crisis came as Latin American republics gained their freedom and presented themselves as potential union members or neighbors. The debate was largely held within the insular world of American domestic policymaking as the leaders of these new republics were never interested in union membership and certainly looked upon neighborly relations as fraught with potential lethality. However, the strength of the Union did not necessarily translate into the daily lives of Americans. Lewis argues that Americans generally preferred state and local power, urging government to stay out of their lives except for eliminating the Spanish, Indians, and British trade restrictions. American policymakers faced a new dilemma in the post-war period as they sought to take a position on the Latin American revolutions and acquire Florida, while avoiding war with Spain and England. Monroe and Clay saw benefits to be gained from the collapse of the Spanish empire, but Adams expressed very real reservations. The crises of 1819-1821 undermined the cohesiveness of federal governance mainly through the invitation of the public into what had hitherto been the secretive world of foreign relations. The election of 1824 furthered this failure in what many sensed was an invalid election. The dismantling of Unionist fervor came in 1828 with Jackson's decidedly anti-Unionist perspectives. Lewis argues that historians don't adequately appreciate the suddenness of Adams' about face and pushing of recognition of five new Latin American republics in 1822 and with it the profundity of our recognition that we had become part of a neighborhood with all of its threatening possibilities. However, by 1828, Americans followed Jackson toward a more limited domestic agenda and a severely reduced role for the federal government. Adams and Clay stand then as the defenders of a domestic and foreign policy ideology that had been eclipsed rather than one that was dawning, their concept of union having been "disavowed by the public and discarded by the policymakers," Lewis, The American Union and the Problem of Neighborhood: The United States and the Collapse of the Spanish Empire, 1783-1829 (Chapel Hill: University of North Carolina Press, 1998), 218.
} 
thoroughly outlined in his first inaugural address. Friendships beneficial to the United States built upon trade served as the primary means to stimulate the internal development of the United States. Adams argued that "Commerce is among the natural rights and duties of men," and he was not alone in believing that foreign states were obligated as a matter of duty to trade with other countries. ${ }^{94}$ This belief gave him hope that the United States might break into trade with the South American republics despite the overwhelming advantage enjoyed there by the British. This was the core tenet of Adams' foreign policy, whether dealing with the Russians or the British, and the primary means by which to spread his American-style republicanism. This understanding of the domestic economic benefits of increased trade relations guided his change of heart toward the republics during his Presidential administration. However, the economic benefits he hoped for never really materialized and his expansive view of relationships in the hemisphere became a liability by $1828 .{ }^{95}$

The bitter partisanism of the late 1820s and 1830s focused Americans on debate over domestic issues with a new-found conviction and to the general exclusion of most foreign issues. In fact, Adams turn as Secretary of State might have been too successful in dispatching the concerns of the hemisphere from the minds of many Americans. The removal of the most severe threats - Spanish, Russia, and France - from active North and South American participation and interest along with the abandonment of the majority of their commercial interests in South America (effectively ceded to the British) allowed a relative peace to preside in foreign relations. ${ }^{96}$ Additionally, Adams and most Americans long-demonstrated themselves uninterested

\footnotetext{
${ }^{94}$ John Quincy Adams, "The Opium War and the Sanctity of Commercial Reciprocity," quoted in D.W. McFadden, "John Quincy Adams, American Commercial Diplomacy, and Russia 1809-1825" The New England Quarterly 66, no. 4 (December 1993), 613.

${ }^{95}$ Walter LaFeber, ed., John Quincy Adams and American Continental Empire: Letters, Papers, and Speeches (Chicago: Quadrangle Books, 1965), 49.

${ }^{96}$ The well-traveled, well-educated, and extremely racist Anglophobic Caleb Cushing is a notable exception in this world of foreign policy placidity in the 1830s. John Belohlavek asserts that "No public figure argued the case for
} 
in European affairs and after 1823 set about extricating themselves from those continental affairs. Yet, this disinterest in foreign affairs doesn't adequately explain how so hot a fire cooled so quickly.

Traditional scholarship of the Monroe Doctrine, including historians focused on John Quincy Adams participation in its formulation, sees the Doctrine as fundamentally a foreign policy issue as well as one only tangentially centered on Latin American/United States/British geopolitics. While recent scholarship widens this view and reforms the myopic focus on United States/Russian relations, it has done little to move the issue from a primarily foreign policy undertaking. However, the Monroe Doctrine's promulgation as well as the political debates over its philosophy and its worth held importance far afield from diplomacy. The Doctrine underlined the entirety of American expansionary fervor in the 1840s and 1850s and, while perhaps not mentioned by name, it amplified the impulse toward intervention and expansion present in the United States self-conceptualization of its national mission. The Doctrine's articulation was both a necessary moment of national reaffirmation from two members of the Founding generation steeped in republican missionism and also a foundational code for a new generation of adventurers whose reading of the nation's founding fictions prompted an international paternalism no less condescending but much more aggressive. Appreciation of the continuing domestic cultural capital of an expansive American view of the hemisphere also helps explain how the philosophy the Doctrine outlined returned quickly to political prominence when needed.

America's role in the world with more intellectual prowess, with more rhetorical skill, and - unfortunately - with a more caustic racial edge. Cushing's lengthy career serves as a mirror of both the man and a young republic struggling to define an identity as it sailed the treacherous water from union to nation." He single-handedly kept the Northeastern Canadian border issue alive, offered Congressional support to American filibusters there, supported settlers in Oregon and their disputes against the British, and was an ardent supporter of action against Cuba. "Race Progress and Destiny: Caleb Cushing and the Quest for American Empire" in Manifest Destiny and Empire, eds. Sam Haynes and Christopher Morris (College Station, TX.: University of Texas Press, 1997), 21-47. 
Yet, Adams, as president, came to realize the deployment of the Doctrine produced success only when unmoored from idealism and tied to aggrandizement.

The wide dissemination of this message prompted its powerful incorporation into domestic politics. The Jacksonian period, while one intensely focused on domestic politics, also represented an era of increasing readership amongst all classes of Americans. These new and growing sources of daily information, along with a few long-form mediums, increased Americans' interest in the world and cultures outside the United States. The press in the early nineteenth century played a critical role in nationalizing the young republic. Even though regional interests and cultures formed nascent sectional identities, newspapers borrowed freely from one another, transcending sectional divisions that became powerfully divisive only in later decades. ${ }^{97}$ Beyond newspapers, one particularly intriguing form of reading was the travelogue. Not surprisingly, many of these vignettes, in numerous penny-press offerings, featured exotic tropical locales, of which Cuba loomed large. Novel writers also capitalized on this expanded interest in foreign locales as they set their works in places that Americans were unlikely to ever visit, but that nonetheless held their rapt attention. Correspondingly, as the American literary appetite grew so too did the knowledge of the political and social lives of these distant cultures. While the majority of Americans never intended on traveling to Cuba, the knowledge of the island, its people, and its political situation kept alive American fascination. If the practice of the Monroe Doctrine assumed a brief centrality in diplomatic strategy, it was symbiotically linked to the concept of domesticity and the defense of a vigorous Union. ${ }^{98}$

\footnotetext{
${ }^{97}$ Donald M. Scott, "Print and the Public Lecture System, 1840-60," in Printing and Society in Early America, ed. William L. Joyce (Worcester, MA.: American Antiquarian Society, 1983), 280-302. Also influential is James W. Carey, Communication as Culture: Essays in Media and Society (New York: Routledge, 2009), 13-69. On the growing popularity of longer forms see Cathy Davidson, Revolution and the Word: The Rise of the Novel in American (New York: Oxford University Press, 1986).

${ }_{98}$ Aisha Finch, following Mary Louise Pratt, Imperial Eyes: Travel Writing and Transculturation (New York: Routledge, 1992) and Anne McClintock, Imperial Leather: Race, Gender, and Sexuality in the Colonial Contest
} 
Adams conceived of the Monroe Doctrine as a flexible policy adaptable to both

generation and situation. He hoped that it might offer the United States and its new generation of

political and cultural leaders a signpost much like Washington's Farewell Address did for men of

his generation. The Doctrine captured both a confident nationalism in the wake of the War of

1812 and the potential benevolent imperialism that the success of this new nationalism promised.

Although focused on the Caribbean and back-grounded by the larger South American issue, the

Doctrine offered an elasticity that could be interpreted as continental, hemispheric, and (much

later on) global in scope. The Monroe Doctrine allowed the coexistence of contradictory foreign-

(New York: Routledge, 1995), explores the ways in which elite European travelogues created a racialized and gendered body of knowledge that shaped ideas about colonial conquest. Finch outlines the importance of travel narratives in shaping the perceptions of Americans toward Cuba. She looks at the travel narratives of American and European writers to show the process through which black women became central to Cuba's colonial perceptions of itself in the mid-nineteenth century. The narratives also demonstrate the anxieties many Cuba elites had as the maleheavy slave trade brought fewer and fewer black women to the island. Black women, along with the reproductive and domestic roles they played, allowed Cuban slaveowners to idealize the plantation society they tried to create and control through meticulous arrangement of barracks designed to encouraged surveillance and reproduction. Cuban elites hoped that enslaved women's notions of marriage, home, and family would inspire an orderly and disciplined plantation complex thereby encouraging natural increase and discouraging aggressive masculinized rebelliousness. She points to the travelers' strange fascination with Cuba's sugar plantations and their impressive technologies of production and control. Travelers to the island were not exclusively appreciative of Cuban society nor were they exclusively sympathetic to slavery. Abolitions, the disabled, scientists, and naturalists also made the journey. In fact, most visitors were Northern intellectuals who, while praising the manners of plantation owners, saw the island as backward, racially dangerous, languishing, and in need of rational guidance. They returned to the United States and set about disseminating these perspectives. "As 'ambassadors of culture' then, white North Americans helped to lay the intellectual and political foundations for future U.S. expansion into Cuba, an island that represented coveted but unconquered territory for much of the nineteenth century. As a group then, the moral and political terrain these travelers inhabited could not be easily reduced to that of the slaveholder, the expansionist, or the imperialist, yet their writings often appeared to imbibe from all three at different moments. Buttressed by presumptions of North Atlantic enlightenment and progress, few failed to comment on the injustices and incapacities of Spanish colonial rule. In ways often unknown to them, these white sojourners traveled with the logic of manifest destiny and the British Empire at their backs, a kind of broader common sense that inlaid its power in their day-to-day actions, and worked itself out in their daily thoughts, conversations, and recordings." Finch, "Scandalous Scarcities: Black Slave Woman, Plantation Domesticity, and Travel Writing in Nineteenth-Century Cuba" Journal of Historical Sociology, 23, no. 1 (March 2010), 101-143. In thinking about the Caribbean as a wider transnational community, Matthew Pratt Guterl outlines the prospects for a wider transamerican planter class that the American South saw itself heading and extending to Cuba and Brazil in American Mediterranean: Southern Slaveholders in the Age of Emancipation (Cambridge: Harvard University Press, 2008). Kirsten Silva Gruesz looks at how Latino writers, particularly Cuba expatriates in the United States, envisioned the Caribbean community and their place and voice in the politics of powers in Ambassadors of Culture: The Transamerican Origins of Latino Writing (Princeton: Princeton University

Press, 2002). Rodrigo Lazo looks at similar issues of how the U.S.-based Cuban press engaged in debates on political developments in Cuba and functioned as a textual front in the formation of that nation, Writing to Cuba: Filibustering and Cuban Exiles in the United States Envisioning Cuba (Chapel Hill: University of North Carolina Press, 2005). 
policy goals: isolation and expansionism matched with the control and protection of other nations. However, the Doctrine did not protect only millennial expansion and commercial freedom through foreign policy means. Domestic cultural phenomena such as domesticity, Indian removal, and slavery can also be linked to the Doctrine. These reverberations helped Americans continually redefined and reimagine their national identity within the framework of both domestic cultural institutions and the country's place in the hemisphere.

Literary texts played a crucial role in transforming the Monroe Doctrine from a foreignpolicy principle into a compelling national domestic ideology by helping Americans negotiate the real and imagined bonds between themselves and people of different races, classes, genders, and nationalities. In this negotiation can be seen the tensions created when foreign policy and diplomacy, conducted largely in secret, layers itself upon domestic ideologies. This arena of contestation exposes both belief systems and their practitioners to public debate and popular anxieties. Adams and United States policymakers were not isolated from the domestic, and their ideas were as much a product of the domestic landscape as they were produced for it. The Monroe Doctrine appears as an articulation of United States public sentiments and ideas already present in literature and journalism. The Doctrine then becomes, rather than just a foreign policy statement, a master-narrative containing multiple arguments about national identity and imperial ambition, whose function was suppression of the tensions at its very heart and the heart of American life in general - the urge to anti-colonialism and democracy seen through eyes of imperialist grandeur. The Monroe Doctrine was the political embrace of the anxious literary/cultural American consciousness that sat at the very center of the multitude of literary narratives about the place of the United States in the world. 99 "The Monroe Doctrine's power lies

\footnotetext{
${ }^{99}$ Gretchen Murphy, Hemispheric Imaginings: The Monroe Doctrine and Narratives of U.S. Empire (Durham: Duke University 2005), investigates this interplay between literature and national consciousness. She sees inherent in the
} 
Monroe Doctrine the same paradox at the heart of the United States; namely, how did an anti-colonial warning against European powers become an instrument of U.S. hegemony in Latin America? She links the doctrine with emergent national identity on the stage of American literature and entertainment. Culture and politics shared the stage in the production of the Monroe Doctrine. She argues that literature not only reflected the ideological struggles and changes of the nineteenth century, but also helped shape and modify those struggles for policymakers and in the popular mind. Her line of argumentation follows Amy Kaplan, The Anarchy of Empire in the Making of U.S. Culture (Cambridge: Harvard University Press, 2005), which looks at the 1890s. Kaplan and Murphy focus on important texts of the respective periods finding in them suggestive themes and echoes of policy debates informing their contexts. Murphy compares John Quincy Adams' July 4, 1822 address with Lydia Maria Child's 1824 novel Hobomok. Both Adams' speech and Child's novel tried to reconcile the territorial expansion of the United States with the policy of salutary "domestic isolation." Adams and Child use similar family metaphors to explain the position of the United States as a lonely defender of republican government in the hemisphere. Both narratives justified further westward expansion as part of the national project of culture building in efforts to break free from the cultural dependence on Great Britain. Both Adams and Child were responding to British criticism about the lack of literature in the United States and about Britain's primacy in the invention of representative government. Adams' speech presented republican government as an American invention, while Child's novel re-enforced the view that "American literature" should deal with the American Indian and the land they inhabited. Anna Brickhouse expands the terrain of literary analysis to a transnational perspective. In Transamerican Literary Relations and the Nineteenth-Century Public Sphere (New York: Cambridge University Press, 2004), she focuses on hemispheric encounters that shaped national literary traditions across the American hemisphere in the early nineteenth century. Taking the thirty years between the Congress of Panama (1826) and the Continental Treaty (1856), Brickhouse shows how the commonly termed American literary Renaissance is, more accurately, a Transamerican renaissance characterized by literary border crossing and intercontinental exchange with attendant cultural, political, and social interdependencies. "The very conception of the American Renaissance ... is inherently dependent upon and sustained not only by nationalist discourses but by the underlying transnational desires and anxieties that such discourses seek to mask," (33). Debra J. Rosenthal, Race Mixture in Nineteenth-Century U.S. and Spanish American Fictions: Gender, Culture, and Nation Building (Chapel Hill: University of North Carolina Press, 2004), looks at nineteenth century U.S. and Spanish American narrative and argues that race mixture was "formative in the history of the Americas primarily in terms of cultural constitution, political organization, nation building, civil identity, and ... literary expression. Racial hybridity can be situated at the heart of the literature of the Americas," (10-11). Mixedrace characters throughout the literature of the Western Hemisphere serve as corporeal sites where competing discourses of race meet and nowhere is the anxiety of national and racial mixture more concentrated than on the female body. From a different racial perspective Erika Lee, “"The Yellow Peril' and Asian Exclusion in the Americas," Pacific Historical Review 76, no. 4 (November 2007), 537- 562, examines mid-nineteenth century transnational conversation about race, migration, and Western hemispheric security conducted among the nations of North and South America as it related to the global migration of Asians and the threat they posed. The view generally espoused was that Asians were inassimilable aliens who brought economic competition, disease, and immorality. "These policies were not separate phenomena but rather resulted from a transnational anti-Asian racism - what I have called hemispheric Orientalism - that flourished and moved across national boundaries." This debate was one actively engaged in by Cuban elite voices as well as huge numbers of Chinese labors that came to the island as a possible solution to the labor shortages there caused by abolition pressures placed by the British on Spanish authorities. On the Chinese in Cuba see Lisa Yun and Ricardo Laremont, "Chinese Coolies and African Slaves in Cuba, 1847-74," Journal of Asian American Studies 4, no. 2 (June 2001), 99-122; Evelyn Hu-Dehart, "Chinese Coolie Labor in Cuba in the Nineteenth Century: Free Labor of Neoslavery," Contributions in Black Studies: A Journal of African and Afro-American Studies: Special Section, Ethnicity, Gender, Culture \& Cuba 12, no. 1 (1994), 38-54; Matthew Pratt Guterl, "After Slavery: Asian Labor, the American South, and the Age of Emancipation," Journal of World History 14, no. 2 (June 2003), 209-41. The New York Times was prolific on the issue of Chinese labor in Cuba. Among the articles published in 1852, just as opinions on revolution were shifting were: "Orientals in America," (4/15/52); "Cotton, Cane and the Coolies," (5/3/52); "Labor in Cuba," (12/10/52) and an extraordinarily direct "Private Letter" on the issue reprinted here. "The wild, uncivilized look of the negroes here strikes one very forcibly. Constantly one see teeth filed like those of a saw, which gives a most shark like look to a large mouth and nearly every darkey one meets, has the long cicatrices on his cheeks or forehead that in Africa mark the tribe or the people to which he belongs. I do not know if these foreigners have increased much in number lately, although we hear on all sides that large cargoes of them have been landed. Indeed, the excess of males on the plantations, and the cruelly hard work, keep the slaves from increasing except from importation. The English will have great difficulty in 
in the fact that it expressed what many Americans, great and humble, were thinking, and were to think in the future. The ideas that it set forth were in the air. The American people have, again and again, found something that appealed to their deepest instincts and traditions in its language, and to this fact the words of 1823 owe their influence." 100

preventing it. Bold and skillful slavers can easily run their vessels into friendly ports. I had strong hopes and still have, that the Chinese emigration may act as a check upon this infernal business. There have been two thousand Celestials in the Island for years. They were imported at an expense of $\$ 125$ a head and receive $\$ 5$ a month for the eight or ten years during which they are bound to their employers. Thus far they have given satisfaction by their industry and intelligence - so much so, that a planter has worked a number of them, said he should pay them $\$ 8$ a month when their time is up rather than lose them. Eight thousand more have been subscribed for and six thousand are said to be on their way hither. Perhaps Providence may make use of the surplus population to drive out the curse of slavery from among us. Who knows where the Chinaman will appear next, now that the whole world is becoming one country?" "Chinese in Cuba - Extract from a Private Letter from Cuba," New York Times, 12/10/52.

${ }^{100}$ Dexter Perkins, A History of the Monroe Doctrine (Boston: Little \& Brown, 1963), 103. The construction of a nationalist/imperialist mythology and its dissemination through an increasingly national print media demonstrate the ways American nationalism developed through the contours of Benedict Anderson's "imagined community." Americans, informed by modernizing mediums of print capitalism, shared national images of communion and discussions of their importance. The widespread faith in God and in the providential destiny of the American people, coupled with the faith's dissemination, lent a messianic dimension to the establishment of national identity. Yet, this domestic identity production was one largely shaped by mental images of those people, cultures, and institutions outside of the United States that Americans hoped to mold in their image. Benedict Anderson, Imagined Communities: Reflections on the Origin and Spread of Nationalism (London: Verso, 1991), ch. 3. Briefly, the historiography of manifest destiny is dense and there is no singular perspective that outshines the other. Among the paradigmatic works that attempt to shed light on explanatory philosophies of expansionistic ideologies. Albert Weinberg, Manifest Destiny: A Study of Nationalist Expansionism in American History (Baltimore: JHU Press, 1935), connects American beliefs regarding democratic governance, millennialism, race theory, and international politics to actual government policy painting a complex and explanatory picture. Frederick Merk, in Manifest Destiny and Mission in American History (New York: Knopf, 1963), reinterprets manifest destiny as a short-lived craze petering out after expansion against Mexico was completed. Merk insists that manifest destiny is no fundamental component of the American mentality. The real fundamental component of American attitudes to world politics can be summed up in the word mission. In searching for the roots and guiding ideology of American foreign policy, Michael Hunt, Ideology and American Foreign Policy (New Haven: Yale University Press, 1987), describes three basic components of this shared ideology: 1) America's vision of national greatness; 2) the American propensity to view the world's population in a hierarchy of races (and later cultures as racial substitutes); and 3) America's growing disappointment and horror at failed revolutions of the $19^{\text {th }}$ and $20^{\text {th }}$ centuries. Thomas Heitala, Manifest Design: Anxious Aggrandizement in Late Jacksonian America (Ithaca: Cornell University Press, 1985), argues for the study of westward expansion as a variant on empire and through this study expansion becomes more of a design than a more ephemeral destiny. He tracks the way in which political leaders of the 1840 s, especially Democrats, at once created an empire and simultaneously denied that what they had created bore any resemblance to the empires held by European nations. "The idealism of westward expansion embodied in the concept of manifest destiny, persists because it helps to reconcile American imperialism with an extremely favorable national image. The assumed benevolence and supposedly accidental nature of American expansion are convenient evasions of the past," (271). Reginald Horsman, Race and Manifest Destiny (Cambridge: Harvard University Press, 1981), examines the origins of racialism in America and shows that a firmly rooted belief in white American superiority was firmly ensconced in the nation's ideology by 1850. The expansion of the United States required a racist ideology to justify the seizure of land from non-whites. Manifest destiny was this ideology in practice. 
Adams, like many Americans, eventually lost sight of South America out of a mix of factors, most notably racism, lack of commercial profitability, and domestic insularity. The complete failure of the Panama Congress and the political capital Adams expended in defending United States participation there left a particularly bad taste in his mouth. When the danger of reconquest and transfer passed and the United States lost potential commercial advantages to the British throughout South America, the American public and their politicians simply ceased caring about South America as a pressing concern. ${ }^{101}$ Similarly, the lost faith in the belief that the new Republics represented the best chance at spreading freedom and democracy drove many Americans to abandon interest in the program of hemispheric republicanism. ${ }^{102}$ Americans perceived South Americans as racially, politically, socially, and intellectually lacking in the

${ }^{101}$ John Johnson discusses why the strong U.S. interest in South America's wars of independence in the early nineteenth century gave way so quickly to U.S. indifference toward the region, thus establishing a cyclical pattern of strong U.S. concern with South America followed by profound neglect. Emphasizing the U.S. concern with national security as the primary objective of Western hemisphere policy, Johnson shows that U.S. policies from 1815 to 1830 created a security framework designed to counter French and Britain threat. These policies in turn reflected deeply negative perceptions of the peoples of South America. "The predominant perceptions were that Iberians, Indians, blacks, and the mixed races that made up the populations of Latin American nations were inferior, that the nations themselves, given their state of development, would be neither dependable allies nor, for the present, valuable trading partners, and that the future of the United States rested on pushing the western frontier all the way to the shores of the Pacific, thereby assuring space for the nation to fulfill its destiny." This situation diminished expectations in the United States that South American nations would become reliable allies or valuable trading partners. Johnson, A Hemisphere Apart: The Foundations Of United States Policy Toward Latin America (Baltimore; Johns Hopkins Press, 1990), 187.

102 Piero Gleijeses investigates the limits Americans placed on their support and sympathy for South Americans. "In the Congressional debates of the period there was much more enthusiasm for the cause of the Greeks than that of the Spanish Americans. Similarly, the press referred frequently to private collections of funds ('liberal donations') for the Greek fighters - not for the Spanish Americans. This is not surprising. The US public could feel a bond with the Greeks - 'it will become even quite fashionable to assist the descendants of those who were the bulwark of light and knowledge in old times, in rescuing themselves from the dominion of a barbarian race'. Unlike the Greeks, however, the Spanish Americans were of dubious whiteness. Unlike the Greeks, they hailed not from a race of giants, but when they were white - from degraded Spanish stock. Some US citizens felt for them the kinship of a common struggle against European colonial rule; others agreed with John Quincy Adams: 'So far as they were contending for independence, I wished well to their cause; but I had seen and yet see no prospect that they would establish free or liberal institutions of government. They are not likely to promote the spirit either of freedom or order by their example.' Geography created a sense of kinship, or, at least, of a shared interest. But it also created tensions. As Bolívar freed his slaves so that they could join the struggle for independence (something no Founding Father did) and the rebel armies included a growing number of blacks (even black officers), US uneasiness toward their swarthy neighbors grew. And as rebel privateers swarmed the Caribbean and South American waters, seeking loot under the pretense of freedom, US shipping suffered, as did the sense of neighborliness." Piero Gleijeses, "The Limits of Sympathy: The United States and the Independence of Spanish America," Journal of Latin American Studies, 24, no. 3 (October 1992), 481-505. 
necessary skills to implement American republicanism. The disappearance of South American potential came largely as a result of the disappointment Americans felt toward the mixed race nationalism on display in the new republics. However, American desire and interest in the Caribbean never waned and entered a new phase during the 1830s. Unlike in South America, United States interest in the Caribbean and in Cuba only grew with each frustrated effort. A renewed rivalry with the British added even more fuel to the fire. ${ }^{103}$

The abolition of slavery throughout the Caribbean became the issue of the middle decades of the nineteenth century and raised the most obstacles to annexation of Cuba. The inspiration for the reinvigoration of American expansionary altruism came from a perceived moral imperative, couched in language similar to Clay’s focus on South America in 1820. Annexation's advocates, like Clay and supporters of recognition, called upon Americans to help the unfortunate Cubans struggling under Spanish rule. However, the welcome mat would only be extended so far as to avoid the difficult issues of amalgamation of the Cuban and American populations. Political and racial mixing of the sort threatened by full Cuban statehood dictated a cautious approach. Partial incorporation (annexation) of the island was preferable to outright statehood and, unlike contiguous territory, was possible due to the geographic isolation of the island - while only 90 miles away, Cuba was away. This was a lesson learned originally by

\footnotetext{
${ }^{103}$ Edward Barlett Rugemer, The Problem of Emancipation: The Caribbean Roots of the American Civil War (Baton Rouge: Louisiana State University Press, 2008), explores the influences of both slave rebellions and British emancipation in the West Indies on the American debate over emancipation. Also instructive and foundational in outlining British abolitionism in the Caribbean is David Murray's Odious Commerce: Britain, Spain and the Abolition of the Cuban Slave Trade (Cambridge: Cambridge University Press, 1980), 208-240. He documents the other side of the debate, focusing on Britain's grave concern with American annexationist interests in Cuba during the 1840s and 1850s, and illustrates the extent to which Britain ironically supported Spain in order to counteract the threat of American empire. On the threat of British abolition and annexation in Texas see the contemporary fiery account of D. Urquhart Annexation of Texas: A Case of War Between England and the United States (London: James Maynard, 1844). More accepting of the British threat of annexation in Texas is Sam Haynes "Anglophobia and the Annexation of Texas: The Quest for National Security" in Sam Haynes and Christopher Morris, eds. Manifest Destiny and Empire (College Station: University of Texas Press, 1997), 115-145. More skeptical of British designs is David Pletcher, Diplomacy and the Annexation of Texas (Columbia: University of Missouri Press, 1973).
} 
Americans during the addition of Louisiana in 1803 and later by the "All Mexico" proponents, both of which struggled to make a case for the incorporation of millions of non-whites into the United States population in the wake of the Louisiana Purchase and Mexican War. ${ }^{104}$ This desire

${ }^{104}$ Ultimately the "All Mexico" movement fell apart on the issue of and concern for the incorporation of millions of non-whites into the American family. The failure of "All Mexico" proponents to gain widespread public support also seems to undermine connections between manifest destiny and mission in American policy. Expansionism was an integral part of the national mission, yet had stopped at the Rio Grande. The problem with "All Mexico" was that incorporating the entirety of Mexico's territory was impossible without incorporating the people who lived there and few Americans were prepared for such a policy, thinking as they did that Mexicans did not have the capacity for republican participation. Senator Edward Hannegan summarized this view, "Mexico and the United States are peopled with utterly unhomogenous races. In no reasonable period could we amalgamate. They are utterly unfit for the blessings and the restraints of rational liberty, because they cannot comprehend the distinction between regulated freedom and that unbridled licentiousness which consults only evil passions of the human heart," quoted in Shelley Streeby, American Sensations: Class, Empire, and the Production of Popular Culture (Berkeley: University of California Press, 2002), 115. In her footnote, Streeby quotes Congressman R.M.T. Hunter "I do not want their people. ... But I have many reasons for desiring to acquire a portion of their territory contiguous to us which is so nearly unoccupied that the influence of these people could not be sensibly felt, as a political element in our system," (320). A popular Democratic Party mouthpiece, the Democratic Review, agreed, "The annexation of the country [Mexico] to the United States would be a calamity. 5,000,000 ignorant and indolent half civilized Indians... would scarcely be a desirable encumbrance even with the natural wealth of Mexico." "Mexico - The Church and Peace" Democratic Review 21, no. 110 (August 1847), 101. However, this concern about absorbing non-Americans to the family was not new. Peter Kastor details the difficulties of adding new territory to the United States in The Nation's Crucible: The Louisiana Purchase and the Creation of America (New Haven: Yale University Press, 2004). The seemingly simple acquisition of Louisiana brought with it an enormous new territory as well as the country's first large population of non-Americans - Native Americans, African Americans, and Francophone residents. Unlike Jon Kukla's A Wilderness So Immense: The Louisiana Purchase and the Destiny of America (New York: Anchor, 2004), which focuses much more on the details of purchase and the labyrinth of foreign policy diplomacy, Kastor focuses on the social ramifications of the purchase. In explaining this process, Kastor debunks many myths including that of the "Americanization" of Louisiana - the belief that Spanish and French residents simply 'lost' to the Americans and gave up their opposition to American culture. Kastor argues that this process should more accurately be termed incorporation, for it was not simply a battle for ethnic supremacy. In fact, most of the residents of Louisiana did not want to return to French rule but instead wanted their political rights as Americans. Kastor sees the chief debate not being the purchase itself and the coming of American power but the length of time residents would be expected to wait for a full voice in the application of the power. In other words, while the federal government stressed a territorial period, Louisiana's residents, much like Cubans asking the Monroe administration for annexation and statehood in 1822, wanted the process to occur immediately. This issue led to another corresponding issue - who would be considered for citizenship in the new territory? In the legal limbo many slaves and free persons of color found themselves, opportunities were ripe for new agency in self-designation; slaves left plantations or revolted, free persons sought to define their property rights, and in western Louisiana, the Caddo Indians negotiated with the federal government and Spanish Mexico in order to form a Neutral Ground where they might maintain their independence. Although these efforts provided futile in the long run, they forced white Louisianans to confront issues of classification and ultimately offered them the surest path to membership in the national community - race based societal regimentation. These were issues again debated when Louisiana applied for statehood in 1812. For the purposes of this study it is important to acknowledge that Americans in the 1840s still remembered the difficulty had by the U.S. with the inclusion of different Europeans into racial and national definition. These issues promised to be complicated by the fact that Cuba was non-contiguous and much more populated than Louisiana was in 1803. Beyond Mexico, Cuba, and the issue of contiguity, the Monroe Doctrine surprisingly suppressed, if momentarily, dreams of a Pacific commercial empire. The national mandate of the Doctrine sought protection of democracy, freedom, and commerce in the hemisphere, and was not a blueprint for the incorporation of racial others as colonial subjects let alone citizens. The fear of the "racial debasement" of U.S. democracy, already present in the 
to redeem a degenerating population in Cuba put many American rhetoricians in a difficult

position as they argued for the general enlightenment of the Cuban (particularly its elite)

population dragged down by a general decay (brought on by Spanish rule).

There should be no surprise, given existing moral and religious justifications made for land expropriation and slavery that American annexationists bandied about with the doubleedged sword of altruism. The inability of the Spanish to make 'proper' use of the island of Cuba gave many in the United States great confidence that Cuba would soon be in American hands.

Congressman M. S. Latham of California summed up this perspective well on the House floor in

his speech he entitled "The Right of Neutral - Cuba."

Spanish power in the Gulf of Mexico has only a nominal existence. It cannot grow and expand while the mother country is declining in influence and power and while the United States are constantly increasing in territory and population. Cuba is a mere Spanish farm, badly worked by tenants for its lazy and thriftless proprietors. It must, in due time, come under the hammer, and there is no party which can afford to pay as high a price for it as ourselves. We cannot allow it to pass from its present proprietors into other hands, and in the case of accident or death of the present holder, we would feel ourselves called upon to administer upon the estate. But we have no desire to take forcible possession by expelling the present owner, as long as we can live in peace with him; in other words as long as we can preserve neighborly relations with him without inconvenience and injury to our property. ${ }^{105}$

This 'inability to develop' argument, based on the guiding rational for Indian removal and

dispossession, was a common refrain in the arguments supporting annexation of Cuba as well as

the undergirding for Americans' thinking on spreading hemisphere democracy. The presence of

British abolitionist impulse in Cuba and corresponding fears of a resultant Haitian-style race

congressional debates about the incorporation of Texas, Mexico, and Cuba reappeared with new intensity with the mention of Asian constituencies. These social and political concerns contributed to the persistent popularity of the interpretation of the Doctrine as one of domestic isolation therefore dictating that American imperial ambitions outside the hemisphere, in Japan for example, were beyond the pale. This prohibition against non-hemispheric territorial expansion therefore necessitated a new tact for U.S. policymakers, one that resulted in a new doctrine of economic spheres of influence and "openings" for trade.

${ }^{105}$ A Century of Lawmaking for a New Nation: U.S. Congressional Documents and Debates, $1774-1875$ Congressional Globe, House of Representatives, 33rd Congress, 1st Session, accessed on March 10, 2011, http://memory.loc.gov/cgi-bin/ampage, 951. 
revolt made the need for elucidation of the American perspective all the more pressing. As

Latham concluded,

It is said that we are impelled to do these things by 'manifest destiny' and I more than half believe it. I believe there are men who, watching the current of popular opinion, are will to be borne along by its waves, and called 'leaders;' while there are other who have not the courage to resist it, even if the current were to carry them over a precipice. These men, whoever they may be, and whatever station they may occupy, can lay no claims to statesmanship' they are more jobbers and journeymen politicians. Men of great mind and character impress their thoughts on the age in which they live; but our political jobbers bear the imprint of popular passion of the hour and follow the age in whatever folly may be uppermost at the time. Sir, destiny is nothing but the final result of all the tendencies of our moral and physical system; it is the effect of the laws of nature whose operations, whenever they are most beneficent, are silent and secret, not boisterous and noisy by fits and starts. We have no doubt a proud mission to follow; but it does not merely consist in the acquisition of territory and in the extension of power. Our calling is a far nobler one. We must cultivate, fertilize, and regenerate the regions that become subject to our rule. It is not merely power but our institutions and laws and our higher civilization that we are bound in the course of time to carry to the most remote part of this continent and to its neighboring islands. Unless we can regenerate and Americanize what we acquire or annex, we shall no improve on former conquerors, but only add another page to the long catalogue of national crime in the world's history... our true power consists in the power of assimilation. We do not conquer and coerce; we attract, assimilate, and reorganize. The former is never accomplished without consuming power and thereby producing waste; the latter is a natural process, combing elements for a new and higher purpose and adding to the strength of all by giving them unity of direction. ${ }^{106}$

Unlike those who feared racial amalgamation, Latham joined in a growing chorus of

Americans that looked toward Cuba as an unique instance where races could be joined. He

believed the creoles of the leadership classes enjoyed enough whiteness from their Spanish

heritage that they might be rehabilitated from years of Spanish neglect. Latham embraced what

he saw as a remarkable ability of America's democratic institutions to draw annexed peoples and immigrants into common mission with the United States rather than imposing ourselves on these populations. This engendered a loyalty that strengthened common bonds and freed the concept of mission and manifest destiny from the overtones of imperialism. However, despite these

\footnotetext{
${ }^{106}$ A Century of Lawmaking for a New Nation: U.S. Congressional Documents and Debates, $1774-1875$ Congressional Globe, House of Representatives, 33rd Congress, 1st Session, accessed on March 10, 2011, http://memory.loc.gov/cgi-bin/ampage, 951.
} 
convenient propositions the Cuba question continued to rest on one simple proposition -

Americans wondered if and when the conditions for annexation of Cuba might ever be right. The nervous expectation of invitation began, but the fear of a conflagration engulfing the Caribbean

never abided. An introspective but unrepentant John Quincy Adams discussed on the floor of the

House in 1837, the coming conflict and prophesized the doom he long-predicted, resultant of too

rapacious a foreign policy enveloping the Southwest and the Caribbean.

But Spain is again convulsed with Civil War for the succession to her crown; she has irretrievably lost all her colonies on both continents of America. It is impossible that she should hold much longer a shadow of dominion over the islands of Cuban and Porto Rico - nor can those islands in their present condition form independent nations capable of protecting themselves. They must for ages remain at the mercy of Great Britain or of these United States. Great Britain is even now about to interfere in this war for the Spanish succession. If by the utter imbecility of the Mexican confederacy this revolt of Texas should lead immediately to its separation from that Republic and its annexation to the United States, I believe it impossible that Great Britain should look on while this operation is performing with indifference. She will see that it must shake her own whole colonial power on this continent, in the Gulf of Mexico and in the Caribbean seas, like an earthquake - she will see, too, that in endangers her own abolition of slavery in her own colonies. A war for the restoration of slavery where it has been abolished, if successful in Texas, must extend over all Mexico and the example will threaten her with imminent danger of a war of colors in her own islands. She will take possession of Cuba and of Porto Rico, by cession from Spain or by the batteries from her wooden walls, and if you ask her by what authority she had done it, she will ask you in return, by what authority you have extended you sea coast from the Sabine to the Rio Bravo. She will ask you a question more perplexing, namely - by what authority you, with freedom, independence, and democracy upon your lips, are waging war of extermination to forge new manacles and fetters, instead of those which are falling from the hands and feet on man. She will carry emancipation and abolition with her in every fold of her flag - while your stars, as they increase in numbers, will be overcast with the murky vapors of oppression and the only portion of your banners visible to the eye will be the blood-stained strips of the task master. ${ }^{107}$

${ }^{107}$ John Quincy Adams quoted in Benjamin Lundy, The War In Texas: A Review Of Facts and Circumstances, Showing That This Contest Is a Crusade Against Mexico (New York: Merrihew and Gunn, 1837), 37. 


\section{Chapter Two: Early Cuban Political Economy}

We passed...within a mile and a half of Guanajay, one of the largest of the interior towns. We noted twelve coffee estates, cafetales, on the road, most of them extensive; two large sugar estates, three more were in sight; two vegas of tobacco, one of ten acres and the other of two; several large potreros, or pastures for cattle, two of them very large...forty sitios, or farms of small extent...some of the sitios had extensive fields of corn...Almost every road of the fields we passed in rapid succession was covered with some luxuriant growth...And in all directions there is high cultivation and a vast produce prepared for the market.

Abiel Abbot, Letters Written in the Interior of Cuba (1829)

I am on my cafetal San José! I no longer see the forest or the numerous palm trees. Nothing of the banana plants. All the coffee trees have been obliterated. The ripened fruit is enveloped in muck and weed. Three giant ceiba trees have been shattered into a thousand pieces scattered among the coffee trees, destroying them by the sheer weight of their thick branches...An indescribable stupor seizes my faculties at that moment. I stop my horse and brace myself so as not to fall off my saddle. Two hurricanes in the space of two years, and of mounting fury, have left morale so utterly dispirited that upon the slightest gust of wind we are terrified by the possibility of a third repetition of this horrific and desolating weather.

Diego Fernandez Herrera, Memoria sobre los huracánes en la Isla de Cuba, (October, 1846)

There is not a single finca, large or small, that has not suffered damage to its workshops or its plantings, to such an extent that the countryside appears as if it has been devastated by fire. The majority of the houses of the potreros, sitios and vegas have disappeared and the ingenios and cafetales have suffered substantial damage.

Anonymous, El Huracán de 1846 en La Habana in El Faro Industrial (October, 1846)

Two massive hurricanes laid waste to Cuba in 1844 and 1846. These storms had two important and immediate effects. First, they exacerbated the general feeling of disorder and unrest on the island in the wake of a purported massive slave conspiracy, La Escalera, uncovered by officials in the winter of 1843. The resulting repression throughout 1844, El Año del Cuero, which felled over 4,000 primarily free-AfroCuban individuals, increased pressure on both the anemic petite bourgeoisie and more influential creole elite to fall in line with Spanish authority in Cuba. This process quelled much of the secessionist and emancipatory fires threatening peninsular rule of the island in the 1840s. Second, the hurricanes hastened the final stages of 
Cuba's full embrace of sugar's dominant role in the social and economic life of the island. This slow process of development began in the immediate aftermath of the revolution in Saint Domingue and blossomed on the island with the growth of railroad infrastructure, the mechanization of sugar production, and the move toward a more liberal free-trade ethos in the Caribbean. The massive infrastructural devastation of the storms combined with increasing labor pressures and rising production/transportation costs forced many tobacco and some coffee farmers to cease operations, sell their slaves and farms, and move into the ranks of the landless petite bourgeoisie. These changes in the social and economic organization of the island eventually encouraged political fissures among the creole elite and between that elite and other socioeconomic groups on the island.

While Cuba and Texas were the twin jewels in the crown of American annexationism, British interests - for their own sake and the interest in checking American hemispheric aims emboldened an equally aggressive abolitionist policy on the part of the British government throughout the Caribbean. ${ }^{108}$ Among all of this, Cubans struggled in coming to grips with new

108 The British, although pushing a very forceful abolition agenda in the Caribbean, were hardly the supporters of as high an intentioned goal as their efforts might at first appear. The process of abolition opened the door to a great deal of privateering in the name of freedom by British naval vessels. A very lucrative after market in contraband "prize slaves" removed from slave ships by the British, sullied the lofty pronouncements of abolition. "...in the 1830's, however important psychologically the formal abolition of chattel slavery was, for most ex-slaves life changed little, if at all, after 1834, or even after the end of the four year period of 'apprenticeship.' Not long after those four years were up, another even larger importation of Prize Negroes began. They found themselves, as the earlier Prize Negroes had, liberated but far from free," Christopher Saunders, "Between Slavery and Freedom: The Importation of Prize Negroes to the Cape in the Aftermath of Emancipation," Kronos 9 (1984), 36-43. The British continued this ambivalence with the passage of laws that allowed British naval vessels to search ships involved in legal or illegal slave transport. Confiscated slaves, so-called "prize negroes" became a redistributable commodity useable by the British to supplement dwindling labor supplies created in the wake of abolition. The British government, calling this system an indentured-based labor arrangement, kept track of and listed those prize slaves whose indentures were soon to expire, at which time the laborers could hire themselves out at their own rates. While the British government increased some protections (age limits, length of service) in the 1840s, to the dismay of those seeking the cheapest labor, they were still a coerced labor force, their conditions of service closer to that of slaves than those of any others in this great age of abolition. The government spread these stores throughout the Caribbean from island to island as labor needs demanded. This attitude continued well into the 1860s as the British sought newly freed slaves for labor after the U.S. Civil War and their efforts gamely encouraged by an amendable Abraham Lincoln. Lincoln, flush with appropriations with Congress, forcefully pursued the search for a freedmen's colony up to his death, redoubling his efforts in his 1862 message to Congress. Lincoln empaneled members of his government 
geopolitical realities in which they were not the sole determiners of their destiny. Cubans of all

races, genders, and economic persuasions realized by the late 1840 s that forces external to the

island unduly affected their political decisions and the prospect of their very existence. The

degree of comfort with this reality did much to define positions on the fractious Cuban political

spectrum and to guide the various reactions Cubans put forward to political pressures that almost

strangled the island throughout the 1840 s and 1850 s.

These deep divisions and their attendant social positioning did not suddenly present

themselves in the 1840 s. Since the 1820 s, the debate over slavery along with British abolitionist

pressures throughout the Caribbean drove many influential creoles to debate the necessity of

slave labor, the structure of trade relations with the United States, and the worth of Spain's

to conduct highly secretive negotiations with the British government to find suitable lands for colonization in the West Indies. Lincoln's messengers worked with both British agents and leaders in the free black community to recruit emigrants for the proposed colonies. Debate about the popularity of the scheme within Lincoln's administration even became a subject of subversion when the president's subordinates began battling for control over a lucrative "colonization fund" of $\$ 600,000$ established by Congress. These interesting side notes certainly cast question upon the even-handedness of Great Britain's professions of the moral necessity of abolition prior to the and cast the actions of the British government in an extremely ambivalent light. While there certainly existed those arguing for freedom in its own right, there was at least an even amount that saw profit to be gained in the moral and economic rearrangement of systems of labor in the Caribbean which the British might control. Britain was desirous, for both self-interested economic and humanitarian reasons, to enforce abolition on the citizens of other countries who engaged in the trade hoping to cement its position in the Caribbean with the most advantageous policy available to it. Phillip W. Magness and Sebastian N. Page, trace the Civil War era negotiations with Britain in Colonization after Emancipation: Lincoln and the Movement for Black Resettlement (Columbia: University of Missouri Press, 2011). On British anti-slavery efforts Seymour Dresher presents the issues most lucidly in The Mighty Experiment: Free Labor versus Slavery in British Emancipation (Cambridge: Cambridge University Press, 2002) and Abolition A History of Slavery and Antislavery (New York: Cambridge University Press, 2009). See also: Richard Huzzey, Freedom Burning: Anti-Slavery and Empire in Victorian Britain (Ithaca: Cornell University Press, 2012); Christopher Leslie Brown, Moral Capital: Foundations of British Abolitionism (Chapel Hill: UNC Press, 2006); Robin Blackburn, The American Crucible: Slavery, Emancipation and Human Rights (London: Verso, 2011); Full text of the 1833 "Act for the Abolition of Slavery throughout the British Colonies," accessed on September 23, 2011, http://www.pdavis.nl/Legis_ 07.htm. The larger context of slavery in Cuba is discussed in: Adam Hochschild, Bury the Chains: The British Struggle to Abolish Slavery (London: Pan Books, 2006); David Murray, Odious Commerce: Britain, Spain and the Abolition of the Cuban Slave Trade (Cambridge: Cambridge University Press, 1980); Hubert Aimes, A History of Slavery in Cuba, 1511 to 1868 (New York: G. P. Putnam, 1907); Cuban AntiSlavery Committee, New York, Slavery in Cuba: A Report Of The Proceedings Of The Meeting, held at Cooper Institute, New York City, December 13, 1872 (Philadelphia: Historic Publications, 1969); Laird Bergad, The Comparative Histories of Slavery in Brazil, Cuba, And the United States (Cambridge: Cambridge University Press, 2007); Mariana Torrente, Slavery in the Island of Cuba (New York: BiblioBazaar, 2008); Rebecca Scott, Slave Emancipation in Cuba (Pittsburgh: University of Pittsburgh Press, 2000); Ada Ferrer, Insurgent Cuba: Race, Nation and Revolution, 1868-1898 (Chapel Hill: University of North Carolina Press, 1999); Aline Helg, Our Rightful Share: The Afro-Cuba Struggle for Equality, 1886-1912 (Chapel Hill: University of North Carolina Press, 1995). 
continued control of the island. ${ }^{109}$ The decisions reached by different communities throughout Cuba and in Cuban expatriate communities in the United States varied greatly, but each took into account the presence of British and American influence as much as that of the Spanish authorities who held sway over daily decision making on the island. The fate of the island was not one that would be made without the input, coercion and, at times, direct imposition of the various non-Cuban stakeholders. Cuban creoles were not alone in determining the contours of Cuban society nor would the outcome express solely the will of the Cuban people. The island's destiny was far too entwined with multiple destinies of the colonial powers that long-centered Cuba in their own national ideologies.

By 1800, the emergent Cuban elite found themselves faced with a pressing reality in the shadow of the Haitian revolution. Early Cuban political economy focused on developing a sociopolitical response to the quick and profound economic changes in the Caribbean basin. Cubans, much less than their American counterparts, were not convinced of their inherent Americanness and showed a reluctance to depart the Spanish family. This ambivalence kept Cuban vision centered squarely on social and economic development of the island within the Spanish Empire, to the frustration of Americans hungry for an effusive partner in annexation. For American and Cuban business interests, economic investment in Cuba and trade with the island, while making union a future possibility, became a more pressing concern than any other political concerns the two peoples might have shared.

Agricultural interests drove and divided the social, political, and economic life of Cuba. European trade and particularly United States commerce pushed the island's agrarian elite to the

\footnotetext{
${ }^{109}$ Chapter Four discusses the differing perspectives, stakeholders, and literary and scholarly debates of the Cuban slavery question and its effect on the power relations among Cubans, both on the island and in expatriate communities in the United States.
} 
forefront of social power. The division between the Spanish government and Cuba's

hacendados, or landed elite, opened wider by the 1850 s precisely over issues surrounding international trade and political reform. The divergence in long-term political and economic interests between Cuba and the metropole mirrored the divergence between the feudal mercantilist domestic politics of an older Europe in juxtaposition with an emerging free-market capitalism centered in the Caribbean. Cubans would have a front row seat in the determination of the direction not only of their future but also in the strength of Spain's long-term economic outlook. As uncertainty grew throughout the 1840s and as the international competition for Cuba smoldered, Cuban hacendados sought larger markets and greater profits. Their efforts grew more complicated with the explosion of the debate over slavery. The social dislocations and upheaval produced by capitalistic intensification griped every class and individual and left Cubans to grapple with definition of themselves and their culture. ${ }^{110}$

\footnotetext{
${ }^{110}$ Among the best and deepest investigations of the early colonial period as part of larger synthetic works on Cuban history is Ramiro Guerra y Sánchez, The Territorial Expansion of the United States: At the Expense of Spain and the Hispanic-American Countries (New York: University Press of America, 2003); Herminio Portell Vilá, Historia de Cuba en Sus Relaciones con los Estados Unidos y España, Vols. 1-2, (Havana: Mnemosyne Publishing, 1969); Hugh Thomas, Cuba: Or The Pursuit of Freedom (New York: Harper and Row Publishers, 1971); Philip Foner, A History of Cuba and Its Relations with the United States, Vol. 1, (McGraw: New York, 1972); Julio le Riverend, An Economic History of Cuba (Havana: Ensayo Book Institute, 1967); Louis Perez, Between Reform and Revolution (Oxford: Oxford University Press, 2007); Richard Gott, Cuba: A New History (New Haven: Yale University Press, 2004); and José Ignacio Rodríguez, Estudio Histórico Sobre el Origen, Desenvolvimiento y Manifestaciones Prácticas de la Idea de la Anexión de la Isla de Cuba a los Estados Unidos de América (Havana: Imprenta La Propaganda Literaria, 1900), 1-50. Among the best historiographical looks at Cuba, including the colonial period are: Robert Freeman Smith, "Twentieth-Century Cuban Historiography," The Hispanic American Historical Review 64, no. 1 (February 1964); Louis A. Pérez Jr., Essays on Cuban History: Historiography and Research (Gainesville: University Presses of Florida, 1995) and Louis A. Pérez, Jr. and Rebecca J. Scott, eds., The Archives of Cuba/ Los Archivos de Cuba (Pittsburgh: University of Pittsburgh Press, 2002); Kate Quinn, "Cuban Historiography in the 1960s: Revisionists, Revolutionaries and the Nationalist Past," Bulletin of Latin American Research 26, no. 3 (June 2007), 378-398; Jacques A. Barbier and Mark A. Burkholder, "Colonial Spanish America, the Bourbon Period," The History Teacher 20, no. 2 (February 1987), 221-250; Damián J. Fernández, ed., Cuban Studies Since the Revolution (Gainesville: University of Florida Press, 1992); and Rebecca J. Scott, Thomas Holt, Frederick Cooper, and Aims McGuinness, eds., Societies After Slavery: A Select Annotated Bibliography of Printed Sources on Cuba, Brazil, British Colonial Africa, South Africa, and the British West Indies (Pittsburgh: University of Pittsburgh Press, 2002).
} 
Historians generally date the emergence of Cuba onto the world stage from 1763 and its rebuilding in the aftermath of a yearlong British occupation. Cuba presented itself an interesting laboratory for the Spanish Crown. The efforts to reassert their control in the island in the wake of British conquering of Havana in 1762 created a template for social control that saw massive investment in Cuba's military provisions. This provisioning, many in the Spanish court and their economic beneficiaries hoped, might more closely bind the island to Spain and strengthen a model of social and military control in Spain's other colonies. The late eighteenth century investment in Cuba laid the groundwork of Cuba's nineteenth century economic transformation in the consequences of its humiliating military defeat. The massive infusions of royal wealth in colonial Cuba after 1763, for Havana's defense and for the purchase of royal slaves to build the defensive infrastructure, undergirded not only the boom in sugar production on the island after 1790, but also drove the loyalty the island showed during the South American independence wars. Indeed, the Spanish state played a central role in the transformation of the Cuban economy from one based on imperial service through Havana - that city generally providing provision and dockage for imperial transport flotillas - to a plantation colony. In fact, the benefits of Spain's massive investment came only as a result of the fusing of material construction in the built environment with the royal blessing of a slave-based labor force completing the construction.

The Spanish Crown became the largest slaveholder on the island and directed most of the labor toward naval shipbuilding and port improvements. The comfort displayed by the Crown in their encouragement and use of slave labor was a demonstration of economic power that the small but growing creole elite never forgot. By the early 1790s, two of the main obstacles to the rapid expansion of sugar production in $\mathrm{Cuba}$ - the shortage of enslaved laborers and competition from the French colony of Saint Domingue - were eliminated. The warfare seen in 1762 that 
initially pushed the Crown toward an enthusiastic embrace of slavery gave way to a private harnessing of that imperial energy and a redirecting of labor's efforts toward agriculturalism and private accumulation. Throughout the hemisphere, Spain had the most to defend and, arguably, the most to lose with challenges to its wealth and rule in the Americas. With the threat of renewed warfare as a spur, the Spanish Bourbons succeeded in using slavery to defend Cuba and establish the economic, martial, and social climate necessary to propel the island's sugar revolution.

There is some debate about the economic importance of the 1762 British occupation, especially the resulting policy of free trade, to later development in Cuba. Several historians argue that Spanish reforms in Cuba were simply part of a much larger series of programs that produced political, military, and social transformations of which British occupation was but a momentary chapter. Certainly, Bourbon reforms played a role prior to 1763 , however these reforms largely left Cuba on its own in terms of taking advantage of them. With a miniature economy and a small population, the advantages these Bourbon reforms offered stood advantageously for Spain's mainland economies, but innocuously for Cuba. Regardless of the moment or motivation, Spanish imperial policy, built upon a developing economic imperative coupled with a strong defensive posture in Havana, focused on massive investment of energy, intellect, and treasure in Cuba. Most of the treasure for Spanish investment in Cuba came from the mines of Mexico and Peru and with the specie movement came an increased hostility in these colonies toward Cuban development. The necessary jumpstart for the island was the coupling of actual economic investment and the economic benefits of slavery with those economic reforms already in place. This massive investment however, placed the Spanish crown in a difficult position as overwhelming currency shortages and colonial supply problems added pressure to 
their budding mercantilist undertaking. ${ }^{111}$

${ }^{111}$ Evelyn Powell Jennings, "War as the 'Forcing House of Change:' State Slavery in Late-Eighteenth-Century Cuba," The William and Mary Quarterly 62, no. 3 (July 2005), 411-440. For the reform programs of the eighteenth century, see Allan J. Kuethe, Cuba, I753-1815: Crown, Military, and Society (Knoxville: University of Tennessee Press, 1986); Sherry Johnson, The Social Transformation of Eighteenth-Century Cuba (Gainesville: University of Florida Press, 2001); Juan B. Amores, Cuba En La Época De Ezpeleta, 1785-I790 (Pamplona: Eunsa, 2000); John Lynch, "British Policy and Spanish America, 1783-1808," Journal of Latin American Studies 1, no. 1 (May 1969), 1-30; Jacques A. Barbier, "The Culmination of the Bourbon Reforms, 1787-1792," Hispanic American Historical Review 57, no. 1 (February 1977), 51-68 and "Peninsular Finance and Colonial Trade: The Dilemma of Charles IV's Spain," Journal of Latin American Studies 12, no. 1 (May 1980), 21-37 and "Indies Revenues and Naval Spending: The Cost of Colonialism for the Spanish Bourbons, 1763-1805," in Warfare in Europe 1792-1815, ed. Frederick Schneid (London: Ashgate, 2007), 3-20; Allan J. Kuethe and G. Douglas Inglis, "Absolutism and Enlightened Reform: Charles III, the Establishment of the Alcabala, and Commercial Reorganization in Cuba," Past and Present 109 (November 1985), 118-43; Allen Kuethe, "Havana in the Eighteenth Century," in Atlantic Port Cities: Economy, Culture, and Society in the Atlantic World 1650-1850, eds. Franklin Knight and Peggy Liss (Knoxville: University of Tennessee Press, 1991) 13-40. Slightly deviating from the 1763 moment is Celia Maria Parcero Torre, expanding on Sherry Johnson's work, who argues that the defense plans for Havana and the development of the sugar industry began before 1762. She points to the Bourbon reforms developing prior to British invasion as the jumpstart of capital investment in the island. The occupation in her narrative merely accelerated a reform program already in place: "To accept this (that the capture of Havana by the English was the point of departure for the sugar boom in Cuba) is to deny what was happening in Cuba in the previous years and, moreover, is to ignore some of the postulates and achievements of the reform policies carried out by the Bourbons." She maintains that while there were clear inadequacies in the defensive and economic investments in the island prior to British capture, the investment capital already flowed prior to 1762; Parcero Torre, La Perdida de la Habana y Las Reformas Borbonicas en Cuba: 1760-1773 (Castille-Leon, Spain: Junta de Castilla y León, Consejería de Educación y Cultura, 1998), 11. On the bankruptcy, trade, and currency problems that decades of war and specie shortages had on the Spanish Empire, particularly in the relation to British capital and competition see: C. Marichal, Bankruptcy of Empire: Mexican Silver and the Wars between Spain, Britain and France, 1760-1810 (Cambridge: Cambridge University Press, 2007), ch. 5; Adrian Pearce, British Trade with Spanish America, 1763-1808 (Liverpool: Liverpool University Press, 2007); John Lynch, "British Policy and Spanish America, 1783-1808," Journal of Latin American Studies 1, no. 1 (1969), 1-30. Adrian Pearce, "The Hope-Barings Contract: Finance and Trade Between Europe and the Americas, 1805-1808," The English Historical Review 124, no. 511 (2009), 1-29, reviews the system of commercial transactions made by the Anglo-Dutch consortium of Hope-Barings during the French Revolutionary Wars. These agreements, linking Spain, Britain, France, the Netherlands, the United States, and Mexico, followed from Spain's urgent need to secure royal funds stockpiled in Mexico that were rendered inaccessible by Britain's wartime blockade of the Atlantic. In return for British acquiescence, the Spanish granted free access to the rich Mexican market for British goods and manufactures and began the opening of trade more generally. Earl J. Hamilton, "Monetary Problems in Spain and Spanish America 1751," The Journal of Economic History, 4, no. 1 (May 1944), 21-48, outlines how the absence of a reactive banking system in Spain to the demand for bullion hastened local shortages and occasionally inconvenienced peninsular businesses. Much more serious was the lack of fractional coinage in New Spain and the other American colonies. The resultant barter, payments in kind, and unregulated issue of tokens by retail merchants and loan sharks inflicted severe hardships upon Indian laborers and poor whites. Cuban planters felt this pinch as well, and perhaps more than their mainland creole brethren, since the former depended entirely on Spanish merchants in Havana for capital fronting. The great distance and infrequent communications hindered supervision of the American mints and encouraged usurious lending practices. War with England forced Spain to issue its first paper money in 1780, and after 1793 successive conflicts with France and England resulted in debilitating inflation. While the paper currency did not circulate in the West Indies, SpanishAmerican colonists were taxed for its redemption and could not escape the repercussions of economic chaos at home. This economic situation was a factor in the conquest of Spain by Napoleon and the early movement for independence in America. Further discussion of these transit and accumulative paths is in: Franklin Knight and Peggy Liss, eds., Atlantic Port Cities: Economy, Culture, and Society in the Atlantic World 1650-1850 (Knoxville: University of Tennessee Press, 1991) and a Iberian peninsular perspective in Patrick O'Flanagan, Port Cities of Atlantic Iberia, 1500-1900 (London: Ashgate, 2008), ch. 2. 
The increased military presence in Cuba opened the door to greater immigration of military officers and Spanish officials to the island. This movement of people led to an intermingling of military families, peninsulares, and Cuban creoles. This social mingling mirrored that of the South American mainland in the previous century. The increase in soldiers stationed on the island had benefits since those soldiers often elected to retire on the island, settling in the countryside and contributing significantly to the growth of rural areas outside of Havana. The increased immigrant population from Spain resulted in peninsular-creole marriages outnumbering creole-creole unions by the 1790s. The small Cuban elite became intertwined with the Spanish military through these familial bonds. These creole sons often took up positions in the colonial bureaucracy, which tied them to the Spanish state through employment and patronage. The intermingling of families and the elevated role of the military in eighteenth century society offers insight into the loyalty shown by Cubans, and particularly the Cuban elite, during the independence era in Latin America. Cubans as a whole became more firmly connected to Spanish rule through marriage and military dependence, rather than alienated as their creole counterparts had on the South American continent. This positioning gave Cuban creoles particularly effective means to bring economic and social pressure on both the Crown's officials and peninsular officials in Cuba, even as the Spanish military connection to the island grew more tenuous into the nineteenth century. As a result of the generalized anxiety, envoys sent from Madrid to the island throughout the late eighteenth century had a royal mandate to negotiate with Havana elites and implement reforms while expanding the Spanish presence in hopes of solidifying Cuban loyalty.

The nineteenth century creation of new wealth in the Caribbean brought with it the creation of a new nobility in Spain, one that was intrinsically related to the structuring of the 
liberal state. That structure related in large part, after 1820, to the scope of Cuban economic processes and responded to a different dynamic rooted in the colonial phenomenon present on the island. The rationalization of the liberal state in Spain grew from a social structure that made possible the political transformations that consolidated on the island after 1830. The Crown's granting of titles, military positions, and economic concessions to the Cuban creole elite throughout the early nineteenth century not only strengthened elite claims on power but also strengthened the bonds between the Spanish court and its Cuban appendage. However, despite this increased prominence in the later period, Cuba's importance in the late eighteenth century was not based on its economic value or the supposed power of the elite in Havana, but rather rested upon the strategic value of the island for the whole of Spanish imperial policy. This valuation prompted the metropolis to implement the liberalization measures in the post-1763 period. These measures, mistakenly interpreted as concessions to Cuban elites, were actually a quick means of tax normalization on expanding Cuban production that provided a strong increase in revenue for the Spanish exchequer. Any concessions in the form of social privileges and even the opening of brief moments of free trade had no real political cost and very little economic cost, all the while providing the Spanish Crown with both a massive economic upside and a secure military watchtower aimed toward the rest of South America. ${ }^{112}$

\footnotetext{
112 Ángel Bahamonde Magro and José Gregorio Cayuela Fernández, "La Creación de Nobleza en Cuba Durante El Siglo XIX," Historia Social 11 (Autumn 1991), 56-82. José A. Piqueras, "La Siempre Fiel Isla se Cuba, O La Lealtad Interesada," Historia Mexicana 58, no. 1 (July-September 2008), 427-486; Pablo Tornero Tinajero, Crecimiento Económico y Transformaciones Sociales. Esclavos, Hacendados y Comerciantes En La Cuba Colonial: 1760-1840 (Madrid: Ministerio de Trabajo y Seguridad Social, 1996); Julio Le Riverend Brusone, "Relaciones entre Nueva España y Cuba (1518-1820)," Revista de Historia de América 37/38 (January-December 1954), 45-108; Verena Stolcke, Marriage, Class and Colour in Nineteenth Century Cuba: A Study of Racial Attitudes and Sexual Values in a Slave Society (Ann Arbor: University of Michigan, 1989); Hugh Thomas, Cuba: The Pursuit of Freedom (New York: Harper and Row, 1971), 88-92; Roger Betencourt, "Cuba's Attempts At Democracy: The Colony," (Paper presented at Cuban Futures International Symposium, Bildner Center/Cuba Project, Graduate Center of the City University of New York, April 2011). Regina Grafe and Alejandra Irigoin, "A Stakeholder Empire: The Political Economy of Spanish Imperial Rule in America," accessed February 12, 2012, http://www2.lse.ac.uk/economicHistory/pdf/WP111.pdf, draw a different conclusion as to the rest of the Spanish empire as they see the colonial elite more participatory in the allocation of tax revenue and in policy creation with
} 
Spanish policies and the resulting population boom fueled significant growth in both urban and rural economic sectors in and around Havana. The subsequent demographic expansion, exploding settlement outward in all directions from Havana, produced profound alterations in the fundamental structures of Cuban economy and society. The arrival of thousands of Spanish officers, their eventual retirement on the island, the granting of military commissions to prominent Cuban creole families, and decades of intermarriage created strong links between Cuba and Spain. These intimate links, far cozier than any that existed between the South American mainland and Iberian Peninsula, gave Cuba an increasing influence in Spanish domestic politics and economics. While military changes were both cause and effect of larger Spanish considerations, once installed these alterations took on a life of their own. Cubans and Spaniards, encouraged by a new closeness, wove the resulting realities into the foundations of social order in Cuba. The effects of this social organizing shaped Cuban society more invasively than just the social contours of elite marriage and salon politics. Downward on the social spectrum, the Spanish government incorporated a huge sector of Cuba's free AfroCuban population into militia service, irrespective of racial and social origins. This embrace of AfroCuban service in such a public institution imbued men of all rank a certain dignity that the creole elite constantly and begrudgingly accommodated. Intermarriage between creole elites and small landholders, both black and white, spread economic benefits further still. Often able to

\footnotetext{
the Spanish government as less predatory in their economic structuring on the mainland of South America than commonly asserted. However, the situation in Cuba, by their own articulation, was completely different as was the place and importance of the island in the Spanish imperial design, particularly after the revolutionary era. Allen Kuethe takes a specific look at the commercial freedom and corresponding political participation available to Cubans. Although his study picks up at an earlier period, he carries forward into the $19^{\text {th }}$ century the mobility and aspiratory successes Cubans enjoyed in the more limited economic period following British evacuation of Havana in 1762. Cuban loyalty, remembered and rewarded in the immediate aftermath, became a distant memory by the 1810s. While the concessions granted (or the remembrance of them given to past generations) might have emboldened planters in the 1790s, as the economic boom picked up speed, Spain and colonial authorities looked to squeeze profit and loyalty out of every transaction; Kuethe, "Guns, Subsidies and Commercial Privilege. Some Historical Factors in the Emergence of the Cuban National Character 1763-1815," Cuban Studies 16 (1986), 123-38.
} 
acquire small parcels of land, military veterans added to the population of smallholders that ringed urban Havana and owed allegiance to the beneficial terms of Spanish treatment for the livelihoods. The Spanish Crown, by consciously spreading benefit throughout society, increased loyalty to the colonial system not only through rising material well-being but also because a broad swath of the population felt generous to the Spanish in return for privileges bestowed by the Crown.

Retired military officers aspired to administrative positions and established high visibility not only as diversified economic producers but also as the rural capitanes de partido who provided political leadership throughout the Havana countryside. These families solidified a middle class political and economic power in rural Cuba built upon engagement in multiple agricultural pursuits - including food production for Havana and tobacco farming (the early agricultural money maker on the island). This military and agricultural middle class offered a political counterbalance to peninsular and creole leaders in Havana and enjoyed a commanding presence demonstrative of the political diversity that shaped the character of eighteenth century Cuba. "Military service afforded a means to arrive; military policy provided an opportunity to remain, a bourgeoning economy offered a chance to prosper."113

\footnotetext{
${ }^{113}$ Sherry Johnson, The Social Transformation of Eighteenth-Century Cuba (Gainesville: University Presses of Florida, 2001), 90, and "La Guerra Contra los Habitantes de los Arrabales:" Changing Patterns of Land Use and Land Tenancy in and around Havana, 1763-1800, Hispanic American Historical Review 77, no. 2 (May 1997), 181209; Allan Kuethe "The Development of the Cuban Military as a Socio-Political Elite, 1763-1783," Hispanic American Historical Review 61, no. 4 (November 1981), 695-704 and "Los Llorones Cubanos: The Socio-Military Basis of Commercial Privilege in the American Trade under Charles IV," in The North American Role in the Spanish Imperial Economy, 1760-1819, eds. Jacques A. Barbier and Allan J. Kuethe (Manchester: Manchester University Press, 1984), 142-57. Note must be made of Sherry Johnson's scathing critique of Captain General Luis de Las Casas and Francisco de Arango y Parreño. Johnson argues that these men, often portrayed as saviors or fathers of Cuban free market capitalism by most historians, were not as beloved by their contemporaries as they are by these subsequent generations of historians. She claims that these twin apostles of enlightened material and scientific progress on the island aligned themselves with a narrowly constructed Cuban elite. Las Casas, allied closely with Arango and the habanero sugar interests, stubbornly championed a modernization of the Cuban infrastructure without consulting beyond this planter elite at a time when military families still wielded great prestige. His willful ignorance of other politically influential classes on the island put him on the defensive over his ambitious infrastructural programs that entailed extensive labor levies. These unpopular taxes, coming without the
} 
The social changes in Cuba were but a portion of the intense changes happening in the eighteenth century Spanish Caribbean. Spatial changes on the island coupled with a reconfiguration of commodity and currency flows within the empire restructured the lives of nearly every subject under the Spanish flag. Furthermore, not all Spaniards, particularly those within the court and elite economic circles on the peninsula, saw the changes within the empire as positive. The repositioning of Cuba within the royal system also opened up jealousies, particularly in relation to Mexican taxpayers who funded much of the imperial projects in Havana. The Mexican situado, predetermined payments taken from Mexican tax and mine receipts, funneled into the immense militarization of the island and fueled Havana's growth. This treasured position along with the massive influx of peninsulares into the island presented Cuba, more so than Spain's other colonies, as a truer extension of Spanish culture to many in the royal court and in domestic politics. This fidelity, in turn, prompted demands from Cubans for certain accommodations on the part of the Crown - a situation going back to 1763 when the Conde de Ricla, sent by the Spanish crown to reclaim the island, offered the Cuban elite unlimited trade as their invitation back into the Spanish fold.

\footnotetext{
necessary political accommodations and layered with class antagonism, led to clashes with the military and retired military composing the capitanes de partido, both of which obstructed his plans. The ensuing alienation exploded into open defiance in the countryside by 1794-95 and led to Las Casas' eventual resignation. Johnson sees in this embarrassment for Las Casas and the growing sugar elite a fault line along which the creole elite broke and one that sowed the seeds of the first creole uprising against Spanish rule in 1808. Arango's close ties to Las Casas and the Captain General's policies hindered the former's influence as he failed to carry forward many of its policy proposals that garnered him such attention and acclaim. The overreach on the part of Las Casas, Arango, and the still embryonic hacendado elite flowed from a serious misreading of the sucrocracy's power during a period where that power had not yet congealed. This overreach fueled an anger on the part of the military elite toward the sucrocracy that lingered far into the $19^{\text {th }}$ century. Consuelo Naranjo Orovio and María Dolores González-Ripoll Navarro discuss the challenges confronted by Arango and Las Casas but offer a less critical review of the conflicts in "Perfiles Del Crecimiento De Una Ciudad: La Habana A Finales Del Siglo XVIII," Tebeto: Anuario del Archivo Histórico Insular de Fuerteventura 5 (1992), 229-248, accessed on May 19, 2012, http://digital.csic.es/handle/10261/15119. González-Ripoll Navarro also focuses specifically on Las Casas historiography in "En Torno A La Figura De Luis De Las Casas, Un Gobierno En Transition," Arbor: Ciencia, Pensamiento Y Cultura 139, no. 547 (1991), 83-89. For more on Arango's life and thinking in the traditionalist vain see Raúl Maestri, Arango y Parreño, El Estadista Sin Estado (Havana: Cuba, Publicaciones de la Secretaria de Educación, 1937) and Francisco Ponte Domínguez, Arango y Parreño, El Estadista Colonial (Havana: Editorial Trópico, 1937).
} 
Cuba also played an important role as a pawn in service to various constituencies fighting within the Spanish court. The court saw Cuba as an important military gate keeper between Europe and South America and hoped that militarization of Cuba might reduce illegal commerce and increase tax revenue. Back home, the inclusion of Cuban tax receipts, the increase in legal Caribbean trade more generally, and the establishment of free trade after 1765, although never continuous, began the slow decline of the Cadiz monopoly and the breaking of that city's merchant and political elite's influence within the Spanish court. Royal orders in 1765 opened trade between Cuban and eight additional Spanish towns, rationalizing tariffs on consumables entering Cuba and sugar and tobacco leaving the island. The new tariff schedule also allowed independent stowage on Cuban ships of both imports and exports, and ultimately extended this system to other Spanish colonies. The diffusion of economic opportunity on the island mirrored, and in important ways fed, the same spread of economic opportunity among the merchant classes, and their benefactors, on the peninsula; doors opened in Cuba settled scores in the courts of Spain's cities. The new Cuban power to influence the policymaking apparatus was apparent to habaneros, creole elites in Havana, and peninsulares alike and undoubtedly drove some of South America's subjects' ill will and jealously that fueled the independence wars of the nineteenth century. Elites throughout South America realized the Spanish crown's wish to develop their Caribbean possessions as moneymaking endeavors as well as important fortified outcroppings for the watchful protection of shipping. Cuba strengthened the empire's geopolitical footing both in the Caribbean and South America. As a result, Cuba became a capital-rich island almost overnight with a liquidity of investment that fueled fluidity, albeit quickly waning by the 1810 s, of opportunity. ${ }^{114}$

\footnotetext{
${ }^{114}$ Allan Kuethe, "Guns, Subsidies and Commercial Privilege. Some Historical Factors in the Emergence of the Cuban National Character 1763-1815," Cuban Studies 16 (1986), 123-38. Altagracia Ortiz, Eighteenth-Century
} 
The slow accretion of political and economic power in Havana also did much to change the physical and social landscape of the surrounding area. Economic reorganization along with the ecological consequences of extensive deforestation caused by Havana's expansion had significant impact on the spatial arrangement, topography, and land use surrounding the island's major city. The eighteenth century development in Cuba, fueled by royal policies, benefited many levels of Havana's society, not just the elite. Midlevel social aspirants took advantage of the prosperity to advance their interests. The area's marginal inhabitants also found the greater prosperity that a healthy economy provided in terms of better provisioning and increased employment opportunities. This generalized disbursement of economic benefit kept the gap between classes modest and made it difficult for royal administrators, the military elite, and the creole bourgeois to impose a narrowly-defined physical or social order on the structure of the arrabales - lower socioeconomic areas ringing Havana. While Havana's propertied creole

Reforms In The Caribbean: Miguel De Muesas, Governor Of Puerto Rico, 1769-76 (Teaneck, NJ: Fairleigh Dickinson University Press, 1983), 43-66. The money coming from Mexico, while on a pretty consistent schedule, set up a system by which enterprising creole lenders extended short term loans to royal interests in Havana in exchange for favors, notable military commissions for their sons. These arrangements caused little concern within a stable imperial structure that both fueled Cuba development and proved remarkably responsive to Cuban concerns. This system was also necessary as the Spanish colonies in the Caribbean lacked a variety of physical, demographic, and mineral deposit advantages that mainland South America enjoyed. The shifting oversight of the Spanish government toward issues of trade in the Caribbean basin more generally is reviewed in: Duvon Clough Corbitt, "Spanish Colonial Governance: The Administrative System in the Floridas, 1781- 1821," Tequesta: The Journal of the Historical Association of Southern Florida 1, no. 2 (August 1942), 41-54: Gilbert C. Din, The Spanish Presence in Louisiana, 1763-1803 (Lafayette: Center for Louisiana Studies, University of Southwestern Louisiana, 1996), 113-123; Daniel Schafer, "A Class of People neither Freemen nor Slaves: From Spanish to American Race Relations in Florida, 1821-1861," Journal of Social History 26 (1993), 587-609; Ralph Lee Woodward, Jr., "Spanish Commercial Policy in Louisiana, 1763-1803," Louisiana History: The Journal of the Louisiana Historical Association 44, no. 2 (Spring 2003), 133-164. Sherry Johnson, "Climate, Community, and Commerce among Florida, Cuba, and the Atlantic World, 1784-1800, The Florida Historical Quarterly 80, no. 4 (Spring 2002), 455482. Johnson draws attention to the importance of St. Augustine in Atlantic trade and rejects the idea that the Spanish colonies in Florida and the Gulf Coast were economic and social backwaters. She sees these areas as important bases of trade, particularly the illicit trade between the United States and Cuba. She sees these areas operating in tandem with Cuba and became the next area that Spain expanded free trade to after the policy worked successfully in Cuba. The East Florida colonies, politically and economically subordinate to Havana, enjoyed similar advantages of trade with the United States and established lucrative relationships with Havana's merchants, notably traders in St. Augustine. Trade among Atlantic port cities led to the accumulation of wealth and extraordinary social advancement. 
families certainly benefited greatly, rising opportunity meant that many sectors of the population were given a tangible reason to support the status quo thereby explaining the colonial roots of Cuba's enigmatic loyalty to Spain.

Clearly, Cuba in the last half of the eighteenth century was not yet the prototypical slave/plantation society, defined by economic structures revolving exclusively around slavery and a singular cash-crop in the tradition of Saint Domingue. There existed throughout the island extraordinary regional variations in social and economic structures; occupational, class, racial, national, and gender differentiations could be extreme among all population sectors, including slaves. Havana, a city enjoying its first sustained attention and growth since its founding, acquired a new rhythm of life. However, while it did not yet establish itself as the powerful center of island life that it became in the nineteenth century, Havana was the growing nexus of the island's commerce. The profound transformation of the island created an extraordinary world of connections and enterprises that breathed on their own, not yet subordinated to sugar. This world of the slave trade, meat products, rum, molasses, machinery, textiles, wood, land, cattle, tobacco, coffee, the merchant marine, commercial operations, small stores, and infrastructural improvements, encouraged an excited accumulative ethos throughout the island. The overwhelming resources needed to buy land and slaves were not hindrances for these urban entrepreneurs interested in other revenue streams. The unprecedented demand for labor exhausted the local Havana supplies and affected a wide circulation of money among groups who had been, until then, struggling for opportunity. Artisans, servants and apprentices, many of whom were free AfroCubans and of mixed race, hitherto in small numbers and with small import, possessed riches in labor that catapulted at least some into economic respectability. With the dispersive effect of a new economic reality fueling a downward expansion of wealth, new 
men and new money enveloped Cuba. The arrival of Spanish commercial connections facilitated the expansion of a process already set in motion by forward-looking Cuban families reactive to their new reality. The drive toward dynamic change came from the established Cuban stock desirous of opportunities that met their perceived station and mirrored those which previously propelled the South American creole elite's wealth - an elite they often jealously compared themselves to. ${ }^{115}$

While social dynamism abounded in Cuba between 1750 and 1790, there were nevertheless significant external and internal warning signs that threatened the order and fluidity of society. Social mobility existed within class boundaries but far less so across class and racial lines. Among the most grievous of problems, at least for the white creole elite, was the growing divergence between a dynamic colonial economy and a stagnant metropolis. Spanish producers increasingly failed at meeting the growing needs of the island. The cumbersome tactic of importing American goods to Spain then placing them on Spanish ships and finally sending them to Cuba grew exhausting and only strengthened calls for trade reform along with encouraging a lucrative smuggling culture. The moments at which the Spanish government relaxed trade restrictions - forced under the British occupation of 1762, again during the American Revolution, and at various but brief points during the European wars of the early nineteenth century - gave Cubans a taste of what unfettered free trade felt like and put into comparative relief the inability of the Iberian mainland to provide for its colony. The disruption produced by each change in policy, depending solely on the crown's whim, further stoked the fires of bewilderment and frustration. Cuban producers looked enviously at Saint Domingue and its

\footnotetext{
${ }^{115}$ Franklin W. Knight, “Origins of Wealth and the Sugar Revolution in Cuba, 1750-1850,” The Hispanic American Historical Review 57, no. 2 (May 1977), 231-253; Sherry Johnson, “'La Guerra Contra los Habitantes de los Arrabales:' Changing Patterns of Land Use and Land Tenancy in and around Havana, 1763-1800," The Hispanic American Historical Review 77, no. 2 (May 1997), 181-209.
} 
North American trade, which accounted for more than the total United States trade with the rest of the Caribbean in 1790. Conversely, the totally number of ships from North America to Cuba, which increased from four in 1776 to 368 in 1782, evaporated to only ten after Spain reinstituted its trade monopoly in $1784 .{ }^{116}$

116 There were four main intervals of lucrative trade between the United States and Cuba prior to the normalization of regular trade relations and the ending of the Spanish trade monopoly in 1817. Generally, the Spanish Crown's machinations in international trade and its tantalization of American commerce were marked with quick and unceremonious changes of heart. While Spain had long-attempted to keep its American colonies locked in exclusive trade to the benefit of a small number of Spanish commercial monopolists, they recognized that theirs' was a losing hand against Caribbean intrusion by both the British, most notably in the seizing of Havana in 1762, and the clandestine trade between Americans and Cubans. The American Revolution increased legitimate exchange between Spain and the United States and made necessary the appointment of agents and consuls. The history of the early development of this commerce, along with its corresponding diplomatic corollaries, can be divided into four episodes dependent upon the existence of peace or war. The first episode corresponded with the American Revolution when Spain decided to enter that conflict against Great Britain in 1779. The British navy quickly crippled its colonial supply trade. As a result, it became necessary to permit Cubans to buy food from the Americans. The resulting trade was hampered by many restrictions, high duties, port charges, and arbitrary detentions of American vessels. After the war the policy benefitting American trade was quickly abandoned. However, this period also saw the Spanish colonies need for labor increase. On February 28, 1789, a Spanish edict was issued permitting the free trade in slaves with any country or carrier. The second episode of active trading began shortly thereafter, when Spain joined the monarchical allies against republican France in 1793 and continued until Spain withdrew temporarily from the war in 1795 . French privateers soon crippled Spanish commerce and Spanish America had to fend for itself. In the meantime, the captain general of Cuba, Don Luis de Las Casas, more enterprising than some of his predecessors, sought to promote Cuban prosperity by admitting United States trade and thereby avoiding some of the more onerous imperial tax dictates. Using discretionary power granted to his office in the wake of British evacuation after the handover of Havana in 1763 (by orders given by the Crown in 1767), he therefore opened Cuban ports to trade in food with the United States, February 23, 1793, and shortly thereafter the exigencies of the war drove the Spanish government to issue a similar order (June 25, 1793). Spain withdrew from the war in 1795 with one of the first acts of peace being an order closing the ports. Spain's re-entrance into the war, this time as an ally of France, necessitated the resumption of Cuban trade with the U.S. as the British moved to counteract Spanish free trade in the Caribbean. Spain threw open all of its American ports as a result of a sweeping royal order in November of 1797. Yet, with French anger (due to assumed American support for British imperial efforts), American shipping was constantly harassed and American trade negotiators hamstrung by Spanish and French obstructionism. Despite this situation, trade flourished in Cuba as the island was receptive to quiet arrivals of American ships with great danger of punishment to their crews. Again, with the arrival of peace in 1801, Spain turned back to monopoly. With the coming of the Napoleonic wars in 1804, the fourth round of trade liberalization began. With Spanish shipping under constant duress, Cuba needed provision and the Spanish leadership there turned to the United States. Consul Henry Hill, a direct if not gruff veteran of U.S. trade negotiations, defended American interests in Cuba and reported voluminously on trade conditions in Havana during the period. These reports fed American interest in Cuban commerce. This was also about the time when Thomas Jefferson involved himself in secret discussion with Francisco de Miranda to offer American aid to early revolutionists in South America. When these discussions came to light, Hill, implicated in taking the temperature of Cuban interest in American protection, left for Jamaica and more delicate consuls took his place. With Napoleon's seizing of the Spanish throne in 1808, the last of the early free-trade eras came to an end. In actuality, the era only ended for the Americans as the decidedly anti-French sentiment in Cuba pushed the island's leaders toward a sudden warming of relations with the British, who thereafter enjoyed open access to Havana. The careers of those involved in the negotiations as well as some others of the periods are presented in: Roy Nichols, "Trade Relations and the Establishment of the United States Consulates in Spanish America, 1779-1809," The Hispanic American Historical Review 13, no. 13 (August 1933), 289-313; Frances Armytage, The Free Port System in the British West Indies: A Study in Commercial Policy, 
The embrace of free trade supercharged Cuban successes in Caribbean commodity flow but also produced upward pressure on prices as the island's rising population increased demand for scare commodities. Along with these supply concerns was the realization that rising domestic agricultural production and necessary commodity importation rendered existing transportation systems inadequate at best. These transportation weaknesses served to disrupt distribution of essential supplies farther beyond the few ports that existed and also hampered the collection and distribution of agricultural produce throughout the island. Spain could not send enough ships at reasonable intervals to meet the rising tide of Cuban needs. Despite free trade promises from the Spanish, the machination of courtiers coupled with continuing royal monopolies kept the economy in chains and left smaller producers increasingly at a comparative disadvantage in world markets. For middling farmers, the royal tobacco monopoly - the Factoría de Tobacos which regulated the production, prices, and distribution of tobacco - was perhaps the clearest example of Spain's economic backwardness. The inadequate banking and economic system proved ill-equipped to deal with Cuba's rapid growth, soaring inflation, and scarcity of specie. These limitations in banking sector proved particularly challenging as they coupled, in the 1790s, with rising demands from the growing agricultural elite for more liquidity in the specie market.

1766-1822 (London: Longmans, Green \&Co., 1953); Javier Cuenca Esteban, "Statistics of Spain’s Colonial Trade, 1792-1820: Consular Duties, Cargo Inventories and Balance of Trade," Hispanic American Historical Review 61, no. 3 (August 1981), 381-428; Dorothy Bume Goebel, "British Trade to the Spanish Colonies, 1796-1823,"

American Historical Review 43, no. 2 (January 1938), 288-303. Interestingly, the British maneuvering in the post 1808 period irked Jefferson and pushed him to entertain a brief dalliance of Cuban annexation after being presented the idea by a Cuban delegation. He responded in kind by sending a secretive group to Captain General Someruelos who responded, not surprisingly, coolly to the idea. As Jefferson left office the matter was largely dropped. However, all of this unrest and politicking perhaps in some way lead to the abortive effort of wealthy landowner Roman de la Luz Sanchez and lawyer Jose Joaquin Infante toward establishing an independent Cuban republic. They went so far as to write a constitution that established dominance by wealthy landowners, Catholicism as the official religion, and wealth requirements for military service. Ironically, both slaves and free Afro-Cubans seemed more amendable to their cause than did their wealthy brethren. Captain General Someruelos quickly put down the movement and relocated the men to prisons in North Africa. Michele Reid-Vazquez, The Year of the Lash Free People of Color in Cuba and the Nineteenth-Century Atlantic World (Athens: UGA Press, 2011), 40-60; Louis Perez, Cuba: Between Reform and Revolution (Oxford: Oxford University Press, 1995) 410-411. 
The substantial investment required for efficient, notably sugar, production and the inadequacy of the banking and economic system combined to handicap small producers and small landholders as well. The pursuit of wealth and the freezing out of large swaths of the previously prosperous middle class illuminated a vicious process of social disintegration, polarized ethnic antagonisms, and increased international political and economic dependency. The confluence of these factors set the foundation of the slave society Cuba became in the 1840s; a society helmed by an adaptive elite, able to negotiate the archaic Spanish political and economic system for their benefit, and a society increasingly uninviting to small producers who threatened the elite's consolidating impulses.

Notable in this process, and helping to draw the disenchanted middling class closer to the elite, was the swift increase in the Cuban slave population in the late eighteenth century. Cubans imported at least 80,000 African slaves between 1785 and 1800. This increase, which accelerated further still after the Crown relented to the free trade in slaves after 1807, drove production and consolidated land gains in the sugar industry throughout the latter half of the eighteenth century. In 1750 there were 62 ingenios, sugar plantations, milling cane in the Havana region. That number rose to 96 in 1761 and 225 by 1792. In 1762 some 300 caballarias (33.6 acres each) of land were cultivated in cane with that number topping 5,000 caballarias by 1792 . The shift in demographic structures resulting from large-scale slave imports and the changing parameters of marketing, credit, and labor allocations due to sugar's expansion had as profound an effect on Cuban society at the end of the century as the military reforms that ushered in the period. ${ }^{117}$

\footnotetext{
${ }^{117}$ Louis A. Pérez, "Cuba and the United States: Origins and Antecedents of Relations, 1760s-1860s," Cuban Studies 21 (1991), 57-82 and Cuba: Between Reform and Revolution (Oxford: Oxford University Press, 1995) chs. 2-4; Philip S. Foner, A History of Cuba and Its Relations with the United States, Vol. I (New York: International Publishers, 1962), chs. 3-5; Richard Gott, Cuba: A New History (New Haven: Yale University Press, 2004), ch. 3; A. Gallenga, The Pearl of the Antilles (New York: Negro Universities Press, 1970) reprint from 1873; James A. Lewis, "Anglo-American Entrepreneurs in Havana: The Background and Significance of the Expulsion of 17841785," in The North American Role in the Spanish Imperial Economy 1760-1819, eds. Jacques Barbier and Allan
} 
The economic and political expansion of the small creole elite's influence coupled with new aggressive governmental policies designed to encourage this expansion, especially during the tenure of Captain General Luis de Las Casas (1790-1796), furthered the physical expansion of a plantation society warming to sugar monoculture. The emergence of Cuban plantation society during the last decade of the eighteenth century coupled with both the rapid rise in the slave population and Cuba's growing economic importance to the Spanish Crown drove governmental policy on the island. These polices helped imbue the relationship between the Captain Generals of the era and the rising plantation elite with a camaraderie and direction that elevated policies and interests beneficial to a select group of society. Although this sugar elite was in rapid ascendency, the continued importance of coffee cultivation and, to a lesser extent, tobacco production cannot be ignored. Sugar estate owners hedged their bets with their continued investment in production of other crops, particularly given that sugar in the late eighteenth and early nineteenth centuries, hemmed in by technological constraints, was not the economic juggernaut that it soon became. Furthermore, these agricultural entrepreneurs remained uncertain of the Spanish government's dedication to free trade and investment in the island. They were wary of over investment in a commodity market still dominated by the world's leading producer, the sugar colony of Saint Domingue.

Given this uneven economic footing, Cuba's developing elite looked to social organization as the most direct path toward solidifying the effects of new political and economic configurations. Family interconnections of a military founding, initially reluctant to embrace the new capitalist ethos of free trade and slavery-based economy, quickly shifted toward plantation

\footnotetext{
Kuethe (Manchester: Manchester University Press, 1984), 112-126; Basil Rauch, American Interest In Cuba: 18481855 (New York: Columbia University Press, 1948), ch. 1; H.E. Friedlander, Historica Económica de Cuba (Havana: Jesús Montero, 1944), chs. 1-4; Julio E. LeRiverend, Historia Económica de Cuba (Havana: Editorial Nacional de Cuba, 1965), chs. 3-6.
} 
agriculture once the boom began and military prestige declined. Equal in importance to

economic growth was the building of new institutions and organizations aimed directly at

furthering the interests of the creole plantation elite. These organizations, which provided

education and social prescription, helped to create an ordered and hierarchical society by placing

the elite at the head of the social table through a designed paternalism engineered to develop a

dependency on the part of the lower classes. Economic changes, layered on a society almost

totally dependent on imports, only hastened this process of dependency. The elite began to fill

the societal spaces, a process which the Spanish Crown found generally uninteresting, and

demanded investment in infrastructural improvements, social programs, and a greater voice for

Cubans in the affairs affecting the island. ${ }^{118}$

Cuba was demonstrative of the effect that the expansion of slavery had in transforming

political economies across the Americas during the nineteenth century. The debate over slavery

and modernity holds a special place in the development of sugar-capitalism in Cuba. ${ }^{119}$ Dale

\footnotetext{
${ }_{118}$ Maria Dolores González-Ripoll Navarro, Cuba, La Isla De Los Ensayos (Madrid: Consejo Superior De Investigaciones Cientificas Escuela De Estudios Hispano-Americanos, 2000); Anthony E. Kaye, "The Second Slavery: Modernity In The Nineteenth-Century South And The Atlantic World," Journal of Southern History 75 (August 2009), 627-650.

119 Manuel Moreno Fraginals' work El Ingenio: Complejo Economico Social Cubano Del Azúcar, 3 vols. (Havana: Editorial de Ciencias Sociales, 1978), guides much of the historiographical debate on the intersection of slavery and modernity in Cuba. Fraginals worked within the broad historical question of how African slavery and Spanish colonialism shaped the peculiarities of Cuban history and culture. His work traces the efforts of Cuban planters to build one of the Atlantic world's major slave societies and their great ambivalence with that project. He argues that despite their success, the internal contradictions of Cuban slavery, the ever-increasing concern about internal policing, and the overwhelming need to shift massive investment toward advancing sugar-producing technology all led to weakening of the system the elite build and ultimately to Cuban slave emancipation. Fraginals not only describes the plantation complex, with the entire range of legal, economic, and political reforms demanded by the Cuban dominant class, but also that class' efforts to build the infrastructure of a unique creole culture through institutions like the Real Sociedad Patriótica de los Amigos del País. In his rendering, creole planters were an ascendant bourgeoisie characterized by the intellectual and entrepreneurial dynamism of their European counterparts. They were also, however, doomed to fail in their historic task of carrying out Cuba's bourgeois revolution because of their fatal reliance on elements of the old pre-modern regime. The most debated aspect of Fraginals' work is his insistence on the premodernity of Cuban society due to the continuance of slavery. Hence, this class that committed itself to the conquest of nature and the mobilization of its country's untapped resources ultimately capitulated under the weight of a history and society out of touch with developing modernity. Ultimately, for Fraginals the sources of wealth and success of the planter class were also the sources of its failures. Authors such as Rebecca Scott and Laird Bergad challenged Fraginals' assumptions about the weight of Cuban slavery's internal
} 
Tomich, referring to this moment as the "second slavery," distinguishes the new articulation of the Atlantic economy from older structures of colonial slavery by its emphasis on new commodities produced in unprecedented quantities in formerly marginal regions. Accompanying capital's spread within these reconfigured polities was a new and profound embrace of industrial production methods. This reconfiguration of industrial capital in the Caribbean became possible after the Haitian Revolution effectively removed Saint Domingue from the competitive playing field and invited new areas and brokers into the Atlantic economy. After 1791, slavery and capital acted as accelerants for expansion into new areas and new crops using human and industrial machinery on incredibly vast scales. As a result, new planter and investment classes gained dominance in rising world markets and acquired new domestic and international power. This power, possessed through the profits reaped from sugar, coffee, and (in the United States) cotton, derived its economic form from the fusing of temporal coincidences with growing demand. Massive upturns in output met increased demand from the growing populations of European and American industrial workers. The demand of average consumers for commodities, previously existing as luxuries, delivered a ready-made consumer base that in-turn promoted greater agricultural production. To meet these demands, planters integrated industrial machines with slave labor; coupling new production techniques on larger scales with the most mobile and adaptable labor force already proven to be malleable, available, and controllable enough, after centuries of experimentation. The second slavery was the perfecting of slavery through the modernity of technological production immersed in the currents of capitalism. ${ }^{120}$

contradictions. They argue that slave labor and the planters that benefitted from it successfully adapted to the technological innovations and embraced modern Atlantic capitalism. On the other hand, they have demonstrated that slave emancipation, not slavery, led to crisis in the organization of sugar production. These revisions, however, have only amplified the centrality of Fraginals' work to any discussion of Cuban slave society by throwing into relief its particular virtues, especially its composition and its ambition to be the portrait of an age.

${ }^{120}$ Dale W. Tomich, Through the Prism of Slavery: Labor, Capital, and World Economy (New York: Rowland and Littlefield, 2004), esp. 56-71; Tomich and Michael Zeuske, eds., "The Second Slavery: Mass Slavery, World- 
The moribund Cuban sugar economy of the late eighteenth century gained momentum from a restructured relationship of its colonial positioning within the Spanish empire. During the 1790s, a coterie of ambitious creole planters and colonial officials developed a detailed design for what Cuba needed in order to seriously enter the world sugar market. This cotillion required elaborate planning because the chief need for Cuban planters was slaves, of which the supply remained dependent on greater access to the transatlantic slave trade (an access that Spain was unlikely to give). Cuban Creole interests argued that securing the best quality slaves in great plentitude required an open market competition amongst all carriers for which Spain had to enact a permanent policy of free trade in African slaves. Aspirant Cuban planters spoke to metropolitan authorities in bald terms, condemning Spain in the process for an economic and cultural backwardness that impeded desperately needed technology investment and market reforms. The Cuban elite, capitalizing on decades of intermarriage, military service, trade experience, and social normalization, used their growing control over all aspects of economic life in Havana to slowly tilt the system of land reform, tariff collection, trade exchange, and monetary policy in their irreversible favor. They consolidated the intellectual, legal, emotional, and physical arrangement of the island, which allowed them to pressure the middle and lower classes into a tacit acceptance of a new status quo resting largely on the property dispossession of small landholders and the labor dispossession of the enslaved.

The creole elite's imbrication into the realm of monetary and industrial modernity in the Atlantic world did not occur overnight. The accretion of the necessary power to instill social dominance enabled Cuban sugar planters to cast themselves simultaneously apart from and

\footnotetext{
Economy, and Comparative Microhistories, Part I," Review: A Journal of the Fernand Braudel Center 31, no. 2 (2008), 91-100. See also Tomich, Slavery in the Circuit of Sugar: Martinique and the World Economy, 1830-1848 (Baltimore: Johns Hopkins University Press, 1990); and Tomich, "World Slavery and Caribbean Capitalism: The Cuban Sugar Industry, 1760-1868,” Theory and Society 20 (1991), 297-319.
} 
above their fellow Cubans. They presented themselves both as leaders of the island and also as members of a free-trade ethos that encouraged participation in obtaining African slaves from all suppliers, new plantation technologies from United States, and advanced processing equipment and scientific knowledge from France. The resulting stability in social and economic relations normalized the very social order the elite sought to create. While these relationships allowed the elite entrance into the swirl of market capitalism, invitation into preeminent social status, and preeminence in the world sugar market, Cuba paid a high price in the reciprocity that these arrangements demanded. Cubans of all social classes became dependent on imports from the United States and submerged under a tidal wave of debt. ${ }^{121}$

The development of the Cuban sugar industry centered initially on the western part of the island. Soon after the turn of the century, cultivation pushed aggressively south and east of Havana and in the process displaced coffee and tobacco producers as the need for land and slaves increased both price and social pressures on smaller producers. Likewise, there existed many simultaneous dividing and unifying pressure points for the white population of the island. Chief among these issues was fear of racialized unrest or worse, revolution. However, this shared fear did not produce shared interest as the economics of profession and even the regional location of Cuban population centers separated the white population into often antagonistic camps.

Differences between eastern and western Cuba presented themselves in every aspect of life. The west, accounting for most of the productive sugar estates, enjoyed a higher standard of living,

\footnotetext{
${ }^{121}$ Dale Tomich, "The Wealth of Empire: Francisco Arango y Parreño, Political Economy, and the Second Slavery in Cuba," Comparative Studies in Society and History 45 (January 2003), 4-28; Juan Alfonso Bravo "Azúcar y clases sociales en Cuba (1511-1959)," Revista Mexicana de Sociología 43, no. 3 (July-September 1981), 1189-1228; Anton L. Allahar, "The Cuban Sugar Planters (1790-1820): "The Most Solid and Brilliant Bourgeois Class in All of Latin America," The Americas 41, (1984) 37-57; Sherry Johnson, The Social Transformation of Eighteenth-Century Cuba (Gainesville: University of Florida Press, 2001), 7-124; J. H. Elliott, Empires of the Atlantic World: Britain and Spain in America, 1492-1830 (New Haven: Yale University Press, 2006), chap. 10; Anthony E. Kaye, "The Second Slavery: Modernity in the Nineteenth-Century South and the Atlantic World," Journal of Southern History 75 (August 2009), 627-650.
} 
held the majority of the island's white population, was the bastion of pro-slavery sentiment, and claimed a more unified elite. The east, with its more diversified yet much smaller economy, was poorer, had more small farmers, depended far less on slavery, exhibited an ambivalent attitude toward the institution, and held only about $20 \%$ of the population with most of that being free AfroCubans. The east also contained large amounts of runaway slaves, a situation that heightened conflict between the elite in the two regions. The eastern planter class, as opposed to their much wealthier western compatriots, was smaller, poorer, and less able and inclined to incorporate new technologies into their production strategies. The east largely avoided much of the change and turbulence gripping the political economy of the west. Since they lacked the capital and technology needed to make their sugar plantations of the scale and capacity of those in the west, the eastern sugar industry largely remained small and familial.

Foreign investment, available credit, laborers, technology, and a new modern entrepreneurial attitude all eluded eastern planters to an extent that they defended slavery less intensely and cared little for the institutional imperial structures that kept the institution in place. The presence of a majority population of free AfroCubans also helped fuel a general lack of interest in slavery's continuance. The presence of smaller producers added to a more diverse economy less committed to sugar and therefore slavery. The lack of planter political dominance also encouraged smaller producers and less-technologically dependent coffee and tobacco producers to remain as important members of the political and economic life of the region. Eastern planters were generally less powerful and less desirous of that power living as they did closer to the population in the region and having less socio-cultural separation and differentiation - exhibited in the west in the vast gulf between enslaved and master. Estates in the east were largely family enterprises demonstrating a continuance of older traditions that translated into a 
generalized lack of ability and interest of participation in the modernizing impulses sweeping the western producers. The eastern population, still able to retain a semblance of traditional Cuban subsistence, was less dependent on the vagaries of foreign trade and exorbitantly taxed imports. Most importantly, the eastern populations, resultant from the social, political, and cultural arrangements of the region, demonstrated little desire toward protection or defense of the colonial structures holding sway in Havana. ${ }^{122}$

Apart from Havana and the surround environs, the Matanzas region experienced the quickest growth in sugar cultivation. As a result, the systematic process of land consolidation taking place around Havana began its concerted march throughout much of the island. This process was characterized by the alienation of small cultivators, the emergence of a fairly politically cohesive sucrocracy, the rise of African slavery as the dominant labor institution, the creation of a social system based on the ideologies of caste, class, race, and color, and the intensification of commercial linkages within the capitalist North Atlantic Economy. This flattening process replicated itself throughout the island as local issues, concerns, and populations gave way to the weight of the sugar elite's all-encompassing vision. The technological and scientific innovations transforming the Caribbean economy had their way in Cuba. Rather than streamlining the process of socialization, however, these productive

\footnotetext{
${ }^{122}$ Duvon C. Corbitt, "Mercedes and Realengos; A Survey of the Public Land System in Cuba, The Hispanic American Historical Review 19, no. 3 (August 1939), 262-285, outlines the legal changes in public land holdings in Cuba as it affected small holders and assisted elite land accumulation. Changes in land tenancy and ownership had a significant impact on the social and economic makeup of the island, with large landholders able to lay claim to land previously held usufruct and communal in many areas. These changes, made by royal resolution in July 1819 and promulgated in Cuba in November of that year, gave landholders property rights to all mercedes (land grants from the king) granted prior to 1729. Anyone who occupied land but could not show the necessary papers could obtain full ownership if he could show a prescriptive right based on forty years' possession. Therefore, from 1819 onward these owners could sell, rent or otherwise dispose of their holdings. As to the realengos (leftover lands still belonging to the crown), communal holders, who had been using such lands between or adjacent to their holdings could claim these tracts in full ownership. The decree suddenly transformed previously held communal lands, to which no one had outright claim, from usufructuaries into owned territories - a process dominated by older families and larger landowners.
} 
improvements upset and bewildered long-established populations and rhythms. The reliance upon large-scale sugar monoculture displaced individuals and divided communities, leaving the elite as the arbiters of the relationship between the modernizing influences of industrial capitalism and their precapitalist economic systems and social values. Sugar production reduced every other rural activity and the accompanying social worth of those actions to insignificance by the mind-1840s. Sugar shaped Cuban society in a more profound way than Spanish policy ever did. "The business of sugar planting," an early observer noted, "is a sort of adventure in which the man that engages, must engage deeply. There is no medium path, and very seldom the possibility of retreat." 123

Changes in the rural landscape functioned no less profoundly than did changes in the urban landscape, particularly in Havana. A diverse labor force adjusted to new needs and expectations in urban labor as a result of the growth in plantation-based enslaved labor. Urban owners, mainly tobacco producers along with commercial servicing firms, employed or used a small number of enslaved AfroCubans, along with those who remained free. This arrangement placed AfroCuban laborers alongside white and Chinese (after the 1850s) workers in all sectors of urban skilled and unskilled labor in Havana's economy. The diversity of the urban workforce along with its size was a constant source of concern for the creole elite that encouraged racial and ethnic division whenever possible. While the ethnic and racial unity in the urban labor force was hampered by the prevalence of various peninsular, creole, and AfroCuban artisan associations, societies, and cabildos (fraternal organizations) - all of which encouraged

\footnotetext{
${ }^{123}$ Bryan Edwards, The History Civil And Commercial, Of The British Colonies In The West Indies: To Which Is Added, An Historical Survey Of The French Colony In The Island Of St. Domingo (London: B. Crosby; for Mundell \& Son, Edinburgh; and J. Mundell, Glasgow, 1800), 287; Laird Bergad, Cuban Rural Society in the Nineteenth Century: The Social and Economic History of Monoculture in Matanzas (Princeton University Press, 1990); Rebecca Scott, "Explaining Abolition: Contradiction, Adaptation and Challenge in Cuban Slave Society, 18601886," Comparative Studies in Society and History 26 (January 1984), 83-111 and Slave Emancipation in Cuba: The Transition to Free Labor, 1860-1899 (Princeton: Princeton University Press, 1985).
} 
sectarianism of Havana's working class - both economic conditions and political determination acted to occasionally unite workers across these ethnic differences. ${ }^{124}$

Among all of these groups, the creole elite emerged strongest from the milieu of colonial subjects demanding attention. Most fundamental to the expression of growing creole power was the design of Havana. The city became, in the minds of its creole planners, a demonstration of the tenuous and terse relationship between the Spanish and the Cubans inscribed on the architecture of Havana. On the front page of the Diario de la Habana of March 19, 1828, an article appeared that celebrated a new monument for Havana's Plaza de Armas. The author reminded his readers, "The Island of Cuba, faithful to its principles and to its duties, has given on this day to the entire world the ultimate proof of its refined loyalty and of its never contradicted patriotism. The magnificent monument that is presented today to public expectation, sponsored by the inhabitants of this heroic capital, presented to the future generations a glorious memory of the virtues of its ancestors." The virtue of loyalty and the self-proclamation of their modernizing

\footnotetext{
${ }^{124}$ Joan Casanovas, Bread, or Bullets! Urban Labor and Spanish Colonialism in Cuba, 1850-1898 (Pittsburgh: University of Pittsburgh Press, 1998), 1-60. The results of this uneasy interracial and interclass unity, however, did not become fully apparent until the 1880s. Particularly after 1868, urban workers determined that reformist options no longer promised benefit and they increasingly joined and supported anarchist-led coalitions. Rather than focusing solely on agricultural labor, Casanovas argues that the urban labor movement, largely anarchist-led by the 1880s, played a central role in shaping the Cuban drive toward independence in the 1890s after it became clear that colonial political reformism was a lost cause. Casanovas reacts to a historiography shaped by Fernando Ortiz's Cuban Counterpoint: Tobacco and Sugar (New York: Knopf, 1947), that labeled sugar a "black" crop and tobacco a "white" one based on the racialized perceptions of its workforce. "In the production of tobacco intelligence is the prime factor; we have already observed that tobacco is liberal, not to say revolutionary. In the production of sugar it is a question of power; sugar is conservative, if not reactionary. I repeat, the production of sugar was always a capitalistic venture because of its great territorial and industrial scope and the size of its long-term investments. Tobacco, child of the savage Indian and the virgin earth, is a free being, bowing its neck to no mechanical yoke, unlike sugar, which is ground to bits by the mill. This has occasioned profound economic and social consequences," 56. Rather, Casanovas illustrates how "This diverse labor force worked together, which increasingly helped urban workers to recognize their common interests," (42). Interestingly, the urban unrest that came to mark the middle of the $19^{\text {th }}$ century in Cuba had a robust refrain on the Iberian Peninsula, as numerous Spanish cities, notably Seville and Valencia, felt urban labor unrest. See, Scott Eastman, Preaching Spanish Nationalism across the Hispanic Atlantic, 1759-1823 (Baton Rouge: LSU Press, 2012), 45-69. On cabildos and efforts at retaining African culture and identity in Cuba see: Philip Howard, Changing History: Afro-Cuban Cabildos and Societies of Color in the Nineteenth Century (Baton Rouge: LSU Press, 1998); and Stephan Palmié, Wizards and Scientists: Explorations in Afro-Cuban Modernity and Tradition (Durham: Duke University Press, 2002).
} 
influence guided the perceptions of Havana's elite. Cuban creoles designed their society and its physical construction in their own image. They hoped to shake off the long-gathered dust of neglect at the hands of Bourdon reformers that looked to South America for the beneficial impact of their royal reforms. The Cuban planter class embraced European Neo-Classicism to represent the budding ideology of material progress while simultaneously rejecting ridicule at the hands of the South American elite that so charmed the Crown. Beyond the interplay between patrons and designers, the reception of the physical construction of Havana and other emerging centers of socially directed urbanity fueled elite status-driven design. The elite hoped the grandiosity of Havana's apparently unique architecture, while serving to demonstrate modernity, might also distract the masses from the mimicry at its heart. Havana thus became an expression of the elite's powerful leadership in an impressively fortified city that projected its physical power outward while internally consolidating the leadership class' social and economic power. They sought a protection of their prestige and wealth through the projection of a linearity that highlighted the current moment, one the creole elite helmed and made, as the pinnacle of progress for the island. Architectural design became one way Cuban colonial elites sought construction of an aesthetic realm of unity and perfection amidst social difference and heterogeneity. They sought a naturality of their claims to power through the construction of a great city built to their specifications and providing a framework for their rule. However, the built environment was but one of the fronts upon which elites waged their battles. ${ }^{125}$

Among the first significant attempts at organization of the Cuban elite was the nearly simultaneous founding of a non-governmental newspaper and the first of Cuba's influential interest groups. The Papel Periódico de La Habana (1790) differed from the long-established

\footnotetext{
${ }^{125}$ Paul Barrett Niell, 'Bajo Su Sombra:' The Narration And Reception Of Colonial Urban Space In Early Nineteenth Century Havana, Cuba (PhD diss., University Of New Mexico, 2008), 15.
} 
and more legalistic official papers of the capital. While these older forms focused mainly on the dissemination of official decrees and notices, the weekly Papel Periódico engaged its readers in different ways, publishing articles and opinion pieces from a local perspective with a focus on agriculture, commerce, and industry. The paper was an important first step in the encouragement of a more public airing of grievances, although the paper's authors and its readers were careful not to push too hard for systemic changes. They generally kept their language and demands appropriate to their relatively comfortable social standing. ${ }^{126}$ Many of the same men involved

\footnotetext{
${ }^{126}$ El Papel Periódico technically published its first edition on October 24, 1790. However, after the first few monthly editions, it became a bi-weekly in mid-1791. The first few editions were dedicated to discussions of the importance of journalism and other philosophical discussions of information, its first edition opening with the article "Discourse on the Newspaper." The more general paper grew incrementally, in both length and variety, depending on the issues of the day and editorial direction throughout the 1790s. Diego de la Berrera had the editorial helm until 1793 when the Sociedad Económica de Amigos del País took control and placed editorial director under a board of directors, among whom the most influential members of Cuban creole elite society sat. The paper was surprisingly encouraged by then Captain General Don Luis de las Casas, who, sensing a growing restlessness among the Havana elite, felt the paper might be a less confrontational outlet for creole anxiety and desire. While some of its articles were penned anonymously, the majority were written by prominent Havana intellectuals. The editors explained that one of the purposes of the Papel in Havana would be to attack harmful habits and customs and to correct the defects many Habaneros saw in their literary, educational, and scientific production. The Papel was a vehicle of ethics and culture, commercial distribution, promotion for agricultural, development of economic policy, and more generally a propaganda arm of the Havana elite. Literary activities were also trumpeted along with reprints of European literature and reviews as well as original poetic works. While the editors and writers preferred economic and cultural issues, they were not afraid of openly debating the slavery issue, with of course the attendant discretion and restraint. The Papel was a way for the elite of Cuba to demonstrate their comfort and understanding of the Enlightenment ideas capturing Europe as well as their ability to promote their own society through an application of those ideas to the unique Cuban experience. There was a great deal of inferiority inscribed on the colonial positioning of Cuba, both in reference to its position within the Spanish empire and in comparison with the international colonies surrounding it in the Caribbean, and the Papel was an opportunity to rectify this positioning. The Papel continued to play an important part in the coalescence and articulation of elite culture and concern well into the $19^{\text {th }}$ century under its various monikers. As Cuba gained a more favored position in the Spanish empire, so too did the paper take on added importance through the forceful articulation of the island's creole demands as well as its ascendant intellectual position vis-à-vis the Iberian mainland. Most scholars focus on the paper's importance in the larger debates of the day, particularly those opinions focused on slavery and economic liberalization. They include the paper as part of larger discussions of these issues and do not focus on the paper itself. Among the best works centering the paper and its production at the beginning of modern Cuban history are: F. Peraza y Sarausa, "El Papel Periodico de la Havana' y los Origenes del Periodismo en Cuba," Revista Interamericana 8 (1958), 368-378; Raul Menocal, ed., El Sesquicentenario del Papel Periodico de la Havana 1790-1940 (Havana: Municipio de la Habana, 1941), accessed on May 23, 2012, http://ufdc.ufl.edu/UF00074127/00001; Otto Olivera Ibarra's "La poesía del 'Papel Periódico de la Habana"' Revista Iberoamericana 11, no. 22 (October 1946), 259-272, which looks at the literature, particularly poetry, that filled the pages of the paper in efforts toward literary differentiation between the mainland and Cuba; Dolores González-Ripoll Navarro, Cuba: La Isla de los Ensayos: Cultura y Sociedad 17901815, (Madrid: Consejo Superior de Investigaciones Científicas, 2000), in which she contextualizes the El Papel, offering sustained analysis of the type of articles being published and painting the larger context of a quickly codifying Criollismo in and around Havana that sought an outlet for the elevation of their literary, social, and scientific prowess; Franco Quinziano, "Fin de siglo en La Habana: Lujo, Apariencias y Ostentación en el Papel
} 
with the Papel Periódico also looked to professionalize their social and economic interests. They

followed the lead of many Hispanic cities and regions that established interest groups focused on lobbying Spanish authorities for greater local control over economic and political issues (or at least a greater responsiveness on the part of Spanish authorities to elite demands). The Sociedad Económica de Amigos del País founded in Havana in December 1792 was part social club, part special interest lobby, and represented the wealthiest and most powerful property-owning families of the region. The group quickly expanded its purview and power through a rapid increase in membership. Recruiting primarily from the creole hacendados, the rolls of the group covered 163 members of the island's elite after just three years of existence. The Sociedad established branches throughout Cuba's largest cities including Sancti Spíritus, Puerto Príncipe and Trinidad. ${ }^{127}$

Periódico de la Havana (1790-1805)," Associazione Ispanisti Italiani 1 (1999), 421-432, places El Papel with El Mercurio Peruano (1790-1795) as a new breed of early platforms of discussion of the Latin American Enlightenment within the framework of local culture and emancipatory aspirations, the press providing a privileged means of expression and dissemination, thereby providing a sense of common identity which promoted independence in Peru and reevaluation in Cuba; and Alina Gutierrez Grova's fascinating look at the early publication of the paper investigating the language used to defend and develop creole autonomy, "Para La Historia de la Lengua Culta Escrita: Aproximación a la Sintaxis del Papel Periódico de la Havana" in La Lengua en Cuba: Estudios, ed. Sergio Valdés Bernal (Cuba: Universidade de Santiago de Compostela, 2007) 57-100.

${ }^{127}$ The Sociedad de Havana still exists, http://www.seap.cult.cu/, with the literature focused on the various Societies still flowing, http://blogs.ua.es/amigospais/category/recursos-electronicos/. The Society's founders modeled their Cuban chapters on mainland economic development societies popular throughout Spain and in Spanish colonies as well. The first was the Sociedad Vascongada de Amigos del Pais, established by Basque Society in 1764 at Vergara, Spain. Many of them focused on specific areas of interest, with the Havana chapter most interested in the viability of an invigorated slave trade. Robert J. Shafer, The Economic Societies in the Spanish World, 1763-1821 (Syracuse: Syracuse University Press, 1958), details the founding, interests, and effects of the societization of Spanish enlightenment thinking. The Sociedades Económicas were founded as part of a movement to stimulate the economic and intellectual development of Spain. Many elite Spaniards recognized that Spain was lagging behind other European states and sought to diffuse and apply the principles of the Enlightenment. Two of the principal promoters of the societies' foundation in Spain were Pedro Rodríguez de Campomanes and Gaspar Melchor de Jovellanos. Both were highly influential statesman and among the most important thinkers in Spain. They saw the societies, apart from their roles as intellectual spaces, on a more practical level, believing that the work of their members could stimulate improvements in agriculture, husbandry, industry, the professions and arts. All involved hoped that the societies could transplant from abroad scientific curiosity, educational reforms, and technological improvement, in hopes of divorcing Spain from medieval influences of both thought and action. Many Spaniards saw the Enlightenment ideas surrounding them on mainland Europe producing little effect in the realm and hoped that the societies could jumpstart a massive intellectual modernization project. These organizations were autonomous, although required to be licensed by royal authority, and their fortunes depended on a combination of the dedication of local members, official patronage, and the receptivity of the local community. Each sought to assist governmental 
The Sociedad grew itself as an institution of wide-ranging influence by dedicating great

effort toward information sharing on various issues that were of concern to their wealthy readers, such as stock raising, mining, commerce, and industry. However, the main focus was clearly agriculture and sugar. The promotion of education, through the funding of schools and scholarships, helped diversify the interests of the Sociedad with even larger efforts made in publishing and the founding of a public library. The Sociedad eventually took over publishing of the Papel Periódico, turning it into a daily paper in 1793. The group held a natural and abiding interest in science and technology, particularly those areas that promised to increase sugar production and raise yields. The various research areas and publications looked toward botany, chemistry, agronomy, and mineralogy as well as to the translation of (particularly French) works

actions in the same direction by disseminating information and encouraging debate in periodicals, starting schools, awarding prizes for creativity, and various other means of community interaction. For more discussion on the Enlightenment, Spain, and Cuba and Sociedades de Economico see: Izaskun Álvarez Cuartero, Memorias de la Ilustración: las Sociedades Económicas de Amigos del País en Cuba: 1783-1832 (Madrid: Real Sociedad Bascongada de los Amigos del País, 2000); Jacquelyn Briggs Kent, “The Enlightenment and Spanish Colonial Administration: The Life and Myth of Alejandro Ramirez y Blanco in Guatemala, Puerto Rico, and Cuba 17771821," (PhD diss., Tulane University, 1997); Lucia Provencio Garrigos, "Clase”, Poder y Matrimonio: Configuracion de un Elite Dirigente: La Sociedad Economica de Cuba de Amigos del Pais," Contrastes: Revista de Historia Moderna 9-10 (1994-1997), 49-90; Jorge I. Dominguez, "Political Participation and the Social Mobilization Hypothesis: Chile, Mexico, Venezuela, and Cuba, 1800-1825," Journal of Interdisciplinary History 5, no. 2 (Autumn 1974), 237-266; Julio Le Riverend Brusone, "Relaciones entre Nueva España y Cuba (15181820), Revista de Historia de América 37/38 (January-December 1954), 45-108; Maria Dolores González-Ripoll," Ocio, lecturas y escritura en la Ilustración cubana," Revista de Indias 60, no. 219 (2000), 331-344; Iris H. W. Engstrand "The Enlightenment in Spain: Influences upon New World Policy," The Americas 41, no. 4 (April 1985), 436-444; Arthur P. Whitaker, "Changing and Unchanging Interpretations of the Enlightenment in Spanish America," Proceedings, American Philosophical Society 114, no. 4 (1970), 257-271; Jorge Canizares-Esguerra Matt D. Childs, and James Sidbury, eds., The Black Urban Atlantic in the Age of the Slave Trade (Philadelphia: University of Pennsylvania Press, 2013); Sherry Johnson, The Social Transformation of Eighteenth-Century Cuba (Gainesville: University Press of Florida, 2001); Allan J. Kuethe, Cuba 1753-1815, Crown, Military and Society (Knoxville: University of Tennessee Press, 1986); Paul B. Miller, Elusive Origins: The Enlightenment in the Modern Caribbean Historical Imagination (Charlottesville : University of Virginia Press, 2010); Arthur Stinchcombe, Sugar Island Slavery in the Age of Enlightenment: Political Economy of the Caribbean World (Princeton: Princeton University Press, 1995); Christopher Iannini, Fatal Revolutions: Natural History, West Indian Slavery, and the Routes of American Literature (Chapel Hill: UNC Press, 2012); Arthur P. Whitaker ed., Latin America and the Enlightenment (Ithaca: Cornell University Press, 1961). More specifically on the impact of slavery on the development of the natural sciences; Franklin Knight, "The Caribbean in the Age of Enlightenment, 17881848," in A Companion to Latin American Literature and Culture, ed. Sara Castro-Klaren (San Francisco: Blackwell, 2008), 228-246; Peggy Liss, Atlantic Empires: The Network of Trade and Revolution, 1713-1826 (Baltimore: Johns Hopkins University, 1982); David Brion Davis, The Problem of Slavery in the Age of Revolution, 1770-1823 (Oxford: Oxford University Press, 1999). 
on cane growing and sugar manufacturing. The Sociedad also served as a political pressure network, with its members pushing the island's Captain Generals to improve transportation networks and shipping facilities with an eye toward greater liberalization of trade. ${ }^{128}$

The creation of these various societies and the arrival of a daily newspaper demonstrated both an element of novelty and a seriousness of purpose on the part of a nascent public eager for news and information. The eagerness and vitality of this expanding creole elite, particularly in Havana, offers a very revealing picture of the concerns and interests at stake in the fastdeveloping new world of early nineteenth century Cuba. The wealth accompanying the upturn of the economy illuminated a growing awareness on the part of the most prescient of elite Cubans that the insurmountable contradictions of imperial rule, as well as the need for progress and independence manifesting itself in the Havana elite, threatened to tear the social fabric of Cuban life apart. This upturn in economic terms found its counterpart in the configuration of a new cultural environment heavily permeated by aspirations and demands for more autonomy in the Spanish colonial structure. The nascent press became the most valuable vehicle for dissemination of these perspectives. The various newspapers and official publications of the Sociedad along with its educational efforts, promoted by the new cultural climate, were indispensable means of disclosure and debate on the subjects undergirding the growing enlightened reformist thinking.

\footnotetext{
${ }^{128}$ Indicative of a more amendable early attitude on the part of the crown and its agent in Havana, the Captain General, toward creole organization, King Charles III actually approved the Sociedad's charter and Captain General Luis de las Casas was named its first honorary president. At its inception, the Sociedad had committees and sections for different projects: Science and Arts, People and Fashion, Commerce and Agriculture and Education. Among its early efforts was leading the effort to pave and light the streets of Havana, larger road construction plans, a determined interest in the introduction of railways, the fight for an end to the snuff and tobacco monopoly, and great effort at abolishing taxes that hindered new industries along with the import of innovative equipment for sugarcane cultivation. Along with efforts at infrastructural improvements was the creation of major institutions that emerged through the work of the Sociedad such as the Havana Botanical Garden and Academy of Drawing, the School of Painting and Sculpture at San Alejandro, various Obstetrics, Music and Nautical Schools, a girls' school in Havana, and the first public library on the island located in Havana. Airelys Campos Herrera and Lilian Grandal Pérez, "La Organización de la Información en la Etapa Colonial. Estudio de un Caso: La Biblioteca de la Sociedad Económica de Amigos del País," Revista Cubana de los Profesionales de la Información y la Comunicación en Salud 15, no. 1 (2007), accessed May 24, 2012, http://bvs.sld.cu/revistas/ aci/vol15_1_07/aci15107.htm.
} 
The creole community became a laboratory of experimental ideas, programs, and projects in a staid colonized society. ${ }^{129}$

The Papel was the chief device of discourse, cataloging various arguments of economics and aesthetics. The paper introduced those aspirational habaneros to a wide range of topics and validated an illuminating whiggish confidence in the power of thought, progress, and science. Beyond technical writing and the application of European models of economics to the Cuban situation, literature played an important role in the creole community's self-evaluation. $E l$ Papel's editors carefully chose pieces that spoke to the concerns of the elite specifically in relation to their dismay that virtue was fast-losing out to an accumulative ethos - an ethos they unabashedly and of course non-ironically championed. The paper was a hoped handbook of discipline and self-exploration for the elite as well as a dramatic excoriation of the lower classes. The editors and their chief audience cast aspirations on the newspaper's pages to encourage the lower class to clean up their act and to persuade colonial functionaries, whom they bitterly accused of limiting creole economic growth for their own private gain, toward an embrace of a new ethos of virtuous and communal profitability. The loss of collective and individual decency

\footnotetext{
${ }^{129}$ Discussion of the self-conceptualization of the emerging hacendado class is reviewed in: Pablo Tornero Tinajero, "Comerciantes, Hacendados y Política Mercantile en Cuba: La Rivalidad Cadiz-Estados Unidos (1763-1800)," Actas de las IV Jornadas de Andalucía y América 1 (1985), 119-145 accessed on May 15, 2012, http://hdl.handle.net/10334/414 and his longer form work Crecimiento Ecónomico y Transformaciones Sociales: Esclavos, Hacendados y Comerciantes en la Cuba Colonial: 1760-1840, (Madrid: Ministerio de Trabajo y Seguridad Social, 1996); María M. Portuondo, "Plantation Factories: Science and Technology in Late-EighteenthCentury Cuba," Technology and Culture 44, no. 2 (2003), 231-257. Alfonso W. Quiroz takes a slightly different approach through his investigation of associations as public spaces in early modern Cuba. He argues Cuba developed associations mainly to meet their specific social and cultural needs. In searching for new spaces of legal autonomy from colonial constraints, elite Cubans pushed for reform far short of revolution. These intersections between civil society and political spheres were always primarily non-violent constitutionalism and reformist struggles rather than armed separatist conflicts. In fact, the moments of open violence, slave uprisings, did much to reverse any feelings of separatism. Instead of an increasingly militant civil society, Quiroz argues that Cuban leaders actually did much to mitigate the most antagonistic elements in the under classes even if they stopped short of offering any of the benefits of colonial reform to small landholders and laborers. Eventually this growing, moderate, and progressively autonomous and diverse civil society contributed to the gradual undermining of colonial despotism. Quiroz, "Free Association and Civil Society in Cuba, 1787-1895," Journal of Latin American Studies 43 (February 2011), 33-64.
} 
was not, in the minds of creole elite, the fault of the quickly developing sugar-production ethos but rather resultant from outdated colonial policies of trade and taxation. The criticism of these policies, at least in the early stages of Cuba's transformation, came from the socially well-placed and focused on poetry and literature. El Papel highlighted writings dealing with issues of daily life, peppered with elite wisdom capsulated in exhaustive literary criticism. Elites designed all of this to highlight, through comparisons with continental standards of cleanliness and decency outlined in European literature, Spain's colonial problems in Cuba and the urgent need for reform. The pursuit of imperial wealth, apart from their own ambitions, drove elite writers to eulogize virtue as abandoned to the avarice and corruption of the crown and its colonial arms in Cuba's peninsular elite. ${ }^{130}$

The arrival of the 1790s marked the first important turning point in Cuban history in regards to a concerted effort at the production of a uniquely Cuban history born from its situational concerns. Newspapers and social societies were spaces essential to the development of a culture valuing of civic debate among islanders and between themselves and their colonial masters. Creole economic accumulation and the rising standards of decency and virtue that their tutelage offered stood at odds with the immoral degeneracy and decadence that the Crown's ethos of accumulation represented. The upturn in economic terms found its corollary in the shaping of a new cultural environment strongly permeated by elite aspirations and demands for more autonomy. El Papel's publication, eagerly greeted by the new cultural climate, was an effective and indispensable means of dissemination of the thematic policies that lead to the spread of enlightened reformist thought. The paper served as a laboratory of ideas, programs and

\footnotetext{
${ }^{130}$ Larry Jensen, Children of Colonial Despotism: Press, Politics, and Culture in Cuba, 1790-1840 (Tampa, FL: University Presses of Florida, 1988), chs. 1-3.
} 
projects in colonial society and as a dais from which the elite attempted to direct the interests, actions, and behaviors of their perceived inferiors. ${ }^{131}$

Predictably, beyond their focus on the civilizing needs of the lower classes, creole elites looked to women of all classes as the best hope for societal improvement. A good deal of attention fell upon women as the conveyers of a new morality that the elite hoped to pass onto Cuba's next generation. El Papel was a privileged platform for indoctrination and the elite agent of feminine civilization. Throughout its pages were calls for a new conceptualization of maternity and femininity. The Cuban elite followed in the example of Europe and the United States by extolling the increasingly precise lines of womanhood inside the home and in society. They sought definition for the appropriate roles women should play along with dependent hopes their generation placed upon them (this view extolled the roles expected of elite women, embraced those roles as normative, and projected them downward throughout the social hierarchy). Education, the crown decided, should play a fundamental role in improving Cuban society. Elites agreed and embraced the crown's cedula authorizing the Sociedad Económica in Havana to direct public education on the island. Importantly, and under pressure from Cubans,

\footnotetext{
${ }^{131}$ Enrique Sainz, La Literatura Cubana de 1700 a 1790, Ciudad de La Habana (Havana: Editorial Letras Cubanas, 1983), particularly chapter 6. Franco Quinziano picks up where Sainz leaves off, adding an important analysis of the interests of the paper, "Fin De Siglo En La Habana: Lujo, Apariencias Y Ostentación En El Papel Periódico De La Havana (1790-1805)," Associazione Ispanisti Italiani 1 (1999), 421-432. Overall however, the best and most comprehensive treatment of the early history and importance of El Papel's development in its social milieu is Cintio Vitier ed., La Literatura en el Papel Periódico de la Havana, 1790-1805 (Havana: Editorial Letras Cubanas, 1990). The importance of the paper Vitier feels was in the responsibility and power of self-definition that the exchange of ideas and the establishment of an elite sensibility of mores helped produce. Topics such as the worthlessness of the idle and vain nobility neglectful of traditional virtues, the criticism of fashion, the trend of feminization that had "contaminated" many young men, the much debated question of education, and the growing dependence on the Crown occupied most of the space in the pages of El Papel. Editors and authors alike feared that a too decadent Cuba, led by a put-upon Havana struggling to bear the effrontery of wayward peninsulares and mindless peasants, would be too weak to support the necessary social, political, infrastructural, economic improvements need to capitalize upon a fast-changing international position. Many hoped the paper might play the utilitarian function, comparable to that traditionally assigned to the theater, which warned of defects and errors and presented the model of good customs useful to all individuals of different social levels. As Vitier puts it, "Cuba began to see its own face and feel the pulse of its own history," (9).
} 
the crown moved to secularize instruction and allow women and girls access to schools. The crown's recognition of the emergent planter class as a major influence encouraged demands for more influence over the future of the island. Educational direction allowed the elite not only control over administration but also allowed them to articulate their unique vision for the cultural and intellectual development of Cuba. The elite's control of instruction and curriculum allowed their view of Cubanidad (Cubanness) to become ascendant, at a time when the racial and social composition of the island was changing dramatically. The Society took to the mission with zeal, opening over 370 schools from 1790 to 1850 . Schools for girls represented, depending on the year, between $30-50 \%$ of the total (coeducational schools emerged in the 1850s). In an 1855 article in the Society's literary magazine, Revista de la Habana, one author argued that by promoting women's education, "In a short period of time the name of our country will be seen written on the list of civilized countries of the world."132

Although the elite placed a high value on education, they did not place an equally high priority on the Church, the institution most often linked with educational provisioning. As most elite families involved themselves with the military early on in Cuba's development, the clergy was largely an ignored path toward social mobility. Elites in Havana, unlike other parts of South America, were virtually absent from the higher clergy in Cuba. The distance of the Havana elite from Santiago de Cuba, where the only eighteenth century bishopric stood, indicated the lack of direct control that the church held in Cuban life. The lack of investment on the part of the elite, as they showed a general disinterest in construction and improvement of churches, further

\footnotetext{
${ }^{132}$ Lucia Provencio Garrigós, , "La Trampa Discursiva Del Elogio A La Maternidad Cubana Del Siglo XIX," Americanía 1 (January 2011), 42-73; Matt Childs, "Sewing" Civilization: Cuban Female Education In The Context Of Africanization, 1800-1860," The Americas 54, no. 1 (July 1997), 83-107, quote on page 85; Luis MartinezFernandez, "Life In A “Male City:” Native And Foreign Elite Women In Nineteenth-Century Havana/Mujeres En Una “Ciudad Masculina;" La Vida Cotidiana De Las Mujeres De Las Clases Altas En La Habana Del Siglo Diecinueve," Cuban Studies 25 (1995), 27-49.
} 
testified to their lack of interest in religious matters fueled by their dislike of the clergy's general anti-slavery position. This lack of religious infusion allowed Cuba to develop its identity apart from a purely Spanish influence, which rested heavily upon the combined strength of Catholicism and the clergy. While clergy elsewhere throughout the empire helped turn their parishioners into the people of Spain - or in the case of independent South America, the clergy played active roles in turning parishioners into citizens of new countries - Cuba held particular civic impulses that revolved around their economic self-definition apart from church community. Liberal Spanish nationalism in the early decades of the nineteenth century displayed wideranging characteristics not conforming to simplistic categorization. However, Cubans assumed that a lack of religiosity, as with so many other aspects of their society, separated them as modern in comparison to Spain's religious traditionalism. ${ }^{133}$

Cuban society, and more specifically Havana's creole elite, managed to capitalize on its organizational, ethical, economic, and literary gains. The elite's new found position and power encouraged intervention in the colonial government and eventually modification of it to their advantage. Although the process was slow, it was indeed inevitable. The economic power they

\footnotetext{
133 Juan Bosco Amores Carredano, "La Sociedad Económica Y Los Intentos De Reforma Universitaria En Cuba (1793-1842)," accessed March 20, 2012, http://dspace.uah.es/jspui/bitstream/10017/5828/1/La\%20Sociedad\%20 Econ\%C3\%B3mica\%20de\%20La\%20Habana\%20y\%20los\%20Intentos\%20de\%20Reforma\%20Universitaria\%20e n\%20Cuba\%20(1793-184).pdf, and "Iglesia y Sociedad En Cuba, 1760-1830," in Tradición Y Reforma En La Iglesia Hispanoamericana, 1750-1840, eds. Francisco Cervantes Bello, Lucrecia Enríquez and Rodolfo Aguirre (México: UNAM, 2010), 302-330; Edelberto Leiva Lajara, Los Dominicos En La Habana. Convento Y Sociedad, 1578-1842 (Havana: Ediciones de la Oficina del Historiador de la Ciudad, Editorial Boloña, 2007); Scott Eastman, "The Religious Origins Of Spanish National Identity, 1793-1812," (presentation to Comunicaciones del Encuentro de Jóvenes Investigadores en Historia Contemporánea de la AHC, Universidad del País Vasco Vitoria, Gasteiz, September 2008). The Dominicans highlight an important exception to the anti-clericalism in Havana. The order had a close relationship with the creole elite of Havana. The elite, tasked with designing a new educational system, turned to the Dominicans as the order had long-concerned itself with educational pursuits. This avenue of shared interest allowed the Dominicans entry into elite circles and allowed the elite use of the clergy as a means to social integration of some illegitimate children. The academic privileges extended to the elite by the Dominicans included exemption from military service and legal immunity in the civil and ecclesiastical courts. Although Dominican priests enjoyed elevated status through the early $19^{\text {th }}$ century, they lost prestige, land, and status after the closing of many monasteries in 1841 .
} 
controlled, based on the cultivation and export of sugarcane and the use of slave labor, soon translated itself through both direct imposition and secretive machination into a quantum leap forward for the circulation of their ideas. The extension of basic educational instruction to the population guided the production of new forms of sociability that materialized in the actions, events, and publications of new creole institutions. These Cuban creole institutions gained power throughout the nineteenth century thanks largely to elements of the Enlightenment taking stronger rhetorical and physical hold in the forms of modernization, the progression of science and technology, and the resulting gentrification of Cuban society. These developments created a tension between the dynamism of Cuba's elites and the decadent strictures of Spanish colonial government. The origin of this tension coincided with and fueled the birth of Cuban criollismolocally based patriotism that presented itself differently than the more revolutionary brand that emerged in Spain's South American colonies. The creole elite's economic, social, cultural, and political self-perception was a juxtapositionary response against the South American separatism that Cuba shied away from. The elevation of Cuba, "the always faithful Isle," as a full-throated reproach of the Bolívarian revolutions, welded the continued existence of Spanish colonialism to the crown's perpetual access to and control of Cuban markets and ports. While awareness of the developmentally different nature of the island persisted and as military designs to retake Gran Colombia launched from Cuba floundered, Cuban creoles embraced this faithfulness not as fidelity to Spanish cultural imposition, but rather as an important pressure point in their fastdeveloping demands toward greater autonomy. Creole affiliation with and integration into new cultural institutions hastened the intellectual formation of the main educational centers of Havana, such as the University and Seminary of San Carlos. This developing universe of readers and writers was the catapult for the social and economic propaganda of the sugar boom and the 
means for defining the oligarchy's attitude on all things, particularly the social phenomenon of slavery. For all intents and purposes, the Enlightenment took, in Cuba, its firmest hold anywhere in the Spanish Empire. ${ }^{134}$

Taken as a formula of both group identity and representation in the world, the developing Cuban creole consciousness of the early nineteenth century was the foundation of the larger modern Cuban identity. Cuban elites of the late eighteenth century pushed into practice what their brothers on the continent already had. The consulados and Economic Societies in Spanish America between 1780 and 1810 decisively shaped both the formulation and implementation of imperial policy. Colonial elites throughout the empire used creole institutions as vehicles to pursue privilege and moderate incremental reform. Members of the elite embraced the Bourbon reforms for their advantage. The prevailing relationship between society and state in Spanish America, at least until the late 1790s, was amicable and mutually supportive. The presence of literary societies and scientific groups, attested to the introduction of new spaces for social and intellectual exchange. The new public spaces, on the page and in the plazas, for meeting and discussion and the means of creating public opinion inevitably led to the establishment a different social relationship between all aspects of society.

\footnotetext{
${ }^{134}$ Dolores González-Ripoll Navarro, Cuba, La Isla de Los Ensayos: Cultura y Sociedad, 1790-1815 (Madrid: Consejo Superior de Investigaciones Cientificas, 1999), 38-78. David Sartorius, in Ever Faithful: Race, Loyalty, and the Ends of Empire in Spanish Cuba, (Durham: Duke University Press, 2014), pushes the interpretative explanation for Cuba's loyalty to Spain further down the social and racial hierarchy. He argues that the pervasive loyalty show to the Spanish Empire in the first half of the $19^{\text {th }}$ century was not an impulse embraced solely by and reserved for the emerging elite. Rather, in the racial dynamism of Cuba's early $19^{\text {th }}$ century, the fluidity of identities opened up avenues of negotiation that many free and enslaved AfroCubans, often portrayed in the historiography as overwhelmingly supportive of independence, hoped to secure through support for Spanish rule. Through the articulation of demand and the establishment and protection of racialized spaces such as militia barracks and cabildos, free and enslaved AfroCubans forced imperial agents to negotiate the support they sought from the, particularly the free, AfroCuban population. The creole elite also found themselves in a position to negotiate with the AfroCuban population and likewise the free AfroCuban population used their positionality to their advantage. As white Cuban creoles recognized, so too did AfroCubans that there was much benefit to be gained in the loyalty that both groups offered.
} 
The elite, to their great fortune, used the new developing social reality and its corresponding power to create and consume knowledge. They synthesized the streams of scientific investigation flowing from international sources as well as domestically produced study into new applications of technology designed to maximize labor efficiency and increase profits. This developing multifaceted identity, reinforced by the ownership of vast acreages, helped the Cuban elite establish their priorities as the guiding vision for Cuban political economy. The growth of the planter class in Cuba was representative of a larger effort at public conversation and pressuring seen throughout South America. Creole identity was disseminated through emerging media such as newspapers, school newsletters, and the longer ponderings of economic and special interest societies. The mediums' creole protagonists, scientists, economists, and social programmers become agents of transformation for the power structures in Cuba. The recurring themes of educational reform, the criticism of customs, and, most divisively, the need for better dealing with the slave issue, permeated every facet of society. Surprisingly, the Captain General of Cuba supported these new communicative sources. Luis de Las Casas under the encouragement of the Encyclopedist-influenced Conde de Aranda, Pedro Pablo Abarca de Bolea, embraced Enlightenment thinking and urged a fusing of peninsular and creole interests. The era saw coalescence of numerous local intelligentsias that collaborated, to varying degrees, with imperial governance and built an emergent public sphere in the political landscape that grew after the collapse of the Spanish crown in 1808. This incipient public sphere took debate into the public squares and created the instruments of dissemination where they had only previous existed in hushed tones by word of mouth. ${ }^{135}$

\footnotetext{
135 The Conde de Aranda, Abarca de Bolea, found himself in a delicate position at the end of the $18^{\text {th }}$ century. His experience is instructive as an example of the precarious position between reform and loyalty that many on and off the island of Cuba found themselves in during the period. He was an ardent supporter of the revolutionary fervor in France beginning in 1789 and he helped softened the official Spanish stance towards the revolution. He pushed for
} 
The enthusiasm shown toward the project of building creole institutions emboldened the

Cuban elite. Their public pronouncements of criticism and the corresponding impulse toward

class development pushed their focus toward economic issues and by extension criticism of

Spanish officials implementing the Crown's colonial policies. The move toward

professionalization of the economy responded to the interrelated desires to maximize profits,

reduced surveillance on foreigners in Spain and argued for a relaxing of mail surveillance and press censorship. However, he found himself on the losing end within the Spanish court as a reactionary tide turned against the French revolutionaries and pushed the Spanish government against the revolutionaries. Even a close supporter like the previously reformist chief minster Conde de Floridablanca, José Moñino y Redondo, who, like Abarca, had advocated reform of the Spanish bureaucracy, commercial freedom in the American colonies, university reform, and improved press liberties, fled from Abarca's support. The allowances made for the distribution of French newspapers were revoked with the death of the French royal family. Stricter orders for inspection of all letters from France proceeded and as Spain was invaded by a wave of refugees, mostly aristocrats and clerics, the clergy was forbidden to preach to refugees. Redondo pushed Spain into the First Coalition and Abarca lost an important ally. In November, 1792 Abarca, too committed to reformism and the Encyclopedists - whose vision was the ideological basis of the revolution - was replaced by Manuel Godoy. Abarca continued to be dean of the State Council, a position from which he led attacks on Godoy. On March 14 1794, before the king, Abarca attacked Godoy's decision to continue the war with France. Godoy used the aggressiveness of Abarca's attack to pressure the king for the latter's dismissal. Godoy exiled Abarca and imprisoned the still-feared Redondo. Interestingly, Redondo would later be released and turned to for leadership of the country after the French invasion of 1807. At the height of his influence in the mid-1780s, Abarca put forward a startlingly prescient vision of American power that Spain would soon contend with and an equally startling suggestion for how to counterbalance that power. "This federal republic (the United States) born pygmy, so to speak and needed the support and strength of two powerful states such as Spain and France to achieve independence. There will come a day when it grows and becomes giant and fearsome colossus even in those regions. So forget the benefits you received from the two powers, and only think of this greatness ... The first step of this power will seize the Floridas in order to dominate the Gulf of Mexico. After this and disturbing our relations with New Spain, aspire to the conquest of this vast empire, we cannot defend against a formidable power established in the same continent and her neighbor...this is apparent from all the possessions of the continent of America, keeping only the islands of Cuba and Puerto Rico in the northern and some of the most suitable in the south, so that they serve as a scale or deposit for the Spanish trade." This view drove him to suggest a commonwealth structure for Spain's empire, with three infantes directing the operations of the vast departments of Meixco, Peru, and everything else with great leeway yet answerable to the crown. This plan withered as did the Conde's power. Abarca's defeat and the great reactionary power given to the string of conservative Cuban Captain Generals following Luis de las Casas represents a lack of intellectual vision for the reform of eighteenth century Spanish society. Even with the momentary reformist ideas of the ministers, Spain saw itself as the 'mother' of America and therefore retained iron tutelage over its colonies. This led to a clash of ideas between the continental aristocracy, which jealously guarded territory and power, and the overseas creole society, desirous of fair representation in the affairs of the empire. Pedro Pablo Abarca de Bolea, $10^{\text {th }}$ Count of Aranda, "Dictamen reservado que el Conde de Aranda dió al Rey sobre la independencia de las colonias inglesas: despues de haver firmado el tratado de paz ajustado en Paris en el año de 1783," in "Documents Relating to Texas and Mexico, 1783-1842," Western Americana Collection, Yale University Archives. Barbara H. Stein, Edge of Crisis: War and Trade in the Spanish Atlantic, 1789-1808 (Baltimore: Johns Hopkins University Press, 2009), 3-91; Antonio Jose Ferrer Benimelli, "El Conde de Aranda: Ese Gran Desconocido," Argensola: Revista de Ciencias Sociales del Instituto de Estudios Altoaragoneses (1971-1974), 23-52; Gabriel B. Paquette, "State-Civil Society Cooperation and Conflict in the Spanish Empire: The Intellectual and Political Activities of the Ultramarine Consulados and Economic Societies, c. 1780-1810," Journal of Latin American Studies 39, 263-298; Victor M. Uribe-Uran, "The Birth of a Public Sphere in Latin America During the Age of Revolution," Comparative Studies in Society and History 42, no. 2 (April 2000), 425-45. 
rationalize production and competition, strengthen the creole position vis-à-vis the crown and island governance, and to coordinate the response toward the ongoing revolution in Saint Domingue. Leading the charge toward this rationalization of the creole elite's was Cuba's leading economist and one of its most influential planters, Francisco de Arango y Parreño. Arango's thoughts on the status of Cuba agriculturalism and its potential, specifically his hope to displace the revolutionizing Saint Domingue as the world's leading sugar producer, established the intellectual framework for much of the discussion that Cuban creoles undertook during the first half of the nineteenth century. He was the chief architect of the not only the Sociedad but also the Real Consulado de Agricultura y Comercio de la Habana (1796), another group representing hacendado interests that took a more active role in expanding public works projects such as building canals, roads, wharves, warehouses and roads, which benefited elite agricultural interests. Creole elites hoped these improvements would not only improve the economic positioning of planters but also give them a larger claim on political power. The developing creole institutions did much to promote the assorted interests of what had been a previously divergent, fractured, and individualistically-minded group. While the defense of local interest and the embrace of a shared singularity of interest were slow in coming, the creation of special interest groups and their expansion into all areas of Cuban intellectual and economic life signified an important shift in consciousness that augured the rise of a more aggressive, independent-minded landed elite. However, that independence was not necessarily one that sought to break the chains of Spanish control but rather one that demanded recognition of the importance of Cuba and its creole elite to Spain's imperial prospects. ${ }^{136}$

\footnotetext{
${ }^{136}$ Maria Dolores González-Ripoll, ed., Francisco Arango Y La Invención De La Cuba Azucarera, (Salamanca: Ediciones Universidad de Salamanca, 2009), is the most comprehensive of the sources on the life and work of Arango. The twenty-one essays contained within focus on wide-ranging topics from Arango's interactions with the Spanish Cortes to his support and development of the scientific environment in Cuba.
} 
Arango, Cuba's voice of modernization, served as spokesman for the emerging creole sugar elite that centered on Havana in the late eighteenth and early nineteenth centuries. Throughout a thirty-year period, beginning in 1792, he did more to vocalize the concerns and demands of the Cuban planter class, with his directed and insightful letters to the Spanish Crown and Spanish legislature - the Cortes, - than any other Cuban on the island. His Obras Públicas provided the theoretical framework for the amazing growth and rapid modernization experienced by the Cuban sugar industry from the 1820 s onward and codified the creole elite's perspectives on the winds of economic and political transformation then blowing through the island. Arango adeptly exploited the juncture of politics and economics in efforts at liberalization of commercial relations between Spain and its Cuban colony. He was also the chief spokesman for the expansion and consolidation of the island's slave trade. ${ }^{137}$

Arango's most substantive argument and corresponding effect on the formation of Cuba's blossoming world position was his emphasis on the Atlantic basin as the emergent center of the new world economic system. He understood the ways in which the United States, French, and Haitian revolutions along with the colonial competition among European nations in the Caribbean created a historical reconstruction of politics and economics that centered Cuba as the bellwether of the Atlantic basin's profound economic and political restructuring. Arango sensed Cuba's need for rapid modernization if it might break free from its retrograde agriculturalism and move instead toward a new economic liberalism. Arango's project, a conceptualization of a new economic configuration thoroughly detailed in his numerous missives, always kept the perspective of his Havana elite in the forefront of his thinking. Fundamentally, he demanded the

\footnotetext{
${ }^{137}$ Maria Dolores González-Ripoll Navarro and Izaskun Alvarez Cuartero, "Vínculos Y Redes De Poder Entre Madrid Y La Habana: Francisco Arango Y Parreño (1765-1837), Ideólogo Y Mediador,” Revista De Indias 61, no. 222 (2001), 291-395.
} 
unfettered continuance of slavery and unlimited resupply of slaves on the island. Slavery, coupled with the removal of Spanish mercantile restrictions and the modernization of sugar production, mutually reinforced the system of free trade that Arango and his colleagues in Havana dreamed might bring them a richness similar to those in pre-revolutionary Saint Domingue. Arango believed that the development of Cuban productive capacity and the unencumbered delivery of its sugar to any port in the world, a complete capitalization on France's problems in Saint Domingue, might catapult Cuban suppliers to the world lead. This position, once solidified, would help to insulate the island's elite from competition, a concern held by many who feared that Haitian unrest was momentary and its loss of world sugar and coffee market dominance only temporary. Arango's approach, a robust institution of slavery within a reinvigorated sugar production regime driven by the reigns of free trade, was a total program for Cuba's social and economic transformation. ${ }^{138}$

Arango's numerous texts, most directly addressed on behalf of his compatriots in the Sociedad to the Spanish crown, culminated in his Discurso Sobre la Agricultura de la Habana y Medios de Fomentarla (Discurso). In his Discurso, he expressed an undying belief in the great benefits found in the amalgamation of liberal political economy and support of slavery. As such, Arango greatly complicates, if not directly contradicts, a whiggish enlightenment linearity that

\footnotetext{
${ }^{138}$ The literature on Arango is rich and mainly, but not exclusively, in Spanish. As he was a profound and early economic thinker, his reach and understanding of the contours of Western Hemispheric political economy is vast, if unfortunately overlooked. As a theoretical compatriot of Adam Smith, Arango's application of systemic economic thinking placed him on the forefront of thinkers and practitioners of a thoroughly modern approach to development and modernization. Among the more general sources on Arango's life and philosophy are: José Gomariz, "Francisco De Arango Y Parreño: El Discurso Esclavista De La Illustracion Cubana," Cuban Studies 35 (2004), 45-61; Maria Dolores González-Ripoll Navarro, "Dos Viajes Y Una Intención: Francisco Arango Y Parreño Y Alejandro Olivan En Europa Y Las Antillas Azucareras, 1794 y 1829," Revista De Indias 62, no. 224, accessed on May, 12, 2012, http:// revistadeindias.revistas.csic.es/index.php/revistadeindias/.../528,consultado el 4 de octubre de 2009; Juan Bosco Amores Carredano "Francisco de Arango y Parreño: La Transición Hacia La Modernidad En Cuba," in Actas del XI Congreso Internacional de AHILA, ed. John Fisher (Liverpool: University of Liverpool, 1998), 507-522 and "El Joven Arango Y Parreño: Origen Del Proyecto Político-Económico De La Sacarocracia Habanera (17861794)," Temas Americanistas 12 (1995), 12-17; William Whatley Pierson, "Francisco de Arango y Parreño," The Hispanic American Historical Review 16, no. 4 (November 1936), 451-478.
} 
proclaims modernity's (and subsequently its handmaiden, capitalism) arrival with the abolition of slavery and the turn toward wage-labor. As the history of nineteenth century Cuba demonstrates, modernity, capitalism, liberalism, and slavery all coexisted to great benefit for elite creoles directing sugar's dominance of the island. Slavery, rather than a vestigiality supplanted by wage labor, was the other half of exploitable labor in the Atlantic system. ${ }^{139}$

In 1793's Discurso, Arango argued that all change must be the result of management reform within the empire's power structure. He saw the current opportunity afforded postHaitian revolution Cuba as a glorious yet fraught one, which threatened socio-economic upheaval if the Spanish persisted in codifying the subordinate relationship of the Cuban elite in relation to colonial authority. While he argued for the continuance of Spanish colonial control of the island, which offered foreign defense and internal security, the management of the socioeconomic project within the imperial structure had to be based on the Cuban creole elite's own autonomous right to rule. The levers of power, Arango argued, would be solidified through an aggressive, audacious, and multifarious plan. The plan's essential components were: the free trade in slaves coupled with the institution's expansion in hopes of providing sufficient labor to grow sugar production; the elimination of all obstacles to intensive agricultural exploitation achieved with improvement in land use through the application of the technology; rapid technological development of sugar manufacturing coupled with greater scientific development

\footnotetext{
139 This is a sentiment neither new nor novel and one that follows the insightful work relating to 'histories of capitalism, particularly in U.S. cotton production by, among others, Edward Baptist, Seth Rockman, and Sven Beckert. An overview of the debate and discussions are various but congealing. Timothy Skenk, "Apostles of Growth," accessed on March 1, 2015, http://www.thenation.com/article/188369/apostles-growth\#; Edward Baptist, The Half Has Never Been Told: Slavery and the Making of American Capitalism (New York: Basic Books, 2014); Sven Beckert, Empire of Cotton: A New History of Global Capitalism.(London: Penguin UK, 2014); Seth Rockman, Scraping By: Wage Labor, Slavery, and Survival in Early Baltimore (Baltimore: Johns Hopkins University Press, 2009):; dam Rothman. "The 'Slave Power' in the United States, 1783-1865," in Steve Fraser and Gary Gerstle, eds. Ruling America: A History of Wealth and Power in a Democracy (Cambridge, MA: Harvard University Press, 2005).
} 
more generally throughout the island; the increase in free trade fueled by the reduction of duties and taxes on Cuban exports and imports; and finally the reduction of the weight of usury in loans needed to bring all of these agriculture and manufacturing dreams to reality. ${ }^{140}$

Arango successfully melded a robust defense of slavery with the Atlantic's rising freetrade ethos. He erased retrograde conceptualizations of mercantile trade and replaced them with appreciation for the union of new liberal political economy and robust institutionalized slavery. He sought to redefine slavery in new terms apart from the languid tradition of the institution's place in the colonial world. The use of slave labor, Arango argued, was not representative of a premodern ethos but rather emblematic of a robust modern capitalism fusing free trade and forced labor into a dynamic productive force. Cuba, in embracing the totality of plantation production through the rationalization of labor, promised to do for agricultural capital what Britain had done for industrial capital. This view centered broadly on the Atlantic world, and specifically the Caribbean, as the premiere area best-positioned to take advantage of their integral role in the emerging system of accumulation. Interestingly, while Arango and his Havana coterie self-consciously saw themselves as a fundamental part of the supercharging of the world economy, their political arrangements with this world economy simultaneously placed them in an increasingly dependent and colonialized position. While Cuban producers enjoyed the rising tide of demand and the invitation into the world economy, they did so dependent on the Spanish for their internal security provisioning and their access to foreign markets, technology, and capital. However, by the early decades of the nineteenth century, Britain presented itself as the main industrialized power that could absorb Cuba's increasing sugar production and provide the credit necessary for investment in the engines, rails, and slaves that fueled this production.

\footnotetext{
${ }^{140}$ Francisco de Arango Y Parreño, "Discurso Sobre La Agricultura En La Habana," in Francisco de Arango Y Parreño: Obras, Vol. I (Havana: Editorial Cultura Popular, 2005), 144-192.
} 
The United States arrived on the scene, soon after, as a potent consumer and supplier for the continuing Cuban transformation. The United States quickly increased demand and New England capital competed with the British for economic superiority in Cuba. While the British sealed trade advantages with the rest of South American, to the chagrin of United States financiers and politicians, Cuba always remained closer to the United States. Yet, despite this closeness, slavery remained problematic for the Cuban elite's vision of society and became the chief issue in the debate over Cuba's economic advancement.

Remarkably, Arango's call for aggressive expansion of plantation agriculture and slavery came at the precise moment of conflagration in Haiti. This was certainly not a coincidence but rather a clear-eyed response to events engulfing Cuba's French neighbor. Arango argued that a fundamental reorganization of Cuban agriculture in efforts to awaken it from a sluggish history was necessary to take advantage of the moment, as he fully expected the French to reassert control over Saint Domingue. Cuba needed to focus beyond a year or two of short term profit and intensify its outlook toward world market domination.

...seeing them, (the French) immersed in a calamity that, if it doesn't destroy all of the prosperity of that colony will retard it indefinitely, it is necessary to look at it not only with compassion, but with political eyes, and, with the faith of a good patriot and a good vassal, announce to the best of kinds the opportunity and the means to give to our agriculture of the islands advantage and preponderance over the French. ${ }^{141}$

Ominously, Arango saw in the Spanish a reluctant partner desirous of stifling commerce.

However, he was less clear as to the goal of these efforts. He viewed Spanish action alternating between purposeful, in hopes of keeping Cuba beholden to peninsular commercial cabals, and more casually, even benignly, neglectful. He also doubted the dedication of some in his cohort toward transforming the Cuban economy. He largely based this view on a less than impressive

\footnotetext{
${ }^{141}$ Arango, "Discurso Sobre La Agricultura," Obras, Vol. I, 158.
} 
Cuban economic track record; one that focused too completely on the Spanish economic imperatives and all too often embraced claims of western hemispheric colonial degeneracy. Arango argued that change was possible through a rejection of self-serving narratives, the abandonment of Spanish protectionism, and a deliberate shift in industry. Cuba's social lethargy and economic backwardness, according to Arango, was in no small part due to outdated mercantile instincts toward mineral extraction and a regressive Spanish tariff system that hamstrung change. Simply articulated, the future of Cuban prosperity for Arango lay in an embrace of the market and its lure of free trade as that mechanism best able to set commodity and slave prices.

The freedom from Spanish market and price controls, or libertad absoluta, was the foundation of Cuba's development plan. Arango held the United States up as an example nation where free trade, slavery, and technological progress spurred its growing presence in the world market. Not only could this balance be struck in Cuban commerce, Arango reasoned, but slavery would also be of even greater benefit to Cuba since Spanish immigration (or any other white immigration) was unable to provide the necessary labor needed to expand agriculture as it had in the United States. Cuba already possessed a good quantity of subsistence and smaller cash crop farmers, yet these numbers were hardly sufficient to create agricultural advantage on the scale Arango envisioned, presuming these smaller producers could even be compelled to work in the cane fields. The demand for free trade placed Arango and the creole elite in the position of demanding an end to royal monopolies in the trade of many commodities, notably tobacco, as an important first step toward capitalizing on broader free trade. Arango was adamant that the inability of Spanish markets to absorb the growth in Cuba commodity output and the Spanish government's inability to provide slaves in substantial enough numbers to fuel agricultural 
growth demanded an opening of trade - a demand the Spanish government finally acquiesced to, albeit with huge tariffs, in $1818 .{ }^{142}$

Arango and the Cuban planter elite arrived fortuitously at the very point when the foundation of British and American free trade ethos began to solidify, producing Spanish consideration for the dangers of Cuban independence. While serious discussions of an imperial break were decades away, Spanish authorities, much like the creole elite, envisioned a time when prosperity might lessen dependence and invite Cuban rejection of the exorbitant economic costs of imperial security on the island. However, for the moment, Cuba, unlike the rest of South America, clung tenaciously to the Spanish crown, which did its part to pull the island ever closer in the wake of Bolívarian revolutions. The Cuban creole program propelled forward, encouraged by Spanish worries, the island's agricultural industrialization and world market integration. Arango argued that the Cuban elite should embrace the job of defining what technology might serve their needs best and to engage actively in bringing that technology to Cuban agriculture. The rich fertile lands of the island, Arango believed, stood ready to rectify the traditional Spanish overreliance on mining and mineral wealth extraction; a process that always held prominence, particularly on the mainland of South American, over agriculture. With the loss of Haiti to world supplies of coffee and sugar, Cuba might help the Spanish empire finally recognize the worth of agricultural export-based wealth streams.

No one still denies or doubts that true wealth consists of agriculture, or commerce and the arts, and that if America had been one of the causes of our decadence, it was because of the disdain that we had for the cultivation of its fertile lands, because of the preference and protection that we accord mining, and because of the miserable method which we conduct our commerce...the very advantage that we enjoy today in the sale of sugars can be disastrous for us if we do not know how to take advantages of it. I have already said, and I

\footnotetext{
${ }^{142}$ In response to Arango's Primer Papel Sobre el Commercio de Negros written in 1789, the Spanish government opened the slave trade to the market for a two-year period, only to close it again at the end of the period. Arango argued that the refusal to reconsider a longer period or to only open the trade at certain periods for certain lengths of time would only encourage speculating and inflationary prices for slaves, thereby further limiting Cuba's agricultural reorganization.
} 
repeat, that if we wish to encourage this branch of industry we must work as though we were in the times preceding the insurrection of the Negros of Guarico (Haiti) so that when they (French) return we do not find ourselves in the sad condition that we were in before. ${ }^{143}$

The slow growing prosperity of the late eighteenth century and the promises of the coming sugar revolution invited greater state scrutiny and intervention in local affairs, including the appointment of more peninsular-minded Captain Generals. The position, as the social and economic fortunes of the island shifted, was a work in progress. The Captain General was the head of Cuban government, approved by the Spanish king and generally satisfied the dual need for political favor repayment and pro-crown stability on the island. By royal cedula of May 1825, the Captain General was given almost complete authority over the island, although some issues of receipt collection rested with the Superintendent who reported to a different royal authority until 1843. The Captain General also shared naval control in a complex way with the Royal Admiralty based in Havana until 1853. ${ }^{144}$ The 1825 decree establishing the Captain General's unlimited political power, hoping to prevent unrest and considered by some on the island to be its true 'constitution,' responded to the threat of military intervention in the island on the part of the newly independent South American republics. Furthermore, the Spanish government sought to dissuade those on the island who, in the wake of revolutions, considered capitalizing on the unsettled political atmosphere. The powers given to the Captain General meant that there would be no power sharing between criollos and peninsulares, a particular

\footnotetext{
${ }^{143}$ Arango, Obras, Vol. I, 144, 158. Peter James Lampros, Merchant-Planter Cooperation and Conflict: The Havana Consulado, 1794-1832, (PhD diss., Tulane University, 1980); and Dale Tomich, "The Wealth of Empire: Francisco Arango y Parreño, Political Economy, and the Second Slavery in Cuba," Comparative Studies in Society and History 45, no. 1 (January 2003), 4-28.

${ }^{144}$ The center of the Spanish naval response to the South American revolutions was Havana, thus the Captain General, having enough on his plate, was relieved of the necessity to direct the naval movement of troops and supplies to counter the independence movement. The Captain General, Admiral and Intendant formed a body, the Junta de Autoridades, designed to coordinate the public voice of its three members. This tripartite organization of Cuban authority generally worked well although there were moments of friction. The Crown gave ultimate authority over all matters financial, political, and military to the Captain General in 1853, largely in the wake of the López expeditions and in response to Captain General Concha's complaints about the lack of centralized authority hamstringing his efforts at adequate response to the uprising.
} 
source of agitation driving the independence-minded South American revolutionaries, in Cuba as

well.

His majesty desiring to obviate any difficulties which might arise in extraordinary cases from a division of authority and the complication of command and control by respective officers, and to the important end of preserving in that previous island his legitimate sovereign rule and public peace... His majesty consequently invest your Excellency with full and unlimited authority to detach from the island, and to send to the Peninsula all officials and person employed in whatsoever capacity and of whatsoever rank and class or condition, whose presence may appear prejudicial, or whose public or private conduct may inspire your with suspicion, replacing them with servants of your majesty who are deserving of the confidence of your Excellency. ${ }^{145}$

Despite the various hands on different levers of power, Captain Generals held sway and increasingly consolidated power on the island throughout the nineteenth century. The influence of the early creole groups and community councils, like the Sociedad, and the sway they held on the political development of the island in the early consolidation period waned greatly throughout and beyond the 1840s. This situation allowed a normalization of the Captain General's unlimited power and made dispute, beyond the constant murmur of dissatisfaction, extremely dangerous. ${ }^{146}$

While numerous Captain Generals sought to wield power, the transformations taking place in Cuban society set up a more confrontation landscape and placed new strains on traditional political, economic, and social relationships. This recalibration contributed to the accelerated pace of cultural change and accompanying conflict. The creole elite sought to awaken a new awareness of their privileged place on the island and the influential position they held within the Spanish empire's economic world. Chief among the differences creoles looked to

\footnotetext{
${ }^{145}$ Portion of royal cedula quoted in French Chadwick, Relations of the United States and Spain - Diplomacy (New York: Scribner and Sons, 1909), 224.

${ }^{146}$ The best treatment of trials and tribulations of the Captain General comes from de la Concha himself, Memorias Sobre El Estado Political Gobierno Y Administracion De La Isla De Cuba Por El Teniente General Jose Gutierrez De La Concha (Madrid: Establecimiento Tipografico de D. Jose Trujillo, 1855), accessed February 20, 2012, http://openlibrary.org/books/OL6932420M/Memorias_sobre_el_estado_poli\%CC\%81tico_gobierno_y_administraci o\%CC\%81n_de_la_isla_de_Cuba.
} 
accentuate between themselves and the peninsulares, who to the annoyance of the Cuban elite enjoyed broad leeway in governance and economic matters, was the creation of a unique creole community consciousness. The shared interests that hacendados like Arango sought to emphasize focused on the growing role Cuban planters had in the Spanish economy along with their desire for greater voice in the political affairs of the island. These business leaders saw themselves as social leaders. Their championing of social development was a demonstration of Cuba's self-perceived moral superiority to the South American and European mainland. Yet, these demonstrations were as self-serving as they were aspirational.

The creole elite recognized the divergence and likely coming conflict between the interests of Spain and their interests in Cuba. The needs of the creole oligarchy based on land and dependent on free trade and forced labor quickly fell out of step with the economic demands of the peninsular elite. Economic change fomented social change, but that social change was not accompanied in Cuba by necessary political change satisfactory to creole demands. The island's shifting cultural landscape saw Cubans, notably the elite, developing cultural forms and institutions that fostered a new sense of identity askew to mainland. However, while the creole elite attempted to enlist the support of the Cuban masses in their growing demands against the Crown, the paternalism of elite cultural institutions and ideology stifled a broad-based effort to find common ground. The Cuban elite, through their social clubs, literature, and developing sense of power, clamored for a society representative of their past accomplishments and commensurate with their future potential. The various forms the Cuban oligarchy chose to use and to venerate never fully shaded their confrontational impulses and often guided their supporters into dangerous territory with Spanish officials. Not surprisingly, their calls for greater participation came at a point when they sensed an opening in the economic and political hold of 
the Empire's grip throughout the Western Hemisphere. However, this proto-nationalism, while prescient, was ambivalent at best, always teetering precariously on the edge of a rhetorical cliff; one which promised racialized revolution, akin to that seen in Saint Domingue, if their footing ever failed. ${ }^{147}$

The early political and economic exuberance felt by many hacendados resulted mainly from the abundance of opportunity they saw all around them in the wake of the uprising in Saint Domingue. For much of the eighteenth century, Cuba suffered from perpetual under-production in the view of those who sought profitability in Cuban agriculturalism. Compared with other colonial economies, Cuban producers had fewer slaves, smaller plantations, and poorer technology than the majority of the Caribbean's other islands. The accretion of these scarcities contributed to an anemic agricultural output, particularly in the sugar industry, which was of minor importance behind tobacco and coffee economies of the island in the late eighteenth century. The output of every productive Caribbean island outpaced that of Cuba's 10,000-ton yearly average - even 68 square mile Saint Christopher was able to match the sugar production of its 46,000 square mile compatriot. However, Saint Domingue (10,700 square miles) provided for Cuban planters the most direct comparison and offered the clearest and most envied example of what they might become in the coming century. In Saint Domingue, roughly 800 estates produced on average 71,000 tons of sugar annually. Almost 3,000 coffee farms produced more than 30,000 tons of coffee, accounting for nearly $60 \%$ of world supply. Cotton and indigo plantations produced amounts that seconded only the United States in world supply. On these

\footnotetext{
${ }^{147}$ Alan J. Kuethe and G. Douglas Iglis, "Absolutism and Enlightened Reform: Charles III, The Establishment of the Alcabala and Commercial Reorganization in Cuba," Past and Present, A Journal of Historical Studies, 109 (November 1985), 118-143; Juan Bosco Amores Carredano, "Las Elites Cubanas y la Estrategia Imperial Borbónica en la Segunda Mitad del Siglo XVIII," in Élites Urbanas en Hispanoamérica, ed. Luis Navarro García (Sevilla: Universidad de Sevilla, 2005), 189-197.
} 
combined plantations and farms nearly 500,000 slaves contributed to the vast wealth which Saint Domingue's agricultural elite enjoyed. Perhaps most important for the success of this elite was the availability of world markets for their products. Only one-third on Saint Domingue's exports arrived in French ports with the rest dominating world markets. Unfortunately, prior to 1791, Cuban planters, suffering under the Spanish imperial yoke, envisioned no way of progress toward their goal of emulation of Saint Domingue's success, particularly as their exports could only legally arrive in the ports of their mainland parent. Cuban planters were too far behind technologically and economically and remained hamstrung by imperial dictates that, while briefly relaxed during the American Revolution, kept a tight watch on Cuban political and economic developments through the person of the Captain General and his court in Havana. Cuban planters lacked the means to expand and the markets to expand into. With the added expense of antiquated production methods and the lower returns, Cuban planters were disinclined to expand and battle the constricted Spanish trade system and its limited markets, retrogressive taxation structures, and lack of royal support. The dominance enjoyed by Saint Domingue's elite insulated them against world-competition and left them seemingly unassailable by fledging Cuban producers. ${ }^{148}$

\footnotetext{
${ }^{148}$ Clarence J. Munford, Michael Zeuske, "For Black Slavery, Class Struggle, Fear and Revolution in St. Domingue and Cuba, 1785-1795," The Journal of Negro History 73, nos. 1-4 (Winter-Autumn 1988), 12-32; Carolyn Fick, "Revolutionary Saint Domingue and the Emerging Atlantic: Paradigms of Sovereignty," Review: A Journal of the Fernand Braudel Center 31, no. 2 (2008), 121-144; Elzbieta Sklodowska, Espectros Y Espejismos: Haití En El Imaginario Cubano (Madrid: Iberoamericana /Vervuert, 2009), 1-100; Rebecca Scott, "Paper Thin: Freedom and Re-enslavement in the Diaspora of the Haitian Revolution," Law and History Review 29, no. 4 (November 2011), 1061-1087; Maria Dolores González-Ripoll Navarro, ed., El Rumor de Haití en Cuba: Temor, Raza y Rebeldía, 1789-1844 (Madrid: Consejo Superior De Investigaciones Cientificas Escuela De Estudios Hispano-Americanos, 2004); Juan Antonio Hernández, "Hacia Una Historia De Lo Imposible: La Revolución Haitiana Y El "Libro De Pinturas" De José Antonio Aponte," (PhD diss., University of Pittsburgh, 2005); Marixa Lasso, "Haiti as an Image of Popular Republicanism in Caribbean Colombia, Cartagena Province (1811-1830)," in The Impact of the Haitian Revolution in the Atlantic World, ed. David Geggus (Charleston: University of South Carolina Press, 2001), 176190; Richard M. Fahoome, "The Transition from Slave Labor to Wage Labor and the Exploitation of Haitian Migrant Workers in Eastern Cuban Sugar Production,” (PhD diss., Wayne State University, 2007), chs. 1-3.
} 
The destruction wrought by the uprising in Saint Domingue on the agricultural fortunes of that island was a fortuitous turn for Cuban planters. The effects of the revolution on the agricultural elite - the destruction of plantations and land, the collapse of production, and the departure of planters and their capital - left the Cubans in a strong position to capitalize on rising demand, higher prices, and panic-inducing shortages in the world market. However, this capitalization needed to be even more literal than figurative and placed a great amount of strain on a newly coordinating Cuban elite. Massive investment in infrastructure, political lobbying, and technological improvement, along with the various physical and philosophical dislocations coming as a result of the pace and amount of change promised to fundamentally remake every landscape of Cuban society. However, the changes came not only as a result of internal motivation but also as a consequence of the arrival of as many as 30,000 French émigrés from Saint Domingue to all sectors of Cuban society - from the elite to the enslaved. While Cubans generally welcomed this infusion of capital and knowledge, particularly in the cultivation of sugar, tobacco, and coffee, these immigrants brought with them a fundamentally different conceptualization of self and community that lent itself well to a clash of cultures. ${ }^{149}$

Layered on top of these local concerns were geopolitical conflicts and competition that buoyed Cuban hopes of quick gains in economic prospects and corresponding political rights. The two decades after the Haitian revolution saw Spain at war, first with France (1793-1795) and then England (1796-1801, 1804-1805). Cubans, as a result, enjoyed a very lucrative easing of

\footnotetext{
${ }^{149}$ Matt Childs, "A Black French General Arrived to Conquer the Island: Images of the Haitian Revolution in Cuba's 1812 Aponte Rebellion," in The impact of the Haitian Revolution in the Atlantic World, ed. David Geggus (Columbia: University of South Carolina Press, 2001) 135-157. John E. Baur, "International Repercussions of the Haitian Revolution," The Americas 26, no. 4 (April 1970), 394-418. As a result of the Napoleonic invasion of Spain, the French were forced out of Cuba beginning in 1809 , most of which $(10,000)$ found their way, with their slaves, to New Orleans. Paul F. Lachance, "The 1809 Immigration of Saint-Domingue Refugees to New Orleans: Reception, Integration and Impact," Louisiana History: The Journal of the Louisiana Historical Association 29, no. 2 (Spring 1988), 109-141(immigration table 111-112); Luiz Perez, "French Refugees to New Orleans in 1809," Publications of the Southern History Association 9 (1905), 293-310.
} 
trade restrictions, specifically with the United States. The Spanish government variously opened Cuban ports to foreign trade and allowed Cuban merchants access to non-Spanish ports and markets. Trade with the United States flourished and established a trend that grew unnervingly for Cubans - Cuba exported sugar, molasses, rum, and coffee and the Americans provided almost $100 \%$ of Cuban foodstuffs (by the 1840s) along with smaller percentages of clothing, manufactured goods, and slaves. However, it was not just the United States that enjoyed the Cuban bounty. The British - to the constant annoyance of the United States - were an almost equally important export destination for Cuban agriculture throughout the first half of the nineteenth century. The profits and freedom enjoyed by the Cuban agricultural and mercantile elite through the late 1810s and the tenuous relationship Cuba had to the peninsula in the wake of the South American revolutions, forced the Spanish government to capitulate. The Spanish Crown, in 1818, made free trade in and out of Cuba a permanent fixture of Spanish imperial policy. However, to offset the profits lost from non-exclusivity, the Spanish government placed high tariffs (20-40\%) on foreign-produced goods and products; products Cubans became increasingly dependent on as their economy shifted progressively toward sugar's dominance. Tariff rates fueled much of the anger the Cuban elite held toward mainland politicians and trade monopolists and played a large part in the agitation for greater political voice they sought as a result of the great wealth they produced for the empire. ${ }^{150}$

The first half of the nineteenth century was a boom time for the Cuban economy fueled by the explosive growth in the sugar industry. While Haitian/French immigrant coffee producers

\footnotetext{
${ }^{150}$ Linda K. Salvucci, “Atlantic Intersections: Early American Commerce and the Rise of the Spanish West Indies (Cuba),"The Business History Review 79, no. 4 (Winter 2005), 781-809 and "Merchants and Diplomats: Philadelphia's Early Trade with Cuba," Pennsylvania Legacies 3, no. 2 (November 2003), 6-10. Sheryllynne Haggerty, The British-Atlantic Trading Community, 1760-1810: Men, Women, and the Distribution of Goods (Leiden: Brill, 2006).
} 
did much to invigorate the moribund Cuban industry and the continued strength of the tobacco sector provided profits, sugar became the productive force behind the island's technological improvement, economic expansion, political rationalization, and steady increase in slave importation. ${ }^{151}$ The immediate growth in the first decade after the Haitian revolution was hurried and improvised. Cuban producers adjusted to both their new position as the world's dominate supplier and to the quick rise in prices on which they sought to capitalize. The number of sugar mills around Havana increased between 1791-1806, growing from 237 to 416, and the zones of cultivation pushed aggressively along the northern coast into areas outside Guanajay and Matanzas - coastal locales that allowed planters quick water access to transportation. Even with the coffee and tobacco industries holding their own, sugar cultivation expanded throughout the island with the somewhat haphazard accommodations of the early period giving way to a muscular and well-coordinated effort in the intervening decades buoyed most significantly by the massive investment in infrastructural improvements from sugar hacendados. The unstoppable inland march of sugar swept aside physical and philosophical obstacles. Sugar barons poured their economic and political capital into shaping the island's character to their own will. The battle was not an easy one as nature and other commodity producers as well as the Spanish government and members of the lower classes (enslaved and free) sought accommodations from the strengthening sucrocracy. The success of the sugar industry progressed through the $1830 \mathrm{~s}$ and 1840s and brought with it many changes: vast acreages fell to the needs of the industry;

\footnotetext{
${ }^{151}$ Coffee production was particularly strong, despite the consolidatory noises of the sugar industry, in the first few decades of the $19^{\text {th }}$ century with the number of cafetales increasing from two in 1774 to 2,067 in 1827 . This explosive growth and the resulting dominance in world share made the rather sudden collapse, helped by significant environmental factors, after the 1830s even more astounding. Interesting excavations demonstrating some of the challenges and success of some of the early sites of production are presented by UNESCO-World Heritage Convention's Archaeological Landscape of the First Coffee Plantations in the South-East of Cuba, accessed on December, 23, 2014, http://whc.unesco.org/en/list/1008/. The British abolitionist presents a contemporary and largely laudatory view of coffee production in comparison to his hype-critical views on sugar production in Travels in the West. Cuba: With Notices of Porto Rico, and the Slave Trade (London: Longman, 1840), 293-317.
} 
forests disappeared; tobacco vegas and coffee cafetales bought or appropriated; cattle grazing land turned to mud; and the Cuban social fabric irrevocably altered. Sugar production began its domination of the island in every way. ${ }^{152}$

The great success of sugar was both cause and effect of larger changes taking place on the island, most notably in the area of transportation. Highway and road construction was traditionally never a top priority. The lack of navigable roads and the negligence that had longaccompanied the poor planning on the island was emblematic of the lackadaisical approach of both Cuban authorities and planters alike toward economic development. Roads were largely dirt and washed out during the rainy seasons. Passages to the interior of the island were largely nonexistent. Mule trains carrying wooden boxes of sugar and molasses were the pinnacle of transportation technology, chiefly attributing to the bleak Cuban agricultural situation and confining the largest producers (even those enjoying the greatest profits as the boom began) to the coasts and few inland rivers in hopes of keeping costs low. Transportation for producers and residents alike was slow, laborious for man and beast, and prohibitively expensive. However, the profits were so handsome and so quick in coming that producers responded slowly to transportation needs. They enjoyed such great initial returns that their now flush accounts offset and buried their transportation costs. Not surprisingly one of the main areas that forward looking members of the Sociedad and the Real Consulado focused on was transportation, specifically the improvement and construction of roads along with the introduction of railroads. The Real Junta de Fomento directed completion of the first rail line between Havana and Güines in 1838, with

\footnotetext{
152 Theresa Singleton "Slavery And Spatial Dialectics On Cuban Coffee Plantations," World Archaeology 33, no. 1 (2001), 98-114.
} 
over 400 miles of track, connecting the major sugar production areas to the principle ports, laid in the next decade. ${ }^{153}$

Road building accelerated throughout the island in hopes of providing arterial lines for new railways. New ports and cities popped up overnight and older ones gained in prestige, power, and population. The export market widened as distant internal sugar zones now connected to the coasts, added their produce to the world supply, and spread investable profit, if unequally, throughout the island. New and previously isolated agricultural lands became profitable sugar zones and a new land rush spurred production and further transportation developments. Rail power also assisted in improving efficiency on sugar plantations. Private rail spurs connected refinery and storage facilities to larger rail lines and helped streamline the movement of product from field to port. Laborious tasks of movement on plantation complexes, usually performed by the enslaved, were now more efficiently completed by railcars. Most notably, railroads changed the physical size and organization of plantations. Traditionally, onequarter to one-third of most plantations were set aside for fuel-wood production. This reserve forestland became superfluous to production once railroads allowed for the delivery of cheap wood and planters found it more profitable to convert their forests to cane fields. Hacendados sent surplus slaves, freed from transportation responsibilities, into the forest to clear and prepare new land for sugar cultivation. Readily available and cheaply deliverable fuel sources encouraged the shift to and profitability of steam power on sugar plantations. Beginning in the 1810 s, steam power remade the productive units on plantations with nearly $70 \%$ of all complexes by 1860 transferring from water and oxen power to fire-driven steam boilers and dryers. Other

\footnotetext{
153 Thomas, Cuba, 122-124; D.C. Corbitt, "El Primer Ferrocarril Construido en Cuba," Revista Cubana, 12 (AprilJune 1938), 179-195; Dale Tomich, "World Slavery and Caribbean Capitalism: The Cuban Sugar Industry, 17601868," Theory and Society 20 (1991), 297-319.
} 
technological advances such as iron-rollers, vacuum boilers, better tools, and new strains of sugar drove production and profits to even higher levels. All of these changes helped Cuban sugar output increase from 72 tons per sugar mill in 1830 to 120 tons by 1841 and 316 tons by 1860. The number of mills increased from 1,000 in 1827 to 2,000 in $1868 .^{154}$

These astounding technological changes had a profound effect on the process of Cuban social development and did more to direct the energy of the island than any other force. The scale of sugar production catapulted a class of men into an entirely new plane of social existence and helped to exclude those coffee and tobacco producers who previously stood shoulder to shoulder with their fellow hacendados. The extraordinary capital resources now required for investment and success in the sugar industry - for machinery, equipment, slaves, private rail lines, and land expansion - formed a coterie of very rich men possessing the necessary initial resources and connection to capital that continuously reinforced their riches with the profits gained from their sugar undertakings. The need to modernize in order to be competitive drove smaller producers of sugar and other commodities out of the market and out of landowning. The movement of capital investment, including extension of credit, to a smaller circle of planters shrank the size of the large-scale investment class and allowed larger producers to gain everincreasing wealth and power. Increased sugar production came at the expense of almost everything else in Cuban society. Technological improvements, in tandem with increased slave imports, shifted the spatial arrangement of sugar making that in turn shifted the way slaves worked, lived, and interacted with sugar and slavery. These massive changes, occurring after the

\footnotetext{
${ }^{154}$ Dale Tomich, "Making the Sugar Frontier, Remaking Sugar: Material Processes, Social Practices and the Cuban Ingenio, 1820-1868" (presented to Cornell History Department Comparative History Colloquium, Ithaca, New York, March 2006); and Heidi Zogbauma, "The Steam Engine In Cuba's Sugar Industry, 1794-1860," Journal of Iberian and Latin American Research 8, no. 2 (2002), 37-60.
} 
1820s, pushed sugar production and slavery to the fore and placed a greater emphasis on control of the enslaved that necessitated physical and mental changes in the policing of plantations. ${ }^{155}$ Coffee production suffered most notably from sugar's rise and the crash was precipitous. Coffee, while always a secondary crop in the Caribbean, had some distinct advantages over sugar. Generally, the crop's land requirements were small and initial investments in machinery or buildings were not required in the same qualities or cost as those of sugar. Therefore, coffee attracted planters of diverse economic and social scales whereas sugar was generally restricted to the wealthy. Coffee also had its drawbacks, most notably, the time to maturity of coffee plants varied greatly depending on the type of coffee. Because of the lag time between the initial investment and the generation of income, coffee was more economically complex and given to erratic swings. Cafetal owners always lived on the edge of collapse and had less investment capital available to bridge the gaps should catastrophe find them. Costs increased and profits fell as cafetales competed with sugar plantations for everything from fuel to slaves to food. Sugar plantations, better positioned on the rising tide of enrichment, gobbled up cafetales at an alarming rate. ${ }^{156}$ Despite the infusion of capital and expertise, particularly and powerfully in

\footnotetext{
${ }^{155}$ Dale Tomich, "Material Process and Industrial Architecture: Innovation on the Cuban Sugar Frontier, 18181857," in Nature, Raw Materials, and Political Economy, eds. Paul Ciccantell, Gay Seidman, David A. Smith (Amsterdam: JAI / Elsevier, 2005), 287-307; and Theresa Singleton "Slavery And Spatial Dialectics On Cuban Coffee Plantations," World Archaeology 33, no. 1 (2001), 98-114. An impressive overview bibliography on sugar production in Cuba is Antonio Santamaría García, "La industria azucarera y la economía de Cuba colonial, Bibliografía," accessed on March 21, 2013, http://digital.csic.es/bitstream/10261/72783/1/Bibiografia\%20Cuiba $\% 20$ azucar\%20y\%20economia\%20XIX\%20(PDF).pdf.

156 The competition for slaves was not confined to purchase. Slave raiding and the capture of runaways was a lucrative enterprise for planters, and the people they paid, looking to enlarge their workforce. The pressure on labor supply increased dramatically in 1831 as cholera swept throughout the western region of the island for at least two years corresponding with a period of skyrocketing sugar prices. Planters tried desperately to keep slave raiders away from their plantations but with the need for slaves exploding on sugar plantations, slave raiding from coffee plantations became the perfect solution. Many of the slave raiders, or rancheadores, were displaced white peasants. These men organized gangs to rove the countryside not only looking for runaways and raiding maroon colonies, but also stealing black laborers from one plantation for sale at others. Although authorities attempted to take safeguards against the worst abuses, plantation owners took more physical approaches to preventing raiding and runaway, including the construction of higher walls around slave quarters. There was of course little difference between slave raiders and outlaws. More generalized banditry served as a response to the elite accumulation of power. The arrival of Canary islanders, as a potential source of white labor in the 1840s produced profound social dislocations and
} 
eastern Cuba, as a result of French-Haitian migrations after 1790, Cuban coffee planters were unable to implement many of the new innovations that allowed producers in other parts of South America to overtake a Cuban industry that lagged far behind their sugar brethren in both technology and clout. Brazil, with a great deal of arable virgin land, vastly expanded its coffee industry while Cubans, hemmed in by sugar's land grab, had nowhere to expand in hopes of balancing stagnant prices with increased production. Unfortunately, the increase in output in rapidly improving productive zones, such as Brazil, Colombia, and Costa Rica, glutted the coffee market and moderated prices in the early nineteenth century. The limited profitability of coffee in Cuba restricting the availability of credit extension to Cuban cafetal owners. Cuban coffee production suffered further as a result of the massive hurricanes of 1844 and 1846 and never fully recovered; the tall old-growth trees, providing the necessary shade for coffee cultivation and the coffee bushes themselves (needing 3-7 years to reach maturity), already under pressure from human deforestation for cane land and fuel wood, lay worthlessly ripped from the earth. The patience, time, and expense needed for replantation was not available. As a result, many cafetal owners sold their land and walked away. The production value of coffee fell from $\$ 80$ million in 1829 to half that in 1849 . The number of cafetales declined by more than $60 \%$ to 782 in 1861. The export weight of coffee fell from a high of 2.5 million arrobas (25 pound units) in

challenges to established order. Banditry was a quintessential peasant response to encroaching modernization, in the form of the growth of the sugar industry, and that banditry's principal protagonists were Canarian immigrants who became sitieros or small farmers producing subsistence crops, and whose world was threatened by the new sugar plantations. Manuel Paz Sanchez, El Bandolerismo en Cuba, 1800-1933 (Tenerife: Centro de la Cultura Popular Canaria, 1993) focuses his first volume on the earlier period. And interesting resource on cholera in Cuba is the mistakenly discovered Cólera 1833 by José Leopoldo Yarini Klupffel. The manuscript, found serendipitously in 1995, highlights the substantial toll taken on slaves of the Guamacaro valley, Matanzas in 1833. He describes the conditions and suffering of the population in the area and the attempts to stem the tide of death. Klupffel, Cólera 1833, accessed June 26, 2011, http://en.wikiversity.org/wiki/C\%C3\%B3lera_en_el_Ingenio. 
1833 to only 154,000 by $1867 .{ }^{157}$ Richard Henry Dana summed up the condition of island in

1859 as he looked back over the previous 15 years.

The successive disastrous hurricanes of 1843 and 1845, which destroyed many and damaged most of the coffee estates, added to the colonial system of the mother-country, which did not give extraordinary protection to this product, are commonly said to have put an end to the coffee plantations. Probably, they only hastened a change which must at some time have come. But the same causes of soil and climate which made Cuba inferior in coffee-growing, gave her a marked superiority in the cultivation of sugar. The damaged plantations were not restored as coffee estates, but were laid down to the sugar-cane; and gradually, first in the western and northern parts, and daily extending easterly and southerly over the entire island, the exquisite cafetales have been prostrated and dismantled, the groves of shade and fruit trees cut down, the avenues and footpaths ploughed up, and the denuded land laid down to wastes of sugar-cane. ${ }^{158}$

Land-rich cattle ranches, whose owners were far less economically and politically well-

connected, fared little better that their coffee farming brethren, with the poor white and black

populations of the island suffering worst of all. ${ }^{159}$ W.M.L. Jay related the voracious appetite of

sugar planters and the effects upon the Cuban landscape.

${ }^{157}$ M.R. Trouillot, "Coffee Planters and Coffee Slaves in the Antilles: The Impact of a Secondary Crop," in Cultivation and Culture: Labor and the Shaping of Slave Life in the Americas, ed. Ira Berlin (Charlottesville: University of Virginia Press, 1995), 124-137; Doria González Fernández, "La Economía Cafetalera Cubana: 17601860," Arbor 547-548 (1991), 161-179; Steven Topik, "The World Coffee Market in the Eighteenth And Nineteenth Centuries, from Colonial To National Regimes," (presented to GEHN Conference, London, England, September 2003); Bergad, Cuban Rural Society in the Nineteenth Century: the Social and Economic History of Monoculture in Matanzas, ch. 2; Rafael de Bivar Marquese, "African Diaspora, Slavery, and the Paraiba Valley Coffee Plantation Landscape: Nineteenth-Century Brazil," Review: A Journal of the Fernand Braudel Center 31, no. 2 (2008), 195215. Cuba's coffee economy largely developed from the efforts of transplanted French exiles from Haiti escaping from the Haitian Revolution. Coffee was produced primarily in the hilly and mountainous regions of both eastern and western Cuba with Havana, Matanzas, and Piñar del Rio enjoying the most success and wealth by the early nineteenth century. Through the 1830s, the investments in coffee production in western Cuba were equal to those in sugar, and the number of enslaved workers on cafetales roughly equal to those on the ingenios. While often overlooked, coffee was an important component of the development of the plantation slavery of Cuba. While the boom was strong it was short lived and involved far fewer producers that sugar. Particularly devastating, beyond competition, was a tariff war between the United States and Spain, with both countries raising retaliatory tariff rates. The U.S. doubling of the tariff on Cuban coffee weakened an already bloated market for the Cubans. Javier Pérez de la Rive, El Café: Historia de su Cultivo y Explotacion en Cuba (Havana: Jesús Montrero, 1944). Natural disasters finished off the downfall by the early 1840s. On hurricanes and the effect of climate on Cuban agriculture see, Louis Perez, Winds of Change: Hurricanes and the Transformation of Nineteenth-Century Cuba (Chapel Hill: University of North Carolina Press, 2001). On the larger effect of climate on Cuban commerce see Sherry Johnson, Climate and Catastrophe in Cuba and the Atlantic World in the Age of Revolution (Chapel Hill: University of North Carolina Press, 2011).

${ }^{158}$ Richard Henry Dana, To Cuba And Back: A Vacation Voyage (Boston: Houghton \& Mifflin, 1859), 99.

${ }^{159}$ Charles Julian Bishko, "The Peninsular Background of Latin American Cattle Ranching," The Hispanic American Historical Review 32, no. 4 (November 1952), 491-515; Fernando Díaz del Olmo, "Hatos Caribeños Y Dehesas Andaluzas: Paisaje Y Estructura Parcelaria," in Cuba y Andalucía Entre Las Dos Orillas, ed. Jesús Raúl 
The coffee-culture, however, is fast declining in Cuba, on account of the little encouragement it receives from the Home Government, the successful competition of Brazil and the French Antilles, and the greater profits of sugar-making. Year by year, therefore, these lovely gardens and groves are cleared, and transformed, as far as the nature of the ground will admit, into a vast monotony of sun-steeped cane-fields. For the cane loves sun, not shade, and wherever it appears, the trees fall, except in the few palm-avenues which are retained for boundaries and roadways, and the shade trees of the casa de vivienda. ${ }^{160}$

Cubans did not solely lose once thriving industries and landscapes, the sugar ingenios

also wreaked havoc on what had been a relatively stable social and cultural landscape of the eighteenth and early nineteenth centuries. Smaller producers with guaranteed markets in Madrid and dependable, if small, profits accumulating yearly, had little incentive toward political agitation and even less motivation in amending a cultural organization that codified their various positions. This calculus changed as sugar expanded across the island. The actions of Arango and his coterie in Havana demonstrated to many on the island that the sugar bosses sought a greater stake in the political life of the island, one that complemented their growing economic influence. However, this growing elite was not equally spread across the island. While sugar expanded into the west of the island, coffee held sway in the east around towns such as Holguín, Bayamo, Guantánamo and Santiago (containing the highest percentage of French émigrés) well into the 1830s. Havana and locales west were the stronghold of the sucrocracy, the center of the industrial and infrastructural improvements under way, and the locus of political power on the island. Western Cuba by 1840 boasted more sugar mills of larger size and greater technological development than the rest of the island and much of the rest of the Western Hemisphere. ${ }^{161}$

\footnotetext{
Navarro Garcia (Seville: Consejo Superior De Investigaciones Cientificas Escuela De Estudios HispanoAmericanos, 2002), 303-333; Alexader von Humboldt, The Island of Cuba, trans. J.M. Thrasher (New York: Derby \& Sons, 1856), ch. 9 .

${ }^{160}$ W.M.L. Jay, My Winter In Cuba (New York: E. P. Button \& Co, 1871), 259-260.

${ }^{161}$ Between 1778 and 1846, the number of sugar mills in Cuba increased from 424 to 1,442. Of that total, 1,065 sat in western Cuba (the 'west' of Cuba encompassed three major sugar cultivating regions with Sancti Spíritus being the eastern most dividing line: 1) The northwestern coast including Havana, Bahía Honda, Matanzas, Pinar del Río inland to Guanajay, Güines and Aacranes, (2) The north-central coastal cities of Matanzas, Cárdenas, Sague la Grande, with Jovellanos and Colón further inland, (3) The south-central coastal cities of Cienfuegos and Trinidad
} 
As the inexorable march toward sugar's dominance continued throughout the 1830 s and 1840s, the relationship Cuba held with the rest of the world gradually shifted as well. The rise of sugar export and the rush to capitalize on its profit fundamentally altered the Cuban economy from one traditionally dependent on small producers and subsistence farmers, able to meet the demands of consumption, toward an export economy dependent on one crop and increasingly one market for purchase and provision. The result of this slow but unalterable change was Cuba's increased dependence on importation of food and fuel from the United States. By 1860, $74 \%$ of the Cuban export market was sugar with almost $50 \%$ of the export (by 1845) going to the United States. In exchange, the United States provided a plethora of foodstuffs and fuel sources to the island, with beef, flour, and lumber accounting for the most voluminous trade. The biggest result of this new trading partnership was a fundamental change in the commercial direction of Cuba. In the first five decades of the nineteenth century, Cuban commercial relations increasingly centered on trade with the United States to an almost complete exclusion of the island's imperial leader. By 1870, Spain accounted for only $6 \%$ of Cuba's total exports. The United States, unlike distant Spain, presented itself as a perfect market for Cubans; the new nation was close by with an active merchant marine, an expanding population, skyrocketing demand, and an impressively growing economy. The historical intimacy between the United States and Cuban bolstered the preference for American trade and did much to encourage the transition to Cuban mono-agricultural production.

stretching inland to Santa Clara, Sancti Spíritus and Camagüey). Double the amount of mills in the West enjoyed the use of steam power than in the East (80\%). The amount of land under sugar cultivation in the West was 12 times that of the East (640,000/50,000 acres). On average the West produced 460,000 tons of sugar per year (433 tons per mill on average) compared with only a 46,000 ton average (155 per mill) in the East. The West accounted for about $90 \%$ of all Cuban production by 1845. Perez, Between Reform and Revolution, 60-65. 
American merchants and producers, notably the major trading houses in Philadelphia, Baltimore, and New York, long-courted the Cuban market and enjoyed fruitful relationships thanks to the presence of American mercantile agents in Havana. While the local and imperial authorities bristled at their presence, going so far as to bar them at some moments, this conduit of trade provided by face to face conversations and deal-making kept the courtship warm even as Spain occasionally sought closer ties with the island. Spanish concerns about the coziness of the United States/Cuban relationship eventually materialized. The Americans provided slaves and manufactured goods in greater number and at lower prices than the mainland could offer. Americans, trading illegally or otherwise, accepted credit agreements (sometimes molasses and sugar became bartered payment) more gladly than their Spanish counterparts and lured Cuban planters to the American market. The always-tumultuous Spain political situation also convinced the Cuban creole elite that Spain and its markets were a poor bet and that the American market, with its greater stability and consistency of demand, was worth even substantial legal risk. ${ }^{162}$

The presence of the United States and the security that its import/export markets offered drove Cubans to an increasingly clear conclusion - Cuban sugar production could be expanded at the expense of subsistence production because the United States export market would always provide in times of natural or imperial commodity shortage. Ultimately, Cuban agriculturalists realized that it was cheaper to rely on food imports for the domestic market that to cut or limit sugar production for the foreign market. Cuban planters resented the encroachment on their lands and their profits by a growing population fueled by the arrival of French immigrants from Haiti

\footnotetext{
162 Roberta Wakefield, “Some Factors in Cuba's Foreign Trade," Economic Geography 13, no. 2 (1937), 109-131; Robert E. Lipsey, "U.S. Foreign Trade and the Balance of Payments, 1800-1913," in Cambridge Economic History of the United States, Vol. II, eds. Stanley Engerman and Robert Gallman (New York: Cambridge University Press, 2000), 685-732; John H. Coatsworth, "American Trade with European Colonies in the Caribbean and South America, 1790-1812," The William and Mary Quarterly 24, no. 2 (April 1967), 243-266; Louis Pérez, Cuba and the United States: Ties of Singular Intimacy (Athens: University of Georgia Press, 2003) chs. 1-2.
} 
and loyalists from the South American mainland - to say nothing of the tens of thousands of slaves requiring provision. To counter the demands that might be placed on them to open up or convert land for food production, Cuban planters made the conscious and cost-effective decision to offshore their domestic provisioning. The United States provided Cuba a purchase market for industrial and consumer supplies that was close, cheap, and secure; and so the calculation came to pass, the number of ships arriving in Cuban ports rose from 150 in 1796 to 1,886 in 1852 .

Ships provisioned in the major trading port cities of the United States brought all shape and size of life's necessities to the Cuban people along with the chief requirement of sugar production, slaves. In return, these ships left Havana and smaller Cuban ports loaded with the once-exotic trappings of aristocratic life - coffee, tobacco, molasses, and sugar - now quickly normalizing among all classes in the exploding United States and European markets. The calculation seemed to work and heralded a new era of Cuban prosperity. Cuban sugar production had the requisite supply system for expansion and the capitalistic energy to make that expansion happen. However, if the wake of the economic decisions the creole elite made, notably the reliance on food importation, social changes and political bickering threatened the delicate equilibrium. The importance of Spain in Cuban economic and social life was in precipitous decline, emboldening creole demands for greater autonomy while simultaneously firing Spanish designs at pulling the island's orbit close to the metropolis once again. Yet, Spain offered Cuban producers neither adequate markets nor sufficient supplies. With the United States able to do both of these things and with Cuban producers more than willing to turn to their northern neighbor, the island's needs and desires grew ever more distinct and divergent from those of Spain. ${ }^{163}$

\footnotetext{
${ }^{163}$ Linda Salvucci and Richard Salvucci, "Cuba and the Latin American Terms of Trade: Old Theories, New Evidence,” Journal of Interdisciplinary History, Vol. 31, no. 2 (Autumn 2000), 197-222. The Salvucci's very
} 
The obstructionist attitude Spain held toward United States/Cuba trade was of constant annoyance to leading Cuban entrepreneurs and remained a main source of political agitation in Havana's elite circles. By the 1840s, the Cuban elite drew the conclusion that their full productive potential could not be reached within the Spanish imperial system. Not surprisingly, as Spain became more and more superfluous to the Cuban elite, the Crown clung more and more tenaciously to their position as the gatekeeper of Cuban trade. The tool the Spanish government used to enforce their control was the tariff. The government's attempt to force Cuban producers to purchase Spanish supplies and use Spanish carriers was at its most bald in the extreme disequilibrium between domestic and foreign tariff rates. A series of tariff laws set the $a d$ valorem rates for foreign products carried by foreign shippers at $29-35 \%$ versus $21-25 \%$ on Spanish carriers. The rate difference on peninsular products carried by foreign ships compared with peninsular products carried by Spanish ships was just as stark, $19 \%$ versus $6 \%$. Adding to Cubans' frustrations was the woeful lack of Spanish peninsular goods that in turn necessitated the dominance of highly taxed foreign goods entering the colony on foreign carriers. To most Cubans and particularly the elite, the goals of the Spanish government were clear: raise revenue; increase remittances; transfer local profits; and gather all surplus revenues. The economic imperatives of sugar production and the resulting prioritization of export production over local consumption forced Cubans of all social classes to pay greatly elevated prices for necessities while hurting profits for producers. The higher prices for necessities and the detrimental effect of regressive taxation hurt the poor most profoundly as they lacked the land to provide for

detailed evaluation of Cuba's Net Barter Terms of Trade (NBTT) indicates statistically the almost complete dependence Cuba had on the United States and Great Britain for imports. The ratio of an index of export prices to an index of import prices shows that Cuba lost $50 \%$ of its export value over 60 years, beginning in 1826. Therefore, while Cuba exported almost $60 \%$ of the world's sugar by the $1860 \mathrm{~s}$, the cost of importation limited a wider distribution and enjoyment of material wealth, with the middle and lower classes dependent on and hurt by importation and urban price setting. 
themselves and the money to purchase the higher priced imports. The poor decried the lack of domestic alternatives and the Havana oligarchy decried the massive drain on the Cuban economy. ${ }^{164}$

Added to the economic morass of the Spanish tariff structure and complicating the fastevolving social dynamic of the island was the massive increase in Cuba's population. Between 1791 (the year of the island's first census) and 1817 the population doubled to 553,033, doubling again by 1862 to $1,396,470 .{ }^{165}$ The increases provided ample opportunities for conflict and concern among the Cuban population and Spanish authorities. The high percentage of AfroCubans (enslaved and free) encouraged the Spanish government, with the support of elite Cubans, to pursue systematic policies designed to increase white immigration to the island. However, it was not just skin color that left many with deep concern. The issue of socioeconomic class divisions, created and exacerbated by the sugar revolution, also threatened the island's stability and became a source of anxiety, often serving to unify the creole and peninsular elite. The creation of new social classes and the reformulation of old relationships came as a result of and produced continuing profound political and psychological changes.

The nineteenth century expansion of sugar and the economic juggernaut unleashed on the island forced a reconceptualization of social class and inexorably changed older personal and communal relationships. These changes portended equally profound changes in the psychological stability of the island. The pace of political change lagged far behind desperately

\footnotetext{
${ }^{164}$ Juan B. Amores, "La Renta del Tabaco en Cuba a Finales del siglo XVIII," in Tabaco Y Economía En El Siglo XVIII, eds. Agustín González Enciso y R.Torres Sánchez (Pamplona: Eunsa, 1999), 123-137; Thomas, Cuba, 128135.

${ }^{165}$ Perez, Reform to Revolution, 64 (Table 4.1). The percentage of slaves in the population reached its highest point in $1827(40 \%)$ declining to $28 \%$ by 1862 due to mortality and the decline of the trade. The percentage of free AfroCubans hovered around $20 \%$ throughout much of the early $19^{\text {th }}$ century with an unknown number of those who had fled into the maroon communities of the central mountains not counted. The combined percentage of slaves and free people of color reached its highest percentage in 1827 (56\%). Alfonso González, "The Population of Cuba," Caribbean Studies 11, no. 2 (July 1971), 74-84.
} 
need adaptations demanded by Cuba's new reality. Throughout the island, whites, whether peninsulare or criollo, proclaimed themselves innately superior to blacks, whether free or enslaved. This clear racial dividing line, the central ideological formulation of the Cuban elite, fell less clearly between whites and blacks of the lower sorts who mingled, married, and dealt economically among themselves with a familiarity that necessitated different, less antagonistic, racial articulations. Still, the stark racial dichotomy of Cuban life gave the middle and upper classes an imperative upon which to build a political and economic exclusiveness. However, this exclusivity was neither the ironclad unifying force it might at first appear nor was it equally beneficial for all those who espoused its tenets.

While racial division allowed elite whites to agree upon their superiority, this division did little to mediate the increasingly rancorous debate taking place among the intricately subdivided producer, merchant, and administrative classes - to these debates must also be added the issues of birthplace and familial blood. Whites generally monopolized church, government, and military jobs with those who owned property able to establish themselves near the top of the political/economic pyramid. However, this ruling elite was not as unified as their skin color might indicate. Three distinct groups, divided by issues of property and politics, made up the ruling class. Creole elites made up the most of the island's proprietors and an overwhelming majority of sugar planters, coffee farmers, ranchers, tobacco farmers, and mine owners. These hacendados controlled the majority of the island's slaves and white laborers and served as landlords to a large-percentage of small producers. However, their power was not unlimited and severely impinged in the areas most necessary to their ascension up the social hierarchy. Cuban hacendados found themselves situated between and largely dependent on the colonial bureaucracy and the mercantile community, both groups made up almost-exclusively of 
peninsulares. This was a difficult spot to reside in given the bombast with which the planters extolled their lofty positioning. The emasculating effect of the creole elite's dependence upon the bureaucracy for political order and social stability along with a similar dependence upon merchants for provisions, loans, transport, and marketing was one of the main sources of friction prompting the unified efforts of creole organization led by Arango beginning in the late 1790s.

These relationships were not completely one-sided as the merchants relied upon the landowners for the commerce that gave them their livelihoods and the colonial bureaucrats relied on the combined efforts of owners and merchants for tax and land revenues as well as tariffs and port charges. This mutual dependence produced an atmosphere in the early decades of the nineteenth century of suspicion and tension mitigated only by the defense of sugar production and slavery; the foundation upon which rested their shared property, protection, prosperity, and privilege. Planters stuck in this debt cycle complained that merchants, by controlling credit, cut deeply into their profits. Conversely, merchants, enjoying the dually insulated positions of distributors and moneylenders, had little incentive to shift their operations or push for more fundamental changes in the Spanish colonial system. Interest rates far outpacing usury levels were not uncommon; a condition that dried up credit for all except the wealthiest of landowners. Many planters complained about the disruptive and perhaps anti-patriotic role merchants played in Cuba. The increasingly vitriolic clash of competing economic positions and ideologies only exacerbated political tensions between the colony and metropole. Regardless of the tensions, Spain enjoyed the increased riches pouring into its coffers as a result of their restrictive trade and taxation policies. This income, particularly welcomed in the wake of colonial loses in South America, became an ever-growing percentage of royal income. Cuba's lucrative administrative positions, passed out as favors to important royal allies, further strengthen resistance to creole 
demands. Dependence on royal patronage placed most colonial officials in Cuba in a position that eschewed disloyalty and reform. ${ }^{166}$

Within this tightly wound and interconnected world came inevitable conflict born from the overlapping interests of self and group. Public administration and mercantile interests, areas systematically and purposefully made off limits to creoles, colluded to produce a trade and governance environment that reinforced and protected peninsular control of the main levers of the economic machine. Colonial bureaucrats, with the full force of the crown behind them, designed government policy and taxation regimes that favored Cuba's peninsular merchants. These interests, fattened by colonial strictures, reciprocated by defending both the economic structure of Spanish administration and the underlying propriety of Spanish rule. Merchants aspired to complete control of the economic flow of the island, while bureaucrats jealously guarded the apparatuses that also guaranteed their aspirations. ${ }^{167}$

The gulf between Cuban producers and the mercantile/bureaucratic cabal only grew wider as a result of the increasing sums of money at stake throughout the nineteenth century. Creole producers demanded freer trade while peninsulares defended Spanish monopoly. As the

\footnotetext{
166 The merchant-planter nexus is well established in the existing literature. See Manuel Moreno Fraginals, El Ingenio: Complejo Económico Social Cubano Del Azúcar, 3 vols. (Havana: Editorial de Ciencias Sociales, 1978); Peter J. Lampros, "Merchant-Planter Cooperation and Conflict: The Havana Consulado, 1794-1832" (PhD diss., Tulane University, 1980); Franklin W Knight, Slave Society in Cuba During the Nineteenth Century (Madison: University of Wisconsin Press, 1970), 14-18, and "Origins of Wealth and the Sugar Revolution in Cuba, 17501850," Hispanic American History Review 57, no. 2 (May 1977), 231-53. See also Linda K. Salvucci, “Anglo American Merchants and Stratagems for Success in Spanish Imperial Markets, 1783-1807," in The North American Role in the Spanish Imperial Economy, 1764-1819, eds. Jacques A. Barbier and Allan J. Kuethe (Manchester: Manchester University Press, 1984), 127-33.

${ }^{167}$ Even an amenable Captain-General such as Luis de Las Casas y Aragorri, who gave his blessing to Arango and the Havana group's efforts, was sure to limit his acquiescence to a limited organization that allowed rationalization of efforts in hopes of raising production and output without offering any promise of greater political voice. And with the relatively quick turnover of Captain Generals in the late $18^{\text {th }}$ and early $19^{\text {th }}$ centuries, any significant action on the part of emboldened creole planters could be quickly suffocated with a more imposing colonial administration, which is precisely what happened in 1796 with the replacement of las Casas by Juan Procopio de Bassecourt y Bryas. The early turnover of Captain Generals and de Las Casas' impact on the position is handled in Dolores González-Ripoll Navarro, Cuba, La Isla De Los Ensayos: Cultura y Sociedad 1790-1815 (Madrid: Consejo Superior De Investigaciones Cientificas Escuela De Estudios Hispano-Americanos, 1999), 79-99.
} 
island shifted to sugar monoculture and became dependent on foreign-produced goods and foodstuffs, merchants located in Havana and other urban centers enjoyed the lion's share of their profits from the control of import flows rather than sugar exportation. Thus, these merchants had no vested interest in lower tariff rates or reduced port taxes. They simply passed their costs onto consumers in a way that producers could not, depending as they did on exportation for profit. Cuban producers resented Spanish imperial and mercantile interests' singular determination to monopolize bureaucratic administration and private trade. The growing class-solidarity of the hacendados drove their demands for greater control over resources, commerce, and public offices. They sought political and economic concessions from the crown not only as a matter of survival but also as a natural right. As interactions with the free markets of Britain, the United States, and the new South American republics increased, Cuban producers became more aware of how backward the system they labored under was in comparison to the wider Atlantic world. The deep interconnection with United States markets generally, and the individual experiences with Americans on the island and in the United States more personally, added fuel to the fires of liberalization. Alexander Humboldt related the struggle among the upper classes of Cuba during his travels in 1820.

The extraordinary expenditures required by the large sugar plantations, and the frequent domestic misfortunes caused by play, luxury, and other evils, place the landed proprietors in a state of absolute dependence upon the merchants. The most frequent loans are those made to the planters, upon condition of repayment from his crop of sugar, or coffee...Thus a crop of one thousand boxes of sugar is sold in anticipation, at a loss of $\$ 4,000$. The demand for money for business transactions, and the scarcity of coin, is so great that the government at times is forced to borrow at ten per cent, and individuals at even twelve and sixteen per cent interest. The great profits made in the African slave-trade, sometimes amounting on a single voyage in Cuba to 100 or 125 per cent, have contributed to increase the rate of interest. ${ }^{168}$

${ }^{168}$ Alexander von Humboldt, Ensayo Politico Sobre La Isla De Cuba (La Habana, Cultural S.A., 1959), $280-281$. 
The tensions felt among the elite reaches of Cuba society made their way downward throughout the island's entire social structure. A small, hearty, and slightly growing middle class also found the peninsular presence odious and meddlesome. The Cuban petit bourgeoisie largely came from salaried professionals, small mill owners, tobacco growers, cattlemen, and coffee producers. These actors, present on the island and in their economic statuses for generations, grew increasingly skeptical and annoyed both at the great influx of mainland South American peninsulares arriving in the wake of the republican revolutions and the waves of Spaniards leaving the Iberian peninsula for better political and economic conditions in Cuba. Cubans sensed correctly that their opportunities as small producers and working professionals would soon be under siege from South American opportunists with better blood lines and heightened expectations of repayment for their loyalties during the revolts. Immigration in the wake of the Haitian revolution also placed a great deal of pressure, particularly in the coffee industry, on small producers who lacked the same economic and labor resources of the French émigrés as well as holding severe disadvantages in agricultural knowledge compared to their French compatriots. These arrivals of economically more secure and politically more conservative elements only served to reinforce the vigorous policing of opportunities available to creoles. New immigrants' experiences with instability and revolt in various settings did not place them in a convivial or compromising mood, seeing as how from their perspective, even slight reform, like that attempted in South America, opened the door to widespread devastation. ${ }^{169}$

However, while the anger of the middle class might have pushed them into greater league with their creole kin higher up the food chain, in fact, their frustration with the colonial structure placed them at odds with the creole planter class who they increasingly saw as implicated along

${ }^{169}$ William Lux, "French Colonization in Cuba, 1791-1809," The Americas 29, no. 1 (July 1972), 57-62. 
with the peninsular administrators. Middle class Cubans saw in the creole elite both a condescending attitude toward the worth of smaller producers and a simultaneous collusion with Spanish authorities, particularly as sugar moved toward dominance and business dealings between the two creole classes grew more antagonistic. Despite elite creole political agitation, smaller producers viewed their interests as opposed to those who had more wealth with which to navigate the excessive taxation regime and to stomach ever-rising domestic commodity prices. Furthermore, the elite's demands for political power were consciously directed toward their own benefits and not toward a general betterment of Cuban standard of living. The defense of the Spanish colonial system for limited benefit was seen most clearly in the creole elite's defense of slavery and the necessity of the military power of the crown to keep revolt at bay. For smaller producers, slavery was of limited practical value, yet they lived with the same fear of race revolt as did the larger producers and Spanish officials who benefited from slavery as a tangible moneymaking enterprise. The scarcity of hard-money, high level of interest-rates, and social implications that the trade in slaves encouraged hurt smaller producers who scrambled to keep their capital liquid and their farms afloat. The psychological wage that white supremacy paid was much more of an abstraction for the middle class producer than it was for the elite. The bourgeois remained doubtful of the elite's availability in protecting a more general sense of wellbeing on the island, particularly when that elite's well-being, their power, and their privilege was imbricated in the continuance of slavery. ${ }^{170}$

Growing numbers of smaller farmers, urban artisans, lover-level civil servants, lessersalaried employees, and unskilled laborers joined the gently rising middle class creoles in voicing their frustration with the direction of island's affairs. The lower classes found themselves

\footnotetext{
${ }^{170}$ Alfonso W. Quiroz, "Implicit Costs of Empire: Bureaucratic Corruption in Nineteenth-Century Cuba," Journal of Latin American Studies 35, no. 3 (August 2003), 473-511.
} 
locked out of loans offered at much higher rates that the already usury level of those offered to bigger producers. Peninsulare political dominance also prevented the lower sorts from even competing for lower-status bureaucratic positions. This lower class of Cubans also stood similarly dependent on exorbitantly-priced imports for basic necessities (although somewhat better positioned than the middle class who had no subsistence capacity), a reality that took a great economic toll on their lives. Their complaints were representative of the larger issues affecting other classes and they met the situation with a similarly voiced critique of the island's creole and peninsular elite. Complicating the economic issues was a much more fraught social setting, as the Cuban's lower classes found the color line not as clearly drawn in their daily lives. In response, they had a greater comfort with the AfroCuban population of the island, born out of economic necessity, which further separated them from the elite. This interaction slightly altered the lower class' racial perspectives from those of the middle class, and drove them toward an even bolder critique of slavery. They saw in the institution both a challenge to their economic positioning as well as a disruptive force in their personal lives. ${ }^{171}$

Yet, elite creoles stopped short of incorporating the powerful concerns of the lower classes in their reform designs. Elite frustrations with the status quo did not produce threats to stability that sought to rework the prevailing social order. Rather, these efforts at reform centered on economic access and equality that sought preservation of the island's racial organization while simultaneously undermining the antiquated political organization imposed by the increasingly anti-capitalist Spanish empire. For creole elites there existed two levels of stability. First, a social organization they enjoyed and sought to protect; and second, an economic/political organization they sought to invert, while accepting Spanish military presence as long as colonial

\footnotetext{
${ }^{171}$ Sherry Johnson, "The Rise and Fall of Creole Participation in the Cuban Slave Trade, 1789-1796," Cuban Studies 30 (2000), 52-78.
} 
structures continued to operate in protection of the prized social stability. In all of these discussions, the specter of Haiti loomed large and could not be allowed to repeat itself in Cuba. Producers, bureaucrats, merchants, and the majority of elite whites sought refuge in the social organization that kept slaves controlled by any means available. Even the most outspoken proponents of greater political freedom self-regulated and limited the grandiosity of their proposals with the fear of race revolution squarely in the center of their minds. Spanish colonial dominance was preferable to their fields aflame and their lives taken. ${ }^{172}$

These were the contours of the debate over which Cuba's future solidified. In the wake of the South American Wars of Independence, Spain moved to bind Cuba closer to its economic and political interests. The crown was in an advantageous position to successfully accomplish this task. The sentiment toward independence on the island was neither particularly strong nor plausible; the island having been fortified and militarized as a base of operations during the Bolívarian wars. This reality should not be surprising in the wake of massive loyalist immigration from Mexico and South America. The pro-imperial peninsular element, arriving with wealth and political connections, did much to drown out the still inarticulate demands of the creole elite. The Spanish administration, with its strengthen hand, made some limited efforts at economic reform in hopes of quelling unrest. Ironically, while the creole elite demanded policies to protect their interests and the bureaucratic positions to implement those policies, the American physical presence on the island and its involvement in the economic life of every Cuban steadily grew. The familiarity the United States and Cuba had with each other placed both in a tenuous position. Beyond the philosophical affinity the United States held for Cuba, the profound economic dependence the island had on the United States strengthened the American role in the

${ }^{172}$ Jose Guadalupe Ortega, "The Cuba Sugar Complex in the Age of Revolution," (PhD diss., UCLA, 2007). 
colony's affairs. However, the problem remained that Cuba was Spanish. As Alexander von Humboldt noted,

Nowhere [in all Spanish America] has been better known European politics and springs that are set in motion to support or bring down a ministry than in Havana. This knowledge of the events and the forecast of the future have served effectively to the inhabitants of the island of Cuba to get rid of the barriers that stop improvements in colonial prosperity. In the interval of time that has occurred since the peace Versailles until the beginning of the revolution in Santo Domingo, Havana seemed ten times closer to Spain than Mexico, Caracas and New Grenada. ${ }^{173}$

Humboldt viewed Cuba as the link between the Americas and Europe, a cultivated area in comparison to the new countries of South America that existed in suspended animation between province, colony, and nation. ${ }^{174}$ Disappointingly, the excitement of cultural building felt by elite Cubans was matched by an intractable disinterest and lack of acceptance among Europeans of these Cuban elite attempts at distinction. As much effort as Arango and others put into debating Cuba's future was as little time as Europeans put into valuation of their efforts. Like Cuba, the United States shared a similarly rejected culture. The new nation was not invited into the European universe and, like Cuba, toiled under the yoke of aspirational rejection and cultural condescension. However, there were also important positive binding aspects that both societies shared which facilitated a continued warm relationship; above and beyond all of these aspects was the simple ethos of accumulation. As Father Felix Varela, exiled in the United States, opined of Cuba in 1824, "It is essential not to make a mistake; in the island of Cuba there is no love for Spain, nor for Colombia, nor for México, nor for anything else but boxes of sugar and bags of coffee." Alexis de Tocqueville ably rejoined regarding the United States, "I know of no country, indeed, where the love of money has taken stronger hold on the affections of men, and where the profounder contempt is expressed for the theory of the permanent equality of property." The two

\footnotetext{
173 Alexander von Humboldt, Ensayo Politico, 202.

${ }^{174}$ Oliver Lubrich, "In the Realm of Ambivalence: Alexander von Humboldt's Discourse on Cuba," German Studies Review 26, no. 1 (February 2003), 63-80.
} 
peoples shared a love of profit, yet there still remained the issue of slavery and the delicate negotiation between free trade liberal capitalism and the moral imperative of abolition. ${ }^{175}$

Eventually, the building of great wealth and the control of great swaths of land encouraged the slow unmooring of the creole sugar elite from the society around them. These planters evolved their thinking to a position where they believed themselves to be no longer dependent on Cuban society for their position. Rather, these hacendados saw their performance in the web of Atlantic capitalism as the source of their power and prestige. The creole elite's defense of privilege forced a defense of slavery and with it came rationalization of their economic and social excess that produced self-inflicted myopia. Their political demands, social organizing, and economic dominance discouraged egalitarianism and produced an insular, paranoid, and unsettled society that habitually teetered on the edge of collapse. The Cuban elite failed at gaining its political voice because they failed to harness any revolutionary fervor among the masses, instead preferring them uninspired, fearful, and dependent. This situation, the seething resentment of all sides toward the others, became the motivation for the great debate over slavery and Cubanidad that captivated Cubans into the 1840s.

\footnotetext{
${ }^{175}$ Father Felix Varela, "Consideraciones Sobre El Estado Actual De La Isla De Cuba,” in Felix Varela: Obras, Vol. II (Havana: Editorial Cultura Popular, 2001), 154; and Alexis de Tocqueville, Democracy in America, accessed May 25, 2012, http://xroads.virginia.edu/ HYPER/DETOC/1_ch03.htm
} 
Chapter Three: The Intellectual Framework and Popular Contours of Annexation

We stand upon the brink of a precipice. We peer into the abyss - we grow sick and dizzy. Our first impulse is to shrink from the danger. Unaccountably we remain. By slow degrees our sickness and dizziness and horror become merged in a cloud of unnamable feeling. By gradations, still more imperceptible, this cloud assumes shape, as did the vapor from the bottle out of which arose the genius in the Arabian Nights. But out of this our cloud upon the precipice's edge, there grows into palpability, a shape, far more terrible than any genius or any demon of a tale, and yet it is but a thought, although a fearful one, and one which chills the very marrow of our bones with the fierceness of the delight of its horror. It is merely the idea of what would be our sensations during the sweeping precipitancy of a fall from such a height. And this fall- this rushing annihilation - for the very reason that it involves that one most ghastly and loathsome of all the most ghastly and loathsome images of death and suffering which have ever presented themselves to our imagination for this very cause do we now the most vividly desire it. And because our reason violently deters us from the brink, therefore do we the most impetuously approach it. There is no passion in nature so demoniacally impatient, as that of him who, shuddering upon the edge of a precipice, thus meditates a Plunge. To indulge, for a moment, in any attempt at thought, is to be inevitably lost; for reflection but urges us to forbear, and therefore it is, I say, that we cannot. If there be no friendly arm to check us, or if we fail in a sudden effort to prostrate ourselves backward from the abyss, we plunge, and are destroyed.

The Imp of the Perverse - Edgar Allan Poe 1845

For a two year period, Narciso López was undoubtedly one of the most popular human

beings in the United States, if not the western hemisphere. The concluding chapters of this study

focus on López's role in the Cuba annexation performance at its highest and most cohesive point

(1848-1853) as well as the sectional turn and failure of annexation after 1854. The development of a joint effort toward annexation unified an impressive swath of Americans with Cuban elites both in the United States and on the island. The present chapter reviews the social, economic, and, intellectual developments from Cuban and American sources that drove the groundswell of American support for the annexation cause. Cuban annexation rested at a unique intersection between the rise in popularity of easily consumable literature, the growth of nationalistic themes in that same literature, the rise of international market capitalism, and Americans' centering of the United States as the hearth of democratic republicanism in response to the failure of the European revolutions of 1848. Annexation of Cuba, as war with Mexico before it, fueled and 
was fueled by the rise of a profoundly expansionistic literature that engaged a voracious reading public in policy debate hitherto unseen in American society. Those producing this literary onslaught appreciated the transmissibility of their ideas on a once unimaginable level and sought to use a variety of new publishing mediums to guide public opinion in a massive and definitive way. The literature also took a predictably laudatory tone as Americans set their political and social experiment apart from the failures on display throughout the world, most notably in the quick collapse of various European revolutions. The annexation of Cuba became a demonstration of a unique American selflessness. American exceptionalism coupled with the dream of annexation offered a new outlet for masculinity in response to the dislocations brought on by the rising market economy. Annexation was also the first step in an American attempt at the perfecting of hemispheric democracy. This desire to perfect democracy abroad played itself out in domestic politics as well with Young American activists pushing the government toward land reform, appropriations for technological improvements, anti-corruption, and increasing civil servant competence.

Tales from the battlefields of Mexico and the Southwest, peppered with the adventuring spirit of men seeking their fortune, captured the imagination and support of a vast new readership. This hagiography combined with López's mustachioed charisma were the factors necessary for the creation of a public relations juggernaut. A generational divide emerged as well, with many younger Americans across the political spectrum seeking the reinvigoration of a republicanism built on the bedrock of territorial expansion, democratic participation, economic interdependency, and the avoidance of the slavery issue. This loose faction of journalists, politicians, businessmen, and ordinary citizens alike sought to unite the nation together though an aggressive, romantic nationalism that harkened back to an earlier design of American 
patriotism and expansion. To this potent combination of nationalism and free trade, López and his supporters used the language of the republican revolutions budding throughout Europe in 1848 to bind their efforts to those of their fellow European revolutionaries and to curry favor with the American public that roundly supported the movement. The final chapters explore Narciso López's attempts at riding the cresting wave of support, the active debate over annexation and abolition among the Cuban and American press, and the disappointing failure of all efforts at annexation resulting specifically from the sectional turn in American politics after 1854. This turn lost Cuban annexation its popular support as Americans came to accept their exceptionalism as perhaps illusory and embraced the possibility that the revolutionary violence present in Europe was possible and perhaps necessary to solve the nation's problems.

A series of most improbable events befell Hungarian revolutionary Lajos Kossuth beginning on December 6, 1851. Kossuth had most recently made his way through Britain after successfully fleeing a devastating defeat at the hands of a combined Russian/Austrian force while serving as Hungarian President of the Committee of National Defense. Even in his previous role as Finance Minister, Kossuth had been much more than a parliamentary minister and governmental bureaucrat. Kossuth established himself as the prime architect of a rapid decentralization of power in Hungary after his thunderous speech of March 3, 1848. Kossuth maneuvered his way to the pinnacle of power in that country, only to be quickly deposed by reactionary continental powers uneasy with the supernova-like burst of democratic agitation throughout Europe during 1848. Kossuth and many other democratically-minded young European workers, reformers, and those uprooted from the land by years of neglect and the onset of rapid industrialization, from Paris to Krakow and Vienna to Rome, rose up to demand political reforms. These reforms focused on greater popular participation in government coupled with a 
concern for the abuses of workers meted out by the industrial ownership classes. Nationalism

and patriotic fervor, a sense of taking national heritage back, accompanied and fueled this

revolutionary emotionalism. ${ }^{176}$

Yet, almost as quickly as it burst forward, reactionary forces throughout the continent

forced the movements to collapse. The black hole left as a result swallowed much of the change

and those pushing for it, while leaving only a vague echo of emotional release. ${ }^{177}$ Kossuth was

one of the lucky firebrands in the leadership ranks of the revolutions who survived. He escaped

the great retribution engulfing central Europe and fled, via Turkey, to England where he enjoyed

a great feeling of camaraderie amongst British policymakers for reasons largely attributable to

the trouble caused by him and his ilk for the Crown's continental enemies. ${ }^{178}$ Kossuth also

\footnotetext{
176 The three best overviews of the Revolutions of 1848, particularly from a European perspective is the less academic but broadly synthetic Mike Rapport, 1848: Year of Revolution (New York: Basic Books, 2009); the more scholarly but equally broad-ranging Jonathan Sperber, The European Revolutions, 1848-1851 (Cambridge: Cambridge University Press, 1994); and the massive and exceedingly thoroughly Dieter Dowe, ed., Europe in 1848: Revolution and Reform (New York: Berghahn Books, 2000). For individual biographical studies of refugees from the revolutions that took up in England see Sabine Freitag, Exiles from European Revolutions: Refugees in MidVictorian England (New York: Berghahn Books, 2003) particularly chapters 8 and 11 which focus on Lajos Kossuth and other fundraising travelers from Hungary and Germany. Thomas Bender, A Nation Among Nations: America's Place in World History (New York: Hill and Wang, 2006), takes up the broader streams of liberalism, national foundation and state building in the $19^{\text {th }}$ century world and frames American history as imbricated in the world political process much more than American historians have often myopically suggested. Republican revolution tied The United States more closely to the European revolutions than Americans of the day might have agreed with or wanted to reckon with. Chapter three pays close attention to the 1840s-1850s and the unifying belief among divergent voices of the importance of the American national project of promoting democracy at home and abroad. The downside of this belief, which synced the United States with the rest of the world, was that this democratic liberty often produced a suffocating demand for uniformity.

${ }^{177}$ Istvan Deak, The Lawful Revolution: Louis Kossuth and the Hungarians, 1848-1849 (New York: Columbia University Press, 1979). Deak focuses primarily on the events in Hungary that led to the exile of Kossuth and explores some of his racial biases as they related to his evaluation of some "less deserving" Slavs living within Hungary's borders as unable and unwilling to enjoy the blessings of freedom. Kossuth's comfort with placing some groups outside the family of freedom came to be a controversial issue during his U.S. tour.

${ }^{178}$ Francis Bowen, one of the few but notable American critics of the Hungary uprising's moral and philosophical points, engaged with Alexis de Tocqueville and his English translator Henry Reeve in a debate on the meanings and interpretations of revolutionary undertakings as well as on Reeve's interpretation and translation of Democracy in America. On Kossuth and the Hungarian revolution he was critical of the racial divisions he saw in their revolutionary aims. "The Magyars assumed the position, therefore of a nation striving to impose or continue the yoke upon the necks of their own dependents, instead of laboring to throw off yoke from their own shoulders." Matthew Mancini, Alexis de Tocqueville and American Intellectuals: From His Times to Ours (New York: Rowman \& Littlefield, 2006), 68.
} 
received a hero's welcome from the British people. He travelled to great acclaim and large crowds, in some cities as high as 75,000, whipped to frenzy by his calls for support against the Russian menace. ${ }^{179}$ British Foreign Secretary Palmerston entertained Kossuth, as did other members of Parliament. The tales of his revolutionary escapades grew to legend. ${ }^{180}$

On December 6, 1851, Kossuth made his way through a train station in New York jammed with frenzied supporters eager to see and touch their revolutionary brother. ${ }^{181}$ He treated them to some brief comments before hustling on his way to a showering of thunderous applause at the hands of the United States Congress at the end of his December $7^{\text {th }}$ address to a joint session. In the body's illustrious, albeit brief, history it had received only one other foreign dignitary directly to its chambers, the Marquis de Lafayette. However, the speech was just the beginning as Kossuth wined and dined with politicians, authors, actors, and dignitaries for much of the next week in Washington and then on to a countrywide tour. ${ }^{182}$ This was nineteenth century stardom on a grandiose level not seen prior in the United States. Americans saw something reflected in the democratic yearnings of this man and his people that they supported.

\footnotetext{
${ }^{179}$ Leslie Mitchell, "Britain's Reaction to the Revolutions," in The Revolutions in Europe, 1848-1849: From Reform to Reaction, eds. R.J.W. Evans and Hartmut Pogge von Strandmann (New York: Oxford University Press, 2000), 83-98. Mitchell demonstrates that the revolutions confirmed for many English observers that they enjoyed a political and social distinctiveness in comparison to their European counterparts. This also resulted, she argues, in the vilification of the Irish and foreigners as threats to British institutions and a unique British social outlook. This production of a certain group of those for whom democracy was ordained matched closely with the racial view of democracy held by Kossuth and many Americans as well as that held by many Cuba political writers. Perhaps it is not at all surprising that Kossuth fits so well with the literary and political milieu of the day. Americans embraced a similar type of distinctiveness as a result of perceived differences between themselves and the continental revolutionaries. Not surprisingly, this distinctiveness was also held as different from and better than the British selfimage.

${ }^{180}$ Eugene Horváth, "Kossuth and Palmerston (1848-1849), The Slavonic and East European Review 9, no. 27 (1931), 612-631.

${ }^{181}$ The New York Times dedicated its December 6 front page to the "Arrival of the Magyar," New York Times, December 6, 1851, accessed May 23, 2013, http://select.nytimes.com/gst/abstract.html?res=F00612FB3C5C167493 C4A91789D95F458584F9

182 The New York Times devoted two full pages to coverage of a reception and dinner at the Astor hotel in Kossuth's honor, included a reprint of his speech from that night (December 15, 1851). "Banquet of the Press to Louis Kossuth at the Astor House! A Splendid Entertainment. Glorious Speech of the Magyar, "New York Times, December 16, 1851, accessed May 23, 2013, http://select.nytimes.com/gst/abstract.html?res=F70D10FB3C5C1 67493C4A81789D95F458584F9.
} 
The poet C.D. Stuart summed up the euphoric national embrace in his New York Times poem of January 6, 1852 entitled To Louis Kossuth.

Kossuth! Thy mission shall not fail-perchance

It must await a more propitious hour,

When less reverence for despotic power

Shall weigh on freedom's rulers, like a trance...

No Magyar! No, thy mission shall not fail;

The world's quick, gushing and tumultuous heart

Beats to your voice-o'er mountain glen and mart...

The peoples' god will surely give thee aid,

And raise thee up a mightier crusade...

For man's first resurrection - Freedom, Life! ${ }^{183}$

Unfortunately for Kossuth, most Americans supported his efforts in voice only and

continued to direct their fervor for democratic expansion southward to Cuba. By the spring of

1852, midway through his national tour, the convivial stance of Americans toward Kossuth

cooled considerably as they wrestled with the implications of his brand of revolution. Politicians

distanced themselves and President Fillmore summed up the mood with a chilly and non-

committal reception to Kossuth's call for American intervention in Europe. The European

revolutions of 1848, while initially injecting the American discourse with great excitement, soon

produced trepidation and skepticism. Kossuth's refusal to engage in the domestic issues roiling

the nation, particularly the issue of slavery, further alienated him from some of his once-adoring

public. Kossuth's brief triumph and predominate travails encapsulated an American public

ambivalence on the nature of transnationality and revolutionary transcendence that the foreign

face of Kossuth came to represent. The revolutions of 1848 took a heavy toll on the population of

${ }^{183}$ C.D. Stuart, “To Louis Kossuth,” New York Times, January 6, 1852, http://select.nytimes.com/gst/abstract.html? res $=$ F00D11FD38 55177493C4A9178AD85F468584F9. In his great exuberance, and later embarrassment, William Seward offered a sweeping Congressional resolution in favor of Kossuth's efforts calling forth aid to be given to the revolutionary. "True wisdom dictates that we lend to European nations, struggling for civil liberty, all possible moral aid to sustain them until they can mature and perfect their strength for that great conflict, through which they are doomed to pass. The nations that we thus lawfully aid to raise up, will constitute a lasting and impregnable bulwark for ourselves." Seward, "Welcome to Kossuth: Speeches of William H. Seward, on the Joint Resolution in Honor of Louis Kossuth," Congressional Speech, December 9, 1851, accessed May 23, 2013, http://books.google.com/books? $\mathrm{id}=\mathrm{h} 9$ NpAAAAMAAJ\&source=gbs_navlinks_s. 
Europe in a physical and visceral way. However, the relatively modest toll taken on Americans, of a mainly intellectual persuasion, had no less of a profound influence on their national psychology. As they watched, initially enraptured, Americans soon grew tired and ultimately distressed with the excessive liberty tinged with socialism and radicalism on display in Europe. As Europe regained its conservative footing by 1850, Americans scoffed at the failure of the many revolutionary movements to capitalize on the example set by the United States. While they embraced the concept of revolution, Americans were uncomfortable with its practice by anyone unaccustomed to proper republican restraint in the midst of societal unrest. ${ }^{184}$

The view that Americans took of their nation's revolution history and the revolutions of 1848 became inextricably intertwined. The perceptions of both series of events mutually reinforced the perceived difference between American and European revolution and the cultures at their respective hearts. The influence of international events, as much as Americans of the day might have claimed otherwise, did much to shape the domestic vision of the American national character. Americans perceived themselves as distant from and exceptional to the revolutions in Europe. The innate superiority of American intention therefore imbued the country's actions with a moral superiority that prevented excess, both in democratic thought and military violence. In this congratulatory atmosphere - fueled by leading American intellectuals, politicians, authors, and Americans of various socio-economic levels, most notably the aspirant middle class - Americans enthusiastically sought to change the slavery-dominated domestic conversation, embrace prosperity, and enlarge democracy in the American image. ${ }^{185}$

\footnotetext{
${ }^{184}$ W. Caleb McDaniel, “' Our Country is the World’: American Abolitionists, Louis Kossuth, and Philanthropic Revolutions," (The Johns Hopkins University Annual Meeting of the OAH, March 25, 2004). John Komlos, Louis Kossuth in American 1851-52 (Buffalo: East Europe Institute, 1973) and Daniel Miller, Louis Kossuth and the Definition of American Character, 1851-52 (Chapel Hill: UNC Press, 1975) both offer good overviews of American anxiety with the European revolutions of 1848 and the collapse of support for Kossuth.

185 Tim Roberts, Distant Revolution: 1848 and the Challenge to American Exceptionalism (Charlottesville: University of Virginia Press, 2009). Cushing Strout, The American Image of the Old World (New York: Harper and
} 
Americans' encounters with the Atlantic world and the unrest they found throughout, from the time of the Revolution until the Civil War, in many ways shaped national identity. Americans developed an aggrandizing appreciation for the remarkable rationality and restraint of the American Revolution that they saw in relief against the backdrop of much more brutal and dehumanizing efforts elsewhere. Excessive violence, most notably in reference to all things French (the Saint Domingue uprising, the Reign of Terror, and the 1848 efforts in Paris), pushed Americans to eschew all things universal in the revolutionary lineage of the country and craft an exceptional American story; one both orderly and magnanimous. The United States, despite its great domestic disputes, then became an asylum of sorts for protection against the passions of social unrest. Rather than seeing the intervening half century of European republican agitation as a continuance of the American example, most Americans by 1850 saw foreign revolt as too dangerous, destabilizing, unruly, and anti-republican (particularly for slaveholders who feared

Row, 1963), is an exploration of the intellectual foundations of the division in the American mind between Europe and the United States. His work with Charles Beard, The Pragmatic Revolt In American History (New Haven; Yale University Press, 1958), tackles the preoccupation with history and revolutionary movements. James Todd Ullman expands on this intellectual unpinning of American exceptionalism in his look at travel writing and the growth of the American bourgeoisie. He argues that "Phenomena such as colonialism, migration, international trade, industrialization, and print culture cut across geographic and political boundaries and were critical to the evolution of bourgeoisie. Complementing these conditions were traditions of cosmological mythology and enlightenment ideals that produced a transnational, if not cosmopolitan, consciousness. Together these contributed to an acute awareness of mobility and spatial difference. Metaphors of travel captured the sense of personal transformation, possibility, and empowerment common within the cultures of bourgeois identity. The romance of travel and encounter became a powerful discursive and psychological device for the construction and reproduction of bourgeois desires such as status, class cohesion, and social dominance in the fluid, socially ambiguous conditions of the day." Ullman, "Geographies of Desire: Bayard Taylor and the Romance of Travel in Bourgeois American Culture, 1820-1880," (PhD diss., Rutgers University, 2007), ii. Melinda Lawson, Patriot Fires: Forging a New American Nationalism in the Civil War North (Lawrence: University of Kansas Press, 2002) focuses on the issues of loyalty and its role in national formation. Joyce Chaplin, "Expansion and Exceptionalism in Early American History," Journal of American History 89, no. 4 (September 2003), 1431-1455, explores the interplay between U.S. expansion and exceptionalism by focusing on the ways Americans looked at their expansion differently that other imperial actors. She does this through an exploration of interdisciplinary approaches in various historical fields and is critical of historians too willing to accept exceptionalism as factual. Various studies look at the development of national identity and republican virtue after the revolution; representative of these are: Daniel Rodgers, "Republicanism: The Career of a Concept" Journal of American History (1992), 11-38; Joanne Freeman, Affairs of Honor: National Politics in the New Republic (New Haven: Yale University Press, 2001); Joyce Appleby Capitalism and a New Social Order: The Republican Vision of the 1790s (New York: New York University Press, 1984). 
the abolitionist universalism on display with British and French abolition in the Caribbean) to be considered even a distant kin to the lofty ideas of a revolution produced by the ideas of the Enlightenment encapsulated in the Declaration of Independence. The erasure of revolutionary violence was the crucial and deciding factor in the American articulation of its mythic national character. Americans used Haiti as the most notable example of differentiation between properly and improperly conducted revolution. Americans of all geographic locations looked upon the Haitian revolution with a mix of terror and bewilderment as they heard stories, many times firsthand, of the unique horrors of the island's revolution. Thus began a successful intellectual process that proceeded with an acceptance of the Haitian revolution as a unique and tragic example of revolutionary bloodlust set off from and exposed as different and even contradictory to the very notion of 'civilized' rebellion. ${ }^{186}$

Southern slaveowners contained their fear with the notion that the revolutionary violence displayed in Haiti was something singular to the island and its inhabitants. For American slaveowners, Haitian slavery contained within its brutality a pathogen that proper vigilance might prevent from spreading to the United States. While some ardent abolitionists welcomed the possibility of an expansive upheaval of freedom in Haiti's wake, many Americans believed

\footnotetext{
${ }^{186}$ Philipp Ziesche, Cosmopolitan Patriots: Americans in Paris in the Age of Revolution (Charlottesville: University of Virginia Press, 2010) and Sarah J. Purcell, Sealed with Blood: War, Sacrifice, and Memory in Revolutionary America (Philadelphia: University of Pennsylvania Press, 2010) explore the vision of revolutionary upheaval seen by Americans in Paris during the 1790s and the commemoration of the American revolution in relief against Paris. Americans used their participation in and observation of revolution on both sides of the Atlantic to further their own political, economic, social, and personal purposes. Terry Bouton, Taming Democracy: "The People," The Founders, and the Troubled Ending of the American Revolution (New York: Oxford University Press, 2009) focuses on the impact of revolutionary ideology on the poorer members of the democracy and their negotiations with the new reality of independence. For the broader effects of 1848 on the United States see: Merle Curti, "Impact of the Revolutions of 1848 on American Thought," Proceedings of the American Philosophical Society 93, no. 3 (June 1949), 209-15; Adam-Max Tuchinsky, “'The Bourgeoisie Will Fall and Fall Forever:' The New York Tribune, the 1848 French Revolution and American Social Democratic Discourse," Journal of American History 92, no. 2 (September 2005), 470-97; Andre Fleche, The Revolution of 1861: The American Civil War in the Age of Nationalist Conflict (Chapel Hill: University of North Carolina Press, 2012); and Matthew David Norman, "Revolutions in the Republican Imagination: American Perceptions of the 1848-1849 Revolutions in Europe" (PhD diss., University of Illinois, 2006).
} 
that if the contagion of revolution, arrested as it was on the island, remained safely separated from North America that the end of slavery might occur in a more nuanced and reserved manner befitting the American revolutionary tradition. Conversely, the violence on display in Haiti also reinforced Southern rationalization of slavery's continuance in the United States as an effective bulwark against racialized upheaval. This fear of contagion and uncontrolled abolition was one felt most intimately by Cuban slaveowners and formed the basis of a psychological bond, beyond the intertwined economic interests, which joined American and Cuban elites seeking to prevent racialized chaos. The tripod of interest, founded in the shadow of the Haitian revolution's threat, between Northern capital, Southern slaveowners, and Cuban elites, fueled moneyed support for annexation and drove efforts at convincing others outside of the elite. Southerners and their Northern industrializing brethren also used the 1848 revolutions to argue that European serfdom along with the structure of European industrial labor was far more severe than either Northern free or Southern slave labor models. For Northern industrial capitalists the fear of foreign contagion prompted a more magnanimous view toward Southern planters with the full knowledge that their economic imbrication with the slavery regime and capital investments in the South threatened to become liabilities during a revolution. Southerners used this to their advantage while also adopting a true belief in the socially stabilizing effect of slavery's continuance. $^{187}$

\footnotetext{
${ }^{187}$ Ashli White, Encountering Revolution: Haiti and the Making of the Early Republic (Baltimore: Johns Hopkins University Press, 2010). White argues that Haiti was one of the guiding factors in the need for articulation on a separate American drive for independence from that of the Haitian revolutionaries. Interestingly, American national insistence on exceptionalism articulated the profound Caribbean influence, even if only in the negative, which Haiti had upon European revolutionaries as well as American society and politics. Paradoxically, the great prohibition against extremism in the defense of liberty issued forth by the mythical American nationalism caused to be the great undoing (1861) of the very non-violence the American ethos sought to protect. Tim Roberts, "Revolutions Have Become the Bloody Toy of the Multitude: European Revolutions, The South, and the Crisis of 1850," Journal of the Early Republic 25, no. 2 (2005), 259-283, explores the South's concern with the revolutions in relation to that region's developing secessionist philosophy. He argues that while the compromise of 1850 quieted much of the noise for secession, it was the failures of the European revolutions that drove home the danger implicit in
} 
Yet, this exceptionalism was not simply a positive expression of American superiority.

The public reactions to the revolutions of 1848 reflected a deeper sense of bewilderment, fear,

and loss of confidence in the post-Mexican war period. Many Americans feared that the essence

of the nation's revolutionary creation might be erased if passion overcame rationalism as it had

in the debates over the Mexican cession. ${ }^{188}$ To head off this concern, made more pressing by the

revolutionary movements. "The specter of the United States replicating scenes of European revolution and reaction prodded legislators to search for ways to avoid the violence of sectional conflict." Although advocates in the South distinguished between secession and revolution, they nonetheless saw the defeat of revolutions in Europe as an authoritarian triumph over "virtuous but disorganized" advocates of republicanism. While they arrived at their suspicion of the European revolutions in different ways, North and South stood together critical and wary of the events on display. Also on Haiti's effect on American visions of the Atlantic and Caribbean worlds as situated in the Enlightenment cauldron of republicanism and rights see: Laurent Dubois, A Colony of Citizens: Revolution and Slave Emancipation in the French Caribbean, 1787-180 (Chapel Hill: University of North Carolina Press, 2004) and "The Haitian Revolution and the Sale of Louisiana," The Southern Quarterly: A Journal of Arts in the South 44, no.3 (Fall 2007), 18-41; Rebecca J. Scott, Degrees of Freedom: Louisiana and Cuba after Slavery (Cambridge: Belknap Press, 2005), 1-30; Lester Langley, The Americas in the Age of Revolution, 1750-1850 (New Haven: Yale University Press, 1996), 7-120; Alfred Hunt, Haiti's Influence on Antebellum America: Slumbering Volcano in the Caribbean, (Baton Rouge: LSU Press, 2006). An interesting look at the effect of the Haitian revolution on American foreign policy is found in Gordon Brown, Toussaint's Clause: The Founding Fathers and the Haitian Revolution (Oxford, MS: University of Mississippi Press, 2005) and Tim Matthewson's, A Proslavery Foreign Policy: HaitianAmerican Relations During the Early Republic (Westport: Praeger, 2003). For the effect of slavery generally on American foreign relations see, Stephen Mitton, "The Free World Confronted: The Problem Of Slavery And Progress In American Foreign Relations, 1833 - 1844," (PhD diss., LSU, 2005); Michael Morrison, "American Reaction to European Revolutions, 1848-1852: Sectionalism, Memory, and the Revolutionary Heritage," Civil War History 49, no. 2 (Summer 2003), 111-132; Jeremy D. Popkin, You Are All Free: The Haitian Revolution and the Abolition of Slavery (New York: Cambridge University Press, 2010); David Barry Gaspar and David Patrick Geggus, eds., A Turbulent Time: The French Revolution and the Greater Caribbean (Bloomington: Indiana University Press, 1997), 178-226; Matt Childs, “A Black French General Arrived to Free the Island: Images of the Haitian Revolution in Cuba's 1812 Aponte Rebellion,' in The Impact of the Haitian Revolution in the Atlantic World, ed. David Patrick Geggus (Columbia: University of South Carolina Press, 2001), 137-156; Edward Baptist, "Hidden in Plain View: Haiti and the Louisiana Purchase," in Echoes of the Haitian Revolution in the Modern World, eds. Elizabeth Hackshaw and Martin Munro (Kingston, Jamaica: UWI Press, 2008); Clarence J. Munford and Michael Zeuske, "Black Slavery, Class Struggle, Fear and Revolution in St. Domingue and Cuba, 1785-1795," The Journal of Negro History 73, no. 1/4 (1988), 12-32; Doris L. Garraway, ed., Tree of Liberty: Cultural Legacies of the Haitian Revolution in the Atlantic World (Charlottesville: University of Virginia Press, 2008) focuses on literary and journalistic impacts of the revolution; Jane Landers, Atlantic Creoles in the Age of Revolution (Cambridge: Harvard University Press, 2010), chs. 1,4-5; Rachel Hope Cleves, The Reign of Terror in America: Visions of Violence from Anti-Jacobinism to Antislavery (New York: Cambridge University Press, 2009) argues that the violence of the Reign of Terror fueled the early antislavery movement among moralistic federalists and Congregationalists.

${ }^{188}$ For the political debate surrounding the Mexican cession, Mexican War, and slavery see: Michael Holt, The Fate of Their Country: Politicians, Slavery Extension, and the Coming of the Civil War (New York: Hill and Wang, 2005), 3-50; Bruce Levine, Half Slave and Half Free: The Roots of Civil War (New York: Hill and Wang, 1992), 145-200; Michael Morrison, Slavery and the American West: The Eclipse of Manifest Destiny and the Coming of the Civil War (Chapel Hill: University of North Carolina Press, 1997), 66-150; Allan Nevins, Ordeal of the Union: Fruits of Manifest Destiny 1847-1852, (New York: Scribner, 1947); David Potter, The Impending Crisis 1848-1861 (New York: Harper Collins, 1976), 18-65; Richard Hofstadter, The Idea of a Party System: The Rise of Legitimate Opposition in the US 1780-1840 (Oakland: University of Califonia Press, 1970); Leonard Richards, The Slave 
chaos in Europe, Americans - unmoored as they were from both the temporal moment of the American Revolution and the physical presence of the era's luminaries - sought a new definition of the Revolutionary period. The exceptionalism implicit in the attempted redefining undergirded the shift from the American experience as example for revolutionary republicans to a view of the American experience as a unique and perhaps unrepeatable effort. Appreciation for the rapidity of change and the ability of even the loftiest revolutionary aspirations to quickly spiral out of control drove a more amendable and conciliatory political climate that moved quickly to drown out more radical voices. The superiority felt toward American political culture and the confidence in its righteousness, fueled by the picture painted of the American Revolution, momentarily solidified a teetering national unity. The American reactions to the European revolutions of 1848 are notable in both their timing and their effect on the perception of filibustering and annexation in Cuba. Ironically, while Americans cooled considerably in their support and interest in the events of Europe at the end of the 1840s, Americans saw in Cuban annexation the dual possibility of perfecting the American revolution in a conservative, limited, and relatively violence-free military effort coupled with an effort to control social chaos and concurrent slave uprising on the island. Americans after all embraced Kossuth for much of the same intellectual reasons. Unlike the more philosophically raucous and confrontationally street

\footnotetext{
Power and Southern Domination 1780-1860 (Baton Rouge: LSU Press, 2000); Joel Silbey, Storm Over Texas: The Annexation Controversy and the Road to the Civil War (New York: Oxford University Press, 2005); David Brown, "Jeffersonian Ideology and the Second Party System," The Historian 62, no. 1 (1999), 17-30; John Craig Hammond, Slavery, Freedom and the Expansion in the Early American West (Charlottesville: University of Virginia Press, 2007); Randolph B. Campbell, An Empire for Slavery: The Peculiar Institution in Texas, 1821-1865 (Baton Rouge: LSU Press, 1991); Andrés Reséndez, Changing National Identities at the Frontier: Texas and New Mexico, 18001850 (New York: Cambridge University Press, 2004); Lacy Ford, Deliver Us from Evil: The Slavery Question in the Old South (New York: Oxford University Press, 2009); Sally Frahm, "The Cross and the Compass: Manifest Destiny, Religious Aspects of the Mexican-American War," The Journal of Popular Culture 35, no. 2 (2001), 8399; Mike Dunning, "Manifest Destiny and the Trans-Mississippi South: Natural Laws and the Extension of Slavery into Mexico," The Journal of Popular Culture 35, no. 2 (2001), 111-127; Matthew Baigell, "Territory, Race, Religion: Images of Manifest Destiny," Smithsonian Studies in American Art 4, nos. 3/4 (1990), 2-21; Kimberly Ann Lamp, "Empire for Slavery: Economic and Territorial Expansion in the American Gulf South, 1835-1860," (PhD diss., Harvard University, 1991).
} 
violent Catholics (Italy) and laborers (France) - pushing hard for workers' rights, greater

economic equality (uncomfortably tending toward socialism), and a fundamental reordering of

society - the Hungarians, as the Americans before them, sought a more limited goal and used

more reserved means towards its accomplishment. ${ }^{189}$

189 Thomas Bender, A Nation Among Nations (New York: Hill and Wang, 2006), is critical of modern American historians replication of this belief in exceptionalism. In his view of U.S. national historiography he notes that while modern historiography and the nation-state emerged together, he is critical of the assumption that "the self-contained nation as the natural carrier of history...The nation cannot be its own historical context," (3). American history, he insists should be situated in a global context and not apart or exceptional to it. Bender is particularly critical of historians who accept the premise that the "American way of empire was even presented as anti-imperialism because it guaranteed openness, in contrast to the exclusivity of the old empires," (233). This American exceptionalism is dangerous both in its belief that peculiar circumstances of American history exempted the United States from many of the struggles and brutalities of Europe and in its continuous reproduction in the national narrative. This is not a denial of varying experiences across national cultures but rather contextualization of connections and similarities as well as the shared engagement of ideas and reaction to related causal forces. Among some of the notable exceptions to the efforts at distancing of Europe were Margaret Fuller and George Sanders. Leslie Eckel, "Margaret Fuller's Conversational Journalism: New York, London, Rome," Arizona Quarterly 63, no. 2 (Spring 2007), 27-50, presents Fuller as a deliberately conscious creator of and participant in the transnational interpretation of American and European culture in conversation. Her active journalism in Italy during the 1848 revolution there pushed her to call on Americans to leave their anti-Catholicism behind and to appreciate the similarities between the goals of Mazzini and those of the American patriots of 1776. Fuller's intellectual prowess placed her in league with and often in conflict with many luminaries of the period including Ralph Waldo Emerson. Her confrontational concepts caused her exclusion from the period's literary canon. Giuseppe Garibaldi was also a topic of general interest on the part of annexationists/independentists. Unlike Mazzini, Garibaldi travelled extensively throughout South America during the 1840s and participated in numerous anti-government uprisings throughout the continent, including in Brazil, Uruguay, and Peru. Numerous American newspapers incorrectly reported (most likely embellishing similar wire reports - one paper noting that 3,000 soldiers accompanied Garibaldi) that he accompanied Narciso López during the 1851 expedition. On the rumor and assertions of Garibaldi in Cuba see: Boston Daily Evening Transcript, "Havana Correspondence," March 27, 1851; Daily Ohio Statesman, "Affairs in Cuba," April 14, 1851; Boston Daily Evening Transcript, "Departure of Garibaldi for California," April 30, 1851; Baltimore Sun, "Further News of the Cuba Expedition," May 3, 1851; New York Weekly Herald, "Movements of Distinguished Individuals," May 3, 1851; and Milwaukee Daily Sentinel \& Gazette, "Cuba," June 4, 1851. Emilia Casanova de Villaverde (founder of the New York City exile independence women's group "Las Hijas de Cuba" and wife of fellow revolutionary Cirilo Villaverde), herself a potent revolutionary voice, reached out to Garibaldi during the 1860s wondering if he supported Cuban independence after it had made its more raciallyembracing and internationalist turn by 1868. "After some reflection, I have concluded that Garibaldi is silent because he is not familiar with the Cuban situation, nor is he aware of the extent of our political aspirations. We began the revolution by liberating our slaves, arming them and including them and including them in the patriotic columns, and you should take this minor point to understand that our goal is universal liberty... and at this time, despite the challenges that we have encountered, the patriots dominate two-thirds of the island" quoted in Lazo, Writing to Cuba, 133. While Cuban exiles met with Kossuth soon after his arrival in New York, according to La Verdad, there's no clear evidence that López and Kossuth broke bread. On general American reactions to the Italian Risorgimento see Dennis Marraro, American Opinion on the Unification of Italy, 1846-1861 (New York: Columbia University Press, 1932). On Fuller's radicalism see Bell Gale Chevigny, "Growing Out of New England: The Emergence of Margaret Fuller's Radicalism," Women's Studies 5 (1977), 65-100. On the use of the European Revolutions in the 1848 presidential campaigns see, Tim Roberts and Dan Howe "The United States and the Revolution of 1848" in The Revolutions in Europe 1848-1849: From Reform to Reaction, eds. Robert Evans and Hartmut Pogge von Strandmann (Oxford: Oxford University Press, 2002), 157-180 and Donald Spencer, Louis Kossuth and Young American: A Study of Sectionalism and Foreign Policy 1848-1852 (Columbia: University of 
The arrival of the two luminaries of independence movements, Narciso López (1848) and Lajos Kossuth (1851), coincided with the ongoing reordering of American society. This reordering engaged all aspects of American society and sought a political consensus that buried the more problematic issues facing the country. Younger Whigs and Democrats made a compelling argument for the unique power of the American economic system to foster these changes and thereby sidestep the more difficult issues within the specifics of that system (most recently the systemic failures and policy decisions that lead to economic collapse after 1837). The debate over western territories and the corresponding shift from purely moral to more aggressive political efforts on the part of abolitionists encouraged both Democrats and Whigs to avoid direct engagement with the slavery question. After the uneven rhetorical debate surrounding Mexico, one that took a deep psychological toll on American political discourse and confidence, events aimed at resurrection of the American psyche became necessities - the most popular of these attempts being annexation of Cuba. Therefore, a shared sense of community bound together by the mythic past of restrained revolution and the rejection of the false idols of revolutionary imitators fused with a rapacious thirst for travel accounts of exotic locales and a

Missouri Press, 1977). For political reactions to the French revolution of 1848 see, Richard C. Rohrs, "American Critics of the French Revolution of 1848," Journal of the Early Republic 14, no. 3 (Fall 1994), 359-377. The overlooking of a long tradition of American violence, revolutionary or otherwise, was at best hypocritical. On American violence see, David Grimsted, American Mobbing, 1828-1861 (New York: Oxford University Press, 1998) and Joshua Rothman, "The Hazards of the Flush Times: Gambling, Mob Violence, and the Anxieties of America's Market Revolution," Journal of American History 95, (2008), 651-677. Americans continued to be divided over the great difference between Protestant and Catholic revolutions as indicated in their views on Italy and their view of European immigrants in the wake of the revolutions of 1848, see: David Sim, "Filibusters, Fenians, and a Contested Neutrality: The Irish Question and U.S. Diplomacy, 1848-1871," American Nineteenth Century History 12, no. 3 (2011), 265-287; Timothy O'Grady, “The Fenian Factor: Influences Of Irish Republicanism's On International History, 1848-1948," (MA Thesis, Hawai'i Pacific University, 2007); John Jentz, "The 48ers and the Politics of the German Labor Movement in Chicago during the Civil War Era: Community Formation and the Rise of a Labor Press," in The German-American Radical Press: The Shaping of a Left Political Culture, 1850-1940, eds. Elliot Shore, Ken Fones-Wolf and James Philip Danky (Urbana: University of Illinois Press, 1992), 49-62; Bruce Levine, The Spirit of 1848: German Immigrants, Labor Conflict, and the Coming of the Civil War (Urbana: University of Illinois Press, 1992). For German participation in the López expeditions see Michael Zeuske, “iCon López a Cuba! Los voluntarios alemanes en la expedición de Narciso López, 1851-1852," Ibero-Americana Pragensia, (1994), 65-88. For a little reflected upon but interesting story of 1848 immigration see, Bertram Korn, "Jewish 48'ers in America," American Jewish Archives, (June 1949), 3-18. 
heavily invested national economic stake in the Cuban economy. These situational aspects, combined with an almost pathological desire to minimize partisan unrest over the issue of slavery, created a network of social relations marked by mutuality and emotional bonds between Americans and Cubans. Despite the explosion of industrial capital and its dislocating effects on Americans of all classes and degrees of freedom, the American market experience existed in terms of the ongoing combative coexistence of two different patterns of American life. One pattern remained dependent on interpersonal relationships of local contexts focused on emotional ties, while the other demonstrated involvement with and increasing dependence on long distance institutional, transactional, and impersonal relationships. Therefore, the United States existed as a patchwork of isolated communities seeking wider networks of trade, influence, and belonging. The spirit of the 1840s sought to build a national character that reasserted the unity many understood to have existed during the immediate post-Revolutionary era while simultaneously engaging with a wider economic market. ${ }^{190}$

\footnotetext{
${ }^{190}$ Elizabeth Varon, Disunion! The Coming of the American Civil War, 1789-1859 (Chapel Hill: UNC Press, 2008). Kurt Weyland, "The Diffusion of Revolution: 1848 in Europe and Latin America," International Organization 63, no. 3 (2009), 391-423. Ian Tyrrell, Transnational Nation: United States History in Global Perspective since 1789 (New York: Oxford University Press, 2007), chs. 1-5; David W. McMillan and David M. Chavis George, "Sense of Community: A Definition and Theory," Journal of Community Psychology 14, (January 1986), 6-23; Christopher Tomlins, Freedom Bound: Law, Labor, and Civic Identity in Colonizing English America, 1580-1865 (New York: Cambridge University Press, 2010), 230-400; Stephen Mihm, A Nation of Counterfeiters: Capitalists, Con Men, and the Making of the United States (Cambridge: Harvard University Press, 2007); Burton Bledstein and Robert Johnson, The Middling Sorts: Explorations in the History of the American Middle Class (New York: Routledge, 2001), 1-100. Thomas Bender, Community and Social Change in American (Baltimore: Johns Hopkins University Press, 1982), critiques the contemporary $19^{\text {th }}$ century lamentations that claimed new modes of industrial economy, developed and solidified in the $19^{\text {th }}$ century, destroyed the natural patterns of kinship and community networks that marked the status quo of earlier American society. Americans bemoaned impersonal contractual connections that eroded and eventually replaced personal ties as modern society replaced traditional communities. Bender is critical of historians and sociologists that embrace a linear concept of social change. Rejecting much in the traditional historiography and opening the way for a host of thought provoking work that appreciates the complexity of economic effect, Bender demonstrates that familial ties were extremely resilient and often strengthened by migration to and involvement with temporal and physical areas of industrial capitalism. He focuses on the myriad negotiations that people made to keep distinctive ethnic cultural patterns alive. For issues of community development, north and south see; Karen Hansen, A Very Social Time - Crafting Community in Antebellum New England, (Berkeley: University of California Press, 1994); Harry L. Watson, "The Common Rights of Mankind": Subsistence, Shad, and Commerce in the Early Republican South," The Journal of American History 83, no. 1 (June 1996), 13-43; Carolyn Earle Billingsley, Communities of Kinship: Antebellum Families and the Settlement of the Cotton Frontier (Athens:
} 
Economic growth seemed to be the most natural realm in which to bridge the conceptual gap present in the slavery debate as well as to offer a point of unity to distract from other issues. The fear of radicalism and socialism, so present in European reactions to 1848, spurred American capitalists' interest in binding Cuba closer through the sinews of trade. The best way to prevent the radicalization of the political and social environments on the island was a transfer of tutelage from one of the decadent monarchies of Europe to the robust exemplar of republican capital growth and stability. The stability of consumer and resource markets did much to delay significant discussions of moral responsibility and slavery. In fact, annexation of Cuba took on a morality of purpose that in many ways replaced the one that more radical voices in the United States demanded toward slavery from the mouths of the political and social elite. The discussion over annexation took on a millennial missionary zeal which helped many Americans commiserate with the economic and political 'enslavement' of elites in Cuba while disavowing

\footnotetext{
University of Georgia Press, 2004); David Hackett Fischer and James C. Kelly, Bound Away: Virginia and the Westward Movement (Charlottesville: University of Virginia Press, 2000); Charles C. Bolton, Poor Whites of the Antebellum South: Tenants and Laborers in Central North Carolina and Northeast Mississippi (Durham: Duke University Press, 1993); Christine Leigh Heyrman, Southern Cross: The Beginnings of the Bible Belt (Chapel Hill: UNC Press, 1998); D. R. Hundley, Social Relations In Our Southern States, accessed on May 20, 2013, http:// docsouth.unc.edu/southlit/ hundley/ hundley.html; Steven Arson, "Yeoman Farmers in a Planters' Republic: Socioeconomic Conditions and Relations in Early National Prince George's County, Maryland," Journal of the Early Republic, 29 (Spring 2009), 63-99; Vernon Burton, In My Father's House Are Many Mansions: Family and Community in Edgefield, South Carolina (Chapel Hill: UNC Press, 1985); Randolph B. Campbell and Richard G. Lowe, Planters \& Plain Folk: Agriculture in Antebellum Texas (Dallas: SMU Press, 1987); Gavin Wright, "Economic Democracy' and the Concentration of Agricultural Wealth in the Cotton South, 18501860," Agricultural History 44, no. 1 (January 1970): 63-93. Mark Wetherington, Plain Folk's Fight: The Civil War and Reconstruction in Piney Woods Georgia (Chapel Hill: UNC Press, 2005); Donald Schaefer, "Yeomen Farmers and Economic Democracy: A Study of Wealth and Economic Mobility in the Western Tobacco Region, 18501860," Explorations in Economic History 15, no. 4 (1978), 421-437; Carl Osthaus, "The Work Ethic of the Plain Folk: Labor and Religion in the Old South," Journal of Southern History 70, no. 4 (November 2004), 745-82; Steven Hahn, The Roots of Southern Populism: Yeoman Farmers and the Transformation of the Georgia Upcountry, 1850-1890 (New York: Oxford University, 1983); William Harris, Plain Folk and Gentry in a Slave Society: White Liberty and Black Slavery in Augusta's Hinterlands (Middleton: Wesleyan University Press, 1985); Susanna Delfino, Michele Gillespie, and Louis M. Kyriakoudes, eds., Southern Society and Its Transformation (Columbia: University of Missouri Press; 2011); Jeremy Atack, "Tenants and Yeomen in the Nineteenth Century," Agricultural History 62, no. 3 (Summer 1988), 6-32. Frank Lawrence Owsley, Plain Folk of the Old South (Nashville: Vanderbilt University Press, 1949); Lacy Ford, Origins of Southern Radicalism: The South Carolina Upcountry, 1800-1860: The South Carolina Upcountry, 1800-1860 (New York: Oxford University Press, 1988).
} 
interest in slavery within their midst. Cuba became the logical extension of American capitalistic expansion. While there developed a national feeling toward Cuba over many decades, this general feeling of kinship strengthened in direct relation to regional sub-national units' interactions with the island. These "circuits" of trade, technology, slavery, and profit eventually bound all sections of the United States to the island. Chief among those connections was the economic binds that drew Cuba close to various capitalist ventures of import and export as well as labor and technology. ${ }^{191}$

The transnationality of the economic setting that bound Cuba to the United States was one long in the making. Far afield from the increasingly monocultural sugar fields of Cuba, were economic webs driving labor and commodity choices across the hemisphere. The Atlantic world of the 1840s was one shaped by interactions among the producers and consumers of these various commodities. This was not simply a condition of market competition and specialization

\footnotetext{
${ }^{191}$ Daniel Rood, "Slavery and The Amber Waves of Grain: Trade, Technology, and Middle-Class Consumption in the Richmond-Rio Circuit, 1760-1860," (presented at Slavery's Capitalism: A New History of American Economic Development, Brown University, April 2011), asserts the concept of circuits which bonded regions of subnational trading partners across the Caribbean. Rood outlines a very interesting competition that sprang up between Baltimore, Philadelphia, and Richmond not only over the milling and export of flour to mainly Rio de Janeiro and Cuba, but also the different quality of flour determining its destination. As sugar monoculture strangled Cuba into the 1850s, lower quality millers flooded the now desperate Cuban market which became one of the most lucrative in the world with customary $700 \%$ per barrel mark ups. Rising demand from Cuban sources fueled aggressive agricultural and industrial expansion of the South's productive base and supports the recent and strong reappraisal of the traditional anti/proto-capitalistic view of the "old" South. Antonio Benitez-Rojo, The Repeating Island: The Caribbean and the Postmodern Perspective (Durham: Duke University Press, 1992), 1-40. Two studies on northern investment in Haiti demonstrate similar impulses for enterprising financiers: James Alexander Dun, "Philadelphia not Philanthropolis: The Limits of Pennsylvanian Antislavery in the Era of the Haitian Revolution," Pennsylvania Magazine of History and Biography 135, no. 1 (January 2011), 73-102; and James Alexander Dun, "“What Avenues Of Commerce Will You Americans Not Explore!:' Commercial Philadelphia's Vantage onto the Early Haitian Revolution," William and Mary Quarterly 62, no. 3 (Summer 2005), 473-504. On the radical abolitionist stirring see, Frederick J. Blue, No Taint of Compromise: Crusaders in Antislavery Politics (Baton Rouge: LSU Press, 2006); John Stauffer, The Black Hearts Of Men: Radical Abolitionists And The Transformation Of Race (Cambridge: Harvard University Press, 2009); Steven Mintz and John Stauffer, eds., The Problem of Evil: Slavery, Freedom, And the Ambiguities of American Reform (Amherst: University of Massachusetts Press, 2007); Jacqueline Bacon, The Humblest May Stand Forth: Rhetoric, Empowerment, and Abolition (Columbia: University of South Carolina Press, 2002); John Craig Hammond and Matthew Mason, eds., Contesting Slavery: The Politics of Bondage and Freedom in the New American Nation (Charlottesville,: University of Virginia Press, 2011); Stanley Harrold, The Rise of Aggressive Abolitionism: Addresses to the Slaves (Lexington: University Press of Kentucky, 2004).
} 
but instead a complex system of causal and reactive entrepreneurialism that highlighted political opportunism as its main reinforcing mechanism. Cuba and the United States existed as practitioners of coterminous systems of slavery and mass production that drove commodity marketization of the Caribbean basin. Productive shifts, both in terms of technology and staple crop choice, facilitated innovations in productive capacity for both partners. This increase encouraged a hemispheric separation of labor, thereby tying Cuba even closer to the United States. By the 1820s, dependence on the American exports became particularly acute since Spanish and Cuban producers became increasingly unable to satisfy the domestic market's agricultural necessities. This Cuban consumptive necessity, most notably the importation of wheat/flour, in turn drove productive decisions in the American agricultural system, notably increasing wheat cultivation and processing in the upper South. While local market producers throughout Cuba continued to produce for their communities, their production increasingly focused toward plantation support and away from general consumption. Small Cuban food producers, eventually driven out of the market by rising material, labor, and transportation costs, lost their land to larger sugar providers. Cuban society on all levels became increasingly dependent on American production. In turn, American producers became more dependent on the island and shifted some of their economic and agricultural decisions based on the needs of the Cuban market. ${ }^{192}$

\footnotetext{
${ }^{192}$ Indicative of this new symbiotic relationship and exemplary of its the dangers was the 1838 La Guerra de Harinas, a tariff war that exploded over Spanish protective tariffs on imported American flour. The American response of higher tariffs on Cuban coffee exports, along with the massive hurricane of 1843, destroyed most of the largest cafetales of the island, further cementing sugar's ascendency. Pro-Annexationist Cora Montgomery bemoaned the Spanish tariff and the crown's attempts to strengthen Iberian flour imports to Cuba in the wake of losing mainland South American markets after independence in "Cuba: The Key of the Mexican Gulf: With Reference to the Coastal Trade of the United States," Hunt's Merchants Magazine XXI, (1849). On the ties between the United States and Cuban economies see: David Eltis, "The U.S. Transatlantic Slave Trade, 1644-1867: An Assessment," Civil War History 54, no. 4 (December 2008), 347-378; Louis Perez, Cuba and the United States: Ties of Singular Intimacy (Athens: University of Georgia Press, 1990), 1-30; Laird Bergad, Cuban Rural Society in the Nineteenth Century: The Social and Economic History of Monoculture in Matanzas, (Princeton: Princeton
} 
These new relationships shaped decision-making concerning debt, production, labor, transportation, and politics. The economic chains of interdependence stretched over hundreds of miles of land and over equally as distant intellectual landscapes of contracts and remittances. Both Whigs and Democrats, hoping to benefit from the success of the Cuban trade, joined in the chorus of economic development and investment in the South; a shared position that also assumed the strengthening of economic connection between different regions of the United States. These connections were in service of strengthening the rationalization of domestic and international economic organization with many boosters seeing open markets in Cuba as a fast way to diversify Southern agricultural and manufacturing pursuits. Supporters of Southern

University Press, 1990); Joan Casanovas, Bread Or Bullets! Urban Labor and Spanish Colonialism in Cuba, 18501898 (Pittsburgh: University of Pittsburgh Press, 1998),15-70; Jonathon Curry-Machado, "Indispensible Aliens: The Influence of Engineering Migrants with Mid-Nineteenth Century Cuban Society," (PhD diss., London Metropolitan University, 2003); Susan Fernandez, Encumbered Cuba: Capital Markets and Revolt, 1878-1895 (Gainesville: University of Florida Press, 2002),1-100; Fe Iglesias Garcia, "The Development of Capitalism in Cuban Sugar Production 1860-1900," in Between Slavery and Free Labor: The Spanish Speaking Caribbean in the Nineteenth Century, eds. Manuel Moreno Fraginals, Frank Moya Pons, and Stanley Engerman (Baltimore: Johns Hopkins University Press, 1985), 54-76; Alan Dye, Cuban Sugar in the Age of Mass Production: Technology and the Economics of the Sugar Central, 1899-1929 (Stanford: Stanford University Press, 1998), 1-60; Sidney Mintz, Sweetness and Power: The Place of Sugar in Modern History (New York: Penguin Books, 1986); Ramiro Guerra y Sanchez, Azúcar y poblacio en las Antillas, (Havana: Editorial de Ciencias Sociales, 1970); Luis FernandezMartinez, Torn Between Empires: Economy, Society and Patterns of Political Thought in the Hispanic Caribbean, 1840-1878, (Athens: University of Georgia Press, 1994), 1-104; Manuel Moreno Fraginals, Sugarmill: The Socioeconomic Complex of Sugar in Cuba, 1760-1860, (New York: Monthly Review Press, 1976); Robert Paquette, Sugar is Made with Blood: The Conspiracy of La Escalera and the Conflict between Empires over Slavery in Cuba, (Middletown, CT: Wesleyan University Press, 1988); Eric Williams, Capitalism and Slavery (Chapel Hill: University of North Carolina Press, 1944); Stephen Chambers, "At Home Among the Dead: North Americans and the 1825 Guamacaro Slave Insurrection," Journal of the Early Republic 33, no.1 (Spring 2013), 61-86 and "The American State of Cuba: The Business of Cuba and U.S. Foreign Policy, 1797-1828," (PhD diss., Brown University, 2013); Richard Follett, The Sugar Masters: Planters and Slaves in Louisiana's Cane World, 1820-1860 (Baton Rouge: LSU Press, 2005); Manuel Barcia, Seeds of Insurrection: Domination and Resistance on Western Cuba Plantations, 1808-1848 (Baton Rouge: LSU Press, 2008) and The Great African Slave Revolt of 1825: Cuba and the Fight for Freedom in Matanzas (Baton Rouge: LSU Press, 2012); Hernán Horna, Transport Modernization and Entrepreneurship in Nineteenth Century Colombia: Cisneros \& Friends (Uppsala, Sweden: University of Uppsala, 1992), 1-50; Dale Tomich, Through the Prism of Slavery: Labor, Capital and World Economy (New York: Rowman \& Littlefield Publishers, 2005), 56-95; Gwendolyn Midlo Hall, Social Control in Slave Plantation Societies: A Comparison of St. Domingue and Cuba (Baltimore: Johns Hopkins University Press, 1971); Leonardo Marques, "Slave Trading in a New World: The Strategies of North American Slave Traders in the Age of Abolition," Journal of the Early Republic, Volume 32, no. 2 (Summer 2012), 233-26; Charles Rappleye, Sons of Providence: The Brown Brothers, the Slave Trade, and the American Revolution (New York: Simon \& Schuster, 2006); Eric Kimball, “'An Essential Link, in a Vast Chain:' New England and the West Indies, 1700-1775” (PhD diss., University of Pittsburgh, 2009); Joseph Avitable, "The Atlantic World Economy and Colonial Connecticut," (PhD diss., University of Rochester, 2009). 
investment also saw growth and modernization in the Southern economy as the surest way

toward greater national economic development and the continuance of political union. As an

added incentive, some saw Southern economic growth as the safest way toward possible

abolition of slavery. The thinking of slightly more moralistic investors argued that with the

abundance of new industrial and agricultural jobs in the South falling to free labor, of a perhaps

predominately white variety (not unlike the aims of some supporters of the Wilmot Proviso),

slavery might fall naturally out of practice. Henry Carey, a leading proponent of greater

investment in the South, outlined the conceptualization of the market economy as it affected the

South in a letter reprinted in his self-bankrolled journal, The Plough, The Loom and The Anvil.

The mill brings people to the neighborhood, and new demands for labor arise and with each step there is an increase in the value of labor, and in the power of consuming its products. Houses are wanted, and stone quarries become valuable, while the demand for timber enables the land-owner to sell his trees instead of killing them. His land increases in value because of the facility of exchanged food and cotton for cloth and iron. A demand arises for numerous smaller articles of food, and gardens, and little farms appear, the high price obtainable for such portions of land offering to the great landowner a strong inducement to the division of his land. The slave who had earned wages in a mill may become an owner of land, or his fellow-slave may cultivate a few acres of cabbage and peas and beans required to meet the demand that has arisen, paying to his master a fixed sum in lieu of his services, retaining the balance as wage. He thus becomes a payer of rent. Each step thus made is but the preparation for a new and greater one. The true way to being about the gradual abolition of slavery must be to endeavor to increase the value of Southern land and Southern labor, to the advantage of both master and servant; a measure that can be accomplished only by an increase in the ration of spades and ploughs, and mills, and furnaces, and other machinery which constitutes wealth, to population. If the Southern man desires to do this he must encourage the owners of such wealth to come or to stay among them. ${ }^{193}$

This view largely joined the two parties together in broad agreement with the basic

precepts of the evolving market revolution. Despite this agreement, the parties endorsed rival

visions of the pathway to success - Democrats supporting laissez-faire capitalism and Whigs

\footnotetext{
${ }^{193}$ Henry Carey, "The Slave Question," The Plough, The Loom, and the Anvil, 1, no. 3 (January 1849), accessed on March 21, 2013, https://play.google.com/books/reader?id=UFYWAQAAIAAJ\&printsec=frontcover\&outpu $\mathrm{t}=$ reader\&hl=en\&pg=GBS.PA401, 405 .
} 
pushing a government-sponsored program of capitalistic development and economic

diversification. Both parties enjoyed the rhetorical use of the concept of classical Jeffersonian

republicanism but neither truly sought a return to those halcyon days. Democrats only showed

conservatism on internal improvements when they perceived the federal government as exerting

too much control, but even then their interest shifted toward how local entities could successfully

secure state-subsidized railroads and federal land grants in their counties. Conversely, the Whigs

explored the balance between slavery and market-orientation in their own party struggles. ${ }^{194}$

\begin{abstract}
${ }^{194}$ Among some of the other interesting discussions of Henry Carey is, "What Constitutes Real Freedom of Trade?" reprinted in The American Review: A Whig Journal, accessed on May 23, 2013, https://play.google.com /store/books/details?id=J4HQAAAAMAAJ. Carey also supported a farmer's journal edited by John Skinner who opened the first volume in 1848 with a meditation on the need for agricultural and industry to move forward together. "A Discourse on the Reciprocal Relations of Agriculture and Other Branches of American Industry," The Plough, The Loom, and the Anvil, accessed on May 23, 2013, https://play.google.com/store/books/details?id=UFYW AQAAIAAJ\&rdid=book-UFYWAQAAIAAJ \&rdot=1. Mathew Carey, The Olive Branch or, An Attempt to Establish an Identity of Interest between Agriculture, Manufactures and Commerce, accessed May 23, 2013, http://archive.org/details/newolive brancho00caregoog. On the reciprocal roles capitalism and the slavery played in developing each other, the South and arguments for Southern exceptionalism see: Joyce Chaplin, An Anxious Pursuit: Agricultural Innovation and Modernity in the Lower South, 1730-1815, (Chapel Hill: University of North Carolina Press, 1993); Mark Smith, Mastered by the Clock: Time, Slavery and Freedom in the American South, (Chapel Hill: UNC Press, 1997); George Winston Smith, "Ante-Bellum Attempts of Northern Business Interested to Redeem the Upper South,” Journal of Southern History 11, no. 2 (May 1945), 177-213; James Gigantino, “Trading in Jersey Souls: New Jersey and the Interstate Slave Trade," Pennsylvania History: A Journal of Mid-Atlantic Studies 77, no. 3 (Summer 2010), 281-302; Frank Byrne, Becoming Bourgeois: Merchant Culture in the South, 1820-1865 (Lexington: University of Kentucky Press, 2006); Douglas Egerton, "Markets Without a Market Revolution: Southern Planters and Capitalism," Journal of the Early Republic 16, no. 2, (Summer 1996), 207-221; Tom Downey, Planting a Capitalist South: Masters, Merchants, and Manufacturers in the Southern Interior, 17901860 (Baton Rouge: Louisiana State University Press, 2006); Lawrence Glickman, “'Buy for the Sake of the Slave:' Abolitionism and the Origins of American Consumer Activism," American Quarterly 56 (December 2004), 889912; Edward Baptist, The Half Has Never Been Told: Slavery and the Making of American Capitalism (New York: Basic Books, 2014); Sven Beckert, Empire of Cotton: A Global History (New York: Knopf, 2014). Contemporary observers argued strongly from both sides of the political divide for a unity of economic purpose. They envisioned factories dotting the Southern green hills and valleys, growing white population, and increasing domestic demand. The increased industrial capacity of the South would allow for greater focus paid by some areas for export commodity production, of which Cuba remained completely dependent, while others focused on refinement for domestic consumption. To some critics, these efforts smacked of the South being thrown the scraps by Northern industry that was directed toward the more lucrative European market. Michele Gillespie, "Building Networks of Knowledge: Henry Merrell and Textile Manufacturing in the Antebellum South," in Technology, Innovation, and Southern Industrialization: From the Antebellum Era to the Computer Age, eds. Susanna Delfino and Michele Gillespie (Columbia: University of Missouri Press, 2009), 97-124. Dale Prentiss, "Economic Progress and Social Dissent in Michigan and Mississippi, 1837-1860," (PhD diss., Stanford, 1990). Paul Quigley Shifting Grounds: Nationalism and the American South, 1848-1865 (Oxford: Oxford University Press, 2011), argues that the consensual view of economic unity displacing concerns over slavery disappeared by the mid-1850s, after which time Southerners felt themselves under constant attack. Southerners rejected the idea of the United States as a nation, saw themselves more in line with the revolutionaries of 1848, and rejected the shared national tradition they extolled only a few years before. Robert Bonner, Mastering America: Southern Slaveholders and the Crisis of American
\end{abstract}


While there existed a component of anti-expansionist and anti-slavery Whigs, their influence waned during and after the Mexican war. The amalgam of an older mercantile elite and newly developed industrial manufacturing class fueled the Whig's embrace of a market capitalism that included participation with and dependence on slavery's continuance. This political and intellectual shift was possible for two reasons. First, the vast wealth promised by engagement with the new economy was hard to reject. This view made the dominant wing of the Whig party more amenable to compromise on the issues of Texas statehood, the prosecution of the Mexican war, and the continuance of slavery. The representatives of constituencies dependent on engagement with Southern agricultural production could ill-afford political alienation of that region. Second, the morally critical wing of the party was hamstrung by the general ambivalence shown toward their natural allies, abolitionists. Thereby, the lamentation of those critical of the party's willingness to pursue profit muted itself with a repellant view of universalist abolition rather than harnessing this impulse to form a productive political agenda within the party. There was also a corresponding generational issue with this new marketoriented wealth creation. The older generation, grown wealthy on the traditional agricultural largess that the slavery-based mercantile organization provided, gave way to a younger generation of investment capitalists looking for the maximization of profit in less tangible, and less morally directed, enterprises like finance. ${ }^{195}$

\footnotetext{
Nationhood (Cambridge: Cambridge University Press, 2009), outlines the process through which Southerners articulated their nationalist perspective including a more public discussion and defense of slavery with a corresponding extolling of the South's religious conservatism. This line follows the seminal work of John McCardell, The Idea of a Southern Nation: Southern Nationalists and Southern Nationalism, 1830-1860 (New York: Norton, 1981), on the creation of Southern intellectual nationalism. Stephanie McCurry, Confederate Reckoning: Power and Politics in the Civil War South, (Cambridge: Harvard University Press, 2010) persuasively argues against all of this political high mindedness by exposing the efforts at Southern nationalism for what they were, simple defenses of the brutality of slavery and the inequality displayed in Southern society.

195 Kinley Brauer, Cotton Versus Conscience; Massachusetts Whig Politics and Southwestern Expansion, $1843-1848$ (Lexington: University of Kentucky Press, 1967); Michael Holt, The Rise and Fall of the American Whig Party: Jacksonian Politics and the Onset of the Civil War, (Oxford: Oxford University Press, 2003); Daniel Walker Howe,
} 
Overlaying this emergent achievement economy was a looming identity crisis. Young politicians and capitalists wondered how a man could define himself as such within this new web of distant connections. The traditional conceptualization of manhood - freedom from dependence, particularly economic dependence - now required a reconfiguration to the new reality of a market dependence that promised stability and wealth accumulation. For the middle and laboring classes, increasingly divorced from the land and dependent on the vagaries of the market, manhood was yet another anxiety-ridden bonding moment across political persuasions. The stress placed upon traditional bonds of community-based relationships also stressed the newly developing and at times bewildering requirements placed on masculinity. Just as men lost a clear direction as heads of families, so too did they lose that direction in the new impersonal communities of the market economy. Therefore, the physical pursuit of annexation schemes by some men and the rhetorical support and consumption of similarly exotic tales by others allowed them to physically or intellectual satisfy the performative needs required of an active male citizen. However, the challenge of self-improvement in the service of masculine selfdevelopment became a chief concern. The ability to configure and chart a path toward selffulfillment offered middle class men an opportunity to engage with the new market economy in

The Political Culture of the American Whigs (Chicago: University of Chicago Press, 1984); David Gold, An Exemplary Whig: Edward Kent and the Whig Disposition in American Politics and Law (Lanham MD: Lexington Books, 2012); David Potter, The Impending Crisis, 1848-1861 (New York: Harper, 1970); Henry Simms, Rise of the Whigs in Virginia, 1824-1840 (Richmond: William Byrd Press, 1929); A.C. Cole, The Whig Party in the South (Washington, DC: American Historical Association, 1914); Paul Murray, The Whigs in Georgia 1825-1853 (Chapel Hill: UNC Press, 1948); Philip Foner, Business \& Slavery: The New York Merchants \& the Irrepressible Conflict (New York: Russell \& Russell, 1968); Jonathan Atkins, "The Whig Party Versus the 'Spoilsmen' of Tennessee," The Historian 57, no. 2 (Winter 1994), 329-341; E. Malcolm Carroll, Origins of the Whig Party (Durham: Duke University Press, 1922); Gregory A. Borchard, "From Pink Lemonade to Salt River: Horace Greeley's Utopia and the Death of the Whig Party," Journalism History 32, no. 1 (Spring 2006), 22-33; Frederick C. Moffatt, "Barnburning and Hunkerism: William Sidney Mount's "Power of Music" Winterthur Portfolio 29, no. 1 (Spring 1994), 19-42; Judah Ginsberg, "Barnburners, Free Soilers, and the New York Republican Party" New York History 57, no. 4 (Oct. 1976), 475-500; Eric Foner, Free Soil, Free Labor, Free Men: The Ideology of the Republican Party Before the Civil War (New York: Oxford University Press, 1970). On the fusion of religion and market ideology see Beth Barton Schweiger, The Gospel Working Up: Progress and the Pulpit in Nineteenth-Century Virginia (Oxford University Press, 2000). 
ways different than laboring men. Regardless of these differences, perhaps not as fundamentally different than at first appearance, men increasingly had these experiences of class and gender definition within an economy of monetization and commodification.

The 1840s represented a moment for middle class men, one in which new means of class and masculine definition presented themselves in relation to new modes of work and social engagement. Chief among these pursuits was striving for economic security in a competitive marketplace of employment and consumption. This cast laboring men as apart from middle class masculinity in the minds of those occupying new upwardly mobile positions in the new economy. "The struggle for economic and social status in a competitive workplace was the primary way in which ordinary young men sought the standing that had previously been identified with the hereditary prerogatives and civic duties of an aristocratic elite. The moral identity of manhood was something to be acquired within, rather than apart from it." Within the new matrix of shifting masculine identities, consumption of mass media - notably improvement guides, political magazines, trade publications, and how-to books - helped the diffusion of previously identified standards of upper class masculinity downward through the social hierarchy. This aspirational belief, that the trappings of aristocratic wealth were available to all, encouraged young men to vigorously engage in the market economy with the hopes of accumulating wealth and breaking dependency. For many, the tales of great speculative investment in land and commodities flowing through the market brought great attention and support for expansionary undertakings designed to add new markets and consumers to the 
American family. The era of manifest destiny became one of tying individual economic success and masculinity to the strength and virility of the nation. ${ }^{196}$

This new generational investment class, searching for the establishment of its masculine energy in service of the new economy, fueled the building of factories, drove the demand for internal improvements such as canals and railroads, and happily propelled the reliance upon slavery as a profit means beyond the traditional agricultural modes of earlier generations. This embrace of slavery encouraged a shift in the system's geographic heart as well as an increase in its physical human toll. The modernizing capitalist system was no less dependent on slavery as an important pillar of its strength, but it offered a greater variety of profit opportunities that depended on the exploitation of new land with new regimes of rationalized brutality to increase yields. The 1837 financial panic, which engulfed the entire nation, demonstrated the overleveraging of both cotton and slaves. The resulting depression ripped bare the reality of the American financial system's bedrock interdependence of Southern agriculture, industrial manufacturing, and Northern capital investment.

\footnotetext{
196 Thomas Augst, The Clerk's Tale: Young Men and Moral Life in Nineteenth-Century America, (Chicago: University of Chicago Press. 2003), quote on page 5; Amy S. Greenberg, Manifest Manhood and the Antebellum American Empire (Cambridge: Cambridge University Press, 2005); Kristin Hoganson, Fighting for American Manhood: How Gender Politics Provoked the Spanish-American and Philippine-American Wars (New Haven: Yale University Press, 2000), 1-20; Matthew Frye Jacobson, Barbarian Virtues: The United States Encounters Foreign Peoples at Home and Abroad, 1876-1917 (Chicago: University of Chicago Press, 1996), 15-78; Ruth Bloch, "The Gendered Meanings of Virtue in Revolutionary America" Signs, 13 (1987), 33-58; Dana Nelson, National Manhood: Capitalist Citizenship and the Imagined Fraternity of White Men, (Durham: Duke University Press 1998); Anthony Rotundo, American Manhood: Transformations in Masculinity from the Revolution to the Modern Era (New York: Basic Books, 1993), 1-40; Craig Friend and Lorri Glover, eds., Southern Manhood: Perspectives on Masculinity in the Old South (Athens: University of Georgia, 2004); Victoria Bynum, Unruly Women: The Politics of Social and Sexual Control in the Old South (Chapel Hill: UNC Press, 1992); Stephanie McCurry, Masters of Small Worlds: Yeoman Households, Gender Relations, and the Political Culture of the Antebellum South Carolina Low Country (New York: Oxford University Press, 1997); Bertram Wyatt-Brown, Honor and Violence in the Old South (New York: Oxford University Press, 1986); John Cawelti, Apostles of the Self-Made Man: Changing Concepts of Success in America (Chicago: University of Chicago, 1965), chs. 1-5: Judy Hilkey, Character Is Capital: Success Manuals and Manhood in Gilded Age America (Chapel Hill: UNC Press, 1997), 1-20; Bruce Burgett, Sentimental Bodies: Sex, Gender, and Citizenship in the Early Republic (Princeton: Princeton University Press, 1998): Stephanie Coontz, The Social Origins of Private Life: A History of American Families, 1600-1900 (New York: Verso, 1988).
} 
Beyond just the production of commodities, new frontier plantation agriculture implemented innovative means of labor rationalization and advanced business practices representative of the modern capitalistic ethos so lauded in Northern conversation. Slavery was not just a Southern problem from which Northern investors stood aloof. Rather, the system of slavery and its practitioners presented a rich opportunity for willful engagement on the part of Northern capital in the system's expansion into new fertile territory. The factory owner and the plantation owner were not bitter rivals but rather unified in a capitalistic enterprise of discrete economic nodes of production and consumption glued together by financiers and their boosterism in hunt of profit. These economic cords bound the geographic regions of the country together in service of United States integration into the Atlantic transit economy of cotton, sugar, textiles, and finance.

Interestingly, these economic arrangements also solidified community bonds in the South through the creation and strengthening of local credit networks that filled lending needs through the mortgaging, often many times over, of slaves and crop output. To make good on these mortgages borrowers and lenders engaged in a unity of maximized output in order to maximize profit. The intra- and inter- regional/national flow of capital investment and repayment increased the severity of demands and the harshness of punishment meted out on plantations on the southwestern frontier and had a direct effect on the treatment and well-being of the enslaved. However, the numerous and regular economic conversations held between Northern industrialists and Southern planters largely moved past the human toll taken in their joint effort toward rationalization and modernization of production, consumption, and monetization in the entire system. Syncing the combination of revolutionary heritage with economic development 
placed the vocabulary of republicanism in the forefront of negotiations between parties and individuals throughout the United States. ${ }^{197}$

The widespread use of republican imagery and language helped Americans come to grips with their individual positioning in regards to the developing market world. The ability to accumulate and have the government remain disinterested in any attempts to moderate that pursuit became a shared mantra. Party became less important than the individual and his local negotiations with modern capital economics and personal profit motive. Their comfort with the realities of the new market and their corresponding political demands focused Americans'

\footnotetext{
${ }^{197}$ Edward Baptist, "Toxic Debt, Liar Loans, and Securitized Human Beings: The Panic of 1837 and the Fate of Slavery," Common Place 10, no. 3 (April 2010), accessed May 23, 2013, http://www.common-place.org/vol-10/no03/baptist/; Richard Kilbourne, Slave Agriculture and Financial Markets in Antebellum America: The Bank of the United States in Mississippi 1831-1852 (London: Pickering \& Chatto, 2006); Bonnie Martin, "Slavery's Invisible Engine: Mortgaging Human Property," The Journal of Southern History 76, no. 4 (November 2010), 817-843; Ronald Bailey, "The Slave(ry) Trade and the Development of Capitalism in the United States: The Textile Industry in New England," Social Science History 14 (Fall 1990), 373-414; Jessica Lepler, The Many Panics of 1837: People, Politics and the Creation of a TransAtlantic Financial Crisis (Cambridge: Cambridge University Press, 2013); Bray Hammond, Banks and Politics in America from the Revolution to the Civil War (Princeton: Princeton University Press, 1960); Sharon Murphy, "Securing Human Property: Slavery, Life Insurance, and Industrialization in the Upper South," Journal of the Early Republic 25 (Fall 2005), 615-652; Howard Bodenhorn, A History of Banking in Antebellum America: Financial Markets and Economic Development in an Era of Nation-Building (Cambridge: Cambridge University Press, 2000); E. J. Balleisen, Navigating Failure: Bankruptcy and Commercial Society in Antebellum America (Chapel Hill: University of North Carolina Press, 2001); Bruce H Mann, Republic of Debtors: Bankruptcy in the Age of American Independence (Cambridge: Harvard University Press, 2009); John Joseph Wallis, Richard E. Sylla, and Arthur Grinath III, "Sovereign Debt and Repudiation: The Emerging-Market Debt Crisis in the U.S. States, 1839-1843," 2004 NBER Working Paper, accessed May 30, 2013, http://www.nber. org/papers/w10753; William B. English "Understanding the Costs of Sovereign Default: American State Debts in the 1840s," American Economic Review, 86 (March 2004), 259-275; John Joseph Wallis, "What Caused the Crisis of 1839?" NBER Historical Working Paper No. 133, April 2001, accessed May 30, 2013, http://www.nber.org/ papers/h0133; Samuel Rezneck, "The Social History of an American Depression, 1837-1843," American Historical Review 40, no. 4 (July 1935), 662-87; Peter L. Rousseau, "Jacksonian Monetary Policy, Specie Flows, and the Panic of 1837," The Journal of Economic History 62, no. 2 (June 2002), 457-488; Joanne Pope Melish, Disowning Slavery: Gradual Emancipation and Race in New England, 1780-1860 (Ithaca: Cornell University Press, 1998); Edward Baptist, "The Slave Labor Camps of Antebellum Florida and the Pushing System," in Florida's WorkingClass Past: Current Perspectives on Labor, Race, and Gender from Spanish Florida to the New Immigration, ed. Robert Cassanello (Gainesville: University Press of Florida, 2009), 30-62; David R. Roediger and Elizabeth D. Esch, eds., The Production of Difference: Race and the Management of Labor in U.S. History, (Oxford: Oxford University Press, 2012); Walter Johnson, Soul by Soul: Life Inside the Antebellum Slave Market (Cambridge: Harvard University Press, 2001); Sergio Lussana, "To See Who Was Best on the Plantation: Enslaved Fighting Contests and Masculinity in the Antebellum Plantation South," The Journal of Southern History 76, no. 4 (November 2010), 901-940; David J. Libby, Slavery and Frontier Mississippi, 1720-1835 (Jackson: University of Mississippi Press, 2004); Adam Rothman, Slave Country: American Expansion and the Origins of the Deep South (Cambridge: Harvard University Press, 2009); Daniel Brett Rood, "Plantation Technocrats: A Social History of Knowledge In The Slaveholding Atlantic World, 1830-1865," (PhD diss., University of California, Irvine, 2010).
} 
attention far below the federal level. This engagement directed their concerns toward an evaluation of expediency based largely on personal and communal economic benefit. The republican promise of the revolution came to play itself out in the promotion and implementation of internal improvements that promised to develop, rationalize, and increase personal prosperity. The support for federal involvement waxed and waned for many according to their private or local interests. On some occasions larger questions of philosophical import brought the revolution into focus and allowed communities to determine the worth of projects in accordance with a now reified generation of republican philosophic forbearers. However, as Americans approached 1850, the language of republicanism supported all types of economic visions that produced a politics largely consensual in its economic outlook, if necessarily divisive in its rhetoric.

Regardless of these personal perspectives on the worthiness of particular projects, the terrain of the debate took place exclusively on a landscape that naturalized the market and the dependency shown by Americans - farmers, industrialists, bankers, laborers, and slaves - on industrial capital. That the elite guiding the debate largely sidestepped accompanying anxieties with the system - the mountain of debt for those on the cotton frontier, the increasing brutality of treatment for slaves, and the tightening demands of industrial labor - should come as no surprise. The underlying assumptions about the natural inevitability of the system produced a consensus that permeated political and social debates. American republicanism and modern industrial capitalism merged into a self-propagating and mutually reinforcing system that largely quieted political opposition to the system's basic tenets and foundational assumptions. The rights of private property and the advocacy of private personal gain hinged on the integration of commercial, productive, and industrial systems. This necessity for integration drove a political 
agreement that allowed negotiation between government and private streams of improvement

funding. Regardless of the source, the projects undertaken focused on the market economy with little regard given to the rhetoric of yeoman agrarianism beyond personal edification and political point scoring. ${ }^{198}$

The younger factions of both political parties seized control of their respective politics and sought to forge policies that placed economic development ahead of all else. This generation used the resultant prosperity to distract attention from the slavery debate. As a mechanism for distraction, the burgeoning American economic leviathan did not erase racial concerns but certainly did much to focus individual attention throughout the nation on immediate economic positioning, thereby abstracting the enslaved and their labor. The Young America faction of the Democratic Party represented the ascendency of a new market-oriented political philosophy from a party traditionally viewed as anti-market. In actuality, there was very little effort needed by the late 1840 s to move the party toward a more market-favorable position, as the reluctance shown toward capitalistic participation was largely a rhetorical device for politicians on both sides of the isle by the close of the Mexican War. Most important for the new direction in the economic philosophy of the parties was the youth of the proponents of these new ideological positions. The

\footnotetext{
198 John Larson, The Market Revolution in American: Liberty, Ambition and the Eclipse of the Common Good (Cambridge: Cambridge University Press, 2010); Seth Rockman, “The Unfree Origins of American Capitalism," in The Economy of Early America: Historical Perspectives and New Directions, ed., Cathy Matson (University Park: Pennsylvania State University Press, 2006), 335-361 and Scraping By: Wage Labor, Slavery, and Survival in Early Baltimore (Baltimore: The Johns Hopkins University Press, 2008); Sean Wilentz, Chants Democratic: New York City \& The Rise of the American Working Class, 1788-1850 (New York: Oxford University Press, 1984); Jonathan Daniel Wells, Origins of the Southern Middle Class, 1800-1861 (Chapel Hill: University of North Carolina Press, 2004); Gavin Wright, Slavery and American Economic Development (Baton Rouge: Louisiana State University Press, 2006); John Majewski, Modernizing a Slave Economy: The Economic Vision of the Confederate Nation (Chapel Hill: University of North Carolina Press, 2009); C.S. Manegold, Ten Hills Farm: The Forgotten History of Slavery in the North (Princeton: Princeton University Press, 2010); Joshua D. Rothman, Flush Times and Fever Dreams: A Story of Capitalism and Slavery in the Age of Jackson, (Athens: University of Georgia Press, 2012); Fletcher Melvin Green, The Role Of The Yankee In The Old South (Athens: University of Georgia Press, 1972); Lindsay Schakenbach, "From Discontented Bostonians to Patriotic Industrialists: The Boston Associates and the Transcontinental Treaty, 1790-1825,” New England Quarterly 84, no. 3 (September 2011), 377-401.
} 
rise of Young America, and a corresponding but less well-defined group within the Whig party, indicated the rise of a younger generation of politician and voter, both of whom were participants in and increasingly comfortable with the wide network of commercial dependency. As the Whigs sought partners in the near-religious practice of governmental improvements and market capitalism, they found willing believers in this new generation of Democrats. Both groups moved past the romantic yeoman agrarianism of the Jeffersonian era (to which Jackson paid necessary reverence) and replaced it with a market orientation focused on technological improvement, business integration, and international commercial expansion.

Politicians and boosters focused on the concept of 'free trade' as the preferred means of mixing private investment with just the right amount of governmental encouragement. Investors and citizens hoped these efforts, coupled with a strong belief in the lowering of protective tariffs, might fuel the economy and bring the United States out of the economic depression brought on by the Panic of 1837 . As economic prosperity picked up steam by the mid-1840s and with the addition of the Mexican cession, Democrats and Whigs across the country wondered how they might make a buck and looked toward their local economic webs for answers. The degree to which the federal government might produce conditions beneficial to personal gain or otherwise encourage state and local governments to do the same became the center of the debate. State and local political leaders also sought ways to balance national party platform with the imperatives of local political and economic demands. In order to placate demands for extensive involvement in economic growth while simultaneously balancing demands for limits on federal involvement in the states, politicians turned toward land grants and infrastructural improvements such as 
harbors, channel dredging, and private-public partnerships, as the most convenient pathways

toward constituent satisfaction. ${ }^{199}$

As Democrats became more comfortable with a traditional Whig economic policy and as

Whigs found ways to encourage internal improvements in less controversial ways, international

trade became linked to the rationalization of local and regional economic patterns of trade.

Democrats and Whigs saw the benefit of the federal government's role of distributer of

resources, particularly land resources, as different and more agreeable than direct government

investment in development projects. This broad economic agreement was possible during an era,

the late 1840 s and early 1850 s, in which there existed a consensus aimed at avoiding direct

\footnotetext{
${ }^{199}$ For the Democratic Party see: Arthur M. Schlesinger Jr., The Age of Jackson (Boston: Little \& Brown, 1945); Wallace Hettle, The Peculiar Democracy: Southern Democrats in Peace and Civil War (Athens: University of Georgia Press, 2001); Jean H. Baker, Affairs of Party: The Political Culture of Northern Democrats in the MidNineteenth Century (Ithaca: Cornell University Press, 1983); Anthony Gene Carey, Parties, Slavery, and the Union in Antebellum Georgia (Athens: University of Georgia Press, 1997); Roy F. Nichols, The Democratic Machine, 1850-1854 (New York: Columbia University Press, 1923); Michael F. Holt, Political Parties and American Political Development: From the Age of Jackson to the Age of Lincoln, (Baton Rouge: LSU Press, 1992); Joel Silbey, A Respectable Minority: The Democratic Party in the Civil War Era, 1860-1868 (New York: W. W. Norton, 1977); Jonathan Earle, Jacksonian Antislavery and the Politics of Free Soil, 1824-1854 (Chapel Hill: UNC Press, 2003); Tyler Anbinder, Nativism and Slavery: The Northern Know Nothings and the Politics of the 1850s (New York: Oxford University Press, 1994); William N. Chambers, The Democrats, 1789-1864: A Short History of a Popular Party (Princeton: D. Van Nostrand, 1964); Jonathan Earle, "The Undaunted Democracy: Jacksonian Antislavery and Free Soil, 1828-1848," (PhD diss., Princeton University, 1996); Douglas W. Jaenicke, "The Rupture of the Antebellum Democratic Party: Prelude to Southern Secession from the Union," Party Politics 1, no. 3 (Fall 1995), 347-367. On the Young American movement specifically see: Edward L. Widmer, Young America: The Flowering of Democracy in New York City (New York: Oxford Univ. Press, 1999); John Stafford, The Literary Criticism of Young America (Berkeley: Univ. of California Press, 1952); Yonatan Eyal, The Young America Movement and the Transformation of the Democratic Party 1828-1861, (Cambridge: Cambridge University Press, 2007); William T. Kerrigan, “'Young America!' Romantic Nationalism in Literature and Politics, 1843-1861," (PhD diss., University of Michigan, 1997); Mark Lause, Young America: Land, Labor, and the Republican Community (Chicago: University of Illinois Press, 2005); Robert E. Riegel, Young America, 1820-1840, (Norman: University of Oklahoma Press, 1949); Brady Harrison, "The Young Americans: Emerson, Walker, and the Early Literature of American Empire," American Studies 40, no.3 (Fall 1999), 75-97; Robert E. Spiller, "Emerson's 'The Young American," Clio 1 (Oct. 1971), 37-41; David B. Danbom, "The Young America Movement," Journal of the Illinois State Historical Society 67, no. 3 (June 1974), 294-306; Merle Curti, "Young America," American Historical Review 32, no. 3 (October 1928), 34-55; Robert W. Johannsen, "Young America and the War with Mexico," in Dueling Eagles: Reinterpreting the U.S.-Mexican War, 1846-48, eds. Richard Francaviglia and Douglas Richmond (Fort Worth: Texas Christian University Press, 2000), 155-75; Siert F. Riepma, "Young America: A Study in American Nationalism Before the Civil War," (PhD diss., Western Reserve University, 1939); Bradley Jay Cartwright, "Young America: Manifest Destiny and the Rhetoric of Race and Gender, 1837-1855" (M.A. thesis, University of Texas at El Paso, 1999); Jere W. Roberson, "The Memphis Commercial Convention of 1853: Southern Dreams and 'Young America,"” Tennessee Historical Quarterly 33, (1974), 279-96.
} 
discussion over issues of slavery. This period also saw the economic development of the nation become more dependent on a unified political and economic modernization. The limited government rhetoric and solutions of earlier periods (notably the rejection of John Quincy Adams' presidential agenda) could not satisfy the new demands of economic pluralism. The pressure came most directly from some of the largest landowners, financiers, and industrialists in the country, a collective group that saw themselves as more economically interconnected and interdependent than ever before. These men set about coordinating their own economic responses to the new realities of the market while reaching out, and in some instances owning, the means of dissemination of the discussion - newspapers and magazines. For instance, the influential editor of the Democratic Review (after it had a taken a more sectional turn) summed up the prevailing wisdom of the era in a critique of some of the older members of the Democratic Party, notably John C. Calhoun.

This interest (infrastructural improvements) can no longer be satisfied or silenced by that local and narrow policy, which, whilst finding favor for the Federal Government to erect lighthouses on salt water, will discern none to authorize it in understanding the removal of snags from a river. Its calls will now be respectfully heard by all statesmen who can grasp new or unsettled questions with that comprehensive sagacity necessary when the proper time has come, to give them a full solution. And when this is once fairly done, it will from that moment be authoritatively settled, by it truth being recognized by an intelligent and patriotic people, who will, thenceforth, cheerfully acquiesce in all such steps. Indeed, what truehearted democrat, whose very being is faith in the adaptation of man to selfgovernment, doubts the innate capacity of a republic to meet the practical questions arising in the affairs of the people. ${ }^{200}$

\footnotetext{
${ }^{200}$ George Sanders, “Northern Lakes and Western Rivers,” Democratic Review 30, no. 163 (January 1852), 13-17. John Larson, Internal Improvement: National Public Works and the Promise of Popular Government in the Early United States (Chapel Hill: University of North Carolina Press, 2000); Stephen Minicucci, "Internal Improvements and the Union, 1790-1860," Studies in American Political Development 18, no. 2 (October 2004), 160-185 and “The Role of Private Transportation in America's $19^{\text {th }}$ Century 'Internal Improvements' Debate," accessed November 26, 2013 http://mises.org/journals/scholar/internal.pdf; Michael Hostetler, "The Early American Quest for Internal Improvements: Distance and Debate," Rhetorica: A Journal of the History of Rhetoric 29, no. 1 (Winter 2011), $53-$ 75; Charles Sellers, The Market Revolution: Jacksonian America, 1815-1846 (Oxford: Oxford University Press, 1994); Daniel Walker Howe, What Hath God Wrought: The Transformation of America, 1815-1848 (Oxford: Oxford University Press, 2009); Carter Goodrich, Government Promotion of American Canals and Railroads, 18001890 (New York: Greenwood Press, 1960); Aaron Marrs, Railroads in the Old South: Pursuing Progress in a Slave Society (Baltimore: Johns Hopkins University Press, 2009); George Rogers Taylor, The Transportation Revolution (New York: Holt, Rinehart and Winston, 1951); Albert Fishlow, American Railroads and the Transformation of the Ante-Bellum Economy (Cambridge: Harvard University Press, 1965).
} 
This question for practicality and adaptability became much easier to answer as the clarity of market modernization dictated participation of both people and government as the only means of providing for financial success. Those that came to this religion early and quickly, the younger generation of political and economic actors, came to define themselves against the "old fogies" of American society. The market also forced many previously provincial Americans toward a more international stance. The vision of the bonds tying the various local economies to a larger American whole became the vision of America's place within the larger world market economy - a place many hoped might soon rival that of Britain. ${ }^{201}$

The significant international partner in the presumed triumph of this diversification of the American economic system was Cuba. One British observer offered up this meditation on the state of American sugar, British colonialism, and Spanish mismanagement of Cuba with an elegant overview of the prevailing view toward the island for most Americans of the period - a view that obligated, even necessitated American action, demanded British inaction, and established both a social and economic imperative to filibustering.

On the whole, I am inclined to think the sugar planting of Louisiana to be a mistake; and should low prices of sugar prevail for some years running, I should not be surprised to see many of the sugar estates abandoned. Under these circumstances one cannot wonder that

\footnotetext{
${ }^{201}$ Americans shook off British criticism of their filibustering, expansionism, and continuance of slavery by reminding the crown of its colonialism throughout the empire, particularly in India. Elizabeth Kelly Gray, "Whisper to Him the Word, 'India:' Trans-Atlantic Critics and American Slavery, 1830-1860," Journal of the Early Republic, Vol. 28, no. 3 (Fall 2008), 379-406. Also on East Indian commercial competition, see James Fichter, So Great A Profit: How the East Indies Trade Transformed Anglo-American Capitalism (Cambridge: Cambridge University Press, 2010). The issue of non-industrial shifts in the emerging market economy also produced dislocation and bewilderment among the rural laborers, artisans, and smallholders particularly in North. Christopher Clark, The Roots of Rural Capitalism: Western Massachusetts, 1780-1860, (Ithaca: Cornell University Press, 1992); Paul E. Johnson, A Shopkeeper's Millennium: Society and Revivals in Rochester, New York, 1815-1837, (New York: Hill and Wang, 1978); Carol Sheriff, The Artificial River: The Erie Canal and the Paradox of Progress, 1817-1862, (New York: Hill and Want, 1997); Hal Barron, Mixed Harvest: The Second Great Transformation in the Rural North, 1870-1930, (Chapel Hill: University of North Carolina Press, 1997) and Those Who Stayed Behind: Rural Society in $19^{\text {th }}$ Century New England (New York: Cambridge University Press, 1988); T.H. Breen, The Marketplace of Revolution: How Consumer Politics Shaped American Independence (New York: Oxford University Press, 2005); Naomi Lamoreaux, "Rethinking the Transition to Capitalism in the Early American Northeast" The Journal of American History 90, no. 2, (September 2003), 437-461; Peter Way, Common Labor: Workers and the Digging of American's Canals 1780-1860 (Baltimore: Johns Hopkins University Press, 1997).
} 
the Louisiana sugar-planters should cast many a longing glance toward the glowing Cuba. There he sees, only 600 miles away, an island, the paradise of sugar planters, whither two days' sail would bring him and his slaves, and where rich and sure crop would reward his capital and labour. At present an old despotic power is playing the dog in the manger, and our energetic Louisianan may flatter himself, without much exaggeration, that he would be conferring a benefit on the world at large at the same time that he was filling his own pockets. This is the fair side of filibustering; of the foul side I shall say nothing just now. Indeed, there is not much need of saying anything against 'private stealin.' When stealing is to be done at all, it should be done in public and on a large scale; then, like murder, it acquires a certain dignity: as witness our East Indian thefts of a kingdom at a time. But one thing seems clear to me: England is not the constable of the world, and if thefts do take place in the Gulf of Mexico, it is no business of ours. Whatever Spain cannot keep, she deserves to lose. We can have as little sympathy with an effete despotism as with a filibustering democracy. There is a subordinate view of filibusterism which should not be all together overlooked. Many respectable Americans look on such adventurous expeditions as a useful 'counter-irritant' to draw off the peccant humours of the body politic...there is always a considerable floating population, made up of the restless and worthless spirits of the whole world, ready for any mischief. ${ }^{202}$

Many Americans sought to take this economic evangelicalism on the harmony of interest on their own shoulders. Northerners moved in large numbers to the upper South hoping to bring the gospel of diversification and industrial growth with them. Northern periodicals that carried advertisements of leading machinery makers praised the Southern ingenuity on display in the region's efforts toward industrialization. Despite these affirmative steps, Northerners remained confident that Southerners, dependent as they were on Northern capital, would not be able to outpace their Northern competitors. The disputes then arising, many hoped, would come to center on economic competition rather than on the issue of slavery. In fact through industrialization many envisioned a new reality of efficient labor and a transition away from slavery.

The cheerful homes of free workers will rapidly supplant the dingy prisons of droning slaves, and when the people have an opportunity to see how much more profitable is the silver than the cord, how much more is done by a man to whom a dollar is paid than by a

\footnotetext{
${ }^{202}$ James Stirling, Letters from the Slave States, accessed November 30, 2013, http://quod.lib.umich.edu/m/moa/ AFK4050.0001.001?view=toc, 127-128; George Smith, "Ante-Bellum Attempts of Northern Business Interests to Redeem the Upper South," The Journal of Southern History 11, no. 2 (June 1945), 177-213.
} 
slave whom it costs a dollar to support, they will begin to understand why South Carolina has not kept pace in prosperity with the northern and eastern states. ${ }^{203}$

However, the true test of the devotion to international market economy was the full enmeshing of oneself within that system of whim and capriciousness. Americans from the North did that in droves by not only traveling to Cuba but also purchasing land and becoming plantation owners there. The arrival and enthusiastic participation of Northerners in plantation agriculture certainly complicates the picture of slavery and does much to expand the geographic foundations of support for slavery's spread. ${ }^{204}$ The propagation of and active participation with slavery on the part of many Northerners offers clear evidence for a national basis of recognition of the institution's importance in the growth of the Atlantic economic system. The economic gains made strengthened the international and personal ties between the United States and Cuba. ${ }^{205}$ However, not only wealthy Americans desirous of plantation profit traveled to Cuba.

\footnotetext{
${ }^{203}$ Charles James, "The Production and Manufacture of Cotton: with Reference to Its Manufacture in the Cotton Growing States," in Merchants' Magazine and Commercial Review, XXI (1849), accessed May 23, 2013, http://books.google.com/books?id=iKARAAAAYAAJ\&dq=Charles\%20James\%20Hunt\%E2\%80\%99s\%20Mercha nts\%E2\%80\%99\%20Magazine \%20and\%20Commercial\%20Review\%2C\%20XXI\&pg=PA492\#v=onepage\&q=The $\% 20$ Production\%20and $\% 20$ Manufacture $\% 20 \mathrm{of} \% 20$ Cotton $\& \mathrm{f}=$ false, $492-502$.

${ }^{204}$ American traveler George Williams remarked: "I find quite a number of Planters from the United States here, and they nearly all hail from the Northern States...The great amount of American capital invested in slave property in Cuba, and the energy with which the new American settlers have entered on the cultivation of new land, the establishment of new American plantations averaging during the last three years, twenty a year, have largely contributed to give impetus to the trade which has been fatal for the efforts for its suppression." Sketches of Travel in the Old and New World (London: Walker, Evans \& Cosgwell, 1871), 38-40. The industrial reorganization of the Cuban sugar industry and American influence and benefit in that process is handled excellently by Daniel Brett Rood, "Plantation Technocrats: A Social History of Knowledge In The Slaveholding Atlantic World, 1830-1865." ${ }^{205}$ Roland T. Ely, "From Counting-house to Cane Field: Moses Taylor and the Cuban Sugar Planter in the Reign of Isabel II, 1833-1868," (PhD diss., Harvard, 1959). The career of Moses Taylor is instructive as he dominated the early American sugar trade, with $75 \%$ of all sugar traveling from Cuba prior to 1830 coming on his ships bound for New York City. Taylor, although he never visited Cuba, built up a robust network on the island, faciliatated by his head of investment there, Henry Coit. Taylor gave Coit, who worked closely with Charles Drake and his company in Cuba, wide latitude to conduct affairs, as Taylor didn't speak Spanish and did hold much understanding of Spanish business culture. Taylor was a business man from the old school that demanded the highest quality product from his suppliers. Interestingly, after the early 1830s, Taylor found more money to be made in extending credit to Cuban planters rather than importing sugar. His new role shifted him toward offering a full array of banking and investment services for Cuban planters, not to mention his catering to his Cuban clients - including arranging for a massive whale skelton for Havana's museum and numerous smaller requests from the elite. By 1872, Taylor invested $\$ 3,000,000$ a year in Cuba sugar planter's profits in American investment markets. (Hodas, 23). In something less than a coincidence, once Taylor left the export market, the quality of Cuban sugar stores decreased perciptiously. While this was certainly as a result of the explosion of production and the great profiteering desire, there certain is
} 
With the increased mechanization and technological development in the sugar industry on the island, many American engineering and industrial technicians travelled to the island and took up residence there. These laborers, largely engaged with building and running steam machines in the sugar mills and with railroad construction, became lightning rods for controversy (for example over 1,800 American workers arrived in Cuba in 1858, one year later the number was over 5,000 with over 50\% staying on the island). Spanish authorities often grew angry at American dominance over certain sectors of sugar production through the use of magic-like information that these technicians possessed. Government officials expressed disappointment that the Spanish crown could offer no support, notably in the area of proper schooling or indigenous engineers, to counteract the growing American influence. However, American emigrants argued that their presence demonstrated Cuba's modernity and helped to mechanize sugar production, as Richard Madden indicated during his travels.

The prosperity of the island has derived no small advantage from those numerous American establishments. Improved models of agriculture, of fabrication, of conveyance, were introduced by Americans. The substitution in Cuba of the old grinding mill, rudely constructed of wood, by steam-engine machinery, is also chiefly due to the Americans. To them, therefore, Cuba is indebted for the various improvements if the fabrication of sugar and modes of conveyance of the produce of its plantations, which enable the proprietors to compete so successfully with those of the English colonies. Cuba, ever since I knew it, has been slowly but steadily becoming Americanized. ${ }^{206}$

something instructive in the shift. Taylor, based on the great respect even his competitors offered him, later helmed New York's City Bank (later Citibank) through the depression of 1837. Daniel Hodas, The Business Career of Moses Taylor (New York: New York University, 1976), recounts Taylor importance in the period "Taylor's evolution from small merchant to banker-industrialist illustrates the contribution one can make to a nation's economic growth. As a leading banker, Taylor headed financial institutions which aggregated the savings of individuals and channeled them into productive areas. He also had the capacity to make the kind of developmental decisions that were essential to continued economic expansion. His continuous merging of enterprises into larger units in order to increase their efficiency and profitability was a forerunner of the rationalization of American industry that took place at the turn of the century," (283). Taylor's relative absence from the discussion in the early sugar period in Cuba is a wonder. His papers are housed at the New York Public Library, http://archives.nypl.org/mss/2955.

${ }^{206}$ Richard Madden, The Island of Cuba: Its Resources, Progress, and Prospects, Considered in Relation Especially to the Influence of Its Prosperity on the Interests of the British West India Colonies (London: C Gilpin, 1848), accessed May 23, 2013, http://archive.org/details/1447268.0001.001.umich.edu, 83. Numerous Captain Generals complained of the American influence and indicated their concerns about the political effect of the American presence. The particularly brutal Leopoldo O'Donnell (1843-1848) registered his great displeasure at the American menace, as he looked dimly on the foreign presence in the wake of the Escalera conspiracy and his repression of 
Simultaneously, the presence of these foreign-born technical workers and the sugar industry's dependence on them highlighted the growing economic dependency the island had upon American markets. These American workers were tangible representations of Cuban dependency to such a degree that they often became scapegoats for much of the racial and political unrest of the period. Of these laborers and the dependence on them shown by modernizing planters, Henry Dana observed, "one of a numerous class whom the sugar culture brings to Cuba...must be machinists, as well engineers, for all the repairs and contrivances, so necessary in a remote place, must fall upon them." ${ }^{207}$

Nevertheless, elite Americans, mostly at a distance from the realities of American and Cuban slavery, became comfortable and conversant in the ways in which slavery added to their wealth. This comfort fueled new economic instruments designed to take advantage of this system of profit, increase the productive burdens on plantation owners, and heighten the harshness and human toll of the domestic and international second slavery. The combined effect placed Cuba as a much closer psychological relation to the United States than even the bonds of trade indicated. The racial imperative of white dominance hardened as the push for profit intensified. In the

\footnotetext{
dissent on the island. This brutality and suppression of dissent largely fueled the annexation movement. See Michele Reid-Vazquez The Year of the Lash: Free People of Color in Cuba and the Nineteenth-Century Atlantic World (Athens: University of Georgia Press, 2011). Also an interesting if largely laudatory contemporary political/family biography is Rafael del Castillo, Historia de la vida militar y politica del Excmo. Sr. Capitan General D. Leopoldo O'Donnell, Conde de Lucena, Vizconde de Aliaga, Duque de Tetuan (Catalonia: La Publicidad, 1860), accessed November 30, 2013, http://books.google.com/books?id=L358UvNcDFYC\&pg=PA3\#v=onepage\&q\&f=false. Captain General Federico Roncali (1848-50), Conde de Alcoy, suggested that slave emancipation might be the best way to limit American influence: "Emancipation might be the only means of preventing the island's take-over by the annexationists...this terrible weapon could...prevent the loss of the island," quoted in Hugh Thomas, Cuba: or the Pursuit of Freedom (New York: Da Capo Press, 1998), 214. See also the many complaints registered comprehensively by Jose be la Concha (1850-52), in his Memorias sobre el estado político, gobierno y administración de la isla de Cuba (Madrid: J. Trujillo, 1855), accessed May 23, 2013, http://babel.hathitrust.org/cgi/pt?id=hvd.32044012436598;view=1 up;seq=9. Americans also invested a great deal in extractive investments in Cuba, particularly coal mining concerns on the northern shores. Basil Rauch, American Interest in Cuba: 1848-1855 (New York: Columbia University Press, 1948), 10-35.

${ }^{207}$ Richard Henry Dana, To Cuba and Back: A Vacation Voyage (Boston: Ticknor, 1859), accessed on May 30, 2013, (http://archive.org/details/tocubabackvacati00danauoft, 60.
} 
United States South, this saw the master-slave relationship become even more coercive and fueled the explosion of internal slave trading through New Orleans. This movement of slaves increased demands for stricter plantation control and management. The rapid growth of American slavery on the western frontier combined force with the spread of capitalism throughout the Atlantic world - a system founded upon the infusion of New England capital, the development of the American and British textile industries, and the rapid increase in demand for Cuban sugar. President Polk relayed as much in his Congressional message of 1846.

By the simultaneous abandonment of the protective tariff policy by Great Britain and the United States new and important markets have already been open for our agricultural and other products, commerce and navigation have received a new impulse, labor and trade have been released from the artificial trammels which have so long fettered them, and to a great extent reciprocity in the exchange of commodities has been introduced at the same time by both countries, and great for the benefit of both. ${ }^{208}$

\footnotetext{
${ }^{208}$ James K. Polk, "State of the Union Message 1846," accessed May 30, 2013,http://www.presidency.ucsb .edu/ws/index.php?pid=29487. Stewart Davenport, Friends of the Unrighteous Mammon: Northern Christians and Market Capitalism, 1815-1860 (Chicago: University of Chicago Press, 2008); Jonathan Curry-Machado, "Privileged Scapegoats - The Manipulation of Migrant Engineering Workers in Mid-Nineteenth Century Cuba," Caribbean Studies 35, no.1 (Winter 2007), 207-245. French planters in Saint Domingue previously enjoyed technological development as a means to greater profitability on the backs of their slaves. James E. McClellan, Colonialism and Science: Saint Domingue in the Old Regime (Baltimore: Johns Hopkins University Press, 1992). On the movement of Northerners to the South see Dennis C. Rousey, "Friends and Foes of Slavery: Foreigners and Northerners in the Old South," Journal of Social History 35, no. 1 (Winter 2001), 373-96. Fletcher Green, The Role of the Yankee in the Old South (Athens: University of Georgia Press, 1972), puts the number of Northerners moving south to Cuba at 360,000. Stephen Chambers, in a remarkably detained but brief study of Northern plantation owners, details the ways in which these Americans were seen as much harsher that Cuban owners in meting out discipline and in matters of spatial control on their plantations. So much so, in fact, that Cuban planters held the Americans responsible for the 1825 Guamacaro slave uprising that left nearly $60 \mathrm{dead}$. In response, as Chambers discusses, American owners placed executed slaves' heads on pikes as a bombastic statement to their Cuban critics. He recounts both planters' and travelers' versions of life and events on the island and in doing so argues that these physical movements of Americans demonstrated the ease and comfort with which they also moved their money and acceptance of slavery. "Cuba had become a central spoke in the trans-Atlantic networks of commodities, specie, and human beings that made the expansion of U.S. capitalism possible... The capitalism of the U.S. North and Caribbean slavery were interdependent, not merely in the push-and-pull of trade but in the ease with which northerners changed their names and raised the Cuban whip. Chambers, "At Home Among the Dead: North Americans and the 1825 Guamacaro Slave Insurrection," Journal of the Early Republic 33, no. 2 (Spring 2013), 62-86. Adam Rothman. Slave Country: American Expansion and the Origins of the Deep South (Cambridge: Harvard University Press, 2005); Edward Baptist, Creating an Old South: Middle Florida's Plantation Frontier before the Civil War (Chapel Hill: UNC Press, 2001), and “'Cuffy,' 'Fancy Maids,' and 'One-Eyed Men:' Rape, Commodification, and the Domestic Slave Trade in the United States," The American Historical Review 106, no. 5 (December 2001), 16191650; Brian Schoen, The Fragile Fabric of Union: Cotton, Federal Politics, and the Global Origins of the Civil War (Baltimore: Johns Hopkins University Press, 2009); Daniel Dupree, Transforming the Cotton Frontier: Madison Country, Alabama 1800-1840 (Baton Rouge: LSP Press, 1997); Tim Lockley, Lines in the Sand: Race and Class in Lowcountry Georgia 1750-1860 (Athens: University of Georgia Press, 2004); Chris Olsen, Political Culture and Secession in Mississippi: Masculinity, Honor and the Antiparty Tradition 1830-1860 (New York: Oxford University
} 
The North American influence in Cuba became overwhelming for Cuban society as Americans made their presence known in various economic pursuits. ${ }^{209}$ Spanish colonial officials, hoping to take advantage of the deepening ties, increased trade duties, port charges, and internal taxes, particularly those directed at Americans and those doing business with them. Despite these attempts and the corresponding increase in the cost of living on the island, wealthy Cubans and Americans accepted this taxation regime as just the normal price to be paid for entre into the lucrative Cuban trade. The lower classes most severely felt the weight of resultant higher commodity prices. Regardless of the cost, American shipping and financial interests followed their agricultural comrades to the island and established commercial houses in Cuba's largest cities - notably Havana, Matanzas, and Cardenas. Richard Madden noticed, "Some districts on the northern shores of the island...have more the character of American than Spanish settlement." This combined effort of money and movement effectively guaranteed American

Press, 2000); Peter and Nicholas Onuf, Nations, Markets, and War: Modern History and the American Civil War (Charlottesville: University of Virginia Press, 2006); Walter Johnson, River of Dark Dreams: Slavery and Empire in the Cotton Kingdom (Cambridge: Harvard University Press, 2013); Matthew Guterl, American Mediterranean: Southern Slaveholders in the Age of Emancipation (Cambridge: Harvard University Press, 2008); Sven Beckert, "Emancipation and Empire: Reconstructing the Worldwide Web of Cotton Production in the Age of the American Civil War," in American Historical Review 109, no. 5 (December 2005), 1405-1438; Ernest Obadele-Starks, Freebooters And Smugglers: The Foreign Slave Trade In The United States After 1808 (Fayetteville: University of Arkansas Press, 2007).

${ }^{209}$ Interestingly, the reduction in peninsular Spanish trade with Cuba limited the sea traffic between the island and Spain. This reduced the opportunity for cultural interaction between residents of Cuba and their countrymen on the Iberian peninsula. This also played a prominent role in the retarding of educational development on the island. The state of schooling, both technical and philosophical, on the island was deplorable and with the movement between the homeland and colony limited, sons of the elite traveled to the United States for schooling, whereby they fell into a different body of economic and political influences. Captain General de la Concha bemoaned the status of education in Cuba and the dangers that lied within. "The remoteness of the Peninsula, the infrequent communication with the Metropolis as compared with that which Cubans have with North American, the decline of our maritime power have contributed to undermining the spirit of nationality, providing powerful encouragement to the youth of the island to obtain education in the United States, where they acquire habits pernicious to the constituted government" de la Concha, Memorias, 541. Victoria-María MacDonald, Latino Education In The United States: A Narrated History From 1513-2000 (New York: Palgrave Macmillan, 2004), 1-88. 
dominance of the Cuban markets leaving Cuban producers dependent on Americans for access to North American markets. ${ }^{210}$

These financial and transport beachheads allowed a foundation from which supporters moved into other areas of financial investment in the island including cafetal and ingenio ownership. Not surprisingly, the number of Americans in Cuba doubled between 1840 and 1860 . These immigrants remade the economic and geographic landscape of the island. American planter D. B. Woodbury and merchant William Safford founded the city of Cardenas in 1828. A weekly trade magazine, The Mercantile Weekly Report, circulated in Havana and directed its content to an American reading audience. Celebrations of George Washington's birthday were yearly occurrences in many Cuban towns. Most notably, the proliferation of mainly womanowned boardinghouses catered to American visitors and less wealthy laborers through the offering of provisions and shelter along with entertainment and social events. These houses were spaces of cultural interaction and diffusion among Cubans and Americans, with the more exclusive clubs and association lodges being some of the most important locations of economic, political, and commercial interaction amongst elite Cubans and Americans. Intermarriage between some of the most influential families north and south of the Florida Straits further enhanced the number and depth of commercial connections. The effect of these connections was an unyielding push toward modernization that deepened United States dominance with American technology, machines, and engineers facilitating that process. Traveler Maturin Ballou observed,

American steam engines are fast taking the place of animal power and more or less are monthly exported for this purpose from New York, Philadelphia and Boston. This creates a demand for engineers and machinists, from whom the Cubans are dependent upon this country and there are said to be at this time two hundreds Bostonians thus engaged at a handsome remuneration upon the island. ${ }^{211}$

\footnotetext{
${ }^{210}$ Richard Madden, The Island of Cuba, 83.

${ }^{211}$ Muturin M. Ballou, History of Cuba: Or Notes of A Traveller in the Tropics (Boston: Philips, Sampson \& Co., 1854), accessed November 30, 2013, http://archive.org/details/historyofcubaorn32812gut, 145. On Washington's birthday, Anonymous, A Winter in the West Indies and Florida (Boston: Wiley and Putnam, 1839), accessed
} 
Given that Cuba was, for all economic purposes, already functioning as part of the United States, the only remaining issue was development of the intellectual case for official transfer of political control. This process, undertaken by various actors, was public and forceful and took place during a period of intense discussion concerning the development of a truly American literary reality. As changes in the economics of the country fueled political shifts, so too did those economic realities fuel an unprecedented growth in the philosophical discussions undergirding American society. At the discussion's heart was a debate over the need for and dissemination of information as necessary to increase knowledge and profit. The goal was a nation that could growth spatially, economically, and intellectually, with the corresponding expectation that territorial ambition, once sated, might yield to a less aggressive, less costly, but continuous expansion of the American mind. This growth would make the need for the revolutionary regeneration that expansion promised non-existent. To accomplish this goal, many Americans promulgated the idea of improving national educational systems. ${ }^{212}$ Some Americans, particularly Whigs, advocated for a system of national universities designed to guide this stabilizing intellectual growth. Most hoped that the United States might better compete in the world of market economics and ideas, a largely European world, with improvement in science and letters. "In short, they wanted to have the cultural institutions that characterized European powers - yet avoid both the monarchies and revolutions of 1848."213

\footnotetext{
November 30, 2013, http://books.google.com/books?id=hCUCAAAAYAAJ\&source =gbs_navlinks_s, 100. On the intimacy of American involvement in the economy of early Cuba see Basil Rauch, American Interest in Cuba (New York: Columbia University Press, 1948).

${ }^{212}$ Larry Reynolds, European Revolutions and the American Literary Renaissance (New Haven: Yale University Press, 1988), argues that the political issues and events that served as a catalyst for the European revolutions also worked to shape American intellectual thought and literary imagination. The revolutions offered up characters, plots, and themes Americans molded to produce their new revolutionary heritage.

${ }^{213}$ Brian Ingrassia, "“From the New World to the Old and Back Again:' Whig University Leaders and TransAtlantic Nationalism in the Era of 1848," Journal of the Early Republic 32, no. 1 (Winter 2012), 668-692. The national university idea never came to fruition in deference to the precepts of federalism and a more diffuse system
} 
The development of an unofficial national curriculum that might guide the lofty debates of the day became the driving motivation of many in the literary set. These efforts centered largely on creating a national literature. This was a cross-sectional effort with college presidents, business men, and the literati from all regions of the United States advocating special attention be paid to development of a literary canon through the training of authors and the encouragement of popular consumption. Diverse voices presented their philosophical points. Philip Lindsley, of Cumberland College (Nashville) remarked on the need for a broad ranging curriculum. "Let us make ample provision for every species of instruction - scientific, literary, professional - which our country demands." The editor of the North American Review, Jared Sparks opined on the application of curriculum to economic life. "Let us have an establishment where we can teach young men something about the operations of their own minds, the doings of the world, and the business of life. Europe is full of such institutions, it is time for one at least in America." This process was also one very much designed at establishing the exceptionalism of American learning as mutually reinforcing of similar efforts in the area of American political culture. The

of state schools. As the political negotiations between Whigs and Democrats continued on the issue of internal improvements, education came to be considered part of them. In response national politicians actively courted and encouraged their old favorite, land-grants, to help with state university creation - a process that was exponentially accelerated after the Civil War under the Morril Acts. For the earlier land grant efforts and the development of the University system see: Edmund B. James, The Origin of the Land Grant Act of 1862 : (the so-called Morrill Act) and Some Account of Its Author, Jonathan B. Turner (Urbana: University of Illinois Press, 1910), accessed December 12, 2013, http://archive.org/details/originoflandgran00jame; Mary Carriel Turner, The Life of Jonathan Baldwin Turner (Urbana: University of Illinois Press, 1961); James Turner and Paul Bernard, "The 'German Model' and the Graduate School: The University of Michigan and the Origin Myth of the American University" in, Language, Religion, Knowledge: Past and Present, ed. James Turner (South Bend: Notre Dame University Press, 2003), 69-94; Eldon L. Johnson, "Misconceptions About the Early Land-Grant Colleges," The Journal of Higher Education 52, no. 4 (July-August 1981), 333-351; Laurence R. Veysey, The Emergence of the American University (Chicago: University of Chicago Press,1965); Burton Bledstein, The Culture of Professionalism: The Middle Class and the Development of Higher Education in American (New York: W.W. Norton, 1976). On religion in development of early universities see George M. Marsden, The Soul of the American University: From Protestant Establishment to Established Nonbelief (New York: Oxford University Press, 1994), 101-112. 
process was widespread and mutually constituting, engaging all sectors of Americans society as well as all walks of American life. ${ }^{214}$

While some advocates engaged in national discussions, just as in the economic realm, the reality of the development and practice of literary exceptionalism fell on the individual shoulders of Americans seeking to tell their story and to consume the stories of others. Industrialization, expansionism, popular literacy, and international trade came together for Americans in a selfreflective and deliberate way in the middle decades of the nineteenth century. The productive source of this interest came from the growing involvement on the part of Americans throughout the country, particularly the economic elite, with cultures throughout the world. The strengthening and binding of the economic connections of market capitalism fueled this involvement. Northerners and Southerners alike engaged with mercantile elite throughout the world; a process that familiarized them with other cultures and national imperatives. This classconsciousness did much to reduce the ferocity of political disagreement and to develop a rapport built upon shared cultural appreciations. This American bourgeoisie developed a desire not only to guide cultural development within the United States but also to continue their own cultural development through interaction with their compatriots throughout the world. As the production of a distinct American culture through the molding of foreign influence and products for American sensibilities continued apace, the material and intellectual trappings of elite status markers were within the grasp of an ever-widening circle of middle class aspirants. This petite bourgeoisie sought to use cultural capital in similar ways as the elite and hoped that through this

\footnotetext{
${ }^{214}$ Philip Lindsley, "Baccalaureate Address, October 2, 1832," and Jared Sparks to George Bancroft, June 10, 1829, both quoted in Ingrassia, "Whig University Leaders." Mark Groen, "The Whig Party and the Rise of Common Schools, 1837-1854," American Educational History Journal 35, no. 1/2 (Spring/Summer 2008), 251-260; John Guillory, Cultural Capital: The Problem of Literary Canon Formation (Chicago: University of Chicago Press, 1993).
} 
appropriation their economic and cultural status might become mutable. Most clearly

encapsulating the social movement and aspiration present in this hopeful mutability was travel

literature. $^{215}$

Travelers to Cuba served a central role in the evolution of the United States nation state and of bourgeois social dominance by facilitating imperial interaction and comparative ideological critique. These elite observers were the ones traveling, searching, translating, and interpreting that which they encountered. However, thanks to the explosion of cheap printing methods, these stories became more widely disseminated and more powerfully felt than ever before. Furthermore, while engagement with far-flung empires and cultures fired the imagination of readers, they - unlike the authors who had the means to travel and escape their parochialism had to place the stories they read in their own unique local settings. Readers used what they read as a lens through which to understand the challenges and happenstance of their daily lives.

Hence, the consumption of travelogues, particularly from the most exotic climes south of the United States, tied many Americans to the world more closely, while simultaneously reminding them of their isolation from the destinations of their imagination. ${ }^{216}$

\footnotetext{
${ }^{215}$ On American cultural development of the early republic, North and South, see: Michael O'Brien, Conjectures of Order: Intellectual Life and the American South, 1810-1860 (Chapel Hill: UNC Press, 2003); Thomas Bender, New York Intellect: A History of Intellectual Life in New York City, from 1750 to the Beginnings of Our Own Time (Baltimore: John Hopkins University Press, 1987) and Intellect and Public Life: Essays on the Social History of Academic Intellectuals in the United States (Baltimore: Johns Hopkins University Press, 1997), 1-40; David Waldstreicher, In the Midst of Perpetual Fetes: The Making of American, Nationalism, 1776-1820 (Chapel Hill: UNC Press, 1997); Adam Arenson, The Great Heart of the Republic: St. Louis and the Cultural Civil War (Cambridge: Harvard University Press, 2011); Louis Menand, The Metaphysical Club: A Story of Ideas in America (New York: Farrar, Straus, and Giroux, 2001); Sven Beckert, The Monied Metropolis: New York City and the Consolidation of the American Bourgeoisie (New York: Cambridge University Press, 2001); and Julian Rosenbaum, ed., The American Bourgeoisie: Distinction and Identity in the Nineteenth Century, (New York: PalgraveMacmillan, 2010). On a specific middle class literary consciousness see, Karen Halttunen, Confidence Men and Painted Women: A Study of Middle-Class Culture in America, 1830-1870 (New Haven: Yale University Press, 1986), and Stuart Blumin, The Emergence of the Middle Class: Social Experience in the American City 1760-1900 (New York: Cambridge University Press, 1989).

${ }^{216}$ James Ullman describes the importance of travel to the self-conceptualization of the emerging middle and upper classes in the United States. "Narratives involving movement and interaction with distant peoples powerfully highlighted the themes of transformation and became central to the bourgeois ideology. They also provided an effective basis upon which to fashion arguments of comparative identity and self-worth. Thus while the new
} 
technological, commercial and social developments were a necessary condition for this new social group's interest in either travel or other lands and people, they provide only part of the explanation...First of all the conditions of mobility and transformation were integral to the social milieu in which the bourgeoisie arose. The social opportunities into which the bourgeoisie emerged were in large part dependent upon actual development of commercial networks and imperial expansion. The manipulation to one's advantage of extended market networks, exploitation of distant resources and willingness to transplant oneself became critical to personal betterment within society. Economic and social improvement was directly linked to the movement through and control over space. Belief in the possibility of personal mobility was central to the liberal values of this new segment of the society. As the ideology of bourgeois society evolved, the figurative or metaphoric examples of travel and encounter became intertwined with the language of success. They also became then a means to achieve mastery over the uncertainties of a changing social context. The mythology of renewal...In the United States, for example, members of the heterogeneous bourgeoisie felt themselves precariously perched at the head of an unsteady social order of which they were assuming the role of stewards. It was perhaps the petite bourgeoisie or middle class who felt caught between a disappearing rural, agrarian society and a newer but not yet fully formed way of life characterized by market relations, industrial production and urbanization. As a group they were part by-product and part producer of this emerging society. Just as the world they were creating remained half formed, their sense of identity as individuals and a class straddled the past and the future." Ullman "Geographies of Desire: Bayard Taylor and The Romance of Travel in Bourgeois American Culture, 1820-1880," (PhD diss., Rutgers University, 2007), 12-13. On travel literature and Cuba see: Louis Perez, Impressions of Cuba in the Nineteenth Century: The Travel Diary of Joseph J. Dimock (New York: Rowman and Littlefield, 1998) and Slaves, Sugar, \& Colonial Society: Travel Accounts of Cuba, 1801-1899 (New York: Scholarly Resources, 1991); Yvon Joseph, Four French Travelers in Nineteenth Century Cuba (New York: Peter Lang, 2008); J.G.L. Wurdermann, Notes on Cuba, (Boston: Littlefield, 1844); Edward Sullivan, Rambles and Shambles in North and South American, (Boston: Carleton Books, 1870); Richard Madden, The Island of Cuba: Its Resources, Progress, and Prospects, Considered in Relation Especially to the Influence of Its Prosperity on the Interests of the British West India Colonies (London: C. Gilpin, 1849); Muturin M. Ballou, History of Cuba: Or Notes of A Traveller in the Tropics (Boston: Philips, Sampson \& Co., 1854); Richard B. Kimball, Cuba and the Cubans, (New York: S. Hueston, 1850); James Alexander, Transatlantic Sketches: Comprising Visits To The Most Interesting Scenes in North \& South America \& West Indies, 2 vols. (London: Richard Bentley, 1833); S.M.L. Jay, My Winter in Cuba (New York: E.P. Button \& co. 1871); Richard Henry Dana, To Cuba and Back (Boston: Ticknor \& Sons, 1859); John Glanville Taylor, The United States and Cuba: Eight Years of Change and Travel (London: R. Bentley, 1851); Carlton Rogers, Incidents of Travel in the Southern States and Cuba (New York: R. Craighead, 1862); Abiel Abbot, Letters Written from the Interior of Cuba (Boston: Bowles and Dearborn, 1829); Julia Ward Howe, A Trip to Cuba (Boston: Ticknor and Fields, 1860); Alexander Jones, Cuba in 1851 (New York : Stringer \& Townshend, 1851); George W. Williams, Sketches of Travel in the Old and New World (London: Walker, Evans \& Cosgwell, 1871); Richard Levis, Diary of a Spring Holiday in Cuba (Philadelphia: Porter and Coates, 1872). Perhaps the most famous Cuban travel writing is Alexander von Humboldt's Political Essay on the Island of Cuba; controversial for its critical view of Cuban slavery which lead to its banning on the island and for a translation controversy surrounding its American publication. On the Humboldt/Thrasher controversy in which Humboldt's American translator, John Trasher, edited out Humboldt's critique of Cuban slavery and race relations see Humboldt's original accusation reprinted in the New York Herald, 8/13/1856, accessed on December 15, 2013, http://press.uchicago.edu/dms/ucp/books/microsites/humboldt/ documents/21-Newspaper08131856.pdf, and translator John Thrasher's response New York Times, 8/16/1856, accessed on December 15, 2013, http://query.nytimes.com/mem/archive-free/pdf?res=9D05E6D91339E134BC4E5 2DFBE66838D649FDE. For scholarly investigations see Vera M. Kutzinski, Political Essay on the Island of Cuba: A Critical Edition (Chicago: University of Chicago Press, 2010) and "Translations of Cuba: Fernando Ortiz, Alexander von Humboldt, and the curious case of John Sidney Thrasher," Atlantic Studies Literary, Cultural and Historical Perspectives 6, no. 3 (Fall 2009), 303-26; Michael Zeuske, "Alexander von Humboldt in Cuba, 1800-01 and 1804: Traces of an Enigma," in Studies in Travel Writing 15, no. 4 (December 2011), 347-358; Oliver Lubrich, "In the Realm of Ambivalence: Alexander von Humboldt's Discourse on Cuba," German Studies Review 26, no. 1 (January 2003), 63-80. For another firsthand account of slavery in Cuba see Joseph John Gurney, A Winter In The West Indies: Described in Familiar Letters to Henry Clay, of Kentucky (London: J. Murray, 1840), letter XIII, accessed May 21, 2013, https://books.google.com/books?id=MbYNAAAAQAAJ\&dq=A\%20Winter\%20In\%20 The $\% 20$ West $\% 20$ Indies $\% 3$ A $\% 20$ Described $\% 20$ in $\% 20$ Familiar\%20Letters $\% 20$ to $\% 20$ Henry $\% 20$ Clay $\% 2$ C $\% 20$ of $\% 2$ 0Kentucky\&pg=PA199\#v=onepage $\& \mathrm{q}=$ letter\%20XIII\&f=false 
The consumer culture then developing in the United States looked to literary development, both high and low brow, to alleviate the anxiety associated with personal position within the market economy. The last and essential key to the rebuilding of the national product was literature. While the destinations and market for travel writing followed a unique American course in the United States, the majority of commonly consumed literature of the 1830s followed European models. Newspapers often reprinted European news stories and European novels were the most popular fiction works in the United States. Lingering regionalism in economics and politics muted any unifying influence a native literature might enjoy. The 1840 s then presented themselves as a particularly angst-ridden moment in the history of the country. While the economics of the era portended a great future, Americans from every political and cultural stripe - Young Americans, Boston and Cambridge intellectuals, Locofocos, Democrats, and Whigs argued whether the nation was on the verge of collapse because it had yet to develop a culture of its own, distinct from what many saw as overwhelming European influence. Given the upheaval on display in the revolutions of 1848, Americans feared the decaying influence of European thought even more.

However, there also existed a series of domestically focused concerns, not as easily ignored as foreign influences, which placed a premium on the cultural project. Many Americans feared that with ever-changing borders, no prima facie claim to their land, a weak central government, no distinct ethnicity, and no mystic past upon which to build cultural and social institutions, the United States as a nation would always be in need of redefining. With that reality, redefining of national status threatened to become all-consuming and unending. This constant state of searching and flux offered no guarantees against continuous revolution. Despondent over the state of books and newspapers and a general lack of American cultural 
invention accompanying the strong economic development of the nation, Americans formulated grand plans to imbue an existing medium, the magazine, with a new spirit and intention. The great hope was that magazines would become a conduit through which Americans might forge a new and unique national culture.

The vital strategies, boundaries, and topics that informed the postbellum magazine were the product of divisive culture wars fought in the post-Jacksonian era. "Culturists" battled over the form American nationalism should and could take. They argued whether the nation could invent and produce a nurturing democratic culture to rival the bitter democratic politics of the day. And they struggled over the problem of delineating the cultural repertoire on which the American magazine would define itself...the goal is to reconceptualize the study of literary texts as attempts to redefine the social order. Newspapers have traditionally been conceived of as the medium of American political expression. Books and novels have traditionally been considered the expression of American culture. But magazines have largely been written off as a form of "female" expression unworthy of study. Magazines were the expression of female culture. But the aim of the 1840s nationalists was to use that culture to reform "male" politics as well as sectarian religious movements and regional parochialism. America in the 1840s was convulsed by seemingly endless religious sectarianism, political partisanship, and cultural warfare between cities and regions. For the early magazinists, all these dilemmas resolved into a single, seemingly intractable problem: how to foster national cohesion in a country built on the socially fragmenting ideology of democratic individualism. Recoiling from the bitter public divisiveness and eventual Civil War wrought by male politics, these magazine editors turned to the female culture of sentimentality, administered through the magazine, as their means for creating national community - but not in its female guise. The culture of sentimentality could not take wide hold until it had run the gauntlet of an intense battle over the gendered nature of American culture. The site of this battle was the American magazine. ${ }^{217}$

The 1830s, prior to the magazine's ascendency, saw the newspaper take on a more direct

role in shaping American's reading habits and interests as well as defining a new approach to

${ }^{217}$ Reynolds J. Scott-Childress, "Cultural Reconstruction: Nation, Race and the Invention of the American Magazine, 1830-1915," (PhD diss., University of Maryland, 2003), 14-15. Scott-Childress designs much of his argument around the issue of sentimentality and the cultural battle found over the concept itself. He explores the debate over the appropriateness of its use in male political or cultural production and its use in a newly conceptualized way, contra newspapers, to widen appeal and to encourage Americans to view the news and debates of the day differently than penny press publishers wished. In seeking this alternative public space that invited men and women into discussion, magazinists had to confront the issue that most of the magazines available were for women and sentimentality was a feminine domain of patterned response and different readership than the masculine, gory, and violent victim-based stories of the penny press. As a way out of this paralyzing conundrum men sought the creation of a masculinized sentimentalized space in the magazine. The newspaper could not hope to accomplish this task because their acutely commercial nature, their regional provincialism, and their traditional political partisanism. In the 1840 s, culturists believed sentimentality, disseminated through the magazine, could counterbalance the destructiveness of male politics. 
transmission of information. This transformation in form drove readers toward new methods of social communication. Society became infinitely bigger and more interconnected as stories and information no longer focused just on elite concerns and consumption. The new form penny presses, in efforts to attract average readers, focused themselves on average happenings. The penny press sold the imagined urban community to readers who related to the happenings of people so like themselves, but whom they would never meet outside of newsprint lines. The interest generated among these new readers pushed the market toward a lower class audience. These newspapers also developed many new literary devices to increase interest, among these was the literary sketch. These often plotless takes on culture and people and their complimentary form, short story flash-fictions, allowed Americans interaction with new people and new literary art forms which paid dividends in the creative output of these same classes of people in the 1840s and 1850s. ${ }^{218}$

The urban landscapes that these newspapers found themselves in required much of their inhabitants, as residents struggled to understand not only the architectural landscape but also the human topography encountered daily on both the page and in reality. The necessity to be literate of these landscapes was especially important for new rural arrivals searching for work and struggling to find the means to secure employment. The penny press therefore took on a local flavor that helped residents of neighborhoods navigate a small percentage of a city's geography but simultaneously assured them that there were other communities engaged in similarly meaningful pursuits. However, the news stories in these papers did more to fracture nascent unity than to encourage it. Most readers' concerns rested on the five-block radius of their daily

\footnotetext{
${ }^{218}$ Michael Schudson, Discovering the News: A Social History of American Newspapers (New York: Basic Books, 1978), ch. 1; and Jeffrey L. Pasley, The Tyranny of Printers: Newspaper Politics in the Early American Republic (Charlottesville: University of Virginia 2002).
} 
existence. This provincial take on meaning was a fundamental change from the political, mercantile, and religious papers and journals that dominated the early literary landscape of the country. The laboring classes of Americans felt little need to observe their national society through the medium of print because they did not perceive a larger society beyond the outskirts of their urban settings. Their concerns were more pedestrian, prosaic, and survival-oriented.

In the mid-1830s, a new group of upwardly mobile newspaper editors transformed the content of the penny presses, if not the form. These publishers, like the magazinists of the 1840s, were entrepreneurs bent on raising their social and economic standing through commerce in the news. They found success because of "the remarkably fluent use of the idiom and ideology prevalent among its public tradesmen." 219 These printers and editors were mostly middle class workingmen from the outskirts of larger cities with no direct links to the urban areas they sought to cover. They, like many in the middle class, were locked out of the traditional sources of information and influence that relationships with politicians and merchants brought others. This produced in the newsmen an active dislike for the games these elites played and a disinterest, if not repulsion for, the thought of kowtowing to upper class sensibilities. As they gained success this chaffing at reproduction of elite news and concerns drove them toward an almost maniacal affinity for their lower class readers, at least in the production of news and ideas that were important to those readers. They were proud opponents of the political and mercantile papers, as well as the readers of those pages. ${ }^{220}$

In the process of finding new sources of news in the streets and among the readers they sold to, these editors invented two attributes of news that became essential to their business

\footnotetext{
${ }^{219}$ Dan Schiller, Objectivity and the News: The Public and the Rise of Commercial Journalism (Philadelphia: University of Pennsylvania Press, 1994), 10.

${ }^{220}$ Daniel Czitrom, Media and the American Mind: From Morse to McLuhan (Chapel Hill: University of North Carolina Press, 1982), 14-70.
} 
success: sensationalism and objectivity. Helping readers see beyond their daily experiences required a medium that stimulated the imagination and that seemed to impart to the readers' imaginations a solid and truthful reality. "The cheap press supporting its defense of public good invoked journalistic objectivity successfully because of the pervasive hold of science over the public imagination, a grip made firmer still by photographic realism.” The cultural forms the penny press adapted to the urban social imagination derived chiefly from the need of these papers to be socially representative of the real experiences of their readers. The papers' low prices and multivalent formats and content were a reaction against the closed world of subscription papers produced for the mercantile and political elite. ${ }^{221}$

The remarkable success of these cultural forms was due to their unique capacity to provide a 'reading' of the city. Each new genre of commercial culture compressed a representation of city life into its format. These new genres had in common a seemingly random, potpourri organization that continued to dramatize the discontinuity, the kaleidoscopic variety, and the quick tempo of city life. Their essence was to create, out of miscellaneousness, little self-contained worlds that were perceived spatially rather than narratively. Like photographs, these pastiches were susceptible to varied interpretations. ${ }^{222}$

Penny press printers used popular literary genres, like crime novels and seduction stories, hoping to capture an already enraptured public to their pages. Calls for reform, produced as a result of popular cases and causes of the day, did much to democratize virtue and concern. The working classes felt an affinity and responsibility to police their actions lest they fall prey to the rapacity on display in other classes that they read so much about in their papers. The knowledge that greed and evil went up and down the social ladder allowed readers to re-envision their personal and class-based social connections. ${ }^{223}$

\footnotetext{
${ }^{221}$ Dan Schiller, Objectivity and the News: The Public and the Rise of Commercial Journalism (Philadelphia: University of Pennsylvania Press, 1994), 181.

${ }^{222}$ William R. Taylor "The Launching of a Commercial Culture: New York City 1860-1930," in Power, Culture and Place: Essays on New York City, ed. John Hull Mollenkopf (New York: Russell Sage Foundation, 1988), 108. ${ }^{223}$ Hazel Dicken-Garcia, Journalistic Standards in Nineteenth-Century America (Madison: University of Wisconsin Press, 1989), 49-96.
} 
However, despite their popularity, the penny press did little to create a sense of national cohesion. They were too intensely local, too competitive, and were too urban in their focus. While they had done much to create a shared urban social experience, that imagined experience linked people only in an immediate area and did so along ever-hardening class lines. A new medium needed to come forward for a truly national cultural and literary experience to take shape. Magazines seemed to be the best medium for devising and disseminating this new national culture. Books were too costly and the most popular were European; newspapers too provincial and ephemeral. Magazines had shelf life and built upon an already existing and voracious appetite among the reading populace. They could be pondered thanks mainly to their more stable physical presence. They allowed authors and editors the space and creative freedom to meander through the ideas of the day while providing powerful outlets of discussion and debate for their readers.

Between 1825 and 1850 publishers launched hundreds of magazines in the United States in an effort to create and then feed demand. Most were not successful, exhibiting chaos of content thrown into a crevasse of competing voices and cultures among their readers. Unfortunately, publishers and readers alike had difficulty coming to grips with the new medium as it looked and acted far different from traditional sources of news and ideas. Eventually and with the fortuitous arrival of a variety of other impulses and influences, most notably the debate over war in Mexico, magazines gained a foothold. They became the country's first medium of mass cultural communication as they crossed regional boundaries and class divisions. Chief among the hopes for magazines was that it might be a different type of publication, one which 
didn't look to Europe for aesthetic cues and sought an indigenous expression of the task bequeathed to Americans - a literary codification of the swirl of American destiny all around. ${ }^{224}$

The United States Magazine and Democratic Review saw as its task "to strike the hitherto silent string of the democratic genius of the age and country as the proper principle of the literature of both... and rallying the mind of the nation from the state of torpor and even of demoralization in which so large a proportion of it is sunk." 225 The Democratic Review lived up to its stated intentions. John L. O'Sullivan and Samuel Langtree created the Democratic Review in 1837, with the goal of promoting American cultural indigenization. From the initial issue there was an abiding sense that democracy was a human as well as divine phenomenon. Although the magazine did not actively take an explicitly pro-Christian agenda, many of the contributors, as most Americans, were practitioners of religion and many had faith in God. The natural affinity between religion and democracy made both essential tools for the remaking of society. O'Sullivan made the combination of literary nationalism, democracy, and religious sensibility, foundational to the political positioning of his new magazine and explicit in his introduction to the first edition. The year 1837 was a precipitous moment to begin a new magazine and create a new approach toward American democracy. Politically, Andrew Jackson passed into history as a former president and the uneasy heir to his throne was untested. Literarily, Ralph Waldo Emerson put forth a weighty call to greater intellectual rigor and American cultural creation rather than reactionary mimicry in "The American Scholar." Additionally, O'Sullivan saw around him a disparity in the popular media as Whig mouthpieces in the newspaper arena

\footnotetext{
${ }^{224}$ Matthew Schneirov, The Dream of a New Social Order: Popular Magazines in America, 1839-1914. (New York: Columbia University Press, 1994), introduction; and John William Tebbel and Mary Ellen Zuckerman, The Magazine in America, 1741-1990 (Oxford: Oxford University Press, 1991), ch. 1.

${ }^{225}$ John L. O'Sullivan, "Introduction: The Democratic Principle, The Importance of Its Assertion, and Application to Our Political System and Literature," Democratic Review 1, no. 1 (October 1837), 15.
} 
dominated much of the political debate. The Democratic Review, he hoped, might bring a fresh voice and a measure of equilibrium to the publishing world of antebellum America. His task became easier as economic changes, particularly the economic depression of the late 1830s, pushed Whig and Democrats closer together politically. ${ }^{226}$

O'Sullivan's conceptualization of democracy was the engine that drove the man and his work. The partisan prism through which much of his work must be viewed does not limit the expansiveness of his vision of American democracy. While he championed a Democratic administration at the head of that democracy, he saw the American experiment as the beginning of a worldwide revolution of political and intellectual scope. O'Sullivan believed that this new constellation of great art, literature, and philosophy should and would spring from the same impulse that had produced the Constitution. He believed that if American politics and culture held together, democracy might spread successfully throughout the hemisphere. ${ }^{227} \mathrm{O}$ 'Sullivan spoke of this spread with secular religiosity;

It is borrowed from the example of the perfect self-government of the physical universe, being written in letters of light on every page of the great bible of Nature. It contains the idea of full and fearless faith in the providence of the Creator. It is essentially involved in Christianity, of which it has been well said that its pervading spirit of democratic equality among men is its highest fact, and one of its most radiant internal evidences of the divinity of its origin.

O'Sullivan's conception of spiritual democracy animated its spread with a philanthropic

disinterest in aggrandizement and benevolence toward all humankind.

For Democracy is the cause of Humanity. It has faith in human nature. It believes in its essential equality and fundamental goodness. It respects, with a solemn reverence to which the proudest artificial institutions and distinctions of society have no claim, the human soul. It is the cause of philanthropy. Its object is to emancipate the mind of the mass of men from

\footnotetext{
${ }^{226}$ Douglas Widmer, Young America: The Flowering of Democracy in New York City (Oxford: Oxford University Press, 1999), ch. 1. One of the more interesting takes on the intersection of culture, literature, the 1837 Panic, and economics is Heinz Tschachler, The Monetary Imagination of Edgar Allan Poe: Banking, Currency and Politics in the Writings (Durham: McFarland, 2013).

${ }^{227}$ Robert Sampson, John L. O'Sullivan and His Times (Kent, OH: Kent State University Press, 2003), chs. 2-3. Surprisingly Sampson's work is the only full-length treatment of O'Sullivan's life.
} 
the degrading and disheartening fetters of social distinctions and advantages; to bid it walk abroad through the free creation in its own majesty; to war against all fraud, oppression, and violence; by striking at their root, to reform all the infinitely varied human misery which has grown out of the old and false ideas by which the world has been so long misgoverned...It is, moreover, a cheerful creed, a creed of high hope and universal love, noble and ennobling; while all others, which imply a distrust of mankind, and of the natural moral principles infused into it by its Creator, for its own self-development and selfregulation, are as gloomy and selfish.

O’Sullivan also spoke deeply on the relationship between democracy and literature. He feared

that the sanctuary of culture rested with an elite who overwhelmingly supported the Whigs. This

was an unacceptable reality for O'Sullivan, who held that,

The democratic cause is one which not only ought to engage the whole mind of the American nation, without any serious division of its energies, to carry forward the noble mission entrusted to her of going before the nations of the world as the representative of the democratic principle and as the constant living exemplar of its results, but which ought peculiarly to commend itself to the generosity of youth, its ardent aspirations after the good and beautiful, its liberal and unselfish freedom from narrow prejudices of interest.

For O'Sullivan youth and ambition, would soon solidify culturally literate America's

leadership of the world toward transcendent democratic reckoning. With that success, he

assumed, would come a vindication of the American experiment. In order to prepare for this

leadership, Americans needed to develop a native literature extolling of the nation's fitness for

leadership, deserving of its position among nations, and capturing of the national soul.

The vital principle of an American national literature must be democracy. Our mind is enslaved to the past and present literature of England... We have a principle--an informing soul--our own, our democracy, though we allow it to languish uncultivated; this must be the animating spirit of our literature, if indeed, we would have a national American literature. There is an immense field open to us, if we would but enter it boldly and cultivate it as our own. All history has to be re-written; political science and the whole scope of all moral truth have to be considered and illustrated in the light of the democratic principle. All old subjects of thought and all new questions arising, connected more or less directly with human existence, have to be taken up again and re-examined in this point of view. ${ }^{228}$

He echoed this perspective five years later.

The spirit of Literature and the spirit of Democracy are one...Literature is not only the natural ally of freedom, political or religious; but it also affords the firmest bulwark the wit of man has yet devised, to protect the interests of freedom... Of all men the author and

\footnotetext{
${ }^{228}$ Preceeding four block quotes from, O’Sullivan, "Introduction," 9-11.
} 
scholar should come nearest to the ideal of the Patriot...Every discovery he makes is for the benefit of his countrymen: every truth vigorously enunciated should instruct them... The novelist, the historian, and the poet...are essentially democratic. ${ }^{229}$

O'Sullivan displayed a sense of optimism about the progress of his project by 1839 . His writing

also displays a racial consistency as well. Throughout his days as editor of The Democratic

Review, O'Sullivan saw the key to the American right of expansion lying mainly in the

superiority of its political system. Yet, while he tried to bury his racial sentiment, the racial

superiority that his contemporaries, such as Ralph Emerson and Walt Whitman tirelessly

championed, remained just below the surface.

The American people having derived their origin from many other nations, and the Declaration of National Independence being entirely based on the great principle of human equality, these facts demonstrate at once our disconnected position as regards any other nation; that we have, in reality, but little connection with the past history of any of them and still less with all antiquity, its glories, or its crimes. On the contrary, our national birth was the beginning of a new history, the formation and progress of an untried political system, which separates us from the past and connects us with the future only; and so far as regards the entire development of the natural rights of man, in moral, political, and national life, we may confidently assume that our country is destined to be the great nation of futurity. It is so destined, because the principle upon which a nation is organized fixes its destiny, and that of equality is perfect, is universal. It presides in all the operations of the physical world, and it is also the conscious law of the soul-the self-evident dictate of morality, which accurately defines the duty of man to man, and consequently man's rights as man. Besides, the truthful annals of any nation furnish abundant evidence that its happiness, its greatness, its duration, were always proportionate to the democratic equality in its system of government. The expansive future is our arena, and for our history. We are entering on its untrodden space, with the truths of God in our minds, beneficent objects in our hearts, and with a clear conscience unsullied by the past. We are the nation of human progress, and who will, what can, set limits to our onward march? ... The far-reaching, the boundless future will be the era of American greatness. In its magnificent domain of space and time, the nation of many nations is destined to manifest to mankind the excellence of divine principles; to establish on earth the noblest temple ever dedicated to the worship of the Most High--the Sacred and the True. Its floor shall be a hemisphere--its roof the firmament of the star-studded heavens, and its congregation a Union of many Republics. ${ }^{230}$

\footnotetext{
${ }^{229}$ John O'Sullivan. "Democracy and Literature." The United States Magazine and Democratic Review 11, no. 50 (August 1842), 196-200.

${ }^{230}$ John L. O'Sullivan, “The Great Nation of Futurity” The United States Magazine and Democratic Review 6 , no. 23 (November 1839), 426. O’Sullivan later supported the Confederacy during the Civil War while in exile in England, so his racial views in 1842 were perhaps an inaccurate snapshot driven more by a refusal to engage with issues of race and slavery rather than an enlightened view on the subjects. Robert J. Scholnick likewise takes an extremely negative view of O'Sullivan and The Democratic Review in 'Extermination and Democracy: O'Sullivan, The Democratic Review, and Empire, 1837-1840," American Periodicals: A Journal of History, Criticism, and Bibliography 15, no. 2 (2005), 123-141. He argues rightfully that the earliest period of the Democratic Review's
} 
The Democratic Review was an excellent example of the new medium of national literary imagination. While it could not convince all Americans of the correctness of its views, as a format it represented the guiding example of literary expansiveness, newsworthy opinionmaking, and self-conscious Americanism. The magazine and its editor sought to mold the new era of American expansionism and achievement. Magazines seized the domain of controversialist debate and the Democratic Review, along with its staunchest challenger The American Whig Review, developed a call and response binary, each hoping to shape the public discourse on issues of the day. From the outset, in its literary selections and editorial matter, The Democratic Review embodied the traits of robust American confidence and became the most aggressive disseminator of those views as well as the chief prognosticator of American hemispheric hegemony through a purported benign and enlightened American democratic expansion. ${ }^{231}$

O'Sullivan tirelessly sought out the most innovative writers of the day, including Herman Melville, Nathaniel Hawthorne, James Fenimore Cooper, John Greenleaf Whittier, Edgar Allen Poe, and Walt Whitman. He pridefully paid them relatively well and combined their poetry and fiction with incisive political commentary. His messianic sense of direction and devotion - a devotion of the young wing of the Democratic Party to checking Whig and European cultural influence - lay bare on the magazine's pages. This younger faction saw as obvious the fact that defective democratic practice sprang from the lingering effects of European culture in both politics and literature. The goal sought by O'Sullivan, his readers, Young America, and the entire

existence should underscore a racial imperative to manifest destiny from the start. While a literary impulse polished the casing of the Democratic Review, its editors and authors consumed and disseminated a distinctive brand of Americanism that fused race (and a corresponding 'whitening' of eligible participants) and politics.

${ }^{231}$ The more literary North American Review (1815-) enjoyed the greatest renown in the United States. 
panoply of literary up-and-comers was a guiding reason for the creation of the United States and a foundation for the firm belief that the country existed as the force for good in the world. Manifest destiny attempted to make a virtue of America's lack of originating myth as a basis for nationhood. To locate such origins, O'Sullivan and other American destinarians lifted that basis off of a biological imperative and placed it onto political culture. America was the embodiment of the democratic ideal. Democracy had to be timeless, boundless, and portable. New methods of transportation and communication, the rapidity of the railroad and the telegraph, the rise of the international market economy, and the growth of easy consumable literature provided shared cultural platforms that helped Americans think across local identities and reaffirm their national character. $^{232}$

The urban hubs of the new democracy were chiefly productive of the print means of distributing the new American ethos of republicanism. Within the mix of ethnicities, politics, religions, and classes in America's major cities, Cuban immigrants ingested the growing calls of republican fraternity and sought to incorporate their concerns toward their homeland into the conversation. Nowhere was the impact of the revolutions of 1848 more vehemently debated and discussed in the United States than in the biggest cities, with New York City and New Orleans leading the way. As profound an influence as Americans had on all aspects of Cuban life, expatriates from the island took up their charge to bring Cuban concerns and culture to the

\footnotetext{
232 The telegraph eventually became the proof of America's millennial role in world history. Many saw the industrial ingenuity used to conquer space and time as a miracle that wove together the spiritual and the material. The telegraph promised the trinity of an unity of interest among men, easy transmission thereby linking all men to a single mind, and strengthening the inevitable worldwide victory of Christianity through its dissemination of the word of God within America's democratic breath. As one observer put it, the telegraph “....gives the preponderance of power to the nations representing the highest elements in humanity...it is the civilized and Christian nations, who, though weak comparatively in numbers, are by these means of communication made more than a match for the hordes of barbarism," quoted in Paul Gilmore, "The Telegraph in Black and White" English Literary History 69, no. 3 (Fall 2002), 820. The first telegraph line was completed in 1844, a year before O'Sullivan's Manifest Destiny editorial.
} 
American people. These efforts built upon Americans' long held interest in all things regarding the island - an interest piqued with the robust movement into the national discussion of the issue of annexation. Political magazines, journals, and newspapers fueled the discussion and widely available travel writings, some bound and others novelized in cheap print sources, exotified the island in the popular imagination. The Cuban literary set in the United States had a mighty job to accomplish but embraced their role and the instruments of dissemination with gusto. The few, but powerful, expatriate voices in New York and New Orleans had to direct Americans toward support for annexation while attempting to offer some of the subtleties of the island's social and political realities. However, the literary bonds that tied the United States and Cuba together, anchored to the economic closeness of the two societies, proved up to the task. The 1840s and 1850s brought Americans and Cubans into robust discussion about the future of the island. Many of the Cuban men, and the few Cuban women, most directly engaged in and representative of the Cuban exile perspective were longtime residents of the United States. For various reasons, a mix of choice and exile, they found themselves living in the major American cities of the day and looking for an outlet for their literary visions and political opinions. These writers - among them Father Felix Varela, José Maria Heredia, Cirilo Villaverde, Miguel Tolón, Pedro Castellón, Juan Zenea, Gaspar Betancourt Cisneros - identified and worked with Americans sympathetic to their cause. They hoped their efforts would keep alive close bonds with dissidents on the island, including the Havana literary circle led by Domingo del Monte. Cuban expatriate magazines and newspapers, free from the censoring eyes of Spanish colonial officials, openly and actively supported filibustering activities, advocated for annexation and armed revolution against Spain, and enthusiastically called Americans to these rhetorical and military causes. Dozens of pamphlets, books, newspapers, broadsides, and magazines 
accompanied speeches and lectures of their publishers and authors. The most popular of these in New York, El Mulato, La Verdad, and El Filibustero and in New Orleans, La Patria - and those having the most determined impact often included English language sections. Much like their American counterparts - The Democratic Review, The American Whig Review, The Atlantic Monthly, The North American Review, and Harpers - there was often poetry accompanying the more trenchant political analysis, with some of that poetry collected in contemporary anthologies produced in New York. American papers and magazines, most notably Moses Yale Beach's New York Sun and O'Sullivan's Democratic Review (two men actively engaged in the political life of the island), echoed many of the Cuban expatriate press' opinions. This communion of philosophy and hopeful action was, for many Cubans, a cry toward their shared ownership in a fraternal society directed at creating a new territorialized gran Cuba that was as much a part of the mind as it would be of physical connections between the two cultures. Therefore, the urban setting of these attempts was as much metaphor as reality with their vibrant and chaotic mixing of cultural lives. ${ }^{233}$

Long before Marti's critique in Our America of living in one imperial setting while criticizing another, Cuban writers experienced the same reality in a not dissimilar situation. The

\footnotetext{
${ }^{233}$ Rodrigo Lazo spends much time throughout his work seeking to uncover the more political side of the group of Cuban writers from this period whom historians have been either anthologized as merely literary authors or seen simply as precursors to the more robust political writings of the Marti era. He writes in application of Deleuze and Guttari's conceptualization of deterritorialization, "Although these texts and their writers could be viewed in relation to national and ethnic literary study, filibustering provides a historical context and theoretical starting point for reading these writings without integrating them into models that rest on the nation or contemporary ethnic labels. Like a filibuster who seeks to capture territory, the writings of Cubans in the US in the 1850s are part of a deterritorialized print culture marked by a desire for territorial connection." His view of filibustering as a "textualmilitary process" is very persuasive. Rodrigo Lazo, "Los Filibusteros: Cuban Writers in the United States and Deterritorialized Print Culture," American Literary History 15, no. 1 (Spring 2003), 89. See also "Filibustering Cuba: Cecilia Valdés and a Memory of Nation in the Americas," American Literature 74 (March 2002), 1-30, and his longer Writing to Cuba: Filibustering and Cuban Exiles in the United States (Chapel Hill: University of North Carolina Press, 2005). Nicolás Kanellos, "A Brief History of Hispanic Periodicals in the United States" in Hispanic Periodicals in the United States, Origins to 1960: A Brief History and Comprehensive Bibliography, ed. Nicolás Kanellos (Houston: Arte Público Press, 2000), 3-130, discuss the influences and effects of the earliest Cuban magazines and newspapers.
} 
poet José Maria Heredia, exiled from Cuba in 1825 for his role in the Conspiración de los Soles y Rayos de Bolívar, was probably the best known of the early Cuban transnationals. He spent most of his life in the literary wilderness of Mexico and visited the United States on a few occasions. The earliest of the more permanent exile communities grew in Philadelphia and New York. Father Felix Varela, from his parish in Philadelphia, established one of the earliest intellectual circuits in the 1820s between Cuba and the United States. He kept in frequent contact with his protégés in Havana who smuggled his anti-Spanish pamphlet, El Habanero, onto the island. However, the 1840s and 1850s saw a large increase in Cuban immigration in the wake of a more repressive political and social reality on the island. The limitation of freedoms, particularly of the press, and the specter of slave revolt on the island provided a background for the emergent expatriate sensibility of the early 1850s. New York and New Orleans became magnets for the Cuban community since these cities were also hotbeds of filibustering and annexationary plotting. In their early efforts at enlisting American support, Cuban writers were happy to encourage the American vision of Cuba as the junior partner against Spanish control. Annexation for all parties involved seemed to be the most direct means toward a quick resolution of the Cuba question. The criticism of the American imperial model, particularly as it related to the possibility of continuance of slavery in an annexed Cuba, remained muted in service of the extolling of an Atlantic fraternity seeking to break the chains of Spain's economic enslavement. This eliding of both the presence of slavery and of the roll that AfroCaribbean revolutionaries played in the foundation of emergent Atlantic republicanism (notably in Haiti) remained in step with the non-discussion of slavery more broadly in the American press. Above all else, the Cuban exile community showed themselves well-versed in harnessing American public 
sentiment by embracing an anticolonial path that encouraged the greatest support, avoided uncomfortable issues, and fell short of a full embrace of Cuban independence. ${ }^{234}$

However, despite the authoritative Cuban voices present in the United States, Americans generally sought to create "a cultural logic of desire and repulsion, of projection and rejection, toward Latin America in general and toward Mexico and Cuba, closest to the United States vision, in particular. That logic revolved variously around 'Spanishness,' 'Indianness,' and related general notions of aristocracy, Catholicism, civilization, free will and self-possession, heteronormative visions of the national family, and the integrity (or lack of integrity) of racial

\footnotetext{
${ }^{234}$ One major outlier to this trend in the United States was the vigorously abolitionist El Mulato. However, it did not start publication until 1854 as its critique of filibustering engaged more directly with the slavery issue. David LuisBrown argues that although El Mulato arrived later in the discussion, that in fact Joven Cuba's conceptualization of Cuban independence/annexation's compatibility with slavery was out of step with the larger exile community's views on abolition as foundational to independence rather than annexation. He investigates this rift in the exile community after 1854 in, "An 1848 for the Americans: The Black Atlantic, 'El Negro Martir' and Cuban Exile Anticolonialism in New York City," American Literary History 21, no. 3 (Fall 2009), 431-460. He expands his argument, focusing on how an anti-colonial/pro-equality vein of this early independentist argument came to establish itself as the main paradigm of literary output in the late $19^{\text {th }}$ century Americas in Waves of Decolonization: Discourses of Race and Hemispheric Citizenship in Cuba, Mexico and the United States (Durham: Duke University Press, 2008). Rodrigo Lazo takes up the changing contours of race and annexation/independence and specifically $E l$ Mulato's role in changing the discussion, particularly after 1851, toward a racial inclusive independence movement in Writing to Cuba, 91-98 and 142-167. On Heredia, who was much more concerned in his exile with the relation between individuals and the natural world than with politics - so much so that he received a pardon from Captain General Tacón upon renouncement of his previous revolutionary experience - see James F. Hamilton, "The Hero's Journey to Niagara in Chateaubriand and Heredia, French and Cuban Exiles," Romance Quarterly 41, no. 2 (Summer 1994), 71-78; Adam Glover, "Crisis and Exile: On José María Heredia’s Romanticism,” Decimonónica 10, no. 1 (Winter 2013), 78-96; and Lee Fontanella, “J. M. Heredia: A Case for Critical Inclusivism," Revista Hispánica Moderna 37, no. 3 (1972-1973), 162-179. On the issue of independence versus annexation there is no definitive answer since much of the strategizing happened off the pages of these print organs. This is a tough spot since if authors like Gerald Poyo are more inclined to offer Cuban writers the benefit of the doubt in their public/private annexationary machinations then we can't be overly critical of Herminio Portell Vilá's extension of the same benefits to Narciso López's "real" intentions as a Cuban liberator. Vilá argued strongly that any accusation of López's intention to keep slavery through annexation was a purely political move designed to curry American favor and to read the winds of the expatriate literary community. Gerald Poyo, With All and For the Good of All: the Emergence of Popular Nationalism in the Cuban Communities of the United States, 1848-1898 (Durham: Duke University Press, 1989), 1-20; Herminio Portell Vilá, Narciso López y Su Época, Vol. 1 (Havana: Cultural and Compania Editora, 1930). The debate on López's intentions was joined by and in many ways is seen through the eyes of his compatriot and secretary in the United States, Cirilo Villaverde. Villaverde was a strong believer in the combination and necessity of literary power, military action and political organization and wrote much before and after his involvement with filibustering that sought to chide reluctant revolutionaries as well as to burnish his own place in the revolutionary movements in Cuba. Rodrigo Lazo, "A Man of Action: Cirilo Villaverde as Transatlantic Revolution Writer," in Recovering the U.S. Hispanic Literary Heritage, Volume 3, eds. Ramón A. Gutiérrez, Genaro M. Padilla, and María Herrera-Sobek (Houston: Arte Publico Press, 1993), 315-331.
} 
categories." Inside the contested spaces of late 1840s literary and cultural life, Cuban writers desperately tried to construct their own conceptualization of transnationality and communal belonging while simultaneously seeking incorporation into American culture. The debates over annexation, while offering hope to this sort of overture, took place in an increasingly paternalistic frame. This minimization of the Cuban voice in United States policy debates did little to stifle the active engagement between Cubans on the island and the exile communities. Ultimately, while exclusion of the Cuban voice did much to solidify the method of American personification of Cubans in the popular imagination, the failure of American annexation eventually freed the conversation from American dominance and allowed its focus to rest on Cuban thoughts and Cuban issues. ${ }^{235}$

The clearest display of this shift from American engagement to a more introspective position existed in the intertwined area of Cuban slavery and political independence. As American interest in annexation waned by the mid-1850s, the debate over annexation as the only legitimate means of separation from Spain and the surest prevention for racialized revolt shifted into a lively debate linking independence with abolition - the presence of slavery being

\footnotetext{
${ }^{235}$ Kirsten Silva Gruesz, Ambassadors of Culture: The Transamerican Origins of Latino Writing, (Princeton: Princeton University Press, 2002), quote on xii. While Gruesz and many other authors argue for a fuller inclusion of the broad Latino presence into the canon of American literature and while undoubtedly this is and should be the case, the corresponding contemporary peripheral appreciation for the Latino presence in the U.S. literary landscape encouraged a greater internal focus on the part of Cuban writers to issues of political importance on the island. This bifurcation created a literature that is transnational and intensely national at the same time, all the while shaped (consciously or otherwise) by these various protonational/national literatures. There was a fluidity that allowed these separate pools to fill, overflow, and recede as the political winds encouraged. Gilles Deleuze and Felix Guattari, $A$ Thousand Plateaus: Capitalism and Schizophrenia (Minneapolis: University of Minnesota, 1980), 3-26. For investigations on the process of literature in developing an attitudinally shared Cuban/American literary culture, particularly the involvement of women on both sides of the divide, see: Kirsten Silva Gruesz "Maria Gowen Brooks, In and Out of the Poe Circle," ESQ: A Journal of the American Renaissance, 54. no.3 (Fall 2008), 75-109, and "The Cafetal of María del Occidente and the Anglo-American Race for Cuba," in The Traffic in Poems: NineteenthCentury Poetry and Transatlantic Exchange, ed. Meredith McGill, (Rutgers University Press, 2008), 37-62; Anna Brickhouse, Transamerican Literary Relations and the Nineteenth-Century Public Sphere (New York: Cambridge University Press, 2004), ch. 4; Louis A. Perez, On Becoming Cuban: Identity, Nationality and Culture (Chapel Hill: UNC Press, 1999), ch. 1; Amanda Claybaugh, The Novel of Purpose: Literature and Social Reform in the AngloAmerican World (Ithaca: Cornell University Press, 2007).
} 
associated with imperial imposition and standing against the true political and racial nature of an independent Cuba. ${ }^{236}$

Despite the obvious economic and cultural connections, Americans twisted themselves trying to erase the influence of the Caribbean at large, and Cuba specifically, on the national character - the relationship was to remain transactional not formative. As Americans looked at the European revolutionaries as a breed apart, juxtaposed against American exceptionalism, so too did they view Cuba at a similar distance. When Americans engaged the Cubans in their communities and in their printed sources, the island and its proponents were merely pieces in political considerations. Even while the economies of the two neighbors grew in intimacy and importance, Americans looked upon the colony as degenerate and corrupt (although salvageable) as opposed to the distinctive and progressive American continental empire.

As the process of American exceptionalism played out in an attempted divorce from the

\footnotetext{
${ }^{236}$ Gerald Poyo, "Evolution of Cuban Separatist Thought in the Émigré Communities of the United States, 18481985," The Hispanic American Historical Review 66, no. 3 (Fall 1986), 485-507; C. Stanley Urban, "The Africanization of Cuba Scare, 1853-1855," The Hispanic American Historical Review 37, no. 1 (Jan. 1957), 29-45; Plutarco González y Torres, The Cuban Question and American Policy, in the Light of Common Sense, 1869, accessed November 23, 2012, http://archive.org/details/cubanquestionan00torrgoog; José Gomariz, "Gertrudis Gómez De Avellaneda Y La Intelectualidad Reformista Cubana. Raza, Blanqueamiento E Identidad Cultural En 'Sab," Caribbean Studies 37, no. 1 (January-June 2009), 97-118; Luis Martinez-Fernandez, "The Sweet And The Bitter: Cuban And Puerto Rican Responses To The Mid-Nineteenth-Century Sugar Challenge," New West Indian Guide 67, nos. 1/2 (1993), 47-67; Jonathan Curry-Machado, "How Cuba Burned With The Ghosts Of British Slavery:' Race, Abolition And The Escalera," Slavery \& Abolition 25, no. 1 (April 2004), 71-93; Anton L. Allahar, "Sugar, Slaves, and the Politics of Annexationism: Cuba, 1840-1855," European Review of Latin American and Caribbean Studies 57 (December 1994), 281-304; Claudette Williams, "Cuban Anti-slavery Narrative Through Postcolonial Eyes: Gertrudis Gómez de Avellaneda's Sab," Bulletin of Latin American Research 27, no. 2 (April 2008), 155-175; José M. Aguilera Manzano, "The Informal Communication Network Built by Domingo Del Monte from Havana between 1824 and 1845," Caribbean Studies 37, no. 1 (January-June 2009), 67-96; Christopher Schmidt-Nowara, "Spanish Cuba: Race and Class in Spanish and Cuban Antislavery Ideology, 1861-1868," Cuban Studies 25, (1995), 101-122; Gema Guevara, "Inexacting Whiteness: Blanqueamiento as a Gender-Specific Trope in the Nineteenth Century," Cuban Studies 36, (2005), 105-128; Josef Opatrny, "Jose Antonio Saco's Path Toward the Idea of Cubanidad," Cuban Studies 24, (1994), 39-56. For an interesting comment on antebellum interactions between American and Cuban society, particularly over the slavery issue, from the perspective of a novel written antebellum but published postbellum see John C. Havard, "Mary Peabody Mann's Juanita: Cuba and US National Identity," Studies in the Novel 44, no. 2 (Summer 2012), 144-163.
} 
failures of the European efforts of 1848, Americans viewed the successes throughout Latin America, when they chose more positive hues, as a successful extension of the United States republican lineage and not as resultant from any innate democratic ability on the part of South American republicans. Cuba remained the confounding hold out; a stubborn colony in a hemisphere awash in democracy. As much as the European revolutions provided a sounding board for American literary development, South America provided the United States a deep canyon of echo for the republican idealism that underlaid manifest destiny's expansionism. The failure of the South American republics to perfectly replicate American revolutionary republicanism authorized, for many Americans, the annexation efforts in Cuba as a way to right the wrongs on display throughout the hemisphere. For proponents, Cuban annexation was not imperialism but renewal and it was a renewal blessed by Cubans themselves. That Americans too greatly equated the feelings of exiles in American cities with the feelings of Cubans on the island would be the great undoing of annexation and, eventually, the American republic. American ignorance of Cuban social realities represented a greater lack of awareness of similar political contours developing in the United States. The growing disconnect between opinion makers and the people in the United States only grew in the shadow of annexation's failure. The postannexation period of the later 1850s was "fraught with the cultural anxieties and desires that attested to a larger crisis of national identity, this imaginary was from the beginning riddled with the contradictions and rhetorical impasses attending a nation whose geographic borders were expanding even as its imagined racial boundaries were narrowing and calcifying." While the hoped outcome of the annexation adventure was a glorious fulfillment of American destiny, the 
ultimate failure of annexation laid bare the hollow belief in American republican

exceptionalism. $^{237}$

${ }^{237}$ Anna Brickhouse, Transamerican Literary Relations, 6-7. Sean X. Goudie, Creole America: The West Indies and the Formation of Literature and Culture in the New Republic (Philadelphia: University of Pennsylvania Press, 2006); Amy Kaplan, The Anarchy of Empire in the Making of U.S. Culture (Cambridge: Harvard University Press, 2005); and James Weldon Long, "Revolutionary Republics: U.S. National Narratives And The Independence Of Latin America, 1810-1846," (PhD diss., Louisiana State University, 2011), all point to American self-definition as imbricated within the greater Atlantic world. 


\section{Chapter Four: The Great Imagining}

To rear in that fair island a slave-holding republic, is only to postpone, not to avert her ruin. The 'Orators of the Human Race,' may consider their professional duty to deny this.

They may tell us that the annexation of

Cuba will bring with its newspapers, and the ballot-box, and representation for the whites, and they may point us to the States of the South, where freedom and slavery have so long lived on amicable terms, and the building of the commonwealth has been safe, while thunderstorm after thunderstorm of thought has overswept the world.

William Henry Hurlbert Gan-Eden: or, Pictures of Cuba, 1854

Slavery, and more specifically the bodies and thoughts of both enslaved and free AfroCubans, tormented the thoughts and nightmares of elite Cuban creoles regardless of the economic depth of their investment and interaction with the sugar complex. The elite projected their anxieties into every pecuniary discussion and political decision made on the island. The elite's efforts, designed to reinforce their social dominance by solidifying their economic power, focused on policing both AfroCuban bodies and these bodies' interactions with the political and economically disadvantaged non-African creole laboring classes. Accompanying this disciplinary regime was a corresponding nationalizing process that sought definition of the Cuban national body through the exclusion of AfroCuban voices. Elite creoles hoped this silencing might be the first step toward the future physical absence of AfroCubans from the island. Therefore, for many white Cuban creoles, the United States was a significant and positive example of a society that successfully balanced the presence of slavery and freedom in an economically vibrant setting. Many of these elite Cubans drew contrast between the vibrancy of the American republic and the degeneracy produced by Spanish colonialism. The long-standing and warm economic embrace shared by the United States and Cuba coupled with an even deeper cultural affinity, displayed in the popular and literary presses along with the popular imagination, fueled unwavering confidence that Cuba could soon be part of the United States. Many in the 
Cuban creole community hoped that, despite the lukewarm reception they gave to various abortive independence movements on the island and the general but low-burning fear they held of racialized revolt, the death of King Ferdinand VII, and the restoration of constitutional government in Spain in 1833 offered some opportunity for political and economic change. These hopes grew and nourished the Cuban economic soul at various points, only to be always disappointed by the Crown's unwillingness to part with controlling interest in the island. This unwillingness resulted from Madrid's long-standing aggravation with the economic coziness between the United States and Cuba.

While the optimism of annexation pervaded a certain strata of the Cuban elite, support on the island among the masses was always muted as it was among an important plurality of conservative Cuban planters. The Cuban debate over annexation was short-lived and ultimately had much less effect on the Cuban geo-political and domestic outlook than it did on the American introspection concerning republicanism, freedom, and slavery. Many elite Cubans, struggling with their concerns over slave rebellion and social destabilization, stood ready and willing for United States entry into Cuban affairs, if only to prevent "Africanization" of the island coming as a result of British abolitionism. However, the majority of Cubans, mainly as a result of the loosening of burdensome Spanish imperial policies, remained skeptical of American intentions and their elite brethren's machinations. Likewise, while the war with Mexico loomed large in the definition of American character and the aggressiveness of its foreign policy, these aggressive American hostilities of the mid-1840s needed some rehabilitation. Cuban annexation offered a more pleasing, self-congratulatory opportunity. Yet, even elite Cuban observers, placated by Spanish concessions, grew skeptical of the United States presence and fearful of a less than magnanimous American approach toward the relationship. 
Throughout the first three decades of the nineteenth century, the Spanish crown, in the wake of the South American revolutions, looked to Cuba as a major source of revenue and held no expectation that the island, if independent, would remain in the Spanish economic orbit. Cuban creoles, given the intense loyalty demonstrated to the crown during the revolutions, stood disappointed yet again in the mid-1840s as the crown continued to ignore their desires. Due to the closeness that developed between the island and the United Sates as a result of the relaxation of travel, taxation, and economic policies, Spanish repression of cultural and economic liberalization intensified. Added to these disappointments for some in the creole elite was the continuing fear that British abolitionist agitation might push the Spanish government to tighten policing of illicit slave imports and, in the face of creole unrest, might outlaw slavery completely to curry favor with the British. The concern over slavery guided every public discussion concerning the future of the Cuban economy and its social experiment. The rapid growth of slave labor, unencumbered by British dalliances, promised increased production, profit, and technology use, thereby increasing the probability that slavery would intensify both in its demands and in its number.

The corresponding growth in the slave population produced the opposite population trend desired by some Cubans who were critical of slavery, since technological improvements weren't uniform across jobs and locales. While technological improvements resulted in decreases in the complexity of tasks, the quantity of work required on any given plantation actually increased.

Owners directed massive amounts of labor effort into more remedial jobs like clearing forest for wood. These efforts encouraged the spatial growth of slavery and demanded its continuance while increasing economic pressures on small farmers and white labor. Part of this process was also the racialization of field labor as a byproduct of slavery, a process that aided the 
development of white Cuban self-consciousness necessary for economic accumulation and social arrangement. While this was not an uncontested process, the efforts and results weighed disproportionately on the AfroCuban population.

However, the hopes for economic liberalization and, if need be, annexation were more deeply rooted than in the simple topsoil of economics. The annexationary period of the 1840s and early 1850s saw Cubans both on the island and in the centers of the exile community, New Orleans and New York, debating the fundamental nature of Cuban identity or Cubanidad. At the heart of this debate rested the institution of slavery both broadly defined and specifically focused on the Cuban variant. The debate over slavery in the 1830s and 1840s intensified tremendously as a result of the dual pressures of internal disorder, resultant from racial and social contestation exemplified most notably in the Aponte and La Escalera slave conspiracies/rebellions, and external abolitionary pressures from the British government. Cuba became the focal point for the international debate on the morality of slavery and foreshadowed the much larger and deadlier conflagration over similar issues that engulfed the United States a decade later.

Rather than simply allying themselves solely with the American South to narrowly protect slavery, Cuban creoles looked to the United States in its antebellum configuration as an inviting example of pro-growth capitalism, fueled by the comfortable involvement of American business interests with American slaveowners. These economic interactions, from which Cuba benefitted greatly, fueled Cuban confidence that American investment in the island's growth might be unencumbered by a correspondingly bothersome abolitionist meddling, such as the kind shown by Cuba's other biggest trading partner, Britain. The great fear in Cuba was that economic stagnation, fueled by Spanish colonialism, might enhance social conflict, encourage civil unrest, and produce a (bi)racial economic revolutionary unity that promised to remake 
Cuban society. While the elite sought to throw off the yoke of Spanish domination, they shared a grave concern about the position of slavery in an annexed or independent Cuba - concern stoked by the Haitian revolution, the menace of British abolition, and the rapid economic and technical changes on the island.

That elite creole Cubans' efforts at freeing themselves from Spanish rule were part of a meticulously cultivated self-aware project should not be disputed. That the contours of this project rested on the foundation of racial differentiation, fueled by the general specter of Saint Domingue and specifics of Cuban slavery should also not be difficult to observe. ${ }^{238}$ While there

${ }^{238}$ Racial definition in Cuba followed a fairly distinctive if fluid organization. Cubans appreciated race as a socioeconomic construct built on a color and class-based, hierarchically arranged structure. In this structure, class gradations overlaid with proximal claims to 'whiteness.' These claims rested largely on definitions of that whiteness put forward by elite creoles protective of their status and reified by the developing capitalistic ethos. Racial and labor definitions closely overlapped with each other. Due to significant economic and technological changes, agricultural labor eventually became synonymous with slavery - a complete absence of whiteness based on the absence of the economic pillar, property ownership, of racial differentiation. Not surprisingly, racial inclusion or exclusion from the national project rested on the distance an individual fell from the phenotypically and economically 'white' Cuban specimen envisioned by the creole elite. One's ability to position individual and family well within the emergent capitalism of the early $19^{\text {th }}$ century Atlantic world solidified a higher (read whiter) place within the structure and with it the allowance of a performative role in the structure's racialized defining of Cuban society. The creole elite added to this color and economic arrangement an a priori claim to the intellectual trappings of the European enlightenment through the systematic creation of knowledge production. The elite funded schools, literary magazines, scientific societies, and debate groups, all of which were off limits to those defined as outside of, and therefore excludable from, participation in the creation of Cuban citizenship. Within these broad categories of 'white' and 'black' existed a great deal of internal and external stratification. The national project of the creole elite (self-defined 'white' Cubans born on the island from Spanish decent) was one largely set in motion by desire for economic and political validation on the part of this elite in reference to the peninsulares (mainland born Spanish in positions of greatest economic and political power on the island). While the demands were often direct, the creole elite, a larger population that the peninsulares, also sought to bolster their claims by solidifying their control over the lesser sorts (poorer whites or guajiros, free AfroCubans, South Asian and Chinese laborers, and the enslaved) through the defining of their whiteness against labor and intellectual deficiencies normalized through the shifts creoles demanded in productive and consumptive structures of the island. These demands were overt and resultant from other systemic demands/choices made by the creole elite. Theirs was a carefully envisioned, if at times hastily deployed, plan that extolled their control over the island's population and used it to cudgel Spanish crown officials into significant concessions. Paradoxically, this same elite demanded help when those concessions threatened delivery of unintended consequences (slave rebellion, economic instability, and external political threat). The wedge position that the creole elite occupied between a Spanish political and economic elite on the island that controlled access to capital/power and an ever menacing, but economically necessary, black presence in their slaves produced the impulse to create a semiotic system to better coalesce a collective identity and corresponding impulse to amplify their importance as an over-compensational response to their many anxieties. The goal was the legitimation of the aspirant creole economic class and a reinforcing of their claims to modernity; not only the modernity of their European intellectual heritage but also their position in the Atlantic world economy. Of course, this project was very much complicated by their stubborn reliance on slavery at a time when both their vision of a whitened Cuban population and world abolitionism reached fever pitch. The need to congeal an elite class consciousness was implicit 
in the sugar boom - a moment when economics reinforced their wisdom and prescience, positioned as they were to capitalize on world demand, but demanded a clear command structure for the inevitable increase in slave importation. Interestingly, while the creole elite based their societal power of their expropriation of land and labor in the far reaching rural hinterlands around some of Cuba's larger cities, these elites looked to the urban areas, notably Havana, to enshrine their intellectual vision in large scale architectural and artistic building projects. These projects were attempts by the elite to assert similar claims of dominance over urban areas that they made on their rural plantations. They hoped to own the cities and thereby impose a racial order in urban areas where they rightfully sensed the most direct challenge to their authority. While the physical threat of the plantation was probably greatest for the slaveholding elite, the layout and social controls exhibited there provided a modicum of imagined safety fueled by their belief in the imaginary armor of their self-righteous paternalism and a strong belief in the docility of their slaves. Yet, the urban spaces "existed as a multivalent text in which colonial subjects, of all classes, exercised some degree of social agency by (re)configuring the meaning of the city in their own ways," (Niell, 22). Here, the creole elite realized, was the canvas upon which the poor white and the free AfroCuban painted a picture very much at odds with the claims of Cuban nationalists in the elite. The picture was more physically mixed and challenging of the quickening pace of labor changes that took work from both classes. This was a concern particularly amongst the free AfroCuban populations in the cities which feared that the elimination of labor opportunity might encourage their (re)enslavement - a fear strengthened by the increasing racial prerogatives offered by the elite in hopes of prying poor whites from an economically configured pan-racial identity that encouraged urban alliance. The attempts at spatial arrangement of the cityscape, like the rearrangement of the plantationscape, were meant to assert cultural and physical authority over the white and black lower classes. The position of free AfroCubans presented the elite with a secondary concern focused on a fear that these urban classes might work toward a racial alliance, through their cabildos (ethnic associations created in Cuba from the late $16^{\text {th }}$ through $19^{\text {th }}$ centuries organized around varyingly defined African/Cuban cultural imperatives based on the Spanish cofradías or fraternal guilds). The elite feared that free AfroCubans, using their freedom of movement and interactions with maroon colonies (palenques) and the enslaved, might head a pan-African union and unleash a race revolution akin to the rebellion in Saint Domingue in 1791. This simplistic and largely color-based view on the part of the elite of a clase de color of African-descended individuals, enslaved or free, overlooked significant differences in the AfroCuban community at the beginning of the sugar boom. Broadly defined, castas (mixed race non-elites) held different and both internally and externally perceived 'higher' societal positions than morenos or negros (phenotypically "black" and generally enslaved individuals). "For example, in Cuba... Stratification based on culture and socioeconomic status occurred between free people of color and enslaved Africans during the nineteenth century, when the whitening process was seen by some Blacks as a desirable method of escaping the 'stain' of slavery and African ancestry. There was also some purchasing of 'whiteness' from the Spanish authorities and discriminating against non-acculturated Blacks on the part of some lighter skinned urban AfroCreoles... The 'free colored class' refers to the freed, largely urban population - these divided into 'pardos,' who had less visible African ancestry and were generally lighter-skinned, and 'morenos,' who were generally darker-skinned and thus considered closer to Africa and slavery. Within the free colored class, some historians understand there to be a 'burgesia de color' or haute-bourgeoisie of pardos and morenos who participated in the Batallones de Pardos y Morenos, or militias of color. These pardos and morenos could also be of a certain African "nation" or 'cabildo de nación.' This introduces the further distinction of place of birth - namely, Africa or Cuba. Slaves born in Africa who had no Spanish blood were called 'bozal,' while 'creoles' (criollos) were born in Cuba and were often of mixed ancestry. Furthermore, bozales were often distinguished by membership in an African nation, such as Arara or Carabali. 'Afro-Cuban' as a term did not emerge in Cuba until the 1920s, through the movement of 'Afrocubanismo,' and it has its own local, cultural history...Cabildos and African nations of birth are examples of how nationality in nineteenth century Cuba was articulated in people's lives as multiple and heterogeneous. This multiplicity and heterogeneity posits a particular problem for a national Cuban identity, and requires a constant forging, buttressing, or strengthening of Cuban nationalism," (Delgado de Torres, 38). On social space and cultural control see Paul Barrett Niell, "'Bajo Su Sombra': The Narration and Reception of Colonial Urban Space In Early Nineteenth Century Havana, Cuba,” (PhD diss., University Of New Mexico, 2008). On issues of race, racial definition and, intra/inter group categorization see: Lena Delgado de Torres, "Reformulating Nationalism in the African Diaspora: The Aponte Rebellion of 1812," CR: The New Centennial Review 3, no. 3 (Fall 2003), 27-46; Philip A. Howard, Changing History: Afro-Cuban Cabildo and Societies of Color in the Nineteenth Century (Baton Rouge: LSU Press, 1998), ch. 1; Ada Ferrer, Insurgent Cuba: Race, Nation, and Revolution, 1868-1898: Race, Nation, and Revolution, 1868-1898 (Chapel Hill: UNC Press, 1999), 1-40; Robin Moore, Nationalizing Blackness: Afrocubanismo and Artistic Revolution in Havana, 1920-1940 (Pittsburgh: University of Pittsburgh Press, 1997), 1-35; Rebecca Jarvis Scott, Slave Emancipation in Cuba: The Transition to 
existed numerous disagreements on how to best accomplish the goal of such a project -

annexation or independence, gradual or immediate emancipation of slaves - the reality for many

Cubans remained that Spanish rule should be and must be ended. That the early period of anti-

Spanish agitation culminated in a push toward annexation to the United States stood as a

powerful articulation of deliberate meditations on expediency tinged with not a small degree of

desperation. Despite the annexationary project's deliberate decision-making, the fear of an

impending and massive slave revolt pushed many in the creole community to disband

moderation in deference to more immediate and potentially lasting solutions as part of the United

States. In the midst of an intense debate over the future of slavery in Cuba one of the leading

lights in the creole community, Gaspar Betancourt Cisneros wrote to his opposite, the equally

influential José Antonio Saco, reminding him "Annexation is not a feeling but a calculation."239

That assertion did not, however, limit the excitement shown by some for annexation, but rather

embraced an understanding, for Cubans at least, that annexation might be an important first step

toward greater achievement of Cuba's economic and social freedom. At which point ideological

freedom and political independence mingled was open for debate, but it was a debate for a future

point. In the interim, the issue of slavery, and race more broadly, guided the discussion's tone

Free Labor, 1860-1899 (Pittsburgh: University of Pittsburgh Press, 2000), 1-45; Aline Helg, Our Rightful Share: The Afro-Cuban Struggle For Equality, 1886-1912 (Chapel Hill: University of North Carolina Press, 1995), 1-20; Pedro Deschamps Chapeaux, El negro en la economía habanera del siglo XIX (Havana: Unión de Escritores y Artistas de Cuba, 1971); Michele Reid-Vazquez, The Year of the Lash: Free People of Color in Cuba and the Nineteenth-century Atlantic World (Athens: University of Georgia Press, 2011), intro; Richard Price, ed., Maroon Societies: Rebel Slave Communities in the Americas (Baltimore: Johns Hopkins University Press, 1996), 1-60; Tiffany Yolanda Jimmece Bryant, "Inter-Subjective And Transnational Racial Effects: The Role Of The United States In The Formation And Evolution Of The Collective Perception And Racial Relations In Cuba, 1898-1902," (PhD diss., Florida International University, 2010), ch. 1.

${ }^{239}$ Cisneros to Saco, October 19, 1848 in María Dolores González-Ripoll, Consuelo Naranjo, Ada Ferrer, Gloria García, and Josef Opatrný, El rumor de Haití en Cuba: temor, raza y rebeldía, 1789-1844 (Madrid: CSIC Press, 2004), 387. 
and immediacy and offered the United States as the most direct means for the prevention of social unrest and economic disruption on the island. ${ }^{240}$

Cuba, by 1820 , sat at the headwaters of a mighty confluence of tumultuous waters. The sugar revolution consolidated its environmental and economic gains, as did those who controlled it, both planters and merchants alike. New lands groaned under sugar's expansion. Coffee and tobacco farmers came under increasing economic and social pressures. Spanish taxation structures remained detrimental according to the creole elite. The crown's relaxation of the trade restrictions enlivened commerce but exacerbated the constricting effects of monoculture. Sugar

\footnotetext{
${ }^{240}$ Among many interesting conversations in his recent dissertation, Alexander Treft offers an engaging summary of the role of ideology in historians' presentations of the true intention of the Cuban creole community in the annexation debate. Most prominent in this debate is the cleavage between López's annexation as carefully meditated-upon first shot for Cuban independence and a reading of López and annexationists (largely among socialist/Marxist historians) as capitalist/American stooges. Tom Chaffin discusses some of these themes as well, but he traces a more U.S. historiographical cleavage between Lopez as all-American representative and Lopez as tool of Southern expansionists. Although the current work's positions on these debates are probably fairly clear at this point, the true motive issue is one that can be safely put aside since decisions made in the moment were outgrowths of economic and social forces in the Caribbean that were far more impactful than the intended outcome of Cuban liberation. Put differently, the results of annexation or independence as a motivation for action were overdetermined. Cuban was too valuable an asset for any country, including the United States, to walk away from it after assisting in its liberation from Spain. At best, Cubans would have been forced to battle the U.S. military after any annexation took place should they have demanded independence. Regardless of the hoped results, a variety of philosophical decisions happened and actions occurred that continually reshaped the individual and group possibilities of action and eventual goals. Regardless of López's positioning, his efforts and those of the Cuban elite, toward independence or annexation would not have easily changed the U.S. side of the discussion - the United States, with all of its concerns about Cuba falling into British hands and of race revolt, could not have idly watched the fledgling nation go the way of an independent Haiti. In the oft-repeated mantra of Marx's The Eighteenth Brumaire of Louis Bonaparte, "Men make their own history, but they do not make it as they please; they do not make it under self-selected circumstances, but under circumstances existing already, given and transmitted from the past. The tradition of all dead generations weighs like a nightmare on the brains of the living. And just as they seem to be occupied with revolutionizing themselves and things, creating something that did not exist before, precisely in such epochs of revolutionary crisis they anxiously conjure up the spirits of the past to their service, borrowing from them names, battle slogans, and costumes in order to present this new scene in world history in time-honored disguise and borrowed language." As a result, historians can argue for the ultimate intentions, or hoped prospects; however, the decisions made and the articulations offered, existed within a geopolitical field of view that prompted certain decisions and results and that would not have tolerated certain actions. Put differently and more specifically in Cuba, independence might not have been possible in 1848. And as always, the true motive debate embodies more of current historiographical debates that historical realities. However, this should not weaken the self-aware process of Cubanidad's creation. The true motive debate remains a slightly different if interrelated issue. Alexander Trefz, "Die USA als Modell einer demokratischen Sklavenrepublik: Exilkubaner und die Annexion Kubas an die Vereinigten Staaten, 1848-1856" (PhD diss., Universität Trier, 2012), intro, particularly pages 20-23, and Tom Chaffin, Fatal Glory: Narciso López and the First Clandestine U.S. War Against Cuba (Baton Rouge: LSU Press, 2003), intro.
} 
producers struggled to keep up with world demand despite massive investments in the technical advancement of production, management, and control on Cuban plantations. This growth produced a corresponding change in the relations of production and labor, thereby ushering in one of the most rapid growths in slave population seen in the Americas. These productive gains occurred despite the presence of a robust and, for many producers, an annoying British abolition effort. As always, underlying the great concern attendant to both the growth of slavery and the strength of abolition was Haiti.

For many Cuban creoles, Haiti became the prototype of sexualized racial revolution, a sword of Damocles hovering above Cuban society to be wielded by supposedly lazy and irresponsible barbarians. In the shadow of the revolt in Saint Domingue, fear inundated Cuba. In response, Spanish colonial authorities, in league with an anxious but still sleepy creole elite, resolutely dedicated their efforts toward preservation of domestic order while embracing efforts to fill the gaping hole in world coffee and sugar production. Importantly, in the aftermath of British seizing of Havana in 1762, the Spanish government acted robustly in developing Cuba's internal economic and military structures through direct crown investment. While many historians place great importance on the thirteen-month British occupation of Havana, the growth of Cuban free trade only began at this date and grew ever stronger with constant imperial infusion of investment and relaxing of Spanish trade policies in the Caribbean prior to $1800 .^{241}$ The prosperity brought to Havana by the infusion of imperial funds for defense projects formed an atmosphere for the development of the capital necessary for sugar plantation expansion after the 1790s. This defense spending, and the stationing of thousands of additional

\footnotetext{
${ }^{241}$ Francis Russell Hart, The Siege And Capture Of Havana, 1762 (Boston: Houghton Mifflin, 1931); David Syrett, England in the Seven Years' War: A Study in Combined Strategy (London: Navy Records Society, 1970); Julian Stafford Corbett, England in the Seven Years' War: A Study in Combined Strategy (Cambridge: University Press, 2010).
} 
imperial troops on the island, furthered the accretion of Spanish colonial investment in both the economic conditions of the peninsular elite and the expansion of slavery. The residue of Haiti, in combination with post-1763 Bourbon economic reforms on the island, the encouragement of crown slavery in and around Havana throughout the latter eighteenth century, the rise of an aggressive and energized creole planter class, and the machinations of Spanish/European politics, motivated Cubans toward fundamental reorganization of their economic landscape backed with a simultaneous installation of a relatively conservative political stance among most inhabitants. ${ }^{242}$

242 The Spanish crown imported around 7,000, almost entirely male, slaves after the British left Havana in 1763 as part of Bourbon reforms aimed at defense fortification in Havana, naval ship building, and coastal fort construction. The crown owned these slaves since the small numbers held by private owners were not sufficient to the projects nor did private owners want to lend their slaves and lose their time and efforts in such laborious tasks. In the area of ship building the crown actually replaced white labor, at the time sufficient for production, with royal slaves. After these undertakings were completed by the 1780s, many of these royal slaves were sold off to private owners at great profit to colonial authorities. The Spanish state was responsible for the successful precursors that fueled Cuban economic growth in the 1800s. The defense project and state spending by the Spanish authorities in Cuba, while temporary, forged deep linkages throughout the economy. The usage of land, procurement of human and material resources, and the public/private relationships affected all major factors of production. Notably, the more casual attitudes toward land quickly moved to a more rationalized system that those in the know took advantage of through various, sometimes dubious, means. The land grab pushed prices higher, which helped some smaller landholders who benefited from royal compensation for their land. However, this massive injection of capital, responsible for the remarkable liquidity in Cuba dried up as the Wars of Independence started throughout Latin America. The desperate attempt to shore up colonial possession necessitated a massive outflow of man, materiel, and money from Cuba to the royal treasury, at a time before the economic benefits of the $18^{\text {th }}$ century's royal projects enjoyed stability. Thusly, Cuban planters, finding themselves in the opportune moment of a vacuum in the sugar industry resultant from the Haitian revolution, were hesitant but intrigued in their response. Loyalty, they believed, might be leveraged. "The state's demand for labor kept wages high, especially for skilled work. The state helped create the economic framework for plantation expansion and modeled the successful deployment of enslaved labor in both skilled trades and in gang labor in menial tasks. The local economy was enriched, as the state contracted out many of the necessities of the fort projects -- slave procurement, transport, brick manufacture, lime and charcoal production. The state purchased provisions and supplies for its troops, workers, and projects. It confiscated, purchased, and rented land and buildings in and around the city," Evelyn Powell Jennings, "State Slavery in the Atlantic Economy: The Case of Cuba in the late Eighteenth Century," (Conference of the Program in Early American Economy and Society, Library Company of Philadelphia, September 2003), 28. J. R. McNeill, Atlantic Empires of France and Spain, Louisbourg and Havana 1700-1763 (Chapel Hill and London: University of North Carolina Press, 1985); Allan Kuethe, Cuba, 1753-1815, Crown, Military, and Society (Knoxville: University of Tennessee Press, 1986); Sherry Johnson, The Social Transformation of Eighteenth Century Cuba (Gainesville: University Press of Florida, 2001), and "'La Guerra Contra los Habitantes de los Arrabales:' Changing Patterns of Land Use and Land Tenancy in and Around Havana, 1763-1800," Hispanic American Historical Review 77, no. 2 (Spring 1997), 181-209; Sue Peabody "Free Soil: The Generation and Circulation of an Atlantic Legal Principle," Slavery and Abolition 32, no. 3 (September 2011), 331-339; Rebecca Scott, "Public Rights and Private Commerce: A Nineteenth-Century Atlantic Creole Itinerary," Current Anthropology 48, no. 2 (April 2007), 237-256; Franklin W. Knight, "Origins of Wealth and Sugar Revolution in Cuba," Hispanic American Historical Review 77, no. 2 
One chief component of the reaction to the Haitian uprising - the exclusion of foreign influence in Havana through an effective quarantining of Cuba from all printed works relaying news from Haiti or Paris and isolation from the undocumented immigration of, particularly French, nationals deployed by colonial leadership in Cuba in consultation with the Spanish Prime Minister - set the tone for an approach toward isolationism employed by Spanish leadership for the next 60 years. ${ }^{243}$ The use of fear, both of slave revolt and political unrest, was the tool embraced by the Spanish government in efforts to combat the influence of the independence movement throughout the rest of Spain's empire. The Spanish government then mixed these same ingredients a decade later in response to British abolition. Fear of contagion mixed with official encouragement of economic development, along with a healthy dose of official censorship, was a remarkably lucid and effective means of maintaining control over the island. Yet, despite the fear that increased slave presence held for the island, creole producers began to embrace the benefit of importing slaves to meet a newfound labor need. With limited white labor available to plantations, a ready world market, and the crown's blessing, sugar producers wanted to move and saw only limited danger in doing so in a quick and robust manner. ${ }^{244}$

(Spring 1997), 231-253.

${ }^{243}$ David Sartorius investigates the very interesting use of passports by issuing governments to define the contours of citizenship in early $19^{\text {th }}$ century Cuba. He argues that Spanish governmental fear of AfroCreole mobility in the Caribbean (among slave and free), forced greater stringency on the need for proper paperwork for passage and disembarking on the island. In the shadow of the Haitian revolution, many officials feared the movement of underground networks of rumor and people that sought to revolutionize other societies outside of Haiti. The 1812 Spanish constitution (not surprisingly given the recent Aponte uprising) denied AfroCubans rights to these citizenship papers which greatly limited travel to and from the island. This denial of rights, set against the backdrop of a perceived loyalty shown to the crown by AfroCubans, fueled intense debates over Cuban legal identities and documentation governing AfroCuban mobility as well as that of other AfroCreoles in the Caribbean. David Sartorius, "Uncommon Winds: Race, Passports, and the Legal Culture of Travel in Cuba," Presentation to Boundaries of Bondage, Frontiers of Freedom: Mobility and Slavery, Race, Nation, and Religiosity in the Atlantic World panel of Conference of Latin American History American Historical Association Annual Meeting, January 9, 2011.

${ }^{244}$ However, many Cubans, like one charged with rebuilding Cuba after British invasion almost a century before, understood the reality facing Cuban sugar planters to which they too were quickly becoming most distinctly aware; there was no alternative labor force in large enough numbers to do the work of producing both sugar and a whiter population. The great hope that annexation would fuel a technological and demographic revolution by enticing Americans moving west to move south instead was at best rhetorical and at worst illusory. Agustín Crame, the 
Cubans, saw the revolution in Haiti as more a failure of discipline and leadership rather

than endemic weakness of slavery.

The French looked at the slaves as beasts, and the Spanish looked at them as men. The principle of those French masters and even their slave legislation has always been excessive vigor, to inspire in their slaves all the fear that they can, believe that only in this manner is it possible for a single white to govern a hundred negroes in the middle of the forest and in the midst of such heavy and continuous tasks. None of the resources that the negro lacks in the French colony are missing in our colonies as much because the laws give them to him as because the masters are careful to observe them because of their utility. The slaves of Havana find themselves today with all the assistance and contentedness that the happiest slaves in the world can obtain, and our civil laws have balanced perfectly the two extremes, that is, the abuses of the owners and the development of insubordination and insolvency of the slave. 245

This internalization of French failure clearly presented itself in the exclusionary pronouncements

of Spanish authorities in Cuba. Initially, they demanded the exit of all foreigners on the island,

but then softened this stance to include both the non-importation of any slaves having contact

with the revolutionaries in Haiti and the exclusion of only those French refugees transporting

their slaves into Cuba. ${ }^{246}$ The Spanish Secretary of State, José Moñino y Redondo (Conde de

military engineer charged with the building of Havana's new fortifications in 1769 , summed up some of the reasons for the reliance on enslaved African labor and presaged the future labor problems of the island. "To think of more migration of new Spaniards would be to sin against good economy. To conduct foreigners would be a costly business, difficult and full of serious obstacles. But even in the case of all things being equal, Europeans would never come to carry out those rigorous country labors that are as though reserved for slavery. Who would come from Europe to be a simple day laborer comparable to an unfortunate slave? And even when one or the other might have accommodated himself to that fate owing to his dismay or misery, where would a competent number be found to do the clearing of new grounds, the cultivating of lands and to employ themselves in the other tasks that the principal products of the island need?" quoted in Evelyn Powell Jennings, "State Slavery in the Atlantic Economy," 29.

${ }^{245}$ Francisco de Arango y Parreño, Representacion de la Ciudad de la Habana a las Cortes Españolas, in Francisco de Arango y Parreño, Obras del Excmo. Señor D. Francisco de Arango y Parreño, Volume 2 (Havana: Howson y Heinen, 1889), 190; Jamie Holeman, “'A Peculiar Character of Mildness:' The Image of a Humane Slavery in Nineteenth-Century Cuba," in Francisco Arango y la Invención de la Cuba Azucarera, ed. Maria Dolores GonzálezRipoll and Izaskun Álvarez Cuartero (Salamanca: Ediciones Universidad de Salamanca, 2010), 41-54.

${ }^{246}$ Captain General Luis de Las Casas, although initially slow to act, eventually moved quickly to limit British and French West Indian slave importation into Havana. He also outlawed the types of tools and weapons slaves could access after the Cuatro Compañeros revolt (1795) in Puerto Príncipe (Camagüey). De Las Casas also made the extraordinary move to expel all English and French speaking slaves brought to Cuba after 1794 and 1790 respectively, thereby effectively declaring the slave trade to be exclusively conducted with the African coast. This did not stop the rebelliousness in the Puerto Príncipe, Trinidad, and Matanzas regions of south central and western Cuba. This unrest continued largely because the Captain General's 1796 proclamation was reported by some on the plantations as issuing freedom to slaves. Successive Captain Generals continuously dealt with ongoing civil unrest at the hands of the enslaved. Yet, despite the repressive techniques imposed by the Spanish colonial officials and the fear of contagion driving their concerns, the influence of events in Haiti seems of limited consequence in many of the reports of uprisings in the early sugar boom period. However, the reading of these ongoing slave revolts exhibits 
Floridablanca), sought to keep Cuba free from involvement in the wider Caribbean landscape

and issued a call to colonial viceroys for neutrality in the Haitian conflict, unless Haitian

revolutionaries threatened Spanish interests.

That your Honors and other principals should take as the rule and instruction not to interfere in order not to support any of the factions in St. Domingue...more than the others, so that in this point a perfect neutrality be observed. However, should groups of evildoers, sea pirates, or Negroes against Whites be formed to destroy the latter, or to commit atrocities or plunder, you should try to act...so that the persecuted shall be provided with provisions, weapons and munitions to the best of one's ability, as well as demonstrations of land and sea power...care should be taken that contact with the insurrection should not spread to Spanish parts and possessions. ${ }^{247}$

While the refusal of Cubans to assist their colonial brethren in Haiti was not perhaps as

ironclad as Spanish authorities would have liked, Cuban producers and the Spanish crown stood handsomely rewarded for their lack of interest in assisting the French. As a result, Cubans now enjoyed unfettered access to domination of the world sugar market if they might harness the opportunity. Therefore, the moment of greatest opportunity for aspiring Cuban sugar capitalists was paradoxically the moment of greatest fear of slavery's presence in Cuba. However, there existed an unbridled confidence that with proper development, discipline, and control of slaves and society, Cuban producers could use the market expansion available to them to ensure the regulation of domestic order through the imposition of new structures of control necessary for both industrial and societal growth. The clarity of this process and the deliberate decision to

a significant break in the historiography. Some historians, such as Robert Paquette, see great correlation between circum-Caribbean events and the uprisings in Cuba, culminating with La Escalera, while others, such as Manuel Barcia, read these events as motivated more by extensions of the African political crises, wars, ethnic conflict, and cultural proclivities held over into daily life in Cuba. The debate is basically over origins or conditions as more important in resistance. Robert Paquette, Sugar is Made with Blood (Middleton, CT: Wesleyan University Press, 1990); Manuel Barcia, Seeds of Insurrection: Domination and Resistance on Western Cuban Plantations, $1808-1848$ (Baton Rouge: LSU Press, 2008) and The Great African Slave Revolt of 1825: Cuba and the Fight for Freedom in Matanzas (Baton Rouge: LSU Press, 2012); Michael Zeuske, "Hidden Markers, Open Secrets: On Naming, RaceMarking, And Race-Making In Cuba," New West Indian Guide 76, no. 3/4 (2002), 211-241.

${ }^{247}$ Correspondence quoted in Clarence Munford and Michael Zeuske, "Black Slavery, Class Struggle, Fear and Revolution in St. Domingue and Cuba, 1785-1795," The Journal of Negro History 73, no. 1/4 (Winter-Autumn, 1988), 27. 
embrace slavery in the shadow of the largest slave uprising in human history offers some indication as to the level of belief the Cuban elite had regarding their ability to control slavery and society in Cuba. An important political component also existed within the broader creole socioeconomic strategy. The embrace of slavery by the sacarocracia titulada placed them on a path of confrontation mixed with acquiescence, on the part of Spanish authorities, who had their own reasons for the great urgency they placed on the process of defining the contours of Cuban society as bulwark against social unrest. ${ }^{248}$

However, the impossibility of the task set before the creole elite and the Spanish colonial leadership, that of separating Cuba from the contagion of Haiti, exposed the nature of the bargain Cuban producers made with the international slave trade and with Spanish colonial rule. The reality of the early sugar boom years in Cuba was the transnationality both of the slave trade and the circuits of communication among those who struggled under its dictates. The 400,000 Africans brought to Cuba between 1800 and 1860 owned no allegiances to the Spanish crown or their Cuban owners. They inhabited a liminal space created by cracks in system of slavery in which the winds of rumor, remembrance, unity, ethnic limitations, and a host of action and reaction between plantations, between free and enslaved, and between Cuba and the rest of the Caribbean world blew unseen but suspected. The great and abiding fear for Cuban planters, a fear that would not speak its name directly, was not specifically Haiti, although the island always remained as a rhetorical catch-all, but rather that the unrest they feared would be an indigenous Cuban variety. Slaveowners feared revolution because of a collection of elements willfully allowed through the discipline and control sieve by the crown in its rush to advance an economic

\footnotetext{
${ }^{248}$ Ibid., 25-29. Matthew Casey, "From Haiti to Cuba and Back: Haitians' Experiences of Migration, Labor, and Return, 1900-1940," (PhD diss., University of Pittsburgh, 2012), 33-50. Marc McLeod, "Undesirable Aliens: Haitian and British West Indian Immigrant Workers in Cuba, 1898 to 1940," (PhD diss., University of Texas at Austin, 2000), 1-34.
} 
cause or pushed through the same sieve by AfroCuban resistance. Of course the main portion of this calculation, the planters' culpability in demanding unlimited trade in sugar and slaves went uncriticized, at least initially. The specter of Haiti, the "Guarico phantasma," became code for all the concerns infecting Cuban elite society. Haiti unleashed a social malaise, one at least partially encouraged by and capitalized upon by Cuban planters, which allowed for a naturalization of Cuba's class system and the atmosphere of paranoia it rested on. ${ }^{249}$

${ }^{249}$ Doris Kadish, ed., Slavery in the Caribbean Francophone World: Distant Voices, Forgotten Acts, Forged Identities (Athens: University of Georgia Press, 2000), describes in her introduction the ghost of Haiti influencing conditions throughout the Atlantic world. She discusses Edouard Glissant's decentering of origin as the guiding impulse of AfroCaribbean resistance and motivation. Instead Glissant, with his application of Deleuze and Guttari's rhizome conceptualization, describes the development of francophone créolité as a "relational Caribbean identity in which diverse cultural traditions come together in a fluid process of constantly changing social, racial, and ethnic interactions," (xx). Glissant rejects the importance of origin and yearning for African primordialism as ignorant of the conditionality that forged AfroCaribbean mentalities. The nostalgia for the past, African rootedness, minimizes the political responsiveness to the immediate stimuli of coloniality and enslavement. He rejects the idea, popular in the work of Kamau Brathwaite, of a mythologized return to the seed of Africanness. This rejection of rootedness is central to a few assertions regarding Cuba. First, overreliance on African imperatives divorces AfroCubans from their political and social surroundings as well as from their efforts at negotiation and control over their environment. This is not to minimize the importance, some historians argue uniqueness, of the continuance of significant African ethnic markers, particularly in reference to AfroCuban cabildos as well as religious practices. However, overreliance on ethnic definition strengthens the exaggerations so potent in condemnations of free AfroCubans' "African Nature" common among the Cuban elite. The acceptance of African sensibilities as directive of AfroCuban actions reifies the exclusionary project built upon concepts of difference asserted by the nationalizing program of the sucrocracy. The Antillanité/créolité project then allows recognition of the interdependence of European and African (and later South Asian/Asian) influences brought together in the slavery/state complex. The contestation present in the socio-political fabrication of Cuban identity provided white creoles with an African 'other' to respond to. However, the repressiveness of these responses drove equally robust reactions on the part of AfroCubans, not a simple yearning for Africa. These AfroCuban responses, predicated on a variety of different and at times contrasting desires, made repression, arrived at through the structure of slavery, more difficult and contestation more immediately visceral. The true goal then seems to be a determination as to how, when and under what conditions AfroCaribbean/Cuban creoles deployed various resources of person, tradition, and condition toward new cultural products and in protection of their developing cultural positions. The process described above also implicates the economic conditioning of the slavery/freedom equation and involves both an appreciation for the Caribbean's central position in the forging of the modern period as well as the region's constituent role in advancing a unity of colonial development and European industrialism. Implicit in this discussion of modernity is the position of labor, wage and slave, and its role in separations between modernities or between modern and premodern societies. The discrepancy between the two modes of labor seems reliant on inspection from a strategically Marxist perspective which extolls wage labor as a defining requisite of modernity, and highlights choice at the moment of labor/contract as humanizing and thus rationally exhibitive of the liberty/pursuit of property model extolled in the Enlightenment reading of modernity. If, however, wage and slave labor can be seen as twin poles marking the ends of a spectrum of labor, then modernity, both its capitalism and its enlightenment, can be seen as present in either condition. Therefore, AfroCuban rebellion in the Aponte and Escalera moments can be seen as demands on Cuban society to live up to the enlightenment model of political self-determinative social incorporation while simultaneously asserting a lived experience outside of that model but not inferior to it or reducible to a condition opposite from desired inclusion. This is also not to overlook the degree of contestation within AfroCaribbean movements as well. Slavery was not outside of capitalism but was a refined system of labor productivity extracted through bodily violence; a system specifically chosen both 
The dichotomous view of Cuban race relations, even in its earliest form during the 1790s, gathered strength from the events in Haiti. The view of a murderous, barely controllable, naturally inferior blackness fueled the desire on the part of the Cuban elite to define, more scientifically and more deliberately, the economic and social structures that could be used in extolling the civilization from which their evolving whiteness derived its power. In order to

for is profitability and its success at social control. Any claims to the otherwise, or attempts at paternalism, were performances designed for the controllers of slaves individually and for societal defenders of slavery broadly. While they disagreed on the nature and importance of slavery, plantation owners and intellectuals endeavored to explain the short-term permissibility of slavery and warn of its long-term negative effects on the project of conjuring whiteness from an intellectual and biological polyglot. These ideas bubble up from a variety of readings shown below, the misreading of that variety is mine alone. Édouard Glissant, Poetics of Relation (University of Michigan Press, 1997); Gilles Deleuze and Félix Guattari, A Thousand Plateaus, (New York: Continuum Press, 2004); Emilia Viotti da Costa, Crowns of Glory, Tears of Blood: The Demerara Slave Rebellion of 1823 (New York: Oxford, 1994); Walter Johnson, "On Agency," Journal of Social History 37, no. 1 (Fall 2003), 113-124 and River of Dark Dreams: Slavery and Empire in the Cotton Kingdom (Boston: Harvard University Press, 2013); Carolyn Fick, The Making of Haiti: The Saint Domingue Revolution from Below (Knoxville: University of Tennessee Press, 1990); David Patrick Geggus, "The Influence of the Haitian Revolution on Blacks in Latin America and the Caribbean," in Blacks, Coloureds and National Identity in Nineteenth-Century Latin America, ed. Nancy Priscilla Naro (London: Institute of Latin American Studies, 2003), 38-59; Antonio Gaztambide-Géigel, "The Invention Of The Caribbean In The $20^{\text {th }}$ Century: The Definitions of the Caribbean as a Historical and Methodological Problem," Social and Economic Studies 53, no. 3 (September 2004), 127-157; Michael J. Drexler, "Haiti, Modernity, and U.S. Identities," Early American Literature 43, no. 2 (2008), 453-465; David Fistein Theory and the Social Revolution in Haiti," Journal of Haitian Studies 15, no. 1/2 (Spring/Fall 2009), 180-202; William Javier Nelson, "The Haitian Political Situation and Its Effect on the Dominican Republic: 1849-1877," The Americas 45, no. 2 (October 1988), 227-235; Clarence J. Munford and Michael Zeuske, "Black Slavery, Class Struggle, Fear and Revolution in St. Domingue and Cuba, 1785-1795," The Journal of Negro History 73, no. 1/4 (Winter-Autumn, 1988), 12-32; Asselin Charles, "Haitian Exceptionalism and Caribbean Consciousness," Journal of Caribbean Literatures 3, no. 2 (Spring 2002), 115-130; Franklin Knight, The Caribbean: The Genesis of a Fragmented Nationalism (New York: Oxford University Press, 1990); Mirlande Hippolyte-Manigat, Haiti and the Caribbean Community (Kingston: Jamaica: ISER, 1980); Steven Hahn, The Political Worlds of Slavery and Freedom (Cambridge: Harvard University Press, 2009); Paul Ricœur, Memory, History, Forgetting (University of Chicago Press, 2004); Nigel O. Bolland, "Creolisation and Creole Societies: A Cultural Nationalist View of Caribbean Social History," Caribbean Quarterly 44, no. 1/2 (March-June, 1998), 1-32; Steve J. Stern, "Feudalism, Capitalism, and the World-System in the Perspective of Latin America and the Caribbean," The American Historical Review 93, no. 4 (October 1988), 829872; Joseph C. Miller, "The Problem of Slavery as History," (paper presented Cornell University, Ithaca, New York, March 12, 2007); Elizabeth Hackshaw and Martin Munro, eds., Echoes of the Haitian Revolution in the Modern World (Kingston, Jamaica: UWI Press, 2008); Viranjini Munasinghe, "Nationalism in Hybrid Spaces: The Production of Impurity out of Purity," American Ethnologist 29, no. 3 (Fall, 2002), 663-692; Ana Pizarro, "Reflections on the Historiography of Caribbean Literature," Callaloo 34 (Winter, 1988), 173-185; Lorna Simmonds, "Civil Disturbances in Western Jamaica, 1838-1865, Jamaican Historical Review 14, (1984), 1-17; Bill Marshall, The French Atlantic: Travels in Culture and History (Liverpool: Liverpool University Press, 2009); Brenda Gayle Plummer, Haiti and the United States: The Psychological Moment (Athens: The University of Georgia Press, 1992); Theda Skocpol, Social Revolutions in the Modern World (New York: Cambridge University Press, 1994); David Patrick Geggus, "Slave Resistance Studies and the Saint Domingue Slave Revolt: Some Preliminary Considerations," (Occasional Paper Series, Florida International University, 1983); Daniel E. Walker, No, More, No, More: Slavery and Cultural Resistance in Havana and New Orleans (Minneapolis: University of Minnesota Press, 2004). 
accomplish this task, the Cuban producer class set about defining the national political body. These efforts, driven by racial imperatives, rested upon rationalizing systems of economic and social control. The chief strategist of this coordinated effort was Francisco Arango. As previously discussed, Arango's influence on early Cuban thought, societal design, and the selfconsciousness of the planter community in and around Havana was immeasurable. As slavery modernized in early nineteenth century Cuba, so too did the ways in which the elite thought about the economic system and the accompanying social control apparatuses reinforcing that system. That the process of racial marking was necessary at all was in large part due to the relatively small amount of slaves on the island prior to the first stage of the sugar boom (17911812). Due to the small size of the slave population, command and control structures of tight discipline seen later in the century had not yet developed nor were those rules in place strongly enforced. The monopoly on the slave trade exercised by the government and the ways in which Spanish authorities used those slaves under the state's direct control led to a certain amount of anxiety among the island's elite whites. The malleability of social positioning based on the ease with which many AfroCubans, initially enslaved by the crown, transitioned to the population of free small-holders left the definitional field of 'black' too broadly defined and AfroCuban mobility too accessible for the comfort of the white-elite ownership class. Francisco Arango proposed a massive expansion of sugar cultivation and slave importation as the most effective way to cement racial imperatives and diminish AfroCuban social maneuverability in Cuban society. However, it was not just a simplistic expansion in the amount of slaves but also the complete modernization of agricultural production that prioritized black enslaved labor as the motor that hastened sugar's spread. Tobacco and coffee production was simply not scalable to the necessary scope to stretch the apparatuses of policing focused on black bodies throughout the 
island. In the evaporation of Haitian sugar production and the stagnation of Jamaican production, Cubans found promised economic success, and the socialization of racial difference. The exclusion of the AfroCuban population from the national project and their sublimation with the enslaved in the fields became the productive negative of Cubanidad. ${ }^{250}$

Economics shaped the social and political order by establishing a community of shared interests among the sugar elite. This group realized that one of the key components of continued economic growth in the sugar industry remained dangerously under provided - labor. Slavery was both the quickest means by which labor need could be met and the perceived natural state of those that planters sought to force to the fields. The rationalization of a discipline structure that more clearly divided races also provided the elite a clearer path toward naturalizing sociocultural division. Yet, the plans to raise importation numbers hit a key snag. The Spanish Cortes in Cadiz took up the issue of the slave trade among other issues important to the colonies in 1810. This was a clear move of recognition on the part of the Spanish crown of British and American moves at cessation of the slave trade in the Atlantic. The issue of the slave trade came to the floor when two Mexican representatives, José Miguel Guridi y Alcocer and Agustín Argüelles, moved beyond just the issue of cessation of the trade toward abolition of slavery throughout Spain's American colonies. Guridi introduced a motion to abolish slavery on March 26, 1811. While similar moves had been made on a few occasions dating back to 1802 , the threat intensified with the presence of British diplomats at the Cortes' debates and as the possibility of compromise on

\footnotetext{
${ }^{250}$ Maria Dolores González-Ripoll Navarro, El rumor de Haití en Cuba: temor, raza y rebeldía, 1789-1844 (Madrid: Editorial CSIC, 2004); Johanna von Grafenstein, "The Atlantic World at the Time of the Haitian Revolution: The Point of View of Francisco de Arango y Parreño," in Latin America and the Atlantic World/ El Mundo atlántico y América Latina 1500-1850, eds. Renate Pieper and Peer Schmidt (Cologne: Böhlau Verlag, 2005), 351-66. The impressive cataloguing of technical and landscape changes on Cuban plantations is visually presented in a collection of paintings along with some insightful commentary on the social effects of changes in plantation design in Justo Germán Cantero, Luis Miguel García Mora, and Antonio Santamaría García, eds., Los ingenios: colección de vistas de los principales ingenios de azúcar de la Isla de Cuba (Madrid: Editorial CSIC Press, 2005).
} 
the part of Spanish government toward their raucous South American colonies threatened to gain traction. $^{251}$ The Cortes delayed action on the proposal, a move that allowed Cuban planters time to protect slavery and expand the slave trade. Arango, tapped by an impressively unified block of colleagues in the Sociedad, Ayuntamieto de la Habana, and the Consulado Comercio to present the Cuban case, addressed his Representacion de la Ciudad de la Habana a las Cortes Españolas (1811) directly to the Cortes. In this petition, Arango outlined not only the economic importance of slavery to Cuba but also produced a defense of what was perhaps the more important aspect of slavery for creole elite; protection of the white population of Cuba.

To open the way for a man to hope for any good is to open the door also to his forgotten and dangerous reflections about being deprived of this good (freedom). It is certainly to arouse in him, if not outright insubordination, then lack of compliance. We need not mention the inconvenience and ills of such attitudes in slavery, seeing them repeated in all times and in all countries. In the stupidity of the Negro and the solitude of our estates lies the most necessary subordination, and all the more to be feared is anything that may loosen this unique resource, this capital defender of the existence of the whites who live with so many Negros..$^{252}$

The Cortes tabled discussion of abolition and emancipation, cognizant as it was of Cuba's growing economic power along with a shared fear that any limitation of slavery might push the island along revolutionary lines similar to the rest of its American colonies. Despite the official cooling of debate, a forceful discussion continued within courtly circles. Arango's chief opponents in this early debate were Joseph Blanco White, an exiled former priest, and geographer Isidoro de Antillón. Their antislavery arguments rested upon two main pillars of argumentation. First, they pointed to the historical lack of Spanish interest in African slavery and

\footnotetext{
${ }^{251}$ Reinaldo Suárez Suárez, "Repercusiones de la Constitucion de Cadiz, Guridi Y Alocercer y la Esclaitud en Cuba," accessed January 10, 2014, http:/www.juridicas.unam.mx/publica /rev/hisder/cont/22/art/art19.htm. The British hoped to exert significant pressure on the Spanish to curtail the trade due to the support they offered the Spanish in military action against the French on the peninsula after 1808.

${ }^{252}$ Francisco Arango, "En defense de la Esclavitud: Representacion de la Ciudad de la Habana a las Cortes Españolas," in Documentos para la Historia de Cuba, Volume I, ed. Hortensia Pichardo (Havana: Editorial de Ciencias Sociales), 251-52.
} 
the limited Spanish need for African slaves. They also pressed a philosophical argument that hinged on equating Spanish disdain for French occupation over the peninsula as akin to the international slave trade's encroachment on African kingdoms' sovereignty. Blanco argued these points in his 1814 pamphlet Bosquejo del comercio de esclavos y reflexiónes sobre este tráfico considerado moral, política y cristianamente.

One must keep in mind that no other European nation has had fewer slaves, considering the extension of its colonies, nor has any other based less of its prosperity on the labor of those unhappy beings than the Spanish nation... Do not forget that you too have seen foreigners set foot in your homeland. Leave in peace that of others. Leave those unhappy Africans the scarce portion of goods that Heaven has bestowed on their land. Leave them in peace so that they can advance little by little along the road of civilization. Just because they are poor and ignorant, can you treat them worse than you would the beasts in the wilderness? They are poor and ignorant. But the same blood runs in their veins that runs in yours. The tears that their eyes shed are just like yours. Like you, they are parents, children, and siblings. Martyrs of Spanish patriotism! . . From this day forward stop the Spaniards from going to the coast of Africa, where they surpass in cruelty and injustice those invaders that destroyed your soul. You, who know what it is to have [your families] ripped from your homes by foreign soldiers, leave to the father his children, and to the husband his wife. ${ }^{253}$

Therefore, critics asserted that Cubans and Spaniards proceeded with great peril if they

chose to look past both their historical approach towards labor and their current situation under

French occupation. Antillón developed this anti-slavery perspective further, arguing that Spanish colonial embrace of the slave trade was a miscalculation that ignored the real strengths of colonial society. While Antillón was anti-African slavery, he believed that Spain enjoyed considerable advantages over its rivals in the Caribbean because of the latter's reliance on dangerous African labor. He reminded his readers that the Haitian rebellion along with the rising populations of free AfroCreoles in British and French Caribbean colonies would force those

\footnotetext{
${ }^{253}$ Joseph Blanco White, Bosquejo del comercio de esclavos y reflexiónes sobre este tráfico considerado moral, política y cristianamente, ed. Manuel Moreno Alonso (Seville: Ediciones Alfar, 1999), 152-157. Christopher Schmidt-Nowara, "Wilberforce Spanished: Joseph Blanco White and Spanish Antislavery, 1808-1814," in Slavery and Antislavery in Spain's Atlantic Empire, eds. Josep M. Fradera and Christopher Schmidt-Nowara (New York: Berghahn Books, 2013), 158-170.
} 
empires to move production to Africa itself to make better use of enslaved labor lest they endure

constant unrest. In contrast, the true benefit for Spain in this imperial rivalry was a large

indigenous workforce in the Spanish colonies beholden to an existing set of laws that would

guide proper treatment and encourage increased productivity. No new apparatuses of control

were necessary for the exploitation of indigenous labor.

It is uncontestable that in our Americas the Indians can take over the labor of the blacks, especially if they are treated with less harshness and arbitrariness than heretofore because of the laws already in place to protect them. These laws are now useless because they have been replaced with unjust and oppressive practices against blacks. Indians' own chiefs and priests and missionaries could direct their labor and teach them farming, with assurances of land and no taxes, that would surely increase their desire to work. Their labor would be the greatest political and moral benefit since eliminating black labor would free us from dependency on the illegal trade with America and allow us to increase our profit since other European producers must pay costs, like clothing, food, and child care, for their slaves. ${ }^{254}$

Arango and the Cuban elite responded to these arguments, eventually winning the day, by

pointing out that slavery had been forced upon the island by the Spanish government and

Catholic Church. "We must never become tired of repeating that the Blacks came and are here

not due to our own fault, but rather to those who opened the way with guns and the full support

of law, and even the Church, which was so interested in liberating their souls from eternal

damnation." 255 The Cortes relented and refused to make any recommendation on abolition,

thereby allowing the slave trade to continue and opening the door to its expansion in 1818 .

The Cuban oligarchs successfully convinced the Spanish government that their economic security and potential for growth (along with Spain's economic enjoyment of that growth) rested

\footnotetext{
${ }^{254}$ Isidoro de Antillón, Disertacion sobre el orígen de la esclavitud de los negros, motios que la han perpetuado, ventajas que se le atribuyen y medios que podrían adoptarse para hacer prosperar nuestras colonias sin la esclavitud de los negros: Leída en la Real Academia Matritense de derecho español y público, el día 2 de abril de 1802 (Madrid: José Busquets, 1820), accessed January 10, 2014, http://books.google.com/books?id=9uBQAAAAc AAJ\&printsec=frontcover\&source $=\mathrm{gbs} \_g e \_s u m m a r y \_r \& c a d=0 \# v=$ onepage \&q\&f=false, 72-73

255 Arango, "En Defensa de la Esclavitud," 256. Arango's thinking on the Haitian threat and his writings to the Spanish state are covered in José Gomariz, "Francisco de Arango y Parreño: El discurso esclavista de la ilustración cubana," Cuban Studies 35 (2004), 45-61. Without question the single broadest volume on Arango's influence on Cuba and the social impact he writing had is Alvarez Izaskun Cuartero, ed., Francisco Arango y la invención de la cuba azucarera (Salamanca: University of Salamanca Press, 2010).
} 
on the exploitation of slave labor. Implicit in this articulation, however, was an understanding that the preservation of internal peace and stability in Cuba would be reliant upon a powerful state apparatus of control. Therefore, the Cuban elite clearly signaled their dedication to remaining in the empire, despite the great dislocation of imperial power stirring in the mainland South American colonies. The Cortes' concession on the slave trade was an equally clear indication of the support for and acceptance of not only the political calculation of Cuban colonial status but also the societal arrangement developing in Cuba. Slavery was the glue that bound Cuba to Spain and slaves, that aspect of Cuban society being necessary to its economic development, had to be completely policed in shared efforts of state discipline and social control. This merging of liberal economic precepts with conservative social and political ones fueled sugar's dominance of the island but also limited the scope of reform that producers might expect from the Spanish. Spanish Minister Calatrava remarked on the Cuban situation that "the fear which Cubans have of the Blacks is the surest means which Spain has for guaranteeing her continued domination in that country." ${ }^{256}$ However, despite the apparent victory of Cuban creole producers in the great slavery debate, Isidoro de Antillón went a step further in his chiding of the Cuban oligarchs. He reminded them of the Haitian example by extolling the benefit of a slaveryfree society in comparison to the dangers that the Haitian revolution transferred to Jamaica and now to Cuba. "There can be no doubt. The blacks will one day find a valiant leader who will avenge them and ensure their independence through force. And we must fear that finding the Crassus to this new Spartacus will not be easy."257

\footnotetext{
${ }^{256}$ Quoted in Jose Luciano Franco, Antonio Maceo: Apuntes para una historia de su vida (Havana: Editorial de Ciencias Sociales, 1975), 32. After the removal of French forces and the reinstallation of King Ferdinand, he rewarded Cuban fidelity with a variety of economic reforms including the removal of crown monopolies on tobacco, land reforms aimed at privatizing crown lands and offering title to hacendados, and most importantly unrestricted free trade in 1818. Lowry Nelson, "The Evolution of the Cuban Land System," Land Economics 24, no. 4 (November 1949), 365-381.

${ }^{257}$ Isidoro de Antillón, Disertacion, 82
} 


\title{
On April 9, 1812, the colonial Cuban government hanged the purported Cuban Spartacus
}

\author{
and then placed his severed head in an iron cage at the entrance to Havana harbor. Spanish
}

officials, to the loud applause of the creole elite and the onlookers that April morning, declared

themselves to be the collective Crassus to this Spartacus - a free AfroCuban named José Antonio

Aponte. Reliant upon a developing apparatus of social and military control with which to instill

discipline on the island, colonial authorities led by Captain General Salvador José de Muro

Salazar (Marque de Someruelos) moved to take control of a contentious situation that saw

numerous revolts throughout western Cuba in the spring of $1812 .{ }^{258}$ From January through

\footnotetext{
${ }^{258}$ As aware as many elite Cubans were of the events recently transpired in Haiti, AfroCubans also recognized the changed cognitive and political landscape after Haiti. The events of the previous two decades were not abstractions to the vast majority of those, enslaved or free, on Cuba. Rather, these new realities presented themselves in the daily arrival of new men and women held in chains, a concerted effort to flood Cuban slavery with African blood, and the diluted the power of the AfroCuban institutions. For owners, the response to Haiti and the ongoing rapid infusion of slaves in Cuba was the creation of command and control apparatuses, from police forces to education, in efforts to control the enslaved, and improve the lot of poor white creoles. All of these efforts aimed at preventing unrest. Haiti for the enslaved was a promise of freedom both achievable and personal. The island's example held the promise of successful systemic uprising, even if in the waiting for general revolution, the enslaved AfroCuban found personal methods to deal with the daily dishonors and abuses of their condition. The presence of bodies on Cuban plantations then demonstrated to both owner and owned that they stood in personal relation to each other and inhabited a contestable space in the tempestuous Atlantic economy. Enslavement gave whites and blacks a vocabulary to discuss discipline, fear, power, and labor in reference to local and global positions. Slaves discussed rumors, transmitted on the docks and interactions of the global economy, and brought their knowledge of a broader Caribbean world home to plantations in a fluid way that circumvented governmental-imposed limitations on schooling, information, and communication. As British abolitionism grew more robust, with the Royal Navy patrolling waters off the African and Cuban coasts searching for illegal slavers, the actions of distant politicians and regional movements of ships and soldiers fueled the intellectual contingencies of the enslaved. Slave revolts, even minor ones, on nearby islands communicated themselves often through the direct experiences of some involved sold off by British or French planters after being identified as too unruly and eagerly snapped off the boats of Spanish merchants capitalizing on desperate Cuban need. Slaves watched British officials patrolling the streets and inspecting boats in Havana harbor and increasingly understood the geopolitical positioning of the Spanish government and Cuban planters. Rumors spread ahead of the Aponte rebellions in 1812 that the Haitian government had taken to seizing slave ships bound for Cuba and brought the now rescued men and women to Haiti. While the probability of these seizures being widespread was slim, belief in the fortuitous combination of distant political decision and local action was a source of hope and perhaps even fuel for revolutionary fires. These rumors and actions certainly made themselves known to owners, overseers, and government officials - all these people were as concerned by the negative repercussions of the political events as the enslaved were encouraged by them. The free AfroCuban population found itself in a similar position of observance and reaction to the combination of long distance and local condition as they responded angrily to the news that the 1812 Spanish Constitution would not extend citizenship protections to mixed race peoples in Cuba. The most interesting reading of these phenomena would be an appreciation for the varied and confusing ways that news beyond plantations influenced action. This was not simply a case of Haiti driving action, but rather a much more complicated web of political and intellectual understandings of the new world the enslaved found themselves forced into. The overview of Spanish slavery and free AfroCuban populations discussed throughout this chapter is guided by a variety of sources and discussions
} 
March of that year, a series of uprisings in various stages of operational realization erupted across Cuba. While initial revolts in the island's interior were suppressed or thwarted by Spanish colonial authorities, the most concerning event was a large insurrection on the Peñas Altas sugar plantation outside of Havana. Spanish officials implicated both free and enslaved AfroCubans in the rebellion at Peñas Altas and in most of the smaller purported rebellions that spring. After extensive investigations, Spanish officials put thirty-two rebels to death and imprisoned hundreds of others. One of the rebels executed was Aponte, a free black carpenter and former colonial militiaman whom colonial authorities saw as the mastermind of the Havana rebellion. Collectively referred to as the Aponte Rebellion, these rebellions signaled the first major challenge to the foresight of massive slave importation. However, they should not be seen simply as slave uprisings but rather as extensions of the various debates and ideas guiding Caribbean action in the early nineteenth century.

To linger on the Aponte rebellion for a moment is important as its causes and outcomes set Cuban discussion and debate on certain trajectories purposely chosen as a result of differing perceptions of the rebellion. Aponte, the man and his free status, presented Cuban society with

including: Ada Ferrer, "Cuban Slavery and Atlantic Antislavery," and Christopher Schmidt-Nowara, "Wilberforce Spanished: Joseph Blanco White and Spanish Antislavery, 1808-1814," and Martín Rodrigo, "Spanish Merchants and the Slave Trade: From Legality to Illegality, 1814-1870," and Michael Zeuske, "The Amistad: Ramón Ferrer, Cuba, and the Transatlantic Dimensions of Slaving and Contraband Trade," all in Slavery And Antislavery In Spain's Atlantic Empire, eds. Josep M. Fradera and Christopher Schmidt-Nowara (New York: Bergham Books, 2013), chs. 5-8; Christopher Schmidt-Nowara, Empire and Antislavery: Spain, Cuba, and Puerto Rico, 1833-1874 (Pittsburgh: University of Pittsburgh Press, 2009), chs. 1-4; Kenneth F. Kiple, Blacks in Colonial Cuba, 1774-1899 (Gainesville: University Press of Florida, 1976); Michele Bernita Reid, "Negotiating a Slave Regime: Free People of Color in Cuba, 1844-1868," (PhD diss., University of Texas, Austin, 2004); Franklin W. Knight, Slave Society in Cuba during the Nineteenth Century (Madison: University of Wisconsin Press, 1970) and "The Free Colored Population in Cuba during the Nineteenth Century," in Sugar Without Slavery: Diversity in Caribbean Economy and Society Since the $17^{\text {th }}$ Century, ed. Verene A. Shepard (Gainesville: University Press of Florida, 2002), 224-247; Luis Martínez-Fernández, Fighting Slavery in the Caribbean: The Life and Times of a British Family in NineteenthCentury Havana (Armonk, New York: M.E. Sharpe, 1998); José Luciano Franco, La conspiración de Aponte, (Havana: Consejo Nacional de Cultura, Publicaciones del Archivo Nacional, 1963) and Comercio clandestion de esclavos (Havana: Editorial de Ciencias Sociales, 1996); Herbert S. Klein, "Colored Militia of Cuba," Caribbean Studies 6, no. 2 (June 1966), 17-27; Manuel Barcia Paz, La resistencia esclava en las plantaciones cubanas, 17901870 (Pinar del Rio, Cuba: Ediciones Vitral, 1998); Laird W. Bergad, Fe Iglesias Garcia, Maria del Carmen Barcia, The Cuban Slave Market, 1790-1880 (Cambridge: Cambridge University Press, 1995). 
an important problem beyond simple concern over slave rebellion. Like other viewers of Haiti such as AfroColombians on Colombia's Caribbean coast, many AfroCubans saw the struggle not as an invitation to a potential race war but rather as an opportunity for demanding more equal rights imbricated in a dignified republicanism that sought, as a key component, the abolition of slavery. While AfroCubans looked toward Haiti as an example of successful AfroCaribbean political activism and toward Colombia as exemplary in its grafting of racial republicanism onto a reluctant society, elite white Cubans looked to Haiti and Colombia as the greatest example of the dangers of integration - namely economic and political stagnation, unrest, and degeneracy. ${ }^{259}$ This is not to argue that all AfroCubans participating in the various uprisings of 1812 were motivated similarly, nor to assert that Aponte and whatever leadership structure existed had absolute command of either message or (wo)men in the uprisings. However, if there was a

\footnotetext{
${ }^{259}$ José Marcial Ramos Guédez, "Simón Bolívar y la abolición de la esclavitud en Venezuela 1810-1830, Problemas y frustraciónde una causa," Revista de Historia de América, 125 (July-December 1999), 7-20. John Lynch, "Bolivar and the Caudillos," The Hispanic American Historical Review 63, no. 1 (February 1983), 3-35; Aline Helg, "Simón Bolívar's Republic: A Bulwark against the 'Tyranny' of the Majority," Revista de Sociologia e Política 20, no. 4 (June 2012), 21-37 and Liberty and Equality in Caribbean Colombia, 1770-1835 (Chapel Hill: UNC Press, 2004). Helg argues that Colombians kept the threat of racialized revolution at bay through the inclusion of mixed race and African descended men in the body politic as opposed to their exclusion by the Spanish constitution of 1812. Marixa Lasso discusses the other aspect of keeping revolt at bay - when pardos argued for greater rights, Colombian government officials accused them of being seditious. She also argues that the contestation of Colombian republicanism was not without racial discord. Marixa Lasso "Race, War and Nation in Caribbean Gran Colombia, Cartagena, 1810-1832," American Historical Review 111, no. 2 (April 2006), 336-61, and "Revisiting Independence Day: Afro-Colombian Politics and Patriot Narratives, Cartagena, 1809-1815," in After Spanish Rule: Postcolonial Predicaments of the Americas, eds. Andrés Guerrero and Mark Thurner (Durham: Duke University Press, 2003), 223-247, and "Haiti as an Image of Popular Republicanism in Caribbean Colombia, Cartagena Province (18111828)," in The Impact of the Haitian Revolution in the Atlantic World, ed. David Geggus (Columbia, SC: University of South Carolina Press, 2001), 176-190, and Myths of Harmony: Race and Republicanism during the Age of Revolution, Colombia 1795-1831, (Pittsburgh: University of Pittsburgh Press, August 2007); Richard W. Slatta and Jane Lucas de Grummond, Simon Bolivar's Quest for Glory (College Station, TX.: Texas A\&M University, 2003); Rebecca A. Earle, Spain and the Independence of Colombia, 1810-1825 (Liverpool: Liverpool University Press, 2000); Alfonso D. Mtinera, "Failing to Construct the Colombian Nation: Race and Class in the Andean-Caribbean Conflict, 1717- 1816" (PhD diss., University of Connecticut, 1995); Nancy Appelbuam, "Whitening the Region: Caucano Mediation and 'Antiqueno Colonization' in Nineteenth Century Colombia," Hispanic American Historical Review 79, no.4 (November 1999), 631-667; Matthew Brown, "Not Forging Nations but Foraging for Them: Uncertain Collective Identities in Gran Colombia," Nations and Nationalism 12, no. 2 (April 2006), 223-240; James Sanders, "Atlantic Republicanism in Nineteenth-Century Colombia: Spanish America's Challenge to the Contours of Atlantic History," Journal of World History 20, no. 1 (March 2009), 131-150; Marcela Echeverri, "Popular Royalists and Revolution in Colombia: Nationalism and Empire, 1780-1820," (PhD diss., New York University, 2008).
} 
structure to republicanism's diffusion there must be an appreciation for the ways that this

incipient republicanism might have guided more participants than acknowledged. Furthermore,

to assert that those on plantations, who rose up or at least considered it, would have held no

reason for their actions beyond immediate retribution and blood lust is to seriously minimize the

appreciation for the political moment sensed by many in the AfroCuban community in the early

1810s. Rumors surrounding the emancipation of slaves by either European or African kings

reported in many official slave testimonies in the wake of the rebellion demonstrate an

appreciation for the political effects of distant decision-making and a respect for some legalistic

opportunities beyond uprising. The Cuban political arrangement also left an interesting landscape

for AfroCubans to move upon. AfroCubans appreciated the pregnancy of action, cognizant as

they were of the robust push on the part of the elite to redefine the Cuban community along

racial lines. ${ }^{260}$

\begin{abstract}
${ }^{260}$ Already by 1812, Arango and others established their contours of national definition that excluded AfroCubans regardless of legal or labor status. "The cultured nations persist in their opinion that for political advantages the liberated bozal as well as the lively cuarterón should be considered as equal even though he might be the son or grandson of very commendable people - the concept of one drop of Negro blood infecting the white to the most remote member even in our senses and our memory do not discover it, we must recall the testimonial of the dead kept in tradition or parchment covered with dust - it seems to be obvious that with the exclusion of any identification with us, the doors to civil liberties should also be closed," Arango, "En Defensa de la Esclavitud," 260. Shockingly, even Arango himself was caught up in the great suspicion in the months of the Aponte rebellions as his role in the organization of the Havana Junta came under scrutiny. After the deposition of both Fernando VII and Charles IV by Napoleon, the creole elite in Cuba, with the knowledge of the Captain General, moved to fill the vacuum left in the wake of French invasion of Spain in 1808. The Junta Superior de Gobierno was to rule until the Spanish throne was restored although ultimately it failed after Arango's decision that not enough residents supported the decision. In the tumult of 1812, Arango's role in the Junta's formation took on a more sinister tone in the hands of rivals who, seeking to prevent Arango from earning a seat from Cuba in the Cortes, accused him of acting against the crown's interests in Cuba. Demonstrative of the dual front of Cuban slavery's debate was Arango and Alexander von Humboldt's earnest debate over the nature of slavery on the island. Much like Arango's earlier travels through Cadiz, Portugal, England, Barbados and Jamaica in early 1790s, Humboldt sought a collection of evidence for his research on the political economy and natural sciences of Latin American. Humboldt visited Cuba briefly on his travels between 1799 and 1804. While on the island he engaged the still developing scientific and literary societies of which Arango was a prime participant. Humboldt's Ensayo Político sobre la Isla de Cuba put forward a broadranging attack on Cuban slavery, noting its presence as the major issue affecting long-term stability on the island. The work was suppressed in Cuba when it arrived in its Spanish translation in 1827, although Arango took great pains to respond thoroughly to its critiques. Humboldt agreed with Arango that urban slaves had perhaps slightly greater legal rights in Cuba than elsewhere but this, he argued, missed the point of the Enlightenment drive toward absolute human freedom. He also traveled to rural areas of the island and observed slaveowners disregarding the legal protections Arango and others argued separated and mitigated Cuban slavery from other Caribbean examples.
\end{abstract}


The gestation of the Haitian revolution by 1810 served as much as a warning for AfroCubans as an example. AfroCubans appreciated shared experiences and conditions among themselves and other AfroCaribbean people and grafted disparate evidence onto their local expressions of possibility and analysis. There is no intellectual leap to appreciate the political concern that AfroCubans, both enslaved and free, felt upon learning that while the elite defined the national body based upon exclusion of their perceived racial markers, the Haiti Constitution embraced a collectivity of national inclusion. "All Haitians will henceforth be known as Negroes" read the 1805 Haitian Constitution, a recognition of shared condition of presence on the island and in the communal struggle to forward Haitian nationhood, while also seeking to sublimate African ethnicities that threatened still to divide. Aponte's positioning and the rebellious atmosphere surrounding him can be viewed as a demand for inclusion in the political development of the Atlantic system; a call for political unity while not seeking a complete overthrow of the political system. Even the leaders of the Haitian uprising extolled patience and circumspection in projecting their example too widely throughout the Caribbean. Jean-Jacques Dessalines recognized the danger of other Europeans internalizing a generalized threat of slave

Humboldt took notice of various aspects of slavery that confounded Cuban protestations of the laxity of the island's system including harsh treatment, length of work days, and astounding sex disparities. Humboldt argued for a gradual legalistic emancipation and used as his strongest evidence the claims that Cuban planters suffered from the inflationary effects of slave pricing. Therefore, these planters would recognize greater profits and more rationalized labor costs if the move away from slavery took place. Furthermore, the greater deployment of technology (realized with the investment of now realized surpluses), in Humboldt's opinion, would also limit the need for additional slaves. Arango published his rejoinder, "Observaciones escritas en 1827 al Ensayo político sobre la isla de Cuba," as a series of close reading notes that highlighted some of the most egregious issues he took with Humboldt's text. Arango, "Observaciones," in Obras del Excmo. Señor D. Francisco de Arango y Parreño, Vol. 2, eds. Vidal Morales y Morales and Manuel Villanova, (Havana: Howson y Hienen, 1889), accessed January 10, 2014, https://archive.org /details/obrasdelexcmose00arangoog, 533-546. Maria Dolores González-Ripoll Navarro, "Vínculos y redes de poder entre Madrid y la habana: Francisco Arango y Parreño, Ideólogo y mediador (17651837), Revista de Indias 61, no. 222 (2001), 291-305. One of the more interesting investigations of Humboldt and his view of Cuban slavery in debate with Arango, a debate which illuminates Humboldt's views on Saint Domingue using Cuba as his lens, is Michael Zeuske, "Alexander von Humboldt y la comparación de las esclavitudes en las Américas," Humboldt im Netz 6, no. 11 (2005), 65-89 and "Humboldt en Cuba, 1800/1801 y 1804 - Huellas de un enigma," Humboldt im Netz 11, no. 20 (2010), 7-19; Philip S. Foner, "Alexander Von Humboldt on Slavery in America," Science \& Society 47, no. 3 (Fall 1983), 330-342; John W. Blassingame, "Foreign Writers View Cuban Slavery," Journal of Negro History, 57, no. 4 (October 1972), 405-24. 
rebellion throughout the Caribbean. "Let us not act as rash revolutionaries and, trying to be the legislators of the Caribbean, pursue fame by troubling the peace of the neighboring islands. Unlike our own country, these island have not been soaked in the blood of their innocent inhabitants, who have no vengeance to take against the authority protecting them."261

Aponte then becomes a name attached to a series of revolts critical of prevailing labor and social organization. The revolutionary moment was desirous of a reconfiguration at the precise moment when the accretion of power and marching centralization of the sucrocracy's control threatened an unchallengeable ascendancy. Aponte, as many others involved in the uprisings, imagined the multiplicity of their citizenships imbricated in various traditions: Afrodiasporic; AfroCuban; circum-Caribbean. As they surveyed their positionality in the current Cuban/AfroCuban cultural and political community, they perceived identities that supported this positionality and appreciated the current threats to the stability of definitions. The year 1812 presented itself as a moment when contestation in many areas, including legal rights potentially offered under the new liberal constitution and the continued protection of those already recognized, could not be missed by AfroCubans. The Aponte rebellion exists as a series of related questions not only of identity but the degree of inclusion of those identities, particularly for free AfroCubans, in a 'new' Cuba. The view of Aponte's rebellion as directed solely at overthrowing slavery decontextualizes much of the contemporary Cuban moment in Atlantic affairs and replicates the contagion effect of Haiti so fervently believed by the Cuban elite. ${ }^{262}$

\footnotetext{
${ }^{261}$ Jean-Jacques Dessalines, Liberte ou la Mort: Proclamation du Général en Chef au Peuple d'Haïti Quartiergénéral des Gonaïves, le ler janvier 1804, an ler de l'Indépendance, accessed Jan. 15, 2014, http://www.windows onhaiti.com/windowsonhaiti/act2.shtml. Dessalines, to some respect, also argued in his comments for a possible difference in severity between French slavery in Saint Domingue and the rest of the Caribbean.

${ }^{262}$ The Aponte rebellion seems to be the moment where action most directly meets the theory of créolité, hybridity, cosmopolitanism, and modernity in regards to Cuba. While I can't do the massive discussion on such issues justice in a footnote, I do think that these issues intersect in important ways and at an important juncture for the current discussion. As opposed to the later La Escalera conspiracy (baldly obvious in its goal for Cuban elites, a political failure for AfroCubans, and occurring at moment after significant reification of the social structure) the Aponte
} 
rebellion makes a forceful entry into the social and political climate of an unstable Spain and Cuba. Given the debates over slavery and over the Spanish constitution in 1810-1812, the Haitian Revolution, the rebellious attitude infectious throughout South America, the lack of firm control the sucrocracy held over Cuba's internal affairs, and the belief that there was soon approaching a moment of social hardening which they could ill-afford to let pass without contestation, AfroCubans moved to cement perceived gains and fight for still more. The great swelling of Caribbean dissent followed a rhizomic, decentralized structure that made origin of thought as imprecise as the goals of that thought. Undoubtedly, in the wake of Haiti there exploded a transnational egalitarianism of varying degrees of radicalism; this despite efforts to contain the Haitian contagion. The Aponte rebellion also points out the imprecision of searching for an inherent tension between liberty and equality in larger implication for the concept of modernity. The conceptualization of liberty on display in Cuba during 1812 was not necessarily one that hoped to end with emancipation on par with Haiti. Thus the Aponte moment can be seen as analogous to numerous moments of revolutionary foment in which actors negotiate participation. The great call for a monocasual abolition/emancipation/revolution impulse presupposes rebellion as the culmination rather than as a part of revolutionary action. Conversely, if emancipation moves beyond that initial rebellious stage and progresses to building on that success, however tentative, through demands for political participation then an alternate reading moves to the fore, one that doesn't produce tension between reading the Aponte moment as a rebellion and as a call for greater political participation. Subsequent struggles within and outside of Cuba might obscure this reading, but there is at least a contemporary understanding on the part of Spanish officials for this reading as demonstrated by their struggle to fully understand the positionality and intent of Aponte. His much spoken about book - a clipbook of various republican figures, ideas, and passages - confiscated by the Spanish authorities speaks to a deeper level of egalitarian demand that the coarse identification of 'rebel' allows. Spanish officials' dismissal of Aponte's book as a treatise or simple literary incendiary belies a rationalization of division between European (read proper) republican production and degenerative Caribbean revolutionary production. This reading of Aponte and his book aimed to reinforce the white creole elite's hegemony in artistic and political production and to reify as subversive artifacts outside of those definitions. This process did much to strengthen a coordinated effort at definition that placed most AfroCuban production, beyond economic commodities, in the realm of subversive. This is most directly and obviously true of AfroCuban bodies. Further complicating the issues is the presence of British abolition efforts in the Caribbean that did much to set the stage both contemporarily and historically for emancipation. An effort at separating the abolitionary efforts of the British from the more visceral radical anti-slavery movements of those enslaved and free AfroCreoles is necessary. The former envisioned a landscape of incremental redeployment of labor forces productive of a modern social structure that reduced demands on revolutionary impulse and thus disruptions to production. The later articulated modernity mutually forged in national sovereignty and racial egalitarianism. This is the modernity envisioned by José Aponte. The modern vision of radical antislavery in Cuba might not have been a truly independent state, a sovereign nation, as much as a protected constituency in an array of competing interests definable and protectable by the Spanish state. In this arrangement, Aponte and other rebels in Cuba might not have envisioned an AfroCuban republic, realizing the difficulty of equality in even a monoracial republic, as much as limiting the power of the directors of labor's energy and asking the Spanish state to balance competing political and labor claims between AfroCubans and the creole elite. This was a moment where the full support of the Spanish government was not yet fully felt by the creole elite, with debates in the Cortes over slavery and voting rights ongoing. These were debates closely monitored by AfroCubans as much as by the elite. As testimony in the Aponte cases demonstrates, AfroCubans had as detailed an understanding of Spanish political debates as creole whites, hamstrung as this understanding for all sides was by distance and quickly shifting local events. Stepping outside of the historical debates over Aponte and the rebellion's existence, real causes, ultimate aims, and level of AfroCuban involvement, that which is undeniable is the wide-ranging nature of Aponte's influences as representative of a larger process of Caribbean interaction. He seems then a true modern collector of the Caribbean pastiche he found himself in as a free AfroCuban. His translation of various AfroCreole experiences gave voice to the involvement of individual experience in a web of entangled histories and presents. Political activities, social concerns, efforts and failures at unity developed at one site informed and nudged revolutions elsewhere. The elite and the enslaved alike recognized the large circuit of revolutionary ideas that threatened Cuban social stability. These concerns drove officials, lacking a clearly developed idea of the worth of these ideas and perhaps a more limited use for them, to define Aponte antagonistically and therefore neatly in the conspiratorial race-rebel role. That Haiti continued to present itself as such an important source of discussion and influence demonstrates the strength of socio-political networks that shaped the Atlantic world as profoundly as did the economic networks. The means of transit were the same and the contexts for reaction produced by changes to these very networks. Stephan Palmie argues that the emergence of these modern and the constituent hybridities 
foundational to that Atlantic modernity were built upon the imprecise space created in the interaction between science and the occult. Aponte then was neither purely conspirator nor acquiescent. While Cuban officials became interpreters of his vision since it was not clear how his notebook materials might translate to operational activities, there exists an alternate space that Aponte might have inhabited which breaks him and the actions in the 1812 rebellions out of a simple rebellion/stability model and understands the actions as a rational calculated reaction to the bodily and political appropriation of AfroCubans' power by an expanding creole elite. There seems to be some demonstration of this perspective in the slave testimonies during and after the 1812 rebellions. While Haiti comes up often in testimonies and was clearly part of the cognitive world of AfroCubans, the attention the Haitian government put into securing the results of their revolution narrowed the possibility for direct Haitian aid. It's not a coincidence that Haitian President Pétion offered Simón Bolívar aid, after the Spanish forced Bolívar to take refuge on the island twice (1815-1816), and Pétion received a guarantee that Bolívar would abolish slavery in Colombia, a guarantee he was of course unable to secure from even the most powerful AfroCuban leaders. They were locked in struggle with a more intractable white leadership class than the one Colombians encountered and therefore any post-

Revolutionary society in Cuba would most likely be one in which freedom was negotiated rather than delivered by Bolívarian fiat. Simply, Pétion would be able to get something for his investment in Colombia that would not be possible in Cuba. The concept of Haiti then became most useful in a metaphoric sense, an exhortation to political action that recognized the locality of action and possibility rather than an entity offering direct aid. Discussion of Haiti by the enslaved and use of Haitian imagery and personas from the revolution by free AfroCubans sustained the revolutionary imagery and was useful for a particular Cuban moment that sought its example. Also important is the possibility that men like Aponte had political ambitions of their own and sought a powerful constituency that might propel them to power not at the head of a government but at least as a representative in it. Free AfroCubans, fearing a loss of their own power, prestige, and position, could have been desirous of harnessing a powerful bloc to encourage Spanish decision-making and an intervention on their behalf to slow the growth of hacendados' power. Freed slaves could be powerful supporters of free AfroCuban politicians and, comprising a good percentage of the population, might have been able to prevail upon Spanish desires to keep Cuba stable and within the empire. Free AfroCubans looked forward to potential allies in political struggles after abolition and hoped to enjoy maybe even electoral success if their support of emancipation projected political strength. While this assumes more political flexibility on the part of the Spanish government, even white creoles were not totally convinced of the Spanish government's commitment to slavery and the debates over abolition and the liberal constitution certainly did not allay those fears. Furthermore, this interpretation complicates the unity of the AfroCuban community but places both free and enslaved in a more self-conscious political moment rather than a simple projection of Haiti onto Cuba. This lack of unity would carry the explanation of AfroCuban cabildos forward in a more satisfying way than efforts that try to find ethnic unity in a system that was predicated on a lack thereof. To think of the Aponte Rebellion (implicit in its naming) as a slave uprising directed or inspired by free AfroCuban networks of influence driven by cabildos argues for a unity of color that stands opposite to the class, social, and national ethnic attributes that the cabildos' foundation and separationist tendencies suggest. The search for origins and continuances in Cuba in the world of cabildos, foregrounding the ethnic imperative rather than the social imperative, serves to miss the opportunity to see the free AfroCuban community as a powerful political advocacy bloc rather than just simply hamstrung by associations with ethnic differences. Perhaps, these cabildos sought support from slaves as a hope to grow their own influence with the Spanish state and in regards to other cabildos. Instead of a failed Haitian style revolution, the rebellions of 1812 could very well have been a self-interested articulation of political ambition and social redefinition. Aponte's interaction with whites, particularly General Luis Francisco Bassave y Cardenas, a wealthy white creole, offers some acknowledgement that Aponte understood alliances in the struggle against shifting political winds as contingent on unique Cuban concerns. Historian José Luciano Franco, La conspiración de Aponte (Havana: Consejo Nacional de Cultura, 1963), in addition to reprinting much of Aponte's testimony about his 'book,' discusses Aponte's recruitment by Bassave in the Masonic Conspiracy of 1810, led by the general. Bassave, popular amongst poor whites and blacks, sought help in developing an combined force to overthrown the Spanish authorities and was actually denounced by both the captain of the black militia, Isidro Moreno, and the Sargent of the Mulatto Regiment, Pedro Alcantara Pacheco. Bassave and his conspirators were imprisoned in Spain but Aponte was undiscovered and carried the planning forward. Recognizing the undergirding of a mixed race uprising already existed, Aponte set about reforming the plan and moving forward with actions already planned. The Spanish authorities sought to break these two rebellions up as to prevent the interpretation of a generalized political revolt. Cuban slaves in their biracial international efforts, looked beyond a racial discourse to fuel revolution. Theirs was not an unthinkable history but rather an articulable and measured one in which they wanted voice in the national discussion. The poles of interpretation of Aponte, both whom find Franco's interpretation less than compelling, are 
However, with the contagion perceived as arrested, Cuban creoles moved forcefully to fortify their political and cultural flanks. They relied on their continuing fidelity to the Spanish government during the South American tumult to extract important economic concessions, as well as to be left largely alone to debate the contours of Cuban social composition. And debate they did, albeit under the cloud of a most disagreeable sort - British abolitionism. The elite response to Aponte, and its foundation of a continuing and generalized fear of Haiti, was to hasten the development of systemic approaches to bodily control of slaves. This control necessitated investment in new policing technologies deployed to dictate the physical arrangement of plantations and uphold limitations on free AfroCubans' access to rural plantations and their slaves. Added to these means of physical control was a broader intellectual effort aimed at defining national participation in a way exclusionary to AfroCubans. These developments began an important second stage of the sugar boom that lasted until the 1860s, one marked by an acceleration of the mechanization, organization, and rationalization of both enslaved bodies and sugar production. The accretion of technology, slaves, land, political power, and economic opportunity fueled the repressive structuring of Cuban society. Despite the

Stephan Palmie, Wizards and Scientists: Explorations in Afro-Cuban Modernity and Tradition (Durham: Duke University Press, 2002), who argues that scholars must be wary of projecting assumptions about the rebels' (like Aponte) subjectivities based on the conclusions drawn on evidence based on "the status positions, role sets, or place within the relations of production that they occupied," (137). Conversely, Matt Childs, The 1812 Aponte Rebellion in Cuba and the Struggle against Atlantic Slavery (Chapel Hill: UNC Press, 2006), shows how Aponte's experience in the tightening racial hierarchy embodied the tensions of Cuban slave society during this period. Lena Delgado de Torres, "Reformulating Nationalism in the African Diaspora: The Aponte Rebellion of 1812," CR: The New Centennial Review 3, no. 3 (Fall 2003), 27-46. Julia Cuero Hewitt, Voices Out of Africa in Twentieth-Century Spanish Caribbean Literature (Lewisburg, PA: Bucknell University Press, 2009); Juan Antonio Hernández, "Hacia Una Historia De Lo Imposible: La Revolución Haitiana Y El 'Libro De Pinturas' De José Antonio Aponte," (PhD diss., University of Pittsburgh, 2006); Gloria García Rodríguez, Voices of the Enslaved in Nineteenth-Century Cuba: A Documentary History (Chapel Hill: University of North Carolina Press, 2011); Ada Ferrer, "Speaking of Haiti: Slavery, Revolution, and Freedom in Cuban Slave Testimony," in The World of the Haitian Revolution, eds. David Patrick Geggus and Norman Fiering (Bloomington: Indiana University Press, 2009), 223-247; David Scott, Conscripts of Modernity: The Tragedy of Colonial Enlightenment (Durham: Duke University Press, 2004); Laurent DuBois, "The Citizen's Trace: The Haitian revolution and the Motor of History," in Magic and Modernity: Interfaces of Revelation and Concealment, eds. Birgit Meyer and Peter Pels (Stanford University Press, 2003), 103128. 
extraordinarily rapid technical improvements in both the biological and mechanical aspect of sugar production, creole producers refused to reduce their dependence on slavery and showed no hesitation in increasing the amount of African bodies they brought to the island. Slavery then clearly paid benefits beyond labor capacity for the creole elite. The presence of slavery structured societal and national priorities, thereby strengthening creole confidence in their unique abilities to lead Cuban society in the same way they led their plantations and the sugar revolution. The presence of slaves normalized the elite's rule due to their successful control of that ever-growing population.

Yet coupled with this control was a simultaneous fear mongering of Cuba's white lower creole classes with elite fears of "Africanization" of the island. This fear drove many elite on the island to long for clearer racial definitions and a general whitening of the Cuban body politic. The ambivalence of color, the need for labor, and the fluidity of race produced a great anxiety and corresponding drive to reify the boundaries of color. The elite used the policing of white women's morality as the means by which race protection and demonstration of 'proper' civilization might be had. Creole elites also held AfroCuban women to these standards as a means of increasing their hegemonic effects. Using these standards to define AfroCuban femininity made the racial dichotomy starker since the inevitable failure of AfroCuban women to achieve true 'femininity' rested largely on systemic AfroCuban exclusion from societal institutions necessary to achieve such a goal. In addition, the great anxiety of color policing was most clearly on display in the political writings of the creole elite and in the racialized fiction of Cuban authors. ${ }^{263}$

\footnotetext{
${ }^{263}$ The arrival of a unique Cuban literature, apart from the political tracts of the day, identified the interrelated issues of race, mixture, and gender as foundational to understanding the peculiar Cuban condition. In his discussion of María de las Mercedes Santa Cruz y Montalvo (Comtesse Merlin/Condesa de Merlín, author of La Havane, a Spanish woman who wrote in French thereby prompting a rejection of her work from the Cuban canon), Roberto
} 
Ignacio Daz sums up her importance to Cuban literature's self-description of early Cubanidad as well as investigating the multivalent personas present in her life and work. The description can stand in well for early Cuban literary development as well. "By interweaving a series of opposing pairs - Cuba and France, Spanish and French, native costumbrismo and European exoticism, memory and present - Merlin creates a hybrid text whose meaning cannot be fully comprehended outside the system of Cuban literature. This hybrid nature expresses itself most clearly in the adoption of literary strategies associated with a diversity of genres, including not only romantic travel writing in the European tradition, but also the cronicas de Indias, the cuadros and narrative fiction of Cuban constumbrismo, and, perhaps more significantly, autobiographical writing," (59). While not present in every work in the early period, the hybridity of style in many early Cuban literary works matched the hybridity on display in Cuban society. The search for origins as productive of contemporary definitions of belonging consumed early Cuban literature. The mutually reinforcing searches for origin, both for literarily created individuals and for actual Cubans, exhibited themselves in the constant tension between autobiographies and literary attempts at communal expression. Authors used their own experiential landscapes or created social worlds through which they moved archetypical characters in effort to produce outcomes that lent themselves to comment on the Cuban condition. Topics of slave fealty, miscegenation, unrequired interracial love, slave discipline, creole mores and customs, Spanish decadence, and Cuban insularism, produced with both realistic and romantic brushes, pushed forward the self-consciousness of producing a national(istic) literature befitting a rising bourgeois. The combination of romantic novel, local customs and, Enlightenment (read European) realism is most clearly seen in another important novel of the time, Cirilo Villaverde's Cecilia Valdés, or Angel's Hill: A Novel of Cuban Customs. The literary pastiche of Cuban writing belied a social pastiche that built into the structures of the Cuban nation a mixture that had to be closely monitored. The political process of race demarcation was on display in the literary world of Havana as well. There existed an interesting fracture in the production of the early canon falling clearly along gendered lines. As Merlín's work was rejected by literary circles in Havana, accusations of plagiarism - not really any different than other generous borrowings in other works by other male authors - added the appropriate fuel to the fire of her exclusion. So excluded was the work of another woman, Gerturdis Gómes de Avellaneda (Sab published in 1841). Not only was the work of both women subversive in that they were women, but Avellaneda, like Merlín, also inverted established racial codes by writing of a slave falling in love with a white woman (although his love remains unrequited through choice and circumstance, leading to a debate as to how subverting the work was). The presence of these works and their controversial, if muted, receptions demonstrates the process of national character and canon production through the choices being made concerning inclusion of literary productions. Merlín and Avellaneda's presence highlights a corresponding effort in the reification of gendered and racial notions of class, specifically the control of the minds and bodies of elite women. Issues of race, intermarriage, and hierarchy were always at the forefront of social production. The protection of whiteness (and the whitening of the population or Blanqueamiento) could be found in the close policing of biological and physical separation. Yet these efforts, although rhetorically robust, weakened in the face of the reality of interracial marriage, particularly among free AfroCubans and poor whites. This failure of policing, identified by elites, necessitated a subsequent process of economic and social exclusion of poor whites from claims on national heritage. As critical transmitters of whiteness, elite white women also fell victim to and participated in, to a degree, an aggressive process of patriarchal hierarchization designed to limit connections between lower races/classes and elite women. The crown moved to strip the Church of marriage oversight in 1805 , demanding that purity of blood be proven to governmental officials before weddings could be conducted, since elites accused the church of an overly lax enforcement of racial prerogatives. Alejandro de la Fuente, claims that almost $50 \%$ of all slave marriages (a source of concern in themselves for hacendados) and slave births were witnessed and godparentship given by whites. The protection of genetic purity became a social organization tool to reduce women's public personae, access to education, and physical mobility - a process supported by literature and politics. Public education, the domain of the elite creole run Sociedad Económica de Amigos del País, allowed a unique avenue for the articulation and solidification of an exclusionary Cubanidad based on access to education. The push toward female education, seen as a means of asserting a European mentality on the island, equated for some a move toward the civilizing force of Enlightenment thinking. Educating elite women also allowed a clear racial line to be drawn between the biological carriers of civilized whiteness as opposed to both poor white and AfroCuban women who had access to neither educational opportunity nor national importance. The restriction of education to elites complemented the multifaceted approach of social limitations in terms of movement, marriage, labor, and notably freedom. Educating elite women was one of many notable attempts to combat the racial changes taking place on the island, accelerated by the explosion in slavery, defined under the board banner of 'Africanization,' (1804 marked the first moment that the AfroCuban population outnumbered whites, 1841 being the first census in which slaves outnumbered whites on the island). The management of educational opportunity, including the types and genders of 
instructors, became a key way for elites, through the Sociedad, to resist 'Africanization' in the face of growing population disproportionality. The surest way to assert an elite identity was through the development of markers of difference that bolstered racial imperatives. Civilization, among cultured people, rested upon education. As a Spanish dictionary asserted in 1853 , "A degree of culture acquired by a country or people when primitive natural rudeness is overcome by beauty, elegance and gentleness of words, practices and customs characteristic of a culture people; the practical application of perfected reasoning, and the noble instincts of humanity; the well-being of the individual and societies. Material Civilization: the progressive development of the arts and industries," (Childs, 95). Therefore the feminine traits of progress (beauty, elegance and gentleness) demanded educational refinement and promulgation and the lack of educational institutions for these efforts was an embarrassment and weakness that required immediate rectification. Through publications, both political and literary, and the design of curriculum, the Sociedad moved obsessively toward institutional improvement and by extension societal perfecting. Cuban civilization became increasing urgent and frequent in its assertion by members of the elite, notably as population demographics slid farther from acceptability. Women's education, following the European model extolled by Rousseau among others, enhanced Cuban civilization not only in the promotion of learning for itself, but also in the civilizing impulse that served to differentiate races based on their access to such learning. However, the impulse toward educating women slowed by the 1850s as the concern about falling birthrates as a result of elite women's refusal to submit their now-educated wills to the trials and drudgery of familial responsibility for other opportunities. Demographic concerns took on immediacy, notably in the face of La Escalera and the annexation debate, which focused elite male concern on developing new bulwarks against AfroCuban demographic strength and continued Spanish military dependency. Educational policy shifted toward making women better mothers - a natural and even more highly civilized state as compared to women who desired to enter the work force. Therefore as early educational policy had served to reinforce racial divisions, by the 1850s the educational activity served to naturalize the equaling of womanhood with motherhood as the foundation of rational state domesticity. Educating women to then educate their young (to different ends for boys and girls) produced the dual impulse toward demographic and intelligence strengthening of the state building process through generational promotion of improvement without the sapping of the reproductive impulse. The bourgeois family then emerged in Cuba, like elsewhere, as a structured apparatus of definitional and physical control. Since the enslaved had no access to legally recognized families, enslaved women remained outside the feminine and therefore their offspring remained outside the nation. Femininity, through the tortured process of educational development and literary production, then came to define a defensible imperative for a civilized society, with domesticity and racial purity serving as the poles between which the Cuban nation might be literally and figuratively produced. These systems of culture, knowledge, and hierarchy production gave the aspirant Cuban nation-state, despite its coloniality, some shape with which to soothe elite anxieties. That some of this reaction was in response to foreign, particularly American, observers critical of Cuban social development should come as no surprise as the performance was as much for internal audiences as it was for external ones. The Cuban elite was after all eliciting and desirous of economic and cultural investment from abroad to augment Cuban claims of sophistication and civility. Ignacio Daz, "Merlin's Foreign House: The Genres of 'La Havane," Cuban Studies, 24 (1994), 57-82, (quote on 59); Matt D. Childs, “'Sewing' Civilization: Cuban Female Education in the Context of Africanization, 1800-1860," The Americas 54, no. 1 (July 1997), 83-107, quote on 95; Arlo Kempf, "The Production of Racial Logic in Cuban Education: An Anti-Colonial Approach," (PhD diss., University of Toronto, 2010), chs. 1-2; Alice R. Wexler, "Sex, Race and Character in Nineteenth Century American Accounts of Cuba," Caribbean Studies 18, no. 3/4 (October 1978-January 1979), 115-130; Adriana Méndez Rodenas, "Voyage to 'La Havane:' The Countess of Merlín's Preview of National Identity," Cuban Studies 16 (1986), 71- 99, and "Identity and Incest in 'Cecilia Valdés': Villaverde and the Origin(s) of the Text," Cuban Studies 24 (1994), 83-104, and "Tropics of Deceit: Desire and the Double in Cuban Antislavery Narrative," Cuban Studies 28 (1998), 83-120; Gema Guevara, "Inexacting Whiteness: Blanqueamiento as a Gender-Specific Trope in the Nineteenth Century," Cuban Studies, 36 (2005), 105-128; Walter Mignolo, "Delinking: The Rhetoric Of Modernity, The Logic Of Coloniality, And The Grammar Of De-Coloniality, "Cultural Studies 21, no. 2 (Spring 2007), 449-514; Maria Lugones, "The Coloniality of Gender," Worlds \& Knowledges Otherwise, (Spring 2008), 116; Anibal Quijano, "Coloniality of Power, Eurocentrism, and Latin America," Nepentla: Views From the South, 1, no. 3 (Fall 2000), 533-580 and "Coloniality and Modernity/Rationality," Cultural Studies 21, no. 2 (Spring 2007), 168-178; Anna Brickhouse, Transamerican Literary Relations and the Nineteenth-Century Public Sphere (New York: Cambridge University Press, 2004); Ann Laura Stoler, "Tense and Tender Ties: The Politics of Comparison in North American History and (Post)Colonial Studies," The Journal of American History 88, no. 3 (December 2001) 829 - 865; Aisha K. Finch, "Scandalous Scarcities: Black Slave Women, Plantation Domesticity, and Travel Writing in Nineteenth-Century Cuba," Journal of Historical Sociology 23, no. 1 (March 2010), 101-143; Reina 
Throughout this proto-nationalist era, the Cuban citizen became creolized, gendered, and racialized. For elite Cuban creoles, the development of a national body, both in the individual and the general, relied on delineated differences based on race and gender. The creole elite sought to differentiate themselves from Spanish peninsulares as well as from AfroCuban creoles on the island. This defining processed on a social and intellectual landscape guided by white men

Barreto, "Subversion in Gertrudis Gómez de Avellaneda's Sab," Decimonónica 3, no.1 (Winter 2006), 1-10; William Luis, Literary Bondage: Slavery in Cuban Narrative (Austin: University of Texas, 1990); Verena MartínezAlier, Marriage, Class and Colour in Nineteenth-Century Cuba: A Study of Racial Attitudes and Sexual Values in a Slave Society (Ann Arbor: University of Michigan, 1989); Mary Louise Pratt, Imperial Eyes: Travel Writing and Transculturation (New York: Routledge, 1992); Tiffany A. Sippial, Prostitution, Modernity, and the Making of the Cuban Republic, 1840-1920 (Chapel Hill: University of North Carolina Press, 2013); Doris Sommer, "Sab C'est Moi," in Foundational Fictions: The National Romances of Latin America (Berkeley: University of California 1991), 114-37; Lorna Valerie Williams, "Gertrudis Gómez de Avellaneda's Sab: The Feminized Slave" in The Representation of Slavery in Cuban Fiction (Columbia: University of Missouri, 1994), 84-118; Brigida Pastor, "Symbiosis between Slavery and Feminism in Gertrudis Gómez de Avellaneda's Sab, Bulletin of Latin American Research 16, no. 2 (1997), 187-196; Teresa Prados-Torreira, Mambisas: Rebel Women in Nineteenth-Century Cuba (Gainesville: University Press of Florida, 2005); Teresa C. Zackodnik, The Mulatta and the Politics of Race (Oxford: University Press of Mississippi, 2004); Kimberly Snyder Manganelli, Transatlantic Spectacles of Race: The Tragic Mulatta and the Tragic Muse (New Brunswick: Rutgers University Press, 2012); Lesley Feracho, Linking the Americas: Race, Hybrid Discourses, and the Reformulation of Feminine Identity (Albany: SUNY Press, 2005); Aline Helg, "Race and Black Mobilization in Colonial and Early Independent Cuba: A Comparative Perspective," Ethnohistory 44, no. 1 (Winter 1997), 53-74; John C. Havard, “Mary Peabody Mann's 'Juanita;' Cuba And Us National Identity," Studies in the Novel 44, no. 2 (Summer 2012), 144-163: Luis Martinez-Fernandez, "Life in a 'Male City;' Native and Foreign Elite Women in Nineteenth-Century Havana," Cuban Studies 25 (1995), 2743; David Luis-Brown, "Slave Rebellion And The Conundrum Of Cosmopolitanism: Plácido And La Escalera In A Neglected Cuban Antislavery Novel By Orihuela," Atlantic Studies 9, no. 2 (April 2012), 209-230; Takkara Keosha Brunson, "Constructing Afro-Cuban Womanhood: Race, Gender, and Citizenship in Republican-Era Cuba, 19021958," (PhD diss., University of Texas, Austin, 2011), ch. 1; Claudette Williams, "Cuban Anti-slavery Narrative through Postcolonial Eyes: Gertrudis Gómez de Avellaneda's Sab," Bulletin of Latin American Research 27, no. 2 (April 2008), 155-175; Vera Kutzinsku, Sugar's Secrets: Race and the Erotics of Cuban Nationalism

(Charlottesville: University of Virginia Press, 1993); Richard Jackson, "Slavery, Racism and Autobiography in Two Early Black Writers: Juan Francisco Manzano and Martín Morúa Delgado," in Voice from Under: Black Narrative in Latin America and the Caribbean, ed. William Luis (Hartford: Greenwood, 1984), 55-64: Edward Mullen, AfroCuban Literature: Critical Junctures (Hartford: Greenwood, 1994); Jill Lane, "Blackface Nationalism, Cuba 18401868," Theatre Journal 50, no. 1 (March 1998), 21-38; Luz Mena, "Stretching the Limits of Gendered Spaces: Black and Mulatto Women in 1830s Havana," Cuban Studies 36 (2005), 87-104; José Gomariz, "Gertrudis Gómez de Avellaneda y la intelectualidad reformista cubana: Raza, blanqueamiento y identidad cultural en Sab," Caribbean Studies 37, no. 1 (January-June 2009), 97-118; Jennifer Morgan, Laboring Women: Gender and Reproduction in New World Slavery (Philadelphia: University of Pennsylvania Press, 2004); William Luis, Literary Bondage: Slavery in Cuban Narrative (Austin: University of Texas Press, 1990); Sarah L. Franklin, Women and Slavery in Nineteenth-Century Colonial Cuba (Rochester: University Rochester Press, 2012); Sueann Caulfield, "The History Of Gender in the Historiography of Latin America," Hispanic American Historical Review 81, no. 3-4 (2001), 449490; Robert Richmond Ellis, "Reading through the Veil of Juan Francisco Manzano: From Homoerotic Violence to the Dream of a Homoracial Bond," Proceeding of the Modern Language Association 113, no. 3 (May 1998), 442435; Margaret Olsen, "Manzano's Zafira and the Performance of Cuban Nationhood," Hispanic Review (Spring 2007), 135-158; Eve Allegra Raimon, The "Tragic Mulatta" Revisited: Race and Nationalism in NineteenthCentury Antislavery Fiction (New Brunswick: Rutgers University Press, 2004). 
hopeful for freedom to conduct their economic affairs free of political interference. This nationalism embraced a capitalistic ethos that looked to market provision for key aspects of economic/class differentiation (ownership and command of property and investment) as well as gender/racial differentiation (control of elite white women in a patriarchal environment that defined proper femininity as contrasted to the lives and work of enslaved women to whom this femininity was not extended). The agricultural intensification on the island embraced an emphasis on labor being the domain of Africans and sought to mark labor, blackness, and African/AfroCuban culture as all outside of the national definition. In the Cuban example, cultural inclusion in the national body politic discussion and working the land became mutually exclusive concepts breaking an important historical fusing of the agriculture's underlying conceptualization as productive of citizenship and reifying of a nation's historical bloodlines. Although plantation owners shifted working the land toward owning the land with the luxury of having others working it for you as a nouveau interpretation of the traditionalism of individual smallholders working the land as productive of citizenship. The need to support the increasingly narrow definitions of Cubanidad forced constant efforts to reinforce the prevailing scaffolding of racial design from both internal threats to its legitimacy and external challenges to its sovereignty. ${ }^{264}$

\footnotetext{
${ }^{264}$ Critiques of foreign investors, plantation owners (first French and then American), and skilled laborers or engineers were common occurrences and ones that allowed the creole elite to produce an insular mentality they hoped might allow the encouragement of a united Cuban face to the threat of foreign ambivalence and exploitation. Cuban planters grew increasingly critical of Americans who owned plantations in Cuba, a group the former perceived as alternatingly lazy and too harsh in their discipline and control of their slaves. American capital houses and shipping concerns further chaffed Cuban creole masculinity as their increasing dependence on foreign capital and markets made clear their dependent position. American engineers (maquinistas) were simultaneous a symbol of Cuban modernity through the necessity for their skills and Cuban dependence on foreign expertise. This dependence exposed a lack of educational development and produced anger in Cubans that made foreign workers targets of constant surveillance and scapegoating. With the explosive growth of sugar cultivation and the almost universal use of steam power on plantations, the need for skilled engineers on practically every plantation was taken for granted, thereby encouraging high wages and a protective attitude on the part of maquinistas of their craft. This need for skilled steam operators and machinists became even more pronounced with the rapid development of Cuba's railroad after 1837 . As one hacendado put it, "every mill, every steam boat, every train locomotive, has to have with
} 
Interestingly, issues of race came close to unifying only the upper classes on the island.

Among the laboring and small producer classes, the racial divide was much narrower and easier to bridge both economically and socially. For the elite, whose members embraced a color-based system of privilege, political opportunities presented themselves as the chief dividing line between gradations on the spectrum. Due to the profound economic changes that reordered the island's consumptive and productive systems, the sucrocracy undeniably held sway in these conversations, particularly given their very forceful attempt to program Cuban nationalism in their image and in response to their prerogatives. Yet, the lower economic classes saw little advantage in the whiteness that the creole elite so fervently designed and incubated. The almost continuous unrest displayed throughout the 1820s and 1830s demonstrated the growing unease shared by poor whites and AfroCubans, both of whom held their own anxieties in the face of

\footnotetext{
it an intelligent foreigner to direct and inspect that engine." When civil unrest broke out, foreign machinists were often not immune from interrogation and imprisonment. The Spanish government also used their presence to deny creole elites their demands as the presence of foreign labor was for the crown an embarrassment and a demonstration of certain economic and intellectual failings of the creole establishment. Attempts to establish schools for engineers and machinists were short-lived and turned out less than 100 Cuban engineers during the 1840s. American engineers, being mainly Northerners, often found themselves caught up in the abolition debate as slaveowners looked askance at their presence and their intentions. Spanish officials reacted particularly harshly to their presence during 1843-44 and implicated a handful in the La Escalera uprising of that period. The American laborers enjoyed freedom of movement on and off the island, traveling back to the United States often, and did not spend much of the year or of their lives in Cuba. Many in the Cuban elite viewed them as transient troublemakers symbolic of an economic and social system that imprisoned the elite on the island. The creole elite hated being reminded that North American merchants invaded Cuba with credit, purchasing crops and extending capital for commodity purchases and provided the chiefs sources for the movement of goods in both directions between Cuban ports and Baltimore, Philadelphia, New York, and New Orleans. Jonathan Curry-Machado, "Privileged Scapegoats: The Manipulation of Migrant Engineering Workers in Mid-Nineteenth Century Cuba," Caribbean Studies 35, no. 1 (January-June 2007), 207-245, quote page 240, and “'Rich Flames and Hired Tears:' Sugar, Sub-Imperial Agents and the Cuban Phoenix of Empire," Journal of Global History 4, Issue 1 (March 2009), 33-56. The New York Times discussed the interesting history of American investment in Cuban in "Cuban Sugar Planters - Men Who Have Been Loved and Made Great Fortunes," March 29, 1896, accessed January 10, 2014, http://query.nytimes. $\mathrm{com} / \mathrm{mem} /$ archive-free/pdf?res=F50D12F63C5415738DDDA00A94DB405B 8685F0D3. The long-term economic effects are discussed in César J. Ayala, "Social and Economic Aspects of Sugar Production in Cuba, 1880-1930," Latin American Research Review 30, no. 1 (Winter 1995), 95-124. On railroads and technology see: Oscar Zanetti Lecuona and Alejandro Garcia, Sugar and Railroads: A Cuban History, 1837-1959 (Chapel Hill: University of North Carolina Press, 1998); Gert J. Oostindie, "Cuban Railroads, 1830-1868: Origins and Effects of 'Progressive Entrepreneurialism," Caribbean Studies 20, no. 3/4 (1988), 24-45; Laird W. Bergad, Cuban Rural Society in the Nineteenth Century: The Social and Economic History of Monoculture in Matanzas (Princeton: Princeton University Press, 1990), Bergad periodizes the sugar boom from 1837 and the appearance of Cuba's first rail lines.
} 
Cuba's enmeshing in Atlantic capitalism. Seen from an economic perspective, the Aponte rebellions along with more generalized civil unrest in the pre-1843 period can be viewed as a resistant response on the part of the non-elite to the growth of capitalism. The vagaries of the market drove both the labor unrest of the enslaved along with the market-based concerns of the increasingly anemic class of small producers and free laborers. Even well-established tobacco and coffee farmers began to lose their social and economic place in society. However, these losses were not fully felt until the late 1840s leaving almost a decade of contestation that only the threat of massive social unrest brought to a momentary end. ${ }^{265}$

\footnotetext{
${ }^{265}$ Alfonzo W. Quiroz challenges the dominant interpretation of a sugar oligarchy hegemony lording over a weak civil society. He argues that Cuban civil society evolved largely undirected by secession or independentist ideology in the earliest period and was driven by, "moderate, multiclass and interracial struggles for increased legal autonomy and rights of free association with only marginal ties to separatism. The foundations of Cuban civil society were manifestly animated by ideas of progress, collaboration and common good encapsulated in a growing 'spirit of association." He follows Larry Jensen's line of argumentation that effort at political reform and constitutional changes were important outgrowths of not just elite demands but also resultant from active public debates before independence was achieved. Jensen's argument depends on the uneven penetration of sugar's agricultural strangle hold, particularly in the east of the island, which allowed for a continuance of small producers, more fluid racial definitions, and less foreign investment dependency in some areas. This accentuated regional differences in economic and population growth, labor structure, and colonial surveillance thereby producing significant differences in the types and strength of regional associational and civic life. The relative poverty and isolation from the Atlantic economy allowed particularly the southern central and eastern parts of the island to experience the sugar boom differently than the more intensely planted areas of the northern and western portions of the island. While compelling, the argument better connects the earlier period (pre-1820) and the later independence era (1860s), which exhibited a more profoundly pan-racial revolution from below feel, than the 1830s-1850s period. Colonial and elite structures came together in the face of slave revolt to curtail the freedoms available in the 1820s and demanded by Cubans in the 1860s. The compression produced by industrialization on sugar plantations, the discipline enforced by overseers, and the arduous labor itself created a solidarity that, despite protestations to the opposite, owners both noticed and feared, and had only minimally effective means at interrupting. This cultural autonomy and labor solidarity strengthened elite fears of rebellion based upon known but unavoidable appreciation of the shared and communicated horrors among the enslaved of their daily existence. This solidarity shared with and potentially harnessed by free AfroCubans pushed many in the creole elite toward a rejection of revolution from below against the Spanish because of the unpredictability of unleashing AfroCuban demands and frustration. The rejection of a cross-spectral uprising pushed elite creoles to fashion a revolution from above or perhaps more accurately a paper revolution that was equally rejected by the mass of Cubans as their revolutions were by the elite. Undoubtedly, elite planters tended more toward crown protection which left creole intellectuals alone, if fractured themselves, in the pushing for annexation - certainly a solution to an intractable problem that held much more appeal for Cubans in the United States than on the island. Alfonzo W. Quiroz "Free Association and Civil Society in Cuba, 1787-1895," Journal of Latin American Studies 43, no. 1 (February 2011), 33-64; Larry Jensen, Children of Colonial Despotism : Press, Politics, and Culture in Cuba, 1790-1840 (Tampa, FL: University Presses of Florida, 1988). For unrest in the 1820 s and 1830s see, Stephen Chambers, "At Home Among the Dead North Americans and the 1825 Guamacaro Slave Insurrection," Journal of the Early Republic 33, no. 1 (Spring 2013), 61-86; Manuel Barcia Paz, Seeds of Insurrection: Domination and Slave Resistance on Cuban Plantations (Baton Rouge: Louisiana State University
} 
The Havana hacendado collective that grew in the early boom period, and that formed the foundation of the sucrocracy of the 1840s and 1850s, found its intellectual and economic leadership in Havana's Real Sociedad Economica. The Sociedad published from 1793 to 1795 , the first series of Memorias addressing the ways in which modernizing their sugar mills might be undertaken. Building on the earlier calls in the pages of El Papel Periodico and the early works of Francisco Arango, the creole producer elite faced key decisions in their modernizing pursuit. All agreed that technology and scientific improvement, along with a corresponding development of a Cuban literature, was paramount not only to compete in the Atlantic market but also to complete the process of intellectual cultivation so important to the modernizing project. However, the progress toward and through the technical modernization necessary to achieve the economies of scale driven toward profit divided producers and limited the range of options open to the elite. Ultimately, decisions toward increasing slave importation while simultaneously improving technology in certain areas of production would be of the greatest benefit. Certainly, the adoption of new machinery and new processes, while not complete throughout the island, brought adjustments in productivity. However, these changes did not fundamentally alter the structure and deepening dependence on slave labor in the production process. The introduction of new technologies also hastened the exclusion of white creole laborers. Positioned as they were over decades in management roles and machinist jobs, technology changes they could not understand now rendered them superfluous. Hacendados welcomed any new technology that promised to free the mill from dependence on these lower-class white "sugar masters." The sugar master, as representative of many in the non-elite classes, suffered a barrage of criticism because of their inability to understand or control new technologies.

Press, 2008), and "Revolts amongst Enslaved Africans in Nineteenth-Century Cuba: A New Look to an Old Problem," The Journal of Caribbean History 39, no. 2 (Spring 2005), 173-200. 
Once replaced, these former skilled laborers, just like many AfroCuban and white nonelite Cubans in other areas of expertise and labor on the island, were shut out economically from putting their knowledge to work in competition with former employers because of the high cost of credit, land, equipment, and upkeep. The credit and labor markets, almost exclusively foreignowned, all favored elite hacendado concerns and investment while ignoring small holders and the landless. The further closing of the already tight investment market to the middling classes was a constant source of frustration for these already frustrated capitalists. The Spanish crown, appreciative of this process, was able to secure the loyalty of the Cuban elite by granting them access to the highest levels of the Spanish court and by giving them economic concessions to promote sugar production and facilitate accumulation of land and the importation of new technology and foreign engineers. However, the Spanish government's more forceful embrace of the sucrocracy after Aponte's rebellion - fueled largely by dramatic increases in tax revenues and the large profits made by many courtiers in the illegal slave trade - compelled many outside the upper tier of Cuban society to understand the forces at work in Cuba as both unmanageable and at this point unavoidable. The concept of enlightened development marshaled the increased use of technology, a finely divided line between white and black based upon gendered imperatives, and merger of intellectual and national creation. All of this built upon the tripartite foundation of slavery's naturality, the assertion of slaves' docility, and slaveowners selfperceived generosity of treatment for their slaves. To the disappointment of many on the island, and despite the great promise of technological development, Cuba's dependence on slave labor also grew exponentially during the boom years. The transition to large-scale production fueled by rail and steam technology did not change the labor or environmental calculation of the sugar boom. Beyond just planting and transport, technology improvements also increased the speed of 
refining which demanded more land under cultivation and the importation of hundreds of thousands of slaves to increase the volume of production to keep up with processing demand. Spanish prioritization of hacendado privilege produced increased yields, environmental degradation, increased repression, and a social distancing that reduced their ability to appreciate the nature of life for the majority of Cubans on and off plantations. ${ }^{266}$

Economic benefit coupled with political stability, particularly in the wake of the massive loss of land and wealth brought by the Independence wars of the 1820s, was a chief concern of the Spanish crown in Cuba. This motivated certain policies that encouraged growth while acceding to some hacendado demands. The anxious position occupied by the crown came after centuries of foreign merchants, bankers, pirates, and armies nibbling away at the empire.

Nowhere was this more apparent or more of a pressing Spanish concern than in Cuba.

Reluctance toward opening the island up to free trade in slaves or goods was widespread in government circles, a cautiousness deemed warranted by most.

Yet, the economic dominance of the Seville-Cádiz network and the enjoyment of various imperial monopolies, many of which evaporated in the wake of Latin American independence, were on life support in Cuba with their eventual demise not short behind. The Cuban economic situation stood as a stark reminder for the Spanish court and its economic backers throughout the peninsula of the economic and political winds rushing through the Atlantic world. There

\footnotetext{
${ }^{266}$ For the combination of science and technology as productive of the early sugar boom see: María M. Portuondo, "Plantation Factories: Science and Technology in Late-Eighteenth-Century," Technology and Culture 44, no. 2 (April 2003), 231-257; Juan Pérez de la Riva, El barracón: esclavitud y capitalismo en Cuba (Barcelona: Crítica, 1978); Whitney Battle-Baptiste, "Sweepin' Spirits: Power and Transformation on the Plantation Landscape," in Archaeology and Preservation of Gendered Landscapes, eds. Sherene Baugher and Suzanne M. Spencer-Wood (New York: Springer Press, 2010), 81-94. Sociedad Economica, Memorias de la Real Sociedad Economica de la Habana (Havana: Sociedad Económica de Amigos del País, 1848), accessed January 20, 2014, http://books.google. com/books?id=ByEsAAAAYAAJ\&pg=PA3\#v=onepage\&q\&f=false. For similar issues concerning the coffee industry in Cuba see, William C. Van Norman, "Shade Grown Slavery: Life and Labor on Coffee Plantations in Western Cuba, 1790-1845," (PhD diss. University of North Carolina at Chapel Hill, 2005).
} 
remained a constant balancing act between acceptance, both on the island and in Spain, of a pervasive liberalism inclusive of individual rights, private property, and the rule of law in competition with the persistence of colonial structures. Numerous Spaniards traveled to Cuba to amass their fortunes before returning to Spain where they invested those profits in further business diversification. The nature of movement in and out of the Cuban economic environment necessitated a lightly leveraged position that kept peninsulares out of plantation administration and in areas that promised quick profits - colonial administration, finance, and slaving. The effort peninsulares put toward protecting certain industries for themselves constantly annoyed hacendados. Further to the anger of Cubans was the ham-fisted move on the part of the crown to preserve their colonial prerogative by reducing the colonial voice through the exclusion of Cuban representation from the Cortes in 1836.

With the mechanization of the sugar industry and the corresponding rise in dependency on slavery, Cuban planters fell more and more under the economic sway of Spanish commercial agents. The arrival of peninsulares engaged in making a quick profit in the world of Cuban credit introduced an important component of colonialism that highlighted, for hacendados, the stark and continuing conflicts of interest between their class and the peninsular upper class. Upwardly mobile mainland Spaniards came to Cuba seeking their fortunes and had the avenues of royal appointments (with guaranteed salaries, access to bribes, and title purchases), and credit servicing (with quickly amassed fortunes in loan interest) available to them. Most in the government world started out as lower-level functionaries, rising to regional offices of import, assuming perhaps governorships and then eventually arrival on the highest level of colonial government in Havana. At each step the availability of economic gain, illicit or otherwise, presented itself. Likewise in the commercial sector, Spaniards relished chances for exploitation, 
subordination, and emasculation in the search for profit from the pockets of desperate planters. These creditors, making their way up through the trenches, in larger mainly American and British commercial houses, sought a pathway to becoming independent agents connecting the larger houses with planters. Their knowledge of the financial side of transactions helped them create contracts and webs of dependency that profited them handsomely to the constant aggravation of hacendados. Commercial agents regularly charging 20-30\% interest on loans and the same in upcharges on commodity goods was not unusual. Whereas in generations past peninsulares might seek entre into the agricultural world, where respect and wealth grew slowly, the sugar boom encouraged get-rich-quick schemes of many a Spaniard who understood the path to success was not in producing sugar but in financing it.

Even the wealthiest of planters found themselves needing recourse to foreign creditors although they were in a position to maintain a relative independence from the Cuban merchants through direct foreign contracting for infrastructural improvements. The reorganization of credit and the ever-increasing amount of required credit shifted mortgages from local to foreign investment bankers with repayment often drawn against future crop yields, earnings, and slaves. These complex mortgage instruments exacerbated the effects of economic crises, poor crop yields, and falling world prices. Two-thirds of Cuba's sugar industry had become mortgaged in this way by the 1860 s, with some $95 \%$ of estates at least partially so. However, economic success began to lag as competition affected world prices. Added to the social and political stresses on the island was the reality of stagnant to falling sugar prices. While production increases in the 1830s brought more sugar to market and as consumption became more of a stable rather than a luxury, demand did not keep pace with production as new sources of worldwide competition, particularly from European beet sugar that was cheaper and easier to 
produce with the application of vacuum pan technology, pushed prices lower. Thus, Cuban producers struggled to retain profitability by increasing production to account for falling prices.

The continuing application of new technology was a key component to this increase in production as was the consolidation of sugar plantations. While the number of plantations actually decreased through the 1840s, this trend represented the exit of some producers to the benefit of others who took their lands and increased the acreage available to them. Some owners willfully sold their land or lost their holdings through foreclosure - encouraged by a process known as refacción through which merchants lent money at up to $20 \%$ interest repaid through future sales with slaves, land, and machines serving as collateral. The number of cafetales and tobacco vegas also fell. Interestingly, these small holders, whether by self-motivated lack of interest or the disinterest of sugar planters in upending their structured labor controls, were reluctant to move into other agricultural pursuits for sugar planters. Pressures fell upon Cuban producers from self-interested sugar purchasers, mainly in the United States, to shift production to lower quality sugar in efforts to protect domestic refining concerns in consuming nations. Cuban producers were under constant pressure to expand output, increase efficiency, and lower prices. The problems of overproduction lay upon the foundation of the abundant influence of foreign nations in the determination of the choices available to Cuban producers. Obviously, the Spanish held disproportionate influence as the colonial master. However, the United States, as chief purchaser of Cuban sugar and chief supplier of Cuban slaves, exerted a fair amount of economic and political influence over the island. The British, consumed as they were with abolition of slavery - both from humanitarian and economic impulses - also kept their thumbs on the scale of decision-making for the island. The British presence, less economically advantageous than the American involvement, was onerously obstructive to the creole elite as 
they saw Spanish/British negotiation over slavery (although the results of which were roundly ignored by most on the island) to be a constant annoyance to their economic and social security. In this economic crunch, planters, particularly those of middling estates, lost their plantations. The banks, however, were not content simply to sit back and receive whatever profits accrued. Banks, merchant companies, and foreign firms who bought foreclosed Cuban plantations regularly sent agents to inspect their purchases and some even took an active role in administering plantations. The same migrant engineers who had begun by assisting Cuban planters took on the role of agents for some foreign companies. These workers were emblematic of Cuban dependency upon foreign capital and the influence of this capital's dominance in Cuban society. Many planters saw foreign workers as complicit in Cuba's ruin since the island's debt burden grew largely with the adoption of technology sold by and operated by foreign engineers. ${ }^{267}$

The crown's agents on the island, with their growing economic importance, also grew more interested in establishing their own claims on Cuba's social organization. They embraced

\footnotetext{
${ }^{267}$ Jonathan Curry-Machado, Cuban Sugar Industry: Transnational Networks and Engineering Migrants in MidNineteenth Century Cuba (London: Palgrave Macmillan, 2011), and "Sub-Imperial Globalisation And The Phoenix Of Empire: Sugar, Engineering And Commerce In Nineteenth-Century Cuba," (Commodities of Empire Working Paper Number Two, Open University \& London Metropolitan University, 2007), accessed January 20, 2014, http://www.open.ac.uk/Arts/ferguson-centre/commodities-of-empire/working-papers/WP02.pdf), and “"In Cane's Shadow:' Commodity Plantations And The Local Agrarian Economy On Cuba's Mid-Nineteenth Century Sugar Frontier," in The Global and Local History of Commodities of Empire, ed. Jonathan Curry-Machado (London: Palgrave Macmillan, 2013), 143-167; Stephen Chambers, "The American State of Cuba: The Business of Cuba and U.S. Foreign Policy, 1797-1825," (PhD diss., Brown University, 2013); David Pretel and Nadia Fernandez de Pinedo, "Technology Transfer and Expert Migration in Nineteenth-Century Cuba," (Max Weber Programme, Working Paper, European University Institute, January 2014), accessed Feb. 27, 2014, http://cadmus.eui.eu/bit stream/handle/1814/29039/MWP_2013_34.pdf, and "Patents, Sugar Technology and Sub-Imperial Institutions in Nineteenth-Century Cuba," History of Technology 30, (2011), 66-89; Roland T. Ely, "From Counting-house to Cane Field: Moses Taylor and the Cuban Sugar Planter in the Reign of Isabel II, 1833-1868," (PhD diss., Harvard, 1959); Luis Martinez-Fernandez, Torn between Empires: Economy, Society, and Patterns of Political Thought in the Hispanic Caribbean, 1840-1878 (Athens: University of Georgia Press, 1994), ch. 3; Manuel Barcia Paz, "Sugar, Slavery, and Bourgeoisie: The Emergence of the Cuban Sugar Industry," in Sugarlandia Revisited: Sugar and Colonialism in Asia and the Americas, eds. Ulbe Bosma, Juan Giusti-Cordero, and G. Roger Knight (New York: Berghahn, 2007), 145-158; Reinaldo Funes Monzote, From Rainforest to Cane Field in Cuba: An Environmental History Since 1492 (Chapel Hill: University of North Carolina Press, 2009).
} 
the more ambivalent racial fluidity that the large amount of free AfroCuban urban laborers brought to the table as a possible means of additional monetization. While numerous Captain Generals, with the crown's blessing, encouraged sugar's ascendency, the crown's political leaders on the island also kept the range of permissible creole demand and challenge narrowly defined. Certainly, the Aponte rebellion and subsequent unrest frightened Spanish officials, but they were not yet ready to fully embrace the consequences of a creole elite unbridled in its demands. The economics of the situation augured well for a creole/peninsular union, but the fear that an empowered creole elite could harness their power toward independence frightened the Spanish and paradoxically encouraged a more liberal approach toward slavery that in turn fueled sugar's expansion. From the earliest period, the Spanish colonial administration sought to use free AfroCubans as a counterweight to both a small but growing slave population, in the 17901810s, and an anxious creole elite. The crown sought acculturation for free AfroCubans as a social and economic class by incorporating them into militias, fire and police forces, and a variety of other professions as a way of limiting their separation from the rest of Cuban society and reducing their rebelliousness. Through these efforts free AfroCubans gained some limited social prestige and as a result of that positioning, some degree of political persuasion with the enslaved. The diversity of professions and the small size of the labor force made free laborers indispensable to the urban environment and to those, like commercial merchants, that depended on the operations of ports for their livelihood.

Early on, free AfroCubans were both an urban proletariat and an urban bourgeoisie. Although they positioned themselves well at the end of the eighteenth century, as the sugar boom started free AfroCubans existed in an increasingly precarious position, distrusted by and confusing to the developing racial and economic hierarchies. The Spanish crown eventually 
came to realize the danger of encouraging this class solidarity, particularly during the Aponte and La Escalera rebellions. Yet fortuitously for the Spanish, the threat of racial unrest, festering thanks to the large free AfroCuban population, paradoxically strengthened the crown's claims for the indispensability of their military presence as protective of the safety of all white Cubans and of hacendados' economic gorging. The combination of wealth creation and fear, the crown hoped, might encourage intellectual development in support of sugar's societal needs while simultaneously keeping political critique and dissent muted. As one Spanish official put it, "I believe that the fear of negroes is worth an army of 100,000 and it will prevent the whites from making any revolutionary attempts." 268

Despite these grave concerns and the presence of revolutionary and abolitionary pressures, Cuba's early nineteenth century was not a period of slavery's vanishing, nor was this moment a last gasp of slavery's conceptualization of labor. Slavery, while contracting in the British Caribbean, intensified in areas of growing commodity production. The collapse of the Haitian slave regime strengthened the Cuba variant. The consumptive colossus of laborers in the United States, along with their European brethren, demanded the conversion of luxury items into staples. Emergent technologies and intelligence traveled to emerging centers of commodity production as did the capital to fuel this growth. However, technology was not linearly applied in a predetermined process, but rather was haltingly negotiated into the production process, uneven across locales and among tasks on plantations. Plantation owners adopted technologies as they could afford and embraced ones that might offer advance in their individual settings, even as

\footnotetext{
268 The quote, attributed to Spanish Prime Minister José María Calatrava y Peinado, was contained within a letter from Cornelius Ness to John Forsyth (12/10/1836) in which Ness recounts his conversation with Calatrava. Calatrava's government helped usher through the 1836 Constitution, which while seen as moderate, caused a reactionary stir that brought the fall of the Minister's government. Letter in William Manning, ed., Diplomatic Correspondence of the United States: Inter-American Affairs, 1831-1860, Vol. 11, (Washington: Carnegie Endowment for International Peace, 1932-39), 303; María Elena Díaz, The Virgin, the King, and the Royal Slaves of El Cobre: Negotiating Freedom in Colonial Cuba, 1670-1780 (Stanford: Stanford University Press, 2000).
} 
societal progress might have moved in different directions and at different speeds. Thus, the failure of some ingenios was not just dependent on the level or type of technology embraced but rather the web of debt, labor, and management in which hacendados enmeshed themselves. The planting and harvesting of cane, across the spectrum, remained mired in primitive, laborintensive forms, while the refining of the cane moved technologically, with great expense, forward. Labor shifted toward the fields as more land needed to fall under cultivation. This process created a good deal of labor unrest among slaves who had negotiated better positions within the plantation structure and from free AfroCuban and poor white wage laborers whose skilled positions disappeared or shifted to foreign engineers.

New technology imposed a new labor regime that leveled slave classes by simplifying the jobs available to them and flattened the conceptualization of free labor by erasing the stratification that previously existed among wage laborers employed on plantations. In this new structure, 'labor' took on an increasingly mono-dimensional aspect, as specialization evaporated and 'skill' became unneeded. This was a discomforting reality to the non-enslaved who became even more dependent on, defined against, and constrained by slavery. Grinding and refining improvements necessitated greater cultivatory yields with every improvement in speed and efficiency on the refining end demanding greater amounts of cane to harvest. The move toward vacuum pans on Cuban plantations, for the crystallization of guarapo (cane juice), and the introduction of centrifuges to separate sugar crystals from molasses, represented the pinnacle of technological achievement and the height of expense for those few plantations that choose to embrace these new technologies. Vacuum pans offered Cuba a competitive advantage against other sugar societies in the Caribbean as their dwindling yields made the technology, as costly as it was for Cuban hacendados to afford, nearly impossible for French and British planters to 
obtain. Additionally, railroads made an important contribution on Cuban plantations. The movement of materials within plantations, particularly wood for fuel, and rail lines between plantations, which carried supplies, labor, and product to ports, proliferated throughout the 1840s.

However, all of these technologies developed slowly and guided hacendados through a tumultuous period (1840s-1850s) eventually producing exponential gains in the 1860s. Unfortunately, for many more conservative old-guard hacendados, the availability and cost of new technology created a crisis point at which only two options presented themselves - invest huge amounts of money on credit to keep pace with output improvements or lose their plantations, either by choice or force. With new plantations costing $\$ 300,000-\$ 500,000$ of initial investment plus an additional $\$ 50,000$ yearly upkeep cost, many owners were unable to sustain plantations while simultaneously adding much-needed new technology. Those that wanted to enter the game, both foreign investors and upwardly mobile creoles, looked to older producers to sellout rather than to create new plantations from scratch. Even Francisco Arango found his lands and fortune in disarray by 1835. Many struggling planters let their lands go and shifted investment to other less expensive but equally risky ventures, like mining. The profits made by some in mining concerns, particularly in the Holguín area, prompted a mini-mineral extraction rush that left more broke than enriched (such was the fate of Narciso López's mining investments). A whole generation of investors, many from older families on the island, suddenly found themselves frozen out of a new elite composed mainly of first and second generation immigrants who through various means, legal and otherwise, ingratiated themselves to the holders of cash and credit that facilitated both groups' economic rise. While this new crop of younger hacendados ascendant in the second phase of the sugar boom gave lip service to using 
technology to reduce labor (slave) needs, the mechanization of the sugar industry, in its failure to reduce planting and harvesting needs, increased rather than decreased labor need. ${ }^{269}$

The reality of dependence on slavery was not lost on the elite and necessitated comfort with an evaluative paradox - their wealth depended on slavery but the quixotic belief that internal order could be kept through a paternalistic agreement with the enslaved was untenable. The essential differences existing between French/British and Spanish Caribbean slavery that many in the elite claimed as support for consensuality in Cuban race relations no longer existed, if they ever had. The intellectual balance struck between profit and survival, one which appeared so lofty from the pen of proponents like Arango, now existed less as an abstraction and more reality, as insurrection grew and labor unrest fueled a simmering rejection of the hallucinations of civility promulgated by hacendados. The belief that their humanitarian overtures fell on

\footnotetext{
${ }^{269}$ The New York Times summed up the state of Cuban plantations and the slave trade in an 1852 article that outlined much of the cost, privilege, and corruption concerns. "The policy of the Government has been extremely liberal to the producers of sugar, with the purpose of building up and fostering that interest as the most productive of revenue to the crown. Great privileges have been secured to the sugar planter, such as exemption from all direct taxes except tithes, and immunity from the sale of their estates by any process to satisfy the claims of creditors. Very many of the planters are large borrowers of money, and I have been informed by capitalists that, owing to the last provision, the current rate of interest on their loans is not less than fifteen per cent, at the same time that the notes of merchants and retailers are readily discounted at six per cent. There is no limit to the rate of interest established by law. A very large capital is required to make a sugar estate. But when the requisite money is at hand, the prices of land are so low that to begin from the foundation is the preferable way for a planter to establish himself. This accounts for the exorbitant usury they are willing to pay. But the more usual way of getting possession of estates is to purchase them in full operation by paying five or ten per cent down, and paying a certain sum, frequently as low as two and a half per cent per annum till the whole be paid. An estate, such as is sold in this way, consists of land, negroes, horses, mules, cattle, hogs, machinery and everything appertaining to a complete establishment. I have heard of sales where the first crop would reimburse the first payment, and each successive crop provide for the current payment, and leave the purchaser from two to four times as much more for regular income. Thus an estate was sold for $\$ 450,000-\$ 50,000$ being paid down, and in ninety days the maturing crop produced $\$ 50,000$, and the remaining $\$ 400,000$ of the purchase money was payable in annual installments of $\$ 10,000$, without interest, and the annual product continues not less than $\$ 50,000$. Cane is seldom planted oftener than once in five years, and on a majority of estates not oftener than once in ten years. When estates are sold, they are sold entire, as above described. The negroes and other stock are not valued separately unless they are separately sold. The rule as to treatment of negroes is said to be 'plenty of feed and plenty of work.' The slaves are driven to the field at dawn, after breakfasting before it is light enough to work; have rest and dinner at noon, work till dark, and then supper and locked up to sleep. Marriage is unknown among them - most of the planters pay no regard to breeding slaves, it is cheaper to buy "green" ones from Africa than to raise them, and intercourse between the sexes, when permitted at all, is promiscuous. The African trade is now flourishing, after a nearly total interruption under Concha, who refused the usual bribes, and exerted himself to prevent the importation of slaves with so much success that their value increased about fifty per cent." "Cuban Affairs," The New York Times, 11/15/52.
} 
unappreciative ears and the prevailing economic imperatives of increased production throughout the 1840s gave plantation owners and by extension their overseers and disciplinarians on the ground carte blanche to break the paternalistic arrangement. For whatever the realities of treatment were, hacendados believed the requirements of civilization spurred them to the methods of command and discipline meted out on their plantations. The seeming lawlessness of plantations and the Spanish government's disinterest in imposing some greater discipline on vindictive hacendados drove the debate over slavery and the potential embrace of drastic answers, including new labor sources. And hence within these tumultuous economic and social winds the debate over slavery became the chief issue of the day - a debate consumed by the fires of abolition, annexation, and revolt. ${ }^{270}$

The material needs of the second phase of Cuba's sugar boom produced new structured needs of physical organization that profoundly altered the historical progression of Cuban sugar farming. The acceleration of demand reorganized ecological relationships with the land as well as labor and economic relationships between planters, creditors, slaves, and wage-laborers. The physical and metaphysical redesign of the ingenio was productive of and responsive to an emergent world capitalism that envisioned labor and land utilization in new ways. This "grammar of innovation" developed in an exploratory soup of technological and economic experimentation that sought a new logic of profitability and social organization. The challenges of scalability and the invitation to new problems as older ones fell away continually presented themselves to a world system that pushed innovation up and down the production chain. While Cuba had land to spare, the growth in the sugar industry was not just a case of expanding

\footnotetext{
${ }^{270}$ Oscar Zanetti and Alejandro García, Sugar and Railroads: A Cuban History 1837-1959 (Chapel Hill: UNC Press, 1998); Roland Ely, "The Old Cuba Trade: Highlights and Case Studies of Cuban-American Interdependence during the Nineteenth Century," Business History Review 38 (Winter 1964), 456-78. Louis A. Perez, "Cuba and the United States: Origins and Antecedents of Relations, 1760-1860s," Cuban Studies 21, (1991), 57-83.
} 
territory. The transformation of Cuban production was a transformation of the plantation as a unit as well as a transformation of its intertwined conceptualizations of time, space, and physicality. The elite goal was a fundamental shift, with technology and science at its foundation, in the economic and political life of Cuba; a remaking of both society and individual. Economics was the basis of Cuban social life, labor organization, and racial definition. The development of the strength of the economic system depended on the use of property in the pursuit of profit; with profitability came social direction and with profitability a clear marker for those who accumulated to lead social development. Thus established, a community of interests existed to fuel improvement and change. Change came first, technologically, in profit-producing areas (agriculture and trade) that could bolster civilizing efforts in other areas. For the creole elite, however, the unleashing of profitability could only be had in the unchained access to world markets. With Spanish coloniality still present on the island, the access was never fully unchained and thus Cuban development retarded. Despite varying levels of profitability, the defense of property as the chief means of social organization allowed no entre of the landless and the enslaved into social negotiation on the national scale. Without question, negotiations of a local and personal nature were contentious and ongoing, with victories gained by both sides although substantially stilted in one direction. However, with the ability to satisfy one's claims to freedom through the use of property, citizenship and self-interest in the nationalizing process remained attenuated for the vast majority of Cubans. The lack of availability of property for the enslaved negated any perceived self-interest and therefore removed the required aspect of recognizable humanity that might be appreciated by hacendados. This equation hence allowed the abrogation of their perceived humane treatment of slaves and a shift by owners toward appreciation and use of slaves as economic units. While this embrace of slaves as economic unit 
was long-standing, the shift away from the patina of paternalism and increased attack by British abolitionists allowed hacendados to speak openly about the economics of their ownership

without recourse to needless moralizing. ${ }^{271}$

\begin{abstract}
${ }^{271}$ Dale Tomich outlines the exemplary thinking of Andre Zaya (1836) and Antonio de Landa (1866), both of whom produced slave management and plantation owner's manuals that serve as bookends to the shifting thoughts on slave labor, efficiency, and discipline. Zaya and Landa produced copious investigatory notes on possible improvements to plantation management and more efficient task/labor assignment. Both men highlighted that the efficiency of plantations was largely shaped by the decisions of their owners regarding the deployment of labor based upon a careful scientific investigation of data pertaining to ongoing productive practices. In this design, the enslaved became units of productive labor to be harnessed and deployed like other force providers such as oxen. On the basis of force over time, an owner could master the art of proper deployment of labor to reduce idle time and increase security. Time, money, and labor all become force and efficiency multipliers. The failure to appreciate these realties was the chief cause of failure on plantations which then threatened the overall system of discipline and profitability - as too little labor produces too much time and too much labor produces discontent, both results leading to revolt. The largest change accompanying this new econometric thinking Tomich argues was "a shift in the concept of governance away from the ethical duties of the Christian master toward his servants, to an instrumental concern with establishing the optimal social conditions for exacting the greatest amount of labor from the slave population and increasing the productivity of the plantation exercise...the order and discipline secured by good governance and justice are the condition for the organization of production...the manuals register the appearance of a new discourse of labor management (dirigir) from within older discourses of slave governance (gobernar)...the latter becomes the condition of the former... with calculation of output and the productive force of slave labor appearing as the essential determinants of the organization of production and labor discipline... gobernar here articulates the need to secure general social order as the condition of production and to regulate the conditions of slave life in accordance with the new demands of labor. Practices concerning slave maintenance and reproduction are no longer treated in terms of ethical responsibility toward dependent but rather in terms of economic calculation and social control. The emergence of this new discourse of management separates the domination of slaves as property from their activities as laborers," (20-30). The establishment of the barracón most notably after 1843 was the clearest example of the attempt to better regulate the time and bodies of the enslaved. The barracónes and other types of walled slave quarters existed first and foremost to prevent slave revolts and runaways. However, plantations owners also feared slave raiding as well. Particularly as prices spiked and labor shortages or disease increased the value of slaves, kidnapping became a common occurrence. The policing of maroon colonies in the hills and mountains of Cuba also became more severe as runaways, despite their discontent and the potential for encouraging other slaves toward running away, became profitable sources of slaves. Yet, both running away and revolts were high on Cuban plantations with slave raiding and maroon poaching continuing unabated throughout the 1840s. Raiding became a lucrative job for peasants pushed out of the labor market. These rancheadores - paid pursuers of runaways organized raiding parties and abducting gangs engendering the hatred of planters and slaves alike. The height of raiding coincided with a massive cholera epidemic during 1831-3 that killed thousands at the point of early profiteering in the sugar world. The push to expand production in order to capitalize upon rising sugar prices coupled with the rapid depletion of the labor force prompted massive raiding and repression of maroon communities rivaled only by the 1844 repression of El Año del Cuero. Tomich, "Making the Sugar Frontier, Remaking Slavery: Material Processes, Social Practices and the Cuban Ingenio, 1820-1868," (paper presented to the Cornell University Comparative History Colloquium, Ithaca, New York, March 27, 2006), 1-35; Theresa Singleton "Slavery And Spatial Dialectics On Cuban Coffee Plantations," World Archaeology 33, no. 1 (2001), 98-114; Juan Pérez de la Riva, El Barracón y Otros Ensayos (Havana: Editorial de Ciencias Sociales, 1975). Rafael de Bivar Marquese takes on very similar issues focusing on the shifts in Brazilian conceptualization of slave control happening in similar ways and at similar times to the Cuban setting. He offers some comparison between two as well in Administração $e$ escravidão: Idéias sobre a gestão da agricultura escravista brasileir (São Paulo: Editora Hucitec/Fapesp, 1999).
\end{abstract}


Within this nexus of change, efficiency became the mode of operation. Planters focused not only on the productivity of individual slaves but also their own productivity in relation to other planters. A generational squabble broke out among the elite, one that focused on the worthiness of hacendados to own and run plantations. Among the newer generation existed the belief that planters unwilling or unable to take advantage of technology to improve output undermined the entire sugar undertaking throughout Cuba. Lack of efficiency endangered all planters, not only in the existential projection of the sucrocracy's dominance over the island but also in the internal security on plantations. Idle slaves, many feared, could only produce devilish ends. Contemporary observers blamed the failures of management often times at the hands of careless or doltish owners. Merchants - extending usury level loans, charging excessive commission rates, colluding to produce artificially low speculative sugar rates, and demanding high commodity resale rates (all productive of an unstable system of ownership) - came in for criticism as well. Notably, while established colonial legislation known as el privilegio de ingenious prevented seizing slaves, land, or equipment for the discharge of debt, money-lending sources often forced waiving of this right as a requirement for loans. Despite the anger these actions produced among some older planters, many leading lights of the newer generation, including Francisco Arango, argued that the elimination of el privilegio would streamline the transfer of good land and resources to those best able to use them. Colonial officials eventually turned against el privilegio, gradually disbanding the centuries old practice beginning in $1848 .{ }^{272}$

\footnotetext{
272 The increasing dependence of the planter class on the Spanish merchant class was striking. By 1850, the planters ceded economic control of the sugar industry to Spanish merchants and foreign capital houses. The Spanish government was effective at moving money through Spanish merchants, thereby protecting their privilege, but Spanish sources of finances were severely limited thus the merchants and British and American financial houses worked closely together. Two-thirds of all Cuban planters mortgaged some portion of their production process, usually to obtain new industrial technology, by the 1850s. The recession of 1857 further exacerbated the precarious conditions and increased foreclosures. For the creole elite, corruption in the slave trade was probably the best example of both the moral and economic depravity of the Spanish merchant class. Merchants largely profited from the illegal trade in slaves by eliciting brides throughout the slave running process. The British asserted that
} 
smugglers could lose four ships to every one they successfully brought in and realize huge profits. Rates for bozales (African slaves) by the 1850 s could regularly run as high as $\$ 1200$, a nearly three-fold increase over prices just a decade earlier. Cubans, in their desire to accumulate more and more slaves, tried to siphon off the trade from Brazil and Puerto Rico. The regular occurrence of epidemic level death from disease in Cuban slaves also added to the pressures. In a settling akin to the internal slave trade in the U.S. during the same period, Merchants would often buy Puerto Rican plantations just to then sell the slaves on them to Cuban planters. The combination of need, profit, and bribery kept the trade in slaves active and lucrative. Accusation that numerous Captain Generals benefitted from the trade frustrated British demands for Spanish/Cuba fealty to their treaty obligations. Captain General Leopoldo O'Donnell, the overseer of the repression after La Escalera, left the island with a reported half million dollars received in bribes (soborno del jefe). His successor, Federico Roncali, charged 51 pesos per imported slave. British Consul Joseph Crawford expressed his displeasure and exasperation with the bribery in 1853. "The Spanish Officers are bribed: the Slave Traders commit their offences and repeat them with the most complete impunity: Commissions sent by the Chief Authority of the Island to investigate such offences are baffled, or corrupted, the Masters and Crews are not punished, the Vessels are allowed to escape." British efforts remained frustrated by not only Spanish indifference but also by British and American participation in the physical avoidance of Royal Navy (West African Squadron) efforts at locating smuggling ships in the Atlantic. Slave ships under Spanish flag were often owned by British and American concerns and often manned by British crews and having fraudulent papers that, while discoverable, often kept prosecution of smugglers in courts over various international jurisdictions for years. Delays in ship boarding, flag changing at sea, obfuscation by port officials, and outright violence and ship running were all common occurrences. These processes only intensified after the British and Spanish negotiated a treaty to end the slave trade to Cuba over a three-year period beginning in 1817. Even after 1820, illegal importation continued unabated, averaging about 20,000 slaves a year with the largest number of 56,000 in 1859 . The concern on the part of many owners that the British and Spanish might collude to stop slave important all together proved ill-founded. For Spanish officials, the personal profit to be made in bringing slaves into Cuba through any means bolstered the now decades-old effort at forging a new plantation economy. For the British merchants, there remained a great deal of profit to be made despite the efforts of a few motivated moralists. More slaves and more sugar benefitted an increasingly narrow and different sliver of Cuban economy life than in earlier periods, to the chagrin of hacendados. David Murray, Odious Commerce: Britain, Spain and the Abolition of the Cuban Slave Trade, (London: Cambridge University Press, 1980), quote on 247. The extensive discussion on Cuban slave trading, bribery and the involvement of Captain Generals is covered in: British House of Commons, Reports from Committees - Report from the Select Committee on Africa -Western Coast (London: British Publishing Office, 1865), 108-115; Adam Hochschild, Bury the Chains: The British Struggle to Abolish Slavery, (London: Macmillan, 2005); Marika Sherwood, After Abolition: Britain and the Slave Trade Since 1807, (London: I.B. Tauris, 2007); Ada Ferrer, "Cuban Slavery and Atlantic Antislavery," Review (Fernand Braudel Center), The Second Slavery: Mass Slavery, World-Economy, and Comparative Microhistories 31, no. 3 (Fall 2008), 267-295; Manuel Moreno Fraginals, Herbert S. Klein and Stanley L. Engerman, "The Level and Structure of Slave Prices on Cuban Plantations in the Mid-Nineteenth Century: Some Comparative Perspectives, The American Historical Review 88, no. 5 (December 1983), 1201-1218; Laird Bergad, "The Economic Viability of Sugar Production Based on Slave Labor in Cuba,1859-1878," Latin American Research Review 24, no. 1 (1989), 95-113; Raul Cepero Bonilla, Azúcar y abolición (Havana: Cenitario, 1848); Alan Dye, Cuban Sugar in the Age of Mass Production: Technology and the Economics of the Sugar Central, 1899-1929 (Stanford: Stanford University Press, 1998); Manuel Moreno Fraginals, "Plantations in the Caribbean: Cuba, Puerto Rico, and the Dominican Republic in the Late Nineteenth-Century," and Fe Iglesias García, "The Development of Capitalism in Cuban Sugar Production, 1860-1900," both in Between Slavery and Free Labor: The Spanish-Speaking Caribbean in the Nineteenth Century, eds. Manuel Moreno Fraginals, Frank Moya Pons and Stanley E. Engerman (Baltimore: Johns Hopkins University Press, 1985), 3-21; Arthur Corwin, Spain and the Abolition of Slavery in Cuba, 1817-1886 (Austin: University of Texas Press, 1967); David Denslow, "Sugar Production in Northeastern Brazil and Cuba, 1858-1908," (PhD diss., Yale University, 1974); Sidney Mintz, Sweetness and Power: The Place of Sugar in Modern History (New York: Viking, 1985); Christopher Lloyd, The Navy and the Slave Trade: The Suppression of the African Slave Trade in the Nineteenth Century (London: Cass Publishing 1968); Herbert Klein, "Consideraciones sobre la viabilidad de la esclavitud y las causas de la abolición en la Cuba del siglo XIX," La Torre 21 (1973), 307-15; Franklin Knight, "Origins of Wealth and the Sugar Revolution in Cuba, 1750-1850," Hispanic American Historical Review 57, no. 2 (May 1977), 23153; Luis Martinez-Fernandez, "The Hispanic Caribbean between Empires, 1840-1868," (PhD diss., Duke University, 1990); David Eltis, "The Nineteenth-Century Transatlantic Slave Trade," Hispanic American Historical 
Adding to these economic issues were different imperial legal protections that caused far more concern and greatly added to creole anxieties. The presence of the unique history and use of AfroCuban cabildos in the protection of the island and the presence of the intermingled practices of coartación and papel existed as constant sources of distress for the creole elite. The 1840s' cultural and legal milieu in Cuba left numerous issues unclearly established, most notably the strength of the institution of slavery and establishment of the national racial family. This lack of clarity neither minimizes the harshness of Cuban slavery nor overemphasizes the social mobility available to slaves. However, there was a remarkable ability for slaves to talk with each other, unify, runaway, buy freedom, marry, earn money, press for legal rights, and interact with free AfroCubans in both rural and urban settings.

AfroCuban cabildos served an important purpose amongst free AfroCubans and existed as an important bridge between free, maroon, and enslaved communities on the island. The strength and vibrancy of the cabildos, or mutual aid societies, was fairly unique among slave systems in the western hemisphere in their mobilization efforts among free and enslaved communities on the island. These groups, built along rules and traditions of similar societies in African communities, drew their strength from the nature of Cuban slavery, reliant as it was on a constant influx of slaves from similar areas in Africa. The transit of these slaves, illicit after 1817 , relied on built streams of commerce that engaged similar areas trip after trip. While these societies existed legally, AfroCuban creoles conducted some efforts, at least among the enslaved, surreptitiously on plantations and among urban slaves. The activities of members in the free community, while closely watched by Spanish authorities, focused on pushing the white creole local ruling class for economic and working conditions concessions. These efforts moved

Review, 67, no. 1 (February 1987), 109-38; Susan Schroeder, Cuba: A Handbook of Historical Statistics, (Boston: G.K. Hall, 1982). 
forward while constant efforts at abolition hid from view. Cabildos, serving as social lifelines for the enslaved and engaging with provisions for both daily activities and emergency situations, closely policed membership, mainly to prevent spy infiltration. Most intriguingly, cabildos often arranged legal support for slaves' efforts at freedom, efforts that most clearly demonstrated for planters the conspiracy afoot against their economic freedom and their existence. ${ }^{273}$

Perhaps even more concerning to planters was the existence of the twin Spanish legal processes of coartación and papel. By the 1850s, hacendados increased their complaints toward these legal processes, which they saw as substantial challenges to their dominion over their slaves. The creole elite argued that the rights extended by the Spanish legal codes allowed slaves to assert an independence within the slave system that threatened to undermine the domination the system rested on. The dual system of self-purchase (coartación) and request for a new owner (pedir papel), while never widespread and generally used more by urban slaves, empowered the

\footnotetext{
${ }^{273}$ Earlier in their history, cabildos often trained in arms and provided military service for the island along with Spanish regulars, a process phased out by the 1810s. Cabildos were extremely adept at navigating the legal structures of church and state that allowed their existence while not sacrificing their revolutionary efforts. As time went by, into the latter half of the $19^{\text {th }}$ century, these societies became more directly involved in organizing conspiracies and, realizing that black revolution alone would not cement economic and social gains, sought to unifying working class Cubans across racial lines. The presence of Spanish rule also left the cabildos in a difficult position as they recognized at least a portion of their efforts at reforming Cuban society placed them in league with the creole elite, against whom they held other grievances. This indicates much of the paradox at the heart of the cabildos - they existed as organizations of resistance and revolution seen as dangerous by elite whites, while simultaneously encouraging AfroCubans to use existing legal structure, educational opportunities, and social participation to adapt to a white dominated society. These societies proved remarkable successful at moving beyond their urban sources of strength and out into the rural hinterlands unifying workers simultaneously against creole exploitation as well as against Spanish colonialism. As industrialization touched rural and urban laborers, white and black alike, cabildos harnessed the power of internal migration, unionization, and a politically motivated working class to center themselves as the revolutionary vanguard by the 1880s. In this process, the cabildos lost their stricter African ethnic basis and embraced a pan-AfroCuban and Cuban stance that foregrounded economic improvement in a less racially stratified legal regime that encouraged a broader basis of support. Philip Howard, Changing History: Afro-Cuban Cabildos and Societies of Color in the Nineteenth Century (Baton Rouge: LSU Press, 1998); Aline Helg, "Race and Black Mobilization in Colonial and Early Independent Cuba: A Comparative Perspective," Ethnohistory 44, no. 1 (Winter 1997), 53-74; Melina Pappademos, "From Cabildos to Continuadora Societies: Political Community in the Black Cuban Imaginary," Negritud: Revista de Estudios Afrolatino-americanos 2, no. 2 (Winter 2009), 152-177; Pedro Deschamps Chapeaux, Los batallones de pardos y morenos libres (Havana: Editorial Arte y Literatura, 1976); David Sartorius, "My Vassals: Free-Colored Militias in Cuba and the Ends of Spanish Empire," Journal of Colonialism and Colonial History 5, no. 2 (Fall 2004), 1-25.
} 
enslaved to demand legal protection in extreme circumstances. These twin processes

undoubtedly existed as a personal negotiating tactic or threat between slave and owner in circumstances that rarely came before Spanish authorities but needed and received attention from owners nonetheless. Coartación required negotiation between owner and slave and locked in a manumission price that could not be easily altered. Papel could be prompted by complaints from slaves to regional authorities about maltreatment and poor provisions. These negotiations, along with the involvement of Spanish judges and lawyers who received testimony from and valued the claims made by slaves, did not specifically appear in older legal codes and built their power through long-recognized customs. In 1842, as a result of the Reglamento de Exclavos, both coartación and papel became legally recognized rights, above the strenuous objections of slaveholders. Some liberal jurists claimed these rights were but the most significant legal protections available to slaves and argued that these legal processes represented much greater control of the enslaved over their own life and labor. The customs that gave legitimacy to slaves' rights prior to 1842 rested upon the history of Spanish state slavery in Cuba, regimented and regulated as it was, and the long history of legal protections, not always adhered to, for slaves in Spanish America. ${ }^{274}$

The nature of early slavery in Cuba and the general under-population of the island during the eighteenth century opened many jobs, particularly skilled urban labor, to slaves imported by the Spanish government that would otherwise have gone to skilled white laborers. This labor arrangement carried over into the sugar-boom era as labor stores grew through the importation of

\footnotetext{
${ }^{274}$ Alejandro de la Fuente, "Slaves and the Creation of Legal Rights in Cuba: Coartación and Papel, Hispanic American Historical Review 87, no. 4 (Fall 2007), 659-692; Michele Bernita Reid, "Negotiating a Slave Regime: Free People of Color in Cuba, 1844-1868, “ (PhD diss., University of Texas, Austin, 2004), 15-20; Bergad, ed., The Cuban Slave Market, 47 - 56; Manuel Moreno Fraginals, Herbert S. Klein, and Stanley L. Engerman, "The Level and Structure of Slave Prices on Cuban Plantations in the Mid-Nineteenth Century: Some Comparative Perspectives," American Historical Review 88, no. 5 (December 1983), 1201-18.
} 
slaves and not insignificant amounts of Spanish citizens. Urban labor, however, continued to be the domain of Afro-Cuban laborers, both free and enslaved. Their active participation and knowledge of the market economy in and around Havana helped slaves gain knowledge of the legal, cultural, and economic organization of creole society; knowledge often moved to rural areas through cabildos. In these urban spaces, the cabildos provided important legal advice and coaching. Slaves tested the legal bounds with more frequency developing a core of case law that strengthened future claims. As the island made the shift to sugar production, these legal customs were now precedent and part of the institution of slavery in Cuba. This was thanks in part to the establishment of Havana's Sindico Procurador (slaves' protector) in 1766. The issuance of the Real Cédula in 1789 further outlined the protections that the Protector's office offered to slaves and detailed guidelines for slave treatment. Thus, the Spanish state made a concerted effort at organizing the presence and treatment of slaves and established a legal framework providing for the legal opportunity for slaves to be their own advocates. While importation of new slaves into Cuba limited the conversation between legal heritage and these new arrivals, there existed a robust-enough network of information moving between urban and rural areas that facilitated the grafting of these protections onto the cultural networks of newly arrived slaves. The enslaved learned how to navigate these legal and cultural networks and used this legal space to take advantage of their rights and the simmering hostilities between colonial and creole elites. Irksome to hacendados was the very existence of both legal avenues that at times forced owners to interact with slaves as legal equals. ${ }^{275}$

\footnotetext{
${ }^{275}$ The degree to which this flexibility made slavery in the Spanish empire different than, or even less harsh than, system elsewhere is still a contentious debate. Daniel Schafer argues that Spanish slavery was less severe than American slavery, at least in the Florida variants. He follows Jane Landers' argument that slavery in St. Augustine under Spanish rule was regulated by a complex series of slave laws, much like Cuba, that developed within an important precedent guided environment. Slaves, while they remained as such, enjoyed a greater set of rights based on the recognition of their inherent humanity that did slaves in the American system. Schafer and Landers compare the differences between Spanish and American slavery in Florida. While there were significant differences between
} 
The hostility between hacendados and the crown's representatives was ongoing and

increasingly rancorous. As municipal royal officials, charged with investigating and in some

cases bringing charges against planters, engaged with papel and coartación cases, the creole elite

began to question Spain's dedication to retaining internal control on the island. Regardless of the

Cuba and St. Augustine in the political, economic, customs, and legal regimes present in each after the beginning of the sugar boom, there remained a shared conceptualization on the part of Spanish officials differing starkly with Americans authorities. This discussion implicates many historians and specialists in an ongoing explication of the Tannenbuam debate. While legal protections continued, the status of Cuba's free AfroCubans fell precipitously as a result of the sugar boom. The more liberal manumission policies that accompanied and resulted from legal protections existed despite racial prejudice in the pre-boom era. The explosion of sugar production increased the pressure on free communities of new discriminatory barriers to labor and social opportunity. This exhibits the differences of local application of Spanish laws. Notably, anti-free AfroCuban hysteria in the wake La Escalera was fully intentioned toward producing a stricter, racially defined regime of control for free and enslaved alike on the island moving into the 1850s. This attempt at elimination of the free class of AfroCubans mirrors the great ambivalence held toward that same class in the United States and signifies a coalescing of the systems in the mid1840s. For both systems, the free racialized individual was an aberration since they shared their perceived racial inferiority with the enslaved yet presented an important contradiction to the slavery regime with their legal status. $L a$ Escalera proved for Cubans and Nat Turner's rebellion proved for Americans that free communities, beyond just historical curiosities, actively threatened to lead rebellion against the system thanks to their greater legal, social, and physical mobility. Therefore limitation of the free communities to the same rights and requirements as slaves was essential, thereby producing a unified system of racial control that treated free and enslaved similarly. Yet despite best efforts, what remained in the Caribbean was a self-awareness of regional identity in which diverse cultures and cultural traditions engaged in a fluid process of ever-shifting racial and social structures. AfroCreoles engaged in various means of social organization and resistance. While slaveholders sought to reduce the fluidity in the system of social control and the legal apparatus of slavery throughout the early $19^{\text {th }}$ century, this effort proved frustrating due to the Spanish government's stodgy adherence to established legal principles as well as increasing British legalism in the pursuit of abolition. AfroCreole legalism was also in constant battle with Spanish white creole legal regionalism. The Spanish creole variant was less a product of a defined goal of reflexivity in the imperial legal realm and more a direct result of "creole legal consciousness" through which they feel empowered to push for legal responsiveness from Spanish authorities while reacting angrily to demands of the enslaved and free AfroCreoles. While they argued for a similarity of legal right and an erasing of distinctions between colony and metropole, these same Spanish creoles showed a comfort with creating peripheral locales within the empire and suspect populations within their jurisdictions. The result corpus of law came as a result of the needs and demands of almost three centuries of jurisprudence for all involved. Despite the time and effort in exploring AfroCuban legalities, their lives depended much more on whether they were in an urban or rural setting with specific laws, written or unwritten, governing other aspects of their lives stemming from this positioning. The debate over the effectiveness of legal protections and the true liberalism and flexibility of the Spanish legal system toward slaves and even free subjects of color throughout the empire as well as in Cuba is ongoing and well summarized in Alejandro de la Fuente, "Slave Law and Claims-Making in Cuba: The Tannenbuam Debate Revisited," Law and History Review 22, no. 2 (Summer 2004), 339-369, and critiqued in the same issue by Christopher Schmidt-Nowara, "Still Continents (and an Island) with Two Histories?," and by María Elena Díaz, "Beyond Tannenbuam." Jane Landers, Black Society in Spanish Florida (Urbana: University of Illinois Press, 1999); Daniel Schafer, “"A Class of People Neither Freeman Nor Slaves:' From Spanish to American Race Relations in Florida 1821-1861,” Journal of Social History 26, (Spring 1993), 587-609; Manuel Barcia Paz, "Fighting with the Enemy's Weapons: The Usage of the Colonial Legal Framework by Nineteenth Cuban Slaves," Atlantic Studies 3, no. 2 (2006), 159-181; Liliana Obregón, "Between Civilisation and Barbarism: Creole Interventions in International Law," Third World Quarterly 27, no. 5 (Winter 2006), 815-832; David W. Cohen and Jack P. Greene eds., Neither Slave Nor Free: The Freedman of African Descent in the Slave Societies of the New World, (Baltimore: Johns Hopkins University Press, 1972). 
locations or effectiveness of coartación and papel or the activities of the cabildos, their combined existences alone were the chief source of concern for creole planters. This social and legal freedom available to the enslaved and the bonds built between slaves and free communities demonstrated the willingness of the Spanish colonial authorities to subvert racial order and the precarious position the elite found themselves in with no real allies, political or otherwise, on the island. The degree to which the Spanish government would use its control over the island to adopt new and concerning regulations regarding Cuba's enslaved population lie at the heart of the intellectual debate over Cuba's future. Central to this debate's importance is evaluating what effect Cuba's incorporation into the Atlantic economy as a sugar colony had on the institution and experience of slavery on the island. Furthermore, these developments must be viewed in a comparative light, evaluating the United States' conceptualization of Cuban slavery as well as that of the British as particularly impactful on the island's ongoing economic and political development. The encouragement of slavery, as an economic and defensive means to the end of Cuba's continuing presence in the empire, was longstanding crown policy. The place sugar's transformative role held in making Cuba a slave society stood alongside imperial defensive military policy as the two most important pillars of Cuba economic and social development. By the beginning of the sugar boom, Spanish governmental involvement in the slave trade, the use of state slaves within Cuba, and the social practices that grew around the institution produced a drastically different and more fluid institution on the island than elsewhere in the Caribbean. Interestingly, white creole attempts at forging social and cultural ties mirrored some of the same concerns and unification efforts that gave the cabildos their strength and power in the AfroCuban community.

The intelligentsia in Havana built upon the earlier efforts at economic and literary 
development in hopes at developing a wide-ranging creole-based attempt at directing Cuban society. As these men considered the possibility of erecting a national impulse upon the foundation of Cuba's social structure, a few things became apparent about relations between the different white creole classes that led them to believe that similar goals might not have been shared by all. The aspirant middle and merchant classes - Spanish immigrants who, living in tight urban groups, failed to become assimilated, monopolized commerce, and acted as bankers to debt-ridden creole planters - were naturally a main support of the colonial regime. Colonial officials retained much of their peninsular wealth and increased it through official and unofficial channels on the island. Sugar planters, although adversely affected by the economic and political organization of Spanish social class, were a conservative group largely reluctant to embrace radical political philosophy. Therefore the defining of a Cuban social ideology, a protonationalism vision, became the project of a small number of creole lawyers, writers, and students. These inquisitive intellectuals, rooted in no particular social class yet enjoying some economic stability and often the younger sons of landowners, set about the work of defining racial and social Cubanidad. However, despite their best efforts, the debates they engaged in were almost exclusively rhetorical affairs when it came to challenging Spanish rule. They remained unable to convert any but a small number of landowners to the idea of independence, abolition, or annexation. This lack of political draw left many intellectuals in Havana exposed and the first targets of Spanish colonial concern, particularly during periods of unrest. Exile, both forced and self-imposed, was a frequent response to persecution. Not surprisingly, these intellectuals focused on education in Havana as the source for promulgation of Cubanidad. They created much of the educational system and intellectual institutions on the island and sought to elevate Cuba to a level of respect throughout Europe. On some accounts these men were 
incredibly successful in developing a vision that held persuasive power, if only in limited intellectual categories.

The intellectual climate of Havana and the island relied on the efforts of a coterie of men who sought to bring reasoned scientific study and investigatory understanding to the process of economic and cultural development. Francisco Arango, the Papel Periódico, the Real Consulado, and the Sociedad Patriótica, among other institutions of study and dissemination in Havana in the 1790s, hastened this intellectual development. The creation of a powerful governmental/intellectual partnership paid dividends for the crown and planters. This partnership, following the prompting of intellectual argumentation, capitalized on the Caribbean currents of revolution and economics that propelled Cuba to the pinnacle of sugar production what Antonio Rojo refers to as the discourse and dominance of the sugar mill. This was the period of institutional and systemic production of modernity in Cuba. This process slowed and the partnership however frayed by the 1830s, as the liberalism hoped for by the intelligentsia was disappointed by a severe profit driven cabal of crown and economic interests taking advantage of the landed classes. Political liberalism was ill-equipped to bear the burden of social development in a racialized system dependent on conservative approaches to social control. This is not to argue that the Havana group was enlightened on the issue of race. While the discussion of Cubanidad was wide ranging, there was a dogmatic focus on issues of race and the active rhetorical efforts to exclude AfroCubans from national inclusion that drove the efforts. This focus was produced by and helped to strengthen the dominance of sugar, the mill, and the plantation as the mode of discussion of all issues pertaining to Cubanidad. The sugar mill was the basis of every relationship and articulation of power on the island and any discussion of race 
would necessitate protection of the organizing labor and racial structures dictated by the sugar

mill.

The machine that transferred, stored, and generated this power was, of course, the sugar mill. The sugar mill was where the concentration of technical, administrative, and commercial knowledge resided. It was an autonomous socioeconomic cell...it was selfsufficient. Being the deterritorializing machine that it was, it rolled over the best lands, burning entire forests in it way, transforming nature and work into sugar, smoke, and debris... under such conditions it was impossible for any rural community unrelated to sugar production to coexist...this situation would contribute decisively to the appearance of small agricultural properties and a marginal population in the residual lands - that is a rural population deprived of space and technological developments, that would in the course of time lose all initiative and economic function. Furthermore, with the arrival of the railroad and the telegraph, the sugar mill system established the island's transport and communication network...it did not take long for sugar to become everything or almost everything - that is a super institution that became the reference point of the weaker institutions on the island, or better yet, a metadiscourse that barely allowed space to a discourse of resistance. ${ }^{276}$

However, despite all of its efforts, the work of the Havana intellectuals enjoyed little recognition outside of its circles. The main reason for this rejection was the concern the group exhibited over slavery on the island and the calls for its elimination through a variety of untenable proposals; proposals that despite their precarious positions most slaveowners did not want to hear. Domingo del Monte and José Antonio Saco were the chief architects of the advance of literature in defense of Cuban social production. Saco was the editor of the Revista Bimestre published by the Sociedad Económica. This group, unlike Arango's generation before them, held little faith in any partnership with the Spanish government. The del Monte/Saco group reveled in their developing sense of creolité and took every opportunity to identify many of the failings of the colonial leadership class. The racial views put forward afforded no place for AfroCubans in the Cuban family. Saco argued, "Cuban nationality of which I have spoken, and the only one that should concern all sensible men, is that formed by the white race...upon white

\footnotetext{
${ }^{276}$ Antonio Benítez Rojo, "Power/Sugar/Literature: Toward a Reinterpretation of Cubanness," Cuban Studies, 16 (1986), 13.
} 
immigration depends agricultural improvement, the perfection of the arts, in one word, the prosperity of Cuba in every sphere; and the steadfast hold that the crumbling edifice, which now threatens us, will be restored confidently on a solid and indestructible base." However, while Saco clearly articulated the problem, the conceptualization of how to reverse direction socially elimination of Africanness by replacing slaves with white wage laborers - without limiting economic growth or affecting sugar production seems at best disingenuous. Saco's dependence on white immigration was only one problem in the equation. Importantly, Saco had no plan, other than repatriation back to Africa, to deal with the tens of thousands of AfroCubans already on the island. While his stance was anti-slavery, his was not an abolitionist perspective contingent on the humanity of all peoples. His anti-slavery advocated a complete removal of African bodies from Cuba. Challenging that perspective was the realization that any move toward abolition would necessitate agreement from two classes, Spanish economic/leadership and creole planters, which had been reluctant at best to make any changes to the system. Of course the concept of independence from Spain was equally outlandish since that would have required or encouraged a liberation of slaves. ${ }^{277}$

This intellectual circle was the first significant effort to combat the growing power of the Spanish colonial/merchant power on one hand and the compromised but still potent power of the landed sucrocracy on the other. While the Havana intellectuals realized their positioning was not strong enough to compete directly, they hoped their argumentation supported by rigorous study and modeling would win the day with the hacendados on the strength of common sense. This creole planter elite, driven to subordinate position by the economic system dominated by peninsular interests and defended by Spanish colonial administrators, yearned, the Havana group

\footnotetext{
${ }^{277}$ Saco quoted in Louis A. Pérez, On Becoming Cuban: Identity, Nationality, and Culture (University of North Carolina Press, 2008), 90.
} 
believed, for an expression of Cuban interest that might give voice to the intellectual and economic frustration of Cubans. ${ }^{278}$

Del Monte and Saco's helming of the Cuba literary scene and their influence in the Sección de Educación gained an important boost when colonial officials gave them permission to form the Comisión Permanente de Literature in 1831. Yet, the antislavery rhetoric that came out of both institutions gave the colonial leadership pause and the efforts halted by 1835 with an associated purge of the Sección taking place as well. Caught up in the purge, thanks to his polemics on the Spanish leadership in the Comisión's magazine Revista Bimestre Cubana, José Saco received orders to first vacate Havana and then eventually leave the island. Saco was the main architect of the emergent elite conceptualization of Cubanidad and as such was much more combative toward the prevailing economic and social structures of the island. He held particular zeal for the removal or departure of Captain General Miguel Tacón. While the sucrocracy and Spanish economic interests viewed slavery, with the crown's blessing, as imperative to development, Saco saw the institution and Spanish presence, in the person of the particularly heinous Tacón, as promoting of social decay. Saco spend a great deal of time studying slave

\footnotetext{
${ }^{278}$ This was the battle between "Cuba Grande and Cuba Pequeña" as Benítez Rojo describes it. The battle pitted the authoritarian, profit driven Cuba rationalized by sugar production's requirements against the older Cuba of small producers, folk traditions and cultural connections with the land. The debate in Cuba sat in response to a general centralization of the Spanish imperial world after Fernando VII's death in 1833 and the rise of his wife and later Baldomero Espartero as Consejo de Renencia for the young Isabel II. Cuba in this process, despite an almost unbroken rise in power and prestige, lost its Cortes representation and remained a colonial possession in status. Many in Cuba saw this status more appropriately conferred upon Spain's former South American colonial backwaters and certainly not for the Cuban cultural and financial economy, particularly after all the intellectual effort put into developing the cultural cache of the island. The identity project of del Monte and the biting criticism that accompanied it slid into overtime in response to these imperial changes. Among some of the earlier thinkers that molded the liberal intellectual project in addition to Saco and del Monte were Félix Varela (later exiled for his role in the Solas y Rayos de Bolivar conspiracy in 1824) and José de las Luz y Caballero. Interestingly all of these men were students at the Seminar of San Carlos, financially supported by Bishop Juan José Díaz de Espada y Landa and based on the influential teachings of José Agustín Caballero. On Varela see: Carlos Manuel de Céspedes GarciaMenocal, "The Life, Thought and Significance of Father Felix Varela," (paper presented at Fordham University, Lincoln Center campus New York, January 27, 2005); Jorge Ibarra Cuesta, Varela el precursor. Un estudio de época (Havana: Editorial de Ciencias Sociales, 2004).
} 
systems through the Caribbean, showing particular interest in Brazil, which were important sources of comparison for him when developing his critiques of Cuban slavery. While the more literary minded del Monte did much to bring romanticism to the letters of Cuba, Saco pulled equally as much weight toward developing the education system of Havana. In education, he argued, lay the redemption of the island. When Captain General Tacón shuttered the Comisión in 1834, largely in response to Saco's growing influence, the later responded with characteristic venom.

Nor is religion the only weapon that has been brought to bear against the academy: there is also politics, but a dubious sort of politics whose rhetoric rails against "the wicked" who are bent on confounding the efforts of "the virtuous." It speaks of the influence which the academy may exert, directly or indirectly, upon the political order. And indeed it does so in both ways, for, in view of the evils that afflict this nation owing to the long reign of ignorance, it is clear that all institutions contributing to the dispersion of darkness and spread of enlightenment must have political importance of the first order. ${ }^{279}$

The divergence of whatever shared interests existed between creoles and the crown accelerated as a result of the Captain General Miguel Tacón's policies. As Spanish skepticism of the creole elite grew throughout the 1830s, the crown's dealings with hacendados grew more cautious most notably in light of the increased rebellious activities of slaves and the loss of the South American continent to revolution. Surveillance of creole planters increased and a political purge of the some of the longest existing creole institutions, including the Real Junta de Fomento and the Sociedad Economica, took place. While these were foreboding annoyances for the more conservative landowners, the Havana intelligentsia bristled. The circumspective atmosphere forced creole intellectuals underground in the promulgation of their opinions and debates on

\footnotetext{
${ }^{279}$ Jose Antonio Saco, "Justa defensa de la Academia Cubana de Literatura contra los violentos ataques que se le han dado en el Diario de la Habana," (New Orleans: Mr. St. Romes, 1834), accessed January 10, 2014, http://nrs.harvard.edu/urn-3:FHCL:473516. Interestingly, the New Orleans imprint on the work was a common device used by del Monte to reduce surveillance of his circle's more critical work even though he did most of the publishing surreptitiously in rural regions outside of Havana. This particular work was secretly printed and distributed from Matanzas.
} 
Cubanidad at the very moment when both were considerably intensified. The creation of a more class-conscious understanding of Cuban society also interested hacendados at a precise moment when economic competition, political constriction of opportunity, and social threat of abolition and "Africanization" most menaced the delicate web constructed in the early boom period. In this anxious environment, the intellectual arguments began to hold a bit more sway with planters. Increasing Spanish intransience in the face of planter demands, the increasing social isolationism of peninsulares developed through exclusionary social clubs, as well as the elimination of Cuban seats in the Cortes, impressed upon the creole elite the need for new political approaches. The foundation of these new political impulses lay upon the new conceptualizations of Cubanidad, a concept the hacendados were suddenly interested in hearing more about from the Havana intelligentsia.

In response to Saco's exile, del Monte founded a tertulia, a socio-political salon, around 1835 and built the effort into a vibrant marketplace of ideas for the elite, albeit one out of sight of colonial officials. ${ }^{280}$ The tertulia was necessary after the closing of the Revista, another of Tacón's consolidatory efforts. One of the new approaches the group took toward publishing in

\footnotetext{
${ }^{280}$ In exile Saco joined up with a group in Madrid named Club de Habaneros which brought together creole and peninsular Cuban reformers. He was once again elected to a seat in the Cortes in 1836 but the exclusion of Cuban seats prevented his serving. The timing was hardly coincidental. After removal from the Cortes, Saco attacked the entire colonial organization, through comparison to the British empire and with words reminiscent of the South American independence period, in a 1837 pamphlet. "Tired of hearing about the advantages enjoyed by Cuba under Spanish rule; tired of hearing that of all the colonies held by European power on the other side of the Atlantic, none is as happy as Cuba; and tired also of suffering the taunts of mercenary publicist and the pedantry of some of the blustering deputies, I take up my pen to sketch some parallels between this island, said to be so fortunate, and some of the English colonies. It is not my intention to portray the government of the latter as a model of perfection. A colonial system is a system of political and commercial restrictions which by their very nature sometime amount to an intolerable despotism and sometimes merely to a light chains composed of gilded links which make in more bearable for the peoples who must carry it. Whatever the case, the condition of a colony is certainly an unenviable one. But when I turn my gaze to Cuba and contemplate the miserable state in which it is sunk, I vow (as befits a Cuban) that I would exchange the fortunes of my country for those of the possession in Canada" Saco, Paralelo entre la Isla de Cuba y algunas colonias inglesas (Madrid: Oficina de Tomas Jordan, 1837), accessed January 16, 2014, http://nrs.harvard.edu/urn-3:FHCL:473514. For more on Saco's intellectual debates see José María Aguilera Manzano, La formación de la identidad cubana: el debate Saco-La Sagra (Havana: Editorial CSIC Press, 2005).
} 
Saco's absence was a turn back toward more literary work. Del Monte, with the help of British Consul Richard Madden, published two non-fiction anti-slavery works - Autobiografía, by former slave Francisco Manzano, and Anselmo Suárez y Romero's novel Francisco, El ingenio o las delicias del campo. Added to these works, del Monte embraced shorter works that extolled the local flavor of Cuba pequeña known as costumbrismo. The goal was to build up a not-quitelost-past of folkways and with this knowledge counterbalance the accretion of power and flattening of difference busily devouring the island at the direction of Captain Generals, slave traders, and moneylenders alike. The Montian literary project had a flattening impulse of its own as it looked to a racial homogenous future that had little resonance with the pre-boom heterogeneous past. The impulse, while vaguely antislavery, seemed to be rooted more in a simplified economic view rather than an embrace of racial equality. Antislavery writing was a means of broadcasting an emerging sense of identity, a national defining which drew rhetorical connections between the enslavement of Africans and Cuba's enslavement at the hands of the Spanish. The slave in these writings represented a uniquely creolized Cuban self that was rejected and controlled by the Spanish. Thereby, antislavery writing was less about cataloguing the struggles of and inhumanities perpetrated against African slaves and more about exercising personal political philosophies and publicizing veiled critiques of the Cuban political system, with slaves playing the role of colonial Cuba in the Spanish imperial system. "Those people who have no influence in the design of the laws they must follow are slaves...those people who don't choose the taxes they pay to the government are slaves...those people who have no political participation and are with basic rights are slaves." Even those AfroCuban writers that did break 
through were largely dependent on the del Monte literary circle for their voice and never gained a foothold against the prevailing antislavery interpretation. ${ }^{281}$

The ambivalence of color and the fluidity of race produced a great anxiety and corresponding drive to reify the boundaries of color in the perceived vacuum of social concern shown by Spanish authorities. Creole intellectuals held the Spanish most responsible for the growing racial disparity on the island by encouraging the importation of slaves to meet the productive demands of sugar. However, the Havana intelligentsia conveniently overlooked that their much extolled societal richness of art, music, letters, and scientific study could be gained only through the massive wealth created by sugar. Hacendados, for their part, were angry that their reliance on slaves chained them to Spanish debt, but overlooked their own culpability in the institution of slavery as owners of the plantations where these enslaved labored. This tensionfilled effort on the part of all creoles to deny the need for more slaves, with a corresponding demand for free access to them and their unlimited importation into the island, motivated much of the racial concern of the period and set the del Monte intellectuals and hacendados on ultimately different paths in the 1850s. These tensions also produced the intellectual rupture over slavery in the elite creole community. ${ }^{282}$

\footnotetext{
${ }^{281}$ La Verdad, March 30 1848. Antonio Vera-León, "Juan Francisco Manzano: el estilo bárbaro de la nación," Hispamérica: Revista de Literature 22, No. 6 (1991), 3-22; Juan Pérez de la Riva, Correspondencia reservada del capitán general Don Miguel de Tacón, 1834-1836 (Havana: Biblioteca Nacional José Martí, 1963), 322-3; Urbano Martinez, Domingo del Monte y su tiempo (Havana: Ediciones Unión, 1997); José M. Aguilera Manzano explores the intense politicking in Cuba and Madrid conducted by the del Monte group, including getting Saco elected to the Cortes in "The Informal Communication Network Built by Domingo Del Monte from Havana between 1824 and 1845," Caribbean Studies 37, no. 1 (January-June 2009), 67-96; Josef Opatrny, “José Antonio Saco's Path Toward the Idea of Cubanidad," Cuban Studies 24 (1994), 39-55; Antonio Benítez Rojo, "Power/Sugar/Literature: Toward a Reinterpretation of Cubanness," Cuban Studies, 16 (1986), 9-31; Manuel De Paz Sánchez, “"El Lugareño' Contra La Esclavocracia: Las Cartas De Gaspar Betancourt Y Cisneros (1803-1866), Revista de Indias 58, no. 214 (1998), 617-639.

282 One of the interesting battles fought among landowners and the intelligentsia was the replacement of African slaves with Chinese and South Asian laborers. Hacendados thought this move would limit the exposure to African culture and violent tendencies perceived by owners and offer a transitional population for the move from slavery to free labor. Yet, many in the del Monte circle felt these moves replaced one racial problem with another, accomplishing little in the result. The issue of cultural degeneration and exposure to threatening impulses still
} 
The presence of the British in the Caribbean, on the island, and in every shadow of intellectual debate exacerbated the producer/intellectual rupture. Elite Cuban producers responded reactively against the threat of British abolitionism throughout the Caribbean and on the island, yet the del Monte group attempted to prevail upon hacendado thinking with constant references to Saint Domingue style race revolution. Additionally, the Havana circle argued that a self-prompted move toward abolition on the part of Cuban creoles promised two-fold impact. First, the need for internal policing provided by the Spanish would evaporate and with it, hopefully, the Spanish. Second, the elimination of the main issue dictating British participation in the political affairs of the island, slavery, promised to eliminate their imperial presence as well. However, despite some social unrest, every decade removed from 1791 combined with every year of economic expansion encouraged a degree of historical forgetting. The main pillar of economic advancement - slavery - placed Cuba on a collision course with the growing tide of Caribbean abolition as well as with a growing internal dissent and perturbation of the massive

threatened the cultural project of the Havana group. Notably the incremental move toward free labor by the 1860s did little to improve the social and economic conditions of these free laborers, particularly Chinese laborers, that entered Cuba in large numbers beginning in the 1840s as legal African slave transport began to bow under the effects of British pressures. Chinese labor in Cuba in the nineteenth century was slavery in every social aspect except the name. The effort to import laborers, while robust, did little to reduce reliance on African slavery. Lisa Yun and Ricardo Rene Laremont, "Chinese Coolies and African Slaves in Cuba, 1847-74," Journal of Asian American Studies 4, no. 2 (June 2001), 99-122; Lisa Yun, The Coolie Speaks: Chinese Indentured Laborers and African Slaves in Cuba (Philadelphia: Temple University Press, 2008); The Cuba Commission Report: A Hidden History of the Chinese in Cuba, (Baltimore: JHU Press, 1993), the report was commissioned in 1876 by the Chinese government who sent a team to investigate abuses against Chinese laborers in Cuba; Walton Look Lai, Indentured Labor, Caribbean Sugar: Chinese and Indian Migrants to the British West Indies, 1838-1918 (Baltimore: JHU Press, 1993); Moon-Ho Jung, Coolies and Cane: Race, Labor, and Sugar in the Age of Emancipation (Baltimore: JHU Press, 2009). Matt Childs points out that corresponding with the efforts to acculturate Chinese laborers in Cuban was an increase in the discussions among the elite regarding the relative lack of civility in "the Orient." This claim was repeatedly supported by assertions of the poor treatment meted to women in those societies. In the creole magazine Sociedad Revista de la Habana (1853) a planter argued, "The Condition of women in barbarous nations is lamentable as they consider her to be no more than a slave...the situation of women in the Orient is deplorable because men consider them as only destined to satisfy their passions. Husbands purchase and sell their wives whenever it pleases them." While Childs finds the connection between Cuban critiques of 'the Orient' and the rise of Chinese laborers in Cuba chronologically tenuous, there is an interesting phenomenon at work in the minds of the elites as they seek to once again extol their own treatment of women as much closer to the civilized idea of Europe. Childs, "Sewing Civilization," quote 97. 
stores of slaves in their midst. The debate over slavery did more to shape the intertwined issues of annexation and independence than any other discussion in the first six decades of the nineteenth century. While I will engage the debate and its foundational position in the annexationist movement fully in the next chapter, a brief statement on the issue as it relates to Cuban thinking will serve to offer a glimpse into the mindset Cuban planters in the early 1800s.

Cuban planters, following the French, British, and American examples, embraced slavery as a necessary implement for agricultural advancement and sought technological advances that further enhanced the physical efforts of their slaves. However, this embrace was ambivalent at best and became increasingly tenuous as abolition, spearheaded by the British, swept through the Caribbean. The British presence in Cuban did much to fuse a crown/planter alliance to the chagrin of antislavery advocates like José Saco. This warm embrace between producers and protectors fueled calls for annexation as one pathway to break the control of the Spanish without threatening prosperity. Therefore the arguments of gradual abolition, under American tutelage, could be made more palatable, the intelligentsia hoped, to hacendados. While always careful to keep British advocates at arm's length and ever ready to accuse them of duplicity in fomenting rebellion (most notably in 1843), intellectuals argued that the benefits of gradual abolition on Cuban terms could be achieved best with the guidance of the American hand. Saco and his ilk came to accept the logic of and need for emancipation as they rejected the concordant moral arguments of equality and humanity attendant to freedom. ${ }^{283}$

\footnotetext{
${ }^{283}$ British abolitionism is a mammoth topic of discussion but one in which Cuba is directly implicated and in many ways was very near the center of, particularly as abolition in Cuba was the backdrop of American-British commercial and political competition in the Caribbean. Of import to the present study are a few questions that preoccupied both contemporary observers and historians. First the humanitarian/economics debate, captivating mid$20^{\text {th }}$ century historiography, centered on the degree to which the intellectual driver of abolition was either a purely humanitarian end or one of profit and comparative advantage. At the debate's heart is the degree to which British governmental policymaking and individual politicians could have been driven solely by humanitarianism if there was no profit motive. The issue of the productivity of Britain's colonial possessions, notably Jamaica, was also a hotly debated issue on both sides of the Atlantic. Finally, the degree to which abolition reverberated, thereby
} 
affecting policy decisions beyond Britain, throughout the Atlantic world was a topic perhaps of most importance. Americans saw a clear attempt at establishing comparative advantage in the abolition of slavery. Duff Green was stinging in his critique. "England finds it impossible to maintain her commercial and manufacturing superiority, because she cannot raise cotton, sugar, etc., as cheap in India as it can be raised in the United States, Cuba, and Brazil, and that her war on slavery and the slave-trade is intended to increase the cost of producing the raw material in the United States, Brazil, and Cuba, that she can sell to other rival manufacturing, continental powers, the product of her East India possessions cheaper than they can purchase from us. If she can do this, having the power to compel her East India subjects to purchase her manufactures, and hers alone, she can, through her manufactures, command the supply of raw material, and thus compel rival manufacturing nations to pay her tribute, while she, in a great measure, controls the manufacture itself. ... Under the aspects of the case, you will find that England has much more than a work of benevolence in the suppression of the slave-trade" (Green to Lewis Cass, January 24, 1842). Regardless, however, of simple economic imperatives, British abolitionism had an important impact on Cuba's internal politics that is more important for the present topic than the economic argument (although separating the two is certainly impossible). The expansion of Cuban slavery and its profitability, demonstrated by not only the output of Cuban ingenios but also by the sharp increase in prices for slaves, stood as a sound remonstration of British efforts to carry their example forward throughout the world. The challenge for those constructing arguments for the moral supremacy and greater productivity of wage labor, driven by the labor's self-interest, lay squarely in the lack of evidence to prove the point. The market share gains made by Cuba in world sugar market as well as the productivity of American cotton producers weakened the economics of abolition. Slavery was not a decaying institution and certainly was not incompatible with the presence of wage labor. In fact, for many defenders of slavery, their system of labor was more than up to the challenge. With this seemingly obvious fact, particularly noticeable to profitable Cuban and American planters along with their Brazilian counterparts, apparent in the economics of the sugar, cotton, and coffee trades, abolition then came to be viewed by many in Cuba as an attempt to weaken the economic growth of its sugar industry, thereby helping British suppliers. Additionally, the humanitarian argument generally held little sway in locales where slavery expanded as owners not only rejected it prima facie but also scoffed at the belief that humanitarianism drove British abolition. However, in the historical long view, the case for intertwined humanitarian and economic impulses is one made with sophistication and rigor. The debates in the 1840s in England over free markets, free trade, and the acceptance in British markets of slave grown sugar (and the associated debates over the British Corn Laws) demonstrates the ongoing importance and continuity of a humanitarian impulse in the process of abolition - an impulse that might have even strengthened after official abolition in 1834. The efforts of the British and Foreign Anti-Slavery Society (formed in 1839) and its literary organ, Anti-Slavery Reporter, to abolition slavery in other countries stirs the muck up a bit, specifically in Cuba, where the economic and humanitarian motives seem equally on display. The Society, initially hostile to the efforts of British West Indian planters to keep freed slaves in long-term apprenticeships, often made common cause with them particularly when it assisted those still enslaved in other countries. However, many in the liberal press grew tired of this continuation of abolition aboard and called for an abandonment of the economic and moral efforts in Cuba. British offers of payment to slaveowners in the Spanish empire further aggrieved British sensibilities. Undeterred, the Society/planter alliance made strong arguments for the curtailment of free trade in commodities produced by enslaved labor while agents for Cuban sources along with consumer advocates in Parliament (they argued that free trade would lower consumer prices and force British producers to become more efficient) squared off in budgetary debates and public fights. This protectionist/free trade debate mirrored a similar argument among anti-slavery advocates on both sides of the protectionist issue and undermined the efforts at the Second World's Anti-Slavery Convention held in London (1843). Intriguingly, the year 1843 was one that held particularly import for Cuba. As the La Escalera conspiracy raged, British abolitionists David Turnbull (travelled to Cuban in 1838 and made British Consul in 1840 but exiled to Jamaica by 1841 after receiving death threats for his work in Havana), Francis Ross Cocking (Vice-Consul) and Richard Madden (British Superintendent of the freed Africans in Havana 1835-40) stood accused of complicity in the planned uprisings throughout Cuba. Turnbull was sentence to death in absentia despite being a British official due to accusations that in his official travels he helped the planning and communication networks of the uprising. Their official presence in Cuba reinforced numerous discussions conducted between the British and Spanish pertaining to the slave trade, with Madden and Turnbull given oversight capacities for the enforcement of Spain's treaty obligations. Regardless of their actually participation (which Cocking for his part claimed was reality in a letter to Foreign Secretary Palmerston from Caracas in 1846) the movement of European abolitionists drew great interest from AfroCaribbean creoles, enslaved and free. Whatever Turnbull's participation (which was probably robust) Palmerston nevertheless cautioned him to be more tactful in correspondence with the Spanish colonial authorities. "You write with so much bitterness of feeling; with so much 
Ironically, the process that led to British abolition within their empire and that fueled their diplomatic pressures in the Caribbean intensified slavery elsewhere, notably in Cuba.

of sneer and irony, that you excite a suspicion that you are actuated by some personal or vindictive motives as much as by a sense of duty ... Moreover, you constantly exaggerate things, which require no exaggeration, and thus you defeat your own purpose" (Palmerston to Turnbull, August 2 1841, quoted in Curry-Machado, "How Cuba Burned," 80). For his part, Madden was particularly engaged with the dissident group of Cuban creoles led by Domingo del Monte and helped publish in Britain the autobiography of freed slave Juan Francisco Manzano that del Monte commissioned. Madden was perhaps equally as aggressive as Turnbull in his distaste for Cuban slavery, on display throughout his work The Island of Cuba. "With respect to my own experience, it is not by particular instances of cruelty or oppression is the fact to be established, that slavery in Cuba is more destructive to human life, more pernicious to society, degrading to the slave, and debasing to the master, more fatal to health and happiness than in any other slave holding country on the face of the habitable globe," (126). Duff Green to Lewis Cass, January 24, 1842 in Duff Green, Facts and Suggestions, Biographical, Historical, Financial and Political, Addressed to the People of the United States (New York: Richardson \& Co., 1866), 153. By far the best treatment of slavery and abolition in Cuba is David Murray, Odious Commerce: Britain, Spain and the Abolition of the Cuban Slave Trade (Cambridge: Cambridge University Press, 2002). Rebecca J. Scott, "Gradual Abolition and the Dynamics of Slave Emancipation in Cuba, 1868-86," The Hispanic American Historical Review 63, No. 3 (August 1983), 449-477; David Turnbull, Travels in the West: Cuba; with Notices of Porto Rico and the Slave Trade, (London: Longman, Orme, Brown, Green, and Longmans, 1840). University College of London's, "Legacies of British Slaveownership," accessed January 17, 2014, http://www.ucl.ac.uk/lbs/, is an investigation of the more than 5,000 British families who claimed compensation for freeing their slaves under Parliament's Slavery Abolition Act 1833. Richard Madden, ed., Poems By a Slave in The Island of Cuba, Recently Liberated; Translated From The Spanish, By R. R. Madden, M.D., With The History of The Early Life of The Negro Poet, Written By Himself; To Which Are Prefixed Two Pieces Descriptive of Cuban Slavery And The Slave-Traffic, by R. R. M., (London, Ward \& Co., 1840), accessed January 17, 2014, http://docsouth.unc.edu/neh/manzano/menu.html and The Island Of Cuba: Its Resources, Progress, And Prospects, Considered In Relation Especially To The Influence Of Its Prosperity On The Interests Of The British West India Colonies., (London, C. Gilpin, 1849), accessed January 17, 2014, http://catalog.hathitrust. org/Record/001447268; David R. Murray, "Richard Robert Madden: His Career as a Slavery Abolitionist," Studies: An Irish Quarterly Review 61, no. 241 (Spring 1972), 41-53; R.J. Boutelle, “"The Most Perfect Picture Of Cuban Slavery:' Transatlantic Bricolage in Manzano's and Madden's Poems by a Slave," Atlantic Studies 10, no. 4 (Fall 2013), 528-549; Gera Burton, Ambivalence and the Postcolonial Subject: The Strategic Alliance of Juan Francisco Manzano and Richard Robert Madden (New York: Peter Lang Publishing, 2004); Natasha Lightfoot, "Race, Class and Resistance: Emancipation and Its Aftermath in Antigua, 1831-1858," (PhD diss., New York University, 2007); Brycchan Carey, British Abolitionism and the Rhetoric of Sensibility: Writing, Sentiment, and Slavery, 1760-1807 (London: Palgrave Macmillan, 2005); Rebecca J. Scott, "Gradual Abolition and the Dynamics of Slave Emancipation in Cuba, 1868-86," The Hispanic American Historical Review 63, no. 3 (August 1983), 449-477; Francisco V. Aguilera and Ramon Céspedes, Notes about Cuba, (New York: Commissioners of the Republic of Cuba, 1872), accessed January 17, 2014, https://archive.org/details/notesaboutcubas100agui; João Pedro Marques, Seymour Drescher, P. C. Emmer, Who Abolished Slavery: Slave Revolts and Abolitionism: A Debate with João Pedro Marques (New York: Berghahn Books, 2010); Great Britain House of Commons Select Committee on the Extinction of Slavery Throughout the British Dominions, Analysis of The Report of a Committee of The House of Commons on The Extinction of Slavery, (London: Committee on the Extinction of Slavery Society for the Abolition of Slavery Throughout British Dominions, 1833), accessed January 17, 2014, http://books.google.com/books?id =97GRJQ8fS cwC\&pg=PP1\#v=onepage\&q\&f=false; Frank Joseph Klingberg, The Anti-Slavery Movement In England: A Study In English Humanitarianism (New York: Archon Books, 1968); Thomas Bunn, "An Essay On The Abolition Of Slavery Throughout The British Dominions: Without Injury To The Master Or His Property, With The Least Possible Injury To The Slave, Without Revolution, And Without Loss To The Revenue," (London: W. P. Penny, 1833), accessed January 17, 2014, http://books.google.com/books?id=H5jBScyJe4gC\&pg=PP7\#v= onepage\&q\&f=false; David Richardson, Abolition and Its Aftermath: The Historical Context 1790-1916 (New York: Routledge, 2013). 
British abolition was indeed an interesting and, at times, paradoxical journey made less intelligible with two centuries of historical study compressed upon the effort. At heart, the debate centers on the productive source of abolition's impulse - humanitarianism or economics. The British took an active and known risk by embracing Smithian faith in the wage labor experiment. While there was a clear economic motive in holding Cuban (and Brazilian) feet to the fire of international agreements, the ends of suppression and any other effort relating to the Great Experiment of abolition always embraced a humanitarian core, lest the economic reality of the failure of wage labor declare the Experiment a failure. In fact, the uneven ferocity of the British attack on Cuban slavery, largely embolden and represented by the priggish moralism of David Turnbull, made the humanitarian impulse all the more convincing. However, economic objectives embraced humanitarian rhetoric out of necessity as well. Americans found it difficult to accept the humanitarian impulse of British abolitionism, believing instead that there was an unseen hand of profitability driving the calculus. Therefore, if wage labor was indeed superior to slavery, the British would have little impulse to pursue abolition as a foreign policy. Wage labor, if in fact a comparative advantage, was one that for a variety of reasons American and Cuban slaveowners were happy to roll the dice against. Yet, as reports detailing the economic collapse resultant from the Great Experiment continued to emerge, producers throughout the Caribbean world, in Cuba, and the United States began to wrestle with the apparent reality of a deeper impulse and more threatening goal driving British policy - true belief in abolition built on the recognition that slavery in fact was the comparative advantage for their competitors. The economic imperative of abolition remained but in a profoundly different and menacing way. If Britain decided to bet their economic future on free labor, that was their choice argued Americans. However, if Britain became a true believer in the cause of abolition and realized that 
slavery hurt their economic outlooks, that was a most threatening calculus for Americans. British aggression was then only a matter of time.

Therefore Cuba sat between two world blocks, one British and one American, vying for the Caribbean generally and Cuba specifically. Britain lost their chance in Texas to both hem in American slavery and capture productive cotton lands. Cuba then became the last of its attempts to cement its direct control of the Caribbean. The British encouragement of Cuban sugar importation despite the abolitionist cause was a powerful tip of the hat and admission of defeat in the face of a lack of devotion to the abolitionist cause among Cuba producers and the Spanish crown. That David Turnbull left Cuba at the moment when the free importation of slave sugar burst into the domestic markets in Liverpool, should not be surprisingly. The British desperately needed to supplement declining Jamaican supplies and feared a disruption of Cuban production. If they refused slave-produced sugar from Cuba, the island would turn even more exclusively toward the United States and its markets thereby decimating the British domestic market. The temporary glut of British sugar, exhausted by 1807, suffered continuing ebbs and flows during war with Napoleon. Abolition then focused attention on productivity. The British, demonstrating capitulation with Cuban sugar importation, lost the free market argument as they watched Cuban producers increase slave importation and technological investment. The resultant world sugar domination by an increasingly efficient Cuban producing class reduced British economic arguments in the Caribbean to farce. Americans took active notice of these debates and came to the startling and disconcerting realization that if free labor agricultural produce was not in fact more profitable and if the British had in fact cut off their economic noses, then their domestic and diplomatic politics threatened an economic moralism that might be as competitive and expansionary as United States foreign policy was in its protective stance on slavery. The British 
had to destroy slavery as a foreign policy imperative in order to protect its homeland economy.

Cuba then became the crown jewel in the diplomatic struggle between Anglo-empires in the

Caribbean. The great British fear remained that after American success against Mexico, the

former's expansionary policies were ascendant in the hemisphere, with the moribund South

American republics standing ineffectually observant of American actions. The rhetoric of the

post-Monroe Doctrine decades through the Mexican war showed through with an American

determination to add action to philosophy. Yet, despite Britain's fears, American held their own

great concern - a third war with the British this time over the economics of the Caribbean. ${ }^{284}$

\footnotetext{
${ }^{284}$ Stephen Mitton, "The Free World Confronted: The Problem of Slavery and Progress in American Foreign Relations, 1833 - 1844," (PhD diss., Louisiana State University, 2005). Mitton argues that it was after 1843, and Britain's admission to the Tyler administration that the Great Experiment was a failure that Southern intransience on the slavery issue took its true antebellum shape as it was not clear before that point if British policy was directed at the eradication of slavery as a moral crusade. The belief that Turnbull's efforts first in Cuba and then from exile in Jamaica were designed to destroy slavery in Cuba through the worst possible means, fomenting of revolution, fueled Southern fears and drove U.S. diplomats into overdrive in the aftermath of La Escalera (issues discussed in chapter five). This is a very provocative part of a very large discussion on the nature of British abolitionism and the profitability of slavery and free wage labor. Historical debates over the decline theory have been robust and continuous since Eric Williams Capitalism and Slavery (1944). The current consensus places the British Caribbean in a much more lucrative position just before abolition and far from contracting, British slavery and profitability both expanded prior to abolition. David Ryden, among others, argues that the adaptability of British planters produced enormous production successes at the end of the $18^{\text {th }}$ century and that these successes contributed to the decrease in production seen during the abolition debates. Furthermore, the compiling of trade numbers indicates that British producers were less affected by an absolute glut than a situational rise and fall of prices and supply based on the complexity of war. Continental sugar prices were 15\% higher and British demand increased $40 \%$ in the 10 -year period before and after 1800. During the Anglo-French conflict, gluts came and went with the rise and falling seas of the French Continental Blockade. Many observers point to the almost universal disinterest abolitionists of the day had toward issues of Caribbean profitability. The Williams paradigm embraces this profitability paradigm and situates the Caribbean as the productive site of Atlantic modernity. From this perspective, operating under the superstructure of diplomacy and economics was the resistant ideology of the subaltern. The fall of British sugar then came from a combination of the inherent tension in the labor system (internal rebellion) and the various economic dislocations of the system of production - including the chaos of the American Revolution, the supercharging of British production in the second half of the $18^{\text {th }}$ century, and soil and planter exhaustion. The reaction against the Williams thesis argues for an adaptive British planter class innovative in their responses to changing market conditions with no specific weaknesses in the system of slavery that predicated its demise. In fact, the overproduction argument of some historians posits that British producers reacted too well to the changes confronting them and that excess productivity doomed the enterprise. The complexity of the arguments obscures the basic fact that British abolition policy was the baseline against which the reactive forces of the Americans and Spanish responded. Abolition fueled philosophical power to demands of the enslaved as a matter of official policy and apart from issues of economics. This position frightened Southern planters to their core. Eric Williams, "Laissez Faire, Sugar and Slavery," Political Society Quarterly 58, no. 1 (March 1943), 67-85; Kevin H. O’Rourke, "The Worldwide Economic Impact of the Revolutionary and Napoleonic Wars," (Paper written for Department of Economics and IIIS, Trinity College Dublin, 2004); Christian Reus-Smit, Individual Rights and the Making of the International System (Cambridge: Cambridge University Press, 2013), ch. 4; David Eltis, Economic Growth and the
} 
However, a focus on the traditional storyline of elite Cuban creoles trying to create a national culture in the hurricane's eye of international diplomatic battles and the looming danger of slavery overlooks one key component, the massive presence and contestation of hundreds of thousands of AfroCubans. The elite voice was not the only one engaged in these conversations. AfroCubans also participated to a great deal in the contestation of national physical and philosophical space both reacting to and forcing reactions from the elite creole intellectual and ownership communities. In fact, the turn toward annexation on the part of many in the elite demonstrates a certain admission that the project of whitening the nationalized prototypical 'Cuban' failed to achieve naturalized results. There could be no 'whitened' Cuba, without the exclusion and elimination of AfroCuban presence, a clear unfathomable possibility. Annexation was an admission of the untenability of the illusory belief that the 'blackness' that the elite feared could be removed from the island. Social control over the AfroCuban presence, in slavery or freedom, was to remain an intractable problem requiring massive amounts of command and control, as well as, social control investment. Fearing the future of freedom, elite creoles believed slavery was the best way to preserve the status quo. Racial difference had to be

Ending of the Transatlantic Slave Trade (Oxford: Oxford University Press, 1987), particularly section II; François Crouzet, "Wars, Blockade, and Economic Change in Europe, 1792-1815," The Journal of Economic History 24, no. 4 (December 1964), 567-588; Hugh Thomas, Cuba, Or, The Pursuit of Freedom (New York: De Capo Press, 1988) 70-109; David Ryden, West Indian Slavery and British Abolition, 1783-1807 (Cambridge: Cambridge University Press, 2009); Ralph M. Henry, "Eric Williams and the Reversal of the Unequal Legacy of 'Capitalism and Slavery," Callaloo 20, no. 4, (Autumn 1997), 829-848; Seymour Drescher, Econocide: British Slavery in the Era of Abolition (Pittsburgh: University of Pittsburgh Press, 1977); John McCusker, "The Economy of the British West Indies, 1763-1790," in Essays in the Economic History of the Atlantic World, ed. John J. McCusker (London: Routledge, 1997), 310-30; Lowell Ragatz, The Fall of the Planter Class in the British Caribbean, 1763-1833 (New York: Octagon Books, 1928); J.R. Ward, British West Indian Slavery, 1750-1834: The Process of Amelioration (New York: Oxford University Press, 1988); Hilary Beckles, "Capitalism, Slavery, and Caribbean Modernity," Callaloo 20, no. 4 (Autumn 1997), 777-789; Fernando Ortiz, Cuban Counterpoint, Tobacco and Sugar (Durham: Duke University Press, 1995); Robin Blackburn, The Making of New World Slavery: From the Baroque to the Modern, 1492-1800,(London: Verso, 1998); David Brion Davis, The Problem of Slavery in Western Culture (Oxford: Oxford University Press, 1988); Thomas Bender, ed., The Anti-Slavery Debate: Capitalism and Abolitionism as a Problem in Historical Interpretation (Berkeley: University of California Press, 1992); C.L.R. James, The Black Jacobins: Toussaint L'Ouverture and the San Domingo Revolution (New York: Vintage Books, 1963); Howard Temperley, “Capitalism, Slavery and Ideology,” Past \& Present 75 (May 1977), 94-118. 
continuously reaffirmed in the physical control of plantation structure and corporal discipline along with the institutionalization of racial difference as an indelible marker of an exclusionary Cubanness. Furthermore, the continuance of slavery offered free AfroCubans a strong demonstration of the tenuous position of their own freedom, particularly noticeable in the contraction of legal rights and the visceral retribution exacted in the wake of civil unrest on the island. While coartacion, cabildos and militia service created an AfroCuban culture with more elasticity than free communities in other slave societies, white creoles grew impatient with demographic efforts at whitening the Cuban stock and unsure of Spain's dedication to that same effort. Therefore an understanding of the moment of greatest civil unrest is perhaps the most beneficial way to understand the daily and unremarkable contestations of the political and social processes underway throughout the island.

In March, 1843, an event - the uncovering of a series of slave uprising conspiracies collectively known as La Escalera - along with its subsequent repression (El Año del Cuero) by Spanish officials, ripped bare the immediacy of the hitherto leisurely pace of debate taking place regarding the island's social and political future. La Escalera was a profound turning point in the Spanish approach to governance in Cuba and the creole mentality surrounding that governance. The result was not only brutal physical repression but also a profound meditation on the continuance of slavery on the island. The various conspiracies heightened paranoia among every class of residents on the island. The Spanish looked upon every subject - slave, creole, AfroCuban, and foreigner alike - as a threat to stability and therefore punishable. The enslaved responded to the reality of massive importation and security/discipline changes with an understanding that they retained few options in response to the changing perceptions and treatments by their owners. Free AfroCubans, upon whom the repression fell most directly, 
sensed a concerted effort at their eradication as a final solution to the vexations their presence had long-produced in the neat racial nationalism of the creole elite. The intelligentsia felt the sting of admonishment in their ranks largely in response to their dogmatic attacks on the crown, various Captain Generals, and slavery. Hacendados, beyond the fear that slave rebellion produced in their daily lives, worried that the economic success of the early boom period might dry up in the face of Spanish acquiescence to abolitionary demands in the light of La Escalera. The rebellions and conspiracies of the early 1840s demonstrated the vibrancy of the underground communications and resistances among the enslaved, the robust network of communications among AfroCubans throughout the island, and the intricate web of interaction among British policy (and in some cases officials) and the enslaved. The moment, many in the AfroCuban community sensed, was politically fortuitous for revolt and perhaps one of the last moments when that revolt might be possible. ${ }^{285}$

285 The literature on the Conspiracy of La Escalera includes: Robert Paquette, Sugar is Made with Blood (Middleton, CT: Wesleyan University Press, 1990); Daisy Cué Fernández, "Plácido y la conspiración de la Escalera," Santiago 42 (June 1981), 145-206; José Luciano Franco, "Introducción al proceso de la Escalera," Boletín del Archivo Nacional 67 (1974), 54-63; Herbert S. Klein, Slavery in the Americas: A Comparative Study of Virginia and Cuba (Chicago: University of Chicago Press, 1967), 193-222; Philip S. Foner, A History of Cuba and Its Relations with the United States, Vol. 1 (New York: International Publishers, 1962), 214-28; Ramiro Guerra y Sánchez, ed., Historia de la nación cubana, 10 vols. (Havana: Editorial Historia de la Nación Cubana, 1952), vol. 3; José de J. Márquez, Plácido y los conspiradores de 1844, (Habana, Imp. la Constancia, 1894); Michele ReidVazquez, The Year of the Lash: Free People of Color in Cuba and the Nineteenth-century Atlantic World (Athens: University of Georgia Press, 2011); David Luis-Brown, "Slave rebellion and the Conundrum of Cosmopolitanism: Plácido and La Escalera in a Neglected Cuban Antislavery Novel by Orihuela," Atlantic Studies 9, Issue 2 (Spring 2012), 209-230; José L. Franco, Plácido: Una polémica que tiene cien años (Havana: Ediciones Unión, 1964); Manuel Barcia Paz, "Exorcising the Storm: Revisiting the Origins of the Repression of the Conspiracy of La Escalera in Cuba," Colonial Latin America Historical Review 15, no. 3 (Summer 2006), 311-326; David Murray, Odious Commerce: Britain, Spain and the Abolition of the Cuban Slave Trade (Cambridge: Cambridge University Press, 2002); A. F. Corwin, Spain and the Abolition of Slavery in Cuba, 1817-1886 (Austin: University of Texas Press 1967); J. Curry-Machado, 'How Cuba Burned with the Ghosts of British Slavery: Race, Abolition and La Escalera," Slavery and Abolition 25, no. 2 (April 2004), 71-93; Mario Hernández, "David Turnbull y el problema de la esclavitud en Cuba," Anuario de Estudios Americanos 14 (1957), 241-99; Roland Labarre, "La conspiración de 1844: un complot por lo menos dudoso y una atroz maquinación," Anuario de Estudios Americanos 43 (1986), 127-41; Matthew D. Childs, The 1812 Aponte Rebellion in Cuba and the Struggle against Atlantic Slavery, (Chapel Hill: University of North Carolina Press, 2006); Luis Martínez-Fernández, "The Havana AngloSpanish Mixed Commission For The Suppression Of The Slave Trade And Cuba's Emancipados," Slavery and Abolition 16, no. 2 (June 1995), 205-25; Duvon Corbitt, "Immigration in Cuba," Hispanic American Historical Review, 22 (May 1942), 280-308; Fernando Armario Sánchez, "La esclavitud en Cuba durante la regencia de Espartero, 1840-1843," Hispania: Revista Española de Historia 43, no. 153 (1983), 129-53; R. B. Sheridan, 
In this configuration La Escalera, while undoubtedly concerning for some on the island and a conspiracy of certain operation ability, was, much like Aponte's rebellion, an attempted opportunity for greater strengthening of social position for a variety of actors. La Ecalera was a clarifying event in the articulation of political interests and designs rather than a panicked expression of surprise and weakening control. However, the revolt's failure further reduced what fluidity still remained in the racial system within Cuba and brought the imperative of raza de color to the fore. Thousands of AfroCubans were accused of collusion in massive conspiracies, both aspirational and operation, tortured and executed during the 1844 repression known as $E l$ Año del Cuero. Spanish officials used investigations into the Escalera conspiracy to uncover the interaction between plantation and urban areas and gave impetus for an almost complete limitation of the rights of AfroCubans. These limitations reduced AfroCubans already precarious station even further and did much to establish a two-tiered racial system, akin to the United States, in Cuba after 1844. Appearance and not blood drove the division in Cuba, with any appearance of African ancestry enough to eliminate the modicum of upward mobility enjoyed prior to 1843 .

\footnotetext{
“'Sweet Malefactor;' the Social Costs of Slavery and Sugar in Jamaica and Cuba, 1807-1854," Economic History Review 29, no. 2 (Spring 1976), 236-57. Aisha K. Finch argues strongly for the existence of the conspiracy at an extreme operational level that was only stopped by active Spanish repression. It must be noted, and the fact wellexplored by Vanessa Michelle Ziegler and Rebecca Scott, that despite the Spanish government's best attempts, the free AfroCuban population was not destroyed in 1844. A concerted and wise decision to curtail some of the more aggressive unionization activities pushed AfroCuban efforts underground and allowed a locus of organization control to continue bruised but coherent. From this perspective, Ziegler argues a multi-class and multi-racial coalition of men and women mobilized against the Spanish regime in 1868 in response to political repression and economic crisis in Cuba. The Cuban separatist movement, driven by the union of the AfroCuban and poor white populations succeeded in ending slavery, enacting a republican constitution, establishing a national government with state and local administrations, holding elections, and in operating an economy based on limited resources. From this perspective, the Year of the Lash operated as both a call to arms and as a push for the refinement of tactic and coalition building. Finch, "Insurgency at the Crossroads: Cuban Slaves and the Conspiracy of La Escalera, 18411844," (PhD diss., New York University, 2007); Ziegler, "The Revolt of 'The Ever-faithful Isle:"” The Ten Years' War in Cuba, 1868-1878," (PhD diss., University of California, Santa Barbara, 2007); Rebecca Scott, Slave Emancipation in Cuba: The Transition to Free Labor, 1860-1899 (Pittsburgh: University of Pittsburgh Press, 2000).
} 
Over the 12 month period after the uncovering of La Escalera, Captain General Leopoldo O'Donnell ordered the torture, imprisonment, and assassination of thousands of mainly free AfroCubans. The rebellion got its name from the method most frequently employed by Spanish officials for eliciting confessions - stretching the accused bound on ladders as their inquisitors whipped them until confession and/or death. This systematic escalation of Spanish authoritarianism over the island during the Year of the Lash served to increase paranoia and resultant terror among all socio-economic groups in Cuban society. Thousands escaped into exile. One group that escaped to Mexico, led by José Moreno wrote to the Spanish Ministry of Justice in an attempt to bypass the decisions and actions of the Captain General. His letter articulated the plight of those AfroCubans caught up in the repression.

We were not among the people of color who planned the secret conspiracy, that was fortunately discovered, but we trembled at the [Military] commissions, for they never were about justice... and we can certify to the tears we shed over our desolate families, such that we ran with the current of emigration far from Cuba, a blessed land, sweet like sugar, a land consecrated by the work with which our fathers earned Christian freedom, and which they then gave to us...Freely, and with legal permission, we came to this foreign land, and have been here for two long years, during that time we have honorably sought to support ourselves with meager resources ... we reverently request that you lift the prohibition, opposing the orders of the Captain General in Cuba...the investigations determined that we are innocent; we have in no way been involved in the conspiracy. ${ }^{286}$

However, with the lack of white labor readily available to limit the need for AfroCubans in industry and militia service throughout the island, the repression on the island threatened to exacerbate an already vexing problem. Free AfroCubans recognized their position, as did whites dependent on their efforts, and they sought to leverage their power, although in the decline, against a system that increasingly threatened their sovereignty. Therefore, the arrival of a massive slave revolt conspiracy and its repression represents a turn towards the modern, or at the least a limited reaction to modernity. The activity toward expression, political action, direction of

\footnotetext{
${ }^{286}$ José Moreno to Ministro de Gracia y Justicia, Campeche, Mexico, June 26, 1846 quoted in Michele Bernita Reid, "Negotiating a Slave Regime: Free People of Color in Cuba, 1844-1868," 1-2.
} 
individual labor output, and the whole panoply of desire associated with modern individualism indicated an embrace of the ideals and aspirations of modernity.

This is not to insinuate, however, that those actively pursuing the defeat of these conspiracies were anti-modern. Rather the reconfiguration of Cuban society after La Escalera was the battle of two opposing capitalistic modernities, each seeking the control over labor input and the benefits of output. The Cuban slavery regime in the 1830s and 1840s, far from fearful, desired a replacement of the patriarchal system of Spanish colonial authority with a more modern economic system based on free trade, taxation rationalization, establishment of a labor system extolling of greater efficiency, and a general winding down of human (notably enslaved) capital necessity. In order for the winding down to take place, or in the Cuban example a shift toward a different work force that satisfied the whitening principle and the labor imperative, a liminal period had to be worked through, one that necessitated removal of the AfroCuban impulse and effort. However, in the shadow of $L a$ Escalera, the Spanish government's vision of modernity came to the fore. Spanish efforts at repression, bordering on liquidation, of the AfroCuban population therefore aimed at demonstrating Spanish martial capacity to all on the island (and to foreign observers perhaps desirous of Cuba and thinking the Spanish weak) as well as demonstrating a solidarity with the creole whitening project. At long last, many in the creole elite hoped, Spanish officials now understood the great threat that reliance on AfroCuban labor brought to Cuba. However, this Spanish/creole embrace was ambivalent as even creoles came under suspicion and some even received harsh punishment from the crown. Spanish acceptance of the need to control the African-descended population on the island was a piecemeal and extremely selective acquiescence to the creole project. The crown made clear, that while there was sympathy with creole fears, Cuba needed and would continue to have Spanish direction. 
La Escalera, even more so than the Aponte rebellion, existed for AfroCubans not as desire to tear down the capitalistic framework of oppression but rather to establish productive control over their own labor. AfroCubans sought a reestablishment of their positionality as skilled laborers and arbiters of their own cultural imperatives. This allows for an appreciation for the AfroCuban understanding of the internal position they held in Cuban society. White creoles sensed the anxiety of AfroCubans and understood the dangers of unrequited political demands, feeling that frustration themselves in respect to Spanish authorities. Creole aspirations for greater sovereignty also stood frustrated in the understanding that greater freedom was in conflict with their dependence on Spanish military force to preserve domestic tranquility. Despite their best efforts, elite creoles increasingly came to the recognition that control rather than elimination of the AfroCuban influence might be the only available goal of their efforts. The presence of too many libres de color, their numbers averaging $20 \%$ of the population through the early 1800 s, made destruction too difficult and morally incomprehensible. The biological effort at whitening the population through generations of careful interracial relations would be too lengthy and too unmanageable. The legal efforts at stripping rights from AfroCubans would be too fraught with Spanish intrigues and active resistance. In a society where social and political stability rested on a bifurcated system of white racial privilege, the presence of free AfroCubans presented a significant and unavoidable problem with no solution. The debate for white creoles shifted toward management systems and the most effective military and social means at promulgating those systems. Even in the wake of La Escalera, the same tensions, repressive structures, economic and social pressures, and AfroCubans' strategies for dealing with these issues remained intact and necessary. 
The Aponte rebellion and La Escalera were different, representing fundamentally different moments for white and black. The rise of sugar changed Cuban society and economics to the political detriment of AfroCubans, particularly in the free community. They stood in a more desperate position by 1843. La Escalera can be seen as a final attempt at protecting the few legal and economic opportunities available to them. However, their simple continuing presence in Cuban society was the problem. There would be no safe space to carve out in a Cuba conceptualized by the creole elite. That group's greatest fear was of the free AfroCuban community since it represented the failure of elite racial politics. AfroCubans were the physical rejection of the blanqueamiento process and the most direct challenge to the biracial conceptualization of nation based upon labor differentiation. Perhaps most concerning for the elite was the perceived position of AfroCubans as the vanguard of racialized revolt. Despite their differences, both the Aponte and La Escalera rebellions, dependent as both were on the work of cabildos and free AfroCubans, were not simply nostalgia for Africa nor an attempt to recreate Africa in Cuba. Rather the efforts, like those on behalf of the creole elite to define Cubanidad, were exhibitions of political and legal responsiveness. AfroCubans held an understanding and cunning exhibited by a self-aware group of participants that exhibited an appreciation for the climate they existed in and a desire to reform boundaries of national inclusion by working across self-imposed and externally directed challenges to group solidarity. This was a situational logic built beyond a simply statement of racial imperatives.

Certainly, the elite viewed the category of 'black' by 1843 as an undifferentiated socioeconomic racial class unified in their desire to destroy Cuba and the white creole community. This belief fueled a much stronger embrace of Spanish colonial efforts at breaking the free AfroCuban class apart from legal protections and societal positioning that both elite creoles and 
Spanish officials hoped might reduce AfroCuban political efforts. This reduced profile, the authorities hoped, might also restrict the visibility of free AfroCubans as aspirants for the enslaved. The efforts at redefinition of the political and national body, led by free AfroCubans, was as much an effort on their part to protect their societal standing as it was an articulation of emancipatory energy on the part of the enslaved. The free AfroCuban population stood in an incredibly arbitrary position that at times encouraged their participation in the creole movement against the Spanish, dependent as these laborers were on the economic opportunities provided by the hacendados. Simultaneously, they sought and offered sympathy for the enslaved, whose dissatisfaction they sought to harness as political leverage. Free AfroCubans existed in a position in which neither side truly embraced their interests or presence as a trustworthy political partner. Their efforts were often seen as self-aggrandizing and self-interested and encouraged skepticism toward their actions that invited, and validated for colonial officials, Spanish repression.

El Año del Cuero's focus on the free AfroCuban community should be no surprise since longstanding skepticism of their motives and confusion over their existence guided creole thinking. The creole intelligentsia suggested gradual elimination of the AfroCuban presence through the removal of the population of color, regardless of status, out of urban areas. They also suggested that on plantations, the abolition of slavery come with a condition of freedom being self-deportation from the island. Finally, a strict whites-only immigration policy for the island would be the master stroke against future unrest. This process promised an elimination of African blood on the island and with it the natural inclination toward resistance and removal of the last impediment to modernization. For the elite, whitening or blanqueamiento not only referred to skin color but also to values, culture, and economics. AfroCubans represented everything the intellectual class was not - a failure of modernization and progress in the 
European definitions of the words. In the interim and with the hopes that the whitening process would be nonviolent, many in the elite shifted their thoughts to conceptualizing the enslaved, despite numerous examples to the contrary, as a docile community benefitting from the measured paternalism of the slaveholding class. The invented docility of their slaves allowed hacendados that ability to blame civil unrest completely on free AfroCubans. This conceptualization united both plantation owners and the intellectuals and developed the philosophical protections for the slavery's short-term continuance largely because this thinking allowed the elite to separate the grateful from ungrateful AfroCubans in their midst. The shift from the gruesome reality of slavery to the dream-like state of fiction's allegorical slavery rested on the belief that white wage-laborers could replace slaves and their presence could redefine labor relations on the island. This last link in the chain of modernity, wage labor, promised to eliminate the African threat to the national body by whitening the population and reducing any challenges to the economic organization of the island.

Eliminating the AfroCuban population promised a protection of elite privilege, built on intelligence or market performance, a flowering of creole culture, and the elimination of need for Spanish colonial and military structures. This last portion of the dream was that part which creoles pointed to as the chief reason why the crown encouraged slavery and ignored their international obligations. José Saco argued for Spanish blame. "I place the blame squarely on the shoulders of the government, which can and should put an end to the infamous African contraband but which instead tolerates it, gives its consent, and even connives by violating treaties and flouting the law, to the scandal of public and private morals." That El Año de Cuero took a toll on the intelligentsia as well should also not come as a surprise. The focus of Captain General Tacón's retaliation was the del Monte circle and the repression exhibited his certainty 
that Cuban was under siege. "The aim of all the fanatics who call themselves friends of the Africans is to light the fires of revolution in our island through the violent emancipation of the slaves.” The poet Gabriel de la Concepción Valdés (Plácido) was killed by firing squad. Francisco Manzano was imprisoned and tortured; del Monte exiled; and Luz y Caballero, along with others in the educational field, barred from teaching. Villaverde bemoaned the toll Tacón's repression took on his class in a letter to del Monte in September of 1844, "Such dejection and such terror has spread among the few who cultivate letters after your departure. If by change a few do meet or write despite the bloody events and massacres they do so with...the most lamentable imbecility... scattered, silent and downcast, because that which is spoken about today is reduced to articles of fashion and theater dances." 287

For the creole elite, the repression went too far. They were not concerned about the punishments meted out to thousands of AfroCubans, largely agreeing with these efforts as productive of greater internal security. Rather, their concerns centered on the increased surveillance and control colonial officials, through a succession of particularly anti-creole

\footnotetext{
${ }^{287}$ Saco, Paralelo entre la Isla de Cuba y algunas colonias inglesas, http://pds.lib.harvard.edu/pds/view /2577607?n=1; Tacón quoted in Murray, Odious Commerce, 119; Villaverde quoted in Rojo, Sugar/Literature/Power, 27. José Gomariz dissects Gertrudis Avellaneda's use of the concepts of gratitude, whitening, and slave docility in her novel Sab in his essay "Gertrudis Gómez De Avellaneda Y La Intelectualidad Reformista Cubana. Raza, Blanqueamiento E Identidad Cultural En Sab," Caribbean Studies 37, no. 1, (JanuaryJune 2009), 97-118, Where I would add to Rojo's suggestion is that Cubanidad arose less out of the discourse and resistance to Sugar shown by Cuba pequeña, and more in the projection of a discourse of Sugar with aspects of Cuba pequeña interspersed within its dominant voice. This interspersing was both an allowance made and a space created by creole intellectuals that sought not an undoing of Sugar's dominance, but rather an embrace of the modernity and elegance. They hoped the civility and Europeanness of Cuban culture, purchased by the benefits of sugar's rise and extolling of a primordial origin of the island, found strength in a whiteness existing before slavery's befouling, yet one that stopped short of acknowledgement of a pre-Columbian existence. The narrative of AfroCuban docility and fear of violent resistant to abjection fueled the bleaching process - better to eliminate the problem as to not deal with the issues and decisions producing it. The embrace of wage labor also broke the spell of Iberian influence, at first uplifting and European, but now besotted by avarice that slavery encouraged. Orlando Patterson, Slavery and Social Death A Comparative Study (Boston: Harvard University Press, 1985); Jane Landers, Atlantic Creoles in the Age of Revolutions (Boston: Harvard University Press, 2010), chs. 4/6; Franz Fanon, Black Skin, White Masks (New York: Grove Press, 1967). Rafael Maria de Labra, a prolific contemporary chronicler of slavery in $19^{\text {th }}$ century Cuba extolled the virtue of the docile slave in 1876, writing in La brutalidad de los negros, (Havana: University of Havana, 1961 reprint) "The distinctive character of the black is the abnegation and humility and endearing love watching the master who treats him kindly," (7).
} 
Captain Generals, extended over creole actions. These conservative colonial leaders reversed the traditional lackadaisical approach many earlier commanders took toward the elite. Since the fall of Spain's South American empire, Cuba remained under martial law through the creation in 1824 of the Comisión Militar Executiva y Permanente. ${ }^{288}$ The Commission, directed by the Captain General, gave all political and military power to his office to dispose of with little interference from other Spanish or creole officials. Gone were the days of the consensual approaches of Captain General Luis de las Casas, instead replaced with repressive structures designed to monitor slaveowners' behavior, curtail free dissent in the newspapers and magazines on the island, purge the creole social and economic institutions of critical thinkers, modernize tax collection thereby reducing illegal imports and exports from the island, and streamline the administration of political and military justice as defined by the crown. Within this structure of decreasing economic and political opportunities along with increasing civil unrest and Spanish repression, some among the creole elite flirted with the embrace of another power that might open up economic opportunity while retaining internal security. While a tiny faction in the elite argued for direct independence, their calls raised concerns that the internal control apparatus in the absence of Spanish troops would be too weak to promise continued economic growth and internal stability. La Escalera then became the background for the rhetorical battle that raged

\footnotetext{
${ }^{288}$ Joaquín Llaverías, La comisión militar Ejecutiva y Permanente de la Isla de Cuba, (Havana: A. Muñiz y hno, 1929). The Spanish government used the Commissions, military courts in their earliest conceptualizations, to punish supporters of the Cadíz Constitution in 1812. The presence of the Commissions as a source of political influence through their reprisal abilities made them easily transferrable to the Cuban situation, particularly in light of the South American revolutions, in order to kept dissent to a minimum. Beginning with the arrival of Captain General Francisco Dionisio Vives (1823-32), told to keep Cuba at any costs, and processing through the dictatorial controls of various men throughout the 1830-1860 period [Mariano Ricafort Palacín y Abarca (1832-1834), Miguel Tacón Rosique (1834-38), Miguel Tacón (1838-January 1840), Jerónimo Valdés (September 1843-October 1843), Leopoldo O'Donnell (1848 to 1850), Federico Roncali (1850-1852), and José Gutiérrez de la Concha (1852-1853 and 1854-59)] the Captain General had almost unlimited powers of command and control throughout the island. The demoted power of Cuba in the 1837 Constitution (most importantly the islands loss of representation in the Cortes) strengthened this dictatorial power even further and left creoles with little recourse to mainland institutions of power. Jesús Raúl Navarro García, Entre exclavos y constitutciónes: el colonialism liberal de 1837 en Cuba (Seville: CISC, 1991).
} 
throughout the late 1840 s and early 1850 s centering on the best way forward for Cuba to balance security and economic growth. The loudest voices in the debate, on both sides of the Florida Straits, saw the best route charted directly to annexation by the United States.

While Cuban historiography traditionally searches for any manifestation of independentism or intellectual emancipation, the struggle prior to La Escalera was not centered on independence nor would that concept have been broached in any real way. The debates of the period focused on Cubanidad and political rights within the broader Spanish system. This debate was possible thanks to monocultural sugar production's reduction of every other rural activity to insignificance by the mind-1840s. Sugar plantations not only ruined cafetales and tobacco vegas but also irrevocably marked Cuban society. While the marking was not uncontested, the societal weight of the parties was disproportionate in the struggle. The power in the debate held by sugar producers came from the presence of high sugar prices and the harnessing of technological innovations that allowed the sucrocracy an influence that existed as powerfully as that of the political decisions made in Madrid or Cadiz. World sugar consumption, particularly in the United States fueled the dreams and social desires of the sugar elite and drove the Spanish crown in their hopes of controlling and profiting from them. Workers, slave traders, and the enslaved influenced the thinking of planters endeavoring to expand the areas devoted to sugarcane. With the chaos of 1843-44, there existed no single, undivided mind in Cuba as to the way forward. However, one intriguing possibility soon presented itself, fueled by the fear that Cuba was on the brink of pulling the Caribbean basin, and perhaps the entire Atlantic economy, into the abyss.

Annexationism grew out of this intersection of politics and economics in efforts designed at redressing the oppression planters perceived from not only the social structure they observed but also from the external weight of a divergent Spanish economic strategy. Intriguingly 
however, annexation existed as an imprecisely deployed liminal stage, some breathing room that might allow for the delay of significant debates on issues of technological development, abolition and wage labor, and perhaps even independence. The United States offered a perceived biracial clarity that the creole elite, both owners and intellectuals, appreciated. The project of annexation rested on the project of naturalization of racial division, which was in turn built on the interplay between literature and politics, society and culture, and economics and race. American traveler and businessman, John G. F. Wunderman, summed up the fear that gripped whites on the island and helped the Spanish quiet creole dissent. "All the horrors of San Domingo massacres were to have been repeated. Many of the whites were to have been flayed and broiled alive, and with the exception of the young women, reserved for a worse fate, all without discrimination of age or sex, were to be massacred." The United States could not sit idly by and let British abolitionism and Spanish impotence dictate Cuban and, by extension, American economic and social futures. Thus began the massive propaganda effort, in word and action, to make the long-delayed dream of an American-Cuban union a reality. ${ }^{289}$

${ }^{289}$ Wurderman, Notes on Cuba, 357. 


\section{Chapter Five: American Vistas}

Liberty Poem for Asia, Africa, Europe, America, Australia, Cuba, and The Archipelagoes of the Sea.

COURAGE! my brother or my sister!

Keep on! Liberty is to be subserved, whatever occurs;

That is nothing, that is quelled by one or two failures, or any number of failures,

or by the indifference or ingratitude of the people,

Or the show of the tushes of power -- soldiers, cannon, penal statutes.

What we believe in waits latent forever through

Asia, Africa, Europe, America, Australia,

Cuba, and all the islands and archipelagoes of the sea;

What we believe in invites no one, promises nothing, sits in calmness and light,

is positive and composed, knows no discouragement,

waits patiently its time -- a year -- a century -- a hundred centuries.

The battle rages with many a loud alarm and frequent advance and retreat, the infidel triumphs -- or supposes he triumphs,

the prison, scaffold, garrote, hand-cuffs, iron necklace and anklet, lead-balls, do their work,

The named and unnamed heroes pass to other spheres,

the great speakers and writers are exiled -- they lie sick in distant lands, the cause is asleep -- the strong throats are choked with their own blood, the young men drop their eye-lashes toward the ground when they meet,

but for all this, liberty has not gone out of the

place, nor the infidel entered into possession.

When liberty goes out of a place, it is not the

first to go, nor the second or third to go,

it waits for all the rest to go -- it is the last.

When there are no more memories of the lovers

of the whole of the nations of the world,

the lovers' names scouted in the public gatherings

by the lips of the orators,

boys not christened after them, but christened

after traitors and murderers instead,

laws for slaves sweet to the taste of people --

the slave-hunt acknowledged,

you or I walking abroad upon the earth, elated

at the sight of slaves, no matter who they are,

and when all life and all the souls of men and

women are discharged from any part of the earth,

then shall the instinct of liberty be discharged

from that part of the earth,

then shall the infidel and the tyrant come into

possession.

Walt Whitman

From Leaves of Grass 1855

Cuba seems an odd choice in comparison to the continents it stands with in Whitman's

estimation. Yet, in both Whitman's mind and the collective American psyche, Cuba in the 
eighteenth and nineteenth centuries held a position of importance disproportionate to its size. However, by 1855 , the year of Whitman's writing, the American yearning for the island took on a pessimistic tone - an unrequited love, an occasion for frustrated patience while liberty “wait(ed) latent forever." Cuba’s position - geographic, economic, political, and diplomatic demanded American attention and elicited popular obsession. United States policymakers and the American people alike allowed the island a place of reverence in both the conceptualization of hemispheric democracy and the American role in encouraging the unfettered spread of that democracy. The heady excitement of revolutionary 1848, the central role Americans embraced for themselves as the arbiters of a new international system, unraveled far beyond continental musing on manifest destiny. The great hubris present in the mid-nineteenth century United States was the belief that only American society could lead the new democratic epoch and that this democracy could paradoxically coexist with slavery. The importance placed on Cuban annexation was not only representative of the importance of this larger democratic mission, with an as of yet unbroken chain of success, but was also the linchpin in the larger effort to finally expel Europe from the hemisphere. Cuba's absorption into the American family promised to strike a decisive blow against the British led free-labor ideology tormenting the hemisphere. The effort was first-rate millennialism conducted with missionary zeal.

However, too strong an emphasis on the destinarian impulse of manifest destiny's supernova-like explosion throughout the western hemisphere endangers the appreciation for the sources of its great strength and success - incisive manipulation of the American domestic political landscape, the paranoia of proslavery expansionism, cagey if aggressive foreign policy machination, and a clear-eyed belief in the superiority of the American republican experiment. These efforts flowed from the minds, words, and efforts of men believing themselves gods on 
earth; men unmoored from traditionalism, unencumbered by self-reliance's conservatism, and emboldened by god's humility in the face of their superior democratic creation. American political economy was the word made real and manifested in the success of territorial and philosophical expansion. Every nationalistic movement exploding in various world battlefields and every acre of territory placed under the American flag fed the optimism that blinded and the passion that drove the practitioners of the Pax Americana.

Ultimately, by the end of the decade, with the death of López along with the wash of abolitionist literature and sentiment after 1854, the confrontational attitude of those who rejected annexation was too forceful in its refusal to yield to an effort with no charismatic figurehead. This end largely obscured the earlier popularity and cross-sectional support López and his efforts enjoyed. López allowed Americans to envision a truncated American empire that ended with Cuban annexation, siphoned off concerns over slavery, and fed conceptualization of engagement with the island devoid of purely expansionistic steps toward areas farther south. The great support of Americans for Narciso López and attempts at Cuban annexation were the last gasps of a holistic nationalism and individualistic masculinity that sought to downplay sectional divisions and stave off challenges from an ascendant manhood which stripped decision-making from individuals and gave it to waffling fearful politicians. The failure of annexation was, for Americans, the failure of robust benevolence in foreign affairs. This failure, according to critics, was a result of the abandonment of the political arena to negotiation, diplomacy, and dissembling accompanied by high-minded rhetoric that demonstrated American duplication of European effeminacy. Increasingly, the American public, beyond just the issue of Cuba, held little interest for the wastrels in Congress that pursued negotiation as the means of virtue and political 'action' 
on the pressing issues of the day. Conversely, annexation's failure, for Cubans, simply encouraged embrace of other more robust independence-minded strategies.

The story of the annexation movement helmed by Narciso López, John L. O’Sullivan, the Havana Club, the Cuban creole intelligentsia, and the New York/New Orleans exile community lays in the perceived similarity of the societies involved in the discussion. The conversation, rather than between two distinct cultures, took place among people largely believing that they were already members of one shared ideology and economy; all that remained was political unification. For Americans supportive of annexation, Cuba offered the hope of siphoning off the looming problem of slavery in newly conquered western territories to the island where the institution was already firmly planted. Cuba promised to lessened American sectional hostilities, supporters of annexation argued, since the numerous slave states carved out of the island would balance the expected free-states emergent in the Mexican cession and harangued by the Wilmot Proviso. Ironically, the inability of Americans to work out a solution to their own slavery contortions by the late-1850s dampened momentum in taking the island. Additionally, the failure of an overly aggressive effort aimed at purchase condemned the project's more discreet diplomatic half.

Beyond the military and diplomatic failures, there remained the tricky issue of Cuban slavery. The fluidity of the Cuban slave system and the widely shared understanding that emancipation was a forgone conclusion flummoxed annexation's supporters' excitement, particularly in the American South. The road to incorporation into the American family promised to be a much rockier one than many supporters believed. The reality of gradual abolition assumed as it was by even the largest of Cuba's sugar planters, stood as a potential and powerful challenge to American slaveowners. Further compounding these concerns was the promise of 
increased competition from Cuban agriculture, noted particularly by Louisiana sugar producers (yet a competition that many in the moribund New Orleans merchant class welcomed). While there was deep economic interest and general agreement in acquiring Cuba, the concern and discussion more pressingly centered on slavery's expansion and the soul of American democratic republicanism.

The creators of Cuban national identity, a concept built upon an exclusive racial definition, looked to annexation as the surest way to solidify that definition through the protection and momentary continuance of slavery. Annexation of Cuba and filibustering attempts to accomplish the task were not only foundational to Cuban identity but were both productive and reflective of American identity as well. This identity, increasingly defined in different and eventually oppositional ways by North and South, might be better referred to as perspectives on republicanism. Both American regional political perspectives claimed purity in their relation to the Revolutionary spirit of 1776 and sought to expand their areas of influence to the detriment of the other. Cuban annexation, and a more generalized southern hemispheric expansion, became a game-changing proposition for the Southern republican proponents who viewed slavery and social hierarchy - in personal, racial, and international relations - as the most natural progression of liberty. While Southern republicanism saw Northern capitalist free-labor ideology as a corruption of the natural progression of human relations, Northern perspective placed increasing importance of the personal morality, that abolition called forward, as the basis of domestic and foreign policy. In the optimism of democracy's spread and the heady excitement of economic expansionism, the López expeditions simultaneously represented a deep wellspring of Americans' belief in the experiment of 1776 and a last grasp of that same optimism, focused as many believed it was on continuing an uneasy peace over the slavery issue. For Cubans as well, 
annexation offered the hope of continued economic advancement, clearer national definition, and an important solidification of an ascendant liberal democratic project set forward on the path of economic and social liberalization.

Cuba and the issues of gradual emancipation, its nationalizing project, and all matter of Cuban social debates were largely abstractions to many involved in the United States side of the debate. Cuba became the latest of many backdrops against which Americans continued fighting the rhetorical battle of their own slavery. Therefore, the annexation debates eventually became two increasingly distinct halves, one Cuban and one American, with equally divergent audiences. Cuba, a land with slavery, presented itself as a much simpler undertaking than the increasingly messy incorporation of the Mexican cession. As new land opened to settlement, the West invited debate over whether slavery might accompany that settlement, unmoored as the territory was by the institution's historical presence. The debates, beginning even before the Mexican War ended, were heated and ominous as well as informed by the debate over the Wilmot proviso among other political issues. Cuba offered an invitation out of this debate. American and Cuban annexationists realized a combination of their rhetoric was essential for success. Yet, neither side truly worked out a full picture of what success meant and what the repercussions of that success might be.

The annexation debate was a situational one used by many to pursue their private personal ends. Principle, for many, was less a driver than potential economic and political gain. Those Americans arguing against annexation aimed their objections at domestic politics they saw as the more important driver of the debate. However, these opponents, focused too narrowly on domestic abolition, struggled to combine their voices and ceded much of the public conversation to annexationists. In this atmosphere, a quick victory in any annexation effort was essential and 
the supporters of such efforts, recognizing the pregnancy of action, moved quickly in bringing their rhetoric into operation. Disaster on both accounts was the result; for as much as Cuban annexation was important to Americans, the effort remained a microcosm of the battles already being waged over American slavery, with the sides too intractably invested for compromise.

The difference in the effect of annexation's failure on Cuba and the United States is instructive to this end. While the former regrouped its efforts at political emancipation and shifted toward multiethnic national building - efforts possible in its much different colonial setting - the latter embraced the failure as a signal failure of the American Union's sovereignty a collapse of the republican programmatic that left no compromise or revision. The failure to take Cuba for many antebellum Americans was a failure of American imagination and confidence. That the burden of saving the Union fell on Cuba's shoulders was the work of a blindly optimistic cabal of opinion makers and opportunists ignorant of the concept of pessimism. Moses Yale Beach, editor of the New York Sun and a chief proponent of annexation summed up the braggadocio of the movement in an editorial imploring President Polk to loose the chains of annexation.

Cuba by geographical position, necessity and right belongs to the United States; it may and must be ours.... To us it is indispensable. We want its harbors for our ships to touch at to and from Mexico-for the accommodation of American and English transatlantic steamersfor its products and trade Cuba by geographical position, necessity and right belongs to the United States, it may and must be ours.... To us it is indispensable. We want its harbors for our ships to touch at to and from Mexico-for the accommodation of American and English transatlantic steamers-for its products and trade, and as the Grand key to the Gulf of Mexico. Give us Cuba, and our possessions are complete. ${ }^{290}$

The naïveté involved in this perspective is embarrassing, both in its belief that Cuba was the president's to give and in its total lack of self-awareness. This rapaciousness fueled a general ignorance of Cuban social concerns. Undoubtedly, for most Americans Cuba, after it plugged the

\footnotetext{
${ }^{290}$ Moses Yale Beach, "Cuba Under the Flag of the United States,” New York Sun, July 23, 1847.
} 
dam of its threatened racial revolution and became the salve for American sectionalist concerns, was, in reality, but one more stepping stone in the exorable march of American democratic victory.

The manifest destiny of filibustering was a different articulation of the now famous brand made necessary by the evaporation of contiguous continental land available to American expansion. Caribbean expansion, now predicated on the reinvigoration of slavery through Cuban annexation and the exploitative money made by North American interests in Cuba, seemed anathema to the American democratic disposition. Therefore a new conceptualization of expansion based on the growth and defense of liberty became necessary. This new articulation rested upon both the need of protection from poorly conceived liberty movements threatening contagion for the United States political experiment and the assurance that slavery was necessary as the liminal stage between mercantilism and capitalism. Cuba shifted in the American mind from an economic object of desire to an urgent solidification of the battles lines of the new American frontier. Annexation promised Cuba as an outpost of protection against contagion of slave revolt driven by British abolitionism and also the festering barbarism of domestic unrest in the South American colonies. The initial annexation of Texas served a similar purpose against a unified threat of British/Mexican abolitionism. Seizing the island allowed a moving of the American frontier south in order to build a buffer, both physical and metaphysical, against British intrigues. As Secretary of State Daniel Webster breathlessly warned regarding British meddling with Cuban slavery,

If this scheme (abolition) should succeed, the influence of Britain in this quarter, it is remarked, will be unlimited. With 600,000 blacks in Cuban and 800,000 in her West India Islands, she will, it is said, strike a death blow at the existence of slavery in the United States. Entrenched at Havana and San Antonio ports as impregnable as the rock of Gibraltar, she will be able to close the two entrances to the Gulf of Mexico and even to prevent the free passage of the commerce of the United States over the Bahama banks and through the Florida Channel. The local authorities are believed not to be entirely ignorant 
of the perils which environ them but are regarded as so torpid as not to be competent to understand the extent and immanency of those perils nor the policy by which Great Britain is guided. ${ }^{291}$

Beyond the military and philosophical strategic importance of the island, investment in

Cuba represented an important diversification of collective American economic development and

personal opportunity. American plantation owners, machinists (maquistadores), travelers, and

political thinkers viewed the island as a new frontier of exploitable business relationships. The

British simultaneously engaged in their own debate over capitalism and the comparative costs of

Jamaican and Cuban production and consumption. ${ }^{292}$ Both situations speak to a decidedly

${ }^{291}$ British House of Commons, "Correspondence between the United States, Spain, and France, concerning alleged Projects of Conquest and Annexation of the Island of Cuba: Presented to both Houses of Commons, Apr. 1853," (London: Harrison \& Son, 1853), accessed on February 10, 2014, http://books.google.com/books?id=avpCAA AAcAAJ \&lpg =PA44\&ots=lurFR5Zb3t\&dq=With\%20600\%2C000\%20blacks\%20in\%20Cuban \%20and $\% 20800 \% 2$ $\mathrm{C} 000 \% 20 \mathrm{in} \% 20 \mathrm{her} \% 20 \mathrm{West} \% 20$ India $\% 20$ Islands\&pg=PA44\#v=onepage \&q=west $\% 20 \mathrm{india} \% 20$ islands $\& \mathrm{f}=$ false, 44.

${ }^{292}$ British engagement with their own imperial expansion, built upon the ideology of a modernist free labor/trade imperative, drove them in continuous search of political openings through which a robust aggressive foreign policy might yield markets to match Britain's supply and demand. In response to these pressures, Robert Peel's government, after much public demand and political wrangling, repealed the isolationist Corn Laws in 1846 (followed three years later by the abandonment of the Navigation Acts). This repeal was representative of a broader movement towards free trade resting upon the perceived superior economic modernity of free labor. The dismantling, or at least reconfiguring of the mercantilist system throughout the 1840 s ushered in an era of relaxation of regulations and restrictions that allowed capital, notably that of the British and to a lesser extent the U.S. industrialists, to flow along with goods and workers to frontiers of specialization, speculation, and profit. Yet the corresponding anti-imperialism, extolled by many a fanciful political and beneficent capitalist, failed to materialize in a complementary manner. While the rhetoric that accompanied the free trade movement envisaged regions specializing in producing goods and materials at a comparative advantage, a trade that might engage independent nations' peaceful economy in the efficient exchange of equals, practical policy continued to embrace the physical and political domination of those productive regions of the world that might best offer their competitive advantage to the metropole. Whether that imperialism rested upon the territorial (colony), political (foreign affairs), or physical (slavery), the concept of free trade (and particularly for the British the extolling of free labor to the eventual detriment of slavery) was central to the projection of British and U.S. economic power in the Atlantic world. While the British held a decidedly weightier stance toward India, the U.S. would also come to develop interests outside the Caribbean. The tools of influence and coercion, as much as the hard power of military prowess, all remained at the ready in the great construction project of the modern Atlantic. As the British Foreign Secretary, George Canning, famously wrote, and later codified in the Treaty of Friendship, Commerce and Navigation (1825) with many of the new Spanish American states, "The deed is done, the nail is driven. Spanish America is free and if we do not mismanage our affairs sadly, she is English." Canning set about a robust trade with the new republics and bargained for their support in his anti-slave trade efforts, just as the United States was shrinking from its outreach to the Latin American republics due mainly to the multiracial governance of these nations (notably on display at the PanAmerican Panama and Lima conferences, 1826 and 1847 respectively). Toward the end of his career Canning remarked on the importance of the process, in a remarkable similar if not more economically driven providentially ordained British civilizing process of manifest destiny, noting that the great effort of his governance was “....in obedience to the Creator in promoting and protecting the salutary process of international trade; commerce was the source of blessings to our race, the bond of nations and the first born peace." These were not agreements discussed 
modern approach in the debates over the spread and flow of capital to the budding investment frontiers along with the type of labor that might accompany these investments. These frontiers were not only south of the United States. While American investors held one eye firmly directed toward Cuba, the profits to be realized in the movement of grains, sugar, manufactures, and people invited the other eye to remain firmly fixed on the western United States. Cuban annexation promised to supercharge the still developing Midwest agricultural economy, which sought foreign supply markets in hopes of capitalizing in the Atlantic economy

among equals, of course, as the Latin American republics desperately desired both British recognition and trade. Yet, despite the one-sided nature, the British were not without their needs as well. The incredibly profitable but raw materially needy British manufacturing economy would inevitably draw the peripheral areas toward it. Most-favored nation status did much to help the British think very highly of themselves and their efforts. The British adopted a similarly uplifting conceptualization of their capital efforts in the world as the Americans did to their political efforts. Both efforts, their practitioners believed, would bring the benefits of progress and civilization to the world. The great debate was who would be at the helm of this effort and whether the march of abolition, accompanying the British economic path, would force the United States into ideological surrender on the question of the institution's continuance in the face of evaporating market share. This competition placed the U.S. and British, along with the Spanish and French - the latter of the two which was engaged in their own intense battle on the South American continent with the British for market saturation - in often antagonistic economic courts. These positionings simultaneously encouraged a tepid, if not always consistent, diplomatic consensus in the Caribbean. Beyond Cuba, the French and British, engaged as they were in South America, feared a chokehold on shipping lanes if Cuba lay in American hands; the island acting like a gigantic tollbooth at the mouth of the Caribbean. The limited reach of the U.S. Navy prevented any real enforcement of the Monroe Doctrine throughout the hemisphere, but in their economic partnerships, the British were quick to realize a strike in the Caribbean would be damaging enough and well within the naval capacity of the United States. However, as much as international sabers rattled in the Caribbean, there was too much at stake in the Atlantic world for the talk to amount to much international action. Edward Rhodes, ed., Presence, Prevention, and Persuasion: A Historical Analysis of Military Force and Political Influence (New York: Lexington Books, 2004), Canning quote on 140; Laura A. White, "The United States in the 1850's as Seen by British Consuls," The Mississippi Valley Historical Review 19, no. 4 (March 1933), 509-536; Richard W. Van Alstyne, "American Filibustering and the British Navy: A Caribbean Analogue of Mediterranean Piracy," The American Journal of International Law 32, no. 1 (January 1938), 138-142; John Vincent Nye, "The Myth of FreeTrade Britain and Fortress France: Tariffs and Trade in the Nineteenth Century," The Journal of Economic History 51, no. 1 (March 1991), 23-46; Douglas Irwin, "Free Trade and Protection in Nineteenth Century Britain and France Revisited: A Comment on Nye," The Journal of Economic History 53, no. 1 (March 1993), 146-152; Cheryl Schonhardt-Bailey, "Lessons in Lobbying for Free Trade in $19^{\text {th }}$-Century Britain: To Concentrate or Not," The American Political Science Review 85, no. 1 (March 1991), 37-58; Jay Sexton, The Monroe Doctrine: Empire and Nation in Nineteenth-Century America (New York: Macmillan 2011); Victor Bulmer-Thomas, ed., Britain and Latin America: A Changing Relationship (Cambridge: Cambridge University Press, 1989), Part I; William W. Kaufmann, British Policy and the Independence of Latin America, 1804-1828 (London: Taylor \& Francis, 1967); H. W. V. Temperley, "The Later American Policy of George Canning," American Historical Review 11 (Summer 1906), 779797 and The Foreign Policy of Canning 1822-1827 (New York: Frank Cass \& co., 1966); C.A. Bayly, Imperial Meridian - Britain's New Imperial Age 1780-1830 (London: Routledge, 1993); J. Gallagher and R. Robinson, "The Imperialism of Free Trade," The Economic History Review 6 (1953), 1-15. On the impact of modern Friendship, Commerce, and Navigation treaties see John F. Coyle, "The Treaty of Friendship, Commerce, and Navigation in the Modern Era," Columbia Journal of Transnational Law 51 (Fall 2013), 302-359. 
like their brethren, Southern cotton producers. James DeBow, in his popular eponymous magazine of the day, fused economics and manifest destiny perhaps a bit clearer than most. "We have a destiny to perform, 'a manifest destiny' over all Mexico, over South America, over the West Indies and Canada. The Sandwich Islands are as necessary to our eastern, as are the isles of the Gulf to our western commerce." Other observers put it a bit less lofty and focused on the hard born truths of commodity and capital flows coupled with the ever-annoying tariffs imposed on American imports to Cuba. The New Orleans Crescent, a pro-annexation/pro-López paper remarked, "The trade between Cuban and the West would be increased ten-fold. Just think when the duty of ten dollars on each barrel of flour is taken off how much greater will be the consumption! The independence of Cuba will be felt on the threshing floors of Minnesota." The New Orleans Delta, looking forward to a trans-Panamanian railroad and United States government investments in steam service on the Gulf of Mexico and the Pacific, remained energized about the reinvigoration of New Orleans helped by Pacific trade. "The Pacific is about to pour her cornucopia into America. It behooves our merchants, whose intelligence, public spirit and enterprise are unsurpassed in the nation, to exert themselves to secure a full share of the enriching harvest to the Emporium of the Southwest. ${ }^{293}$ Cuba was the foundation of a new westward expansion of Northern mercantile capital investment resting on the strength of a 'new' market enjoying tariff free consumption. The continued strength of Northern banking and industry relied on promised returns of investment in western agricultural development that were in turn reliant upon unfettered trade with Cuba. Not lost on the Crescent and New Orleans' mercantile promoters of annexation was the reinvigoration that southern trade routes promised

\footnotetext{
${ }^{293}$ James Dunwoody DeBow, “The Late Cuba Expedition,” DeBow's Review, 9 (1850), 167. New Orleans Crescent, May 24, 1850. The New Orleans Delta, September 17, 1849.
} 
their city as well. ${ }^{294}$

The result of annexationary filibustering in Cuba should be introduced at the onset,

Narciso López along with 173 other filibusterers, out of about 400, died on this last filibuster of

August $1851 .^{295}$ These deaths, particularly of Americans in Cuba, surprised many, as numerous

\begin{abstract}
${ }^{294}$ This bubble economy of Northern investment in western agricultural popped with the failure to eliminate tariffs after annexation's collapse. The resultant reduction in trade with Cuba, and other international markets, coupled with overproduction following a decade of Northern investment in western agriculture, led to the financial Panic of 1857. New Orleans looms large in the encouragement of filibustering and as instructive participant in the economic shifts of the 1840s and 1850s that caused much anxiety in the Southern economic mind. The city worked so hard on behalf of annexation because it saw in Cuba the possibility of regaining its substantial role in the U.S. economy. Merchants in the city were continuously searching for new markets and, in the shadows of their dependence on moving cotton and slaves, they desperately sought to diversify the basis of their wealth. None of this is to suggest that New Orleans suffered any sort of sudden economic collapse, but rather to assert that the slow divestment of massive amounts of investment capital and carrying capacity reduced the city's financial houses to mere subsidiaries of eastern capital. These declining fortunes whetted an already familiar appetite with the city's promoters. The Caribbean was a known entity with traditional ties auguring well for an economic amalgamation. New Orleans business and capital men were enthusiastic supporters of López and, later, John Quitman. The hope sprang forward that proximity to Cuba would keep labor and shipping costs down and standing trade ties with the island would facilitate the process of scaling trade after annexation. The undercapitalization of New Orleans banks would not be an impediment to growing already existing trade. New Orleans suffered in the middle decades of the 1800s from a loss of logistical dominance, long-enjoyed by the north/south movement of trade along the Mississippi, to the exploding east/west trade along rail lines dominated by Atlantic coast cities. Higher labor and insurance costs on the wharves, a holdover from happier times, further limited the prospects. By 1850, New Orleans' percentage of Midwestern trade cratered and with it a sense of desperation enveloped the business community of the city. In response, the city's press and elite moved to capitalize on the filibustering excitement. City leaders formed Annexation Committees to raise money and soldiers for Narciso López. Cuba promised to turn the economic tide for the city and replace lost Midwestern and Southern trade receipts. While the slave trade continued to pour money into the city, those proceeds largely drained off to the ledger sheets of distant banks. Local laborers, of blue and whitecollar stripe, and local business gained only a glancing accommodation for services provided. Men of standing joined by men of serving rubbed elbows in service to the idea of filibustering at massive gatherings, parades, and fundraisers. Whigs and Democrats, politicians, editors, and lawyers came together on annexation committees to raise money and craft the narrative expanding out from the city's pro-annexation press. Chester Stanley, "Urban New Orleans and the Cuban question during the Lopez Expeditions of 1849-1851: A Local Study in 'Manifest Destiny,' (MA thesis, LSU Agricultural and Mining College, 1936); Judith Kelleher Schafer, Becoming Free, Remaining Free: Manumission and Enslavement in New Orleans, 1846-1862 (Baton Rouge: Louisiana State University Press, 2003); Jennifer M. Spear, Race, Sex, and Social Order in Early New Orleans (Baltimore: JHU Press, 2010); Eric Arnesen, Waterfront Workers of New Orleans: Race, Class, and Politics 1863-1923, (Chicago: University of Illinois 1994); Robert Reinders, End of an Era: New Orleans, 1850-1860 (New York: Pelican Publishing, 1999); Caryn Cosse Bell, Revolution, Romanticism, and the Afro-Creole Protest Tradition in Louisiana, 1718-1868 (Baton Rouge: LSU Press, 2004); Walter Johnson, Soul By Soul: Life Inside the Antebellum Slave Market (Boston: Harvard University Press, 2009); Arnold R. Hirsch, Joseph Logsdon, eds., Creole New Orleans: Race and Americanization (Baton Rouge: LSU Press, 1992); Gwendolyn Midlo Hall, Africans in Colonial Louisiana: The Development of Afro-Creole Culture in the Eighteenth Century (Baton Rouge: LSU Press, 1995); Kimberly S. Hanger, Bounded Lives, Bounded Places: Free Black Society in Colonial New Orleans, 1769-1803 (Durham: Duke University Press, 1997). David Pletcher, The Diplomacy of Annexation: Texas, Oregon and the Mexican War (Columbia: University of Missouri Press, 1973).

${ }^{295}$ After his arrival in the United States, Narciso López launched three filibusters to Cuba. As soon as he arrived in the U.S. in 1848, López made contact with the American press and others interested in supporting his efforts including the New York Consejo Cubana, frustrated as they were in their failure to find a leader for the military side
\end{abstract}


of their cause. For the 1849 expedition he choose Round Island, Mississippi as the disembarking muster point with three ships chartered (two in New York and one in New Orleans) to transport 600 volunteers. President Zachary Taylor's government took swift action against the mission with the U.S. Navy successfully blockading and waiting out the soldiers on Round Island. In the wake of this failure and as a result of a rift with the New York group, López moved his base of operations southward, first to Washington D.C., then Savannah and eventually New Orleans. The southern move brought the issue of slavery into greater focus for supporters and opponents alike. He set about attracting influential Southern policy and military leaders. Such luminaries as Jefferson Davis and Robert E. Lee rebuffed López's leadership offers. He was able to entice Mississippi's Governor, John Quitman, to the cause but his support was only to materialize after a successful landing by López. The second filibuster of around 500 men set out for Cuban in 1850, but when local support failed to materialize, after López's landing at Cardenas, and with much of the local population joining the Spanish against him, López quickly retreated to Key West. The general and his men scattered quickly, only about 30 minutes ahead of U.S. ships pursuing them. López licked his wounds in Jacksonville where he was arrested and brought to New Orleans to stand trial for violations of the Neutrality Act of 1818. Numerous other men received indictments in the undertaking as well, including Governor Quitman which forced him to resign from his office. All the accused faced no punishment as the overwhelmingly pro-annexation population of New Orleans fielded jurors that refused to convict. López, perhaps a bit too buoyed by the trials' results, began planning another expedition for the summer of 1851. In August 1851, López once again departed for Cuba with several hundred men (mostly Americans, Hungarians, and Germans). Of the 400 hundred men that accompanied López on the last filibuster, about 200 died at Spanish hands, either on the battle field or in front of a firing squad. Fifty-one men, died outside Castle Atares at Havana on the morning of August 16, 1851 in full view of approximately three thousand people gathered for the occasion of their execution by firing squad. The Spanish captured these men, under the military direction of William L. Crittenden, the previous evening as they attempted to flee Bahia Honda, Cuba for Key West. Crittenden, his unit now only 50 of the original 120 he commanded when they separated from the main landing force, decided to beat a hasty retreat as it became apparent that there would be no reinforcements nor any support coming from the Cuban people. The main force, under the direction of López, continued their march toward the interior and the town of Las Posas where López hoped support might be more forthcoming and time for drilling and disciplining might be had. Both leaders found no support and the countryside almost deserted, as the Spanish army anticipating the filibusters' landing had cleared most of the residents out and set about harassing both filibustering divisions. The filibusterers confronted this disastrous situation due to a variety of conceptual reasons existing long before their landing but exacerbated nonetheless by López's poor strategic decisions. López split the group of approximately 400 filibusters that landed with him at El Morrillo around 4 a.m. on August 12 almost immediately upon arrival. He left about 120 soldiers under Crittenden's command at El Morrillo to guard supplies with the intention of reuniting the forces at the inland town of Las Posas. Upon arrival at Las Posas on August 13, López realized Spanish troops were much closer than anticipated, thanks to their superior reconnaissance, and that his men would have to drill elsewhere. However, López, concerned that too hasty of a retreat from Las Posas threatened to permanently cut off his force from Crittenden's, sent word that the American should make for Las Posas at one. Crittenden, given to a sense of his superior command in comparison to López's and not wanting to abandon the army's supplies, refused to gather his troops quickly and lingered at his position of Tabla de Agua halfway between El Morrillo and Las Posas. Over breakfast on the morning of August 13 they faced a surprise attack by Spanish forces. While they beat this attack back, Crittenden, flush with victory in the skirmish, left with an even smaller detachment in pursuit of the Spanish. Crittenden, moving into the jungle with about 80 men, left the remainder of his men under the control of J.A. Kelly. However, the folly of Crittenden's decision soon presented itself, as a much larger Spanish force lay in wait and isolated Crittenden's force from that of Kelly. Fearing his exposed position, but prior to knowing of Crittenden's fate, Kelly moved his forces quickly toward Las Posas and rejoined López. Unfortunately for López, Kelly's reinforcements were insubstantial in the face of the overwhelming 800-man strong Spanish force that engaged López at Las Posas while Crittenden had been battling his own Spanish troops in and around Tabla de Agua. Adding to the growing desperation of the day was Crittenden's inability to end-run Spanish forces and rejoin with López's division. While López held off the Spanish army, he also decided that the situation in Las Posas was untenable and after hearing no news of Crittenden's forces from his scouts decided to move from the town. López moved his troops deeper into the mountains and adopted a strategy of constant movement in hopes of finding ongoing uprisings, encouraging new uprisings, or providentially happening upon other American forces which would have had no real reason to be there but so were the desperate thoughts of the López and his men. López's force dwindled to 250 ill-equipped, ill-provisioned, and aimlessly wandering men. These men put up a valiant effort outside of Cafetal de Frias, a plantation once owned by López's in-laws where they stopped for rest and food, but were eventually attacked by about 900 Spanish soldiers. Their 
press outlets and individuals of various stations prophesied an easy victory. Some papers even printed headlines of López's great victory over the Spanish while he was desperately eluding capture in the Cuban jungle. ${ }^{296}$ The public reaction to the great disappointment of the mission

most momentary success came with the killing of the Spanish commander of forces, General Enna. However, López's troops were unwilling to pursue the retreating Spanish and missed an opportunity. López's men went on to wander in the mountains, the force melting into the countryside as deserters left regularly, for another week. As they made their way to the town of San Cristobal, where supporters of the filibusters supposed resided (although this story surely was exaggerated by López), the Spanish army finished off the emaciated, musketless, shoeless filibustering force outside the city with only a few, including López, escaping into the brush. On August 26, Captain General Concha issued a general amnesty from execution for those in López's force that surrendered. López surrendered to a different fate on August 28, as he was excluded from the general amnesty order and had longoperated under a dead sentence issued by Concha. López also stood unaware at the time of his capture that Crittenden's men were already dead more than two weeks, captured on four small boats disembarking from El Morrillo on August 14 after failing to reunite with López's men. The Spanish garroted López for public eyes on September 1, 1851. Tom Chaffin, Fatal Glory: Narciso López and the First Clandestine U.S. War Against Cuba (Baton Rouge: LSU Press, 2003), is the most comprehensive examination of the daily activities, in both the U.S. and Cuba, of the filibustering community. His chronological approach traces the events over a three year period and is exhaustively detailed in its timeline and presentation. Robert May, The Southern Dream of a Caribbean Empire, 1854-1861 (Baton Rouge: LSU Press, 1973); Rodrigo Lazo, Writing to Cuba: Filibustering and Cuban Exiles in the United States: Filibustering and Cuban Exiles in the United States (Chapel Hill: UNC Press, 2005); Antonio de la Cova, "Filibusters and Freemasons: The Sworn Obligation," Journal of the Early Republic 17, no. 1 (Spring 1997), 95-120, and Cuban Confederate Colonel: The Life of Ambrosio Jose Gonzales (Columbia: University of South Carolina Press, 2003); Gerald E. Poyo, With All, and for the Good of All: The Emergence of Popular Nationalism in the Cuban Communities of the United States, 1848-1898 (Durham: Duke University Press, 1989); United States Department of State, Correspondence on the López Expedition to Cuba, 1849-1851 (General Records of the Department of State, Record Group 59 catalogued by Antonio de la Cova, accessed on March 16, 2015, http://www.latinamericanstudies.org/filibusters/Lopez-expedition-correspondence-RG-59.pdf); Richard W. Leopold, The Growth of American Foreign Policy: A History (New York: Knopf, 1962), 36-40; Thomas R. Hietala, Manifest Design: American Exceptionalism and Empire (Ithaca: Cornell University Press, 2003); Gretchen Murphy, Hemispheric Imaginings: The Monroe Doctrine and Narratives of U.S. Empire (Durham: Duke University Press, 2005). On U.S. neutrality laws and the Neutrality Act of 1818 see Charles Ghequiere Fenwick, The Neutrality Laws of the United States (New York: Carnegie Endowment for International Peace, 1913);

${ }^{296}$ A rioting mob in New Orleans on August 21, 1851 focused its anger on the anti-filibustering Cuban newspaper La Unión for allegedly being bribed by the Spanish Consul J.Y. Laborde, to construct false reports detailing the failure of López's last filibuster. As a result, residents of New Orleans burned the newspaper's offices, the Spanish Consulate, and Spanish businesses, although the reports of bribery were untrue and the reports of failure remained correct. Yet, the emotion was not just as a result of the particularly devastating defeat. López's previous filibuster to Cuba in 1850 was rife with a similar overconfidence of his supporters in the press. Moses Beach's Sun, so sure of López's victory in his second filibustering attempt, thanks largely to reported revolts on the island, printed victory headlines before the General's landing at Cárdenas, "The New York Sun is in receipt of the GLOROIOUS NEWS OF THE SUCCESSFUL LANDING OF THE CUBAN PATRIOTS, AND THE COMMENCEMENT OF A GENERAL REVOLUTION FOR FREEDOM THROUGHOUT THE ISLAND OF CUBA! Liberty has triumphed! CUBA IS FREE!" (New York Sun 5/241850) Beach was taken to task the next day by the less that amused and even less supportive New York Herald who pointed out that the Sun had also published the same day as its headline, a wire report about the retreat of López's forces. "It is more than sickening - it is criminal, to see such stuff palmed upon an intelligent community, in the face of the simple facts recorded in our columns, and received by every journal yesterday, from Cuba. Nothing can save the expedition from utter and overwhelming defeat. The contrivers and supporters of the silly expedition are guilty of piracy and murder, and ought to be punished accordingly," (New York Herald 5/25/1850). 
was not surprising. New Orleans burned the afternoon news reached that city of the death of,

among 50 others, William Crittenden. ${ }^{297}$ Crittenden and his men, in the hours after their capture,

${ }^{297}$ The great lament for Crittenden, his charges, many of them Kentuckians, and the failure of the filibuster came largely as a result of the reprinting of Crittenden's letter to his uncle John in various newspapers along with the description by many of the same papers of the scene of his execution. Stories told of a bloodthirsty crowd hacking the bodies of the executed Americans and carrying their body parts as souvenirs. The Louisiana Courier (9/1/1851) reported, undoubtedly apocryphal, "One of the waiters at a Havana barroom showed to everybody proof of the glorious act he had performed, the testicles of one of the victims, which he had cut." La Unión burned on August $21^{\text {st }}$ largely due to its denial of the Crittenden massacre along with the belief that there were Spanish spies on the docks in New Orleans that must have tipped off the Spanish garrison at Havana to the arrival of the filibuster. $L a$ Union, alternatively named La Hablador and La Patria, existed as a thorn in the side of the pro-annexation press and took up the criticism in the Spanish press early than just about another other Cuban-American publication. The paper's editors, E. Juan Gómez and Victoriano Alemán, were long-time critics of U.S. efforts in Mexico and shifted that anti-expansionism to the paper's anti-annexations. The editors were often at odds with the vehemently proannexation New Orleans press and missed no opportunity to heap scorn on their competitors and fanciful filibusterers. Although the paper was certainly not pro-Spanish like the New York paper La Cronica, that was contemptuous of annexation for entirely different reasons. Typical of La Union critiques was one published a day before its offices came under attack and burned to the ground at the hands of an angry mob that ransacked Cuban run business, including the Consulate, the day after William Crittenden was killed in Havana. "Our language is mild when compared to the harsh and violent style of several Northern newspapers but perhaps it sounds harsh to the ears of the Filibusters on account of its truthfulness and because it comes from a source that looks like Spanish. We have just as much right as any other citizen of the United States to censure and criticize whatever we deem deserving of our censure and criticism. In no other country has the press such an influence and at the same time is so wretchedly conducted and its influence so abused as this." Tom Reilly, "A Spanish-Language Voice of Dissent in Antebellum New Orleans." Louisiana History: The Journal of the Louisiana Historical Association 23, No. 4 (Autumn 1982), 325-339 (quote on 337-338); Richard Tansey, "Southern Expansionism: Urban Interests in the Cuban Filibusters," Plantation Society in the Americas 1 (June 1979), 227-251. Rodrigo Lazo discuses La Cronica in Writing to Cuba, chapter 2. In addition, the perception that the U.S. representative in Cuba, Allen F. Owen, did nothing to stop the executions raised anger. Owen, so criticized, took to the Washington Republic (9/24/1851-Reprinted in the New York Times) to defend himself in an open letter proclaiming that he had neither the time nor power to intervene. "The charge of indifference to the dreadful condition of such a number of men, the bitterest enemy I have on earth will not believe... if it were allowed on such an occasion, I would most solemnly declare before God that, in my judgment, at the time and under the circumstances, it was not in my power to have an interview with the prisoners or to have done anything on their behalf." This effort produced a vicious condemnation by John Kelly, one of López's filibusters, who accused Owen of cowardice and treachery, "This (Owen's defense) is the most perfect collection of falsehood I ever met with, and is only equaled in absurdity by the audacity of the man in thus attempting to justify his conduct through the American press. Mr. Owen's conduct, I should think he was more in dread of getting in prison himself than anxious to get others out. The Governor General exercises great influence over cowardly wretches like Allen F. Owen, no matter what country they may hail from. Hence I account, in a great measure, for his neglect of duty in permitting the Americans to be shot" (New York Times, 10/28/51). Crittenden's purported last words upon refusing to kneel with his back to the firing squad, "I kneel to no one other than God," prompted an outpouring of emotion, including poems by Mary E. Wilson ("A Kentuckian Kneels to None but God") and Laura Lorimor's ("Death of Crittenden"). Representative of the emotion was this stanza "They bade the proud chief of that band/ Kneel low when the death volley came/And, bowed on that sun-guarded strand/Pour forth his high spirit of flame; Deep and haughty arose his firm tone/Unchecked by surroundings of woe/“I kneel to high heaven alone/And ne'er tum my back on the foe I!" The scene of execution of Crittenden and his men is gruesomely retold in a compendium of documents and narrative from, Anderson C. Quisenberry, López's Expeditions to Cuba 1850 and 1851, (Louisville: John Morton \& Co., 1906), poems quoted on 138-139. There is some evidence that points to the possible reinterpretation of Col. Theodore O'Hara's poem "Bivouac of the Dead," (https://www.uky.edu/Kentucky Culture/bivouac.html) to honor those killed on López's last filibuster. O'Hara, a veteran of the Mexican war, purportedly wrote the poem to honor fallen Kentuckian servicemen after the battle of Buena Vista in 1847. However, the poem was commonly rewritten in the years after its publication and appears to have been in 1850 by 
saw the filibustering effort more transparently than anyone else had in the preceding three years.

Crittenden, the nephew of the then Attorney General John J. Crittenden, composed two letters

prior to his execution. Both of these letters assessed the efforts of annexation's supporters at the

massive public relations campaign waged over the previous three years as well as the nature of

López as a commander. In his briefer, yet more direct letter, Crittenden lamented his present

condition.

Dear Uncle:

In a few minutes some fifty of us will be shot. We came here with López. You will do me the justice to believe that my motives were good. I was deceived by López. He, as well as the public press, assured me that the island was in a state of prosperous revolution. I am commanded to finish writing at once. I will die like a man. ${ }^{298}$

the Frankfort Yeoman (according to the New York Times, http://query.nytimes.com/mem/archivefree/pdf?_r=1\&res=9F06E4DD1039E733 A25752C1A96E9C946197D6CF). O'Hara was a veteran of the López expeditions, suffering a severe injury during the Cardenas mission of 1850. He supported John Quitman's efforts as well, however when they failed he rejoined the U.S. military. Some suggest he reworked the poem again after 1851 in honor of his fallen Kentucky brethren.

${ }^{298}$ Many of the letters reprinted by Quisenberry echo Crittenden's assessment. Representative among the sentiments of the foot soldiers in Crittenden's charge was the following in a letter from a Private Gilman: "HAVANA, ON BOARD OF MAN-OF-WAR, 8 o'clock a.m., August 16, 1851. My dear friends: About fifty of us, Colonel Crittenden's command, were taken prisoners yesterday; have not received our sentence yet, but no doubt we will be shot before sunset. López, the scoundrel, has deceived us; there is no doubt but all those reports about Cubans rising were all trumped up in New Orleans. López took nearly all of his command and deserted us. We were attacked by some five hundred or seven hundred of the Queen's troops on the second day after we landed. Our own gallant Colonel Crittenden did all that any man could do, but we saw we had been deceived, and retreated to the seashore with the intention of getting off to our country, if possible." Another soldier, Honore Vienne echoed the sentiment in his final letter's opening, "Deceived by false visions, I embarked in the expedition to Cuba," quoted in Quisenberry, López's Expeditions to Cuba 1850 and 1851, 134-135. Other critical examinations by veterans of the expedition came to light soon after the filibuster's failure including William Bland's scathing, The Awful Doom of the Traitor or the Terrible Fate of the Deluded and Guilty: A Full Disclosure of the Character and Selfish Designs of General López who Decoyed a Multitude of Our Best and Bravest Citizens to an Awful and Untimely Grave in the Island of Cuba (Cincinnati: HM Rulison, 1852). Most other retellings were fairly laudatory and surprisingly measured, if given to momentary flourishes such as describing filibustering as "the most extraordinary piece of Knight-errantry on record - at least since the days of a certain Spanish Gentlemen dubbed Don Quixote." Most were written by "veterans" of at least one filibuster, so they claimed. Quote from O.D.O.O., The History of the Late expedition to Cuba, (New Orleans: The Office of The Daily Delta, 1850); Richardson Hardy, An Authentic History of the Cuban Expeditions (Cincinnati: Lorenzo Stratton, 1850); Lucy Holcomb Pickens, (writing as H. M. Hardimann), The Free Flag of Cuba; or the Martyrdom of López (New York: DeWitt and Davenport, 1854) and critically explored in Orville Vernon Burton and Georganne B. Burton, The Free Flag of Cuba: the Lost Novel of Lucy Holcombe Pickens (Baton Rouge: LSU Press, 2002). One of the more interesting and seemingly cautionary renderings of the López expeditions was the anonymously authored (yet fictitiously named "Miss Delaplain") A Thrilling and Exciting Account of the Sufferings and Horrible Tortures Inflicted on Mortimer Bowers and Miss Sophia Delaplain, by the Spanish Authorities, for a Supposed Participation with Gen. López in the Invasion of Cuba (Charleston: Barclay and Crosson \& co., 1851). The story, set in New York City (while published in Charleston owing a bit to the broad appeal of filibustering tales), tells of a young woman who falls in love with man, Mortimer Bowers. As he is of the lowly sort Sophie's father compels her to choose love or family. She chooses Bowers and they hop aboard a steamer, interestingly named Henry Clay, ostensibly headed to California but which is in fact heading filibustering 
Annexation's failure, by that point, for Crittenden and his fellow soldiers was abundantly clear.

Yet, the residents of New Orleans and numerous other cities throughout the United States had a

completely irrational view on the prospects for annexation's success.

This irrationality of annexation's promise existed for many Cubans as well. Protection

from the United States promised Cuba a more independent economic and political survival. The

imagining of this Cuban proto-nationality was the source of vigorous debate in the expatriate

community and engaged an officially censored, but no less insightful, domestic group in Cuba.

\begin{abstract}
in Cuba. This was a common occurrence of the day that gave both filibuster and sympathetic port authorities legal cover. The passengers, duped by filibusterers and hopeful of augmentation of their numbers, connive a plot to appear to accept enlistment in order to receive weapons only to turn on the crew off the coast of Cuba. The ensuing battle leaves both sides depleted and the ringleaders, Bowers and Delaplain adrift off the Cuban coast. The Spanish authorities pick them up and, after accusing Bowers of being a spy, draw and quarter him in front of his love. She is able to escape to tell her story with the help of the wife of Don Martin, the couple's Spanish torturer. While much of the lure of filibustering for young men was a reinvigoration of their moribund masculinity, A Thrilling and Exciting Account, published at the height of the López excitement, and prior to his death, warned of filibustering's threat to that masculinity (death) and undermining of respectable femininity (rejection of family and inheritance). The book reminded many that although liberation was a laudable goal, failure might result in enslavement and undermined white American racial stock, a trope seemingly on loan from the debate over the 'All Mexico' push five years earlier. Of great interest on the issue of purported mistaken identity was the matter of López's final filibuster's leaving from New Orleans. As the Pampero steamed out in the early hours of August 4, 1851, the Port Collector was not stationed properly at his post to make the necessary inquiries as to prevent López and his men from leaving the port of New Orleans. The U.S. government made a robust indictment of the Collector of the Port at New Orleans, William Freret. In not so many words, the Treasury Department accused Ferret, due to his annexation sympathies, of shirking his duties to stop the filibusterers leaving the port that morning. This was a long-standing problem on the part of the federal government. Although the Neutrality Act of 1818 had made illegal the kinds of filibustering activities conducted throughout the 1850 s, the uneven enforcement, willful refusal to stop filibusters on the part of military men and bureaucrats alike, and the chicanery of the filibusterers themselves, many claiming they were prospectors headed for California, made prevention impossible. Robert May investigates this phenomenon as it affected the U.S. military in "Young American Males and Filibustering in The Age of Manifest Destiny: The United States Army as a Cultural Mirror," The Journal of American History 78, no. 3 (December 1991), 857-886. "At first glance, the army would seem a most unlikely institution to foster filibustering. The service had a history of antifilibustering responsibilities back to the Washington administration, and the prevention of filibusters emerged as one of the army's most important peacetime mission by the late 1830s. One might well expect the nation's officers and enlisted men to despise their filibuster antagonists. Yet sympathy for filibustering infiltrated army ranks. Some soldiers even resigned commissions and deserted ranks to join filibustering expeditions. While it would be misleading to brush the whole army with the stain of filibustering because of the derelictions and sentiments of a portion of its personnel, it would also be wrong to exempt the United States soldiers from filibustering's spell. The army held up a cultural mirror to its nation," 862 - 863. The records of the Treasury/Freret conflict are found in Ferret's published work in defense of his actions, Correspondence between the Treasury Department in Relations to the Cuba Expedition and William Freret, Late Collector, (New Orleans: Alex Levy \& co., 1851). Roy Emerson Curtis, "The Law of Hostile Military Expeditions as Applied by the United States," The American Journal of International Law 8, no. 1 (January 1914), 1-37, focuses on the intricate international legal issues raised by filibustering.
\end{abstract}


Annexation, by 1848, while beset with pitfalls became the only way forward for most, but decidedly not all, observers of the Cuban intelligentsia thinking about the issue. Despite the near unanimity among elite opinion makers, the majority of Cubans on the island rejected out of hand the entire premise that their elite brethren spilled so much ink and blood over in the intervening decade after La Escalera. The lack of interest shown annexation by common Cubans (enslaved or otherwise) grew further from deep suspicion of Spanish imperial decisions and British/French diplomatic maneuvering. The Cuban people's healthy distrust of elite Cuban creoles displayed itself at the very moment when American interest and confidence in annexation was at its peak. The positioning of common Cubans also stood at great odds with that of the rabidly proannexation common set in the United States.

The speedy rejection of annexation's lure by Cuba's people forced the Cuban creole elite toward a quick reconfiguration of means and ends that, to their credit, they performed with great haste. A new conceptualization of Cuban nationalism, based upon independence (necessitating a multi-class and multi-racial effort) rather than annexation, gripped the conversations in Cuba after the López defeat in 1851 and eventually pulled expatriate discussions away from support for American-led filibustering fully by 1855. Conversely, the failure of the López expeditions, notably his final fateful 1851 effort, had the diametrically opposite effect on the American population. ${ }^{299}$ López's failures, for many Americans, were indicative of simple weaknesses in

\footnotetext{
${ }^{299}$ For example, the Knights of the Golden Circle, formed in Kentucky in 1854, sought to carry annexation's work forward by capturing a circle of territory throughout the Caribbean, South American and Mexico that might be annexed to the United States and incorporated as slave states. In the aftermath of Crittenden's execution and ensuing riots, New Orleans flooded with hooligans and filibusterers begging for transport and action against Cuba to reinforce López and his remaining forces. Newspapers openly called for donations of money and materiel and a 35 member Cuban Committee formed to organize a new and immediate filibuster to Cuba. A mass meeting developed on August 26. 1851 for the purpose of planning the expedition yet all of the excitement fell apart by early September, when on the 4 of that month, news came that López was dead and his men dispersed or imprisoned. This pent up frustration for filibustering does much to explain the popularity of William Walker's expeditions and the Golden Circle's activities later in the decade. Stanley Urban, "New Orleans and the Cuban Question," 90-100; Donald Shaw Frazier, Blood and Treasure: Confederate Empire in the Southwest (College Station: Texas A\&M
} 
planning and demonstrative of too great a reliance upon the Cubans themselves. An editorial in the New York Daily Times summed up the frustration with the Cuban response to López's filibuster. "If the Cubans are really anxious for independence, why did they fight them with the utmost fierceness, from the time they first landed upon their shores? Why did they regard them as robbers and pirates, if they had bespoken their aid as allies and friends?" The loss of American lives on López's final voyage fueled demands for revenge and reinvigorated calls for annexation by conquest not invitation. ${ }^{300}$

Press, 1995); Ollinger Crenshaw, “The Knights of the Golden Circle: The Career of George Bickley," American Historical Review 47, no. 1 (October 1941), 23-50. C.A. Bridges, "The Knights of the Golden Circle: A Filibustering Fantasy," Southwestern Historical Quarterly 44, no. 3 (January 1941), 287-302.

${ }^{300}$ New York Daily Times, September 23, 1851. The rejection of annexation's allure on the island of Cuba demonstrated the shifting sands in the debate over Cuban nationalism. While the rejection of annexation was not complete, there was a new emergent conceptualization of Cuban nationalism that foregrounded a multi-racial independentist instinct that stood at odds with the pro and anti-annexation ideologies best exemplified by the debate between Jose Antonio Saco and Gaspar Betancourt Cisneros. The disagreement between Saco and Betancourt was fundamentally a discussion about the timing, not the inevitability of abolition. While López might have oversold and over invested in the possibility of Cuban supporters joining his forces after they reached Cuba, other more independence minded revolts embroiled the Trinidad and Puerto Príncipe areas almost simultaneously. The declaration of intention promulgated by the rebels in Puerto Príncipe made the shift clear, “...in the ranks of Independence we have to count all the free sons of Cuba, whatever may be the color of their race." This attempt at indigenous revolt was a clear signal of the shift in perspective on the national identity of independence-minded Cubans and the understanding that abolition would be an essential part of the process. Saco, a strong opponent of annexation, represented a racial exclusive conceptualization of Cuba's proto-nationalism, one that had to first deal with the issue of slavery prior to independence. Annexation, from his perspective, did nothing to improve the lot of white Cubans since replacing Spain with the United States allowed the specter of slavery to remain and, in all respects, intensify. Saco constantly warned about the coming demographic dangers inherent in slavery; dangers implicitly accepted by those who continued importation and labor of slaves in Cuba. Saco, like the British, adopted the position that free white labor was the best way forward for Cuba. This impulse did not come first from any particular humanitarian or economic perspective, but rather a solid belief that the African presence, in whatever form, weakened the future Cuban national stock. Free labor might have supplementary benefits such as reduced production costs and greater acceptance of Cuban goods in particularly British ports, but at its heart Saco's program was one of racial purification. Uncooperative Captain Generals, the Spanish Cortes, and many of his fellow creole intellectuals consistently disappointed Saco's racial, economic, and political efforts. Saco, like Domingo Del Monte, was a tireless lobbyist for the implementation of special laws giving Cuban greater self-rule with a direct goal to limit the power of the position of Captain General; a fight that Cubans consistently lost during the 1830s and 1840s. Cuba remained an occupied state with no rights to parliamentary representation, with slavery foisted upon them by the Spanish, and ruled by autocratic Captain Generals - a state remarkably similar, Saco noted, to the one the American colonies complained of in 1776. Del Monte was no friend of annexation as well. "What they (annexationists) will achieve is not annexation, nor liberty...but persecution, firing squads, prisons and disgrace and tem more years of a state of siege and special laws," (Schmidt-Nowara, 31). Like Saco, he favored an imperial solution and opened his literary salon in Havana in the late 1830s to encourage an intellectual working through of these issues. Yet, given his disinclination toward annexation, Saco, doing most of his writing and politicking from Madrid in the annexation period, found the rights and protections enjoyed by Canada in the British empire to be the most becoming opportunity for mimicry, his reasoning resting largely on the "whitening process" he observed throughout the empire. Spain's true sin was encouraging slavery, from which he felt came the need for political 
inequality in the Spanish Empire. "I place the blame squarely on the shoulders of the (Spanish) government, which can and should put an end to the infamous African contraband but which instead tolerates it, give its consent, and even connives by violating treaties and flouting the law, to the scandal of public and private morals," (Opatrny, 45). The moral decay, Saco feared, prevented any attempt toward Cuban independence and a white Cuban republic. As one of his contemporaries, Félix Tanco observed, "While watching our boys and girls at their waltzes and contredanses, who can fail to be struck by how closely their movements mimic those of the Negroes at their gatherings? Who can fail to see that the dancers' steps echo the drums of their Tangos? It is all purely African, and the poor and innocent Negroes, without intending to, and with no other power than that born of the life they lead in relation to us, are taking revenge for the cruel treatment we have inflicted upon them by infecting us with customs and manners that are appropriate to the savages of Africa," (Opatrny, 47). Cubanidad and protection of the concept's whiteness became all-consuming for Saco. In his most direct work on the issues of annexation, "Ideas on the Incorporation of Cuba into The United States," Saco bemoaned the overconfidence his compatriots held toward absorption into the American family and feared the loss of Cubanidad before the concept even took hold. "Without pretending that I shall be able to convert a single Cuban to my own particular point of view, I must for my own part declare that, while aware of the benefits that Cuban would reap by associating itself with those States, I am left with a secret sorrow at the bottom of my heart for the resulting loss of Cuban nationality... we must never forget that the Anglo-Saxon race differs greatly from our own in its origins, language, religions and in its manners and customs; and that since it knows itself to be capable of overwhelming the Cuban population by sheer force of numbers, it must aspire to taking over the political direction of the affairs of Cuba. It will succeed not merely by its numerical strength but equally through its self-appointed role of mentor and protector, far more advanced that we in matters of government," (Opatrny, 50). These racial concerns pushed Saco toward political reconfiguration and removal of slave labor while remaining in the Spanish orbit. The social fear of slavery lead others to embrace annexation and the power of the United States as the surest means of economic and social protection. Saco's perspective put him at odds with many producers in Cuba and many of his fellow intellectuals who, following the articulation of Gaspar Betancourt Cisneros, argued for annexation as the correct path forward. Cisneros (who signed his letters $L a$ Lugareño) argued that political amalgamation was the surest path to both prevent the race war in the immediate future that Saco so feared and to sort out the logistics of the longer term nation/race building project Saco supported. "These believers (annexationists) fall into two classes: one sees in annexation the means of preserving its slaves, and however much they may try to hide the fact, that is their principle aim, if not the only thing that leads them to embrace annexationism. Others find in annexation the possibility of avoiding a sudden liberation of slaves, gaining a breathing space in which to take measures for their own salvation: doubling the white populations perhaps in ten or twenty years, introducing machines, tools, capital, skills, which will improve and replace the present means to work and riches," (Opatrny, 51). For Cisneros, annexation was a carefully developed calculation that embraced U.S. protection, investment, and guidance in the short term for a future that might illuminate itself at a later date. Cisneros also held up Saco's claims to racial purity amongst the creole elite for some ridicule. "What origins!...do not tell me that you desire that nationality for your country! No! Give me Turks, Arabs, Russians. Give me demons, anything but the product of Spaniards, Congos, Mandingas, and not (though luckily the plan has been frustrated) Malays to complete the mosaic of populations, ideas, customs, institutions, habits, and sentiments of degenerate, enslaved men who sing and laugh to the sound of chains, who tolerate their own degradation and vilely prostrate themselves before their masters," (Schmidt-Nowara, 30). Of course the two men's positions, exemplary of the larger Cuban intellectual debate, were not drastically far apart in their desire to establish a national space - making real what had been an imagined community up until that point. The point at which sovereignty was achievable was a distant one for both, with only the paths toward that goal divergent. The intellectual component of Cuban nationalism was the backing half of the more visceral political/military work of compromise in the empire/annexation. That the streams of this nationalistic ideology moved at different speeds should not be surprising. Both Saco and Betancourt assumed that Spain was reluctant toward modernity, certainly in the political sense of the word, and that any nationalism would develop in opposition to traditional Spanish approaches toward the island and toward imperial rule. The push toward that oppositional modernity split them; Betancourt seeing the United States as the means of further modernizing Cuba as relations already had and Saco, on the other hand, advocating accommodation in order to preserve Cuba's racial heritage. Josef Opatrny, US Expansionism and Cuban Annexationism in the 1850s (Prague: Charles University, 1990); Josep M. Fradera and Christopher Schmidt-Nowara, eds., Slavery And Antislavery In Spain's Atlantic Empire (New York: Berghahn Books, 2013); Graciella Cruz Taura, “Annexation and National Identity: Cuba's Mid-Nineteenth-Century Debate," Cuban Studies 27 (1997), 90-109; Rafael Soto Paz, La falsa cubanidad de Saco, Luz y Del Monte (Havana: Editorial Alfa, 1941); Anita Arroyo, Jose Antonio Saco: Su Influencia en la Cultura y en las Ideas Politicas de Cuba (Madrid: Ediciones Universal, 2001); 
If López's frosty August, 1851 welcome at El Morrillo was any indication, the tide on the island had already turned against annexation. While some Cuban support for annexation lingered, the vast majority of Cubans seemed largely ambivalent at best toward American annexation, a feeling demonstrated by the extremely small handful of villagers that turned out to support the López filibusters. ${ }^{301}$ The "common sorts" largely ignored or were maybe just plain confused by López's landing at Cardenas in 1850 and again on his final voyage of 1851 . The massive repression during the Year of the Lash encouraged those AfroCubans and poorer creoles who might have been interested in assisting the expeditions to be perhaps more circumspect in any enthusiasm shown for an under-gunned and disorganized band of ne'er-do-wells. The elite's obsessive concern with social control was not lost on the population, particularly among those whose class and race was the most widely and brutally terrorized in 1844 . The massive movement of Spanish troops to counter the filibusters also kept a tight lid on support as did the growing divergence and mistrust between the common classes and the hacendado elite.

However, despite the clarity of Crittenden and his men on the issue of annexation's hollowness, the majority of Americans did not similarly see the issue. This contradictory result - the clarity of annexation's hollow promises seen from the Cuban perspective confronting an invigorated American recommitment to annexation post-1851 - belies a reality on the island that was much at odds with the image constructed by the American press in the United States. The divisions among Cuban creoles on the island were much deeper than the overwhelming pro-annexation Cuban expatriate perspective on display for American consumption from the early Cuban-

\footnotetext{
Harry Iceland, The Motives of Gaspar Betancourt Cisneros, 1830-1866, for Advocating Cuba's Annexation to the United States (New York: Harper, 1965); Federico Córdova, Gaspar Betancourt Cisneros, el Lugareño (Havana: Editorial Trópico, 1938); John Patrick Leary, "Cuba in the American Imaginary: Literature and National Culture in Cuba and the United States, 1848-1958," (PhD diss., New York University, 2009), chs. 1-2.

${ }^{301}$ As Crittenden put the matter in another, longer letter to a family friend Dr. Lucien Hensley, "During my short sojourn in this island I have not met a single patriot... I am sure that in this part of the island López has no friends," (Quisenberry, 90).
} 
American press. The expatiate community's direct participation in the annexation movement in the United States blinded, even their group, to the profound lack of direction and interest existing on the island.

The competition in Cuban between various groups - autonomistas, guided by the del Monte/Saco group, anexionistas, guided by the American in Cuba John Thrasher and Cuban hacendado Miguel Aldama, and independentistas, a group not all together unified by a single cadre of speakers until the 1860 s and then by the Sociedad Republicana - for dominance in message production clouded the intellectual and social battlefield and prevailed in producing a malaise that limited direction and action. Generally, the autonomistas, under heavy Spanish censorship, gained the upper hand on the island, while the Betancourt wing of the anexionistas held sway in the United States from their New York center (a change of venue necessitated by Thrasher's expulsion from Cuba in 1851). The autonomistas did not come to control the message of Cuba completely of their own doing or even on the strength of their message. The relative prosperity enjoyed by the island's elite, those most in the position to command attention and promulgate their opinions, generally encouraged a conservatism of direction action against the Spanish. The specter of slave revolt was still too strong and the outcomes of annexation too uncertain to encourage pledging of vast fortunes to the undertaking. The natural output for frustration was the push for greater political rights in the empire with a corresponding recognition of the special role Cuba played for Spain. Most important for the consideration of varying strategies for political participation was the recognition on the part of many Cubans that the political and social landscape changed by the mid-1850s. ${ }^{302}$

\footnotetext{
302 Roger Betancourt, “Cuba's Initial attempt at Democracy, 1790-1820: Its Long-Term Consequences,” (paper presented at Cuba Futures International Symposium, Bildner Center New York, April 2011); J. C. M. Ogelsby, “The Cuban Autonomist Movement's Perception of Canada, 1865-1898: Its Implication,” The Americas 48, no. 4 (April 1992), 445-461; Ramiro Guerra y Sánchez, Manual de Historia de Cuba (Havana: Cultural, 1964), $324-339$.
} 
While the 1830s and 1840s witnessed an increase in social dissent, both among whites and blacks in Cuba, - including slave rebellions, government repression, abolition pressures, and military surveillance - the 1850s demonstrated a political shift in Spain that softened the metropole's approach toward governance. This shift occurred more by circumstance than absolute design. Most notably, Captain Generals changed their approach to governance. Their rigidity of doctrine, encouraged by the unrest seen during La Escalera, and their repressive tactics migrated to a more consensual form of rule, particularly as they came to understand the real threats of annexation and rebellion by the 1850s. The use of the illegal slave trade for their own gains along with their constant threat of employing the enslaved as soldiers in the event of revolution constantly angered creoles and were practices, that while not totally abandoned, moved underground. The removal of Captain General Pezuela, a man on the brink of abolishing slavery on the island, his replacing with returning pro-slavery advocate José Gutiérrez de la Concha, and concessions given to the Cuban elite precipitated much more amenable creole elite reactions in the post-1854 period. In addition, the Carlist wars, pitting constitutionalists and absolutist forces against each other in Spain and the increasing participation of Britain and France in the internal affairs of Spain distracted homeland rule away from the island. The return of the Espartero government in Spain facilitated a softening of the Spanish grip on the island thereby allowing Captain Generals more flexibility in policy implementation. A moderate Spanish government offered hacendados the hope of more stable economic and political opportunities to stave off international competition from beet sugar, lower slave prices, and rationalize/lower tariffs. While annexationism gripped the insular circles of the Club de la 
Habana, its pull was never sufficient to motivate the totality of planters on the island and even fewer common Cubans. ${ }^{303}$

The editors of the United States-based La Verdad, led by Cisneros and funded by and printed on presses of Moses Beach, set about counteracting the autonomista influence that threatened Cuban-American unity on the annexationist effort. The public and direct effort taken by La Verdad and Cisneros to counter Saco's vision demonstrated to a great degree the lack of strength the annexationist cause held in Cuba. In almost pleading or at least self-convincing tones La Verdad's editors' set about countering Saco's recrimination of annexation. Their Réplica de don José A. Saco a los anexionistas que han impugnado sus ideas sobre la incorporación de Cuba en los Estado Unidos reads like a conservative manifesto of discreet and non-confrontational transfer. "The annexationist party is unified in its motives for seeking incorporation into the United States. Some expect more, others less, in terms of realizing individual interests. The majority, however, see it as a political change which will secure their slave property. Others see it as a means of ending Spanish domination in a non-violent and gradual way." 304 Yet, Saco's perspective was not that far removed from the annexationists, who also feared slave revolt and embraced a shift to free labor. Saco's racial views pushed him to embrace an even more strident message as it related to African blood, free labor, and Cuba's future. "It is exceedingly clear that what I desire passionately, not by violent or revolutionary means, but calmly and peacefully, is the reduction, the extinction, if it were possible, of the black

\footnotetext{
${ }^{303}$ Charles S. Esdaile, Spain in the Liberal Age: From Constitution to Civil War, 1808-1939 (New York: Wiley, 2000), 70-100; Hugh Thomas, Cuba, Or, The Pursuit of Freedom, (New York: Da Capo Press, 1998) 1-90. Luis Martínez-Fernández, Fighting Slavery in the Caribbean: The Life and Times of a British Family in Nineteenthcentury Havana, (New York: M.E. Sharpe, 1998), 120-150. Pezuela set about purging peninsulares conspiring in the illegal slave trade, proposed importing free African apprentice labor, offered freedom to all slaves that arrived in Cuba after 1820, and asserted most onerously for hacendados the right for his officers to search plantations and free slaves not properly registered. His plan engendered so much resentment mainly due to the fear that increased African migration, of any type, would only worsen the "Africanization" problem that so consumed creoles. 304 “A Series of Articles on the Cuban Question," La Verdad, March 1, 1849.
} 
race; and I desire it because on the American continent it can turn out to be the most powerful weapon for bringing about the ruin of our island." 305

While the slavery debate undergirded the entirety of the annexation discussion, the discussion did not break neatly into antagonistic sides. The Cuban voices of immediate abolition were few and largely drowned out by the more complex discussion over gradual emancipation, repatriation of the enslaved to the African continent, and replacement for lost labor found in increased migration from Europe, China, India, and the United States. The strongest voices supportive of annexation argued their perspective on slavery with little ambiguity - the institution must be preserved in the short term and the continued Spanish presence actively threatened social stability on the island by intimating that slavery's continuance was always dependent on colonial capriciousness. As La Verdad argued; "We do not wish, nor are we even able to think about slow and gradual emancipation, while Cuba and her sons depend on Spain and are subject to the vacillations, narrowness, immorality and rapaciousness of the Spanish government... our patriotic conscience obligates us to present Cuba as a model worthy of imitation in such delicate matters, to the government of the United States."306 The Cuban sugar elite and a large number of those in the expatriate community believed that the stability of Cuban society, bound as it was in their minds to the preservation of slavery, could only be protected, in the wake of British abolitionism in the Caribbean, with separation from Spain and subsequent connection to the United States. Cubans feared their own unleashing of a revolution against Spain that, if not properly and widely supported by the island's white population, could quickly follow the trajectory of Haiti. In the aftermath of an uncontrolled rebellion many creole politicians and writers feared not only the destruction of their plantations and the expulsion of all

\footnotetext{
305 Saco, Contra la anexión, (Havana: Libreria Cervantes, 1928), 82

${ }^{306}$ Editors of La Verdad, "Cuestión negrera de la Isla de Cuba,” (New York: La Verdad, 1851), 6.
} 
whites from Cuba, but also, in the eyes of even anti-annexationists like José Antonio Saco, "the complete destruction of the Cuban race." ${ }^{307}$ As the Haitian example before it, Cuban revolution could have a devastating end for white Creoles or at best an ambivalent future of political and economic turmoil as exampled by the multi-racial Colombian political landscape. Yet despite these fears, there were some who doubted annexation as a long-term solution.

While there was almost universal acceptance of slavery's worth in the short-term aftermath of a break from Spain, many looked at this liminal period as potentially fraught with danger. Pro-annexation Cubans, both in the United States and in Cuba, wondered what might become of the island if the Americans' debates over slavery moved to a more dangerous plane and if Cuban slavery became the center point of that debate. Skeptics were wary of the uneasy peace, built upon economic strength, between political and moral factions in the United States. They feared that should that peace become more militarized, similar repercussions of uncontrolled revolution might befall the United States. The reality of slavery serving so important a part of the Cuban conceptualization of their economy and social stability drove many to fear that the issue of Cuban annexation might be the paradoxical wedge that threatened to drive apart American political factions. The failure of annexation's full-fruition most directly threatened Cubans who would remain alone in the midst of their slaves and unprotected from slave revolt by the departed Spanish and the failed Americans. Therefore, leading annexationists argued in increasingly clear terms that abolition was a forgone conclusion on the island, as in the United States, and that slavery would remain a vestigiality only for the allowance of a peaceful transition to free labor. The leading Cuban voices of the annexation movement thus made the deft articulation for the continuance of slavery as productive of eventual abolition. As Cisneros

\footnotetext{
307 José Antonio Saco, Ideas sobre la incorporación de Cuba en los Estados Unidos, Obras, vol. III, (Havana: Imagen Contemporánea, 2001), 278.
} 
never tired of reminding, "Annexation, my dear Saco, is not a sentiment, it is a calculation; even

more - it is the overbearing law of necessity; it is the sacred right of self-preservation. Spain

cannot protect us. Spain has to sacrifice us to the interests of Europe. Spain can make counts and

marquises, courtiers and sycophants, but not free men.” Yet, after the American annexationary

menace receded, largely at the hands of the Pierce administration, and Cuban internal politics

improved, Spain was in fact able to deal with the abolitionist demands, largely driven by the

British, on the island. ${ }^{308}$

The project of Cuban annexationists built upon the island's nationalizing project which in

turn built upon the interplay between literature and politics, society and culture, and most

notably, economics and race. The debate over slavery and race in Cuba was as intense as any in

\footnotetext{
${ }^{308}$ Cisneros quoted in Poyo, With All, and for the Good of All, 4. Lester D. Langley, "Slavery, Reform, and American policy in Cuba, 1823-1878," Revista de Historia de América 65/66 (January-December 1968), 71-84. Cuban purchase, despite the tantrums of Pierre Soulé over the Black Warrior affair and Buchanan's comical overreach of the Ostend "manifesto" was a long-term non-starter. The Ostend "manifesto" resulted from the Black Warrior affair. The Black Warrior was a merchant steamer that often stopped at Havana. On February 28, 1854, the ship was boarded and seized by Spanish authorities, under the direction of Captain General Pezuela. The crew stood in Spanish custody and a heavy fine imposed on the captain. Sensing an opportunity the pro-annexation forces played their hand and howled for war. Soulé, then Minister to Spain, demanded Pezuela's resignation and together with James Mason and James Buchanan (U.S. Minsters to France and Great Britain respectively) and with the blessing of Secretary of State William Marcy, issued the "manifesto" after their meeting in Ostend, Belgium (October 9-11, 1854). The document outlined the ridiculous premise and demands of the Pierce administration. "Our past history forbids that we should acquire the island of Cuba without the consent of Spain unless justified by the great law of self-preservation...After we shall have offered Spain a price for Cuba, far beyond its present value, it will be time to consider the question; 'Does Cuba in the possession of Spain seriously endanger peace and our cherished Union?' Should this question be answered in the affirmative, then by every law, human and divine, we shall be justified in wresting it from Spain.” The document, spearheaded by the notorious annexationary hothead Soulé was laughably rejected throughout Europe and derided by the Spanish. Given long-standing American aggression, the tone and pomposity was hardly surprising, although the issue followed Buchanan on the campaign trail in 1856. Ostend Manifesto text, http://xroads.virginia.edu/ hyper/hns/ostend/ostend.html. "Cuba and the Ostend Manifesto," Harper's Monthly Magazine, May 1870, 898-901; Gavin B. Henderson, "Southern Designs on Cuba, 1854-1857 and Some European Opinions," The Journal of Southern History 5, no. 3. (August 1939), 371-385; Preston Moore, "Pierre Soulé: Southern Expansionist and Promoter," The Journal of Southern History 21, no. 2 (May 1965), 203-223; Lars Schoultz, Beneath the United States: A History of U.S. Policy Toward Latin America (Cambridge: Harvard University Press, 1998), 39-58; C. Stanley Urban, "The Ideology of Southern Imperialism: New Orleans and the Caribbean, 1845-1860," Louisiana Historical Quarterly 39, no. 1 (January 1956), 48-73; James Cortada, Spain and the American Civil War: Relations At Mid-Century 1855-1868 (Philadelphia: American Philosophical Society, 1980) and "Economic Issues in Caribbean Politics: Rivalry between Spain and the United States in Cuba, 1848-1898," Revista de Historia de América 86 (July-December 1978), 233-267; Amos Ettinger, The Mission to Spain of Pierre Soulé, 1853-1855: A Study in the Cuban Diplomacy of the United States (New Haven: Yale University Press, 1932).
} 
the world, enhanced as it was by Cuba's position in the worldwide battle over abolition. Unease over race in Cuba, fueled by a literary explosion of fictional and political production, reached a fever pitch by the 1840s. In the prologue to his classic novel Cecilia Valdes, Carlos Villaverde, who was Narciso López's secretary and Cuban revolutionary in his own right, drew a clear distinction between creating literature and creating revolution. "Once outside of Cuba, I reformed my lifestyle: I exchanged my literary tastes for more noble thoughts; I passed from the world of illusions to the world of realities." For Villaverde, among others on the island and in the expatriate community, the distinction between illusion and reality separated a purely literary exercise from the field of political engagement that he saw as necessary to successful revolution. His goal, as was the goal of many of Cuba's literary generation of the 1840s, was a revolutionizing of the existing Cuban worldview in response to what had been a more philosophical approach to reform favored by the creole elite prior to 1843 . This does not minimize the intellectual, spiritual, and philosophical torment and yearning felt by many expatriate writers in the 1850 s and beyond. Rather the changed literary and philosophical landscape points to a rethinking of the relationship between the printed word and revolution. This was a new relationship that placed primacy on writing as another weapon in the war of persuasion - a manifestation of literary romanticism in the realism of the popular political press. This translation of literary to political consciousness, made more difficult by the presence of slavery and censorship in Cuba, called forth an active role from practitioners. The literary debates surrounding annexation coupled with Narciso López's actions demonstrated that culture could share center stage with politics in the making of foreign affairs. The political and popular 
literature of the period not only reflected the ideological struggles of the mid-nineteenth century, but also shaped and modified those struggles for policymakers and in the popular mind. ${ }^{309}$

Americans allowed themselves an appreciation for the shared experience and anxieties of Cuban creoles. Southerners in particular appreciated the colonial position of whites on the island in reference to imperial power and internal domestic racial threat. The racial essentializing project, largely conducted on the frontier in American society and literature, allowed a similar political and literary categorization of Cuban slaves and other sectors of Cuban society as distinct from the uplifting elite creole community. However, while Americans gave some thought to the complexities of Cuban society, it was Cubans themselves that most vociferously debated the issues facing the island and its delicate social balance. Cubans developed a literature independent of the American-favored travelogue in order to both codify some cultural notions while challenging others in profound and foundational ways. Cubans wove racial demarcation, in varying configurations, into the social meanings of politics and culture. Narciso López, steeped

\footnotetext{
${ }^{309}$ Rodrigo Lazo, "Filibustering Cuba: Cecilia Valdés and a Memory of Nation in the Americas," American Literature 74, no. 1 (2002), 1-30, and “'A Man of Action' Carlos Villaverde as Trans-American Revolutionary Writer," in Recovering the U.S. Hispanic Literary Heritage, Volume 3, eds. Ramón A. Gutiérrez, Genaro M. Padilla, and María Herrera-Sobek (Houston: Arte Publico Press, 1993), 315-340; Gerald Eugene Poyo, "Cuban Émigré Communities In The United States And The Independence Of Their Homeland, 1852-1895," (PhD diss., University of Florida, 1983). López's activities helped fuel the imaginations of those who would play a large role moving forward in the Cuba independence movement, particularly Villaverde who became influential in 1860s. Rodrigo Lazo defined this literary approach and the vigorous debates held in the Cuban-American press as "textual filibustering." This textual-military process contextualizes both the fictional and non-fictional productions of the period. However, the difference between genres did not indicate a lack of politicality or polemicism on the part of either. These authors, or los filibusteros, built upon a tradition extending back to the earliest Cuban immigrants of the 1820s, among them Father Felix Varela who founded El Habanero in New York (1824) and the exiled Cuban poet Jose Maria Heredia, whose poem Niagara was published by William Cullen Bryant's magazine The Review and Literary Gazette in 1824. Lazo, joined by Kirsten Silva Gruesz (Ambassadors of Culture: The Transamerican Origins of Latino Writing), argues that these transnational writers, poets, and activists, were all part of a deterritorialized print culture marked, most notably, by an intense desire for physical connection to a homeland. Lazo notes this condition of individuals, broken free from the mooring of national or territorial definition (desterrado), drove desire for political control as much as it fueled the personal yearning for belonging. Recognition of these conditions came from editors of the period as seen in the early Cuban compilations of desterrado literature such as Terube Tolón's Leyendas cubanos, Pedro Santacilia's El arpa del proscripto, and the multi-authored El laud del desterrado (all published between 1856-1858). For the Cuban literary tradition see Cintio Vitier, Lo cubano el la poesía (Santa Clara: Universidad Central de Las Villas, 1958).
} 
in the racial cauldron of Cuban society, drew on notions of republicanism that combined

freedom, slavery, and expansion in the Jeffersonian/Jacksonian tradition. He hoped this

perspective, amenable to many Americans, might also join the creole community together,

knowing as he did that fear of slave revolt drove many of the arguments for reform on the island

toward a more conservative position. ${ }^{310}$

\begin{abstract}
${ }^{310}$ Ezra Tawil, The Making of Racial Sentiment: Slavery and the Birth of the Frontier Romance (Cambridge: Cambridge University Press, 2008), 1-70. While Tawil argues that the novel became an important site for meditation on the nature of race and enlightenment notions of rights and property in the U.S. tradition. These works also explored the notion of romance, both on the physical and racial frontiers. Cuban novels of the period are no less important and represent many of the same characteristics as their U.S. literary counterparts. Novels allowed ideological contexts to exist with and to measure each other simultaneously rather than structuring those contexts along lines of displacement. Tawil identifies racialized sentimentalism as the process that allows this simultaneity and breaks novelization of difference free from more bodily-defined conceptualizations of difference based on scientifically observable phenomenology. The novel, he argues, forged a connection between race and the "psychological and emotional interior," (11). Therefore, the novel in this conceptualization, "...contributed to the formation of one of the most fateful concepts in the history of American culture: that of racial essences, their relation to emotional capacity, and, by extension, the relative suitability of various peoples for a place in the national community," (25). Thereby, the resulting paradox placed the reader in the position of feeling emotional bonds with characters of various races while simultaneously appreciating racial difference resultant from those emotions much more intensely. The Cuban novels of the period are similar in their racial imperatives and character development. However, the coordinated theme of miscegenation looms large in the Cuban canon. Similar terrain is explored by Saidiya Hartman and Julie Ellison on the racial politics of subjectivity, subjugation, and literary definition in Scenes of Subjection: Terror, Slavery, and Self-Making in Nineteenth-Century America (New York: Oxford University Press, 1997). Historian Joseph Allen Stout tied the frontier to filibustering as a phenomenon "spawned by the frontier and nourished by the spirit of expansionist adventurism which permeated all facets of American society during the 1850s." Stout, The Liberators; Filibustering Expeditions Into Mexico, 1848-1862 and the Last Thrust of Manifest Destiny (New York: Westernlore Press, 1973), 185. Christopher Lukasik, Discerning Characters: The Culture of Appearance in Early America (Philadelphia: University of Pennsylvania Press, 2010), investigates the transition from the $18^{\text {th }}$ century emphasis on performance and manners to the search for a more tangible and tactile corporeal legibility. Physical appearance then became an unchanging decoder through which to understand similarly unchanging personality traits. From this physical and emotional manifestation then emerged a relationship between appearance and social distinction and finally a tension between racial appearance and nationalism. The conflict between the immutable and the fluid in literary characters mimicked and informed the historical presence of nations and people. Doris Sommer takes up the issue of the Cuban novel Sab in her book Foundational Fictions. In all of these works is found an important shared conceptualization of the nationalizing process based on racial imperative and exclusion that gained steam into the early and mid-1800s. Fiction and non-fiction works dealt with the political explication of slavery, race, and nation and both genres shared a broad readership. Cuban fiction, although or perhaps because of its controversial subject matters and presentations, found a home in the more aggressive literary circles of Havana and Madrid. Since many of the readers of these works were the same writers producing political works, there is clear expression of similar ideas throughout, regardless of audience. Perhaps the main difference was the hope of the more political authors that their work might move Cubans toward a powerful reactive end, proscription rather than description. Four works present themselves as fundamental to interpreting the selfconceptualizations of the Cuban creole literary community seeking to define the Cuban national project in the 1840s. This moment, not unlike the process in the United States, was one that Cubans embraced in efforts to solidifying, along racial lines, the cultural and economic gains made under Spanish rule and the powerful articulation of national longing. Not surprisingly one of the chief methods of this solidification was the novelization of the plantation life and love in the Cuban $19^{\text {th }}$ century. The foundational fictions are well known to Cuba literary scholars and each presents a slightly different perspective on racial configurations of the period as well as differing critical receptions
\end{abstract}


Clearly the issue of slavery dominated the political and literary discussions of annexation. López's agnosticism on slavery mimicked the perspective of his biggest source of support in the United States, the Young America movement. They fused expansionism and republicanism with a tolerance of slavery, and harnessed the excitement brought by the European revolts of 1848 to their cause. The coordinated belief that talk of slavery could be silenced and expansion could continue without regard to such talk proved the backbone of the Young America movement. This movement embraced all those regardless of party who sought a middle path in the debate and that looked toward the country's past as ample demonstration that walking such a path was lucrative and indeed possible. In the hands of Young America's supporters, manifest destiny was a self-conscious creation of political propagandists but not one of benevolence. Rather, this invention, crafted and incubated for very specific reasons, aimed at producing, and hopefully forestalling, certain ends. The ideology had as its central precept political congeniality anchored in further monetization of regional and sectional unities and relationships. These relationships would, supporters hoped, prevent sectional war or disunion through the expansion of territory and associated economic opportunity. Of course, these hopes rested squarely on the

of the worth of each work. Gertrudis Gómez de Avellaneda's work Sab probably enjoys the most studied position in the Cuban national canon followed by Cirilo Villaverde's Cecilia Valdéz and Condesa de Merlin's Viaje a La Habana and an intriguing performance piece produced by Juan Francisco Manzano entitled Zafira. Each identifies key pieces of the Cuban national character and help to both summarize prevailing debates while also adding key interpretations of these debates. These texts, while varying in their narrative structures were as productive of the debates engulfing the island on the nature of and political expediency of slavery as they were reactive to them. They all demonstrate that race relations and the inclusion/exclusion of AfroCubans into the nationalizing project would remain the driving force of the gathering political and economic debates over annexation. Debra J. Rosenthal, Race Mixture in Nineteenth-century U.S. and Spanish American Fictions: Gender, Culture, and Nation Building (Chapel Hill: UNC Press, 2004); Stephanie LeMenager, Manifest and Other Destinies: Territorial Fictions of the Nineteenth-Century United States (Lincoln: University of Nebraska Press, 2004); John Patrick Leary, "Cuba in the American imaginary: Literature and National Culture in Cuba and the United States, 1848-1958," (PhD diss., NYU, 2009); Tiffany Yolanda Jimmece Bryant, "Inter-Subjective And Transnational Racial Effects: The Role Of The United States In The Formation And Evolution Of The Collective Perception And Racial Relations In Cuba, 18981902," (PhD diss., Florida International University, 2010); James F. Hamilton, "The Hero's Journey to Niagara in Chateaubriand and Heredia, French and Cuban Exiles," Romance Quarterly 41, no. 2 (1994), 71-78; Sean X. Goudie, Creole America: The West Indies and the Formation of Literature and Culture in the New Republic (Philadelphia: University of Pennsylvania Press, 2006). 
understanding that the total prohibition of the discussion of slavery was essential to success.

Narciso López recognized that silence on the slavery question was essential to encouraging support for annexation and therefore kept his feelings on slavery, like many in the Young

America ranks that supported him, suspiciously quiet. He largely embraced the path set forward by Stephen Douglas, who upon seeking the presidential nomination of the Democrats urged the party and Americans generally, "to come together on the basis of entire silence on the slavery question.” Douglas, much as López, believed that the economic promise of Cuba might be enough to ease sectional divisions. ${ }^{311}$

Sectional division and its prevention was a topic that engrossed Americans and fueled much of the intellectual spirit of the day. Ralph Waldo Emerson, one of the most influential of nineteenth century public thinkers in the United States, first gave voice to a new moral spirit he believed to be hiding subconsciously in the fiber of the American character with his speech "The Young American" delivered on February 7, 1844. While many expressed doubts on the righteousness of the American cause, particularly in the debates surrounding war with Mexico,

\footnotetext{
${ }^{311}$ Robert Walter Johannsen, Stephen A. Douglas (Urbana: University of Illinois Press, 1973), 339-401. Douglas gave his views on Cuba reportedly after being exhorted for his opinions by a crowd listening to him speak in New Orleans in 1858. "It is our destiny to have Cuba and it is folly to debate the question. It naturally belongs to the American continent. It guards the mouth of the Mississippi River which is the heart of the American continent and the body of the American nation. Its acquisition is a matter of time only. Our government should adopt the policy of receiving Cuba as soon as a fair and just opportunity shall be presented. Whether that opportunity occur next year or the year after whenever the occasion arises and the opportunity presents itself it should be embraced. The same is true of Central America and Mexico. It will not do to say we have territory enough. When the Constitution was formed there was enough yet in a few years afterward we needed more. We acquired Louisiana and Florida Texas and California just as the increase in our population and our interests demanded. When in 1850 the Clayton Bulwer treaty was sent to the Senate for ratification I fought it to the end. They then asked what I wanted with Central America. I told them I did not want it then but the time would come when we must have it. They then asked what my objection to the treaty was, I told them, I objected to that among other clauses of it which said that neither Great Britain nor the United States should ever buy annex colonize or acquire any portion of Central America. I said I would never consent to a treaty with any foreign power. Our republic will endure for thousands of years. Progress will be the law of its destiny. It will gain new strength with every state brought into the confederacy. Then there will be peace and harmony between the free states and the slave states. The more degrees of latitude and longitude embraced beneath our Constitution the better. The greater the variety of productions the better for then we shall have the principles of free trade apply to the important staples of the world making us the greatest planting as well as the greatest manufacturing the greatest commercial as well as the greatest agricultural power on the globe." James Washington Sheahan, The Life of Stephen A. Douglas (New York: Harper, 1860), 122-123.
} 
Emerson optimistically imagined the youth of the country giving themselves willingly to the continued betterment of American society. He also saw in his generation the desire, commitment, and responsibility to press the gains of American democracy beyond the bonds that geography and the government imposed upon the nation.

In every age of the world, there has been a leading nation, one of a more generous sentiment, whose eminent citizens were willing to stand for the interests of general justice and humanity, at the risk of being called, by the men of the moment, chimerical and fantastic. Which should be that nation but these States? Which should lead that movement, if not New England? Who should lead the leaders, but the Young American?

Emerson envisioned a robust generational action on the part of younger Americans whom he saw as driven to act by what he assumed was a benevolent impulse. However, his encouragement of "the increasing disposition of private adventurers to assume its (the government's) fallen functions" demonstrated that democracy's spread was not just a rhetorical effort. Territorial expansion was, for Emerson, a momentary grafting of democracy by Americans onto places that only needed a jumpstart toward success. American possession of new territory was not the ultimate goal; rather it was democracy's occupation he encouraged. Emerson believed that the United States, possessing a generosity of spirit and a deep desire to ameliorate hardship wherever it existed, could only follow the plan nature laid out for it.

Men are narrow and selfish, but Genius or Destiny is not narrow, but beneficent. It is not discovered in their calculated and voluntary activity, but in what befalls, with or without design. Only what is inevitable interests us, and it turns out that love and good are inevitable, and in the course of things. That Genius has infused itself into nature. It indicates itself by a small excess of good, a small balance in brute facts always favorable to the side of reason. ${ }^{312}$

The goodness of fortune and the blessing of territorial greatness preached by Emerson were powerful and constant motivators for Young Americans judiciously practicing the faith of

\footnotetext{
${ }^{312}$ Ralph Waldo Emerson, “The Young American,” accessed March 12, 2011, http://www.emersoncentral.com/ youngam.htm, (all quotes contained within); Brady Harrison "The Young Americans: Emerson, Walker and the Early Literature of American Empire," American Studies 40, no.3 (Fall 1999), 75-97.
} 
American republicanism. "That serene Power interposes the check upon the caprices and officiousness of our wills. ${ }^{313}$ However, in the robust belief of this rhetorical greatness also lay the seeds of its undoing, for as Emerson saw the beneficence of American expansion as a gentle democratic breeze, the supporters of manifest destiny had long-valued supremacy over amicability and used the ephemera of optimism as a mere basis for imperialism. This is the moment when ideology and practice met, where a new envisioning and expansion of American power claimed ascendancy. Contained within Emerson's call to Young Americans was the conflict between idealism and imperialism; at its heart was the paradoxical desire to improve the human condition while seeking material gain from that improvement. ${ }^{314}$ While Young Americans envisioned and applauded United States leadership in the spread of hemispheric democracy, their confidence blinded them to the possibility that democracy's spread might give succor to subjugation. The rhetoric of democracy and liberty made available to supporters of filibustering and the filibusters themselves a sense of the collective American self that offered the cover of elegance to undertakings that were anything but. The conceptualization of liberty found in the most rabid supporters of aggressive expansion in the Caribbean should not be surprising. The American philosophy and intellectual structure allowed a malleability of

\footnotetext{
${ }^{313}$ Emerson, "The Young American."

${ }^{314}$ Eric Cheyfitz, The Poetics of Imperialism: Translation and Colonialism from The Tempest to Tarzan (Philadelphia, PA: University of Pennsylvania Press, 1997), argues for a complicated view of Emerson. Language, in Cheyfitz's view, serves as the means to power for the American imperial self. Cheyfitz reads The Tempest as a prologue to American literature and argues that "the imperial figure that conquers time and space is not technology but eloquence," (32). In describing the need for this eloquence, primarily expressed literarily, Cheyfitz looks upon its nature as inseparable from technology. He invokes Marx's belief that well into the 1850s the mechanical arts sought to justify themselves in terms of the literary. However, after the Civil War it is the literary which had to earn its positioning and practicality in reference to ascendant mechanical arts. "Before the Civil War, despite the flowering of the machine, the principle force of technology was still eloquence, whereas after the war, marking the decline in the idea of a classical education as normative, technology became the principle form of eloquence," (32). For Cheyfitz, Emerson imagined an American-self dominating the world through willpower and words - he did after all call upon Young Americans to lead the world in 1844 using this conceptualization of self he developed in "Selfreliance." However, Emerson's theories of language, eloquence, and self belie the contradictory impulses in his philosophy. Even as he contended that right action flowed from right language for the betterment of humanity, he saw a colossus of the self that used the technology of language to impose its will upon others.
} 
application flexible enough that poets and filibusterers alike availed themselves of the core tenets to their own ends. ${ }^{315}$

The American West and movement there, although possessing a decided lack of finality and offering no guarantee of success, helped Americans appreciate the new American landscape as a spiritual agent in a way once considered applicable only to belief in God. Westward expansion helped Americans,

quickly enough to advance ... into a new and more excellent social state than history has recorded...In other words, efforts to get Americans to imagine the West in conjunction with their national and personal destinies gave the national congregation a quasi-Christian way of describing their ambitions...Successfully bringing civilization to the West depended on recognizing the grand design, the obviously well-laid plan, for the country to span the continent from the Atlantic to the Pacific coasts. ${ }^{316}$

The West held the great promise of communion for the North and South in the completion of the ordained American project. However, slavery's expansion into this new territory threatened to sully the effort as charges of sectional opportunism bandied about. Opponents of Northern dominance saw abolitionism and its proponents' refusal to abandon their own racism a simple rhetorical means to control the South. These critics found Northern focus on the South's desire for a tropical empire as a ploy to deflect attention away from Northerners own unacknowledged moral culpability, monetary investment, and managerial expertise in the slave trade. There was no doubt that the Northern establishment was keenly invested in the protection of whiteness and the imperialism of the nineteenth century. Focusing on the South's racial problem allowed an eliding of its own white supremacy. This ignorance of the local effects of slavery in deference to the benefit of industrial profit and the refusal to engage with indigenous populations of the West

\footnotetext{
${ }^{315}$ Bernard Cohen, “Emerson's 'The Young American' and Hawthorne's 'The Intelligence Office,' American Literature 26, no. 1 (March 1954), 32-43.

${ }^{316}$ Ryan Ruckel, “'A Kind Providence' and 'The Right to Self-Preservation;' How Andrew Jackson, Emersonian Whiggery, and Frontier Calvinism Shaped the Course of American Political Culture," (PhD diss., Louisiana State University, 2006), 146.
} 
and the Caribbean was the mode repeated by the filibusters and their supporters in Cuba. This ignorance of conditions on the ground did much to short-circuit any support that local

populations might have offered in Cuba. ${ }^{317}$

${ }^{317}$ The British, always quick to criticize aggression in the personal and national characters of Americans, came in for their own critique from Americans who pointed to India as a glaring blind spot in the empire's movement to free labor. The humanitarian aspect of abolition gave the British a moral cudgel to use in their diplomatic circles. Yet, Americans pointed to India and the East India Company as a glaring case of hypocrisy. James Stirling, an Englishman who travelled the U.S. in the 1850s acknowledged this hypocrisy in British critique of filibustering. In Letters from the Slave States, he wrote, "... when stealing is to be done at all it should be done in public and on a large scale; then, like murder, it acquires a certain dignity; as witness or East Indian thefts of a kingdom at a time." George Train, an American merchant and trader agreed with Stirling's assertion. "All the (East India) Company's servants believe in the infallibility of the Company an excuse is found for everything the Honorable Company may do. American slavery is horrible but the Indian ryot system is a blessing to the native. Annexation in America is robbery; in India friendship and protection. The Court of Directors may do what they please the Governor General proclaims it and the servants far and wide say amen." Stirling and Train also had much to say about Cuban annexation. Stirling, Letters from the Slave States (London: Parker and Son, 1857), accessed on March 10, 2014, $\mathrm{http} / / /$ books.google.com/books?id=KB3_5mnSvOsC\&vq=cuba\&pg=PR4\#v=onepage\&q\&f=false, 127 . George Francis Train, An American Merchant In Europe, Asia, And Australia: A Series Of Letters From Java, Singapore, China, Bengal, Egypt, The Holy Land, The Crimea And Its Battle Grounds, England, Melbourne, Sydney, Etc, Etc, (New York: Putnam \& co, 1857) accessed on March 10, 2014, http://books.google.com/books?id=i--

DWHB7ywC\&pg=PR1\#v=onepage \&q\&f=false. In the midst of the annexation furor, India exploded in rebellion in 1857. The Sepoy rebellion brought into stark relief the social dynamic present in India. As predisposed as Americans might have been to gloat or to take some satisfaction at the hollowness of British morality, India was a growing source of trade with the United States. The American press focused on the conflict as much from a selfaggrandizing perspective as from a concern about the potential economic effects on the American economy. The Sepoy rebellion also offered some grist for the American abolitionist movement. Frederick Douglass encouraged his followers during his "West Indian Freedom Speech" (August 3, 1857) to use the Sepoy's example in their fights with white Americans, including Garrisonians whom he saw as too interested in defending their white privilege while arguing for abolition. "I know, my friends, that in some quarters the efforts of colored people meet with very little encouragement. We may fight, but we must fight like the Sepoys of India, under white officers. This class of Abolitionists don't like colored celebrations, they don't like colored conventions, they don't like colored antislavery fairs for the support of colored newspapers. They don't like any demonstrations whatever in which colored men take a leading part. They talk of the proud Anglo-Saxon blood as flippantly as those who profess to believe in the natural inferiority of races. Your humble speaker has been branded as an ingrate, because he has ventured to stand up on his own and to plead our common cause as a colored man, rather than as a Garrisonian. I hold it to be no part of gratitude to allow our white friends to do all the work, while we merely hold their coats. Opposition of the sort now referred to is partisan position, and we need not mind it. The white people at large will not largely be influenced by it. They will see and appreciate all honest efforts on our part to improve our condition as a people." Douglass, "West Indian Freedom Speech," accessed March 10, 2014, http://www.lib.rochester.edu/index.cfm?PAGE=4398. The Sepoy rebellion also put into relief the problem of emancipation for those who opposed it based on their perception of the impossibility of integrating different races. In words that echo the concerns of José Saco, John Townsend in The Doom of Slavery in the Union predicted ruin for emancipated slaves at the hands of abolitionist. "Thus will commence that war between the races which every reflecting mind perceives to be inevitable where an inferior and degraded race has been forced by foreign interference to an equality with their former master race. In such a war with the whites well-armed and acquainted with their use and double in number to the blacks who doubts the result. Horrible tragedies may be enacted in a few neighborhoods but it must soon terminate in the indiscriminate slaughter of the negros by tens of thousands and hundreds of thousands until they shall be either exterminated or driven out of the country. The late insurrection in British India comes in here as an illustration and proof of two things: 1st that an inferior and superior race cannot live together in the same country on terms of equality and; $2 \mathrm{~d}$ that in the struggle for ascendancy although the inferior race was perhaps fifty times more numerous they were in due time completely 
The invention of American national culture became, in the 1840s, an obsession among the literati in hopes of alleviating some of the sectional animosity bubbling to the surface. Much like the Cuban elite, these men, and a handful of women, did not endeavor simply to speak to each other, but to actively mold the ideas, beliefs, politics, and minds of their fellow citizens. This American elite, always existing with very porous borders of genre, class, and location, envisioned both high and low literature as the vital means for cultivating national character. Culture, they believed, was after all the only lasting trace of a nation's greatness. They sought a succinct summation of America's history emboldened by God's divine blessing as expressed through the yearning, at the crossroads of their own moment, for a unique national spirit. Unfortunately, American authors had little opportunity and outlet to produce these new native forms. Whig-leaning critics were benign nationalists. They saw American unity not as created but rather as the hopeful inevitable outcome of national expansion and technological progress. Democratic critics tended to be anxious nationalists, perpetually fearing that America was collapsing into a culture-less abyss. Therefore the purposeful creation of shared culture was a fraught undertaking for those of any political persuasion. ${ }^{318}$

For Young Americans, however, the United States was not just a nation but also a

\footnotetext{
subdued by the superior intelligence and courage of the white man. And such will be the doom of the negros of the South in any war with the whites. How stupendous then is the folly and crime of the Abolitionist who under pretence of benefitting the slave would plunge him down into so miserable a doom!" Townsend, The Doom of Slavery in the Union: Its Safety Out of It, (Charleston: Evans and Cogswell, 1860), accessed March 10, 2014, http://books.google.com/books?id=Tv2-zlYJa5sC\&vq=cuba\&pg=PA1\#v=onepage\&q\&f=false, 24. Elizabeth Kelly Gray, "Whisper to Him the Word 'India:' Trans-Atlantic Critics and American Slavery, 1830-1860," Journal of the Early Republic 28, no. 3 (Fall 2008), 379-406; Sven Beckert, "Emancipation and Empire: Reconstructing the Worldwide Web of Cotton Production in the Age of the American Civil War," American Historical Review 109, no. 5 (December 2004), 1405-1438; Nicholas Dirks, The Scandal of Empire: India and the Creation of Imperial Britain (Cambridge: Cambridge University Press, 2006); Ainslie Embree, ed., India in 1857: Mutiny or War of Independence (Delhi: Heath, 1963). On the use and application of managerial and industrial techniques developed in the North and applied in the South see, David R. Roediger and Elizabeth D. Esch, The Production of Difference:

Race and the Management of Labor in U.S. History (New York: Oxford University Press, 2012), chs. 1-3.

${ }^{318}$ Daniel Walker Howe, The Political Culture of the American Whigs (Chicago: University of Chicago Press, 1979), chs. 1-2.
} 
conveyance for the covenantal promise to the peoples of the world. America they believed should not only seek internal improvement, but also an explosion of that improvement throughout the hemisphere. Although not scripture, in the mind of the Young Americans, John Louis O' Sullivan's The United States Magazine and Democratic Review was the distillation of the $d /$ Democratic faith in the new age in which they lived. This younger generation wanted to spread the new faith of democracy with a proselytizing zeal which traditional party politics was ill suited for. O'Sullivan, for his part, had long-seen the link between literature and national cohesion. In 1839 he wrote,

And our literature!-Oh, when will it breathe the spirit of our republican institutions? When will it be imbued with the God-like aspiration of intellectual freedom-the elevating principle of equality? When will it assert its national independence, and speak the soul-the heart of the American people? We need only be inspired by the magnificent scenery of our own world, imbibe the fresh enthusiasm of a new heaven and a new earth...Is not nature as original in this, our Western hemisphere, as in that of the East? All this will be our future history, to establish on earth the moral dignity and salvation of man - the immutable truth and beneficence of God. For this blessed mission to the nations of the world, which are shut out from the life-giving light of truth, has America been chosen; and her high example shall smite unto death the tyranny of kings, hierarchs, and oligarchs, and carry the glad tidings of peace and good will where myriads now endure an existence scarcely more enviable than that of beasts of the field. Who, then, can doubt that our country is destined to be the great nation of futurity? ${ }^{319}$

A new extra-political force, a faith-imbued democracy backed by a robust literature extolling its virtues, was necessary for the continuance of the republic. The impulse present in every shred of literature of the period feared that the United States stood simultaneously on the precipice of failure and destined for success. O'Sullivan succinctly summed up his belief in the faith of democracy as protectant against ruin. "What, indeed, is Democracy but Christianity in its earthly aspect, Christianity made effective among the political relations of men." ${ }^{320}$ Democracy was the

\footnotetext{
319 John L. O'Sullivan, “The Great Nation of Futurity” The United States Magazine and Democratic Review 6, no. 23 (November 1839).

${ }^{320}$ John L. O'Sullivan, “The Course of Civilization,” The United States Magazine and Democratic Review 6, 23 (November 1839), 216-7; Robert J. Scholnick, "Extermination and Democracy: O’Sullivan, The Democratic Review, and Empire, 1837-1840," American Periodicals: A Journal of History, Criticism, and Bibliography 15, no. 2 (2005) 123-141.
} 
key to a new world life, led by the United States and empowered by the confidence in success that a Christianized democracy offered to energize Americans. Therefore anyone who disagreed with the democratizing mission of the United States stood as an impediment to God's will.

American Protestant missionaries took note of the messianic vision of the spread of American democracy. Although they did not abandon the traditional pillars of Christian faith, as O'Sullivan had in melding Christianity and democratic metals, Protestant missionaries found the advance of American culture seductive for their own and for God's purposes. These missionaries, trained at institutions of higher education and funded by The American Board of Commissioners for Foreign Missions, merged their mission to redeem the Holy Land (and by extension the whole world) with the belief that American political, economic, and social culture was the ideal version of godly-ordained Western culture. As the self-perceived religious/secular vanguard, American Christians felt a simultaneous duty to spread American culture and Christianity - synonymous concepts in the minds of many missionaries. Reverend John Codman spoke of this duty in 1836 .

How can we better testify our appreciation of [America's] free institutions, than by laboring to plant them in other lands? For where the Gospel goes in its purity and power, there will follow in its train the blessings of civilization, and good government...Coming himself from a land of freedom, he [the missionary] will naturally spread around him an atmosphere of liberty. ${ }^{321}$

This connection between God, Western civilization, the United States, and manifest destiny was locked in place for at least two hundred years before Codman spoke of his parishioners' divine mission. From John Winthrop to the founding generation to John L. O'Sullivan and the

\footnotetext{
${ }^{321}$ Codman quoted in Lawrence Davidson "Christian Zionism as a Representation of American Manifest Destiny" Critical Middle Eastern Studies, 14, no. 2 (Summer 2005), 158-160. Clifton Phillips, Protestant America and the Pagan World (Cambridge: Harvard University Press, 1969). It should not be surprising, particularly given the rise of the Know Nothings in the mid-1850s, that the Catholicism of Spain would be a major issue in the drive for redemptive expansion into Cuba. Rosemary Radford Ruether America, Amerikkka: Elect Nation and Imperial Violence, (Chicago: Equinox, 2007); Nicholas Guyatt, Providence and the Invention of the United States, 1607-1876 (New York: Cambridge University Press, 2007).
} 
filibusters, God's blessing has always been assumed upon the proceedings of the national American project.

Countless Americans, not just those in the Young American camp, believed that Providence chose, expected, and prepared the United States for an exemplary role among the nations. This elect status made itself most apparent in the application of religious democracy for and by its population. This glory resided, however, in the near future since Europe's cultural influence, first brought about through its imperial conquests and control over the continents of the Western Hemisphere, delayed the implementation of American destiny. Americans struggled to overcome this decadent lineage. The narrow American societal selfishness now being displayed in warring cultural, economic, and political factions was the clearest outcome of this state of incubation. This lack of unity also deprived the United States of a native literature and philosophy, thus precluding the chance to put a true religion of democracy into practice. However, the development of a national literature, stoked in the fires of spiritual democracy, would produce in the United States an impulse toward growing new structures and institutions appropriate for an ideal democracy. These structures, imbued with missionary zeal, offered humanity the fulfillment of America's promised divine destiny. As Walt Whitman explained in an editorial in his Brooklyn paper, The Eagle,

For the time will surely come - that holy millennium of liberty-when the 'Victory of endurance born' shall lift the masses of the down-trodden of Europe, and make them achieve something of that destiny which we may suppose God intends eligible for mankind. And this problem is to be worked out through the people, territory, and government of the United States. ${ }^{322}$

For Young America there could be no religion of democracy, without a literature of democracy. Nor could religious belief be substituted for democracy since God would fade away at such point

\footnotetext{
${ }^{322}$ Walt Whitman, "American Futurity," in The Gathering of the Forces Vol. 1, eds. Cleveland Rodgers and John Black (New York: G. P. Putnam's Sons, 1920), 28.
} 
as the United States, the vehicle for God's grace, fused the almighty's will together with its destiny - there would be no separation between Christianity and American democracy.

The mid-1840s therefore represented a crystallizing moment for the swirling ideas of American exceptionalism present in the founding DNA of the nation. American history showed the roots of this idea well back into the eighteenth century, rifling through the works of American clerics, poets, politicians, editors and the great swath of citizens. With the Mexican war the belief that only American democratic institutions should and could beneficially and benevolently control the western hemisphere proved correct and remarkably easy to accomplish. ${ }^{323}$ In July 1845 issue of The Democratic Review John O'Sullivan summarized the prevailing mood of the editorial sheets of the Democratic press.

Why, were other reasoning wanting, in favor of now elevating this question of the reception of Texas into the Union, out of the lower region of our past party dissensions, up to its proper level of a high and broad nationality, it surely is to be found, found abundantly, in the manner in which other nations have undertaken to intrude themselves into it, between us and the proper parties to the case, in a spirit of hostile interference against us, for the avowed object of thwarting our policy and hampering our power, limiting our greatness and checking the fulfillment of our manifest destiny to overspread the continent allotted by Providence for the free development of our yearly multiplying millions. ${ }^{324}$

Not simply tapping into long-standing ideas, Young Americans self-consciously invented an American literature and corresponding programmatic. Using ideas that were paradoxically amorphous and direct, with their messianic mentality retaining its dangerous imperialist styling, many Americans soon put word into action throughout the hemisphere. The politicians of the age

\footnotetext{
${ }^{323}$ Anders Stephanson in Manifest Destiny: American Expansion and the Empire of Right (New York: Hill \& Wang, 1995 ) argues that the nationalism of the 1840s pushed "the notion that the United States was a sacred-secular project, a mission of world historical significance in a designated continental setting of no determinate limits," 28. He sees important differences between the American and European models of nationalism. Stephanson claims that, where the European model emphasized a glorious and homogeneous ancestry and ancient traditions tied to ancestral lands, the American nationalism of manifest destiny avoided talk of the distant past and instead focused on the future. This future succeedingly built upon the unique American take on ancient activities common to all humans migration to lands of distinctly superior advantage. This placed the United States in the continuum of human experience even as Americans projected the country's foundation as a significant rupture with that continuity. ${ }^{324}$ John L. O'Sullivan “Annexation,” The United States Magazine and Democratic Review 15, no. 1 (July 1845).
} 
carried that philosophy to their logical policy ends being the men of policymaking ability. They were the ones to close the circle of influence and pave the way for filibusters a generation later, to imbue their political beliefs with meaning through action. John Quincy Adams and James Monroe put forth the doctrine, a capstone of Jeffersonian democratic expansionism, but Narciso López, his supporters, and his fellow "men of action" sought the ultimate end - democratically ordained expansion.

This excitement allowed territorial expansion and the electricity of political selfdetermination to obscure the moral paradox that slavery left for annexation's ideologues. This paradox was even easier to ignore due to the support offered annexation by Cubans. Cuba Joven embraced these concerns and approaches as well as the excitement of greater political rights and economic opportunities under the American flag. This excitement fused with the elite hacendado interest in preventing immediate slave emancipation and race war. Certainly, political supplication to yet another imperial power was not preferable to independence, but it presented itself as better than massive social upheaval promised by slave insurrection. One of the conduits carrying these conversations between Young American and Cuba Joven was the American press, composed of both Cuban expatriates and Americans. These youthful connections among politically influential men (and a few women) propelled the issue of Cuban annexation to the forefront of popular and private political discussions. The story of Cuba and the United States was, at its heart, a frontier love story that defined the cultures of both as simultaneously separate from and indispensable to each other. While many travelers expressed their appreciation for the exoticism of the Cuban locale, they were simultaneously comfortable in their physical surroundings and in their social surroundings populated as they were by Cubans in the same economic circles. Elite Cubans by in large embraced American visitors, with many of whom they 
shared mutually beneficial economic relationships. Cubans of lower economic station also shared some warmth with American visitors since the American tourists were a source of income in the many shops and guest houses around Havana. Furthermore, intermarriage with important creole Cuban families encouraged the naturalization of shared aspirations between the Cuban creole and American mercantile elite.

One of the men at the forefront of the popular articulation of annexationist ideology came to Cuba through intermarriage. John O'Sullivan arrived in Havana on his honeymoon in January 1847. While on the island, he sensed the rumblings of discontent and dedicated himself to annexation after he attending a meeting of the Club de la Habana. O'Sullivan's sister married a Cuban man, Cristóbal Mádan, then an important member of the $C l u b$, thereby facilitating the American's entre into elite creole society on the island. O'Sullivan's entry into this Havana circle enhanced his access to those that shared his vision within that community and fueled his abiding desire to successfully guide the annexation program to fruition. Joining the proceedings at the Havana meeting was the editor of the New York Sun and a man who would dominate the media discussion like no other, Moses Yale Beach. Beach and the New York Sun, rabidly supportive of the Mexican war, looked to Cuba as the next logical front in expansion's broad vision. $^{325}$

\footnotetext{
${ }^{325}$ Also in attendance at the meeting were other titans of annexation and members of the Club-José Antonio Echevarría, Miguel de Aldama, José Luis Alfonso, and the Club's only American member, John Thrasher, editor of El Faro Industrial. Mádan was an economic and social giant in Cuban society and a founding member of the Havana Club; a group working surreptitiously for the defeat of Spanish colonialism. He was also one of the group's main ideological exporters through his work with the Cuban Council, the American counterpart of the Havana Club, conducting affairs on behalf of annexation in New York City. Mádan was an interesting and long-time figure in the annexation/independence movement. He was almost entirely based in New York, arriving at age 16 to learn English and the mercantile business. After arriving in 1822 he welcomed both his former tutor Father Félix Varela, in December 1823 and then the poet José María Heredia. Mádan's family immigrated to Cuba from Ireland in the 1760s. His family became successful on the ground floor of the sugar boom in the Matanzas region in the early $19^{\text {th }}$ century and like so many Cuban men he arrived in New York to learn the sugar trade at one of the numerous "counting houses" on South Street that acted as the economic agents for Cuban families, keeping accounts for them and investing their money in the United States. Mádan spent time in between New York and Havana and kept successful law practices in both places, although he listed 'gentleman' as his profession on his 1850 U.S. citizenship
} 
Those in attendance at the Havana meeting agreed that annexation was the best path forward and that Beach would take the lead pressing the case in the American press while also printing a Spanish language American paper, La Verdad, that would guide the process in the expatriate community. O'Sullivan agreed to a quieter role, capitalizing on his previously welldeveloped connections honed as a Democratic Party operative and political lobbyist to the Polk administration. Astoundingly, the $C l u b$ agreed to repay the United States treasury up to $\$ 100$ million if Polk could arrange purchase. O’Sullivan, joined by Senator Stephen Douglas, pressed his case quickly, calling upon Secretary of State Buchanan and President Polk in May of 1847. O'Sullivan, cognizant of the intense debate over slave territory unleashed by the Mexican war, made clear to both men that Cuban annexation offered benefits for every region of the country and would be popular with the American people. O'Sullivan also made clear that the safety and security of the country hung in the balance with British and French menace in the Caribbean a real concern. The Polk administration had an opportunity with swift action, O'Sullivan pressed in letters throughout the summer, to make its mark on the commercial history of the United States and the world. ${ }^{326}$

Unfortunately, the impetuous Beach undercut O'Sullivan's efforts with the beginning of the editor's raucous press campaign in July, 1847. Two editorials that month, one by Jane application. By the late 1860s his economic life was in disarray due to Cuban economic embargos against those whom had left the island. On the history of the Sun and Beach's secret trips to Mexico on behalf of the Polk administration that included him and Jane Storms (eventually McManus Storms Cazneau) fleeing Mexican bounties for their capture, see Frank O'Brien, The Story of the Sun, New York 1833-1928 (New York: George H. Doran \& co., 1918), accessed on March 10, 2014, http://books.google.com/books?id=c43uFLQAiDgC\&pg=PA1\#v= onepage\&q\&f=false, and Anna Kasten Nelson, "Mission to Mexico - Moses Y. Beach, Secret Agent," New York Historical Society Quarterly 59 (1975), 227-245. For more on O'Sullivan see, Sheldon Harris, "The Public Career of John Louis O'Sullivan," (PhD diss., Columbia University, 1958); Julius W. Pratt, “John Louis O'Sullivan and Manifest Destiny," New York History 19, no. 3 (July 1933), 213-234; Sheldon H. Harris, "John Louis O’Sullivan and the Election of 1844 in New York," New York History 41, no. 3 (July 1960), 278-298; and Robert Sampson, John O'Sullivan and His Times (Kent, Ohio: Kent State University Press, 2003).

${ }^{326}$ James Knox Polk, The Diary of James K. Polk During His Presidency, 1845 to 1849, Vol. 1, ed. Milo Quaife (Chicago: A.C. McClurg, 1910), 23-25. 
McManus Cazneau (writing as Cora Montgomery) and the other by Beach, outlined their January meeting in Havana and indicated (with a great deal of projection based on the small number of attendees and the similarity of their sentiment) that many Cubans, including members of the elite, stood ready to join the American family. "The moment has arrived," Beach wrote, "to place Cuba in our hands and under our flag. Cuba is in the market for sale, and we are authorized by parties eminently able to fulfill what they propose, to say that if the United States will offer the Spanish government one hundred million dollars, Cuba is ours and that with one week's notice, the whole amount will be raised and paid over by the inhabitants of the island." O'Sullivan called the articles "foolish" and urged Polk and Buchanan to move quickly with the Spanish as to prevent the passions of the American people from overwhelming delicate diplomatic discussion. Beach didn't relent and published almost 40 more articles on Cuba in the second half of 1847. Polk, although indicating his great interest in Cuba's purchase, was too preoccupied with the culmination of the Mexican war to place much time toward the effort; an oft-repeated lack of diplomatic action on the followed by many of Polk's successors. ${ }^{327}$

\footnotetext{
${ }^{327}$ New York Sun, July 23, 1847. Basil Rauch, American Interest in Cuba, 1848-1855 (Chicago: Octagon Books, 1948), 58-70. Although filibustering was an overwhelming male sphere, this is not to suggest that women didn't play important roles. Jane McManus Storms Cazneau along with her husband William Cazneau were tireless advocates for commercial expansion in the Caribbean, including Cuban annexation. Jane penned numerous articles for the Sun and was a public and private advocate for the cause. She was among the first to fuse the arguments for Cuban annexation to Spanish degeneracy, expansive commercial growth, the fear of "Africanization," and the paradoxical weakening of American slavery resultant from annexation. Cuba was, however, only the first in a string of gems needed to solidify American control of the Caribbean. Both William and Jane grew increasingly concerned about the depredations against the Monroe Doctrine and saw a more robust American foreign policy driven by commercial interest as the strongest hedge against French encroachment in Mexico and the fast developing issues in the Dominican Republic in the late 1840s. The Cazneau's entered the Dominican situation, with William receiving a special appointment from the State Department to conduct negotiations in hopes of protecting U.S. commercial interests from Haitian attacks and European interference. Haiti had occupied Santo Domingo after its declaration of independence from Spain in 1821, but before the former Spanish colony received protection from Gran Colombia after the colony's requested annexation to Bolívar's republic in 1822. The Dominicans again declared independence, this time from Haiti, 20 years later in 1844 under the direction of La Trinitaria, led by Juan Pable Duarte. In the chaos of warfare over the next 20 years, as Haitian troops came and went at various points throughout the 1840s and 1850 s, the U.S. and Europeans attempted to protect their interests on the island. William Cazneau's attempts to negotiation a commercial deal with the Dominican government that excluded Europeans from consideration failed. The Cazneaus later became directly involved in William Walker's filibusters to Nicaragua in exchange for mining consideration he granted them in his protectorate. They also involved themselves in a guano venture and an effort
} 
Despite the loud voices of popular criticism that found their target more often with recalcitrant Whig administrations, the avowed policy of the United States government throughout the 1850s, regardless of presidential partisanism, was for purchase of Cuba and not public or private military invasion there. This policy aimed most directly at preventing violent slave revolt on the island. The fear of "Africanization" of Cuba in a post-invasion power vacuum drove the policies of the Polk, Taylor, Fillmore, Pierce and Buchanan administrations. While Taylor, prior to his death, and Fillmore, largely for his robust prosecution of filibusters, suffered the most vehement condemnation, the assertion that purchase was the preferred means of transfer prompted presidential action toward lack of support for filibustering. President Polk, in the twilight of his administration went so far as to divert troops returning from the Mexican war away from a layover stop in Havana after rumors of their military intentions became known. United States consul in Havana, Robert Campbell, also reported to the Spanish authorities rumors of an indigenous uprising being organized by Narciso López, thereby prompting the general's quick exit from the island just ahead of Spanish officials. Zachary Taylor, in a presidential proclamation offering no government assistance for those that ignored his heed, warned Americans not to take part in López’s first filibuster of 1849.

It is the duty of this Government to observe the faith of treaties and to prevent any aggression by our citizens upon the territories of friendly nations. I have therefore thought it necessary and proper to issue this my proclamation to warn all citizens of the United States who shall connect themselves with an enterprise so grossly in violation of our laws and our treaty obligations that they will thereby subject themselves to the heavy penalties

\footnotetext{
during the Civil War to relocated freed slaves to the Dominican Republic. William O. Scroggs, Filibusters and Financiers: The Story of William Walker and His Associates (New York: MacMillan, 1916); Charles Callan Tansill, The United States and Santo Domingoe, 1798-1873 (Baltimore: Johns Hopkins University Press, 1938); Eugenio Matibag, Haitian-Dominican Counterpoint: Nation, State, and Race on Hispaniola (New York: Macmillan, 2003); Millery Polyné, “'Expansion Now!' Haiti, 'Santo Domingo,' and Frederick Douglass at the Intersection of U.S. And Caribbean Pan-Americanism," Caribbean Studies 34, no. 2 (July-December 2006), 3-45; Robert E. May, "Lobbyists for Commercial Empire; Jane Cazneau, William Cazneau, and US Caribbean Policy, 1846-1878," Pacific Historical Review 48, no. 3 (August 1979), 383-412; Linda S. Hudson, Mistress of Manifest Destiny: A Biography of Jane McManus Storm Cazneau, 1807-1878 (Houston: Texas State Historical Association, 2001).
} 
denounced against them by our acts of Congress and will forfeit their claim to the protection of their country. ${ }^{328}$

Fillmore instructed United States Attorneys along the Gulf to prosecute filibuster organizers to the full extent of the law and dispatched the navy to break up López's "Round Island" filibuster, a decision that earned the president particularly harsh criticism. However, he was equally harsh in his articulation of the problem he faced.

Whereas there is reason to believe that a military expedition is about to be fitted out in the United States with intention to invade the island of Cuba a colony of Spain with which this country is at peace and whereas it is believed that this expedition is instigated and set on foot chiefly by foreigners who dare to make our shores the scene of their guilty and hostile preparations against a friendly power and seek by falsehood and misrepresentation to seduce our own citizens especially the young and inconsiderate into their wicked schemes an ungrateful return for the benefits conferred upon them by this people in permitting them to make our country an asylum from oppression and in flagrant abuse of the hospitality thus extended to them And whereas such expeditions can only be regarded as adventures for plunder and robbery and must meet the condemnation of the civilized world whilst they are derogatory to the character of our country in violation of the laws of nations and expressly prohibited by our own.

Franklin Pierce played his own role in quieting the filibustering process. In private conversation with Cuban filibustering's new chief John Quitman, the President convinced Quitman to forfeit leadership of the abandoned 1854-55 effort. James Buchanan, hoping to quell filibustering excitement late in the 1850 s, openly asserted his administration's intention to purchase the island in one of his first addresses to Congress. Critics of the decade's presidents always accused antifilibustering public stances with hypocrisy believing that presidents held private confidences encouraging of filibustering activities. These critiques, sometimes bolstered by the actions of presidents - mostly notably Pierce's appointment of the vehemently pro-Cuban annexationist Pierre Soulé as minister to Spain, - belied the reality for presidents and ambassadors of a

\footnotetext{
${ }^{328}$ Zachary Taylor, "Proclamation 51 - Warning to United States Citizens Against Participating in an Unlawful Invasion of Cuba, August 11, 1849," reprinted in Calderon Carlisle, "Report to the Spanish legation: with reference to the legal aspect of hostilities committed by vessels specially adapted, in whole or in part, within the United States to warlike uses and by military expeditions and enterprises carried on from the territory of the United States against the Spanish dominion in Cuba during the present insurrection (Havana: no mark, 1896), accessed March 10, 2014, http://books.google.com/books?id=ZkZuAAAAMAAJ\&pg=PP1\#v=onepage\&q\&f=false, 8 .
} 
conservative approach toward Spain regarding Cuba. Much more problematic for enforcement

officials was the lack of manpower, military power, and evidence (to say nothing of filibustering

sympathies amongst jurors and government officials) available to those in the fledging United

States government apparatus intent on prosecution. ${ }^{329}$

\footnotetext{
${ }^{329}$ Millard Fillmore, "A Proclamation," reprinted in Calderon Carlisle, "Report to the Spanish legation: with reference to the legal aspect of hostilities committed by vessels specially adapted, in whole or in part, within the United States to warlike uses and by military expeditions and enterprises carried on from the territory of the United States against the Spanish dominion in Cuba during the present insurrection (Havana: no mark, 1896), accessed March 10, 2014, http://books.google.com/books?id=ZkZuAAAAMAAJ\&pg=PP1\#v=onepage\&q\&f=false, 9. Astoundingly, pages 1-19 list the presidential proclamations regarding filibustering from Washington through Cleveland and they each read almost exactly the same in their warnings and critiques of filibustering. The press pursued every rumor and innuendo to its logical end when accusing presidents of complicity in or overzealous persecution of filibustering. Fillmore, paradoxically, the various partisan presses claimed, stood on both sides simultaneously; at once an opponent of liberty and also a supporter of filibusters. Filibustering, if anything, presented an almost constant source of embarrassment to U.S. officials. James Gadsden, in the negotiations over the Gadsden Purchase and after William Walker's short lived Lower California adventure, complained to Franklin Pierce about the difficulties of convincing Mexican authorities that the U.S. did not approve of such action. A task made more difficult when Pierce acknowledged Walker's government and struck an anti-filibustering provision from the treaty (both moves more likely power plays of negotiation and deviations from the norm rather than public shows of the administration's hand). Pierce's administration was robust in its pursuit of filibusters and effectively ended the best organized and funded of those aimed at Cuba when the president directly informed John Quitman, seated across from him at the time in the Oval Office, of his intention to prevent his efforts at annexation. James Buchanan, author of the Ostend Manifesto, brought high hopes from supporters of Cuban filibustering and equally sharp criticisms from those who saw a slave-power conspiracy in his administration actions. His continued support for Walker's new claims in Nicaragua didn't help matters. Yet, the public actions, declarations, and personas of the filibusters, so clearly on display in massive public gatherings and in the press throughout the $1850 \mathrm{~s}$, forced presidents to confront the threatened aggression. Interestingly, in the case of Buchanan, his efforts against William Walker's Nicaraguan filibusters appeared to many Southern observers as anti-Southern, since Walker's failure prevented the spread of slavery to Central America. Robert May, "The Slave Power Conspiracy Revisited: United States Presidents and Filibustering 1848-1861," in Union \& Emancipation: Essays on Politics and Race in the Civil War Era, eds., David W. Blight and Brooks D. Simpson (Kent, Ohio: Kent State University Press, 1997), 7-29; Robert May, John A. Quitman: Old South Crusader (Baton Rouge: LSU Press, 1985), 228-253; J. F. H. Claiborne, The Life and Correspondence of John Anthony Quitman, (New York: Harper and Brothers, 1860); K. Jack Bauer, Zachary Taylor: Soldier, Planter, Statesman of the Old Southwest (Baton Rouge: LSU Press, 1993), 253-290; Durwood Ball, Army Regulars on the Western Frontier, 1848-1861 (Norman: University of Oklahoma Press, 2001), 89-127; Joel H. Silbey, Storm over Texas: The Annexation Controversy and the Road to Civil War (Oxford: Oxford University Press, 2005); Ivory Chamberlain, Thomas Moses Foote, Biography of Millard Fillmore (New York: Thomas \& Lathrops, 1856), 179-200; Robert Mosley, "Cuba In American Foreign Relations (1848-1861): As Shown In Messages Of The Presidents And Debates In Congress," (MA Thesis, Washington \& Lee University, 1930); Antonio de la Cova, "The Taylor Administration versus Mississippi Sovereignty: The Round Island Expedition of 1849," Journal of Mississippi History 62, no.4 (Winter 2000), 295-327; David Grimsted, American Mobbing 1828-1861: Toward the Civil War (Oxford: Oxford University Press, 1998); Robert Merry, A Country of Vast Designs (New York: Simon and Schuster, 2009); Stephen Dando-Collins, Tycoon's War: How Cornelius Vanderbilt Invaded a Country to Overthrow America's Most Famous Military Adventurer (New York: DeCapo Publishing, 2009).
} 
Among the more prominent issues for every American president of the era was an ongoing concern that too aggressive a stance, whether official policy or accommodation of private schemes, might produce a hardening of the diplomatic environment and a corresponding invitation to another European power to guarantee Spain's ownership. ${ }^{330}$ As a result of the López expeditions, Spain prevailed upon the French and British to suggest a tripartite pact guaranteeing non-interference. While then Secretary of State Daniel Webster might have pursued a moreamendable European policy, his sudden death in late 1852 left the response and pursuance of United States diplomatic efforts to Edward Everett, who reiterated long-standing policy to reject any efforts at European interference in the hemisphere. Everett, in his official response, put forward many of the traditional American arguments indicating a lack of interest in the island (placating European governments) coupled with a desire for continued internal control of Cuba's slaves. Everett's articulation of United States policy coupled with his clarity of American

\footnotetext{
${ }^{330}$ Secrecy played a main role in the official attempts at purchase and a much less plausible role in the planning of filibusters (given the massive amounts of attention events and even private efforts garnered). Michael Rogin uses the juxtaposition between spectacle and secrecy to highlight the importance of both in the creation of a persuasive public policy. Although Rogin is speaking of the Iran/Contra affair in the late 1980s, his ideas about policy as exhibited in the public sphere are instructive. Spectacle, filibustering for instance, is not only a diversionary tactic away from some "real" policy goals. Political spectacle in the postmodern empire, in other words, is itself a form of power and not simply window dressing that diverts attention from the secret substance of American foreign policy. If we substitute López and his backers for the U.S. government as the creators of foreign policy regarding Cuba, we can look for a greater truth in their public pronouncements other than simple 'cover' for secretive Southern plotting. In fact, given the impotency of attempts at purchase, the very public pronouncements of the filibusterers and the spectacle that chased López throughout the country, were probably clearer articulations of policy than anything the U.S. government crafted. The confusion between the public and covert is what produces power. For Rogin, it was Ronald Reagan and his ability to master the stage, 'the spectacle,' that prevented his acknowledgement of secret misdeeds during Iran/Contra (maybe akin to the Filibuster's trials in 1850) from hurting his political and public standing. In the current example, López and his allies deployed his public persona in a way that allowed him to bolster his standing and gain trust. This helped allay fears on the part of many who supported him but were not privy to his and others' secret machinations to go along with him. Paradoxically, this positioning also allowed López and his supporters to criticize the U.S. government, particularly Presidents Taylor and Fillmore for their private dealings with Spain while claiming an a priori right to conduct at least a portion of the Cuban annexation negotiations among interested parties in private. This mistrust of government secrecy reached its pinnacle with the publication of the Ostend Manifesto. The public saw through the folly and accused it of being a Southern gambit driven by Soulé's bombast. Clearly, the cult of personality López enjoyed was the very thing that bounded a diverse political, social, and cultural array of supported together in support for Cuban freedom. Michael Rogin, “"Make My Day' Spectacle as Amnesia in Imperial Politics," in Cultures of United States Imperialism, ed. Amy Greenberg and Donald Pease (Durham: Duke University Press, 1994), 499-534.
} 
purpose in establishing American parity on the international level is worth quoting, if for nothing

else, than to read of the Secretary's fear of the public response to an agreement with European

powers.

The President fully concurs with his predecessors, who have on more than one occasion authorized the declaration that the United States could not see with indifference the island of Cuba fall into possession of any other European government than Spain; not, however, because we should be dissatisfied with any natural increase of territory and power on the part of France or England... In like manner, the United States have, within the same period, greatly increased their territory. These accessions of territory have probably caused no uneasiness to the great European powers, as they have been brought about by the operation of natural causes, and without any disturbance of the international relations of the principal States. They have been followed, also, by a great increase of mutually beneficial commercial intercourse between the United States and Europe. But the case would be different in reference to the transfer of Cuba from Spain to any other European power. That event could not take place without a serious derangement of the international system now existing, and it would indicate designs in reference to this hemisphere which could not but awaken alarm in the United States... The island of Cuba lies at our doors. It commands the approach to the Gulf of Mexico, which washes the shores of five of our States. It bars the entrance of that great river which drains half the North American continent, and with its tributaries forms the largest system of internal water-communication in the world. It keeps watch at the doorway of our intercourse with California by the isthmus route...The President has given ample proof of the sincerity with which he holds these views. He has thrown the whole force of his constitutional power against all illegal attacks upon the island. It would have been perfectly easy for him, without any seeming neglect of duty, to allow projects of a formidable character to gather strength by connivance...Cuba, at this moment, costs more to Spain than the entire naval and military establishments of the United States costs the federal government. So far from being really injured by the loss of the island, there is no doubt that, were it peacefully transferred to the United States, a prosperous commerce between Cuba and Spain, resulting from ancient associations and common language and tastes, would be far more productive than the best contrived system of colonial taxation...I will but allude to an evil of the first magnitude: I mean the African slave-trade, in the suppression of which France and England take a lively interest - an evil which still forms a great reproach upon the civilization of Christendom, and perpetuates the barbarism of Africa, but for which, it is to be feared, there is no hope of a complete remedy while Cuba remains a Spanish colony. Even now the President cannot doubt that both France and England would prefer any change in the condition of Cuba to that which is most to be apprehended, viz.: an internal convulsion which should renew the horrors and the fate of San Domingo. I will intimate a final objection to the proposed convention. M. de Turgot and Lord Malmesbury put forward, as the reason for entering into such a compact, "the attacks which have lately been made on the island of Cuba by lawless bands of adventurers from the United States, with the avowed design of taking possession of that island." The President is convinced that the conclusion of such a treaty, instead of putting a stop to these lawless proceedings, would give a new and powerful impulse to them. It would strike a death-blow to the conservative policy hitherto pursued in this country toward Cuba. No administration of this government, however strong in the public confidence in other respects, could stand a day under the odium of having stipulated with the great powers of Europe, that in no future time, under no change of circumstances, by no amicable 
arrangement with Spain, by no act of lawful war (should that calamity unfortunately occur), by no consent of the inhabitants of the island, should they, like the possessions of Spain on the American continent, succeed in rendering themselves independent; in fine, by no overruling necessity of self-preservation should the United States make the acquisition of Cuba. ${ }^{331}$

To return to the beginning for a moment, the Cuban cause received an important early jolt

when, in May 1848, Senator Lewis Cass introduced a bill that included, among other provisions,

the purchase of Cuba. The bill, mainly focused on potential American response to British

\footnotetext{
${ }^{331}$ Edward Everett to The Comte De Sartiges, December 1, 1852 in Alexander Hill Everett, Cuba; The Everett Letters on Cuba, (Boston, G. H. Ellis, 1897), 15-20; Everett's ascension to the Secretary's chair had an important impact on the proceedings as A.A. Ettinger demonstrates fairly convincingly that Fillmore and Webster conducted a fairly secret negotiation, at the time, with the British and French foreign offices. Alluding to the Administration's interest in the treaty, Webster schooled his British and French colleagues on the intricacies of the domestic situation and the finesse needed to make a deal. Fillmore was ill at ease in his second inaugural in which he dedicated over one-third of his speech to the final López filibuster. "Such is the melancholy result of this illegal and ill-fated expedition. Thus thoughtless young men have been induced by false and fraudulent representations to violate the law of their country through rash and unfounded expectations of assisting to accomplish political revolutions in other states, and have lost their lives in the undertaking. Too severe a judgment can hardly be passed by the indignant sense of the community upon those who, being better informed themselves, have yet led away the ardor of youth and an ill-directed love of political liberty...These originators of the invasion of Cuba seem to have determined with coolness and system upon an undertaking which should disgrace their country, violate its laws, and put to hazard the lives of ill-informed and deluded men. You will consider whether further legislation be necessary to prevent the perpetration of such offenses in future. No individuals have a right to hazard the peace of the country or to violate its laws upon vague notions of altering or reforming governments in other states." Fillmore, "Second Inaugural Address," accessed March 15, 2014, http://www.presidency.ucsb.edu/ws/?pid=29492. At a quiet meeting with his British and French counterparts, Webster indicated that President Fillmore's concern for the upcoming election (in which he was eventually passed over for the Whig party nomination in favor of Winfield Scott) held their options limited. As described by British Minister John Crampton, "He (Webster) assured us, however that we could not state too strongly to our respective governments his own entire concurrence in their view with regard to Cuba. As long as Mr. Fillmore is President and I am at the head of the State Department, nothing will happen which the French and English governments could fear. We are on the eve of a Presidential election and every attempt to resurrect a question which will certainly meet much opposition in the country presents, at such time, particular difficulties. The people of the South are in favour of acquisition of Cuba, in demanding that an effort be made for acquisition by legitimate means, that is to say by way of purchase... the publicity given to the project begun by Mr. Buchanan will have been of such a nature as to serve his interest in the Northern States (he was standing for Vicepresident in 1852) and consequently the action of the present administration in this matter will be more free. There is in our people, I need not tell you, a sort of vulgar reluctance to make conventions with crowned heads unless absolutely necessary and the general principle of the foreign policy of this country has been never to from entangling alliances." The reality of American electoral politics shaped the diplomatic approach toward Cuba. A. A. Ettinger, "The Proposed Anglo-Franco-American Treaty of 1852 to Guarantee Cuba to Spain," Transactions of the Royal Historical Society 4, no. 13 (1930), 49-185, (quote on 166); James Morton Callahan, Cuba and International Relations: A Historical Study in American Diplomacy (Baltimore: Johns Hopkins Press, 1899); Lester D. Langley, "The Whigs and the López Expeditions to Cuba, 1849-1851: A Chapter in Frustrating Diplomacy," Revista de Historia de América 71 (January-June 1971), 9-22; Robert Dalzell, Daniel Webster and the Trial of American Nationalism, 1843-1852 (Boston: Houghton Mifflin, 1973); Edward Mihalkanin, American Statesmen: Secretaries of State from John Jay to Colin Powell (Westport, CT: Greenwood Press, 2004), 175-190; Allan Nevins, Ordeal of the Union, Vol. 1: Fruits of Manifest Destiny, 1847-1852 (New York: Scribner, 1940); Kenneth Shewmaker, "Daniel Webster and the Politics of Foreign Policy, 1850-1852," Journal of American History, 63 (September 1976), 303-315; Robert Remini, Daniel Webster: The Man and His Time (New York: Norton, 1997), chs. 30-41.
} 
interests in the Yucatán region. The area found itself in open war (the Caste War) at that moment and these hostilities gave Cass the opportunity to press the issue of Cuba's strategic importance, particularly given the annoyingly everlasting presence of the British in the Caribbean. "The Gulf of Mexico must be practically an American lake. It should be a cardinal principle in our policy never to be lost sight of, that the command of the Gulf of Mexico must never pass into foreign hands." The issue of race also overlaid much of the Yucatán debate with Cass and those supporting intervention in the conflict, and even American annexation of Yucatán, focused on protecting both white settlers from indigenous Mexican attack and preventing the British from using the unrest as a reason to take the Yucatán for themselves. Cass also referenced the region's importance to Cuban security and its potential use as a staging ground for British or Mexican annexation of the island. Conversely, Ohio Representative Joseph Root took the opposite tact and argued that the Yucatán's indigenous population should be encouraged to rightfully claim their fair share against their Mexican creole oppressors. However, Root eventually conceded, "my sympathies were, first, in favor of the white race; but those who went on this ground must show better samples of the white man than these Spaniards before they would get up his sympathies very high." Despite the tensions, the parties settled the issued with a peace treaty in May, 1848. However, the Yucatán debates' direct applicability to the Cuba situation must be noted. American politicians used arguments that later made appearance in the Cuban debates. Those who forwarded a racial argument against the "indigenous savagery" of the Yucatánese (Cass himself argued the Yucatánese were as unfit for rule "as much as our Indians, whose conduct they closely imitate in this war of extermination") alluded to the threat of Saint Domingue if the uprising of the indigenous Yucatánese found international encouragement. The application of this racial uprising paranoia to later Cuban debates was present in some American 
politicians abiding fear that the Spanish government, under British sway, might incite indigenous/slave populations to rebel against creole property owners. Therefore, annexation of Cuba was in actuality the only plausible American action to prevent "Africanization" of the island. The Yucatán example collated the arguments in support of Cuban annexation and can be seen as a rhetorical dry run on both sides of the issue. ${ }^{332}$

While President Polk remained reservedly interested in acquiring Cuba, events on the island soon forced the issue to the forefront of United States policymaking. The United States

\footnotetext{
${ }^{332}$ Cass and Root quoted in Shelley Streeby, American Sensations: Class, Empire, and the Production of Popular Culture (Sacramento: University of California Press, 2002), 180-190. The introduction of Cuba into the postMexican war debates indicates the rising importance of the issue of purchase and annexation. Stephen Douglas' participation was particularly important representing as he did the rising influence of the railroad and steamboat interests that demonstrated the practical investment in annexation of U.S. business interests. Men like George Law, an important financial supporter of Douglas' career and owner of the U.S. Mail Steamship Company, wanted to move more commerce in and out of Cuba and sought government action to open up the profit center. Annexation meant lower tariffs, more passengers, and an already existing infrastructure on the island that guaranteed a return on minimal necessary investment. The Yucatán debate also brought John Calhoun's voice to the public debate for one of the last times. Ever the pessimist, John Calhoun opposed annexation of Yucatán because he argued it provided no strategic value, could not sustain any commercial agricultural, and would introduce a confounding racial amalgamation challenge like the incorporation of all Mexico. ("Speech on the Proposed Occupation of the Yucatan, May 15, 1848 in Richard Cralle, ed., The Works of John C. Calhoun: Speeches Delivered in the House of Representatives and in the Senate of the United States (New York: D. Appleton, 1888), 454-479. Calhoun's view on Cuban annexation was also a moving target throughout much of his career. Ambrosio Gonzalez penned an open letter to the Charleston Mercury (8/31/51) in the shadow of López's failure (and a year after Calhoun's death) that argued, despite recent public discussions, that Calhoun strongly supported annexation. Although this seems to be a bit of wishful thinking directed at burnishing the López movement's reputation, in tatters after the Crittenden executions. The evidence of Calhoun's reluctance toward territorial expansion was long-standing faith going back to the Monroe administration and strengthened by his 1848 Senate resolution against Mexican annexation, and his Yucatán speech. In that speech Calhoun outlined his comfort with Cuba remaining Spanish. "So long as Cuba remains in the hands of Spain - a friendly power - a power of which we have no dread - it should continue to be, as it has been the policy of all administrations ever since I have been connected with the Government, to let Cuba remain there," ("Occupation of the Yucatán," 466). Calhoun's correspondents entertained the issue in numerous letters written to him in the summer and fall of 1849, including one from O'Sullivan that closed with a slight flourish. "[PS] If I, a 'New York Free-Soiler,' am so deeply interested in behalf of this movement, what ought not be the enthusiasm of a Southern Gentlemen." The insinuation stands clear, O'Sullivan felt Calhoun in need of convincing which grew impossible with Calhoun's failing health, removal from public view, and death during the López heydays. O'Sullivan to Calhoun, August 24, 1849, in John C. Calhoun, The Papers of John C. Calhoun, Vol. 27, ed. William Hemphill (Columbia: University of South Carolina Press, 2003), 32. U.S. soldiers had little interest as well. Said one graduating Army cadet, "People say we must go to Yucatan. Hope not. Cuba's my weakness - after that - Yucatan if you please. In the meantime let the peons there elevate the standards of humanity by cutting each other's throats-and thus rid the world of some of the worst species [of] men of humanity extant;" (Henry Jackson Hunt to James Duncan, June 2, 1848 quoted in May, "Cultural Mirror," 880. Paul Bergeron, The Presidency of James K. Polk (Lawrence: University Press of Kansas, 1987), 106-108. Nelson Reed, The Caste War of Yucatán (Stanford: Stanford University Press, 2002).
} 
consul in Havana, Robert Campbell, wrote to Secretary of State Buchanan indicating a state of general unrest in and around Havana.

Notwithstanding the want of many of the requisites to ensure success, there appears every probability that the Island will soon be in a state of civil war...if revolution is attempted and succeeds immediate application would be made to the United States for annexation as the most intelligent of the Creoles have an abiding conviction of their utter incapacity for self-government, a conviction which must be felt by anyone who has had opportunities of student or even observing their character. ${ }^{333}$

Herein laid an oft-repeated trope of the American approach to Cuban creole elites and for that matter the leaders of Europe's revolutions of 1848; beyond economic and political gain, the arrival of the United States offered the hope of more efficient deployment of intellectual and economic resources. Just as Americans had long-justified their expropriation of lands belong to American Indians with calls of misuse through lack of cultivatory use, so too the moral imperative existed to liberate Cuban lands from misuse. The imperial misappropriation of the island was doubly troubling since it was not only predatory - a perversion of the natural order of equitable interchange among sovereign entities - but also encouraging of a sloth in the Cuban psyche that demanded recalibration. The Cuban in the American mind, unlike the American Indian, wanted to do more and to be more, wanted to be self-possessed, and wanted to be more American in their makeup and outlook. Maturin Ballou, an American visitor to Cuba and militant expansionist, further suggested that a lack of masculinity was responsible for Spanish dominance of Cuba.

It appears almost incredible that an intelligent people, within so short a distance of our southern coast, constantly visited by citizens of free republic, and having the example of a successful revolt set them by men of the same race both in the north and south, weighed down by oppressions almost without parallel, should never have aimed as effectual blow at their oppressors. It would seem that the softness of the unrivalled climate of those skies beneath which it is luxury only to exist, has unnerved them, and that the effeminate spirit of the original inhabitant has descended in retribution to the posterity of the conquistadores. ${ }^{334}$

\footnotetext{
${ }^{333}$ Robert Campbell to James Buchanan, May 18, 1848 quoted in Chaffin, Narciso López, 31.

${ }^{334}$ Maturin Ballou, A History of Cuba, (Boston: Phillips, Sampson, and Co., 1854), 37.
} 
The racial issue was also one that remained constantly in the background thoughts of

Americans who felt that race impacted the Cuban creole ability toward self-governance since the bulk of their time and effort was directed toward preservation and not innovation in politics. Julia

Ward Howe observed weakness as also produced by the closeness of races on the island.

The black and white races are, by all accounts, more mingled in Cuba than in any part of our own country. People who have long been resident there assure us that some of the wealthiest and most important families are of mixed blood. I have not seen in Cuba anything that corresponds to our ideal separation of the two sets of human beings, living in distinctness one from the other, hating and wronging each other with the fierceness of enemies in the death grapple. ${ }^{335}$

Jane Storm McManus focused on the social conditions that, when added to the political concerns demanded action.

Borne down by foreign soldiers for whose support she is taxed until almost the necessaries of life are doubled in price; deprived of freedom of speech, of press, and conscience; forbid to discuss or even petition for relief, and overwhelmed by importations of slaves from Africa, whose presence she does not desire, but who are held upon her disarmed citizens in perpetual threat, Cuba has reached that point of suffering in which it becomes suicide and crime to remain passive. ${ }^{336}$

The racial repercussions of uncontrolled revolt added to the great concern about the social and political abilities of the Cuban creoles. Polk was in a bit more settled mood with the nomination of Lewis Cass, an annexation supporter, as Democratic candidate for president. The President figured that any political damage done in the pursuit of Cuban annexation would already follow Cass on the campaign trail anyways, thus allowing the president a freer hand in pursuing the island. ${ }^{337}$ Polk feared, however, that overthrow of Spanish rule at the hands of an unfit creole

\footnotetext{
${ }^{335}$ Julia Ward Howe, A Trip to Cuba (New York: Negro Universities Press, 1969), 31

${ }^{336}$ Jane Maria McManus Cazneau, The Queen of Islands and the King of Rivers (New York: Charles Wood, 1850), $1-2$.

${ }^{337}$ The disappointment at the failure of Martin Van Buren to capture the Democratic nomination and presidency in 1848 pushed many disillusioned Young Americans, like O'Sullivan from active public politics. Free Soil Democrats also balked at Van Buren's failure, as they came to see the entire nomination process being more about placation of Southern Democrats rather than the capturing of progressive liberalism in the wake of revolt throughout Europe. The shared disgusted only grew with the nomination of Lewis Cass, a well-known popular sovereignty advocate, and the perceived monstrous failure of moral courage shown by the Democrats in his nomination. Zachary Taylor's eventual election and the failure of conviction it represented exacerbated the feelings of betrayal for many in the Young
} 
effort or, conversely, that effort's failure would strengthen Spanish control and British/French

interference. He was less encouraged when Senator Jefferson Davis along with members of the freshly established pro-annexation New York Consejo Cubano - a group of expatriates, José Iznaga, Gaspar Cisneros, and Alonse Betancourt, writing and printing La Verdad - visited the White House and indicated the furthering of the creole rebellion's operational momentum. Polk wrote of the meeting in his diary. "They spoke of the desire of the Cubans to throw off the Spanish Yoke and to become annexed to the United States They did not ask the interference of this government." Unbeknownst to the White House visitors was Polk's determination to scuttle the entire undertaking by informing the Spanish Minister in Washington of the information the president had been given by O'Sullivan, Douglas, Davis, and the Consejo Cubano. Polk also sent letters to Madrid informing the Spanish government of the danger and to Major General William Butler in Mexico instructing him to prevent the movement of any Americans offering their assistance in the uprising. Polk's reasoning was clear as he related again in his diary. "The best

America camp. Paradoxically, the issue of slavery took on an added local dimension that replaced the primary allegiance to party in the era. The Lincoln and Douglas debates represented the deeper division in the country and the importance of slavery in local and state debates. Senatorial debates were an interesting representation of the increased ferocity of debates over slavery on the local level as the elections for state representatives produced solid delegates for appointment of Senators. Therefore the debates over slavery among vying politicians for the federal Senate produced an associated rigidity among state representatives who had to demonstrate their bonafides, usually based on the slavery issue, in order to secure votes for state office to then dependably vote on a Senate appointment. Robert May, Slavery, Race, and Conquest in the Tropics: Lincoln, Douglas, and the Future of Latin America, (New York: Cambridge University Press, 2013); David Schleicher, "The Seventeenth Amendment And Federalism In An Age Of National Political Parties," accessed on March 15, 2014, http://www.law.gmu.edu/assets/files/publications/ working_papers/1333 SeventeenthAmendmentandFederalism.pdf; Herbert Donovan, The Barnburners: A Study Of The Internal Movements In The Political History of NY State And The Resulting Changes In Political Affiliation (New York: NYU Press, 1925); Jerome Mushkat, Tammany: The Evolution Of A Political Machine (Syracuse: Syracuse University Press, 1971); Richard Scott, Workers In The Metropolis: Class, Ethnicity And Youth In Antebellum America (Ithaca; Cornell University, 1990); Sean Wilentz, The Rise of American Democracy: Jefferson to Lincoln (New York: W. W. Norton \& Company, 2006); Michael Holt, The Rise and Fall of the American Whig Party: Jacksonian Politics and the Onset of the Civil War (Oxford: Oxford University Press, 2003); Leo Hershkowitz, "The Loco-Foco Party Of New York: Its Origin And Career," New York Historical Society Quarterly 46 (July 1962), 305-29, Eric Foner, Free Soil, Free Labor, Free Men: The Ideology Of The Republican Party Before The Civil War (Oxford: Oxford University Press, 1995); Harry L. Watson, Liberty and Power: The Politics of Jacksonian America (New York: Hill and Wang, 1995); Joanne B. Freeman Affairs of Honor: National Politics in the New Republic (New Haven: Yale University Press, 2002); Joyce Appleby, Inheriting the Revolution: The First Generation of Americans (New York: Belknap, 2001). 
mode of approaching Spain with the view to purchase Cuba would be to do so in a manner to satisfy them of our friendly disposition, and that we did not intend to take part in any revolution by which the Spanish authority would be overthrown." Thus alerted to the danger, the Club de la Habana ditched its plans to move ahead with the revolt, giving just enough time to the Club's second choice to head the mission, Narciso López, to leave Cuba before arrest. ${ }^{338}$

Clearly, many Americans stood ready to embrace Cuba's annexation as enthusiastically as many in the creole elite advocated for it. However, the United States was not to be a quiet partner, but rather a boisterous political, economic, and literary advocate for amalgamation.

The extension of empire by CONQUEST will soon be superseded by the irrepressible desire of states to become united to each other by the NEW LAW OF ANNEXATION. This is already inspiring no inconsiderable proportion of the inhabitants of every nation on this continent to become an integral part of our own great Republic. The history of the future will be, in a continually increasing degree, a detail of the rapid operation of this principle [of ANNEXATION], until the world shall be completely united and bound together by the tracks of its intercommunication, the combination of its interests, the sympathies of its intelligence, and the unity and oneness of its hopes; and the last triumph which is ordered by Providence, has realization in the dawn of that period when all the nations of the earth shall be as ONE PEOPLE (capitalization in original). ${ }^{339}$

Cuban annexation was the dominant topic in the wake of the Mexican War; a perceived palate cleanser of republican purism and a tonic for the bald expansionism of 1846-48. The New York

Times declared on October 22, 1852, "The Cuban question is now the leading one of the

\footnotetext{
${ }^{338}$ James K. Polk, Diary of James K. Polk, Vol. III, 498, 488. The Club de la Habana originally chose American General William Worth, who accepted their offered of $\$ 3$ million to lead the expedition in 1848, augmented with American troops and irregulars leaving Mexico with him. Worth marched his troops to Vera Cruz where they were tantalizing close to embarking for Cuba. López, in the meantime, agreed to the Club's request to delay his own planned uprising until Worth's force of 5000 landed in Cuba. Worth travelled to Washington with Ambrosio Gonzalez, the Club's representative, and dispatched his own man to Havana to check out preparations. Just before the filibuster, Worth (not coincidentally) received transfer orders from the War Department, which prompted his withdrawal from the operation. He died of cholera on May 7, 1849. Worth's travels, the prominence of his public persona, the Polk administration's concerns about Mexico as launching ground for filibusters, and the complete inability to protect secrecy (a recurring problem for Cuban annexation) all sank the project. Edward Wallace, General William Jenkins Worth, Monterey's Forgotten Hero (Dallas: SMU Press, 1953); Robert May, Manifest Destiny's Underworld: Filibustering in Antebellum America (Chapel Hill: University of North Carolina Press, 2002), chs. 1-3.

339 "Cuba," Putnam's Monthly Magazine, January 1853, 5-16. The author of "What Impression Do We, and Should We, Make Abroad?" Putnam's, October 1853, 345-54, similarly contrasted a "young, fresh, and surpassingly vigorous" United States with such "exhausted" nations as Spain.
} 
time." ${ }^{340}$ The excited engagement by Cuban creole elites on the island and expatriates in New York and New Orleans further fed the annexation fever. While the slavery debate retained its preeminent place in local and national discussions, annexationists, fueled by their conceptualizations of American manifest destiny and with explicit Cuban support, redirected public attention on Cuba as the next recipient of a grandly patriotic foreign policy. An important component of supporters' efforts, beyond the economic interests many held in Cuban, was a hope that American unity under the banner of annexation might smooth domestic differences over slavery and distract energy away from local friction on that issue. In an effort that rivaled modern day media campaigns built on strategies of simultaneity, market saturation, and message targeting, Cuban and American supporters of annexation put forward a robust, timely, and overwhelming campaign. The widespread reach of the public relations effort and the perceived marketability of this effort by publishers, despite the lack of opinion polling, demonstrated an overwhelming support for the effort to take Cuba.

The popularity of cause and personal notoriety of López was fairly indisputable. As the New Orleans Delta pointed out by equating filibustering with liberation in 1850, "The

\footnotetext{
${ }^{340}$ James W. Cortada, “The New York Times, Spain and Cuba, 1851-1869," Revista de Historia de América 77/78 (January - December 1974), 61-75. The Times held a certain detachment from the annexation issue although there existed a clear antagonism for the efforts' realism and the abrasive foreign policy of various presidents. As the paper printed in response to the bombast of the Buchanan administration "There is probably no court in Europe which regards this country with greater detestation than that of Madrid. This is due partly to recollection of the piratical attempts made, without any adequate opposition from our government, upon her dominions, and partly to the loud denunciations of 'Spanish outrages' which have been officially and offensively issued by the present Administration' (January 13, 1857). The Times also saw the rising crisis in Santo Domingo as a result of aggressive foreign policy and the Spanish response against Haitian incursion as an attempt to beat back U.S. influence on the island. References to Haiti seem to drastically fall off in American debates throughout the 1850s. The reference to its revolution became more of the obligatory footnote rather than burning threat. This seems a result of the effective elimination of the events (history) and reality (present) of its role as a geopolitical actor, despite its efforts in the Dominican Republic. This reaction to Haiti also seems, at least in part, as a response to domestic issues of which Cuba and Britain was the more direct gravitational forces acting upon political decisions. Edward E Baptist, "Hidden in Plain View: Haiti and the Louisiana Purchase," in Echoes of the Haitian Revolution in the Modern World, eds. Elizabeth Hackshaw and Martin Munro (Kingston, Jamaica: UWI Press, 2008); James A. Padgett, "Diplomats to Haiti and Their Diplomacy," The Journal of Negro History 25, no. 3 (July 1940), 265-330; Rayford Logan, The Diplomatic Relations of the United States with Haiti, 1766-1892 (Chapel Hill: UNC Press, 1941).
} 
fashionable word for the members of the late Expedition to Cuba is filibuster. Terms, bestowed in reproach, are often accepted as compliments by those to whom they are applied. So it is with the gallant young men who formed the late Expedition to Cuba...thus, therefore, the word 'Filibuster' has acquired a significance and popularity, which is likely to give it considerable run. It has entirely superseded the world 'Liberator."” The arrival of Narciso López did not begin the Cuban annexation movement in the United States. However, his arrival hastened the public debate and gave proponents an important leader for their push. Certainly, Narciso López's character can be called into question. Thomas William Wilson, a clear opponent of annexation, did as much soon after the general's death in 1851. "In regard to his capacity, he was inferior, and his morals, as may be conjectured, were of a very low cast. The gambling table reduced him to low shift of borrowing money from everybody in his acquaintance who would make him a loan, and his last few years in Cuba witnessed him as associate of the lowest characters in society." Most historians, following this general view of López, dispense with him using a few cursory remarks about López's Venezuelan birth, service in the Spanish military against the revolutionary movement of Simon Bolívar in Colombia, return to Spain and participation in the Spanish Civil War, and finally his rising to General with corresponding official appointments in Cuba, including a governorship of the Trinidad region on the southwest coast of Cuba. ${ }^{341}$

Yet, something profoundly changed in Narciso López between the years 1843 and 1848 . His personal economic problems, the recall to Spain of his benefactor Captain General Valdés and with it his patronage position in Cuba, his covert links with David Turnbull and British agitators, and his involvement with the Club de la Habana, all radicalized his views on Spanish

\footnotetext{
${ }^{341}$ New Orleans Delta, June 23, 1850; Thomas William Wilson, An Authentic Narrative Of The Piratical Descents Upon Cuba Made By Hordes From The United States: Headed By Narciso López, A Native Of South America; To Which Are Added, Some Interesting Letters And Declarations From The Prisoners, With A List Of Their Names \&C (Havana: Self Published, 1851), 4.
} 
rule. This was an astounding change of mindset, particularly notable from a man who, as governor of Trinidad, was known for his severe punishment of Cuban criminals and dissidents. The language of freedom or annexation was always imprecise for López. He rightfully sensed the strong support of those who economically and politically drove his efforts for the amalgamation of American and Cuban slavery. However, he grew to prominence in the Colombian cauldron and had Simon Bolívar's example as experiential knowledge. Although an adversary of the Liberator, López understood the intense conflict surrounding Colombian slavery, Afro-Colombian liberation, and national definition. These were issues, as intertwined as they were thorny, on which López presciently prevaricated. He allowed supporters to imbue the concept of annexation with whichever conceptualization of his motives and goals they chose. Undoubtedly, there was widespread support for the López's undertakings and he fashioned himself Cuba's El Libertador. Like Bolívar, he had long ago lost his fortune, land, and title, and now only had political success as a lifeline to immortality. Throughout his three years in the United States, López surpassed the popularity of any foreign or American born public figure of the nineteenth century. The mustachioed general, together with his Cuban and American supporters, brought the United States to the very brink of annexation of Cuba. His four attempts to wrest the island from Spanish control (one which promoted his exile to the United States and three launched from American shores) were the events of the post-Mexican war period. The magnetism of man and cause drew all he encountered toward his efforts. ${ }^{342}$

\footnotetext{
${ }^{342}$ Where to start with López's intentions, character, and importance? Much like evolving interpretations of $\mathrm{La}$ Escalera, Cuban racial nationalism, and sugar's historical tail, interpretations of López move through similar periods of historical and political reinterpretation. Contemporarily in the 1850s, the impact of the López's efforts on the 1868 rebellion is muted. As he had little impact on the island itself in his military attempts, his was not a name or cause taken up by many Cubans, particularly AfroCubans. This is particularly due to the quick pivot creoles on the island make away from annexation. The $20^{\text {th }}$ century interpretation, driven by Portell-Vilá's biographies, is more sympathetic and more embracing of López's importance to the Cuban independence movement. This largely rests on Portell-Vilá's insistence that López's use of annexation and silence on slavery were situationally necessary actions designed to elicit American support. The tide turned again after the 1959 revolution, when López became an
} 
What tragedies befell Narciso López from 1843-1848 are a blur. He lost most of his family's and his wife's money on a series of failed business ventures, including a mining concern in Cienfuegos where began his first abortive uprising (Conspiración Mina de la Rosa Cubana), which earned him and his compatriot Cirilo Villaverde death sentences. He wrote nothing public in the period save a fragmentary journal, which his chief biographer (Herminio Portell-Vilá) claims to have seen in preparing his three volumes on López's life yet is nonexistent today, and four one-page circulars outlining his ambitions (all of which were undoubtedly prepared by someone else, probably his secretary Cirilo Villaverde). Additionally, López did pen some private letters but they were more introductory and summative in their content). What is known is that the incredible tumult that Cuba felt in that three-year period did much to energize the independence movement on the island. The results of two massive hurricanes, a slave uprising conspiracy and numerous revolts, a substantial move away from coffee production, British abolitionist agitation, the fear of "Africanization" of the island, the emergence of a self-aware bourgeoisie, and a succession of severe Captain Generals, did much to radicalize portions of the Cuban creole elite. And so it was, López, along with many in the island's upper echelon, jumped from the cauldron of Cuban political affairs into the equally tempestuous fires of American expansionism.

If Narciso López enthusiastically played the roles of liberator, underdog, swashbuckler, hero, and patriot, then Americans enthusiastically responded in kind to his exhortations. Yet, the general while flesh and bone, had he not existed, would have been invented by Americans of the 1850s. For the American psyche found in López the physical manifestation of the vision held of

\footnotetext{
American stooge and agent of imperialism. López's life is recounted in summation in A. Filibustero, The Life of General López and History of the Late Attempted Revolution in Cuba (New York: Dewitt \& Davenport Publishing, 1851) and in numerous newspaper and journal features of the period such as, "General López, the Cuban Patriot," Democratic Review 26, no. 140 (February 1850).
} 
the American passion story. However, the physical vessel was of earthly creation, susceptible to death and only momentarily able to capture attention before dimly fading from memory. The fact that history largely forgets López, William Walker, Lajos Kossuth, John L. O’Sullivan, John Quitman (to say nothing of the historical erasure of the early Cuban expatriate community's luminaries) hints at the ephemeral nature of their efforts and the ceaseless archetypal revolutionist shopping that the American story encourages. An interchangeable array of characters paraded through the scenery of antebellum society and politics, each one uniquely able to example some signal trait important to American self-conceptualization. Some of these characters exhibited a variety of these traits and with this good fortune they captivated a rabid population. Supporters saw in López not just someone to support but a world citizen simultaneously embracing of the American dream and representative of its self-promoting drive to conquer against all obstacles. Even López's critics, in their dressing down of his personal traits and felonious actions, stood in awe of his abilities. Certainly, those critical of the General saw his foreignness as disqualifying him for such extravagant displays of basic American traits. However, it was that very foreignness that, for supporters, demonstrated their highest aspirations of the encouragement and support of indigenous independence movements wherever they sprang up throughout the world.

This was to be a benevolent conquering, accomplished initially with kindling and sparks in the souls of the restless throughout the world, and later fueled by the combustibility of democracy's inevitability. López counted Northerners and Southerners among his supports, roughly equal in number and excitement. Mercantilists, capitalists, agriculturalists, rural and urban dwellers, farmers and factory workers, Democrats and Whigs all embraced the General, both the ideology of his mission and his physical presence at events throughout the United 
States. His was a complicated undertaking, with his reasoning often hidden from public view.

Yet, this was an undertaking that, with much effort on his part, could easy be stretched to satisfy

an array of desires in the multitudes. Surprisingly, given the common historical assertion that

López existed solely as a stooge of Southern slave interests, among the most skeptical of

annexation by filibustering were both large cotton planters in the southeast, concerned with the

loss of British trade in retaliation for United States military efforts and Louisiana sugar producers who feared Cuban competition. ${ }^{343}$

López was one of many upwardly mobile men in the 1840s and 1850s. Having lost his money but not his ambition, López, just as the young men who fought alongside him and those who supported his efforts, sought ways to articulate their masculinity beyond the simple accumulation of capital. The premise of filibustering lay upon the intertwined web of masculinity, patriotism, republican idealism, and willful ignorance of reality all of which operated in the pages of pamphlets and newspapers, the daises of public meeting spectacles, the purchasing of bonds, public lectures, and staged plays that all offered outlets for frustrated masculinity. As the New York Daily Tribune spoke of filibustering and its adherents, "young men of that class who are usually most ready for any adventure that promises movement, no

\footnotetext{
${ }^{343}$ Free-soilers had little use for López's efforts as well. However, practical free-soilism (a belief in the political importance of halting slavery's spread without necessarily embracing abolition or equality) must be separated from a more vehement strain practiced by a smaller group of abolitionist free-soilers. The practical political practitioners prevaricated, as did López, on the issue of slavery where it already existed and were not convinced that López didn't intend to abolition slavery in Cuba, if gradually and despite a lack of clarity on whom might be in this decisionmaking position in an independent Cuba. As William O. Scroggs argued in his look at William Walker, a dedicated expansionist and slavery defender, even Walker got his start in the free soil politics of the early Californian political landscape. Horace Greeley, through his anti-slavery New York Tribune, was the most ardent critic of López, understanding with great insight his true intentions. Typical of his opinion on López's efforts and its leader's subterfuge was an editorial written just prior to the final filibustering attempt in 1851. "The 'revolutions' in Europe, which The Tribune has favored all looked to the Enfranchisement and Elevation of the Laboring Class - the Cultivators of the Soil - as their chief end. The 'revolution' in Cuba proposes to leave the cultivators of her soil in the position of beasts or chattels, subject to be flogged, starved, sold or tortured as the caprice or fancied interest of the landlord caste shall dictate." New York Daily Tribune, April 28, 1851. On concerns about annexation from the more conservative Southern planter class see Richard Follett, The Sugar Masters: Planters and Slaves in Louisiana's Cane World, 1820-1860 (Baton Rouge: LSU Press, 2005).
} 
matter in what direction or for what purpose." Newspapers, politicians, and even Presidents continuously referred to the youth of filibusters; a group of men with limited options searching for a rite of passage. As Harpers Monthly pointed out, "López appeals to that class of our people whose opinions of the morality and legality of any action depend upon its success or failure.” Filibustering seemed as just another career option and one that allowed a personal setting of the masculine scales to balance. "What business have a set of Transatlantic degenerate don sons of bitches as the inhabitants of old Spain to rule such a garden spot."344

López and his press surrogate, John O’Sullivan shared much in their lives, with paths and ideals as well as personal space placing the two men together in close proximity until López's untimely demise. These two men shared much after the deaths as well, namely the obfuscation of history. López, a highly decorated Spanish general who took up the mantle of Cuban freedom celebrated in his day throughout the United States by Americans and Cubans alike, exists today as a footnote to what is usually seen by most students of American history as the prelude to the inexorable slide toward radical sectionalism and Civil War. O'Sullivan, an extremely influential editor, died poor and forgotten in 1895 all but lost to history until his name became inextricably linked to what is now seen as his greatest achievement, giving name to the swirl of ideas which guided the development of the United States from its founding. For an intense three-year period, López and O'Sullivan, along with a diverse cast of politicians, financiers, journalists, and foot soldiers, crisscrossed the cities and front pages of the country enlisting support for an undertaking of national glory and personal satisfaction. And so it was to be these two men's

\footnotetext{
${ }^{344}$ New York Daily Tribune, August 30 1849. Harper's Monthly, October 3 1851, 693. Lawrence Berry Washington unaddressed letter, July 28, 1851 quoted in May, "Young American Males and Filibustering in the Age of Manifest Destiny: The United States Army as Cultural Mirror," 862.
} 
intertwined destiny, spectacularly failing at manifesting their dream, in Andrew Jackson's words, of "extending the area of freedom" south to Cuba. ${ }^{345}$

O’Sullivan and López shared a biography of yearning, much like many of the men motivated by their mission. The American history of movement, violence, and martial spirit spoke to the men who dedicated themselves to the propagation of filibustering's mission both in print and in person. Narciso López was representative of the declining fortunes of the non-elite Cuban, an unsuccessful mine owner after he fell out of favor with the colonial leadership in early 1840s Havana. O'Sullivan, having left his political and publishing careers, was rudderless in the society of the 1850s. The United States of the 1840s and 1850s was a nation not in harmony with its past or future but one that was increasingly pulling apart. The influential elite sought to think and expand their way out of the problems around them, problems that were steadily worsening. While previous generations of Americans had a continent stretching out in front of them filling them with wonder and the awe at future perfectionism, this generation stewed in the cauldron of debate, discord, animosity, and brinkmanship. Manifest destiny shifted from positive expression of an optimism bolstered by the hope of a perfected future toward a pessimistic last gasp for the founding American ideology. The way had been lost, the future obscured, failure seethed all around. Whether these men sought to get the last dollars made before the impending war or actually believed in the possibility of resurrection through their efforts, they could only at best forestall a future that looked as uncertain and perhaps as bleak as any previous point in their lives. This is the story of men who should have had nothing to fear trying to come to grips with a future, which threatened to make good on the one fear that was unavoidable - disunion.

\footnotetext{
${ }^{345}$ James Parton, Life of Andrew Jackson, Vol. III (Boston: Houghton, 1888), 658.
} 
The early 1850s represented a crisis in American masculinity. Men increasingly saw themselves unable to control their destinies as political events stripped the autonomy of decisionmaking from their hands. The anxiety cut across class, regional, and ethnic lines. The New York Tribune identified the combination of hunger and disillusionment that played out literally, at times. "There were some Hungarian and Italian refugees in this expedition but we are assured that they enlisted only because they had no other means of saving themselves from starving." While the New York Herald described attendees at a López rally in Jersey City as those "chiefly of the hard fisted working class, fired with the contagious enthusiasm that seems spreading all over the land." Filibustering masculinized manifest destiny by imbuing the undertaking with a direction and aspiration that distracted from the myriad personal reasons that prompted the initial decision to join up. Filibustering connected the personal to the national in an aspirational stance that allowed communal success to imbue an individual life of questionable worth with engagement of national and international politics. The veneer of legitimacy of filibustering presented individuals with the same veneer of legitimacy for their life's decisions, including the questionably legal decision to filibuster. The outlet of army service or political participation steadily lost ground to various schemes of movement, settlement, and swashbuckling that weakened institutionalism and associationism in deference to individualism and personal profit. $^{346}$

John O'Sullivan represented a new breed of men in the 1840s; Young Americans they called themselves. However, that name calls into being a homogeneity that simply did not exist. For while some of these young men, who sought for themselves a piece of the economic and political pies, brandished the optimism of youth and the fervent belief in the simultaneous

\footnotetext{
${ }^{346}$ New York Daily Tribune, April 30, 1851. New York Herald, August 28, 1851.
} 
freshness and strength of their outlook, there was an abiding pessimism for others that layered the exuberance of territorial and political expansion with an overwhelming disappointment with themselves and their society. The prevarication of men who spoke of action but relented in its application belied a mentality wracked with such a degree of self-doubt that only the verbosity of manifest destiny could drown it out. López's death in 1851 only intensified the process as newspaper stories kept the dream of Cuban filibustering alive by stoking the fires of revenge, recommitment to the cause, and the martyrdom of the patriot generals, both López and Crittenden. The most intriguing possibility that filibustering offered was an allegiance to a deeper republicanism and a purer embrace of American constitutionalism than did the sorted and compromised world of politics. Thus filibustering and the confidence it delivered to men creating the nation's destiny - men who would otherwise not receive the opportunity - along with the reverberation of the critical or laudatory societal discussions of such exploits fueled the dream of adventure. ${ }^{347}$

The goal of those who supported López was to bring freedom to Cuba. This was an amorphous concept explained in a variety of different ways depending on the setting, the speaker and the audience. The removal of Spanish power from the island was a given. Yet, this assumption was the only certainty. What would become of the hundreds of thousands of

\footnotetext{
${ }^{347}$ George D. Bayard, representative of this restless generation of adventurers wrote to his mother in April 1856 of his hopes and ambitions that might be made possible by filibustering and easier still than being in the Army. "Several of us talk of going to Nicaragua. If I am not pleased with my Corps I think I will probably resign \& go there. I could easily obtain a Captains commission \& there is a good opening. Walker is greatly in want of scientific men $\&$ then he will want especially in organizing his ordnance and artillery. With that commission one or two campaigns there would be more pleasant than Indian fighting in New Mexico \& the probabilities are that something would 'turn up' there \& in our Army there is no hope of anything of that kind. Even should I not be pleased with the life there I could resign \& return benefited at least by military experience which would come in play in the event of a war, in the meantime devoting my attention to Law. This however is the worst side of the picture for I think in Nicaragua to a young man of energy \& talent, 'there is no such word as fail.' Besides the opportunity of distinguishing myself there would be fine opportunities for making a fortune. It is a fine country \& wealthy Gold mines have already been discovered. What do you say to Nicaragua?" (quoted in May, "Cultural Mirror," 883).
} 
enslaved Cubans? Who would run the island? What role would the United States government play? Where did economic interests fit into this scenario? And what of the Spanish government in defeat? The precise meaning of Cuban freedom was always and necessarily unclear. The ultimate goal loitered somewhere between independence and annexation, however cornering supporters on the exact definition of success remained difficult. What was unwavering regardless of the lack of clarity concerning the means and ends of Cuban freedom was the large amount of publicity which followed López wherever he went. His was an ego and a plan not amenable to covert meetings and smoky backrooms. His words and actions as well as those of his supporters paraded, often literally, for the eyes and minds of intrigued and inspired Americans.

One such display was the violent culture of a highly masculinized urbanity that made up the backbone of aggressive expansionists driven to filibustering. The possibility that filibustering might continue their adventuring washed away the fear of some of these men that the opportunity for valor had passed with the ending of the Mexican war; the possibilities of redemption in filibustering stoked like a raging fire by the supportive press outlets of the day. Urban men were the target audience for filibustering parades, speeches, press pieces, balls, bond sale events, novels, and the celebratory ephemeral that created a new consciousness. Public events invigorated filibustering, as filibustering reinvigorated the public meeting tradition. While this new type of public meeting was narrower in focus than those in the public tradition's heyday of the 1830s, the enthusiasm felt was no less powerful and motivational. Large public gatherings featuring speeches, drinking, appeals for donations, and enlistment opportunities, fused a violent gendered vision of American destiny with a reassertion of aggressive masculinity within families and communities, made necessary by the bewildering transformations taking place in the American economic landscape. 
The nonpartisan makeup of the meetings was widely discussed by the press outlets both supportive and critical of López, as was an appreciation for the size and interstate coordination of these public meetings. The message, the speakers, and the order of events were largely scripted and followed a similar progression in city after city. Events lasted hours, with rising drunkenness and fiery rhetoric increasing expectation and encouraging a frenzied response upon emotional release. Some cities and towns added parades and social fund raisers that included visual panoply of banners, floats, and speeches extolling the greatness of America's vision and, after his death, the revenge for Spanish violence against López and his men. Crowds numbering in the thousands at some locations, including 15,000 in Philadelphia, drank in the familiar rhetoric of manifest destiny. One speaker at a López event summed up the expansiveness of the American manifest dream. "Nor shall this movement cease with the independence of Cuba. What is begun there will extend to Mexico and in less than two years the American continent clear to Patagonia will be part and parcel of the United States." ${ }^{348}$

The clarity and consistency of message and the size of meetings throughout the country speaks to the cross-regional and cross-partisan appeal to masculinity and patriotism that allowed filibustering to minimized political difference. The chief goal was encouraging men to place to the side the complicating details of politics and religion and to embrace the belief that piracy and republicanism might excuse their disregard for the letter of the law. These hopes for support also preyed upon the personal concerns of problems at home, or for hopes of monetary and land remuneration after a successful filibuster. Filibustering meetings therefore foreshadowed an acceptable and extralegal communal violence in service to higher ideals of nation and cause that many critics of the European revolutions of 1848 found so distasteful in those examples. In

\footnotetext{
${ }^{348}$ New York Herald August 23, 1851.
} 
addition, the embrace of a similar martial spirit found in the secessionist discussion already

occurring in important ways after the commercial conventions of 1850 was a direct outgrowth of

the filibustering mentality. Yet, the hope at the beginning of the decade remained the

reinvigoration of American values through the reestablishment of robust American manhood

aimed at foreign foes. ${ }^{349}$

${ }^{349}$ Newspaper articles describing López events in New York City, Savannah, Memphis, Philadelphia, Baltimore, Saint Louis and Cincinnati are found in the Baltimore Sun, June 27, 1850; Cincinnati Enquirer, Aug. 28, 1851; New York Herald, Aug. 24, 26-28, Sept. 4. 1851. Amy Greenberg, "Pirates, Patriots, and Public Meetings Antebellum Expansionism and Urban Culture," Journal of Urban History 31, no. 5 (July 2005), 634-650; Paul Gilje, The Road to Mobocracy: Popular Disorder in NYC (Chapel Hill: UNC Press, 1987). Newspaper reprinting of details of these meetings allowed even those who couldn't attend to commune with the filibusters. The meetings, beyond just propagandizing, actively encouraged donation collection and enlistment. Volunteers would traverse the crowds looking for both while speeches and events progressed. Numerous magazines and newspapers referenced the overwhelming masculine domain of filibustering, however, women did play some roles in the undertakings and historians have taken note. Although no women appear to have travelled with the López expeditions, in the creative literature of the day, female authors and characters take to the discussion of filibustering with dedication. Women also asserted their interests and concerns as propagandists, planners, fundraisers, and by exerting their influences over men debating the issue as whether to join or not. Most notably among this influential crowd were Jane McManus Cazneau and Lucy Petway Holocombe. The latter's work, dedicated to John Quitman, told the story of López's final voyage with a mix of factual and fictional stories and characters in efforts to encourage Quitman's leadership of the Cuban mission. Other fictional works from Elizabeth Livermore (The Quadroon's Triumph) and Lois Melissa Judd (Censoria Lictoria) strive to criticize filibustering and the political current productive of it while embracing some traditionally prescribed feminine attributes. Women also took active and public roles, included parading and organizing fundraising efforts such as balls and concerts. Some wealthier women placed direct pressure upon their husbands and politicians for economic and political help for filibustering throughout the period. Other women took a public and active anti-filibustering position, concerned about the social and personal familial toll that missions took on communities and homes. Journalist Anne Royall was an outspoken critic of the disregard for legality that many filibusters showed and Anna Ella Carroll published, Review of Pierce's Administration, which argued the U.S. economy would benefit more from promotion of trade rather than territorial growth. Yet later, she published A Star of the West, in which she defended Walker's raids to Nicaragua claiming that he was sent from God to liberate Central America from papists and Spanish despots. Not surprisingly, the wife of Democratic Review owner George Sanders (after purchasing it from O'Sullivan) circulated among the political elite in Washington pressing the case for pro-expansionist legislation and funding. Humorously, John Quitman confessed to his diary that he kept his activities with the New York Council a secret from his wife, convinced as he was that she would disapprove of his filibustering. Women also played an important damage control role, as many a mother and wife intervened to mitigate the repercussions of the impulsive decisions of sons and husbands. While there did not exist a perfect overlap of the perspectives men and women held toward filibustering, there was a good degree of complementary intersection that fueled as much as it discouraged. Robert E. May, "Reconsidering Antebellum U.S. Women's History: Gender, Filibustering, and American's Quest for Empire," American Quarterly 57, No. 4 (December 2005), 1155-1188; Amy Kaplan, "Manifest Domesticity," American Literature 70, No. 3, (September 1998), 581-606; Gail Bederman. Manliness \& Civilization: A Cultural History Of Gender And Race In The United States, 1880-1917 (Chicago: University of Chicago Press, 1995); Paula Baker, "The Domestication of Politics: Women and American Political Society: 1780-1920" American Historical Review 89, no. 3 (June 1984), 620-647; Lynnea Magnuson, "In the Service of Columbia: Gendered Politics and Manifest Destiny Expansion," (PhD diss., University of Illinois, 2001); Edward Crapol, ed., Women and American Foreign Policy: Lobbyists, Critics, and Insiders (Westport: Greenwood Press, 1987); Edward L. Widmer, Young America: The Flowering of Democracy in New York City (Oxford: Oxford University Press, 2000); Susan Jean Tracy, In The Master's Eye Representations Of Women, Blacks, And Poor Whites In Antebellum Southern Literature (Amherst: University of Massachusetts Press, 
The rapid failure of López's expeditions left some with a source of concern. The supporters, now radicalized and excited with revenge, redoubled their efforts at the precise moment when Cuban interest on the island dissipated just as quickly. The pro-annexation Cuban expatriate press moved from support to lionization. El Filibustero spoke in the most glowing terms of López's efforts, forgetting the acrimony between him and the New York Junta, and developing the steps now necessary to avenge his untimely death. "While General López was alive the Cuban cause had no greater nor more just representative; he was known throughout the world as the leader and defender of the rights of the Cuban people." As the poet Juan Zenea wrote of López's effect, “López has died, it is true: but time slips away and from his own ashes will spring liberty." 350

Ironically, one of the great sources of López's defeat was the failure of the annexationist press to penetrate Cuba. The long-standing assumption of many in the United States remained that exemplars of the Cuban-American press, like La Verdad and El Filibustero, circulated as widely, if surreptitiously, in Cuba as in the United States. However, the complete lack of support López reckoned with upon his last filibuster caused some in the Cuban-American press to question their efforts. El Filibustero's editors came to the realization and capitulated in their last edition of February 25, 1854. "Our papers circulate very little or not at all on the island. We have come to believe that the Cuban revolution should not be carried out with publications and papers, but rather with arms, gunpowder and bullets." The literary effort was too distant and too oblique

1995); E. Anthony Rotundo, American Manhood: Transformations In Masculinity From The Revolution To The Modern Era (New York: Basic Books, 1993); Jane P Tompkins, Sensational Designs: The Cultural Work Of American Fiction, 1790-1860 (New York: Oxford University Press, 1985); Elizabeth Moss, Domestic Novelists In The Old South Defenders Of Southern Culture (Baton Rouge: Louisiana State University Press, 1992); Mary Kelley, Private Woman, Public Stage: Literary Domesticity In Nineteenth-Century America (New York: Oxford University Press, 1984); Amy Kaplan, The Anarchy Of Empire In The Making Of U.S. Culture (Cambridge: Harvard University Press, 2002).

${ }^{350}$ Zenea quoted in Lazo, Writing Cuba, 98-99. 
to actively push Cuban society away from their accommodationist perspective. In this moment, the pro-annexationist voice became more American and the Cuban-American press became more critical of the racial and political motives for filibustering, particularly after $1855 .{ }^{351}$

There was, of course, in all of these debates a complete and most likely willful misrepresentation of the possibility of slavery's elimination. The role Cuba played in reducing sectional tensions, for Americans, rested almost entirely on slavery's continuance on the island as a safety valve. Conversely, annexation, even for the Cisneros group, offered the hope of more peaceful transference to abolition. As Cisneros alerted Saco, "In the end slavery will be eliminated, but it will be done as it should be, the gangrene will be removed by an expert surgeon and not with a butcher's ax." Cristóbal Mádan looked to American slavery as exemplary in a society that had long ago outlawed the (legal) trade, thereby allowing slaves the generational ability to breed out their savagery and produced, in his mind, a lesser desire to revolt. This reality was implicitly clear to him in the lack of rebellions in the United States. Conversely, in Cuba, he argued, the continuance of the trade for many decades longer resulted in a more savage and less capable slave population. Therefore, annexation offered the hope of a conservative development of society more ready for abolition. However, as rhetoric in the United States took on a more sectional and aggressive tone, making the continuance of slavery in Cuba as in the United States all but assured for an undetermined period of time, the annexationists in the Cuban community came in for a good amount of criticism. The relative unity in the Cuban-American press, ascribing as it did to the loftier aspirations of American republicanism, broke down and with it came critical editors accusing Cuban annexationists of being tools of the American slave

${ }^{351}$ El Filibustero, February 25, 1854. 
interests. The paradox of selling annexation as helpful of abolition while understanding that

American involvement made abolition impossible, hid barely beneath the surface. ${ }^{352}$

The realization that Spain was not going to sell Cuba to the United States further

complicated issues. The breakdown of diplomatic negotiation left armed invasion as the only

plausible answer for those desirous of Cuba. Opponents of annexation, some increasingly in the

Cuban expatriate community, argued that these haphazard and dangerous invasions only

threatened to destabilize Cuban society. These concerns coupled with Spain's mid-1850s

liberalization of its Cuba policy heightened expectations that compromises with the crown were

possible and the need for a new approach, a swing toward the autonomistas, warranted. The

minority voice now belonged to the annexationists, who toiled onward with limited economic

opportunities and dwindling hope of operational realization. This group also shifted their

perspective to a more clearly separationist perspective. Annexation was for all intents and

purposes dead in the Cuban mind by 1855. However, Americans thinking on the issue of Cuban

annexation failed to mirror the shift in Cuban thinking. ${ }^{353}$

\footnotetext{
${ }^{352}$ By $1854 \mathrm{La}$ Verdad came under withering attack from El Mulato a chief competitor both in circulation and message. Instead of a racially exclusive definition of Cuban nationalism, El Mulato, as its name implied, opposed annexation, supported abolition, and broaden the definition of Cuban to include all races and ethnicities. Although not always able to live up to its ideal, the paper's egalitarian perspective drove much of its editorializing aimed at ridiculing El Verdad. In 1854, for the tenth anniversary of La Escalera, a serialized story entitled "El negro Mártir" appeared in the magazine and attempted to establish parallels between African and Jewish diaspora and to harness and explore the sense of loss in the Cuban expatriate community. The story, set during the uprising, imagines slave uprising as a necessary corrective to the American and French revolutions while explicitly linking La Escalera to the Haiti Revolution. Thus Atlantic republicanism must both reckon with and include the experiences of AfroCreoles throughout the hemisphere in any republican efforts that promised success. El Mulato clearly demonstrated the significant shift occurring in the Cuban-American press and community over the issue of annexation and nationalism. David Luis Brown, “An 1848 for the Americas: the Black Atlantic, 'El negro mártir,' and Cuban Exile Anticolonialism," American Literary History 21, no. 3 (2009), 431-463. The safety valve these has a long pedigree in U.S. historical circles, Frederick Merk, "A Safety Valve Thesis and Texan Annexation," Mississippi Valley Historical Review 49 (1962), 413-436; Frederick Jackson Turner, The Frontier in American History, accessed on March 20, 2014, http://www.gutenberg.org/ebooks/22994. Un Hacendado (Cristóbal Mádan), Llamamiento de la isla de Cuba a la nacion española (New York: Estevan Hallet, 1856).

${ }^{353}$ The gulf between Cuban and American annexationists opened after 1854. While rabid American expansionists took an increasingly antagonist turn after the failure of 1851, the Cuban voice searched for a mitigated compromise. After López's death, his secretary, Cirilo Villaverde, among others took the lead in articulating a unified position of Cuban self-determination made possible after a future successful uprising (through a combination of external and
} 
John Thrasher and Gaspar Betancourt Cisneros put forward a remarkably similar line of argumentation on the merits of annexation and filibustering in September of 1854 (the third anniversary of López's ill-fated end). They aimed their response to those claims that proponents of annexation repeated since López's arrival in $1848 .{ }^{354}$ The two men sharing the dais that day at the Mechanics Hall in New Orleans shared much the same treatment at the hands of the Spanish

\footnotetext{
internal military processes). This effort helped to unify the Cuban annexationist and independentist factions. This unity came together in the Sociedad Republicana and its print mouthpiece La Voz de América. This new selfdeterminist construction allowed solicitation of international help coupled with the understanding that Cubans would make their decisions about the future only after Spain left the island. This new reality effectively took sale off the table as the democratic will of the Cuban people would then be bypassed. This Cuban approach to popular sovereignty held as its highest goal the promotion of rebellion and strengthened the independentismo movement now ascribed to by all of the leading Cuban factions. After 1855, there existed little if any support for active U.S. involvement in Cuban independence beyond moral support. The independence movement learned from the annexation camp's mistakes, namely that the landing of a filibustering force would not be enough to encourage revolt. Therefore, U.S. policy, both official and unofficial, aimed at annexation through purchase or filibuster became openly hostile to the ends being pursued by Cubans. The lack of speed and seriousness perceived by many Cubans that guided U.S. foreign policy convinced the creole community that the U.S. people and government would never make the necessary compromises to assist Cuba. Regardless of the abstractions of party and sectional difference and despite the breathless talk and pontification, Cubans came to realize that the prioritization the U.S. placed on their relations with European powers relegated American assistance for Cuban to a by-product of opportunism bereft of conviction or effort. The conservative Cuban elite came in for criticism as well for their timidity and reluctance to force confrontation with Spain over concerns beyond their immediate political or economic orbit. The reliance on the perspective and support of the elite hamstrung efforts and limited the dispersal of revolutionary feeling throughout the island. As one editor opined, "it is important that the revolution be made by the Cuban people and for the Cuban people and to do this it is important to remove the reigns from the hands of a few Viejos Ricos and their faithful servants and leaders. Illustrious men, the people and the middle classes provide the lever of all revolutions," quoted in Poyo, "Villaverde," 493. Carrying this view forward, La Voz de America, relayed the following in 1866, "La Sociedad Republicana has recognized the error (of relying on clase oligarca and has tried and succeeded in raising the spirit of the PEOPLE, and has finally ensured that the REVOLUTION no longer represents the egotistical aspirations of the aristocratic slaveholders, but is an ostensible manifestation of the desires of the PEOPLE in general; the ignorant, the peasant, the cigar maker, the freedman, the slave, the real PEOPLE." ( $\mathrm{La} \mathrm{Voz}$, September 20, 1866.) In observation of the U.S. Civil War, many Cubans realized the worth of including slaves in articulating the category "people" and that this inclusion could come about with no large disruption or slave uprising. Cuban independentists came to realize that emancipation and revolution mutually reinforced and encouraged each other.

354 "Cuba mourns her glorious dead! Her children, who have preferred to drink from the bitter cup of exile even to its very dregs...their hopes wither and their free impulses are hidden before the tyrant... it is this union for love or for hate, for glory or for vengeance, that constitutes a true union of the living before the tomb of the glorious dead...this band of heroic martyrs has solved for us the great questions of the American press... here (in the U.S.) man is prosperous because his enterprise and his labour are untrammeled, here man is happy because he is free... They have striven to imitate them, colonists have hugged these glorious precepts to their hearts and everywhere have driven the slave of tyranny from the Continent...For Cuba...such was the aim and such the mission our hero dead...Yes! That mission will be carried out. The blood of the martyrs for Cuban freedom has cemented the union of the races." Thrasher and Cisneros, Addresses Delivered At The Celebration Of The Third Anniversary In Honor Of The Martyrs For Cuban Freedom At The Mechanics' Institute Hall, New Orleans, Sept. 1, 1854 (New Orleans: Sherman, Wharton \& Co. 1854).
} 
in Cuba. Their mutual exile from the island, much like López's, fueled them with a mixture of self-interest and a fair bit of vengeance. However, they also shared a much more pressing and visceral concern - enlisting material and military support for an audacious new filibuster planned for the following year under the direction of General John Quitman. Cisneros recognized his own need for a victory in Cuba, as the president of the Cuban Revolutionary Junta, a new group formed in New York in response to the failure of López's efforts. To the chagrin of many, the overwhelming optimism expressed by the media, the soldiers, and the people as it related to the López missions left many stunned and a bit disorganized after his failure; they never envisioned the need for a backup plan. The New York Junta moved quickly to reach out to notable Americans who might be enlisted for support of a new filibuster. The planners also realized that time was of the essence, with public arousal just as likely to cool at a moment's notice. However, the reality remained that Americans misread the potential for support of annexation among Cuba's largely poor and black population because they saw in annexation a solution to American problems that Cubans were uninterested in helping them solve. The mythical status given Cuba produced the great hope that the island was the economic and social tonic needed to subvert the American slavery question. Despite the meticulous planning in 1852 and 1853, interest in annexation cooled considerably, a fact overlooked by planners north of the Florida Straits but not lost on the political elite on the island.

John Thrasher held for himself or was honored by (depending on your view of his efforts at self-promotion) a grand dinner in New Orleans on July 14, 1852, that was "largely attended, and enthusiasm prevailed.” A dinner so large and important, that the New York Times took note, although the story consisted of a two line wire report which elegantly summed up the exhaustion that many papers now felt toward the filibustering effort in the wake of López's failure. 
(Interestingly, and unexplored - if only suggested in this current work, was the effect López's failures had on support for Kossuth's efforts). Thrasher, although not a filibuster himself, played a role as large, if not larger, than O'Sullivan and Beach in the annexation effort. Unlike his two press conspirators, whom he met at the Havana planning meeting in 1848 and had since stayed in contact with, Thrasher kept Havana as the center of his efforts. Thrasher was a long-time Havana resident and thrived on the danger and intrigue that the annexation underground on the island provided. Unlike O'Sullivan, Beach, and many of the other American annexationists of rank, Thrasher paid a price for his efforts. The Spanish government imprisoned him in the wake of the López missions. His eventual freedom required extraordinary efforts on the part of Secretary of State Daniel Webster and the American minister in Madrid Daniel Barringer to have his sentence commuted by the Spanish authorities. ${ }^{355}$ As a result, there awaited lavish dinners and huzzahs

355 "Dinner to Mr. Thrasher," New York Times, July 21, 1852. Daniel Webster spent a great deal of the winter of 1851 working on John Thrasher's situation. The core issue for Webster was determining Thrasher's citizenship status, American or Spanish, and with it the protections and requests that might be afforded on his behalf. Webster's letters to a variety of individuals, including representatives of the British and Spanish governments, are a fascinating working through of the concepts of citizenship, nationality, and international law as they stood in the period. Since Thrasher resided in Havana for many years, conducting business and publishing there, and, according to some sources, surrendered his American citizenship by swearing allegiance to the Spanish crown, Webster remained doubtful of his ability to direct the situation and push for Thrasher's release. The Spanish, in their belief that he was a subject of the crown, convicted Thrasher of treason and sentenced to eight years in prison. Complicating matters was Thrasher's public statements, published in numerous papers, declaring his innocence, anger, and claims of American citizenship. His Letter to Captain General de la Concha, dated March 22, 1852, was an inflammatory piece of rhetoric, excerpts of which made their way to the American press, further pressurizing the situation. When Thrasher was a young boy his parents took him to Havana where he eventually enjoyed a successful mercantile career. As agitation for filibustering picked up, he abandoned his businesses for journalism, purchasing in 1849 the Faro Industrial the only liberal newspaper in the city of Havana. The paper, while thinly veiling its proclivities in the guise of literature, was suppressed in September 1851 and its publisher, Thrasher, sent to prison. Upon his hero's welcome in New Orleans he established a Sunday journal called the Beacon of Cuba. He was also one of the main members of the Junta from 1853-1855 that organized a filibustering expedition to be led by General John A.

Quitman. The failure of the Quitman enterprise saw Thrasher then serve as a correspondent for Noticioso de Nuevo York, a job that took him to Central and South America. One of the more interesting passages from Webster comes from a letter addressed to President Fillmore in which he thinks through the demographic realities of American citizenship. "The Supreme Court of the United States has decided 'that a person who remove to a foreign country, settles himself there and engages in the trade of the country, furnishes by these acts such evidence of an intention permanently to reside in that country, as to stamp him with its national character'; and that undoubtedly is in full accordance with the sentiments of the most eminent writers, as well as with those of other high judicial tribunals on the subject. No government has carried this general presumption farther than that of the United States, since it is well known that hundreds of thousands of persons are now living in this country who have not sworn any allegiance to this government, nor been domiciled amongst us by any regular court proceedings. What degree of alarm would it 
upon his return. This return also reinvigorated a filibustering enterprise that took on a

\author{
distinctively more American flavor after $1855 .^{356}$
}

not give to this vastly numerous class of men, actually living amongst us as inhabitants of the United States to learn that by removing to this country they had not transferred their allegiance from the government of which they were originally subjects to this government? And, on the other hand, what would be the condition of this country and its government, if the sovereigns of Europe, from whose dominions they have emigrated, were supposed to have still a right to interpose to protect such inhabitants against the penalties which might be justly incurred by them in consequence of their violation of the laws of the United States." To these issues of citizenship and protection, an annoyed Captain General de la Concha responded, “.... when it is remembered that he was a domiciled foreigner. In assuming this character of his own free will he swore to be faithful to our government and in return he enjoyed certain rights and privileges which as simply a foreigner he could not have possessed. Will Mr. Thrasher still say that he cannot be charged with treason? The fact of his having been compelled to discontinue the publication of the 'Faro' for want of naturalization is of no importance. It has already been said that domiciled foreigners are allowed to exercise certain callings and professions and those that are naturalized all. Among the former the privilege of publishing newspapers is not and could not be comprised without manifest to public security. Nor is this privilege granted to all Spaniards because the circumstances of this island require that the government exercise the utmost circumspection on this point. How then could privilege have been extended to domiciled foreigners and much less to a citizen of that country whence the piratical expeditions had sailed?" Daniel Webster, "The Case of Thrasher," The Works of Daniel Webster, Vol. 6 (Boston: Little, Brown and Company, 1890), 523. The full diplomatic cables are contained in a report to the U.S. House of Representatives from President Fillmore upon their request, House Documents, Otherwise Publ. as Executive Documents: $13^{\text {th }}$ Congress, $2 d$ Session-49 ${ }^{\text {th }}$ Congress, 1 st Session, $32 d$ Congress, $1^{\text {st }}$ Session, Ex Document \#10, accessed on March 12, 2014, http://books.google.com/books?id=4YcFAA AAQAAJ\&dq=john\%20thrasher\%20cuba\&pg=RA1-PA92\#v=onepage \&q=john\%20thrasher\%20cuba\&f=false, 1 32, (de la Concha quoted on 26).

356 Thrasher also published a translation of his own reading of Humboldt's Ensayo politico sobre la isla de Cuba in 1856. He changed the title to The Island of Cuba, and included a preliminary essay he penned. Thrasher's opening essay and his translation was a work of political persuasion for the American audience, most notably eliminating Humboldt's criticism of Cuban slavery. His suppression of the part of Humboldt's work that most directly contradicted his own racial views drew harsh criticism from Humboldt in the American press. Thrasher's translation, entering the vicious debates between the Saco and Cisneros camps, attempted to place a heavy hand on the scale arguing for the protection of Cuban slavery through annexation. Thrasher's El Faro Industrial de la Habana thinly veiled its critiques of Spanish authorities by occasionally "supporting" their efforts or by obliquely criticizing the actions of filibusters. In 1850 after López's second attempt, the so-called Cardenas expedition, the Faro Industrial published a pamphlet ostensibly critical of his efforts entitled "Memoria y recoleción de documentos para la historia de la ridícula invasion." These efforts at sarcasm were too smart by half and Thrasher found himself arrested and imprisoned after the last López expedition. Herminio Portell Vilá claims his codename in the annexation community on the island was El Yankee. During the month of López's invasion, the El Faro reprinted official descriptions of the Spanish harassment of the filibusterers along with tongue in cheek sarcastic poems and advertisements designed to ridicule the official Spanish story. The tolerance of Captain General de la Concha for El Faro extended solely to give the appearance of a free press, however, the sarcasm was too much to bear and entirely too public an affront particularly given the recent filibustering events. The final straw was not, surprisingly, the attempts at comedy but rather the lack of remorse shown for the death of Spanish General Enna, whom López's men killed during the last filibuster. While de la Concha often used the paper for his own devices, as it had to pass through the inspection of his chief censor, he explained why he shuttered publication, "...finally the articles and poems that frequently escaped the wisdom or vigilance of the censor, and which contained phrases and concepts with a double meaning, on which the authors then commented in their own circles...I preferred then to let the journal keep its miserable life, bereft of subscribers, until a better opportunity presented itself; and its conduct, in the midst of the general grief about the death of the valorous General Enna, promptly presented me with such an opportunity....after announcing with a few lines...the news of the general's death, it printed a sequel to an article entitled 'La sonrisa.' All of Havana looked upon this publication with contempt." The entire Humboldt-Thrasher controversy is highlighted by Vera Kutzinski, including the reprinted letter exchanges between Thrasher and Humboldt at http://www.press.uchicago.edu/books/humboldt/1_7_thrasher.html and in her translation of Fernando Ortiz's 
The increased interest in taking Cuba was not solely a product of revenge scenarios. The great explosion of concern about the "Africanization" of the island once again placed the issue of annexation squarely in the public debate after 1853. While supporters of annexation always harbored fears of "Africanization," diplomatic events in the Caribbean convinced many that British efforts at fomenting slave revolt in Cuban were at long last coming to fruition. ${ }^{357}$ Interestingly, this was the moment where a turn toward the more sectional support of filibustering became more obvious to many observers. ${ }^{358}$ The overwhelming concern about slavery and abolition, once again at the heart of the annexation impulse, intensified with the turn toward a multi-racial Cuban independence movement. The increasingly loss of interest on the American public's part was a recognition on the part of some American observers of the changing political landscape on the island. The efforts at purchase, now widely understood to be continuously progressing in the background, as they had since the 1840 s, also cooled much of the fervor for filibustering. Finally, the resoluteness of Spanish defense gave even the staunchest of annexation's supporters, such as John Quitman, a significant moment of pause. ${ }^{359}$

Humboldt's Translator in the Context of Cuban History," Atlantic Studies 6, no. 3 (December 2009), 327-343, quote on 334.

${ }^{357}$ The concept of "Africanization" seemed to played dual roles for contemporary users of the word. First and perhaps more commonly, the term referred to the introduction of non-African labor that might then create a racial problem with the presence of Afro-Creole Cubans no longer controlled by slavery. The other usage, the result of the first situation, was the overrunning of white rule on the island as a result of race revolution akin to Haiti.

${ }^{358}$ Although the New York Times remained confused by the great interest of the South in Cuba. "The Southern states consider the acquisition of Cuba as a matter of special importance to it. We do not: nor are we surprised to find, among Southern men, that differences of sentiment and of action which the State deplores. The Cuban question is primarily a Northern question. The only way in which the acquisition of that island could benefit the South, would be by adding one more slave state to the Union and so increasing the political power of slavery. But Cuba, if acquired, must be a province before it enters the Confederacy," (4/8/1858).

${ }^{359} \mathrm{Naval}$ and military strength of Spain played an important role in the repelling the López invasions. The availability of Spanish naval steamers contributed to the protection of the coastline and harassment of López's maritime movements. His approach and retreats from the island, notably on the last two filibusters, occurred under much duress. Spanish steamers pursued López to Key West after his 1850 landing at Cardenas, giving the retreating general and his charges less than a 30-minute head start. López's landing decisions on the ill-fated last mission changed significantly due to his fear that Spanish patrol vessels knew of his presence. The quickness of movement after landing occurred largely as a result of the rapidity and confusion of movement in the first minutes of arrival, fearing as they did Spanish pursuit. Spanish railroad construction, largely for military purposes, occurred during the period as well allowing for large-scale troop movements throughout the island. López and Crittenden received quite 
The "Africanization" scare of 1853-1855 added fuel to the diplomatic fire of British menace. State legislatures throughout the United States, including Louisiana's, condemned British actions at forcing the abolition issue in Cuba, fearing that the encouragement of freelabor immigration into Cuba coupled with the abolition of slavery might encourage demands for freedom in the United States South, to say nothing of a massive exodus of freed slaves from the island. The degree to which the actors involved - the Pierce administration, Cuban creoles in exile and on the island, British and French diplomats, and American filibusterers - truly felt this "Africanization" fear rather than simply using is a cover for their pursuance of their ends remains a difficult question to answer. However, the great time and care placed in the various lines of argumentation indicates that there was an honest and generalized anxiety that prompted at least some of the concern. Certainly, annexationists like John Quitman, selected by the New York Consejo Cubana to lead a new filibuster in 1854 , used the concern to fuel filibustering interest and donations to great effect. One the other side, British planters in Jamaica and Barbados generally supported any efforts directed at Cuba that might curtail the Spanish colony’s advantages in the world market. The French, as well, sought to continue their efforts at extending the recent outlawing of slavery in their realm throughout the Caribbean after 1848. The

a welcome from Spanish regulars, also serving to further quell any sympathy from local residents, on their last filibuster thanks largely to military railway construction and use. While the failures of the López filibusters depended on a good amount of poor planning and even poorer execution, exaggeration of the weakness of Spanish response and an underestimation of their ability to protect Cuba did not aid the cause. Carlos Alfaro Zaforteza, "The Moderado Party and the Introduction of Steam Power in the Spanish Navy, 1844-1854," War in History 13 (October 2006), 441-67. The bolstering of Spanish forces was well known by U.S. and Cuban American papers. As the Cincinnati Nonpareil made clear, Spain was not in the mood to suffer American hostilities. "Important from Spain. WHOLE SPANISH FLEET GOING TO CUBA--La Patria states, that in addition to the increase in military forces in Cuba, the naval force is likewise to be greatly augmented. The whole of the Spanish Navy, except that portion actually required to guard the home coast, is to be dispatched immediately to Cuba, in anticipation of the contemplated invasion. The Cuban authorities will therefore shortly have at their disposal-1 Seventy-ton, 4 Frigates, 5 Corvettes, 8 Steam Frigates, 11 brigs and smaller vessels, besides gunboats in any quantity. The Spaniards hope with this force, and this army, effectually to suppress any attempt at invasion by the Yankees, or revolt by the native Cubans. The formidable preparations of the Spaniards indicate, and truly too, that the movement in and out of Cuba, for the freedom of that Island, is affair," (5/7/1850). 
diplomatic pressure brought on Cuba by the British and French therefore held strong economic

motivations coupled with the hope that a tripartite effort toward abolition might pressure the

United States toward the same. ${ }^{360}$

${ }^{360}$ The British brought particularly serious pressure to bear on the Spanish in October 1853, arguing that the reforms remained necessary in effort to deal with the lethargic Spanish efforts at fulfilling their treaty obligations aimed at abolition $(1817,1835)$. The two most vexing proposals were the elimination, by Captain General Pezuela (an abolitionist who adopted the program with gusto), of rural estates' immunity from search for and seizure of illegally held slaves along with the registration of all slaves held on the island. Pezuela further enflamed concern when he took to the official Spanish press and, in a series of articles, condemned the long-standing accommodation of the illegal slave trade by the island's previous Captain Generals. He threw even more kindling on the fire with his extolling of the superiority of free labor to slave labor. Rumors abounded of secret treaties between the British and Spanish and the French and Spanish aimed at placing the island under European control. In this generalized atmosphere of foreign involvement coupled with Spanish authorities scouring the countryside registering slaves and searching for illegal imports, a fever pitch came forth in the requirement that all slaveowners publically present themselves to local magistrates and produce full purchase information, under penalty of fine and their slaves' freedom if they failed to comply. Owners realized, based on treaties signed between the Spanish and British, that in essence all slaves brought to the island after 1820 arrived there illegally. The Spanish government went one step further and, in fears that the Quitman filibuster was eminent, began arming free blacks and mixed race creoles. Cuba, many feared, might already be lost to abolition. The rump faction of pro-annexation expats in New York and New Orleans, after López's death, turned to Quitman, an ardent supporter of slavery, to lead a renewed filibustering effort. This last burst of annexationary interest on the part of annexationists came as a result of the racial imperative still present through 1854 in Cuban annexationist ideology. The collapse of the Quitman filibuster made it clear to many Cubans in the U.S. that a military imposition of freedom was not persuasive to the majority of Cubans on the island. Quitman feared that the increasingly Southern effort aimed at protecting the region from Northern political and economic aggression through annexation and Caribbean expansionary counterweight would be in grave jeopardy if Cuba established itself as a biracial nation, either independent or within the Spanish orbit. Quitman, as many Southerners, also suspected the Pierce administration lacked the interest or resolve to purchase the island from Spain. Filibustering was the last best hope for protecting Cuba from "Africanization" and by extension prohibiting a similar fate in the United States. William Langley indicated as much in a letter to Quitman in January, 1855. "The acquisition of Cuba I regard as the only hope of the South. Whether it comes into the Union or not, will matter little as far as the South is concerned. With the aid of Cuba, she can make her own terms either in or out of the Union," (Urban, 38). An author, writing to John Thrasher echoed the sentiment. "Cuba is the paramount enterprise of the age - the grand work to secure the South against malign influences from any quarter and the consummation of it will place an immovable keystone in the arch of the Union," (Urban, 38). Immense diplomatic pressure fell on the Pierce administration in the summer and fall of 1854, but to no official response. Senator John Slidell of Louisiana advocated for the repeal of the Neutrality Law of 1818, in debates over the annexation issue. Yet the Pierce administration determined that purchase allowed the least confrontational attempt at acquiring Cuba, particularly given the growing animosity resultant from the Kansas-Nebraska Act's passage. The anger produced by the Act kept compromise at bay and Cuba remained a contentious issue. Annexation, on the heels of the perceived capitulation to Southern slave power, would have made the political landscape even more toxic. In their "Appeal of the Independent Democrats in Congress to the People of the United States" - issued in response to the introduction of the Kansas-Nebraska Bill (January 1854) - Salmon Chase, Charles Sumner, Joshua Giddings, Edward Wade, Gerrit Smith and Alexander De Witt chided the supporters of the bill with a vitriolic attack. "We arraign this bill as a gross violation of a sacred pledge; as a criminal betrayal of precious rights; as part and parcel of an atrocious plot to exclude from a vast unoccupied region immigrants from the Old World and free laborers from our own States, and convert it into a dreary region of despotism, inhabited by masters and slaves." http://teachingamericanhistory.org /library/document/ appeal-of-the-independent-democrats/. Spain fully cognizant of Pierce's desire to purchase and his difficulties in the political arena, but fearful that filibuster planning continued unabated, played its advantage and informed the administration of Quitman's plans, having placed spies inside the planning effort. Spanish efforts, couched in terms that expressed their fears that a new filibuster might wreck purchase plans, forced Pierce's hand as 
With fear so abundant but the desire so diffuse and tepid, the looming question then remained, why was the annexation of Cuba so imperative to Americans? The answer centered on the intense debate over slavery in the United States, a debate in which Cuba was a surrogate for the American conceptualization of itself and its place in the world. Annexation defined republicanism in different ways for both North and South. For men of capital, whether derived from industrialized or agriculturalized human labor, republicanism as realized through freedom, liberty, and constitutionalism held a comfort with the extraction of profit from abstracted labor in a way which prevented claims from that labor source on the republican promise. Whether slave or free, the articulation of difference between owners of time and/or the bodies of their charges, allowed for an actuarial agreement that labor was exploitable in the pursuit of profit. The investment ownership class held confidence that the rising tide of Atlantic commerce would raise all boats on waters that remained safely cloistered from the stagnant tide pools of the laboring classes. A similar approach, North and South, to exploitability fostered a comfort with expansionism in search of markets, labor supplies, and speculation. However, this investment promoted reliance on world exchange that made investors susceptible to fluctuation in those expanding markets. Cuba presented itself as a reservoir of marketizable opportunity and potential.

official U.S. pressure killed the effort. President Pierce prevailed directly upon Quitman in a quiet but clear meeting. The Spanish moved quickly as well and replaced the petulant Pezuela with a cooler hand and one more amendable to slavery in the person of Captain General José de la Concha. Spain's decision to remove Pezuela became easier as a result of the U.S. minster in Spain's, the annexationist and anti-Spanish firebrand Pierre Soulé, demands in answer to Pezuela's actions in the Black Warrior affair. That affair, played to the hilt by the annexation crowd, involved the seizing of the American ship over a relatively minor technical detail dealing with the ship's manifest. Pezuela's actions, helped by the howls from the annexationist press, demonstrated for many the condescension of Spanish authorities in Cuba. Therefore, the return of de la Concha, celebrated by the elite in Spain and Cuba, was as much fortuitous as it was strategic, since de la Concha's return did much to reduce revolutionary fires. He moved quickly to strengthen his rule and his wealth, returning to many of his previous leadership approaches established during his first tenure on the island. C. Stanley Urban, "The Africanization of Cuba Scare, 1853-1855," The Hispanic American Historical Review 37, no. 1 (February 1957), 29-45, quotes on 38. 
Annexation's possibility encouraged the conceptualization of a shared web of interests.

American investment, supporters hoped, might continue as trade rationalization progressed under an annexed Cuba. The human and seed science efficiencies of Southern agriculture, prompting the region to unknown economic heights by the mid-1850s, and the greater mechanization of production, continuously mastered by British and New England factories along with the Southern slavery discipline/control juggernaut, promised to cure the traditional perceptions of Cuban laziness and inefficiency. As the New Orleans Bee breathlessly exhorted,

There is no earthly use in seeking to plant slavery in Northern territory; climactic influences are against us there, and slavery will not flourish where white labor can compete with it successfully. But southward we have almost a boundless field of enterprise lying before us. There is Cuba... Slave labor there already gives rich returns, and annexation to the Union would introduce superior American management in that island and raise the productivity of the individual slave laborers... Let the people of the South cease an unavailing effort to force slavery into ungenial climes, and strive to plant it where it would naturally tend. ${ }^{361}$

Increased United States investment in Cuba, unfettered by Spanish oversight, augured for increases in: technology, notably in sugar production; white immigration, in the persons of excess white American population drawn to the island by jobs and land in a process that Saco would have approved of; excess slave population that might be transferred to the United States as internal trade and therefore not in violation of importation bans (to say nothing of the robust illegal trade that subsumed Cuba and the Gulf throughout the 1850s); and, conversely, a destination for United States slaves sold south instead of west in the internal trade. ${ }^{362}$

\footnotetext{
${ }^{361}$ New Orleans Bee, August 14, 1858.

${ }^{362}$ Northern capitalists' eventual rejection of Southern expansionism, resting on changing notions of elite urban masculinity that elevated family and community investment to the detriment of expansionary visions of republican territorial strength, surely hackled Southern sensibilities. Amy S. Greenberg, "A Gray-Eyed Man: Character, Appearance, and Filibustering," Journal of the Early Republic 20, no. 4 (Winter, 2000), 673-699; Robert E. May, "The Domestic Consequences of American Imperialism: Filibustering and Howard Pyle's Pirates," American Studies 46, no. 2 (Summer 2005), 37-61.
} 
Yet by the mid-1850s the general perception in southern climes of the United States was that the Federal government embraced Northern concerns, economic and otherwise, more fully and forcefully than those of the agricultural and export heartland. The only solution to this reality was an explosion of interest outward in hopes of raising Southern claims on the national consciousness through investment in areas Southerners held the keys to. As the decade progressed, Southern capitalists saw and felt themselves in a struggle for their future in a world that was, as yet, not solidified and therefore remained malleable in their image. Hence the articulation of Southern republicanism, one that embraced the naturality of Southern capital's right to dominance as equal to that of Northern articulation, rested solidly on embrace of slavery as an essential and uplifting component of expansionism.

This "cunning of reason" reflected in slavery's presence, ad memoriam, supported the Southern claim to the moral high ground. That morality rested upon an unwavering belief that the Northern cabal and its economic artificiality was soon to be destroyed by the natural path of Southern capital design. This design included the important moralism of providing uplift to a downtrodden race. The North needed a variety of artificial apparatuses to fulfill their economic dreams - railroads, wage labor, tariff control - while the division of race and the embedding of difference in every exchange on display in the Southern economic and social arrangement explained a more direct connection to history, progress, and modernity. Slavery for some and republican virtue for others, Southerners argued, had long been the blueprint for a great society's advancement. Southern capital advancement was only possible through the casting off of Northern/artificial dominance. The testing ground for that intuitive process was Cuba. That filibustering and annexation failed so spectacularly did far more to call into question Southern pronouncements than did failure in lands where the outcome was expected and overdetermined 
by political and economic weaknesses absent in Cuba (The Southern mind rejected both

Nicaragua's underdevelopment and Mexico's racial depravity as cause of their failures in those domains). The protection of slavery in Cuba, under Southern auspices, was essential to Cuban society and Southern society alike and formed the bedrock of Southern claims for the true lineage of the revolutionary spirit of 1776 . The failure of Cuban annexation dealt a significant blow to Southern republicanism. Yet, Southerners felt their republicanism failed in Cuba not of its own accord. The tepid political and diplomatic approaches to annexation, perceived by Southerners as controlled by Northern interests, purposefully limited the martial spirit of the republicanism. The failure was endemic of the Northern approach to politics and economics, both of which corrupted the nature of all things. Southerners argued this was the reality of Northern aggression, pointing to the neutering of even otherwise dependable politicians such as James Buchanan, a man who longed after Cuba like no other. Many Southerners supportive of annexation believed the North purposely drove their efforts to failure through obstructive moralism. Other Southerners, not necessarily supportive of annexation, heard their brethren's arguments and filed Northern actions into the cabinet of paranoid grievances. ${ }^{363}$

Anger and disappointment at another presumed Southern sympathizer, President Franklin Pierce, encapsulated an early version of secessionist argumentation based on the illegitimacy of presidential action. Pierce's direct squashing of the Quitman filibuster demonstrated to supporters the illegitimate and artificially meddling use of presidential obstructionism against the naturally ordained taking of Cuba. Filibustering, beyond simply adding territory, offered its

\footnotetext{
${ }^{363}$ Walter Johnson, River of Dark Dreams: Slavery and Empire in the Cotton Kingdom (Cambridge: Harvard University Press, 2013); Edward Baptist, "The Second Slavery and the First American Republic," (paper presented at Cornell University, May 23, 2012, http://www.almanack.unifesp.br/public/journals/1/Edward_Baptist_ texto_Forum.pdf). The reinvigoration of a demand for reopening the Atlantic slave trade can be seen in direct relation to the failure of Cuban annexation and with it the failure of transfer of Cuban slaves to the United States. Barton J. Bernstein, "Southern Politics and Attempts to Reopen the African Slave Trade," The Journal of Negro History 51, no. 1 (January 1966), 16-35.
} 
allegiance to constitutional checks and balances, a limitation on presidential power, and the demonstration of a robust republicanism of a different cloth - a type of popular nullification. Supporters argued that the people spoke loudly on the issue of annexation, represented by the popularity of the efforts, and politicians should move aside and let destiny unfold. The opportunity of purchasing the island was a failure because it rested upon the artificiality of politics, morals, and diplomacy. Filibustering was popular sovereignty in foreign affairs. The naturality of slavery and its reifying of racial and social hierarchies made republicanism and slavery seem as natural allies to annexation's supporters. This proslavery ideology thought itself triumphant after the removal of the execrable Whig Fillmore and his anti-expansionist persecution of López. However, the equally damning running through of "the Northerner with Southern sympathies," Pierce, demonstrates the complete breakdown of clear party differentiation over the issue of Cuba and along with it the complete breakdown of Southern obsequiousness to federal power. More so than any other issue in the 1850s, the desire for Cuba was both representative of and constituent of a consensus that cut across professed party lines. Within the economic world of antebellum politics, profit and patronage often spoke louder that platform and ideology.

Popular interest drove otherwise professed Democrats, Whigs, and Freesoilers toward an unnatural embrace of the philosophy of annexation/purchase. The Cuba question produced contortions of personal, community, and regional expediency that also allowed and encouraged agnosticism on the issue of slavery. The marginal early American voices against annexation had more to do with the influence of abolition that any particular allegiance toward party. The equation of filibustering and annexation in Cuba was purposeful. Supporters and opponents could use the bifurcated policy to paint their arguments in broad strokes. Those against Cuban 
adventurism, on the whole, saw lawlessness and greed, a pecuniary aggressiveness representative of the poor breeding of those involved in grievous depravations against sovereign nations. While at other moments, those same people opponents might be made more supportive of annexation, in the individual, by finding the patriotism of filibusterers as akin to the founding generation and Cuba a historical facsimile of the American colonies. This bipolarism was particularly true when the imposition of external control, presidential prohibition for instance, deprived men of their decision-making powers to filibuster or not. Individuals had no requirement to offer reverence to the laws of the United States if they assumed no protection of its government. John Henderson's exposition is worth quoting at length for its clarity of purpose, succinct summary of Southern political reality, and demonstrative use of fidelity to the Constitution and human rights to defend filibustering.

The history of nations teaches one universal truth - namely, that administrative power in Government has an eternal tendency to augmentation... The captivating bauble is ever being fondled and nursed into extension, and under pleas of necessity, the public good, or the bolder warrant of undisguised usurpation, its dimensions are enlarged...I do much regret that President Pierce has made his present demonstration in this line of bad precedents. For, though he has avoided the libelous vulgarities indulged in by the late Administration... and has perpetrated no such discreditable blunder as to affect to commission the military... still it is submitted his views, policy and opinions, so published, are not timely and well advised, and the power asserted more than questionable...General Pierce says that it is 'in virtue of the authority vested by the constitution in the President of the United States' that he issues this proclamation. Now, we have many laws of Congress which give the power or make it the duty of the President to issue proclamations in the particular cases which these laws have specified. Such is his duty by law in cases of domestic insurrections. But our neutrality laws have enjoined no such duty and given no such power. And to all who have read the constitution of the United States it is sufficient to say, it contains no express authority to the President to issue proclamations of this or any other description; and I maintain the authority is not fairly implied.

The President recites that information 'has been received that sundry persons, citizens of the United States, and others residing therein, are engaged in organizing and fitting out a military expedition for the invasion of the Island of Cuba.' Where this expedition is being organized and fitted out, and from whence it is intended to move for the invasion of Cuba, is not indicated...That a citizen of the United States may, within the United States, use his means and money to promote an expedition to be organized out of the United States, and to be carried on from without the United States against Cuba, and not involve this Government in any breach of its treaty with Spain, or involve the neutrality of the Government in violation of the act of 1818 , are propositions too plain, and too well 
established by the decision of our courts, and our diplomatic correspondence, to be plausibly questioned...The Cuban believes the tyranny under which he suffers is lawless, insatiate, and cruel in the last degree, and that he is deprived of all participation in selfgovernment. Who doubts the fact? The fact admitted, the power then, which controls him, is a sheer wicked despotism. May the Cuban rightfully conspire and struggle to overthrow this despotism, and may he rightfully invoke assistance to this end? To deny this is to repudiate the integrity of our own independence, for we so struggled, and sought, and obtained private, secret aid from the French people. And it will not do for hypocrisy, cant, and falsehood to assail the purity of motive and action as to assistance so sought and so to be given.

The mock morality taught from high places in censure of such conduct, the agreement among the minions or apologists of arbitrary power to call such aid piracy, robbery, and plunder, will not change the facts. This quarrel, all know, is essentially the cause of the Cuban against an unmitigated tyranny; and no American citizen was ever justly chargeable with the folly or the wrong of claiming a right of invasion or of conquest of the island of Cuba. The right of revolution is the Cuban's; the right of an American citizen is to aid them if he pleases, so he does not violate the laws of his country in doing so. The American citizen is not the property of his government. It is his right to peril himself in any war or popular strife abroad he sees it to hazard. And he well knows, if the enterprise is one unprotected by the flag of his country, the peril is his own. Shall we, who encourage the people of every nation to a renunciation of their natal allegiance, question this right? Be it known, therefore, that we - at whom, it is supposed, the denunciations of this proclamation are aimed - profess to believe ourselves as pious, moral and patriotic as any of our fellowcitizens who would lecture or censure us...If the cause of Cuba be right, we feel how pointless and exaggerated the efforts to brand us with either moral or political wrong, in giving it our countenance and support.

These were the sentiments of Young America. There is yet enough of the spirit of young America extant, to frown at the fogyism that would obliterate the precious record from our memories...All law writers admit there may be a naked tyranny that has no right of protection, or respect from the laws of nations. Nor can the tyrant claim any legal protection even for his personal security. Mr. Madison says: 'It is not denied that there may be cases in which a respect to the general principles of liberty - the essential right of the people, or the overruling sentiments of humanity might require a government, whether new or old, to be treated as an illegitimate despotism."

Now, I challenge any one to cite me to a single element in the power which crushes Cuba, that entitles that power to be respected as the legitimate government of the people of Cuba. The Cubans then have good cause to revolt. But this power, too, in the wantonness of violence, is now being exerted to an end, dangerous to the interests of our Southern citizens. And these, together, make augmented grounds of our sympathy, and excite many, it is presumed, to such lawful and legitimate action as may relieve the oppressed Cubans, and insure our own domestic security...

When it was fashionable at Washington, in 1825, to sympathize with the oppressed Greeks, there were no presidential threats of prosecuting John Q. Adams, Henry Clay, Daniel Webster, Mr. Forsythe, Gen. Lafayette and others...And it was well known to all of these gentlemen, that he was openly to take men and material aid from the Port of New York in furtherance of his military enterprise. The act of 1818 was then in force, and our country 
was at peace with the Turks. And I shall not pretend, but the act so meditated, was in violation of that law. But I allude to the fact to show that even the conservative Intelligencer did not accuse these persons as instigating robbery or piracy — or of entertaining sentiments and wishes derogatory to them as gentlemen, patriots and good citizens. And, as giving special éclat to the preparations for that expedition, Mr. Adams, then just elected to office, gave to the same Greek filibuster a regular passport under the great seal of the State. If such, then, were the honors of such an enterprise, and such its advocates and promoters, can it be that the aspersions of the proclamation against those who are supposed to sympathize in an equally meritorious cause, can be well deserved? Much might be said of the President's imputations of lawlessly complicating the question of peace and war...

Now, all these threats of the Executive to obtrude his zeal and his wishes, and even his presence, by subordinate agents, and his supernumerary attorneys, into the courts of justice, to effect a conviction, can have no proper, pure and good result. And, however modestly or truly disclaiming to seek an undue influence with the judge, yet such intrusions could not leave his infirm humanity as erect and self-poised as if his mind was not burdened with the Executive energies and anxieties so manifested and paraded before him.

Though having but slight participation in whatever movement there is now being made for the redemption of Cuba, and the security of the South, I am willing to shoulder my share of the responsibility. Not wholly unknown to the American people, I have some pride of reputation, and claim to entertain as high a respect for law, for truth, and for such virtues as are comprised in the character of a good citizen, as those may affect to have who can use official station as a license to propagate detraction. And before the American people I thus defend myself against all disparaging charges and insinuations contained in the President's proclamation, so far as I am concerned. ${ }^{364}$

What is interesting about Henderson's defense is its migration from a statement of broad encouragement, much like those produced by López's supporters earlier in the decade, to one of intense self-righteousness that sought no wider audience other than history. There existed no law that could compete with history and securing one's place in its pantheon. The higher moral law of liberty (the existence of which was rejected by pro-slavery advocates when abolitionists spoke of it) drove no compromises nor would the annexationist perspective on the necessity of action. Annexationists believed themselves to be upholding the highest principles of Madisonian republicanism, a posture they believed those that opposed annexation forfeited the right to claim. The sectional turn regarding filibustering to Cuba saw its genesis in the vacuum of presidential

\footnotetext{
364 John Henderson, “Considerations on The Constitutionality of The President's Proclamations," (New Orleans: Daily Delta, 1854).
} 
leadership, the desire for revenge, and the insecurity bordering on paranoia that began its rapid creep upon the Southern mind. The rigidity of the language and the staunchness of its defense were indicative of the developing perspective of Southern politicians and laity of the period. Even the motives of so-called amendable presidents were cast as illegitimate in the face of universals like liberty, freedom, and sectional security. A certain amount of missionism entered the political discourse that attempted to imbue annexation, for Southerners, with the same moral/religious reverence that abolition attempted to extol upon its own ideological adherents. Purchase and diplomatic negotiation were not legitimate sources of concern that affected annexationists. These political efforts were rather examples of effeminacy and the decadence of abolitionism that sought legalism rather than action in pursuit of completion. The Southern pursuit received a shot in the arm from the election of Franklin Pierce, only to be disappointed by prevarication and ambivalence once his administration fell under Northern sway.

The failure to annex Cuba and to shore up Southern economic hopes of wresting some financial control back from New York and Chicago banks pushed Southerners toward more aggressive political reckonings. Economic gain, a song that many sang regardless of region, encouraged consensus of goal, even if the continuance of slavery was an untoward subsidiary result. However, baldness in political demands and the unfettered expansion of slavery with seemingly no shared gain raised the hackles of Northern politicians and more importantly the Northern public. Fueled by a fusion of abolitionist moralism, Southern belligerent pettiness, and media bombast, Northern public opinion became convinced of a great conspiracy that held out no promise of republican growth through territorial expansion but only promised to further strengthen the Southern political hand. 
However, in efforts to save the movement some supporters of annexation claimed Cuban addition to the United States as a means to limiting slavery's growth and existence in the United States. Surely, Cuba might enter the Union as a slave state(s) but the island would draw production now expensively occupying land in the Border States. Eventually, slavery would disappear from those areas as agricultural capital naturally flowed to the areas of least political and economic resistance. Cisneros wrote to Saco of this eventuality. "The Cuban annexationist party is strongly rooted in the United States. Even the abolitionists and the supporters of Free Soil Free Labor, see in annexation the quickest means of putting an end to the great humanitarian and social question. To tear the island away from Spain is to overcome virtually, the trade in human flesh." American observers saw this hopeful reality as well. Henry Carey argued that gradual abolition would help the Southern economy. "The true way to bring about the gradual abolition of slavery must be to endeavor to increase the value of Southern land and Southern labor, to the advantage of both master and servant; a measure that can be accomplished only by an increase in the ration of spades and ploughs, and mills, and furnaces, and other machinery which constitutes wealth, to populations. If the Southern man desires to do this he must encourage the owners of such wealth to come or to stay among them." Anti-slavery advocate William Jay wrote to Lewis Tappan, in hopes of convincing, perhaps himself, that, "The people of this country while acting with deliberation will do what they think will give them the most money. I believe that slavery will cease but in obedience to the commands not of god but of mammon." 365

\footnotetext{
${ }^{365}$ Saco, Contra la anexión, 17. Henry Carey "The Slave Question," The Plough, the Loom and the Anvil, 1 (1849) 207-209. Tappan quoted in George Winston Smith, "Ante-Bellum Attempts of Northern Business Interests to 'Redeem' the Upper South,” The Journal of Southern History 11, no. 2 (May 1945), 177-213, quote on 182.
} 
Those who feared the economic competition from Cuba also had their fears explained away. Concerns about Louisiana's sugar production were thoroughly dissected and drove many supporters to argue, much like with the slavery question, that annexation would bring stability to domestic sugar production and, in fact, strengthen the American agricultural effort. Representative Edward Chastain outlined the reasoning of supporters of annexation in a speech in Congress during February of 1855 . He extolled the virtue of Southern planters as the main reason not to fear Cuban sugar.

But, sir, let us suppose that Cuba has thrown off the Spanish yoke, established her independence, and asked to be admitted into the American Union. The honorable member meets the application with an objection on which he seemed to lay much stress - namely, that the admission of Cuba would paralyze the vast slave interest at the South engaged in raising sugar. This, sir, is a fallacy, and, I regret to add, a somewhat popular one. The sugargrowing region of the South, and the slave interest engaged in that pursuit, would be immeasurably benefited by such an acquisition. Such, at least, is the opinion of those who have examined this subject carefully and practically; whose opportunities for acquiring correct information have been ample, and whose interests, and feelings, and sympathies are all identified with the sugar-growing interests of Louisiana. I will quote from an article on this subject which appeared in De Bow's Review for July, 1854, from the pen of one of the most accomplished and patriotic of Louisiana's sons: 'The establishment of a free government in Cuba could not produce any immediate prejudice to the sugar-planting interest of Louisiana, for it would not disturb in any way the fiscal protection which the present tariff extends to it. It is the subsequent admission of that island as one of the States of this Union which is supposed to nurture disaster and ruin for the sugar planters of Louisiana. But I do not entertain the belief that this event is pregnant with ruin, or even with injury to the sugar-planting interests of this State; and to suppose that such a result would follow the admission of Cuba into the Union, I would suggest the following reflections: The product of sugar to the acre in Cuba differs very slightly from that in Louisiana, while the difference in the amount produced per hand is even less than the difference of product to the acre, and is probably in favor of the Louisiana planter, from his improved system of culture, and better care and feeding of his hands. The great elements of the less cost of production of sugar in Cuba than in this country consist in the superior cheapness of labor and the lower value of land there. The average value of field-hands in Cuba is $\$ 500$, while in Louisiana their value is $\$ 1,200$; and the mean value of land is well known to be far less than here. In these great items consist almost the entire advantage which the planter of Cuba possesses over him of Louisiana. In other respects he labors under disadvantages; for instance, the cost of his supplies, which is greater from his greater distance from their place of production. The first great result of the establishment of a free government in Cuba, or of its admission to this confederacy, would be the immediate cessation of the African slave trade, and the appreciation in value of the slaves there, consequent upon the cutting off of this source of cheap supply. Next in the scale of economic results attending the admission of Cuba to the Union would be the equalization of the value of slaves. They could not remain at an average value of $\$ 500$ there, while they 
bore that of $\$ 1,200$ in Louisiana, and freedom of intercourse between the two countries existed. Such an equalization in the value of labor in this country and in Cuba would contribute a great degree to an equalization of the cost of production of sugar in each, increased in Cuba and diminishing it in Louisiana, in the exact proportion of its effects upon the value of labor respectively. The increase in the cost of production of this staple in Cuba would afford a far more permanent and efficient protection to the sugar-planter of Louisiana than the present fiscal impost upon sugar; while, so long as Cuba is enabled to produce it at less cost than Louisiana, and the desire in the North to obtain cheap sugar exists, the danger to the sugar-planting interest in this country will not only remain, but continue to increase.' 366

These attempts at economic rationality followed the Young America call sheet, yet rang empty as their moment passed into history by the late 1850 s. The clear representative sectionalism on display in Chastain's thinking supports this abandonment of consensual economics. Previously, Young America's economics sought communion of national cause through economic growth irrespective of geography, preferred labor method, party, or station. International markets and commercial opportunity spoke loudest with little regard for morality. Democrats abandoned the Jeffersonian agrarian dream for progressive prosperity based on market driven commerce. Not that the two had been separate in the decades prior, but the conceptualization of the market now contained room for an ideological meshing. Young America gave philosophical voice to economic realities that long-existed. Democrats grew comfortable talking in Whigs' terms. Men like John O’Sullivan and Stephen Douglas pumped out speeches and articles articulating the case for a broad American republicanism shared through the market mechanisms of expansion, robust patriotism, and political millennialism. The United States hoped to press their power and advantage in the world political and economic market place through dominance in international trade. In a slightly overwrought speech, Ohio Senator William Allen discussed the new economic realities in reference to our competition with Britain.

It is in this commercial rivalry of the two nations of the old and of the new system, that the great contest has begun, which involves their political destinies. For, sir, it is commerce,

\footnotetext{
${ }^{366}$ Hon. E. W. Chastain of Georgia, "The Acquisition of Cuba, In Reply To the Speech of Mr. Boyce, Of South Carolina," accessed March 14, 2014, https://archive.org/details/speechofhonewcha00chas.
} 
which now regulates the international relations of the world. It is upon commerce, that the new code of the law of nations is based. It was upon commerce, that the British Empire was founded. It is by commercial monopoly alone, that it can be sustained. It is the danger to which that monopoly is exposed, from other nations, and chiefly, from the United States, which renders the British empire more precarious, at this day, than ever before, and feebler, by far, than any other of the old leading monarchies of Europe...England sternly resolves to brave the peril; and, armed against the world, she goes forth, with fire and sword, to open new highways for her commerce in the East, that she may post-pone, yet longer, the catastrophe which awaits her. For this reason it is, that she turns her cannon, also upon the States of South America. For the same reason it is, that she now seeks, by the possession of Oregon, to extend her sway upon the American front of the Pacific Ocean; because, if successful, she not only adds positive strength to herself, but by our loss of that region, subtracts positive strength from us - the most dangerous of her rivals, commercially and politically. ${ }^{367}$

Young Americans also pushed for internal conduits of movement in order to capitalize

upon the international movement of goods. The pathways of international trade anchored to the rational movement of goods and people internally throughout the United States. These interests pushed Young America to demand government internal improvements and investments in rivers, harbors, railroads, and wharves. Shipping magnates George Sanders and George Law lobbied Congress and found willing ears attached to politicians like Stephen Douglas, himself trying to complete a transcontinental railroad bill.

It will be the work of years and progress gradually, from east to west, keeping up a connected chain of communication, and following the tide of emigration, and the settlement of the country. In addition to the India and China trade, and the vast commerce of the Pacific Ocean, which would pass over this route, you must create a further necessity for the road, by subduing the wilderness, and people it with hardy and industrious population, who would soon have a surplus produce, without the means of getting it to market, and require, for their own consumption, immense quantities of good and merchandise which they could not obtain, at reasonable rates, for want of proper facilities of transportation; and that necessity will make the road. ${ }^{368}$

Yet the movement that more and more commerce took west to east via railroads was a concern to Southern boosters, particularly in New Orleans. Boosters of the city feared the gains of

\footnotetext{
${ }^{367}$ William Allen, "Speech of Hon. William Allen, of Ohio delivered in the Senate of United States, February 10 and 11, 1846, on our relations with England; being the opening speech pending the Oregon notice (1846)," accessed on January 20, 2014, https://archive.org/details/cihm_16594.

${ }^{368}$ Stephen Douglas to Asa Whitney quoted in Henry Nash Smith, Virgin Land: The American West as Symbol and Myth (Boston: Harvard University Press, 1950), 33.
} 
commerce might not be felt equally throughout the country. Of course it must be noted that these improvements also largely aided the movement of slaves throughout the Southwest as well. And with this emphasis on expansion and internal improvement, Cuba became, in the hands of politicians and pressmen, a key component to these infrastructural improvements. Consequently, Cuba, which received interest across the political and geographic spectrum, stood as an example of the convergence of political perspective in service to commercial expansion that limited political participation and difference in the electoral landscape. This apparent consensus in politics allowed politicians to think less of partisan outcomes and, as a result, engage in highly damaging and risky political decision-making. These disastrous policies, presented in the highly charged atmosphere of the 1850s exacerbated latent economic suspicions held by those not convinced by Young America’s storytelling. Sectionalism sprang less from political concerns and more as a direct result of the economic reordering of American society. The South, whose capitalists directed their economic ideology slightly differently, felt increasingly painted in a corner - one in which the collapse of slavery might come as a result. The consensus of Young America's economics broke down by the mid-1850s. ${ }^{369}$

Revolution and economics came together in a profound way. Much like in the case of Kossuth and Hungarian assistance, sympathy for cause could not produce official policy. The reluctance to enter the European fray, beyond statements of support, on the part of the United States government held true on the issue of Cuba. Beyond very quiet attempts at purchase, the

\footnotetext{
${ }^{369}$ Robert May, "Epilogue to the Missouri Compromise: The South, The Balance of Power, and the Tropics in the 1850s," Plantation Society 1, no.1 (June 1979), 201-225; Adelaida Zorina, "On the Genesis of Capitalism in Nineteenth-Century Cuba," Latin American Perspectives 2, no. 4, (1975), 7-20; Daniel Rood, "Herman Merivale's Black Legend: Rethinking The Intellectual History Of Free Trade Imperialism," NWIG: New West Indian Guide 80, no. 3/4 (2006), 163-189; Edward B. Rugemer, "The Southern Response to British Abolitionism: The Maturation of Proslavery Apologetics," The Journal of Southern History 70, No. 2 (May 2004), 221-248; George B. Crawford, "Cotton, Land, and Sustenance: Toward the Limits of Abundance in Late Antebellum Georgia," The Georgia Historical Quarterly 72, no. 2 (Summer 1988), 215-247; Kimberly Lamp, "Empire for Slavery: Economic and Territorial Expansion in the American Gulf-South, 1835-1860," (PhD diss., Harvard University, 1991).
} 
government showed no particular interest in military efforts. While many hoped that filibustering might produce a change in Cuba's status, this was going to be territorial expansion on the cheap and, much like in Texas, would place the United States government in a reactive mode once annexation became possible. Certainly the proximity of Cuba to the southern coast of the United States made private expedition more personally and logistically possible than it was in Europe, although there were some Americans who did cross the Atlantic to fight in the revolts of 1848 . However, Cuba held out a more profound importance, particularly for American slavery, than the revolutions in Europe. While the ideology of republicanism spoke to the American population and politicians generally, the articulation of that republicanism had different foundations for the South that wove slavery into the conceptualization of American republicanism and Cuba as its cornerstone. Cuban slavery was the last wall of defense against Northern and British abolitionist radicalism's convergence on the South. Social self-determinism and freedom from abolitionism were hallmarks of the Southern conceptualization of republicanism. For many in the North, López came to occupy a diminished status largely for his ambivalence on the slavery question, an ambivalence that mortally wounded the effort and popularity of another great hero, Lajos Kossuth. Both men arrived during the fugitive slave crisis. Abolitionists looked for these two figurative "fugitive slaves" to become full-throated allies in the cause against the slave power they felt pressing its demands ever more forcefully. Abolitionists, like William Lloyd Garrison blamed the men's excessive patriotism as the source of their refusal to condemn slavery in deference to the desire for their nations' independences. However, this criticism bristled supporters of annexation. They saw abolitionists, particularly Garrison's followers, as practitioners of not only unhelpful ideologies, but also advocates of the destruction of the United States. 
In 1850, the Democratic Review spoke of abolitionists, in the person of William Lloyd Garrison, as "Fanatics who recognize no country, no friends, no kindred. They are the friends of the entire human race, and nothing less than the circumference of the world can set bounds to their philanthropy. They desert their duties to country, their kindred, and their friends to go wandering about the world." Many Southerners also applied the critique to Northern capitalists who invested in far-flung enterprises like vultures picking the flesh and flying away. They knew no locality and investment in the agricultural practice like landowners did. Industrialists exploited workers but did not need to interact with them to benefit from this exploitation. Capital investment, speculation, lending, insuring - all of these things - made no connection to individual laborers. While Northern capitalists benefitted just a much from the extracted labor of slaves, Southerners argued they paid none of the social, physical, and mental costs that burdened plantation owners on a daily basis. ${ }^{370}$

The great debate of the 1850 s centered on the morality of slavery and specifically, the morality of using enslaved human beings to benefit economic progress and cultural civilization. Southern desires focused on claiming the prerogative in defining American freedom by fusing popular sovereignty and slavery together. In order to accomplish this task, thereby allowing their claim to a superior Americanism, Southerners drew distinction between the American Revolution and the European revolts of 1848. The failure of the European revolts lay in the violence and extremism on display as compared to the socially conservative revolution the American patriots led beginning in 1776 . The embrace of absolute equality was a grotesque distortion of the principles underlying the American Revolution. Slavery, as representative of social hierarchy, was imperative to a true rendering of American republicanism. Southerners

370 “The Conspiracy of Fanaticism," Democratic Review 26, no. 143 (May 1850). 
argued that the failures of 1848 demonstrated that not all are ready for freedom and selfgovernance. This clash between world philanthropy and national patriotism rested on the revolutionary vanguard's reliance on violence. ${ }^{371}$

The social tumult unleashed by revolt in Europe reinforced Southern fears that worse chaos and retribution would flow from abolition in the United States. Southerners, drawing on the retroactively invented non-violent consensuality of the American Revolution, used the perceived legalistic process of independence from Britain to argue that the concept of secession was essentially the logical continuance of conservative revolt and warranted no violent response from the North. The concern also held that if the federal government claimed the right to intervene in the affairs of sovereign nations, such as the support Kossuth requested, this might invite federal incursion into the post-secession South. In this articulation, filibustering took on an added importance since it held personal and non-governmental participation as the impetus for action. Therefore, filibustering established a conceptualization of extra-legal individualism that undergirded secessionist ideology and invalidated governmental action in its prevention. ${ }^{372}$

Filibustering also offered the hope that North and South might rekindle the revolutionary fire in the rhetoric of annexation. Cuba might help put aside the regional and personal differences threatening to engulf the United States with appeals to a different time and generation. The distrust of the revolutions of 1848 thus came from their apparent ideological similarity to the United States example. The fear that the American revolutionary experiment might end in a similar bloodbath to those on display in Europe shocked and bewildered Americans, as they

\footnotetext{
${ }^{371}$ W. Caleb McDaniel, “'Our Country Is the World:' American Abolitionists, Louis Kossuth, and Philanthropic Revolutions," (paper presented to the Annual Meeting of the OAH, March 25, 2004); Ronald Walters, The Antislavery Appeal: American Abolitionism after 1830 (Baltimore: JHU Press, 1978).

372 Peter Hamish Wilson, 1848: The Year of Revolutions (New York: Ashgate, 2006); Timothy Mason Roberts, Distant Revolutions: 1848 and the Challenge to American Exceptionalism (Charlottesville: University of Virginia Press, 2009); Michael A. Morrison, “American Reaction to European Revolutions, 1848-1852: Sectionalism, Memory, and the Revolutionary Heritage," Civil War History 49, no.2 (2003), 111-132.
} 
found themselves disengaged from the revolutionary generation that produced the very levelheadedness so perceived and so needed in the 1850s. South Carolina Senator Isaac Holmes voiced these fears upon the death of John Quincy Adams, a man with whom he bitterly quarreled. "This is no common bereavement, the chain which linked our hearts with gifted spirits of former times has been rudely snapped. The lips from which flowed those living and glorious truths that our father uttered are closed in death."

However, the unity searched for in annexation proved elusive. Northern and Southern politicians and their respective presses took great pains to demonstrate each region's superior claims to the revolutionary generation's legacy. This debate, in one respect, directed its attention at wrestling the power of definition of the American Revolution away from the European interlopers. The other important aspect aimed at seizing the moral high ground in domestic debates, most centered or touched on slavery. The double impact and concern with contagion, both Northern and European, on the part of the South produced tenacity in the debate and corresponding vehemence in their assertions. The failure of the European revolutions, coming just as sectional tensions reached a new plateau, added to the great anxiety clouding the debate. The importance of returning the United States to its cherished position on top of the revolutionary hill was not only national but also international. Yet, Young America was unable to shoulder the burden. To the chagrin of many, the demagoguery that sapped the energy and clarity of Europe's revolts presented itself in American politics. Despite, Narciso López's assertion, in one of his few writings, that his filibusterers were, "Sons of Washington," the problem remained that these sons, many observers pointed out, were drunkards in search of plunder and not up to the comparison. The great fear Americans held was the recognition that

\footnotetext{
${ }^{373}$ Morrison, “American Reaction,” 116.
} 
perhaps our politics hadn't influenced Europe as much as its ideologies threatened to influence United States politics. Perhaps violent conflict was the more likely outcome of the republican experiment. Therefore, Cuba and the promise of a legal transition, through purchase or creole embrace of annexation, offered a redemptive quality to both the Cubans, as this generation's American revolutionists, and to Americans desperate for some quantitative evidence of their nation's ongoing example and worth. The only things holding the United States together was a revolutionary language that imbued every decision with a missionary direction coupled with a capitalism that offered a limited ability to join together a diversifying and dividing population. The market steadily weakened as a unifying entity after 1857 when the South finally received some tangible demonstration of the superiority of their economic project. They emerged from the Panic of 1857 with the sense that the North needed Southern commerce more than the South needed Northern industry. The South embraced this evidence and the resultant increase in the region's confidence. ${ }^{374}$

\footnotetext{
${ }^{374}$ The South emerged relatively unscathed from the Panic of 1857 and in many respects economically more confident than at any point since 1837. The Panic is traditionally blamed on low foreign demand for Western grains, due to the ending of the Crimean war, coupled with over investment in Western railroads by British and Northern investment companies. Increasing land and building prices, in hopes of supercharging the western trade, created a bubble waiting for the pin of lower demand and lower prices. Through these woes cotton demand remained steady and prices dropped only modestly. Southern papers, like the Richmond South, gloated, "the present crisis will show that the slave labor staples of the South will furnish the means of extrication from commercial indebtedness," and Northern papers agreed. Said Harper's Weekly, "but for the cotton crop the revulsion would have left us prostrate." This strength in the Southern economy encouraged greater Northern and foreign investment southward, opening up credit for mechanization and other improvements. James Huston, while he agrees with the traditional points of emphasis, points out compellingly that accounting must also be made, as contemporary observers did, of the uneven effects of the Panic throughout the county. Additionally, he argues for the importance of monetary policy and its effect on the liquidity of the markets (the Palmerston government's circumvention of specie requirement under the Bank Charter Act of 1844, touched off concerns which travelled across the Atlantic). "There were some weaknesses in the business reporters' theory about the causes of the Panic of 1857. They did not as a general rule bring into their discussion certain monetary considerations, such as the effect which California gold discoveries had on the money supply, and the consequent inflation which haunted the antebellum decade. Nor did they observe the reduction of foreign investments in the West when the Crimean War ended, caused partially by the readjustment of French and British interest rates." Hurston, "Western Grains and the Panic of 1857," Agricultural History 57, no. 1 (January 1983), 14-32, quotes on 23, 31. Adding to the unrest was the Dred Scott decision and the reckoning with further upheaval in the markets. The weakness of the Western market and the drying up of its investment potential encouraged some back to the Cuba well as a potential source of investment, particularly for hard hit Northern investors. James Bennett of the New York Herald argued, "acquisition of new territories would spur business back
} 
The economic concern shown by Southerners stood upon the perceived affront of free laborists against slavery. This anti-slavery aggressiveness stood as assumed fact in the minds of Southern capitalists. However, while the British danger might be kept at bay, a reality made easier with Cuban annexation, the intrusion of Northern free laborists in the South irritated, concerned, and flummoxed Southerners. Rather than a gradual abolition of slavery in the United States, a result many predicted with the annexing of Cuba, Northern business interests in the sway of abolitionists took direct action to erase slavery where it already existed. In the wake of the economic depression beginning in 1837 , the South, excoriated for is overreliance on agriculture for its economic lifeblood and lambasted for the over-speculation and questionable banking practices that hastened the crash, moved to diversify its various portfolios in a hostile protest against Northern domination perceived to have encouraged at least a portion of the South's investment and thus the crash. By the 1850s, this hostility toward Northern economic command and control produced two answers. First, the South looked for markets, partners, and capital investments that mitigated Northern dominance. Expansion was an outgrowth of these capital desires. Second, by at least 1850 , as exemplified by the Commercial Conventions of that year, the economic hostility merged with a strong political hostility speaking openly of disunion.

\footnotetext{
because new land opens new employments for labor, constructs new way for the conveyance of man and his products everywhere, and by extending the field of its usefulness gives a greater value to every man's labor and every man's wealth." Not wanting to engage the always unhelpful and unreliable purchase of Cuba, along with knowing a war with Spain was impossible, Buchanan decided to work with the other levers available to him, namely tariff rates. In addition to being lightly touched by the Panic, the South also received the generous lowered tariffs of 1857. The Tariff of 1857 bottomed out rates at $17 \%$ signaling victory for Southern politicians and producers. The episode demonstrated for the South the lack of necessity, both economically and politically, they had in reliance upon Northern demands and economic ideology. James L. Huston, The Panic of 1857 and the Coming of the Civil War (Baton Rouge: LSU Press, 1999), ch. 7 deals with the Congressional debates and Cuba issue. Charles Calomiris and Larry Schweikart, "The Panic of 1857: Origins, Transmission, and Containment," Journal of Economic History 51, no. 4 (December 1991), 807-834, found that Southern banks weathered the specie storm well. Morgan Kelly and Cormac Ó Gráda, "Market Contagion: Evidence from the Panics of 1854 and 1857," The American Economic Review 90, no. 5 (December 2000), 1110-1124; Jay Sexton, Debtor Diplomacy: Finance and American Foreign Relations in the Civil War Era, 1837-1873 (Oxford: Oxford University Press, 2005); Richard Franklin Bensel, Yankee Leviathan: The Origins of Central State Authority in America, 1859-1877 (Cambridge: Cambridge University Press, 1990).
} 
The confidence gained through lucrative business relations with world markets, the diversification of the Southern manufacturing base, the relatively light toll taken by the Panic of 1857, the possibility of Cuban annexation, the dominance of presidential elections in the 1850s, and the political capitulation of Northern interests in the tariff debate of 1858 all led the South not only toward a belief in the political possibility of secession but also in the perceived likelihood of success. The failure in Cuba cast a cloud over the entire process, as the recognition of the political certainty of Northern demographic dominance in the House and territorial dominance on the continent seemed a fait accompli, thereby warranting of the paranoia invading the Southern mind. This paranoia had an economic source as groups like the New England Emigrant Aid Company encouraged white immigration first to Kansas in 1854 and then, more ominously, to Virginia in 1856. While these were not massive undertakings, they forced Southerners to take note of these groups' motives. The Massachusetts Emigrant Aid Company made its intentions quite clear in their incorporation documents of 1854 ,

In view of the establishment by such agencies of a new Free State in that magnificent region, it is unnecessary to dwell in detail on the advantages which this enterprise holds out to the country at large. It determines in the right way the institutions of the unsettled Territories, in less time than the discussion of them has required in Congress. It opens to those who are in want in the Eastern States, a home and a competence, without the suffering hitherto incident to emigration. For the Company is the pioneer; and provides, before the settler arrives, the conveniences which he first requires. Such a removal of an over-crowded population is one of the greatest advantages to Eastern cities. Again, the enterprise opens commercial advantages to the commercial States, just in proportion to the population which it creates, of free men who furnish a market to our manufactures and imports. Whether the new line of States shall be Free States or Slave States, is a question deeply interesting to those who are to provide the manufactures for their consumption. Especially will it prove an advantage to Massachusetts, if she create the new state by her foresight - supply the first necessities to its inhabitants- and open, in the outset, communications between their homes and her ports and factories. ${ }^{375}$

\footnotetext{
375 Samuel Johnson, “The New England Emigrant Aid Company,” (PhD diss., University of Wisconsin, 1935); “The Report of the Committee of the Massachusetts Emigrant Aid Society with the Act of Incorporation," accessed March 7, 2014, http://www.kancoll.org/books/emig_aid/emigrant.htm. Russell K. Hickman, "Speculative Activities of the Emigrant Aid Company," Kansas Historical Quarterly 4, no. 3 (August 1935), 235-267.
} 
Perhaps more ominous was the political traction the idea of spreading free labor gained in the halls of Congress, with free soil Republicans and the Northern press. Virginian John Underwood went on a media blitz extolling the benefits of free wage labor and economic nationalism to anyone who would listen. His speaking tour at hundreds of Republican events earned him the derision of his fellow planters but it enlisted many important newspapers, as well as some of the largest capital men in New England, in support of the efforts. The new and more robust effort that resulted in 1857 - North American Emigrant Aid and Homestead Company set its sights on a much larger geographic area, including Missouri, Texas, and Virginia. The Company director's audacious plan involved building factories, homes, towns, and railroads all on property the company purchased. This was a massive program of population and capital movement that threatened the South and its conceptualization of labor and republican society. Yet it was a project that its supporters, like Ali Thayer and Henry Carey, instinctually believed the South might be amenable to as a result of the economic fluctuations of the past decades. A Philadelphia North American editorial in June 1857 argued that the West might actually be a source of shared unity and concern between North and South.

Since the demon of speculation has set up his red flag in the West, and is attracting purchasers of lands, not for improvement, but for a rise, the immigrant in moderate circumstances will soon be driven to fresh fields and pastures still newer, to greater distances, and to cheaper soil. This is the time, then, for the South by a masterly magnanimity which will produce them handsome profit, to overlook all this abolition nonsense and encourage emigration to their vacant lands. ${ }^{376}$

Southerners rejected the pretty noise and simply looked to a rampant free labor ideology closing in on all sides. The British threatened abolition, slave uprising, and biracial republicanism while the North threatened competition, speculation, and political dominance. The

\footnotetext{
${ }^{376}$ Philadelphia North American, June 2, 1857. Paul Quigley, Shifting Grounds: Nationalism and the American South, 1848-1865 (New York: Oxford University Press, 2011).
} 
demographic shifts that emigration would bring to the South threatened to tip the scales permanently in favor of abolition. Therefore, retaining slavery, in the Southern mind, was akin to retaining political independence and protecting the chief outlet for their republican practice. Every battlefield of the institution's protection then became necessary. In the threat of the perceived Northern aggression, Kansas then became the American Cuba. Heavily armed 'filibusters' washed over the state, vying for political control over its agricultural, social, and slave-status futures. The brutality of the fight, both political and physically, shocked the nation and left the South with the impression that Northern abolition and free labor would hound their interests regardless of locale or compromise. However, as the Panic of 1857 set in, the South expanded trade with international markets and sensed that separation might be possible to protect slavery. The British seemed more than happy, just as with Cuban sugar, to trade and prosper with slave commodity production. The South, seeing the creation of the national union as a contract based on self-interest and rational relations, argued that as property of investment and industry remained protected in the Constitutional agreement, so too must slaves and land be treated similarly. However, the constitutional act lacked the primordialism of blood or history of European nationalisms and stood devoid of morality. The agreement's only enforceable aspect was contract law and once abrogated, as the South claimed the North had done, the document became voidable.

Beyond their legalism, Southerners embraced an almost aristocratic appreciation for their role in social hierarchy and direction of the region's culture. This appreciation promoted a loathing of their Northern brethren who lacked even the most remote interest in the natural ordering of people. As London Times war correspondent, William Russell recounted of his interviews throughout the South, 
That voice (a South Carolina planter) says, 'If we could only get one of the Royal race of England to rule over us, we should be content.' Let there be no misconception on this point. That sentiment, varied in a hundred ways, has been repeated to me over and over again. There is a general admission that the means to such an end are wanting, and that the desire cannot be gratified. But the admiration for monarchial institutions on the English model, for privileged classes, and for a landed aristocracy and gentry, is undisguised, and apparently genuine. With the pride of having achieved their independence, is mingled in the South Carolinians' hearts a strange regret at the result and consequences, and many are they who 'would go back tomorrow if we could.' An intense affection for the British connection, a love of British habits and customs, a respect for British sentiment, law, authority, order, civilization and literature, pre-eminently distinguish the inhabitants of this State, who, glorying in their descent from ancient families on the three islands, whose fortunes they still follow, and with whose members they maintain not infrequently familiar relations, regard with an aversion of which it is impossible to give an idea to one who has not seen its manifestations, the people of New England and the populations of the Northern States, whom they regard as tainted beyond cure by the venom of 'Puritanism.' It is absolutely astounding to a stranger who aims at the preservation of a decent neutrality to mark the violence of these opinions. 'If that confounded ship had sunk with those Pilgrim Fathers on board,' says one, 'we never would have been driven to these extremities!' 'We could have got on with the fanatics if they had been either Christians or gentlemen,' says another; 'for in the first case they would have acted with common charity, and in the second they would have fought when they insulted us; but there are neither Christians nor gentlemen among them I.' 'Anything on the earth!' exclaims a third, 'any form of government, any tyranny or despotism you will; but' - and here is an appeal more terrible than the adjuration of all the Gods - 'nothing on earth shall ever induce us to submit to any union with the brutal, bigoted blackguards of the New England States, who neither comprehend nor regard the feelings of gentlemen! Man, woman and child, we'll die first.' Imagine these and an infinite variety of similar sentiments uttered by courtly, well educated men, who set great store on a nice observance of the usages of society, and who are only moved to extreme bitterness and anger when they speak of the North, and you will tail to conceive the intensity of the dislike of the South Carolinians for the free States. There are national antipathies on our side of the Atlantic, which are tolerably strong, and have been unfortunately pertinacious and long lived. The hatred of the Italian for the Tedesco, of the Greek for the Turk, of the Turk for the Russian, is warm and fierce enough to satisfy the Prince of Darkness, not to speak of a few little pet aversions among allied Powers and the atoms of composite empires; but they are all mere indifference and neutrality of feeling compared to the animosity evinced by the 'gentry' of South Carolina for the 'rabble of the North.'...The North is to South Carolina a corrupt and evil thing, to which for long years she has been bound by burning chains, while monopolists and manufacturers fed on her tender limbs. She has been bound in a Maxentius union to the object she loathes. New England is to her the incarnation of moral and political wickedness and social corruption. It is the source of everything, which South Carolina hates, and of the torrents of free thought and taxed manufactures of Abolitionism and of filibustering, which have flooded the land... It is the merchants of New York who fit out ships for the slave trade, and carry it on in Yankee ships. It is the capital of the North which supports, and it is Northern men who concoct and execute, the filibustering expeditions which have brought discredit on the slaveholding States. In the large cities people are corrupted by itinerant and ignorant lecturers - in the towns and in the country by an unprincipled press... ${ }^{377}$

377 “Russell's Letters to the London Times, " reprinted in Sacramento Daily Union, July 6, 1861, accessed March 14, 2014, http://cdnc.ucr.edu/cgi-bin/cdnc?a=d\&d=SDU18610706.2.15 
Daniel Webster, during the debates over the Compromise of 1850, grew exasperated with talk of

bloodless secession, aware as he was of the Nashville Convention of 1850.

I hear with pain and anguish and distress the word secession especially when it falls from the lips of those who are eminently patriotic and known to the country and known all over the world for their political services. Secession! Peaceable secession! Sir your eyes and mine are never destined to see that miracle. The dismemberment of this vast country without convulsion! The breaking up of the fountains of the great deep without ruffling the surface! Who is so foolish I beg everybody's pardon as to expect to see any such thing? Sir he who sees these States now revolving in harmony around a common centre and expects to see them quit their places and fly off without convulsion may look the next hour to see the heavenly bodies rush from their spheres and jostle against each other in the realms of space without producing the crush of the universe. There can be no such thing as a peaceable secession. Peaceable secession is an utter impossibility. Is the great constitution under which we live here covering this whole country is it to be thawed and melted away by secession as the snows on the mountain melt under the influence of a vernal sun disappear almost unobserved and die off? No sir! No sir! I will not state what might produce the disruption of the States, but sir, I see it as plainly as I see the sun in heaven. I see that disruption must produce such a war as I will not describe in its twofold characters. ${ }^{378}$

\footnotetext{
${ }^{378}$ Daniel Webster, "Mr. Clay's Compromise Resolutions," in Abridgment of the Debates of Congress, from 1789 to 1856: Volume 7, March 1850, accessed March 14, 2014, http://books.google.com/books?id=PGkFAAAAQ AAJ\&lpg=PA430\&ots=9-AT65PXz8\&dq= there $\% 2$ is $\% 20$ no $\% 20$ such $\% 20$ thing $\% 20$ as $\% 20$ peaceable $\% 20$ secession $\& p g=P A 430 \# v=$ onepage $\& q=$ there $\% 20$ is $\%$ 20no\%20such $\% 20$ thing $\% 20$ as $\% 20$ peaceable $\% 20$ secession $\& \mathrm{f}=$ false, $429-430$. The Nashville Convention attendees seemed to have every intention of proposing dissolution in 1850. George Goldthwaite from Alabama summed up the feelings of many in attendance. "It could not be disguised that the civilized world was leagued abroad against us. Revolutionary France had, the first thing, set free three hundred thousand slaves, who had vindicated their claim by rapine and murder. England had done the same thing, and other nations of Europe the same also. The whole of continental Europe with the exception of the weaker powers, had taken the same ground; and on this continent, we had seen, in the last few years, fourteen States deliberately instruction their senators and representatives in Congress to restrict slavery to its present limits; thus endangering the institution. Party ties at the North had been sundered and scattered to the winds in favour of this action....and the mean, infamous and contemptible party, whose members, a few years since, were mobbed in the house and churches of the North, was not countenanced, its views adopted in the pulpits and in the philosophy of the schools, and sanctioned by men high in position there... Whilst our slaves were increasing, our territory was decreasing, and although the period could not be defined, the time would come, under this condition of things when we should have to give up our property. Seeing this, we must prepare for this action of the North. The only true principle is, to force upon the minds of the Northern people the idea that if this is persevered in, the effect must be ultimately to dissolve the Union...He (a Virginia delegate) could see no reason why secession should produce war, either in relation to the navigation of the Mississippi, or the division of the public lands. Suppose it did? Suppose it produced not only war, but famine and destruction. Suppose the fertile fields around the beautiful city were deluged in blood! Is that any reason why we should ignominiously submit and put off that evil day? Would gentlemen be willing to avoid war upon the terms put upon us by our Northern brethren - terms involving degradation and disgrace? "The Southern Convention," Southern Quarterly Review, (July 1850), accessed March 5, 2014, http://quod.lib.umich.edu/m/moajrnl/acp1141.2-02.003/235?node=acp1141.202.003\%3A11\&view=image\&size=100, 227-229. Goldthwaite's fellow attendee William Trescot made similar arguments about disunion but focused on the productive aspects of the South's agriculture and its place in world commerce. "Now where has nature placed the great controlling power of American commerce? In the South and as an unavoidable inference, does it follow that the industrial economy and the system of foreign relations of the nation, so far as based on commercial principles, should spring from, and be controlled by the cotton growing States? Why is it otherwise, but that in this nation there is another section supported by interests antagonist to these,
} 
A turn then undertook the efforts at annexation by the middle years of the 1850s. A significant recalibration of means and ends distracted attention away from a few additional attempts at idle talk and annexation. These efforts, notably in Cuba and Nicaragua, of an obvious and noted Southern variety, exhausted public and political patience. Americans quickly moved to more pressing and domestic matters. The Cuban dilemma, in which Americans found so much self-definition and democratic worth, a society beset with problems born of slavery but manageable with American tutelage, now existed as not a distant abstraction but rather as a growing domestic crisis. Critiques of Cuban annexation, political dalliance, and the entire conceptualization of the bedrock of the first half of the nineteenth century - manifest destiny now became commonplace and accepted. Cuba, annexation's opponents argued, must be left to its own issues and solutions as now the fire had come home. Cuban interest cooled considerable as well. The New York Junta and its New Orleans' affiliate gently moved on from its offer to

in other words, a section which is in fact, a foreign power. We have shown that in the vital principle of political organization, the relation of labour and capital, the North and the South are irreconcilably hostile, that their social and political systems cannot co-exist - that the one in the nature of things wages internecine war against the other. Now we need not attempt to prove that cotton can be produced in quantities sufficient for the world's wants, only where labour and capital stand in the relation of master and slave...Again. Our foreign relations are every day assuming growing and graver importance. And here the same antagonism of interest develops itself. The two principles of the foreign system of the great Northern section, as expressed by their statesmen and leading journals, being, 1. The extension of their commercial interests in foreign markets, bringing them into active diplomatic rivalry with Great Britain; and, 2. The manifestation of a spirit of propagandist license, inspiring them to intermeddle in the domestic struggles of every foreign nation, where there arises a contest between constituted authority and revolutionary restlessness. The annexation of Canada, which is fast becoming from a remote speculation, a matter of party policy. The hasty welcome to the socialist government of France - a government which signalized its brief history by colonial emancipation and domestic bankruptcy - the demagogue denunciation of the Austrian court - are all significant indications of popular sentiment and national systems. Now look at the position of the South cultivated by a slave population - supplying the staple of the world's manufacture, and ranged in imposing strength around the Gulf of Mexico, so as to command the trade of the Isthmus connection - what should be the foundation principles of her foreign relations. 1. A close alliance with the few great manufacturing nations, an anxiety to see them creating markets and multiplying their production; and, 2. An unchangeable resolution to leave the interior affairs of other nations to their own discussion, and a careful abstinence from all legislative reflection on foreign institutions, which, like our own, may be censured only because they are not comprehended. With these two basis of foreign action, and the command of the Gulf and the cotton trade, the South would be, in the maturity of her strength, the guardian of the world's commerce - the grave and impartial centre of that new balance of power, which, at no distant day, will it be adjusted by the experience of the old and the energy of the new world, working together for the best interests of humanity." Trescot, Position and Course of the South, accessed March 10, 2014, https://archive.org/details/position courseof00tres, 12-13. 
John Quitman. An 1854 editorial in Putnam's entitled "Annexation," only a year removed from its inspirational "Cuba" editorial, sounded a murkier, hesitant, and almost self-convincing tone.

Perhaps the author embraced a society a bit closer to his desk.

As the inheritors of whatever is best in modern civilization, possessed of a political and social policy which we deem superior to every other, carrying with us wherever we go the living seeds of freedom, of intelligence, of religion; our advent everywhere, but particularly among the savage and stationary tribes who are nearest to us, must be a redemption and a blessing. South America and the islands of the sea ought to rise up to meet us at our coming, and the desert and the solitary places be glad that the hour for breaking their fatal enchantments, the hour of their emancipation, had arrived. ${ }^{379}$

However, the most telling exposure of manifest destiny's hollowness was the public denunciation of its tenants. Despite all of these political, economic, and social pressures, the doom of annexation and filibustering of the 1850s flowed most clearly from the pens of the satirists. As the news and the national discussion progressed from bleak to hopeless, the carcass of transcendent republicanism now lay for the taking by the same press that once set dreams of hemispheric Americanism alight. Whereas early 1850s criticism of annexation was the domain of the sullen acolytes of abolition's curse, by the end of the decade, satire mixed with a good sense of foreboding became the intellectual and popular mode of the day. ${ }^{380}$ In the same magazine that published such ringing endorsements of manifest destiny as "Cuba" appeared a short story by Herman Melville, entitled "Benito Cereno." Toward the end of that story Melville

\footnotetext{
379 “Annexation," Putnam's, Feb. 1854, 191.

${ }^{380}$ Seba Smith was perhaps one of the most popular of American satirists in the 1850s. Smith created the character of Major Jack Downing, a Yankee philosopher and sometimes rube, who produced insightful and biting critiques of luminaries and lowlights alike. While Downing got his start ridiculing the partisan politics of the 1830s, he shifted his focus to expansion by the 1850s. The Major held a great concern with the growing demagoguery, partisanship, and excesses on display from figures such as Lewis Cass, James Buchanan, Stephen Douglas, and James Polk, who came in for special attention. He held expansionism and manifest destiny as arrogant expressions, resultant from partisanship, unbecoming the United States. His great concern was that the success of manifest destiny would mean the destruction of the republic because the arrogance of national supremacy, which territorial growth encouraged, embarrassed the truth of virtuous republicanism. For Downing, expansion was scourge upon the whole lot of 1850s politicians regardless of party or region. John H. Schroeder, "Major Jack Downing and American Expansionism: Seba Smith's Political Satire, 1847-1856," The New England Quarterly 50, no. 2 (June 1977), 214-233; Todd Nathan Thompson, "Modest Proposals: American Satire and Political Change from Franklin to Lincoln," (PhD diss., University of Illinois, Chicago, 2008).
} 
exposes what he believed to be the underlying motivation of American expansionism in Cuba.

American filibusters in his story are encouraged by their commander to overrun a Spanish ship for riches rather than principle. "To encourage the sailors, they were told, that the Spanish captain considered his ship good as lost; that she and her cargo, including some gold and silver, were worth more than a thousand doubloons. Take her, and no small part should be theirs. The sailors replied with a shout."381

Melville, as many Americans exhausted from the decade long Cuban filibustering affair, read manifest destiny as camouflage for something much darker. As discord became secession, the reality came to pass that the United States was no longer exceptional. The ideology of that belief was dead. The American republican experiment collapsed into catastrophic violence, as had the South American republics, the European revolutions, and, despite great protestations to the opposite, the American Revolution. American expansionism now appeared as corrupt as European colonialism. The failure in Cuba was the failure of Americans' envisioned flowering of hemisphere democracy. The folly of it all is perhaps the clearest indicator of the complete vacuousness of the effort. Americans truly believed the annexation of Cuba would happen because it should happen - the United States ordained it. Despite the massive support, encouragement, and intellectual importance placed on annexation efforts, the facts remained that only one of López filibusters became operational and landed only 400 men against a Spanish garrison of at least 40,000 soldiers on the island. From that last attempt in 1851, approximately

\footnotetext{
${ }^{381}$ Herman Melville, Billy Budd, Sailor and Other Stories (New York: Penguin, 1986), 235. Allan Moore Emery, "Benito Cereno" and Manifest Destiny," Nineteenth-Century Fiction 39, no. 1 (June 1984), 4868 , argues that textual evidence exists of Melville's desire to explore the subject of American expansionism in "Benito Cereno." Michael Rogin argued similarly for a critical reading of Moby Dick in Subversive Genealogy: The Political and Art of Herman Melville (New York: Knopf, 1983), 102-51. James Duban, Melville's Major Fiction: Politics, Theology and Imagination (De Kalb: Northern Illinois Press, 1983), 82-148; Andy Doolen, Fugitive Empire: Locating Early American Imperialism (Minneapolis: University of Minnesota Press, 2005), 185-200; Dana D. Nelson, The Word in Black and White: Reading "Race" in American Literature, 1638-1867 (Oxford: Oxford University Press, 1994), 109-130.
} 
200 men returned. These loses, although removed from American shores, portended the wicked bloodshed of four years and 650,000 lives that was necessary to finally stamp out the foolishness of manifest destiny. Undoubtedly, slavery's expansion triggered secession and the Civil War. However, it was the possible expansion of slavery southward to Cuba more than into Kansas or other Western territories that provoked the passion necessary for dissolution. The obsession for Cuba transubstantiated the wine of expectancy into the blood of civil war.

The perspective to be gained on the period is best realized with the passage of time. The long process of Cuban independence from Spain began earnestly in 1868, when José Marti was fifteen, and continued for another 30 years. In April of 1887, Martí saw the great bard of American liberty, Walt Whitman, speak in New York City during the hagiographic period of the American's career. After that occasion he wrote a lengthy essay entitled "The Poet Walt Whitman," printed in La Nación a few days later. While the language seems triumphant and laudatory, beneath the surface seethes sarcasm and a full appreciation for the hell that Whitman's words encapsulated. One can read "America" and "Whitman" interchangeably throughout.

Hark to Walt Whitman. His exercise of himself raises him into majesty, his tolerance into justice, his sense of order into happiness. He who lives in an aristocratic creed is an oyster in its shell, seeing only the prison that enfolds it, and believing, in the darkness, that this is the world. And what inside the shell seems a portentous strife becomes in the light of day, the natural movement of fluids in the energetic pulse of the world. The world, to Walt Whitman, was always as it is today. It suffices that a thing exists for one to know that it must have existed before, and when its existence shall not be needed, it will not exist...It is a matter of reflecting in words the noise of settling multitudes, of toiling cities, of tamed oceans and enslaved rivers. Should Walt Whitman then match rhymes and put into mild couplets these mountains of merchandise, forests of thorns, towns full of ships, battles where millions of men lay down their lives to insure the laws, and a sun that holds sway over all and pours its limpid fire into the vast landscape. Oh, no! Walt Whitman speaks in Biblical verses; without music, although after hearing them for a short time one realizes that these sounds ring like the earth's mighty shell when it is trodden by triumphant armies, barefoot and glorious. At times Whitman's language is like the front of a butcher shop hung with beef carcasses; at other it resembles the song of patriarchs seated in circle, with the sadness of the world at the time of day when smoke loses itself among the 
clouds... Whitman must melt everything in the oven of his heart; over everything the white beard should be allowed to fall. ${ }^{382}$

382 José Martí "The Poet Walt Whitman" La Nacion, April 17, 1887 reprinted in Whitman and the World, eds. Gay Wilson, Allen Folsum and Ed Folsum (Iowa City, IA: University of Iowa Press, 1995), 96-106. 


\section{BIBLIOGRAPHY}

\section{Newspapers and Magazines}

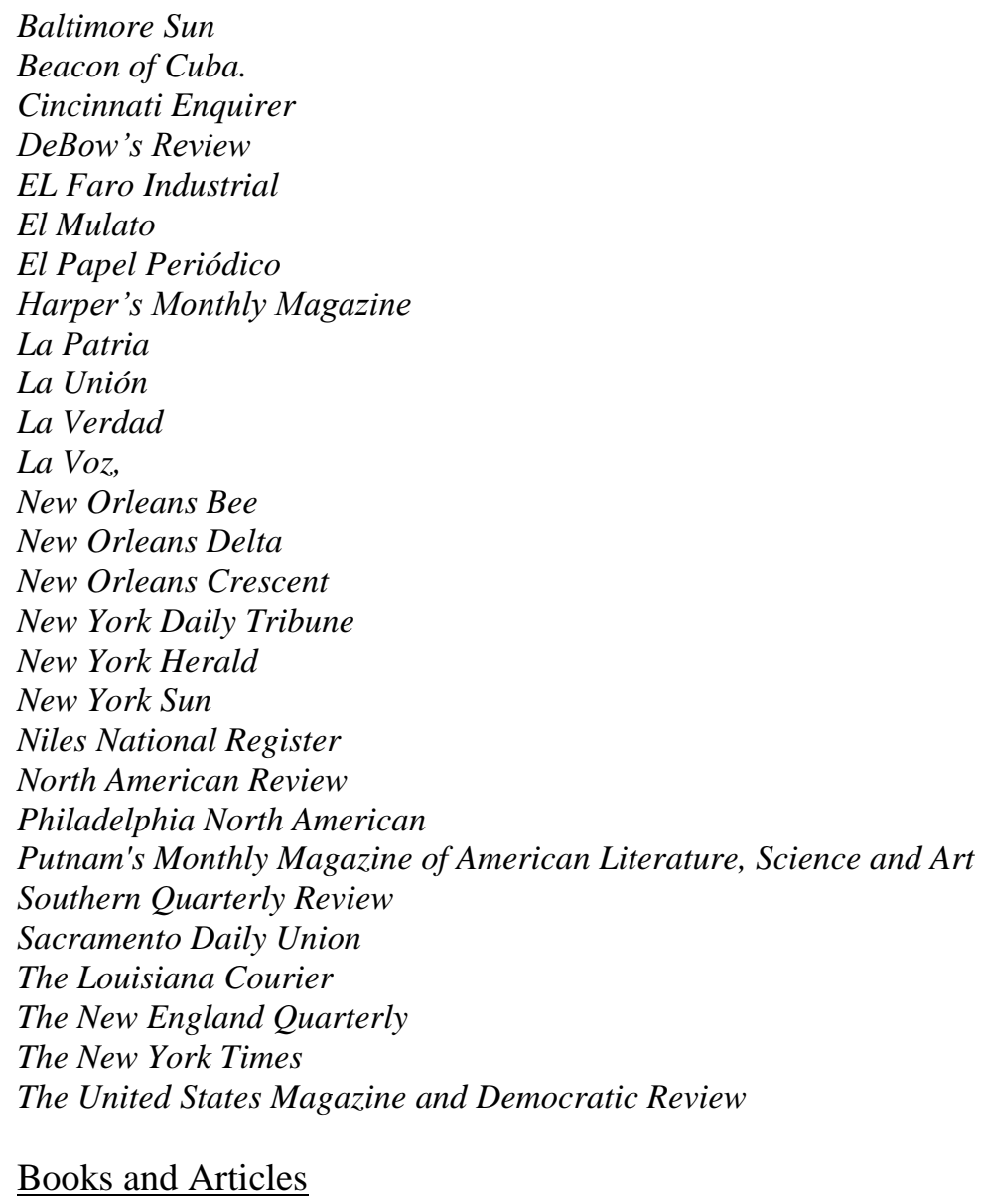

$\underline{\text { Books and Articles }}$

A. Filibustero. The Life of General López and History of the Late Attempted Revolution in Cuba. New York: Dewitt \& Davenport Publishing, 1851.

Abarca de Bolea, Pedro Pablo. "Dictamen reservado que el Conde de Aranda dió al Rey sobre la independencia de las colonias inglesas: despues de haver firmado el tratado de paz ajustado en Paris en el año de 1783." In “Documents Relating to Texas and Mexico, 1783-1842," Western Americana Collection, Yale University Archives.

Abbot, Abiel. Letters Written from the Interior of Cuba. Boston: Bowles and Dearborn, 1829.

Adams, Charles Francis, ed. Memoirs of John Quincy Adams Comprising Portions of His Diary 1795-1848, Vol. 18. Philadelphia: J. Lippincott \& Co., 1874-1923.

Adams, John Quincy. Speech to the U.S. House of Representatives on Foreign Policy. Accessed on March 1, 2011. http://millercenter.org/scripps/archive/speeches/detail/3484.

-----. Inaugural Address March 4, 1825. Accessed March 14, 2011. http://avalon.law.yale.edu/19th_century/ qadams.asp.

-----. A Compilation of the Messages and Papers of the Presidents, Vol. 2. Accessed on March 10. 2011. 
http://onlinebooks.library.upenn.edu/webbin/metabook?id=mppresidents, 904.

----- "The Opium War and the Sanctity of Commercial Reciprocity." Proceedings of the Massachusetts Historical Society 42 (October 1909-June 1910): 295-325.

Adams, Sean Patrick. "The Tao of John Quincy Adams." Common-Place 9, no. 1 (October 2008). Accessed on January 21, 2011. http://www.common-place.org/vol-09/no-01/adams/.

Aguilera, Francisco V. and Ramon Céspedes. Notes about Cuba. New York: Commissioners of the Republic of Cuba, 1872. Accessed January 17, 2014. https://archive.org/details/notesaboutcubasl00agui.

Alexander, James. Transatlantic Sketches: Comprising Visits to the Most Interesting Scenes in North \& South America \& West Indies, 2 vols. London: Richard Bentley, 1833.

Allahar, Anton L. "Sugar, Slaves, and the Politics of Annexationism: Cuba, 1840-1855." European Review of Latin American and Caribbean Studies 57 (December 1994): 281-304.

----. "The Cuban Sugar Planters (1790-1820): 'The Most Solid and Brilliant Bourgeois Class in All of Latin America." The Americas 41, (1984): 37-57.

Allen, William. "Speech of Hon. William Allen, of Ohio delivered in the Senate of United States, February 10 and 11, 1846, on our relations with England; being the opening speech pending the Oregon notice (1846)." Accessed on January 20, 2014. https://archive.org/details/cihm_16594.

Aimes, Hubert. A History of Slavery in Cuba, 1511 to 1868. New York: G. P. Putnam, 1907.

Amores, Juan B. Cuba En La Época De Ezpeleta, 1785-I790. Pamplona: Eunsa, 2000.

-----. “La Renta del Tabaco en Cuba a Finales del siglo XVIII.” In Tabaco Y Economía En El Siglo XVIII, edited by Agustín González Enciso y R.Torres Sánchez, 123-137. Pamplona: Eunsa, 1999.

Anbinder, Tyler. Nativism and Slavery: The Northern Know Nothings and the Politics of the 1850s. New York: Oxford University Press, 1994.

Anderson, Benedict. Imagined Communities: Reflections on the Origin and Spread of Nationalism. London: Verso, 1991).

Anderson C. Quisenberry, López's Expeditions to Cuba 1850 and 1851, (Louisville: John Morton \& Co., 1906),

Anonymous, ("Miss Delaplain"). A Thrilling and Exciting Account of the Sufferings and Horrible Tortures Inflicted on Mortimer Bowers and Miss Sophia Delaplain, by the Spanish Authorities, for a Supposed Participation with Gen. López in the Invasion of Cuba. Charleston: Barclay and Crosson \& co., 1851.

Anonymous. A Winter in the West Indies and Florida. Boston: Wiley and Putnam, 1839. Accessed November 30, 2013. http://books.google.com/books?id=hCUCAAAAYAAJ\&source =gbs_navlinks_s.

Antillón, Isidoro de. Disertacion sobre el orígen de la esclavitud de los negros, motios que la han perpetuado, ventajas que se le atribuyen y medios que podrían adoptarse para hacer prosperar nuestras colonias sin la esclavitud de los negros: Leída en la Real Academia Matritense de derecho español y público, el día 2 de abril de 1802 (Madrid: José Busquets, 1820). Accessed January 10, 2014. http://books.google.com/books? $\mathrm{id}=9 \mathrm{uBQAAAAc}$ AAJ\&printsec=frontcover\&source $=\mathrm{gbs} \_\mathrm{ge} \_$summary_r$\& \mathrm{cad}=0 \# \mathrm{v}=$ onepage $\& \mathrm{q} \& \mathrm{f}=\mathrm{false}$.

Appelbuam, Nancy. "Whitening the Region: Caucano Mediation and 'Antiqueno Colonization' in Nineteenth Century Colombia." Hispanic American Historical Review 79, no.4 (November 1999): 631-667.

Appleby, Joyce. Capitalism and a New Social Order: The Republican Vision of the 1790s. New York: New York University Press, 1984. 
----. Inheriting the Revolution: The First Generation of Americans. New York: Belknap, 2001.

Arango Y Parreño, Francisco. "Discurso Sobre La Agricultura En La Habana.” In Francisco de Arango y Parrreño, Francisco de Arango Y Parreño: Obras, Vol. I, 144-192. Havana: Editorial Cultura Popular, 2005.

-----. Representacion de la Ciudad de la Habana a las Cortes Españolas. In Francisco de Arango y Parreño, Obras del Excmo. Señor D. Francisco de Arango y Parreño, Volume 2. Havana: Howson y Heinen, 1889.

-----. "En defense de la Esclavitud: Representacion de la Ciudad de la Habana a las Cortes Españolas." In Documentos para la Historia de Cuba, Volume I, edited by Hortensia Pichardo, 250-265. Havana: Editorial de Ciencias Sociales.

-----. “Observaciones.” Accessed January 10, 2014. https://archive.org/details/obrasdelexcmose00arangoog.

Arenson, Adam. The Great Heart of the Republic: St. Louis and the Cultural Civil War. Cambridge: Harvard University Press, 2011.

Armytage, Frances. The Free Port System in the British West Indies: A Study in Commercial Policy, 1766-1822. London: Longmans, Green \&Co., 1953.

Arnesen, Eric. Waterfront Workers of New Orleans: Race, Class, and Politics 1863-1923. Chicago: University of Illinois 1994.

Arroyo, Anita. Jose Antonio Saco: Su Influencia en la Cultura y en las Ideas Politicas de Cuba. Madrid: Ediciones Universal, 2001.

Arson, Steven. "Yeoman Farmers in a Planters' Republic: Socioeconomic Conditions and Relations in Early National Prince George's County, Maryland." Journal of the Early Republic, 29 (Spring 2009): 63-99.

Atack, Jeremy. "Tenants and Yeomen in the Nineteenth Century." Agricultural History 62, no. 3 (Summer 1988): 632.

Atkins, Jonathan. “The Whig Party Versus the 'Spoilsmen' of Tennessee.” The Historian 57, no. 2 (Winter 1994): 329-341.

Augst, Thomas. The Clerk's Tale: Young Men and Moral Life in Nineteenth-Century America. Chicago: University of Chicago Press 2003.

Avitable, Joseph. "The Atlantic World Economy and Colonial Connecticut." PhD diss., University of Rochester, 2009.

Ayala, César J. “Social and Economic Aspects of Sugar Production in Cuba, 1880-1930.” Latin American Research Review 30, no. 1 (Winter 1995): 95-124.

Bacon, Jacqueline. The Humblest May Stand Forth: Rhetoric, Empowerment, and Abolition. Columbia: University of South Carolina Press, 2002.

Baigell, Matthew. "Territory, Race, Religion: Images of Manifest Destiny." Smithsonian Studies in American Art 4, nos. 3/4 (1990): 2-21.

Bailey, Ronald. "The Slave(ry) Trade and the Development of Capitalism in the United States: The Textile Industry in New England." Social Science History 14 (Fall 1990): 373-414.

Baker, Jean. Affairs of Party: The Political Culture of Northern Democrats in the Mid-Nineteenth Century. New York: Fordham University Press, 1983. 
Baker, Paula. "The Domestication of Politics: Women and American Political Society: 1780-1920." American Historical Review 89, no. 3 (June 1984): 620-647.

Balleisen, E. J. Navigating Failure: Bankruptcy and Commercial Society in Antebellum America. Chapel Hill: University of North Carolina Press, 2001.

Ball, Durwood. Army Regulars on the Western Frontier, 1848-1861. Norman: University of Oklahoma Press, 2001.

Ballou, Muturin M. History of Cuba: Or Notes of A Traveller in the Tropics. Boston: Philips, Sampson\& Co., 1854. Accessed November 30, 2013. http://archive.org/details/historyofcubaorn32812gut.

Baptist, Edward. "Hidden in Plain View: Haiti and the Louisiana Purchase." In Echoes of the Haitian Revolution in the Modern World, edited by Elizabeth Hackshaw and Martin Munro, 1-27. Kingston, Jamaica: UWI Press, 2008.

----- "The Second Slavery and the First American Republic." Paper presented at Cornell University, May 23, 2012. http://www.almanack.unifesp.br/public/journals/1/Edward_Baptist_texto_Forum.pdf.

----. "The Slave Labor Camps of Antebellum Florida and the Pushing System.” In Florida's Working-Class Past: Current Perspectives on Labor, Race, and Gender from Spanish Florida to the New Immigration, edited by Robert Cassanello, 30-62. Gainesville: University Press of Florida, 2009.

----. Creating an Old South: Middle Florida's Plantation Frontier before the Civil War. Chapel Hill: UNC Press, 2001.

----.. '“Cuffy,' 'Fancy Maids,' and 'One-Eyed Men:' Rape, Commodification, and the Domestic Slave Trade in the United States.” The American Historical Review 106, no. 5 (December 2001): 1619-1650.

----- "Toxic Debt, Liar Loans, and Securitized Human Beings: The Panic of 1837 and the Fate of Slavery." Common Place 10, no. 3 (April 2010). Accessed May 23, 2013. http://www.common-place.org/vol-10/no03/baptist/.

----. The Half Has Never Been Told: Slavery and the Making of American Capitalism. New York: Basic Books, I 2014.

Barbier, Jacques A. “The Culmination of the Bourbon Reforms, 1787-1792." Hispanic American Historical Review 57, no. 1 (February 1977): 51-68.

----. "Peninsular Finance and Colonial Trade: The Dilemma of Charles IV's Spain.” Journal of Latin American Studies 12, no. 1 (May 1980): 21-37.

----- "Indies Revenues and Naval Spending: The Cost of Colonialism for the Spanish Bourbons, 1763-1805." In Warfare in Europe 1792-1815, edited by Frederick Schneid, 3-20. London: Ashgate, 2007.

Barbier, Jacques A. and Mark A. Burkholder. "Colonial Spanish America, the Bourbon Period.” The History Teacher 20, no. 2 (February 1987): 221-250.

Barcia, Manuel. Seeds of Insurrection: Domination and Resistance on Western Cuba Plantations, 1808-1848. Baton Rouge: LSU Press, 2008.

----. The Great African Slave Revolt of 1825: Cuba and the Fight for Freedom in Matanzas. Baton Rouge: LSU Press, 2012.

Barreto, Reina. "Subversion in Gertrudis Gómez de Avellaneda’s Sab.” Decimonónica 3, no.1 (Winter 2006): 1-10. 
Barron, Hal. Mixed Harvest: The Second Great Transformation in the Rural North, 1870-1930. Chapel Hill: University of North Carolina Press, 1997.

-----. Those Who Stayed Behind: Rural Society in $19^{\text {th }}$ Century New England. New York: Cambridge University Press, 1988.

Battle-Baptiste, Whitney. “Sweepin' Spirits: Power and Transformation on the Plantation Landscape.” In Archaeology and Preservation of Gendered Landscapes, edited by Sherene Baugher and Suzanne M. Spencer-Wood, 81-94. New York: Springer Press, 2010.

Bauer, K. Jack. Zachary Taylor: Soldier, Planter, Statesman of the Old Southwest. Baton Rouge: LSU Press, 1993.

Baur, John E. “International Repercussions of the Haitian Revolution.” The Americas 26, no. 4 (April 1970): 394418.

Bayly, C.A. Imperial Meridian - Britain's New Imperial Age 1780-1830. London: Routledge, 1993.

Beard, Charles. The Pragmatic Revolt in American History. New Haven; Yale University Press, 1958.

Beckert, Sven. The Monied Metropolis: New York City and the Consolidation of the American Bourgeoisie. New York: Cambridge University Press, 2001.

-----. "Emancipation and Empire: Reconstructing the Worldwide Web of Cotton Production in the Age of the American Civil War.” American Historical Review 109, no. 5 (December 2004): 1405-1438.

-----. Empire of Cotton: A New History of Global Capitalism. London: Penguin UK, 2014.

Beckles, Hilary. "Capitalism, Slavery, and Caribbean Modernity.” Callaloo 20, no. 4 (Autumn 1997): 777-789.

Bederman. Gail. Manliness \& Civilization: A Cultural History of Gender and Race in the United States, 18801917. Chicago: University of Chicago Press, 1995.

Bell, Caryn Cosse. Revolution, Romanticism, and the Afro-Creole Protest Tradition in Louisiana, 1718-1868. Baton Rouge: LSU Press, 2004.

Belohlavek, John "Race Progress and Destiny: Caleb Cushing and the Quest for American Empire." In Manifest Destiny and Empire, edited by Sam Haynes and Christopher Morris, 21-47. College Station, Texas: University of Texas Press.

Bemis, Samuel Flagg. A Diplomatic History of the United States. New York: Holt, 1942.

-----. “John Quincy Adams and George Washington.” Massachusetts Historical Society Proceedings 67 (1945): 365 384.

-----. John Quincy Adams and the Foundations of American Foreign Policy. New York: W.W. Norton, 1949.

Bender, Thomas. A Nation Among Nations: America's Place in World History. New York: Hill and Wang, 2006.

-----. Community and Social Change in American. Baltimore: Johns Hopkins University Press, 1982.

-----. A Nation among Nations. New York: Hill and Wang, 2006.

-----. New York Intellect: A History of Intellectual Life in New York City, from 1750 to the Beginnings of Our Own Time. Baltimore: John Hopkins University Press, 1987.

-----. Intellect and Public Life: Essays on the Social History of Academic Intellectuals in the United States. 
Baltimore: Johns Hopkins University Press, 1997.

Bender, Thomas, ed. The Anti-Slavery Debate: Capitalism and Abolitionism as a Problem in Historical Interpretation. Berkeley: University of California Press, 1992.

Benimelli, Antonio Jose Ferrer. "El Conde de Aranda: Ese Gran Desconocido." Argensola: Revista de Ciencias Sociales del Instituto de Estudios Altoaragoneses (1971-1974): 23-52.

Benitez-Rojo, Antonio. The Repeating Island: The Caribbean and the Postmodern Perspective. Durham: Duke University Press, 1992.

Benns, F. Lee. The American Struggle for the British West Indian Carrying Trade, 1815-1830. Bloomington, IN: University of Indian Press.

Bensel, Richard Franklin. Yankee Leviathan: The Origins of Central State Authority in America. 1859-1877. Cambridge: Cambridge University Press, 1990.

Benton, Thomas Hart. Abridgment of the Debates of Congress from 1789 to 1856: From Gales and Seaton's Annals Of Congress, Vol. I-VII. New York: D. Appleton and Company, 1858.

Bergad, Laird. Cuban Rural Society in the Nineteenth Century: The Social and Economic History of Monoculture in Matanzas. Princeton: Princeton University Press, 1990.

----. The Comparative Histories of Slavery in Brazil, Cuba, and the United States. Cambridge: Cambridge University Press, 2007.

-----. "The Economic Viability of Sugar Production Based on Slave Labor in Cuba, 1859-1878." Latin American Research Review 24, no. 1 (1989): 95-113.

Bergad, Laird W., Fe Iglesias Garcia, and Maria del Carmen Barcia. The Cuban Slave Market, 1790-1880. Cambridge: Cambridge University Press, 1995.

Bergeron, Paul. The Presidency of James K. Polk. Lawrence: University Press of Kansas, 1987.

Bernstein, Barton J. "Southern Politics and Attempts to Reopen the African Slave Trade." The Journal of Negro History 51, no. 1 (January 1966): 16-35.

Betancourt, Roger. “Cuba's Initial Attempt at Democracy, 1790-1820: Its Long-Term Consequences.” Paper presented at Cuban Futures International Symposium, Bildner Center/Cuba Project, Graduate Center of the City University of New York, April 2, 2011.

Bierck, Harold, ed. Selected Writings of Bolivar. New York: Colonial Press, 1951.

Billingsley, Carolyn Earle. Communities of Kinship: Antebellum Families and the Settlement of the Cotton Frontier. Athens: University of Georgia Press, 2004.

Bishko, Charles Julian. "The Peninsular Background of Latin American Cattle Ranching." The Hispanic American Historical Review 32, no. 4 (November 1952): 491-515.

Blackburn, Robin. The American Crucible: Slavery, Emancipation and Human Rights. London: Verso, 2011.

-----. The Making of New World Slavery: From the Baroque to the Modern, 1492-1800. London: Verso, 1998.

Bland, William. The Awful Doom of the Traitor or the Terrible Fate of the Deluded and Guilty: A Full Disclosure of the Character and Selfish Designs of General López who Decoyed a Multitude of Our Best and Bravest Citizens to an Awful and Untimely Grave in the Island of Cuba. Cincinnati: HM Rulison, 1852. 
Blassingame, John W. “Foreign Writers View Cuban Slavery.” Journal of Negro History, 57, no. 4 (October 1972): 405-24.

Bledstein, Burton. The Culture of Professionalism: The Middle Class and the Development of Higher Education in American. New York: W.W. Norton, 1976.

Bledstein, Burton and Robert Johnson. The Middling Sorts: Explorations in the History of the American Middle Class. New York: Routledge, 2001.

Bloch, Ruth. "The Gendered Meanings of Virtue in Revolutionary America." Signs, 13 (1987): 33-58.

Blue, Frederick J. No Taint of Compromise: Crusaders in Antislavery Politics. Baton Rouge: LSU Press, 2006.

Blumin, Stuart. The Emergence of the Middle Class: Social Experience in the American City 1760-1900. New York: Cambridge University Press, 1989.

Bodenhorn, Howard. A History of Banking in Antebellum America: Financial Markets and Economic Development in an Era of Nation-Building. Cambridge: Cambridge University Press, 2000.

Bolland, Nigel O. "Creolisation and Creole Societies: A Cultural Nationalist View of Caribbean Social History." Caribbean Quarterly 44, no. 1/2 (March-June, 1998): 1-32.

Bolton, Charles C. Poor Whites of the Antebellum South: Tenants and Laborers in Central North Carolina and Northeast Mississippi. Durham: Duke University Press, 1993.

Bonilla, Raul Cepero. Azúcar y abolición. Havana: Cenitario, 1848."

Bonner, Robert. Mastering America: Southern Slaveholders and the Crisis of American Nationhood. Cambridge: Cambridge University Press, 2009.

Bonsal, Stephan. When the French Were Here. New York: Kennikat Press, 1968.

Borchard, Gregory A. "From Pink Lemonade to Salt River: Horace Greeley's Utopia and the Death of the Whig Party." Journalism History 32, no. 1 (Spring 2006): 22-23.

Bornholdt, Laura. Baltimore and Early Pan-Americanism: A Study in the Background of the Monroe Doctrine. Northhampton, MA: Smith College, 1949.

----.. "Baltimore as a Port of Propaganda for Latin American Independence." PhD diss., Yale University, 1945.

Boutelle, R.J. “'The Most Perfect Picture of Cuban Slavery:' Transatlantic Bricolage in Manzano's and Madden's Poems by a Slave." Atlantic Studies 10, no. 4 (Fall 2013): 528-549.

Bouton, Terry. Taming Democracy: “The People," The Founders, and the Troubled Ending of the American Revolution. New York: Oxford University Press, 2009.

Breen, T.H. The Marketplace of Revolution: How Consumer Politics Shaped American Independence. New York: Oxford University Press, 2005.

Bradley, Ed. "Fighting for Texas: Filibuster James Long, the Adams-Onís Treaty, and the Monroe Administration." The Southwestern Historical Quarterly 102, no. 3 (January 1999): 322-342.

Bravo, Juan Alfonso. “Azúcar y clases sociales en Cuba (1511-1959).” Revista Mexicana de Sociología 43, no. 3 (July-September 1981): 1189-1228. 
Brickhouse, Anna. Transamerican Literary Relations and the Nineteenth-Century Public Sphere. New York: Cambridge University Press, 2004.

Bridges, C.A. "The Knights of the Golden Circle: A Filibustering Fantasy." Southwestern Historical Quarterly 44, no. 3 (January 1941): 287-302.

Brooks, Phillip Coolidge. Diplomacy and the Borderlands: The Adams-Onís Treaty of 1819. Berkeley, CA: University of California Press, 1939.

Brown, Charles. Agents of Manifest Destiny: The Lives and Times of the Filibusters. Chapel Hill: UNC Press, 1980.

Brown, Christopher Leslie. Moral Capital: Foundations of British Abolitionism. Chapel Hill: UNC Press, 2006.

Brown, David Luis. “An 1848 for the Americas: the Black Atlantic, 'El negro mártir,' and Cuban Exile Anticolonialism." American Literary History 21, no. 3 (2009): 431-463.

Brown, David. "Jeffersonian Ideology and the Second Party System.” The Historian 62, no. 1 (1999): 17-30.

Brown, Gordon. Toussaint's Clause: The Founding Fathers and the Haitian Revolution. Oxford, MS: University of Mississippi Press, 2005.

Brown, Matthew. "Not Forging Nations but Foraging for Them: Uncertain Collective Identities in Gran Colombia." Nations and Nationalism 12, no. 2 (April 2006): 223-240.

Brunson, Takkara Keosha. "Constructing Afro-Cuban Womanhood: Race, Gender, and Citizenship in RepublicanEra Cuba, 1902-1958.” PhD diss., University of Texas, Austin, 2011.

Brusone, Julio Le Riverend. "Relaciones entre Nueva España y Cuba (1518-1820)." Revista de Historia de América 37/38 (January-December 1954): 45-108.

Bryant, Tiffany Yolanda Jimmece. "Inter-Subjective and Transnational Racial Effects: The Role of The United States in the Formation and Evolution of the Collective Perception and Racial Relations in Cuba, 18981902.” PhD diss., Florida International University, 2010.

Brauer, Kinley. Cotton Versus Conscience; Massachusetts Whig Politics and Southwestern Expansion, 1843-1848. Lexington: University of Kentucky Press, 1967.

Bullen, Roger. "The Great Powers and the Iberian Peninsula, 1815-48," in Europe's Balance of Power, 1815-1848, edited by Alan Sked, 54-78. New York: Harper and Row, 1979.

Bulmer-Thomas, Victor, ed. Britain and Latin America: A Changing Relationship. Cambridge: Cambridge University Press, 1989.

Bunn, Thomas. "An Essay On The Abolition Of Slavery Throughout The British Dominions: Without Injury to The Master or His Property, With the Least Possible Injury to the Slave, Without Revolution, And Without Loss to the Revenue." London: W. P. Penny, 1833. Accessed January 17, 2014. http://books.google. com/books?id=H5jBScyJe4gC\&pg=PP7\#v= onepage\&q\&f=false.

Burgett, Bruce. Sentimental Bodies: Sex, Gender, and Citizenship in the Early Republic. Princeton: Princeton University Press, 1998.

Burton, Gera. Ambivalence and the Postcolonial Subject: The Strategic Alliance of Juan Francisco Manzano and Richard Robert Madden. New York: Peter Lang Publishing, 2004.

Burton, Orville Vernon and Georganne B. Burton. The Free Flag of Cuba: the Lost Novel of Lucy Holcombe Pickens. Baton Rouge: LSU Press, 2002. 
Burton, Vernon. In My Father's House Are Many Mansions: Family and Community in Edgefield, South Carolina. Chapel Hill: UNC Press, 1985.

Bynum, Victoria. Unruly Women: The Politics of Social and Sexual Control in the Old South. Chapel Hill: UNC Press, 1992.

Byrne, Frank. Becoming Bourgeois: Merchant Culture in the South, 1820-1865. Lexington: University of Kentucky Press, 2006.

Caldwell, Robert Granville. The López Expeditions to Cuba, 1848-51. Princeton: Princeton University Press, 1915.

Callahan, James Morton. Cuba and International Relations: A Historical Study in American Diplomacy. Baltimore: Johns Hopkins Press, 1899.

Calomiris, Charles and Larry Schweikart. "The Panic of 1857: Origins, Transmission, and Containment.” Journal of Economic History 51, no. 4 (December 1991): 807-834.

Campbell, Randolph Bluford. "Henry Clay and the Emerging Nations of Spanish America, 1815-1829." PhD diss., University of Virginia, 1966.

-----. An Empire for Slavery: The Peculiar Institution in Texas, 1821-1865. Baton Rouge: LSU Press, 1991.

Campbell, Randolph B. and Richard G. Lowe. Planters \& Plain Folk: Agriculture in Antebellum Texas. Dallas: SMU Press, 1987.

Cantero, Justo Germán, Luis Miguel García Mora, and Antonio Santamaría García, eds. Los ingenios: colección de vistas de los principales ingenios de azúcar de la Isla de Cuba. Madrid: Editorial CSIC Press, 2005.

Canizares-Esguerra, Jorge, Matt D. Childs, and James Sidbury, eds. The Black Urban Atlantic in the Age of the Slave Trade. Philadelphia: University of Pennsylvania Press, 2013.

Carey, Anthony Gene. Parties, Slavery, and the Union in Antebellum Georgia. Athens: University of Georgia Press, 1997.

Carey, Brycchan. British Abolitionism and the Rhetoric of Sensibility: Writing, Sentiment, and Slavery, $1760-1807$. London: Palgrave Macmillan, 2005.

Carey, Henry. "What Constitutes Real Freedom of Trade?" Reprinted in The American Review: A Whig Journal. Accessed on May 23, 2013. https://play.google.com/store/books/details?id=J4HQAAAAMAAJ.

-----. “The Slave Question.” The Plough, the Loom and the Anvil, 1 (1849): 207-209.

Carey, James W. Communication as Culture: Essays in Media and Society. New York: Routledge, 2009.

Carey, Mathew. The Olive Branch or, An Attempt to Establish an Identity of Interest between Agriculture, Manufactures and Commerce. Accessed May 23, 2013. http://archive.org/details/newolive brancho00caregoog.

Carlisle, Calderon. "Report to the Spanish legation: with reference to the legal aspect of hostilities committed by vessels specially adapted, in whole or in part, within the United States to warlike uses and by military expeditions and enterprises carried on from the territory of the United States against the Spanish dominion in Cuba during the present insurrection. Havana: no mark, 1896. Accessed March 10, 2014. http://books.google.com/books?id=ZkZuAAAAMAAJ\&pg=PP1\#v=onepage \&q\&f=false.

Carmelo, Richard Arena. “Philadelphia-Spanish New Orleans Trade: 1789- 1805.” PhD diss., University of 
Pennsylvania, 1959.

Carredano, Juan Bosco Amores. "La Sociedad Económica Y Los Intentos De Reforma Universitaria En Cuba (17931842).” Accessed March 20, 2012. http://dspace.uah.es/jspui/bitstream/10017/5828/1/La\%20Sociedad\%20 Econ\%C3\%B3mica\%20de\%20La\%20Habana\%20y\%20los\%20Intentos\%20de\%20Reforma\%20Universita ria\%20en\%20Cuba\%20(1793-184).pdf.

----. “Iglesia y Sociedad En Cuba, 1760-1830,” in Tradición Y Reforma En La Iglesia Hispanoamericana, 17501840, edited by Francisco Cervantes Bello, Lucrecia Enríquez and Rodolfo Aguirre, 302-330. México: UNAM, 2010.

-----. "Francisco de Arango y Parreño: La Transición Hacia La Modernidad En Cuba.” In Actas del XI Congreso Internacional de AHILA, edited by John Fisher, 507-522. Liverpool: University of Liverpool, 1998.

-----. "El Joven Arango Y Parreño: Origen Del Proyecto Político-Económico De La Sacarocracia Habanera (17861794).” Temas Americanistas 12 (1995): 12-17.

-----. “Las Elites Cubanas y la Estrategia Imperial Borbónica en la Segunda Mitad del Siglo XVIII.” In Élites Urbanas en Hispanoamérica, edited by Luis Navarro García, 189-197. Sevilla: Universidad de Sevilla, 2005.

Carroll, E. Malcolm. Origins of the Whig Party. Durham: Duke University Press, 1922.

Cartwright, Bradley Jay. "Young America: Manifest Destiny and the Rhetoric of Race and Gender, 1837-1855." M.A. thesis, University of Texas at El Paso, 1999.

Casanovas, Joan. Bread or Bullets! Urban Labor and Spanish Colonialism in Cuba, 1850-1898. Pittsburgh: University of Pittsburgh Press, 1998.

Casey, Matthew. "From Haiti to Cuba and Back: Haitians' Experiences of Migration, Labor, and Return, 19001940.” PhD diss., University of Pittsburgh, 2012.

Castillo, Rafael del. Historia de la vida militar y politica del Excmo. Sr. Capitan General D. Leopoldo O'Donnell, Conde de Lucena, Vizconde de Aliaga, Duque de Tetuan. Catalonia: La Publicidad, 1860. Accessed November 30, 2013. http://books.google.com/books?id=g60_AAAAcAAJ\&lpg=PA528\&ots=7F9yLLqN po\&pg $=\mathrm{PA} 3 \# \mathrm{v}=$ onepage $\& \mathrm{q} \& \mathrm{f}=$ false.

Caulfield, Sueann. "The History of Gender in the Historiography of Latin America." Hispanic American Historical Review 81, no. 3-4 (2001): 449-490.

Cawelti, John. Apostles of the Self-Made Man: Changing Concepts of Success in America. Chicago: University of Chicago, 1965.

Cazneau, Jane Maria McManus. The Queen of Islands and the King of Rivers. New York: Charles Wood, 1850.

Chadwick, French Ensor. The Relations of the United States and Spain: Diplomacy. New York: Scribner's \& Sons, 1909.

Chaffin, Tom. Fatal Glory: Narciso López and the First Clandestine U.S. War Against Cuba. Charlottesville: UVA Press, 1996.

Chamberlain, Ivory and Thomas Moses Foote. Biography of Millard Fillmore. New York: Thomas \& Lathrops, 1856), 179-200.

Chambers, Stephen. "At Home Among the Dead: North Americans and the 1825 Guamacaro Slave Insurrection." Journal of the Early Republic 33, no. 2 (Spring 2013): 62-86. 
----. "The American State of Cuba: The Business of Cuba and U.S. Foreign Policy, 1797-1828." PhD diss., Brown University, 2013.

Chambers, William N. The Democrats, 1789-1864: A Short History of a Popular Party. Princeton: D. Van Nostrand, 1964.

Chapeaux, Pedro Deschamps. Los batallones de pardos y morenos libres. Havana: Editorial Arte y Literatura, 1976.

-----. El negro en la economía habanera del siglo XIX. Havana: Unión de Escritores y Artistas de Cuba, 1971.

Chaplin, Joyce. An Anxious Pursuit: Agricultural Innovation and Modernity in the Lower South, 1730-1815. Chapel Hill: University of North Carolina Press, 1993.

----- "Expansion and Exceptionalism in Early American History." Journal of American History 89, no. 4 (2003): $1431-1455$.

Charles, Asselin. "Haitian Exceptionalism and Caribbean Consciousness." Journal of Caribbean Literatures 3, no. 2 (Spring 2002): 115-130.

Chastain, E. W. "The Acquisition of Cuba, In Reply To the Speech of Mr. Boyce, Of South Carolina." Accessed March 14, 2014. https://archive.org/details/speechofhonewcha00chas.

Chevigny, Bell Gale. "Growing Out of New England: The Emergence of Margaret Fuller's Radicalism.” Women's Studies 5 (1977): 65-100.

Cheyfitz, Eric. The Poetics of Imperialism: Translation and Colonialism from The Tempest to Tarzan. Philadelphia, PA: University of Pennsylvania Press, 1997.

Childs, Matthew D. The 1812 Aponte Rebellion in Cuba and the Struggle against Atlantic Slavery. Chapel Hill: University of North Carolina Press, 2006.

----- "Sewing" Civilization: Cuban Female Education in the Context of Africanization, 1800-1860." The Americas 54, no. 1 (July 1997): 83-107.

----- "A Black French General Arrived to Conquer the Island: Images of the Haitian Revolution in Cuba's 1812 Aponte Rebellion." In The impact of the Haitian Revolution in the Atlantic World, edited by David Geggus, 135-157. Columbia: University of South Carolina Press, 2001.

Chinese Government. The Cuba Commission Report: A Hidden History of the Chinese in Cuba. Baltimore: JHU Press, 1993.

Claiborne, J. F. H. The Life and Correspondence of John Anthony Quitman. New York: Harper and Brothers, 1860.

Clark, Christopher. The Roots of Rural Capitalism: Western Massachusetts, 1780-1860. Ithaca: Cornell University Press, 1992.

Claybaugh Amanda. The Novel of Purpose: Literature and Social Reform in the Anglo-American World. Ithaca: Cornell University Press, 2007.

Cleves, Rachel Hope. The Reign of Terror in America: Visions of Violence from Anti-Jacobinism to Antislavery. New York: Cambridge University Press, 2009.

Coatsworth, John H. "American Trade with European Colonies in the Caribbean and South America, 1790-1812," The William and Mary Quarterly 24, no. 2 (April 1967): 243-266. 
Cohen, Bernard. “Emerson's ‘The Young American' and Hawthorne's 'The Intelligence Office.' American Literature 26, no. 1 (March 1954): 32-43.

Cohen, David W. and Jack P. Greene, eds. Neither Slave nor Free: The Freedman of African Descent in the Slave Societies of the New World. Baltimore: Johns Hopkins University Press, 1972.

Cole, A.C. The Whig Party in the South. Washington, DC: American Historical Association, 1914.

Colton, Calvin, ed. The Life, Correspondence, and Speeches of Henry Clay, Vol. V, Speeches. New York: A.S. Barnes, 1857.

Concha, Jose Gutierrez de la. Memorias Sobre El Estado Political Gobierno Y Administracion De La Isla De Cuba Por El Teniente General Jose Gutierrez De La Concha. Madrid: Establecimiento Tipografico de D. Jose Trujillo, 1855. Accessed February 20, 2012. http://openlibrary.org/books/OL6932420M/Memorias_sobre _el_estado_poli\%CC\%81tico_gobierno_y_administracio \%CC\%81n_de_la_isla_de_Cuba.

Coontz, Stephanie. The Social Origins of Private Life: A History of American Families, 1600-1900. New York: Verso, 1988.

Corbett, Julian Stafford. England in the Seven Years' War: A Study in Combined Strategy. Cambridge: University Press, 2010.

Corbitt, Duvon Clough. "Spanish Colonial Governance: The Administrative System in the Floridas, 1781- 1821." Tequesta: The Journal of the Historical Association of Southern Florida 1, no. 2 (August 1942): 41-54.

-----. "Mercedes and Realengos; A Survey of the Public Land System in Cuba." The Hispanic American Historical Review 19, no. 3 (August 1939): 262-285.

-----. "El Primer Ferrocarril Construido en Cuba.” Revista Cubana, 12 (April-June 1938): 179-195.

----. “Immigration in Cuba.” Hispanic American Historical Review, 22 (May 1942): 280-308.

Córdova, Federico. Gaspar Betancourt Cisneros, el Lugareño. Havana: Editorial Trópico, 1938.

Cortada, James W. "The New York Times, Spain and Cuba, 1851-1869." Revista de Historia de América 77/78 (January-December 1974): 61-75.

-----. Spain and the American Civil War: Relations at Mid-Century 1855-1868. Philadelphia: American Philosophical Society, 1980.

-----. "Economic Issues in Caribbean Politics: Rivalry between Spain and the United States in Cuba, 1848-1898." Revista de Historia de América 86 (July-December 1978): 233-267.

Corwin, Arthur. Spain and the Abolition of Slavery in Cuba, 1817-1886. Austin: University of Texas Press, 1967.

Cox, Isaac J. "The Border Missions of General George Mathews." The Mississippi Valley Historical Review 12, No. 3 (December 1925): 309-333.

Cova, Antonio de la "Filibusters and Freemasons: The Sworn Obligation." Journal of the Early Republic 17, no. 1 (Spring 1997): 95-120.

----. Cuban Confederate Colonel: The Life of Ambrosio Jose Gonzales. Columbia: University of South Carolina Press, 2003.

-----. "The Taylor Administration versus Mississippi Sovereignty: The Round Island Expedition of 1849.” Journal 
of Mississippi History 62, no.4 (Winter 2000): 295-327.

Coyle, John F. "The Treaty of Friendship, Commerce, and Navigation in the Modern Era." Columbia Journal of Transnational Law 51 (Fall 2013): 302-359.

Cralle, Richard, ed. The Works of John C. Calhoun: Speeches Delivered in the House of Representatives and in the Senate of the United States. New York: D. Appleton, 1888.

Crapol, Edward, ed. Women and American Foreign Policy: Lobbyists, Critics, and Insiders. Westport: Greenwood Press, 1987.

Crawford, George B. "Cotton, Land, and Sustenance: Toward the Limits of Abundance in Late Antebellum Georgia.” The Georgia Historical Quarterly 72, no. 2 (Summer 1988): 215-247.

Crenshaw, Ollinger. "The Knights of the Golden Circle: The Career of George Bickley.” American Historical Review 47, no. 1 (October 1941): 23-50.

Crouzet, François. "Wars, Blockade, and Economic Change in Europe, 1792-1815," The Journal of Economic History 24, no. 4 (December 1964): 567-588.

Cruz Taura, Graciella. “Annexation and National Identity: Cuba's Mid-Nineteenth-Century Debate.” Cuban Studies 27 (1997): 90-109.

Curtis, Roy Emerson. "The Law of Hostile Military Expeditions as Applied by the United States." The American Journal of International Law 8, no. 1 (January 1914): 1-37.

Cuartero, Izaskun Álvarez. Memorias de la Ilustración: las Sociedades Económicas de Amigos del País en Cuba: 1783-1832. Madrid: Real Sociedad Bascongada de los Amigos del País, 2000.

Cuartero, Alvarez Izaskun ed. Francisco Arango y la invención de la cuba azucarera. Salamanca: University of Salamanca Press, 2010.

Cuban Anti-Slavery Committee, New York. Slavery in Cuba: A Report of the Proceedings of the Meeting, Held at Cooper Institute, New York City, December 13, 1872. Philadelphia: Historic Publications, 1969.

Cuesta, Jorge Ibarra. Varela el precursor. Un estudio de Época. Havana: Editorial de Ciencias Sociales, 2004.

Cummins, Light T. "John Quincy Adams and Latin American Nationalism.” Revista de Historia de América 86 (July-December, 1978): 221-231.

Curry-Machado, Jonathon. "Indispensible Aliens: The Influence of Engineering Migrants with Mid-Nineteenth Century Cuban Society.” PhD diss., London Metropolitan University, 2003.

-----. "Privileged Scapegoats - The Manipulation of Migrant Engineering Workers in Mid- Nineteenth Century Cuba." Caribbean Studies 35, no.1 (Winter 2007): 207-245.

-----. “How Cuba Burned With The Ghosts Of British Slavery:' Race, Abolition and The Escalera.” Slavery \& Abolition 25, no. 1 (April 2004): 71-93.

----- "'Rich flames and hired tears:' Sugar, Sub-Imperial Agents and The Cuban Phoenix of Empire.” Journal of Global History 4, Issue 1 (March 2009): 33-56.

-----. Cuban Sugar Industry: Transnational Networks and Engineering Migrants in Mid-Nineteenth Century Cuba. London: Palgrave Macmillan, 2011.

----. "Sub-Imperial Globalisation and the Phoenix of Empire: Sugar, Engineering and Commerce in Nineteenth- 
Century Cuba." Commodities of Empire Working Paper Number Two, Open University \& London Metropolitan University, 2007. Accessed January 20, 2014. http://www.open.ac.uk/Arts/fergusoncentre/commodities-of-empire/working-papers/WP02.pdf.

-----. “'In Cane's Shadow:' Commodity Plantations and The Local Agrarian Economy on Cuba's Mid-Nineteenth Century Sugar Frontier." In The Global and Local History of Commodities of Empire, edited by Jonathan Curry-Machado. London: Palgrave Macmillan, 2013.

Curti, Merle. "Impact of the Revolutions of 1848 on American Thought." Proceedings of the American Philosophical Society 93, no. 3 (June 1949): 209-15.

----.."Young America." American Historical Review 32, no. 3 (October 1928): 34-55.

Cusick, James G. The Other War of 1812: The Patriot War and the American Invasion of Spanish East Florida. Athens: UGA Press, 2003.

Czitrom, Daniel. Media and the American Mind: From Morse to McLuhan. Chapel Hill: University of North Carolina Press, 1982.

Dalzell, Robert. Daniel Webster and the Trial of American Nationalism, 1843-1852. Boston: Houghton Mifflin, 1973.

Dana, Richard Henry. To Cuba and Back: A Vacation Voyage. Boston: Ticknor, 1859. Accessed on May 30, 2013. http://archive.org/details/tocubabackvacati00danauoft.

Danbom, David B. “The Young America Movement." Journal of the Illinois State Historical Society 67, no. 3 (June 1974): 294-306.

Dangerfield, George. The Awakening of American Nationalism: 1815-1828. Prospect Heights, IL: Waveland Press, 1965.

Davenport, Stewart. Friends of the Unrighteous Mammon: Northern Christians and Market Capitalism, 1815-1860. Chicago: University of Chicago Press, 2008.

Davidson, Cathy. Revolution and the Word: The Rise of the Novel in American. New York: Oxford University Press, 1986.

Davidson, Lawrence. "Christian Zionism as a Representation of American Manifest Destiny." Critical Middle Eastern Studies, 14, no. 2 (Summer 2005): 158-160.

Davis, David Brion. The Problem of Slavery in the Age of Revolution, 1770-1823. Oxford: Oxford University Press, 1999.

Daz, Ignacio. “Merlin’s Foreign House: The Genres of 'La Havane.”' Cuban Studies, 24 (1994): 57-82.

De Chateaubriand, M. The Congress of Verona Comprising a Portion of Memoirs of His Own Time. London: Richard Bentley, 1838.

Deak, Istvan. The Lawful Revolution: Louis Kossuth and the Hungarians, 1848-1849. New York: Columbia University Press, 1979.

Deleuze, Gilles and Felix Guattari. A Thousand Plateaus: Capitalism and Schizophrenia. Minneapolis: University of Minnesota, 1980.

Delfiner, Henry A. “Alexander I, The Holy Alliance and Clemens Metternich: A Reappraisal.” East European Quarterly, XXXVII, no. 2 (June 2003): 127-150. 
Delfino, Susanna, Michele Gillespie, and Louis M. Kyriakoudes, eds. Southern Society and Its Transformation. Columbia: University of Missouri Press; 2011.

Delgado de Torres, Lena. "Reformulating Nationalism in the African Diaspora: The Aponte Rebellion of 1812." CR: The New Centennial Review 3, no. 3 (Fall 2003): 27-46.

Denslow, David. “Sugar Production in Northeastern Brazil and Cuba, 1858-1908.” PhD diss., Yale University, 1974.

Department of State, United States. Correspondence on the López Expedition to Cuba, 1849-1851. General Records of the Department of State, Record Group 59.

Dessalines, Jean-Jacques. Liberte ou la Mort: Proclamation du Général en Chef au Peuple d'Haïti Quartier-général des Gonaïves, le ler janvier 1804, an ler de l'Indépendance. Accessed Jan. 15, 2014. http://www. Windowsonhaiti.com/windowsonhaiti/act2.shtml.

Díaz, María Elena. The Virgin, the King, and the Royal Slaves of El Cobre: Negotiating Freedom in Colonial Cuba, 1670-1780. Stanford: Stanford University Press, 2000.

-----. "Beyond Tannenbuam.” Law and History Review 22, no. 2 (Summer 2004): 45-78.

Díaz del Olmo, Fernando. "Hatos Caribeños Y Dehesas Andaluzas: Paisaje Y Estructura Parcelaria.” In Cuba y Andalucía Entre Las Dos Orillas, edited by Jesús Raúl Navarro Garcia, 303-333. Seville: Consejo Superior De Investigaciones Cientificas Escuela De Estudios Hispano-Americanos, 2002.

Dicken-Garcia, Hazel. Journalistic Standards in Nineteenth-Century America. Madison: University of Wisconsin Press, 1989.

Din, Gilbert C. The Spanish Presence in Louisiana, 1763-1803. Lafayette: Center for Louisiana Studies, University of Southwestern Louisiana, 1996.

Dirks, Nicholas. The Scandal of Empire: India and the Creation of Imperial Britain. Cambridge: Cambridge University Press, 2006.

Domínguez, Francisco Ponte. Arango y Parreño, El Estadista Colonial. Havana: Editorial Trópico, 1937.

Dominguez, Jorge I. "Political Participation and the Social Mobilization Hypothesis: Chile, Mexico, Venezuela, and Cuba, 1800-1825.” Journal of Interdisciplinary History 5, no. 2 (Autumn 1974): 237-266.

Donovan, Herbert. The Barnburners: A Study of the Internal Movements in the Political History of NY States And The Resulting Changes in Political Affiliation. New York: NYU Press, 1925.

Doolen, Andy. Fugitive Empire: Locating Early American Imperialism. Minneapolis: University of Minnesota Press, 2005.

Douglass, Fredrick. “West Indian Freedom Speech.” Accessed March 10, 2014. http://www.lib.rochester.edu/ index.cfm?PAGE=4398.

Dowe, Dieter, ed. Europe in 1848: Revolution and Reform. New York: Berghahn Books, 2000.

Downey, Tom. Planting a Capitalist South: Masters, Merchants, and Manufacturers in the Southern Interior, 17901860. Baton Rouge: Louisiana State University Press, 2006.

Drescher, Seymour. Econocide: British Slavery in the Era of Abolition. Pittsburgh: University of Pittsburgh Press, 1977. 
----. The Mighty Experiment: Free Labor versus Slavery in British Emancipation. Cambridge: Cambridge University Press, 2002.

-----. Abolition - A History of Slavery and Antislavery. New York: Cambridge University Press, 2009.

Drexler, Michael J. “Haiti, Modernity, and U.S. Identities.” Early American Literature 43, no. 2 (2008): 453-465.

Duban, James. Melville's Major Fiction: Politics, Theology and Imagination. De Kalb, IL.: Northern Illinois Press, 1983.

Dubois, Laurent. A Colony of Citizens: Revolution and Slave Emancipation in the French Caribbean, 1787-1804. Chapel Hill: University of North Carolina Press, 2004.

-----. "The Haitian Revolution and the Sale of Louisiana." The Southern Quarterly: A Journal of Arts in the South 44, no.3 (Fall 2007): 18-41.

-----. "The Citizen's Trace: The Haitian revolution and the Motor of History." In Magic and Modernity: Interfaces of Revelation and Concealment, edited by Birgit Meyer and Peter Pels, 130-158. Stanford University Press, 2003.

Dun, James Alexander. "Philadelphia not Philanthropolis: The Limits of Pennsylvanian Antislavery in the Era of the Haitian Revolution.” Pennsylvania Magazine of History and Biography 135, no. 1 (January 2011): 73-102.

----. “'What Avenues of Commerce Will You Americans Not Explore!:' Commercial Philadelphia’s Vantage onto the Early Haitian Revolution." William and Mary Quarterly 62, no. 3 (Summer 2005): 473-504.

Dunning, Mike. "Manifest Destiny and the Trans-Mississippi South: Natural Laws and the Extension of Slavery into Mexico." The Journal of Popular Culture 35, no. 2 (2001): 111-127.

Dupree, Daniel. Transforming the Cotton Frontier: Madison Country, Alabama 1800-1840. Baton Rouge: LSP Press, 1997.

Dye, Alan. Cuban Sugar in the Age of Mass Production: Technology and the Economics of the Sugar Central, 18991929. Stanford: Stanford University Press, 1998.

Earle, Jonathan. "The Undaunted Democracy: Jacksonian Antislavery and Free Soil, 1828-1848." PhD diss., Princeton University, 1996.

----. Jacksonian Antislavery and the Politics of Free Soil, 1824-1854. Chapel Hill: UNC Press, 2003.

Earle, Rebecca A. Spain and the Independence of Colombia, 1810-1825. Liverpool: Liverpool University Press, 2000.

Eastman, Scott. Preaching Spanish Nationalism across the Hispanic Atlantic, 1759-1823. Baton Rouge: LSU Press, 2012.

----- “The Religious Origins of Spanish National Identity, 1793-1812.” Presentation to Comunicaciones del Encuentro de Jóvenes Investigadores en Historia Contemporánea de la AHC, Universidad del País Vasco Vitoria, Gasteiz, September 2008.

Echeverri, Marcela. "Popular Royalists and Revolution in Colombia: Nationalism and Empire, 1780—1820." PhD diss., New York University, 2008.

Eckel, Leslie. “Margaret Fuller’s Conversational Journalism: New York, London, Rome.” Arizona Quarterly 63, no. 2 (Spring 2007): 27-50.

Editors of La Verdad, “Cuestión negrera de la Isla de Cuba.” New York: La Verdad, 1851. 
Edwards, Bryan. The History Civil and Commercial, Of the British Colonies in the West Indies: To Which Is Added, An Historical Survey Of The French Colony In The Island Of St. Domingo. London: B. Crosby for Mundell \& Son, Edinburgh; and J. Mundell, Glasgow, 1800.

Egerton, Douglas. "Markets Without a Market Revolution: Southern Planters and Capitalism." Journal of the Early Republic 16, no. 2, (Summer 1996): 207-221.

Elliott, J. H. Empires of the Atlantic World: Britain and Spain in America, 1492-1830. New Haven: Yale University Press, 2006.

Ellis, Robert Richmond. "Reading through the Veil of Juan Francisco Manzano: From Homoerotic Violence to the Dream of a Homoracial Bond:” Proceeding of the Modern Language Association 113, no. 3 (May 1998): 442-435.

Eltis, David. “The U.S. Transatlantic Slave Trade, 1644-1867: An Assessment." Civil War History 54, no. 4 (December 2008): 347-378.

-----. “The Nineteenth-Century Transatlantic Slave Trade.” Hispanic American Historical Review, 67, no. 1 (February 1987): 109-38.

-----. Economic Growth and the Ending of the Transatlantic Slave Trade. Oxford: Oxford University Press, 1987.

Ely, Roland T. "From Counting-house to Cane Field: Moses Taylor and the Cuban Sugar Planter in the Reign of Isabel II, 1833-1868.” PhD diss., Harvard, 1959.

-----. "The Old Cuba Trade: Highlights and Case Studies of Cuban-American Interdependence during the Nineteenth Century." Business History Review 38 (Winter 1964): 456-78.

Embree, Ainslie ed. India in 1857: Mutiny or War of Independence. Delhi: Heath, 1963.

Emerson, Ralph Waldo. “The Young American.” Accessed March 12, 2011. http://www.emersoncentral.com/ youngam.htm.

Emery, Allan Moore. "Benito Cereno" and Manifest Destiny." Nineteenth-Century Fiction 39, no. 1 (June 1984): 48-68.

English, William B. “Understanding the Costs of Sovereign Default: American State Debts in the 1840's.” American Economic Review, 86 (March 2004): 259-275.

Engstrand, Iris H. W. “The Enlightenment in Spain: Influences upon New World Policy.” The Americas 41, no. 4 (April 1985): 436-444.

Esdaile, Charles S. Spain in the Liberal Age: From Constitution to Civil War, 1808-1939. New York: Wiley, 2000.

Esteban, Javier Cuenca. "Statistics of Spain's Colonial Trade, 1792-1820: Consular Duties, Cargo Inventories and Balance of Trade." Hispanic American Historical Review 61, no. 3 (August 1981): 381-428.

Ettinger, A. A. "The Proposed Anglo-Franco-American Treaty of 1852 to Guarantee Cuba to Spain." Transactions of the Royal Historical Society 4, no. 13 (1930): 49-185.

-----. The Mission to Spain of Pierre Soulé, 1853-1855: A Study in the Cuban Diplomacy of the United States. New Haven: Yale University Press, 1932.

Everett, Alexander Hill. Cuba; The Everett Letters on Cuba. Boston, G. H. Ellis, 1897. 
Eyal, Yonatan. The Young America Movement and the Transformation of the Democratic Party 1828-1861. Cambridge: Cambridge University Press, 2007.

Fanon, Franz. Black Skin, White Masks. New York: Grove Press, 1967.

Fehrenback, Charles. "Moderados and Exaltados: The Liberal Opposition to Ferdinand VII: 1814-1823." The Hispanic American Historical Review 50, no. 1 (February, 1970): 52-69.

Fenwick, Charles Ghequiere. The Neutrality Laws of the United States. New York: Carnegie Endowment for International Peace, 1913.

Feracho, Lesley. Linking the Americas: Race, Hybrid Discourses, and the Reformulation of Feminine Identity. Albany: SUNY Press, 2005.

Fernández, Daisy Cué. "Plácido y la conspiración de la Escalera.” Santiago 42 (June 1981): 145-20.

Fernández, Damián J., ed. Cuban Studies Since the Revolution. Gainesville: University of Florida Press, 1992.

Fernández, Susan. Encumbered Cuba: Capital Markets and Revolt, 1878-1895. Gainesville: University of Florida Press, 2002.

Fernández-Martinez, Luis. Torn Between Empires: Economy, Society and Patterns of Political Thought in the Hispanic Caribbean, 1840-1878. Athens: University of Georgia Press, 1994.

Ferrer, Ada "Cuban Slavery and Atlantic Antislavery." Review (Fernand Braudel Center), The Second Slavery: Mass Slavery, World-Economy, and Comparative Microhistories 31, no. 3 (Fall 2008): 267-295.

----. "Speaking of Haiti: Slavery, Revolution, and Freedom in Cuban Slave Testimony." In The World of the Haitian Revolution, edited by David Patrick Geggus and Norman Fiering, 223-247. Bloomington: Indiana University Press, 2009).

-----. Insurgent Cuba: Race, Nation, and Revolution, 1868-1898: Race, Nation, and Revolution, 1868-1898. Chapel Hill: UNC Press, 1999.

Fichter, James. So Great A Profit: How the East Indies Trade Transformed Anglo-American Capitalism. Cambridge: Cambridge University Press, 2010.

Fick, Carolyn. The Making of Haiti: The Saint Domingue Revolution from Below. Knoxville: University of Tennessee Press, 1990.

-----. "Revolutionary Saint Domingue and the Emerging Atlantic: Paradigms of Sovereignty." Review: A Journal of the Fernand Braudel Center 31, no. 2 (2008): 121-144.

Fillmore, Millard. "Second Inaugural Address.” Accessed March 15, 2014. http://www.presidency.ucsb. edu/ws/?pid=29492.

-----. House Documents, Otherwise Publ. as Executive Documents: $13^{\text {th }}$ Congress, $2 d$ Session-49 ${ }^{\text {th }}$ Congress, 1st Session, 32d Congress, $1^{\text {st }}$ Session, Ex Document \#10. Accessed on March 12, 2014. http://books.google.com/books?id=4YcFAA AAQAAJ\&dq=john\%20thrasher\%20cuba\&pg=RA1 PA92\#v=onepage \&q=john\%20thrasher\%20cuba\&f=false.

Finch, Aisha K. "Scandalous Scarcities: Black Slave Women, Plantation Domesticity, and Travel Writing in Nineteenth-Century Cuba.” Journal of Historical Sociology 23, no. 1 (March 2010): 101-143.

----. "Insurgency at the Crossroads: Cuban Slaves and the Conspiracy of La Escalera, 1841-1844." PhD 
diss., New York University, 2007.

Fioravanti, Marco. "Domestic Enemy: Poisoning and Resistance to the Slave Order in the $19^{\text {th }}$ Century French Antilles." Historia Constitucional 14 (2013): 503-524.

Fischer, David Hackett and James C. Kelly. Bound Away: Virginia and the Westward Movement. Charlottesville: University of Virginia Press, 2000.

Fishlow, Albert. American Railroads and the Transformation of the Ante-Bellum Economy. Cambridge: Harvard University Press, 1965.

Fistein, David. "Theory and the Social Revolution in Haiti." Journal of Haitian Studies 15, no. 1/2 (Spring/Fall 2009): 180-202.

Fleche, Andre. The Revolution of 1861: The American Civil War in the Age of Nationalist Conflict. Chapel Hill: University of North Carolina Press, 2012.

Flint, Henry Martyn ed. The Life and Speeches of Stephen A. Douglas. New York: Derby and Jackson, 1860.

Foley, John, ed. The Jeffersonian Cyclopedia. New York: Funk and Wagnall, 1900.

Follett, Richard. The Sugar Masters: Planters and Slaves in Louisiana's Cane World, 1820-1860. Baton Rouge: LSU Press, 2005.

Folsum, Allen, Gay Wilson and Ed Folsum, eds. Whitman and the World. Iowa City, IA: University of Iowa Press, 1995.

Foner, Eric. Free Soil, Free Labor, Free Men: The Ideology of the Republican Party Before the Civil War. Oxford: Oxford University Press, 1970.

Foner, Philip S. Business \& Slavery: The New York Merchants \& the Irrepressible Conflict. New York: Russell \& Russell, 1968.

-----. A History of Cuba and Its Relations with the United States, Vol. 1. New York: International Publishers, 1962.

----.."Alexander Von Humboldt on Slavery in America.” Science \& Society 47, no. 3 (Fall 1983): 330-342.

Fontanella, Lee. “J. M. Heredia: A Case for Critical Inclusivism.” Revista Hispánica Moderna 37, no. 3 (19721973): 162-179.

Ford, Lacy. Deliver Us from Evil: The Slavery Question in the Old South. New York: Oxford University Press, 2009.

-----. Origins of Southern Radicalism: The South Carolina Upcountry, 1800-1860: The South Carolina Upcountry, 1800-1860. New York: Oxford University Press, 1988.

Ford, Worthington Chauncey, ed. Writings of John Quincy Adams. New York: Macmillan, 1917.

Fortoul, Gil. Historia Constitucional de Venezuela. Berlin: C. Heyman, 1907.

Fradera Josep M. and Christopher Schmidt-Nowara, eds. Slavery and Antislavery in Spain's Atlantic Empire. New York: Berghahn Books, 2013.

Fraginals, Manuel Moreno "Plantations in the Caribbean: Cuba, Puerto Rico, and the Dominican Republic in the 
Late Nineteenth-Century." In Between Slavery and Free Labor: The Spanish-Speaking Caribbean in the Nineteenth Century, edited Manuel Moreno Fraginals, Frank Moya Pons and Stanley E. Engerman, 3-21. Baltimore: Johns Hopkins University Press, 1985.

----. El Ingenio: Complejo Economico Social Cubano Del Azúcar, 3 vols. Havana: Editorial de Ciencias Sociales, 1978.

----. Sugarmill: The Socio-economic Complex of Sugar in Cuba, 1760-1860. New York: Monthly Review Press, 1976.

Fraginals, Manuel Moreno, Herbert S. Klein, and Stanley L. Engerman. "The Level and Structure of Slave Prices on Cuban Plantations in the Mid-Nineteenth Century: Some Comparative Perspectives." American Historical Review 88, no. 5 (December 1983): 1201-18.

Frahm, Sally. "The Cross and the Compass: Manifest Destiny, Religious Aspects of the Mexican-American War." The Journal of Popular Culture 35, no. 2 (2001): 83-99.

Franco, José Luciano. "Introducción al proceso de la Escalera.” Boletín del Archivo Nacional 67 (1974): 54-63.

-----. Plácido: Una polémica que tiene cien años. Havana: Ediciones Unión, 1964.

-----. Antonio Maceo: Apuntes para una historia de su vida. Havana: Editorial de Ciencias Sociales, 1975.

----. La conspiración de Aponte. Havana: Consejo Nacional de Cultura, Publicaciones del Archivo Nacional, 1963.

----. Comercio clandestion de esclavos. Havana: Editorial de Ciencias Sociales, 1996.

Franklin, Sarah L. Women and Slavery in Nineteenth-Century Colonial Cuba. Rochester: University Rochester Press, 2012.

Franklin, John Hope. The Militant South, 1800-1861. Cambridge, MA.: Belknap Press, 1956.

Frazier, Donald Shaw. Blood and Treasure: Confederate Empire in the Southwest. College Station: Texas A\&M Press, 1995.

Freeman, Joanne. Affairs of Honor: National Politics in the New Republic. New Haven: Yale University Press, 2001.

Freitag, Sabine. Exiles from European Revolutions: Refugees in Mid-Victorian England. New York: Berghahn Books, 2003.

Freret, William. Correspondence between the Treasury Department in Relations to the Cuba Expedition and William Freret, Late Collector. New Orleans: Alex Levy \& co., 1851.

Friedlander, H.E. Historica Económica de Cuba. Havana: Jesús Montero, 1944.

Friend, Craig and Lorri Glover, eds. Southern Manhood: Perspectives on Masculinity in the Old South. Athens: University of Georgia, 2004.

Fuente, Alejandro de la. "Slaves and the Creation of Legal Rights in Cuba: Coartación and Papel." Hispanic American Historical Review 87, no. 4 (Fall 2007): 659-692.

----. "Slave Law and Claims-Making in Cuba: The Tannenbuam Debate Revisited." Law and History Review 22, no. 2 (Summer 2004): 339-369.

Gallagher, J. and R. Robinson. “The Imperialism of Free Trade.” The Economic History Review 6 (1953): 1-15. 
Gallenga, Antonio. The Pearl of the Antilles. New York: Negro Universities Press, 1970. Reprint from 1873.

García, Antonio Santamaría. "La industria azucarera y la economía de Cuba colonial: Bibliografía.” Accessed on March 21, 2013. http://digital.csic.es/bitstream/10261/72783/1/Bibiografia\%20Cuiba\%20azucar $\% 20 \mathrm{y} \% 20 \mathrm{economia} \% 20 \mathrm{XIX} \% 20(\mathrm{PDF}) . \mathrm{pdf}$.

Garcia, Fe Iglesias. “The Development of Capitalism in Cuban Sugar Production 1860-1900.” In Between Slavery and Free Labor: The Spanish Speaking Caribbean in the Nineteenth Century, edited Manuel Moreno Fraginals, Frank Moya Pons, and Stanley Engerman, 54-76. Baltimore: Johns Hopkins University Press, 1985.

García, Jesús Raúl Navarro. Entre exclavos y constitutciónes: el colonialism liberal de 1837 en Cuba. Seville: CISC, 1991.

Garcia-Menocal, Carlos Manuel de Céspedes. "The Life, Thought and Significance of Father Felix Varela." Paper presented at Fordham University, Lincoln Center campus New York, January 27, 2005.

Garraway, Doris L. ed. Tree of Liberty: Cultural Legacies of the Haitian Revolution in the Atlantic World. Charlottesville: University of Virginia Press, 2008.

Garrigos, Lucia Provencio. “Clase”, Poder y Matrimonio: Configuracion de un Elite Dirigente: La Sociedad Economica de Cuba de Amigos del Pais.” Contrastes: Revista de Historia Moderna 9-10 (1994-1997): 4990 .

-----. “La Trampa Discursiva Del Elogio A La Maternidad Cubana Del Siglo XIX.” Americanía 1 (January 2011): 42-73.

Gaspar, David Barry and David Patrick Geggus, eds. A Turbulent Time: The French Revolution and the Greater Caribbean. Bloomington: Indiana University Press, 1997.

Gaztambide-Géigel, Antonio. "The Invention Of The Caribbean In The $20^{\text {th }}$ Century: The Definitions of the Caribbean as a Historical and Methodological Problem." Social and Economic Studies 53, no. 3 (September 2004): 127-157.

Geggus, David Patrick. "Slave Resistance Studies and the Saint Domingue Slave Revolt: Some Preliminary Considerations." Occasional Paper Series, Florida International University, Paper 4, 1983.

----. "The Influence of the Haitian Revolution on Blacks in Latin America and the Caribbean.” In Blacks, Coloureds and National Identity in Nineteenth-Century Latin America, edited by Nancy Priscilla Naro, 3859. London: Institute of Latin American Studies, 2003.

Genovese, Eugene. The Political Economy of Slavery: Studies in the Economy and Society of the Slave South. New York: Pantheon, 1965.

Gigantino, James. "Trading in Jersey Souls: New Jersey and the Interstate Slave Trade.” Pennsylvania History: A Journal of Mid-Atlantic Studies 77, no. 3 (Summer 2010): 281-302.

Gilderhaus, Mark T. “The Monroe Doctrine: Meanings and Implications." Presidential Studies Quarterly 36, no. 1 (March, 2006): 5-16.

Gilje, Paul. The Road to Mobocracy: Popular Disorder in NYC. Chapel Hill: UNC Press,1987.

Gillespie, Michele. "Building Networks of Knowledge: Henry Merrell and Textile Manufacturing in the Antebellum South.” In Technology, Innovation, and Southern Industrialization: From the Antebellum Era to the Computer Age, edited by Susanna Delfino and Michele Gillespie, 97-124. Columbia: University 
Missouri Press, 2009.

Gilmore, Paul. “The Telegraph in Black and White.” English Literary History 69, no. 3 (Fall 2002): 805-833.

Ginsberg, Judah. "Barnburners, Free Soilers, and the New York Republican Party." New York History 57, no. 4 (October 1976): 475-500.

Gleijeses, Piero. "The Limits of Sympathy: The United States and the Independence of Spanish America." Journal of Latin American Studies, 24, no. 3 (October, 1992): 481-505.

Glickman, Lawrence. "'Buy for the Sake of the Slave:' Abolitionism and the Origins of American Consumer Activism.” American Quarterly 56 (December 2004): 889-912.

Glissant, Édouard. Poetics of Relation. Ann Arbor: University of Michigan Press, 1997.

Glover, Adam. “Crisis and Exile: On José María Heredia’s Romanticism.” Decimonónica 10, no. 1 (Winter 2013 ): 78-96.

Goebel, Dorothy Bume. "British Trade to the Spanish Colonies, 1796-1823." American Historical Review 43, no. 2 (January 1938): 288-303.

Gold, David. An Exemplary Whig: Edward Kent and the Whig Disposition in American Politics and Law. Lanham MD: Lexington Books, 2012.

Goldthwaite, George. "The Southern Convention.” Accessed March 5, 2014. http:/quod.lib.umich.edu/m/moajrnl/ acp1141.2-02.003/235?node=acp1141.2-02.003\%3A11\&view=image \&size=100, 227-229.

Gomariz, José. "Gertrudis Gómez de Avellaneda y la intelectualidad reformista cubana: Raza, blanqueamiento y identidad cultural en Sab." Caribbean Studies 37, no. 1 (January-June 2009): 97-118.

-----. "Francisco de Arango y Parreño: El discurso esclavista de la ilustración cubana." Cuban Studies 35 (2004): 45 61.

González, Alfonso. “The Population of Cuba,” Caribbean Studies 11, no. 2 (July 1971): 74-84.

González, Ambrosio Gonzalez. "Liberation Of The Gem Of The Antilles: An Interesting Account of This Initial \ Movement from Gen. Ambrosio Jose Gonzalez, Second in Command to Gen. Lopez.” New Orleans Times Democrat, March 10, 1884.

González-Fernández, Doria. “La Economía Cafetalera Cubana: 1760-1860.” Arbor 547-548 (1991): 161-179;

González-Ripoll, Maria Dolores, ed. Francisco Arango Y La Invención De La Cuba Azucarera. Salamanca: Ediciones Universidad de Salamanca, 2009.

----. “Francisco Arango Y Parreño (1765-1837), Ideólogo Y Mediador.” Revista De Indias 61, no. 222 (2001): 291395.

González-Ripoll, María Dolores, Consuelo Naranjo, Ada Ferrer, Gloria García, and Josef Opatrný. El rumor de Haití en Cuba: temor, raza y rebeldía, 1789-1844. Madrid: CSIC Press, 2004.

González y Torres, Plutarco. The Cuban Question and American Policy, in the Light of Common Sense, 1869. Accessed November 23, 2012. http://archive.org/details/cubanquestionan00torrgoog.

Goodrich, Carter. Government Promotion of American Canals and Railroads, 1800-1890. New York: Greenwood Press, 1960. 
Gott, Richard. Cuba: A New History. New Haven: Yale University Press, 2004.

Goudie, Sean X. Creole America: The West Indies and the Formation of Literature and Culture in the New Republic. Philadelphia: University of Pennsylvania Press, 2006.

Grafe, Regina and Alejandra Irigoin. "A Stakeholder Empire: The Political Economy of Spanish Imperial Rule in America.” Accessed February 12, 2012. http://www2.1se.ac.uk/economicHistory/pdf/WP111.pdf.

Grafenstein, Johanna von. "The Atlantic World at the Time of the Haitian Revolution: The Point of View of Francisco de Arango y Parreño." In Latin America and the Atlantic World/ El Mundo atlántico y América Latina 1500-1850, edited by Renate Pieper and Peer Schmidt, 351-366. Cologne: Böhlau Verlag, 2005.

Gray, Elizabeth Kelly. "Whisper to Him the Word 'India:' Trans-Atlantic Critics and American Slavery, 18301860." Journal of the Early Republic 28, no. 3 (Fall 2008): 379-406.

Green, Duff. Facts and Suggestions, Biographical, Historical, Financial and Political, Addressed to the People of the United States. New York: Richardson \& Co., 1866.

Green, Fletcher Melvin. The Role of the Yankee in the Old South. Athens: University of Georgia Press, 1972.

Greenberg, Amy S. Manifest Manhood and the Antebellum American Empire. Cambridge: Cambridge University Press, 2005.

----. “A Gray-Eyed Man: Character, Appearance, and Filibustering.” Journal of the Early Republic 20, no. 4 (Winter 2000): 673-699.

-----. "Pirates, Patriots, and Public Meetings Antebellum Expansionism and Urban Culture." Journal of Urban History 31, no. 5 (July 2005): 634-650.

Greenstein, Fred I. “The Political Professionalism of James Monroe.” Presidential Studies Quarterly 39, no. 2 (June 2009): 275-282.

Grimsted, David. American Mobbing 1828-1861: Toward the Civil War. Oxford: Oxford University Press, 1998.

Groen, Mark. "The Whig Party and the Rise of Common Schools, 1837-1854." American Educational History Journal 35, no. 1/2 (Spring/Summer 2008): 251-260.

Grova, Alina Gutierrez. "Para La Historia de la Lengua Culta Escrita: Aproximación a la Sintaxis del Papel Periódico de la Havana." In La Lengua en Cuba: Estudios, edited by Sergio Valdés Bernal, 57-100. Cuba: Universidade de Santiago de Compostela, 2007.

Gruesz, Kirsten Silva. Ambassadors of Culture: The Transamerican Origins of Latino Writing. Princeton: Princeton University Press, 2002.

-----. "Maria Gowen Brooks, In and Out of the Poe Circle." ESQ: A Journal of the American Renaissance, 54. no.3 (Fall 2008): 75-109.

----. "The Cafetal of María del Occidente and the Anglo-American Race for Cuba." In The Traffic in Poems: Nineteenth-Century Poetry and Transatlantic Exchange, edited by Meredith McGill, 37-62. New Brunswick: Rutgers University Press, 2008.

Guédez, José Marcial Ramos. "Simón Bolívar y la abolición de la esclavitud en Venezuela 1810-1830, Problemas y frustraciónde una causa." Revista de Historia de América, 125 (July-December 1999): 7-20.

Gurney, Joseph John. A Winter in The West Indies: Described In Familiar Letters to Henry Clay, of Kentucky. London: J. Murray, 1840. 
Guerra y Sánchez, Ramiro. The Territorial Expansion of the United States: At the Expense of Spain and the Hispanic-American Countries. New York: University Press of America, 2003.

----. Manual de Historia de Cuba. Havana: Cultural, 1964Guevara, Gema. "Inexacting Whiteness: Blanqueamiento as a Gender-Specific Trope in the Nineteenth Century.” Cuban Studies 36, (2005): 105-128.

-----. Azúcar y poblacio en las Antillas. Havana: Editorial de Ciencias Sociales, 1999.

Guerra y Sánchez, Ramiro, ed. Historia de la nación cubana, vol. 3. Havana: Editorial Historia de la Nación Cubana, 1952

Guevara, Gema. "Inexacting Whiteness: Blanqueamiento as a Gender-Specific Trope in the Nineteenth Century." Cuban Studies, 36 (2005): 105-128.

Guillory, John. Cultural Capital: The Problem of Literary Canon Formation. Chicago: University of Chicago Press, 1993.

Guterl. Matthew Pratt. American Mediterranean: Southern Slaveholders in the Age of Emancipation. Cambridge: Harvard University Press, 2008.

----- "After Slavery: Asian Labor, the American South, and the Age of Emancipation.” Journal of World History 14, no. 2 (June 2003): 209-41.

Guyatt, Nicholas. Providence and the Invention of the United States, 1607-1876. New York: Cambridge University Press, 2007.

Hackshaw, Elizabeth and Martin Munro, eds. Echoes of the Haitian Revolution in the Modern World. Kingston, Jamaica: UWI Press, 2008.

Hahn, Steven. The Roots of Southern Populism: Yeoman Farmers and the Transformation of the Georgia Upcountry, 1850-1890. New York: Oxford University, 1983.

----- The Political Worlds of Slavery and Freedom. Cambridge: Harvard University Press, 2009.

Haggerty, Sheryllynne. The British-Atlantic Trading Community, 1760-1810: Men, Women, and the Distribution of Goods. Leiden: Brill, 2006.

Hall, Gwendolyn Midlo. Africans in Colonial Louisiana: The Development of Afro-Creole Culture in the Eighteenth Century. Baton Rouge: LSU Press, 1995.

-----. Social Control in Slave Plantation Societies: A Comparison of St. Domingue and Cuba. Baltimore: Johns Hopkins University Press, 1971.

Halttunen, Karen, Confidence Men and Painted Women: A Study of Middle-class Culture in America, 1830-1870. New Haven: Yale University Press, 1986.

Hamilton, Earl J. "Monetary Problems in Spain and Spanish America 1751." The Journal of Economic History, 4, no. 1 (May 1944): 21-48.

Hamilton, James F. "The Hero's Journey to Niagara in Chateaubriand and Heredia, French and Cuban Exiles." Romance Quarterly 41, no. 2 (Summer 1994): 71-78.

Hamilton, Stan, ed. The Writings of James Monroe, Vol. 1. New York: Putnam, 1902.

Hammond, Bray. Banks and Politics in America from the Revolution to the Civil War. Princeton: Princeton University Press, 1960.

Hammond, John Craig. Slavery, Freedom and the Expansion in the Early American West. Charlottesville: 
University of Virginia Press, 2007.

Hammond, John Craig and Matthew Mason, eds. Contesting Slavery: The Politics of Bondage and Freedom in the New American Nation. Charlottesville: University of Virginia Press, 2011.

Hanger, Kimberly S. Bounded Lives, Bounded Places: Free Black Society in Colonial New Orleans, 1769-1803. Durham: Duke University Press, 1997.

Hansen, Karen. A Very Social Time - Crafting Community in Antebellum New England. Berkeley: University of California Press, 1994.

Hardy, Richardson. An Authentic History of the Cuban Expeditions. Cincinnati: Lorenzo Stratton, 1850.

Harris, Sheldon H. “The Public Career of John Louis O’Sullivan.” PhD diss., Columbia University, 1958.

----. “John Louis O'Sullivan and the Election of 1844 in New York.” New York History 41, no. 3 (July 1960): 278298.

Harris, William. Plain Folk and Gentry in a Slave Society: White Liberty and Black Slavery in Augusta's Hinterlands. Middleton: Wesleyan University Press, 1985.

Harrison, Brady. "The Young Americans: Emerson, Walker and the Early Literature of American Empire." American Studies 40, no.3 (Fall 1999): 75-97.

Harrold, Stanley. The Rise of Aggressive Abolitionism: Addresses to the Slaves. Lexington: University Press of Kentucky, 2004.

Hart, Francis Russell. The Siege and Capture of Havana, 1762. Boston: Houghton Mifflin, 1931.

Hartman, Saidiya and Julie Ellison. Scenes of Subjection: Terror, Slavery, and Self-Making in Nineteenth-Century America. New York: Oxford University Press, 1997.

Havard, John C. “Mary Peabody Mann's 'Juanita;' Cuba and Us National Identity.” Studies in the Novel 44, no. 2 (Summer 2012): 144-163.

Haynes, Sam. "Anglophobia and the Annexation of Texas: The Quest for National Security." In Manifest Destiny and Empire: American Antebellum Expansion, edited by Thomas Johannsen, 115-13. Austin: University of Texas Press, 1998.

-----. Unfinished Revolution: The Early American Republic in a British World. Charlottesville: University of Virginia Press, 2010.

-----. "Anglophobia and the Annexation of Texas: The Quest for National Security.” In Manifest Destiny and Empire, edited Sam Haynes and Christopher Morris, 115-145. College Station: University of Texas Press, 1997.

Heidler David S. and Jeanne T. Heidler. Henry Clay: The Essential American. New York: Random House, 2010.

Heitala, Thomas. Manifest Design: Anxious Aggrandizement in Late Jacksonian America. Ithaca: Cornell University Press, 1985.

Helg, Aline. Our Rightful Share: The Afro-Cuba Struggle for Equality, 1886-1912. Chapel Hill: University of North Carolina Press, 1995.

-----. "Simón Bolívar's Republic: A Bulwark against the 'Tyranny' of the Majority.” Revista de Sociologia e Política 20, no. 4 (June 2012): 21-37. 
-----. Liberty and Equality in Caribbean Colombia, 1770-1835. Chapel Hill: UNC Press, 2004.

----- "Race and Black Mobilization in Colonial and Early Independent Cuba: A Comparative Perspective." Ethnohistory 44, no. 1. (Winter 1997): 53-74.

Hemphill, W. Edwin, ed. The Papers of John C. Calhoun, Vol. VIII. Columbia, SC.: University of South Carolina Press, 1975.

Henderson, Gavin B. "Southern Designs on Cuba, 1854-1857 and Some European Opinions." The Journal of Southern History 5, no. 3. (August 1939): 371-385.

Henderson, John. "Considerations on The Constitutionality of The President's Proclamations." New Orleans: Daily Delta, 1854.

Henry, Ralph M. "Eric Williams and the Reversal of the Unequal Legacy of 'Capitalism and Slavery:"' Callaloo 20, no. 4, (Autumn 1997): 829-848.

Hernández, Juan Antonio. "Hacia Una Historia De Lo Imposible: La Revolución Haitiana Y El 'Libro De Pinturas' De José Antonio Aponte." PhD diss., University of Pittsburgh, 2005.

Hernández, Mario. "David Turnbull y el problema de la esclavitud en Cuba." Anuario de Estudios Americanos 14 (1957): 241-99.

Herrera, Airelys Campos and Lilian Grandal Pérez, "La Organización de la Información en la Etapa Colonial. Estudio de un Caso: La Biblioteca de la Sociedad Económica de Amigos del País." Revista Cubana de los Profesionales de la Información y la Comunicación en Salud 15, no. 1 (2007). Accessed May 24, 2012. http://bvs.sld.cu/revistas/aci/vol15_1_07/aci15107.htm.

Hershkowitz, Leo. “The Loco-Foco Party of New York: Its Origin and Career.” New York Historical Society Quarterly 46 (July 1962): 305-29.

Hettle, Wallace. The Peculiar Democracy: Southern Democrats in Peace and Civil War. Athens: University of Georgia Press, 2001.

Hewitt, Julia Cuero. Voices Out of Africa in Twentieth-Century Spanish Caribbean Literature. Lewisburg, PA: Bucknell University Press, 2009.

Heyrman, Christine Leigh. Southern Cross: The Beginnings of the Bible Belt. Chapel Hill: UNC Press, 1998.

Hickman Russell K., "Speculative Activities of the Emigrant Aid Company.” Kansas Historical Quarterly 4, no. 3 (August 1935): 235-267.

Hietala, Thomas R. Manifest Design: American Exceptionalism and Empire. Ithaca: Cornell University Press, 2003.

Hilkey, Judy. Character Is Capital: Success Manuals and Manhood in Gilded Age America. Chapel Hill: UNC Press, 1997.

Hirsch, Arnold R. and Joseph Logsdon, eds., Creole New Orleans: Race and Americanization. Baton Rouge: LSU Press, 1992.

Hippolyte-Manigat, Mirlande. Haiti and the Caribbean Community. Kingston: Jamaica: ISER, 1980.

Hochschild, Adam. Bury the Chains: The British Struggle to Abolish Slavery. London: Macmillan, 2005. 
Hofstadter, Richard. The Idea of a Party System: The Rise of Legitimate Opposition in the US 1780-1840. Oakland: University of Califonia Press, 1969.

Hoganson, Kristin. Fighting for American Manhood: How Gender Politics Provoked the Spanish-American and Philippine-American Wars. New Haven: Yale University Press, 2000.

Holeman, Jamie ““A Peculiar Character of Mildness:' The Image of a Humane Slavery in Nineteenth-Century Cuba." In Francisco Arango y la Invención de la Cuba Azucarera, edited by Maria Dolores GonzálezRipoll and Izaskun Álvarez Cuartero, 41-54. Salamanca: Ediciones Universidad de Salamanca, 2010.

Hollingsworth, C. "Cirilo Villaverde and Realism: The Theme of Slavery in Cecilia Valdes." Caribbean Studies 15, no. 4 (January 1976): 29-42.

Holt, Michael. The Rise and Fall of the American Whig Party: Jacksonian Politics and the Onset of the Civil War. Oxford: Oxford University Press, 2003.

----- The Fate of Their Country: Politicians, Slavery Extension, and the Coming of the Civil War. New York: Hill and Wang, 2005.

-----. Political Parties and American Political Development: From the Age of Jackson to the Age of Lincoln. Baton Rouge: LSU Press, 1992.

Horna, Hernán. Transport Modernization and Entrepreneurship in Nineteenth Century Colombia: Cisneros \& Friends. Uppsala, Sweden: University of Uppsala, 1992.

Horváth, Eugene. "Kossuth and Palmerston (1848-1849)." The Slavonic and East European Review 9, no. 27 (1931): 612-631.

Hoskins, Halford L. "The Hispanic American Policy of Henry Clay, 1816-1828." The Hispanic American Historical Review 7, no. 4 (November 1927): 460-478.

Hostetler, Michael. "The Early American Quest for Internal Improvements: Distance and Debate." Rhetorica: A Journal of the History of Rhetoric 29, no. 1 (Winter 2011): 53-75.

House of Commons, Great Britain. "Correspondence between the United States, Spain, and France, concerning alleged Projects of Conquest and Annexation of the Island of Cuba: Presented to both Houses of Commons, Apr. 1853." London: Harrison \& Son, 1853. Accessed on February 10, 2014. http://books.google.com /books /about/Correspondence_between_the_United_States.html?id=avpCAAAAcAAJ.

-----. Reports from Committees - Report from the Select Committee on Africa -Western Coast. London: British Publishing Office, 1865.

House of Commons Select Committee on the Extinction of Slavery Throughout the British Dominions, Great Britain. Analysis of The Report of a Committee of The House of Commons on The Extinction of Slavery. London: Committee on the Extinction of Slavery Society for the Abolition of Slavery Throughout British Dominions, 1833. Accessed January 17, 2014. http://books.google.com/books?id =97GRJQ8fS $\mathrm{cwC} \& p g=\mathrm{PP} 1 \# \mathrm{v}=$ onepage $\& \mathrm{q} \& \mathrm{f}=$ false.

Howard, Philip A. Changing History: Afro-Cuban Cabildo and Societies of Color in the Nineteenth Century. Baton Rouge: LSU Press, 1998.

Howe, Daniel Walker. What Hath God Wrought: The Transformation of America, 1815-1848. Oxford: Oxford University Press, 2009.

-----. The Political Culture of the American Whigs. Chicago: University of Chicago Press, 1984. 
Howe, Julia Ward. A Trip to Cuba. Boston: Ticknor and Fields, 1860.

Hopkins, James, ed. The Papers of Henry Clay, Vol. 4. Lexington, KT.: University of Kentucky, 1972.

Horsman, Reginald. Race and Manifest Destiny. Cambridge: Harvard University Press, 1981.

Howard, Philip. Changing History: Afro-Cuban Cabildos and Societies of Color in the Nineteenth Century. Baton Rouge: LSU Press, 1998.

Hu-Dehart, Evelyn. "Chinese Coolie Labor in Cuba in the Nineteenth Century: Free Labor of Neoslavery." Contributions in Black Studies: A Journal of African and Afro-American Studies: Special Section, Ethnicity, Gender, Culture \& Cuba 12, no. 1 (1994): 38-54.

Hudson, Linda S. Mistress of Manifest Destiny: A Biography of Jane McManus Storm Cazneau, 1807-1878. Houston: Texas State Historical Association, 2001.

Humboldt, Alexander von. The Island of Cuba. Trans. J.M. Thrasher. New York: Derby \& Sons, 1856.

-----. Ensayo Politico Sobre La Isla De Cuba. La Habana, Cultural S.A., 1959.

Hundley, D. R. Social Relations in Our Southern States. Accessed on May 20, 2013. http://docsouth.unc.edu/ southlit/ hundley/ hundley.html.

Hunt, Alfred. Haiti's Influence on Antebellum America: Slumbering Volcano in the Caribbean. Baton Rouge: LSU Press, 2006.

Hunt, Michael. Ideology and American Foreign Policy. New Haven: Yale University Press, 1987.

Hurston, James L. "Western Grains and the Panic of 1857.” Agricultural History 57, no. 1 (January 1983): 14-32.

-----. The Panic of 1857 and the Coming of the Civil War. Baton Rouge: LSU Press, 1999.

Huzzey, Richard. Freedom Burning: Anti-Slavery and Empire in Victorian Britain. Ithaca: Cornell University Press, 2012.

Iannini, Christopher. Fatal Revolutions: Natural History, West Indian Slavery, and the Routes of American Literature. Chapel Hill: UNC Press, 2012.

Ibarra, Otto Olivera. "La poesía del 'Papel Periódico de la Habana." Revista Iberoamericana 11, no. 22 (October 1946): 259-272.

Iceland, Harry. The Motives of Gaspar Betancourt Cisneros, 1830-1866, for Advocating Cuba's Annexation to the United States. New York: Harper, 1965.

Ingrassia, Brian. "'From the New World to the Old and Back Again:' Whig University Leaders and Trans-Atlantic Nationalism in the Era of 1848." Journal of the Early Republic 32, no. 1 (Winter 2012): 668-692.

Irwin, Douglas. "Free Trade and Protection in Nineteenth Century Britain and France Revisited: A Comment on Nye." The Journal of Economic History 53, no. 1 (March 1993): 146-152.

Jackson, Richard. "Slavery, Racism and Autobiography in Two Early Black Writers: Juan Francisco Manzano and Martín Morúa Delgado." In Voice from Under: Black Narrative in Latin America and the Caribbean, edited by William Luis, 55-64. Hartford: Greenwood, 1984.

Jacobson, Matthew Frye. Barbarian Virtues: The United States Encounters Foreign Peoples at Home and Abroad, 1876-1917. Chicago: University of Chicago Press, 1996.

Jaenicke, Douglas W. "The Rupture of the Antebellum Democratic Party: Prelude to Southern Secession from the 
Union." Party Politics 1, no. 3 (Fall 1995): 347-367.

James, C.L.R. The Black Jacobins: Toussaint L'Ouverture and the San Domingo Revolution. New York: Vintage Books, 1963.

James, Charles. "The Production and Manufacture of Cotton: with Reference to Its Manufacture in the Cotton Growing States.” In Merchants' Magazine and Commercial Review, XXI (1849). Accessed May 23, 2013. http://books.google.com/books?id=iKARAAAAYAAJ\&pg=PP1\#v=onepage \&q\&f=false.

James, Edmund B. The Origin of the Land Grant Act of 1862: (the so-called Morrill Act) and Some Account of Its Author, Jonathan B. Turner. Urbana: University of Illinois Press, 1910. Accessed December 12, 2013. http://archive.org/details/originoflandgran00jame;

Jay, W.M.L. My winter in Cuba. New York: E. P. Button \& Co, 1871.

Jefferson, Thomas. The Works of Thomas Jefferson, Federal Edition. New York and London: G.P. Putnam \& Sons, 1904-5. Accessed on September 9, 2010. http://oll.libertyfund.org/ title/806/87618.

Jennings, Evelyn Powell. "War as the "Forcing House of Change:" State Slavery in Late-Eighteenth-Century Cuba." The William and Mary Quarterly 62, no. 3 (July 2005): 411-440.

-----. "State Slavery in the Atlantic Economy: The Case of Cuba in the late Eighteenth Century." Conference of the Program in Early American Economy and Society, Library Company of Philadelphia, September 2003.

Jensen, Larry. Children of Colonial Despotism: Press, Politics, and Culture in Cuba, 1790-1840. Tampa, FL: University Presses of Florida, 1988.

Jentz, John. "The 48ers and the Politics of the German Labor Movement in Chicago during the Civil War Era: Community Formation and the Rise of a Labor Press." In The German-American Radical Press: The Shaping of a Left Political Culture, 1850-1940, edited by Elliot Shore, Ken Fones-Wolf and James Philip Danky, 49-62. Urbana: University of Illinois Press, 1992.

Johannsen, Robert Walter. Stephen A. Douglas. Urbana: University of Illinois Press, 1973.

----. "Young America and the War with Mexico." In Dueling Eagles: Reinterpreting the U.S.-Mexican War, 184648, edited by Richard Francaviglia and Douglas Richmond, 155-175. Fort Worth: Texas Christian University Press, 2000.

Johnson, Eldon L. "Misconceptions about the Early Land-Grant Colleges." The Journal of Higher Education 52, no. 4 (July-August 1981): 333-351.

Johnson, John. A Hemisphere Apart: The Foundations of United States Policy Toward Latin America. Baltimore; Johns Hopkins Press, 1990.

Johnson, Paul E.A Shopkeeper's Millennium: Society and Revivals in Rochester, New York, 1815-1837. New York: Hill and Wang, 1978.

Johnson, Samuel. "The New England Emigrant Aid Company.” PhD diss., University of Wisconsin, 1935.

Johnson, Sherry. The Social Transformation of Eighteenth-Century Cuba. Gainesville: University of Florida Press, 2001.

----. "Climate, Community, and Commerce among Florida, Cuba, and the Atlantic World, 1784-1800. The Florida Historical Quarterly 80, no. 4 (Spring 2002): 455-482.

----. "La Guerra Contra los Habitantes de los Arrabales:” Changing Patterns of Land Use and Land Tenancy in and 
around Havana, 1763-1800.” Hispanic American Historical Review 77, no. 2 (May 1997): 181-209.

-----. "The Rise and Fall of Creole Participation in the Cuban Slave Trade, 1789-1796." Cuban Studies 30 (2000): $52-78$.

-----. Climate and Catastrophe in Cuba and the Atlantic World in the Age of Revolution. Chapel Hill: University of North Carolina Press, 2011.

-----. The Social Transformation of Eighteenth Century Cuba. Gainesville: University Press of Florida, 2001.

-----. “'La Guerra Contra los Habitantes de los Arrabales:' Changing Patterns of Land Use and Land Tenancy in and Around Havana, 1763-1800.” Hispanic American Historical Review 77, no. 2 (Spring 1997): 181-209.

Johnson, Walter. “On Agency.” Journal of Social History 37, no. 1 (Fall 2003): 113-124.

-----. Soul by Soul: Life Inside the Antebellum Slave Market. Cambridge: Harvard University Press, 2001.

----- River of Dark Dreams: Slavery and Empire in the Cotton Kingdom. Cambridge: Harvard University Press, 2013.

Jones, Alexander. Cuba in 1851. New York: Stringer \&Townshend, 1851.

Joseph, Yvon. Four French Travelers in Nineteenth Century Cuba. New York: Peter Lang, 2008.

Jung, Moon-Ho. Coolies and Cane: Race, Labor, and Sugar in the Age of Emancipation. Baltimore: JHU Press, 2009.

Jusserand, Jean Jules. With Americans of Past and Present Days. New York: Scribner's \& Sons, 1915.

Kadish, Doris ed. Slavery in the Caribbean Francophone World: Distant Voices, Forgotten Acts, Forged Identities. Athens: University of Georgia Press, 2000.

Kagan, Robert. Dangerous Nation: America's Place in the World, from its Earliest Days to the Dawn of the 20th Century. New York: Knopf, 1996.

Kanellos, Nicolás. "A Brief History of Hispanic Periodicals in the United States." In Hispanic Periodicals in the United States, Origins to 1960: A Brief History and Comprehensive Bibliography, edited by Nicolás Kanellos, 1-100. Houston: Arte Público Press, 2000.

Kaplan, Amy. The Anarchy of Empire in the Making of U.S. Culture. Cambridge: Harvard University Press, 2005.

-----. "Manifest Domesticity.” American Literature 70, No. 3, (September 1998): 581-606.

Kastor, Peter. The Nation's Crucible: The Louisiana Purchase and the Creation of America. New Haven: Yale University Press, 2004.

Kaufmann, William W. British Policy and the Independence of Latin America, 1804-1828. London: Taylor \& Francis, 1967

Kaye, Anthony E. "The Second Slavery: Modernity in the Nineteenth-Century South and the Atlantic World." Journal of Southern History 75 (August 2009): 627-650.

Keehn, David C. Knights of the Golden Circle: Secret Empire, Southern Secession, Civil War. Baton Rouge: Louisiana State University Press, 2013.

Kelley, Mary. Private Woman, Public Stage: Literary Domesticity in Nineteenth-Century America. New York: 
Oxford University Press, 1984.

Kelly, Morgan and Cormac Ó Gráda. "Market Contagion: Evidence from the Panics of 1854 and 1857.” The American Economic Review 90, no. 5 (December 2000): 1110-1124.

Kempf, Arlo. "The Production of Racial Logic in Cuban Education: An Anti-Colonial Approach.” PhD diss., University of Toronto, 2010.

Kent, Jacquelyn Briggs. "The Enlightenment and Spanish Colonial Administration: The Life and Myth of Alejandro Ramirez y Blanco in Guatemala, Puerto Rico, and Cuba 1777-1821.” PhD diss., Tulane University, 1997.

Kerrigan, William T. “'Young America!' Romantic Nationalism in Literature and Politics, 1843-1861.” PhD diss., University of Michigan, 1997.

Kilbourne, Richard. Slave Agriculture and Financial Markets in Antebellum America: The Bank of the United States in Mississippi 1831-1852. London: Pickering \& Chatto, 2006.

Kimball, Eric. “'An Essential Link, in a Vast Chain': New England and the West Indies, 1700-1775.” PhD diss., University of Pittsburgh, 2009.

Kimball, Richard B. Cuba and the Cubans. New York: S. Hueston, 1850.

Kiple, Kenneth F. Blacks in Colonial Cuba, 1774-1899. Gainesville: University Press of Florida, 1976.

Klein, Herbert S. “Colored Militia of Cuba.” Caribbean Studies 6, no. 2 (June 1966): 17-27.

----- "Consideraciones sobre la viabilidad de la esclavitud y las causas de la abolición en la Cuba del siglo XIX." La Torre 21, (1973): 307-15.

-----. Slavery in the Americas: A Comparative Study of Virginia and Cuba. Chicago: University of Chicago Press, 1967.

Klement, Frank. Dark Lanterns: Secret Political Societies, Conspiracies, and Treason Trials in the Civil War. Baton Rouge: LSU press, 1984.

Klingberg, Frank Joseph. The Anti-Slavery Movement in England: A Study in English Humanitarianism. New York: Archon Books, 1968.

Klupffel, Yarini. Cólera.. Accessed June 26, 2011. http://en.wikiversity.org/wiki/C\%C3\%B3lera_en_el_Ingenio.

Knight, Franklin W. Slave Society in Cuba during the Nineteenth Century. Madison: University of Wisconsin Press, 1970.

----. "The Free Colored Population in Cuba during the Nineteenth Century." In Sugar Without Slavery: Diversity in Caribbean Economy and Society Since the $17^{\text {th }}$ Century, edited by Verene A. Shepard, 220-240.

Gainesville: University Press of Florida, 2002.

----. "Origins of Wealth and the Sugar Revolution in Cuba, 1750-1850." Hispanic American Historical Review 57, no. 2 (May 1977): 231-53.

----- The Caribbean: The Genesis of a Fragmented Nationalism. New York: Oxford University Press, 1990.

----- "The Caribbean in the Age of Enlightenment, 1788-1848," in A Companion to Latin American Literature and Culture, edited by Sara Castro-Klaren, 228-246. San Francisco: Blackwell, 2008.

Knight, Franklin and Peggy Liss, eds. Atlantic Port Cities: Economy, Culture, and Society in the Atlantic 
World 1650-1850. Knoxville: University of Tennessee Press, 1991.

Komlos, John. Louis Kossuth in American 1851-52. Buffalo: East Europe Institute, 1973.

Korn, Bertram. “Jewish 48'ers in America.” American Jewish Archives, (June 1949): 3-18.

Kukla, Jon. A Wilderness So Immense: The Louisiana Purchase and the Destiny of America. New York: Anchor, 2004.

Kuethe, Allan J. Cuba, I753-1815: Crown, Military, and Society. Knoxville: University of Tennessee Press, 1986.

----- "Guns, Subsidies and Commercial Privilege: Some Historical Factors in the Emergence of the Cuban National Character 1763-1815." Cuban Studies 16 (1986): 123-38.

-----. "The Development of the Cuban Military as a Socio-Political Elite, 1763-1783." Hispanic American Historical Review 61, no. 4 (November 1981): 695-704.

-----. "Los Llorones Cubanos: The Socio-Military Basis of Commercial Privilege in the American Trade under Charles IV." In The North American Role in the Spanish Imperial Economy, 1760-1819, edited by Jacques A. Barbier and Allan J. Kuethe, 142-157. Manchester: Manchester University Press, 1984.

-----. "Havana in the Eighteenth Century." In Atlantic Port Cities: Economy, Culture, and Society in the Atlantic World 1650-1850, edited by Franklin Knight and Peggy Liss, 13-40. Knoxville: University of Tennessee Press, 1991.

Kuethe, Alan J. and G. Douglas Iglis. "Absolutism and Enlightened Reform: Charles III, The Establishment of the Alcabala and Commercial Reorganization in Cuba." Past and Present, A Journal of Historical Studies, 109 (November 1985): 118-143.

Kushner, Howard. Conflict on the Northwest Coast: American-Russian Rivalry in the Pacific Northwest. 1790-1867 Westport, Conn.: Greenwood Press, 1975.

Kutzinski, Vera M. Political Essay on the Island of Cuba: A Critical Edition. Chicago: University of Chicago Press, 2010.

-----. "Translations of Cuba: Fernando Ortiz, Alexander von Humboldt, and the Curious Case of John Sidney Thrasher." Atlantic Studies Literary, Cultural and Historical Perspectives 6, no. 3 (Fall 2009): 303-26.

-----. Sugar's Secrets: Race and the Erotics of Cuban Nationalism. Charlottesville: University of Virginia Press, 1993.

Labarre, Roland. "La conspiración de 1844: un complot por lo menos dudoso y una atroz maquinación.” Anuario de Estudios Americanos 43 (1986): 127-41.

Lachance, Paul F. "The 1809 Immigration of Saint-Domingue Refugees to New Orleans: Reception, Integration and Impact." Louisiana History: The Journal of the Louisiana Historical Association 29, no. 2 (Spring 1988): 109-141.

LaFeber, Walter, ed. John Quincy Adams and American Continental Empire: Letters, Papers, and Speeches. Chicago: Quadrangle Books, 1965).

Lai, Walton Look. Indentured Labor, Caribbean Sugar: Chinese and Indian Migrants to the British West Indies, 1838-1918. Baltimore: JHU Press, 1993.

Lajara, Edelberto Leiva. Los Dominicos En La Habana. Convento Y Sociedad, 1578-1842. Havana: Ediciones de la Oficina del Historiador de la Ciudad, Editorial Boloña, 2007. 
Lamp, Kimberly. "Empire for Slavery: Economic and Territorial Expansion in the American Gulf-South, 18351860.” PhD diss., Harvard University, 1991.

Lamoreaux, Naomi. "Rethinking the Transition to Capitalism in the Early American Northeast." The Journal of American History 90, no. 2, (September 2003): 437-461.

Lampros, Peter J. "Merchant-Planter Cooperation and Conflict: The Havana Consulado, 1794-1832." PhD diss., Tulane University, 1980.

Landers, Jane. Black Society in Spanish Florida. Urbana: University of Illinois Press, 1999.

-----. Atlantic Creoles in the Age of Revolution. Cambridge: Harvard University Press, 2010.

Lane, Jill. “Blackface Nationalism, Cuba 1840-1868.” Theatre Journal 50, no. 1 (March 1998): 21-38.

Lang, Daniel and Greg Russell. "The Ethics of Power in American Diplomacy: The Statecraft of John Quincy Adams." The Review of Politics 52, no. 1 (Winter 1990): 3-31.

Langley, Lester. The Americas in the Age of Revolution, 1750-1850. New Haven: Yale University Press, 1996.

----. "Slavery, Reform, and American policy in Cuba, 1823-1878." Revista de Historia de América 65/66 (JanuaryDecember 1968): 71-84.

-----. "The Whigs and the López Expeditions to Cuba, 1849-1851: A Chapter in Frustrating Diplomacy.” Revista de Historia de América 71 (January-June 1971): 9-22.

Larson, John. The Market Revolution in American: Liberty, Ambition and the Eclipse of the Common Good. Cambridge: Cambridge University Press, 2010.

-----. Internal Improvement: National Public Works and the Promise of Popular Government in the Early United States. Chapel Hill: University of North Carolina Press, 2000.

Lasso, Marixa. "Race, War and Nation in Caribbean Gran Colombia, Cartagena, 1810-1832." American Historical Review 111, no. 2 (April 2006): 336-61.

----- "Revisiting Independence Day: Afro-Colombian Politics and Patriot Narratives, Cartagena, 1809-1815." In After Spanish Rule: Postcolonial Predicaments of the Americas, edited by Andrés Guerrero and Mark Thurner, 223-247. Durham: Duke University Press, 2003.

----- "Haiti as an Image of Popular Republicanism in Caribbean Colombia, Cartagena Province (1811-1828).” In The Impact of the Haitian Revolution in the Atlantic World, edited by David Geggus, 176-190. Columbia, SC: University of South Carolina Press, 2001.

-----. Myths of Harmony: Race and Republicanism during the Age of Revolution, Colombia 1795-1831. Pittsburgh: University of Pittsburgh Press, August 2007.

Review 26, no. 1 (January 2003): 63-80.

Lause, Mark. Young America: Land, Labor, and the Republican Community. Chicago: University of Illinois Press, 2005.

Lawson Gary and Guy Seidman. The Constitution of Empire: Territorial Expansion and American Legal History. New Haven: Yale University Press, 2008.

Lawson, Melinda. Patriot Fires: Forging a New American Nationalism in the Civil War North. Lawrence: University of Kansas Press, 2002. 
Lazo, Rodrigo. "Los Filibusteros: Cuban Writers in the United States and Deterritorialized Print Culture." American Literary History 15, no. 1 (Spring 2003): 87-106.

----- "Filibustering Cuba: Cecilia Valdés and a Memory of Nation in the Americas." American Literature 74 (March 2002): 1-30.

-----. Writing to Cuba: Filibustering and Cuban Exiles in the United States. Chapel Hill: University of North Carolina Press, 2005.

----- "A Man of Action: Cirilo Villaverde as Transatlantic Revolution Writer.” In Recovering the U.S. Hispanic Literary Heritage, Volume 3, edited by Ramón A. Gutiérrez, Genaro M. Padilla, and María Herrera-Sobek, 315-331. Houston: Arte Publico Press, 1993.

le Riverend, Julio. An Economic History of Cuba. Havana: Ensayo Book Institute, 1967.

Leary, John Patrick. "Cuba in the American Imaginary: Literature and National Culture in Cuba and the United States, 1848-1958." PhD diss., New York University, 2009.

Lee, Erika. “"The Yellow Peril' and Asian Exclusion in the Americas.” Pacific Historical Review 76, no. 4 (November, 2007): 537- 562.

LeMenager, Stephanie. Manifest and Other Destinies: Territorial Fictions of the Nineteenth-Century United States. Lincoln: University of Nebraska Press, 2004.

Leopold, Richard W. The Growth of American Foreign Policy: A History. New York: Knopf, 1962.

Lepler, Jessica. The Many Panics of 1837: People, Politics and the Creation of a TransAtlantic Financial Crisis. Cambridge: Cambridge University Press, 2013.

Levine, Bruce. Half Slave and Half Free: The Roots of Civil War. New York: Hill and Wang, 1992.

-----. The Spirit of 1848: German Immigrants, Labor Conflict, and the Coming of the Civil War. Urbana: University of Illinois Press, 1992.

Levis, Richard. Diary of a Spring Holiday in Cuba. Philadelphia: Porter and Coates, 1872.

Lewis, Charles Lee. Admiral de Grasse and American Independence. Boston: Ayers \& co, 1945.

Lewis, James Allen. "New Spain during the American Revolution, 1779-1783: A Viceroyalty at War." PhD diss., Duke University, 1975.

Lewis, James L. The American Union and the Problem of Neighborhood: The United States and the Collapse of the Spanish Empire, 1783-1829. Chapel Hill: University of North Carolina Press, 1998.

Lewis, James A. "Anglo-American Entrepreneurs in Havana: The Background and Significance of the Expulsion of 1784-1785." In The North American Role in the Spanish Imperial Economy 1760-1819, edited by Jacques Barbier and Allan Kuethe, 112-126. Manchester: Manchester University Press, 1984.

Libby, David J. Slavery and Frontier Mississippi, 1720-1835. Jackson: University of Mississippi Press, 2004.

Lightfoot, Natasha. "Race, Class and Resistance: Emancipation and Its Aftermath in Antigua, 1831-1858.” PhD diss., New York University, 2007.

Lincoln, Abraham. "Second Lecture on Discoveries and Inventions before the Phil Alpha Society at Illinois College, Jacksonville, Illinois, February 11, 1859.” Accessed February 15, 2012. http://www.abrahamlincolnonline. 
org/ lincoln/ speeches/ discoveries.htm.

Lipsey, Robert E. "U.S. Foreign Trade and the Balance of Payments, 1800-1913." in Cambridge Economic History of the United States, Vol. II, edited by Stanley Engerman and Robert Gallman, 685-732. New York: Cambridge University Press, 2000.

Liss, Peggy. Atlantic Empires: The Network of Trade and Revolution, 1713-1826. Baltimore: Johns Hopkins University, 1982.

Llaverías, Joaquín. La comisión militar Ejecutiva y Permanente de la Isla de Cuba. Havana: A. Muñiz y hno, 1929.

Lloyd, Christopher. The Navy and the Slave Trade: The Suppression of the African Slave Trade in the Nineteenth Century. London: Cass Publishing 1968.

Lloyd, E.M. “Canning and Spanish America.” Transactions of the Royal Historical Society 18 (1904): 77-105.

Lockey, Joseph Byrne. Pan-Americanism-Its Beginnings. New York: Macmillan Company, 1920.

Lockley, Tim. Lines in the Sand: Race and Class in Lowcountry Georgia 1750-1860. Athens: University of Georgia Press, 2004.

Logan, Rayford. The Diplomatic Relations of the United States with Haiti, 1766-1892. Chapel Hill: UNC Press, 1941.

Long, James Weldon. "Revolutionary Republics: U.S. National Narratives and the Independence of Latin America, 1810-1846.” PhD diss., Louisiana State University, 2011.

Loughran, Trish. The Republic in Print: Print Culture in the Age of U.S. Nation Building, 1770-1870. New York: Columbia University Press, 2007.

Lubrich, Oliver. "In the Realm of Ambivalence: Alexander von Humboldt's Discourse on Cuba." German Studies Review 26, no. 1 (February 2003): 63-80.

Lugones, Maria. "The Coloniality of Gender." Worlds \& Knowledges Otherwise, (Spring 2008): 1-16.

Luis, William. Literary Bondage: Slavery in Cuban Narrative. Austin: University of Texas Press, 1990.

Luis-Brown, David. "Slave Rebellion and the Conundrum of Cosmopolitanism: Plácido and La Escalera in a Neglected Cuban Antislavery Novel by Orihuela.” Atlantic Studies 9, Issue 2 (Spring 2012): 209-230.

-----. "An 1848 for the Americans: The Black Atlantic, 'El Negro Martir' and Cuban Exile Anticolonialism in New York City.” American Literary History 21, no. 3 (Fall 2009): 431-460.

-----. Waves of Decolonization: Discourses of Race and Hemispheric Citizenship in Cuba, Mexico and the United States. Durham: Duke University Press, 2008.

Lukasik, Christopher. Discerning Characters: The Culture of Appearance in Early America. Philadelphia: University of Pennsylvania Press, 2010.

Lull, Francisco Ferrer and J. Hefter, “The Spanish Louisiana Regiment in the Floridas 1779-1781.” Military Collector and Historian 16 (Fall 1964): 79-80.

Lundy, Benjamin. The War in Texas: A Review of Facts and Circumstances, Showing That This Contest Is a Crusade Against Mexico. New York: Merrihew and Gunn, 1837).

Lussana, Sergio. "To See Who Was Best on the Plantation: Enslaved Fighting Contests and Masculinity in the 
Antebellum Plantation South.” The Journal of Southern History 76, no. 4 (November 2010): 901-940.

Lux, William. "French Colonization in Cuba, 1791-1809.” The Americas 29, no. 1 (July 1972): 57-62.

Lynch, John. "Bolivar and the Caudillos." The Hispanic American Historical Review 63, no. 1 (February 1983): 335.

-----. “British Policy and Spanish America, 1783-1808.” Journal of Latin American Studies 1, no. 1 (May 1969): 130.

MacDonald, Victoria-María. Latino Education in The United States: A Narrated History From 1513-2000. New York: Palgrave Macmillan, 2004.

Madden, Richard, ed. Poems by a Slave in The Island of Cuba, Recently Liberated; Translated From The Spanish, By R. R. Madden, M.D., With The History of The Early Life of The Negro Poet, Written By Himself; To Which Are Prefixed Two Pieces Descriptive of Cuban Slavery And The Slave-Traffic, by R. R. M. London, Ward \& Co., 1840. Accessed January 17, 2014. http://docsouth.unc.edu/neh/manzano/menu.html.

-----. The Island Of Cuba: Its Resources, Progress, and Prospects, Considered In Relation Especially To The Influence of Its Prosperity on the Interests of the British West India Colonies. London: C. Gilpin, 1849. Accessed January 17, 2014. http://catalog.hathitrust.org/Record/001447268.

Maestri, Raúl. Arango y Parreño, El Estadista Sin Estado. Havana: Cuba, Publicaciones de la Secretaria de Educación, 1937.

Magness, Phillip W. and Sebastian N. Page. Colonization after Emancipation: Lincoln and the Movement for Black Resettlement. Columbia: University of Missouri Press, 2011.

Magnuson, Lynnea. "In the Service of Columbia: Gendered Politics and Manifest Destiny Expansion." PhD diss., University of Illinois, 2001.

Magro, Ángel Bahamonde and José Gregorio Cayuela Fernández. "La Creación de Nobleza en Cuba Durante El Siglo XIX.” Historia Social 11 (Autumn 1991): 56-82.

Majewski, John. Modernizing a Slave Economy: The Economic Vision of the Confederate Nation. Chapel Hill: University of North Carolina Press, 2009.

Malanson, Jeffrey. "The Congressional Debate over U.S. Participation in the Congress of Panama, 1825-1826: Washington's Farewell Address, Monroe's Doctrine and the Fundamental Principles of U.S. Foreign Policy.” Diplomatic History 30, no. 5 (Winter 2006): 813-838.

Mallory, Daniel, ed. The Life and Speeches of the Honorable Henry Clay, Vol. 1. New York: Robert Bixby \& Co., 1843.

Mancini, Matthew. Alexis de Tocqueville and American Intellectuals: From His Times to Ours. New York: Rowman \& Littlefield, 2006.

Manegold, C.S. Ten Hills Farm: The Forgotten History of Slavery in the North. Princeton: Princeton University Press, 2010.

Manganelli, Kimberly Snyder. Transatlantic Spectacles of Race: The Tragic Mulatta and the Tragic Muse. New Brunswick: Rutgers University Press, 2012.

Mann, Bruce H. Republic of Debtors: Bankruptcy in the Age of American Independence. Cambridge: Harvard University Press, 2009. 
Manning, William. Early Diplomatic Relations between the United States and Mexico. Baltimore: Johns Hopkins Press, 1916.

Manning, William, ed. Diplomatic Correspondence of the United States: Inter-American Affairs, 1831-1860, Vol. 11. Washington: Carnegie Endowment for International Peace, 1932-39.

Manzano, José M. Aguilera. “The Informal Communication Network Built by Domingo Del Monte from Havana between 1824 and 1845." Caribbean Studies 37, no. 1 (January-June 2009): 67-96.

-----. La formación de la identidad cubana: el debate Saco-La Sagra. Havana: Editorial CSIC Press, 2005.

Margaret Olsen, "Manzano's Zafira and the Performance of Cuban Nationhood." Hispanic Review (Spring 2007): 135-158.

Maria de Labra, Rafael. La brutalidad de los negros. Havana: University of Havana, 1961.

Marichal, Carlos. Bankruptcy of Empire: Mexican Silver and the Wars between Spain, Britain and France, 1760 1810. Cambridge: Cambridge University Press, 2007.

Marques, Leonardo. "Slave Trading in a New World: The Strategies of North American Slave Traders in the Age of Abolition." Journal of the Early Republic, Volume 32, no. 2 (Summer 2012): 233-26.

Marques, João Pedro, Seymour Drescher, and P. C. Emmer. Who Abolished Slavery: Slave Revolts and Abolitionism: A Debate with João Pedro Marques. New York: Berghahn Books, 2010.

Márquez, José. Plácido y los conspiradores de 1844. Havana: Impresion la Constancia, 1894.

Marquese, Rafael de Bivar. "African Diaspora, Slavery, and the Paraiba Valley Coffee Plantation Landscape." Nineteenth-Century Brazil." Review: A Journal of the Fernand Braudel Center 31, no. 2 (2008): 195-215.

-----. Administração e escravidão: Idéias sobre a gestão da agricultura escravista brasileira. São Paulo: Editora Hucitec/Fapesp, 1999.

----- Feitores do corpo, missionários da mente: Senhores, letrados e o controle dos escravos nas Américas, 16601860. São Paulo: Companhia das Letras, 2004.

Marquese, Rafael de Bivar and Marcia Regina Berbel. "The Absence of Race: Slavery, Citizenship, and Pro-slavery Ideology in the Cortes of Lisbon and in the Constitutional Assembly of Rio de Janeiro (1821-1824)." Social History 32, no. 4 (2007): 415-433.

Marraro, Dennis. American Opinion on the Unification of Italy, 1846-1861. New York: Columbia University Press, 1932.

Marrs, Aaron. Railroads in the Old South: Pursuing Progress in a Slave Society. Baltimore: Johns Hopkins University Press, 2009.

Marsden, George M. The Soul of the American University: From Protestant Establishment to Established Nonbelief. New York: Oxford University Press, 1994.

Marshall, Bill. The French Atlantic: Travels in Culture and History. Liverpool: Liverpool University Press, 2009.

Marshall, John. McCulloch v. Maryland, March 6, 1819. Accessed March 14, 2011. http://law2.umkc.edu/ faculty/projects/ftrials/conlaw/mcculloch.html.

Martin, Bonnie. "Slavery’s Invisible Engine: Mortgaging Human Property." The Journal of Southern History 76, no. 4 (November 2010): 817-843. 
Martínez, Urbano. Domingo del Monte y su tiempo. Havana: Ediciones Unión, 1997.

Martínez-Alier, Verena. Marriage, Class and Colour in Nineteenth-Century Cuba: A Study of Racial Attitudes and Sexual Values in a Slave Society. Ann Arbor: University of Michigan, 1989.

Martínez-Fernández, Luis. "The Havana Anglo-Spanish Mixed Commission for the Suppression of the Slave Trade and Cuba's Emancipados.” Slavery and Abolition 16, no. 2 (June 1995): 205-25.

----. Fighting Slavery in the Caribbean: The Life and Times of a British Family in Nineteenth-century Havana. New York: M.E. Sharpe, 1998.

----. “The Hispanic Caribbean between Empires, 1840-1868.” PhD diss., Duke University, 1990.

-----. Torn between Empires: Economy, Society, and Patterns of Political Thought in the Hispanic Caribbean, 18401878. Athens: University of Georgia Press, 1994.

-----. "The Sweet and the Bitter: Cuban and Puerto Rican Responses to the Mid-Nineteenth-Century Sugar Challenge." New West Indian Guide 67, nos. 1/2 (1993): 47-67.

-----. "Life in A "Male City:" Native and Foreign Elite Women in Nineteenth-Century Havana/Mujeres En Una "Ciudad Masculina;" La Vida Cotidiana De Las Mujeres De Las Clases Altas En La Habana Del Siglo Diecinueve.” Cuban Studies 25 (1995): 27-49.

Massachusetts Emigrant Aid Co. "The Report of the Committee of the Massachusetts Emigrant Aid Society with the Act of Incorporation.” Accessed March 7, 2014. http://www.kancoll.org/books/emig_aid/emigrant.htm.

Matibag, Eugenio. Haitian-Dominican Counterpoint: Nation, State, and Race on Hispaniola. New York: Macmillan, 2003.

Matthewson, Tim. A Proslavery Foreign Policy: Haitian-American Relations during the Early Republic. Westport: Praeger, 2003.

May, Robert. John A. Quitman: Old South Crusader. Baton Rouge: LSU Press, 1985.

----- “The Slave Power Conspiracy Revisited: United States Presidents and Filibustering 1848-1861.” in Union \& Emancipation: Essays on Politics and Race in the Civil War Era, edited by David W. Blight and Brooks D. Simpson, 7-29. Kent, Ohio: Kent State University Press, 1997.

-----. “Lobbyists for Commercial Empire; Jane Cazneau, William Cazneau, and US Caribbean Policy, 1846-1878.” Pacific Historical Review 48, no. 3 (August 1979): 383-412.

-----. The Southern Dream of a Caribbean Empire, 1854-1861. Baton Rouge: LSU Press, 1973.

----. Slavery, Race, and Conquest in the Tropics: Lincoln, Douglas, and the Future of Latin America. New York: Cambridge University Press, 2013.

----. "Epilogue to the Missouri Compromise: The South, The Balance of Power, and the Tropics in the 1850s." Plantation Society 1, no.1 (June 1979): 201-225.

-----. "The Domestic Consequences of American Imperialism: Filibustering and Howard Pyle's Pirates," American Studies 46, no. 2 (Summer 2005): 37-61.

----. “Reconsidering Antebellum U.S. Women's History: Gender, Filibustering, and American's Quest for Empire." American Quarterly 57, No. 4 (December 2005): 1155-1188.

-----. "Young American Males and Filibustering in the Age of Manifest Destiny: The United States Army as 
Cultural Mirror,"

-----. Manifest Destiny's Underworld: Filibustering in Antebellum America. Chapel Hill: University of North Carolina Press, 2002.

-----. The Making of the Monroe Doctrine. Cambridge: Harvard University Press, 1975.

McCardell, John. The Idea of a Southern Nation: Southern Nationalists and Southern Nationalism, 1830-1860. New York: W.W. Norton, 1979.

McClellan, James E. Colonialism and Science: Saint Domingue in the Old Regime. Baltimore: Johns Hopkins University Press, 1992.

McClintock, Anne. Imperial Leather: Race, Gender, and Sexuality in the Colonial Contest. New York: Routledge, 1995.

McCurry, Stephanie. Confederate Reckoning: Power and Politics in the Civil War South. Cambridge: Harvard University Press, 2010.

-----. Masters of Small Worlds: Yeoman Households, Gender Relations, and the Political Culture of the Antebellum South Carolina Low Country. New York: Oxford University Press, 1997.

McCusker, John. "The Economy of the British West Indies, 1763-1790." In Essays in the Economic History of the Atlantic World, edited by John J. McCusker, 310-330. London: Routledge, 1997.

McDaniel, W. Caleb. “'Our Country is the World:' American Abolitionists, Louis Kossuth, and Philanthropic Revolutions.” The Johns Hopkins University Annual Meeting of the OAH, March 25, 2004.

McDermott, John Francis, ed. The Spanish in the Mississippi Valley 1762-1784. Urbana: University of Illinois Press, 1974.

McFadden, David W. “John Quincy Adams, American Commercial Diplomacy, and Russia, 1809-1825.” The New England Quarterly 66, no. 4 (December 1993): 613-629.

McLeod, Marc. "Undesirable Aliens: Haitian and British West Indian Immigrant Workers in Cuba, 1898 to 1940." PhD diss., University of Texas at Austin, 2000.

McMichael, Andrew. "The Kemper Rebellion: Filibustering and Resident Anglo American Loyalty in Spanish West Florida." The Journal of the Louisiana Historical Association 43, No. 2 (Spring 2002): 133-165.

McMillan David W. and David M. Chavis George. "Sense of Community: A Definition and Theory." Journal of Community Psychology 14, (January 1986): 6-23.

McNeill, J. R. Atlantic Empires of France and Spain, Louisbourg and Havana 1700-1763. Chapel Hill and London: University of North Carolina Press, 1985.

McPherson, Edward. The Political History of the United States, During the Great Rebellion. Washington DC: James Chapman, 1882.

Melish, Joanne Pope. Disowning Slavery: Gradual Emancipation and Race in New England, 1780-1860. Ithaca: Cornell University Press, 1998.

Melton, Buckner. Aaron Burr: Conspiracy to Treason. New York: Wiley \& Sons, 2002.

Melville, Herman. Billy Budd, Sailor and Other Stories. New York: Penguin, 1986. 
Mena, Luz. "Stretching the Limits of Gendered Spaces: Black and Mulatto Women in 1830s Havana." Cuban Studies 36 (2005): 87-104.

Menand, Louis. The Metaphysical Club: A Story of Ideas in America. New York: Farrar, Straus, and Giroux, 2001.

Menocal, Raul, ed. El Sesquicentenario del Papel Periodico de la Havana 1790-1940. Havana: Municipio de la Habana, 1941. Accessed on May 23, 2012. http://ufdc.ufl.edu/UF00074127/00001.

Merk, Frederick. Manifest Destiny and Mission in American History: A Reinterpretation. New York: Alfred A. Knopf, 1963.

-----. “A Safety Valve Thesis and Texan Annexation.” Mississippi Valley Historical Review 49 (1962): 413-436.

Merry, Robert. A Country of Vast Designs. New York: Simon and Schuster, 2009.

Mignolo, Walter. "Delinking: The Rhetoric of Modernity, the Logic of Coloniality, and the Grammar of DeColoniality." Cultural Studies 21, no. 2 (Spring 2007): 449-514.

Mihalkanin, Edward. American Statesmen: Secretaries of State from John Jay to Colin Powell. Westport, CT: Greenwood Press, 2004.

Mihm, Stephen. A Nation of Counterfeiters: Capitalists, Con Men, and the Making of the United States. Cambridge: Harvard University Press, 2007.

Miller, Daniel. Louis Kossuth and the Definition of American Character, 1851-52. Chapel Hill: UNC Press, 1975.

Miller, Joseph C. "The Problem of Slavery as History." Paper presented at Cornell University, Ithaca, New York, March 12, 2007.

Miller, Paul B. Elusive Origins: The Enlightenment in the Modern Caribbean Historical Imagination. Charlottesville: University of Virginia Press, 2010.

Miner, Craig. Seeding Civil War: Kansas in the National News, 1845-1858. Lawrence: University Press of Kansas, 2008.

Minicucci, Stephen. "Internal Improvements and the Union, 1790-1860." Studies in American Political Development 18, no. 2 (October 2004): 160-185.

----- "The Roll of Private Transportation in America's $19^{\text {th }}$-Century 'Internal Improvements' Debate.” Accessed November 26, 2013. http://mises.org/journals/scholar /internal.pdf.

Mintz, Sidney. Sweetness and Power: The Place of Sugar in Modern History. New York: Penguin Books, 1986.

Mintz Steven and John Stauffer, eds. The Problem of Evil: Slavery, Freedom, and the Ambiguities of American Reform. Amherst: University of Massachusetts Press, 2007.

Mitchell, Leslie. "Britain's Reaction to the Revolutions." In The Revolutions in Europe, 1848-1849: From Reform to Reaction, edited by R.J.W. Evans and Hartmut Pogge von Strandmann, 83-98. New York: Oxford University Press, 2000.

Mitton, Stephen. "The Free World Confronted: The Problem of Slavery and Progress in American Foreign Relations, 1833 - 1844.” PhD diss., Louisiana State University, 2005.

Moffatt, Frederick C. "Barnburning and Hunkerism: William Sidney Mount's "Power of Music." Winterthur Portfolio 29, no. 1 (Spring 1994): 19-42. 
Monroe, James. Second Inaugural Address, March 5, 1820. Accessed on January 21, 2011. http://www.vlib.us/ amdocs/texts/09monr2.htm.

----- “Address to a Joint Session of Congress - December 2, 1823.” Accessed March 21, 2011. http://www.ourdocument s.gov/doc.php?flash=true \&doc=23.

Montgomery, Cora. "Cuba: The Key of the Mexican Gulf: With Reference to the Coastal Trade of the United States." Hunt's Merchants Magazine XXI, (1849).

Monzote, Reinaldo Funes. From Rainforest to Cane Field in Cuba: An Environmental History since 1492. Chapel Hill: University of North Carolina Press, 2009.

Moore, J. B. "Henry Clay and Pan-Americanism.” Columbia University Quarterly 7, (September, 1915): 1-16.

Moore, Preston. "Pierre Soulé: Southern Expansionist and Promoter." The Journal of Southern History 21, no. 2 (May 1965): 203-223.

Moore, Robin. Nationalizing Blackness: Afrocubanismo and Artistic Revolution in Havana, 1920-1940. University of Pittsburgh Press, 1997.

Morgan, Jennifer. Laboring Women: Gender and Reproduction in New World Slavery. Philadelphia: University of Pennsylvania Press, 2004.

Morrison, Michael A. “American Reaction to European Revolutions, 1848-1852: Sectionalism, Memory, and the Revolutionary Heritage.” Civil War History 49, no.2 (2003): 111-132.

----. Slavery and the American West: The Eclipse of Manifest Destiny and the Coming of the Civil War. Chapel Hill: University of North Carolina Press, 1997.

Mosley, Robert. "Cuba in American Foreign Relations (1848-1861): As Shown In Messages of the Presidents and Debates in Congress." MA Thesis, Washington \& Lee University, 1930.

Moss, Elizabeth. Domestic Novelists in the Old South Defenders of Southern Culture. Baton Rouge: Louisiana State University Press, 1992.

Mtinera, Alfonso D. "Failing to Construct the Colombian Nation: Race and Class in the Andean-Caribbean Conflict, 1717- 1816." PhD diss., University of Connecticut, 1995.

Mullen, Edward. Afro-Cuban Literature: Critical Junctures. Hartford: Greenwood, 1994.

Munasinghe, Viranjini. "Nationalism in Hybrid Spaces: The Production of Impurity out of Purity." American Ethnologist 29, no. 3 (Fall, 2002): 663-692.

Munford, Clarence J. and Michael Zeuske. "For Black Slavery, Class Struggle, Fear and Revolution in St. Domingue and Cuba, 1785-1795." The Journal of Negro History 73, nos. 1-4 (Winter-Autumn 1988): 1232 .

Murphy, Gretchen. Hemispheric Imaginings: The Monroe Doctrine and Narratives of U.S. Empire. Durham: Duke University Press, 2005.

Murphy, Sharon. "Securing Human Property: Slavery, Life Insurance, and Industrialization in the Upper South." Journal of the Early Republic 25 (Fall 2005): 615-652.

Murray, David. Odious Commerce: Britain, Spain and the Abolition of the Cuban Slave Trade. Cambridge: Cambridge University Press, 1980. 
----- "Richard Robert Madden: His Career as a Slavery Abolitionist." Studies: An Irish Quarterly Review 61, no. 241 (Spring 1972): 41-53.

Murray, Paul. The Whigs in Georgia 1825-1853. Chapel Hill: UNC Press, 1948.

Mushkat, Jerome. Tammany: The Evolution of a Political Machine. Syracuse: Syracuse University Press, 1971.

Nakajima, Hiroo, "The Monroe Doctrine and Russia: American Views of Czar Alexander I and Their Influence upon Early Russian-American Relations.” Diplomatic History 31, no. 3 (June 2007): 439-463.

Navarro, Maria Dolores González-Ripoll. "En Torno A La Figura De Luis De Las Casas, Un Gobierno En Transition." Arbor: Ciencia, Pensamiento Y Cultura 139, no. 547 (1991): 83-89.

----. Cuba, La Isla De Los Ensayos: Cultura y Sociedad 1790-1815. Madrid: Consejo Superior De Investigaciones Cientificas Escuela De Estudios Hispano-Americanos, 2000.

-----. "Ocio, lecturas y escritura en la Ilustración cubana." Revista de Indias 60, no. 219 (2000): 331-344.

----- "Vínculos y redes de poder entre Madrid y la habana: Francisco Arango y Parreño, Ideólogo y mediador (1765-1837). Revista de Indias 61, no. 222 (2001): 291-305.

-----. El rumor de Haití en Cuba: temor, raza y rebeldía, 1789-1844. Madrid: Editorial CSIC, 2004.

----.. “Dos Viajes Y Una Intención: Francisco Arango Y Parreño Y Alejandro Olivan En Europa Y Las Antillas Azucareras, 1794 y 1829." Revista De Indias 62, no. 224. Accessed on May, 12, 2012. http:// revistadeindias.revistas.csic.es/index.php/revistadeindias/.../528,consultado el 4 de octubre de 2009.

Navarro, Maria Dolores González-Ripoll and Izaskun Alvarez Cuartero. "Vínculos y redes de poder entre Madrid y La Habana: Francisco Arango y Parreño (1765-1837), ideólogo y mediador." Revista de Indias, 61, no. 222, (2001): 291-306.

Nelson, Anna Kasten. "Mission to Mexico - Moses Y. Beach, Secret Agent." New York Historical Society Quarterly 59 (1975): 227-245.

Nelson, Dana D. The Word in Black and White: Reading "Race" in American Literature, 1638-1867. Oxford: Oxford University Press, 1994.

-----. National Manhood: Capitalist Citizenship and the Imagined Fraternity of White Men. Durham: Duke University Press 1998.

Nelson, Lowry. “The Evolution of the Cuban Land System.” Land Economics 24, no. 4 (November 1949): 365-381.

Nelson, William Javier. "The Haitian Political Situation and Its Effect on the Dominican Republic: 1849-1877." The Americas 45, no. 2 (October 1988): 227-235.

Nevins, Allan. Ordeal of the Union: Fruits of Manifest Destiny 1847-1852. New York: Scribner, 1947.

Nichols, Irby C. The European Pentarchy and the Congress of Verona, 1822. The Hague: Martinus Nijhoff, 1971.

Nichols, Roy F. The Democratic Machine, 1850-1854. New York: Columbia University Press, 1923.

----. "Trade Relations and the Establishment of the United States Consulates in Spanish America, 1779-1809." The Hispanic American Historical Review 13, no. 13 (August 1933): 289-313.

Niell, Paul Barrett. 'Bajo Su Sombra': The Narration and Reception of Colonial Urban Space in Early Nineteenth Century Havana, Cuba. PhD diss., University Of New Mexico, 2008. 
Norman, Matthew David. "Revolutions in the Republican Imagination: American Perceptions of the 1848-1849 Revolutions in Europe.” PhD diss., University of Illinois, 2006.

Nugent, Walter. Habits of Empire. New York: Knopf, 2008.

Nye, John Vincent. "The Myth of Free-Trade Britain and Fortress France: Tariffs and Trade in the Nineteenth Century." The Journal of Economic History 51, no. 1 (March 1991): 23-46.

Obadele-Starks, Ernest. Freebooters and Smugglers: The Foreign Slave Trade in The United States after 1808. Fayetteville: University of Arkansas Press, 2007.

Obregón, Liliana. "Between Civilisation and Barbarism: Creole Interventions in International Law." Third World Quarterly 27, no. 5 (Winter 2006): 815-832.

O'Brien, Frank. The Story of the Sun, New York 1833-1928. New York: George H. Doran \& co., 1918. Accessed on March 10, 2014. http://books.google.com/books?id=c43uFLQAiDgC\&pg=PA1\#v=onepage\&q\&f=false.

O'Brien, Michael. Conjectures of Order: Intellectual Life and the American South, 1810-1860. Chapel Hill: UNC Press, 2003.

O.D.O.O. The History of the Late expedition to Cuba. New Orleans: The Office of The Daily Delta, 1850.

O’Flanagan, Patrick. Port Cities of Atlantic Iberia, 1500-1900. London: Ashgate, 2008.

Ogelsby, J. C. M. “The Cuban Autonomist Movement's Perception of Canada, 1865-1898: Its Implication.” The Americas 48, no. 4 (April 1992): 445-461.

O'Grady, Timothy. "The Fenian Factor: Influences of Irish Republicanism's On International History, 1848-1948." MA Thesis, Hawai’i Pacific University, 2007.

Olsen, Chris. Political Culture and Secession in Mississippi: Masculinity, Honor and the Antiparty Tradition 18301860. New York: Oxford University Press, 2000.

Onuf, Peter and Nicholas Onuf. Nations, Markets, and War: Modern History and the American Civil War. Charlottesville: University of Virginia Press, 2006.

Oostindie, Gert J. "Cuban Railroads, 1830-1868: Origins and Effects of 'Progressive Entrepreneurialism."” Caribbean Studies 20, no. 3/4 (1988): 24-45.

Opatrny, Josef. US Expansionism and Cuban Annexationism in the 1850s. Prague: Charles University, 1990.

----. “José Antonio Saco’s Path toward the Idea of Cubanidad.” Cuban Studies 24 (1994): 39-55.

O'Rourke, Kevin H. "The Worldwide Economic Impact of the Revolutionary and Napoleonic Wars." Paper written for Department of Economics and IIIS, Trinity College Dublin, 2004.

Orovio, Consuelo Naranjo and María Dolores González-Ripoll Navarro. "Perfiles Del Crecimiento De Una Ciudad: La Habana A Finales Del Siglo XVIII.” Tebeto: Anuario del Archivo Histórico Insular de Fuerteventura 5 (1992): 229-248. Accessed on May 19, 2012. http://digital.csic.es/handle/10261/15119.

Ortega, Jose Guadalupe. "The Cuba Sugar Complex in the Age of Revolution.” PhD diss., UCLA, 2007.

Ortiz, Altagracia. Eighteenth-Century Reforms in the Caribbean: Miguel De Muesas, Governor of Puerto Rico, 1769-76. Teaneck, NJ: Fairleigh Dickinson University Press, 1983. 
Ortiz, Fernando. Cuban Counterpoint, Tobacco and Sugar. Durham: Duke University Press, 1995.

----. Humboldt's Translator in the Context of Cuban History." Atlantic Studies 6, no. 3 (December 2009): 327-343.

Osthaus, Carl. "The Work Ethic of the Plain Folk: Labor and Religion in the Old South.” Journal of Southern History 70, no. 4 (November 2004): 745-82.

O’Sullivan John L. “Annexation,” The United States Magazine and Democratic Review 15, no. 1 (July 1845): 5-10.

-----. “The Great Nation of Futurity” The United States Magazine and Democratic Review 6, no. 23 (November 1839): 426-430.

----- "The Course of Civilization.” The United States Magazine and Democratic Review 6, 23 (November 1839): 216-7.

----- "Introduction: The Democratic Principle, The Importance of Its Assertion, and Application to Our Political System and Literature." Democratic Review 1, no. 1 (October 1837): 1-20.

Owsley, Frank Lawrence. Plain Folk of the Old South. Nashville: Vanderbilt University Press, 1949.

Padgett, James A. "Diplomats to Haiti and Their Diplomacy." The Journal of Negro History 25, no. 3 (July 1940): 265-330.

Palmié, Stephan. Wizards and Scientists: Explorations in Afro-Cuban Modernity and Tradition. Durham: Duke University Press, 2002.

Pappademos, Melina. "From Cabildos to Continuadora Societies: Political Community in the Black Cuban Imaginary." Negritud: Revista de Estudios Afrolatino-americanos 2, no. 2 (Winter 2009): 152-177.

Paquette, Robert. Sugar is Made with Blood: The Conspiracy of La Escalera and the Conflict between Empires over Slavery in Cuba. Middletown, CT: Wesleyan University Press, 1988.

Paquette, Gabriel B. "State-Civil Society Cooperation and Conflict in the Spanish Empire: The Intellectual and Political Activities of the Ultramarine Consulados and Economic Societies, c. 1780-1810." Journal of Latin American Studies 39, no. 2 (2007): 263-298.

Parsons, Lynn Hudson. Andrew Jackson, John Quincy Adams, and the Election of 1828. Oxford: Oxford University Press, 2009.

Parton, James. Life of Andrew Jackson. Boston: Houghton, 1888.

Pasley, Jeffrey L. The Tyranny of Printers: Newspaper Politics in the Early American Republic. Charlottesville: University of Virginia 2002.

Pastor, Brigida. "Symbiosis between Slavery and Feminism in Gertrudis Gómez de Avellaneda's Sab." Bulletin of Latin American Research 16, no. 2 (1997): 187-196.

Patterson, Orlando Slavery and Social Death A Comparative Study. Boston: Harvard University Press, 1985.

Paz, Manuel Barcia. La resistencia esclava en las plantaciones cubanas, 1790-1870. Pinar del Rio, Cuba: Ediciones Vitral, 1998.

----. "Exorcising the Storm: Revisiting the Origins of the Repression of the Conspiracy of La Escalera in Cuba." Colonial Latin America Historical Review 15, no. 3 (Summer 2006): 311-326.

----- "Sugar, Slavery, and Bourgeoisie: The Emergence of the Cuban Sugar Industry." In Sugarlandia Revisited: 
Sugar and Colonialism in Asia and the Americas, edited by Ulbe Bosma, Juan Giusti-Cordero and G. Roger Knight, 145-158. New York: Berghahn, 2007.

-----. Seeds of Insurrection: Domination and Slave Resistance on Cuban Plantations. Baton Rouge: Louisiana State University Press, 2008.

----- "Revolts amongst Enslaved Africans in Nineteenth-Century Cuba: A New Look to an Old Problem." The Journal of Caribbean History 39, no. 2 (Spring 2005): 173-200.

----. "Fighting with the Enemy's Weapons: The Usage of the Colonial Legal Framework by Nineteenth Cuban Slaves." Atlantic Studies 3, no. 2 (2006): 159-181.

Peabody, Sue "Free Soil: The Generation and Circulation of an Atlantic Legal Principle." Slavery and Abolition 32, no. 3 (September 2011): 331-339.

Pearce, Adrian. British Trade with Spanish America, 1763-1808. Liverpool: Liverpool University Press, 2007.

----. "The Hope-Barings Contract: Finance and Trade between Europe and the Americas, 1805-1808." The English Historical Review 124, no. 511 (2009): 1-29.

Peraza y Sarausa, F. “El Papel Periodico de la Havana’ y los Origenes del Periodismo en Cuba.” Revista Interamericana 8 (1958): 368-378.

Perez, Louis A. Cuba Between Reform and Revolution. Oxford: Oxford University Press, 2007.

----. Essays on Cuban History: Historiography and Research. Gainesville: University Presses of Florida, 1995.

----. "Cuba and the United States: Origins and Antecedents of Relations, 1760s-1860s." Cuban Studies 21 (1991): 57-82.

-----. Winds of Change: Hurricanes and the Transformation of Nineteenth-Century Cuba. Chapel Hill: University of North Carolina Press, 2001.

-----. Cuba and the United States: Ties of Singular Intimacy. Athens: University of Georgia Press, 1990.

-----. On Becoming Cuban: Identity, Nationality and Culture. Chapel Hill: UNC Press, 1999.

----. Cuba and the United States: Ties of Singular Intimacy. Athens: University of Georgia Press, 2003.

-----. Impressions of Cuba in the Nineteenth Century: The Travel Diary of Joseph J. Dimock. New York: Rowman and Littlefield, 1998.

----. Slaves, Sugar, \& Colonial Society: Travel Accounts of Cuba, 1801-1899. New York: Scholarly Resources, 1991.

Perez, Louis A. and Rebecca J. Scott, eds. The Archives of Cuba/ Los Archivos de Cuba. Pittsburgh: University of Pittsburgh Press, 2002.

Pérez de la Riva, Juan. El barracón: esclavitud y capitalismo en Cuba. Barcelona: Crítica, 1978.

-----. El Barracón y Otros Ensayos. Havana: Editorial de Ciencias Sociales, 1975.

Pérez de la Rive, Javier. El Café: Historia de su Cultivo y Explotacion en Cuba. Havana: Jesús Montrero, 1944.

Perez, Luiz. "French Refugees to New Orleans in 1809." Publications of the Southern History Association 9 (1905): 293-310. 
Perkins, Dexter. A History of the Monroe Doctrine. Boston: Little \& Brown, 1963.

Petrie, Charles, ed. George Canning. London: Eyre \& Spottiswoode, 1946.

Phillips, Clifton. Protestant America and the Pagan World, Cambridge: Harvard University Press, 1969.

Pickens, Lucy Holcomb, (writing as H. M. Hardimann). The Free Flag of Cuba; or the Martyrdom of López. New York: DeWitt and Davenport, 1854.

Pierson, William Whatley. "Francisco de Arango y Parreño." The Hispanic American Historical Review 16, no. 4 (November 1936): 451-478.

Piqueras, José A. “La Siempre Fiel Isla se Cuba, O La Lealtad Interesada.” Historia Mexicana 58, no. 1 (JulySeptember 2008): 427-486.

Pizarro, Ana “Reflections on the Historiography of Caribbean Literature.” Callaloo 34 (Winter, 1988): 173-185.

Pletcher, David M. The Diplomacy of Annexation: Texas, Oregon and the Mexican War. Columbia, MO.: University of Missouri Press, 1973.

Plummer, Brenda Gayle. Haiti and the United States: The Psychological Moment. Athens: The University of Georgia Press, 1992.

Polk, James Knox. The Diary of James K. Polk During His Presidency, 1845 to 1849, Vol. 1, edited by Milo Quaife. Chicago: A.C. McClurg, 1910.

-----. "State of the Union Message 1846." Accessed May 30, 2013. http://www.presidency.ucsb.edu /ws/index.php?pid=29487.

Polyné, Millery. “'Expansion Now!' Haiti, 'Santo Domingo,' and Frederick Douglass at the Intersection of U.S. And Caribbean Pan-Americanism." Caribbean Studies 34, no. 2 (July-December 2006): 3-45.

Popkin, Jeremy D. You Are All Free: The Haitian Revolution and the Abolition of Slavery. New York: Cambridge University Press, 2010.

Portell Vilá, Herminio. Narciso López y Su Época, Vol. 1. Havana: Cultural and Compania Editora, 1930.

-----. Los Otros Extranjeros en la Revolucion Norteamericana. Havana: Ediciones Universal, 1978.

-----. Historia de Cuba en Sus Relaciones con los Estados Unidos y España, Vols. 1-2. Havana: Mnemosyne Publishing, 1969.

Portolano, Marlana. “John Quincy Adams’s Rhetorical Crusade for Astronomy.” Isis 91, no. 3 (September, 2000): 480-503.

Portuondo, María M. "Plantation Factories: Science and Technology in Late-Eighteenth-Century." Technology and Culture 44, no. 2 (April 2003): 231-257.

Potter, David. The Impending Crisis 1848-1861. New York: Harper Collins, 1976.

Poyo, Gerald Eugene. "Cuban Émigré Communities in the United States and the Independence of Their Homeland, 1852-1895." PhD diss., University of Florida, 1983.

-----. With All and For the Good of All: the Emergence of Popular Nationalism in the Cuban Communities of the United States, 1848-1898. Durham: Duke University Press, 1989. 
----. "Evolution of Cuban Separatist Thought in the Émigré Communities of the United States, 1848-1985." The Hispanic American Historical Review 66, no. 3 (Fall 1986): 485-507.

Prados-Torreira, Teresa. Mambisas: Rebel Women in Nineteenth-Century Cuba. Gainesville: University Press of Florida, 2005.

Pratt, Julius W. “John Louis O’Sullivan and Manifest Destiny.” New York History 19, no. 3 (July 1933): 213-234.

Pratt, Mary Louise. Imperial Eyes: Travel Writing and Transculturation. New York: Routledge, 1992.

Prentiss, Dale. "Economic Progress and Social Dissent in Michigan and Mississippi, 1837-1860." PhD diss., Stanford, 1990.

Pretel David and Nadia Fernandez de Pinedo. "Technology Transfer and Expert Migration in Nineteenth-Century Cuba.” Max Weber Programme, Working Paper, European University Institute, January 2014. Accessed Feb. 27, 2014. http://cadmus.eui.eu/bitstream/ handle/1814/29039/MWP_2013_34.pdf.

-----. "Patents, Sugar Technology and Sub-Imperial Institutions in Nineteenth-Century Cuba." History of Technology 30, (2011): 66-89.

Price, Richard ed. Maroon Societies: Rebel Slave Communities in the Americas. Baltimore: Johns Hopkins University Press, 1996.

Purcell, Sarah J. Sealed with Blood: War, Sacrifice, and Memory in Revolutionary America. Philadelphia: University of Pennsylvania Press, 2010.

Quigley, Paul. Shifting Grounds: Nationalism and the American South, 1848-1865. New York: Oxford University Press, 2011.

Quijano, Anibal. "Coloniality of Power, Eurocentrism, and Latin America." Nepentla: Views From the South, 1, no. 3 (Fall 2000): 533-580.

-----. “Coloniality and Modernity/Rationality,” Cultural Studies 21, no. 2 (Spring 2007): 168-178.

Quinn, Kate. "Cuban Historiography in the 1960s: Revisionists, Revolutionaries and the Nationalist Past." Bulletin of Latin American Research 26, no. 3 (June 2007): 378-398.

Quinziano, Franco. "Fin de siglo en La Habana: Lujo, Apariencias y Ostentación en el Papel Periódico de la Havana (1790-1805)," Associazione Ispanisti Italiani 1 (1999): 421-432.

Quiroz, Alfonso W. "Implicit Costs of Empire: Bureaucratic Corruption in Nineteenth-Century Cuba." Journal of Latin American Studies 35, no. 3 (August 2003): 473-511.

Quiroz, Alfonso. "Free Association and Civil Society in Cuba, 1787-1895." Journal of Latin American Studies 43 (February 2011): 33-64.

Ragatz, Lowell. The Fall of the Planter Class in the British Caribbean, 1763-1833. New York: Octagon Books, 1928.

Raimon, Eve Allegra. The "Tragic Mulatta" Revisited: Race and Nationalism in Nineteenth-Century Antislavery Fiction. New Brunswick: Rutgers 2006.

Rappleye, Charles. Sons of Providence: The Brown Brothers, the Slave Trade, and the American Revolution. New York: Simon \& Schuster, 2006.

Rapport, Mike. 1848: Year of Revolution. New York: Basic Books, 2009. 
Rathbun, Lyon. “The Ciceronian Rhetoric of John Quincy Adams.” Rhetoric 18, no. 2 (Spring 2000): $175-231$.

Rauch, Basil. American Interest in Cuba: 1848-1855. New York: Columbia University Press, 1948.

Reed, Nelson. The Caste War of Yucatán. Stanford: Stanford University Press, 2002.

Reid, Michele Bernita. "Negotiating a Slave Regime: Free People of Color in Cuba, 1844-1868." PhD diss., University of Texas, Austin, 2004.

Reid-Vazquez, Michele. The Year of the Lash: Free People of Color in Cuba and the Nineteenth-Century Atlantic World. Athens: University of Georgia Press, 2011.

Reilly, Tom. “A Spanish-Language Voice of Dissent in Antebellum New Orleans.” Louisiana History: The Journal of the Louisiana Historical Association 23, No. 4 (Autumn 1982): 325-339.

Reinders, Robert. End of an Era: New Orleans, 1850-1860. New York: Pelican Publishing, 1999.

Reinhold, Frances L. "New Research on the First Pan-American Congress Held at Panama in 1826." The Hispanic American Historical Review 18, no. 3 (August 1938): 342-363.

Remini, Robert. Henry Clay: Statesman for the Union. New York: Norton, 1991.

----. Daniel Webster: The Man and His Time. New York: Norton, 1997.

Reséndez, Andrés. Changing National Identities at the Frontier: Texas and New Mexico, 1800-1850. New York: Cambridge University Press, 2004.

Reus-Smit, Christian. Individual Rights and the Making of the International System. Cambridge: Cambridge University Press, 2013.

Reynolds, Larry. European Revolutions and the American Literary Renaissance. New Haven: Yale University Press, 1988.

Rezneck, Samuel. "The Social History of an American Depression, 1837-1843." American Historical Review 40, no. 4 (July 1935): 662-687.

Rhodes, Edward, ed. Presence, Prevention, and Persuasion: A Historical Analysis of Military Force and Political Influence. New York: Lexington Books, 2004.

Richards, Leonard. The Slave Power and Southern Domination 1780-1860. Baton Rouge: LSU Press, 2000.

Richardson, David. Abolition and Its Aftermath: The Historical Context 1790-1916. New York: Routledge, 2013.

Ricœur, Paul. Memory, History, Forgetting. University of Chicago Press, 2004.

Riegel, Robert E. Young America, 1820-1840. Norman: University of Oklahoma Press, 1949.

Riepma, Siert F. "Young America: A Study in American Nationalism before the Civil War." PhD diss., Western Reserve University, 1939.

Riva, Juan Pérez de la. Correspondencia reservada del capitán general Don Miguel de Tacón, 1834-1836. Havana: Biblioteca Nacional José Martí, 1963.

Roberson, Jere W. "The Memphis Commercial Convention of 1853: Southern Dreams and 'Young America."” Tennessee Historical Quarterly 33, (1974): 279-96. 
Roberts, Timothy Mason. Distant Revolution: 1848 and the Challenge to American Exceptionalism. Charlottesville: University of Virginia Press, 2009.

----. "Revolutions Have Become the Bloody Toy of the Multitude: European Revolutions, The South, and the Crisis of 1850." Journal of the Early Republic 25, no. 2 (2005): 259-283.

Roberts, Tim and Dan Howe. "The United States and the Revolution of 1848." In The Revolutions in Europe 18481849: From Reform to Reaction, edited by Robert Evans and Hartmut Pogge von Strandmann, 157-180. Oxford: Oxford University Press, 2002.

Robertson, David. The Trial of Aaron Burr for Treason. New York: James Cockcroft \& Co., 1875.

Robertson, William Spence. Francisco de Miranda and the Revolutionizing of Spanish America. Washington: Government Printing Office, 1909.

Rockman, Seth. "The Unfree Origins of American Capitalism.” In The Economy of Early America: Historical Perspectives and New Directions, edited by Cathy Matson, 335-361. University Park: Pennsylvania State University Press, 2006.

----. Scraping By: Wage Labor, Slavery, and Survival in Early Baltimore. Baltimore: The Johns Hopkins University Press, 2008.

Rodenas, Adriana Méndez. "Voyage to 'La Havane:' The Countess of Merlín's Preview of National Identity." Cuban Studies 16 (1986): 71- 99.

----. "Identity and Incest in 'Cecilia Valdés': Villaverde and the Origin(s) of the Text." Cuban Studies 24 (1994): 83-104.

----. "Tropics of Deceit: Desire and the Double in Cuban Antislavery Narrative." Cuban Studies 28 (1998): 83-120.

Rodgers, Daniel. "Republicanism: The Career of a Concept." Journal of American History, 79 (1992): 11-38.

Rodrigo, Martín. "Spanish Merchants and the Slave Trade: From Legality to Illegality, 1814-1870." In Slavery and Antislavery in Spain's Atlantic Empire, edited by Josep M. Fradera and Christopher Schmidt-Nowara, 176200. New York: Bergham Books, 2013.

Rodríguez, Gloria García. Voices of the Enslaved in Nineteenth-Century Cuba: A Documentary History. Chapel Hill: University of North Carolina Press, 2011.

Rodríguez, José Ignacio. Estudio Histórico Sobre el Origen, Desenvolvimiento y Manifestaciones Prácticas de la Idea de la Anexión de la Isla de Cuba a los Estados Unidos de América. Havana: Imprenta La Propaganda Literaria, 1900.

Roediger David R. and Elizabeth D. Esch. The Production of Difference: Race and the Management of Labor in U.S. History. New York: Oxford University Press, 2012.

Rogers, Carlton. Incidents of Travel in the Southern States and Cuba. New York: R. Craighead, 1862.

Rogin, Michael. “'Make My Day' Spectacle as Amnesia in Imperial Politics.” in Cultures of United States Imperialism, edited by Amy Greenberg and Donald Pease, 499-534. Durham: Duke University Press, 1993.

----. Moby Dick in Subversive Genealogy: The Political and Art of Herman Melville. New York: Knopf, 1983.

Rohrs, Richard C. "American Critics of the French Revolution of 1848." Journal of the Early Republic 14, no. 3 (Fall 1994): 359-377. 
Rojo, Antonio Benítez “Power/Sugar/Literature: Toward a Reinterpretation of Cubanness.” Cuban Studies, 16 (1986): 9-31.

Rood, Daniel Brett. "Plantation Technocrats: A Social History of Knowledge in The Slaveholding Atlantic World, 1830-1865.” PhD diss., University of California, Irvine, 2010.

----. "Slavery and The Amber Waves of Grain: Trade, Technology, and Middle-Class Consumption in the Richmond-Rio Circuit, 1760-1860." Presented at Slavery's Capitalism: A New History of American Economic Development, Brown University, April 2011.

-----. "Herman Merivale's Black Legend: Rethinking The Intellectual History of Free Trade Imperialism." NWIG: New West Indian Guide 80, no. 3/4 (2006): 163-189.

Rosenbaum, Julian, ed. The American Bourgeoisie: Distinction and Identity in the Nineteenth Century. New York: Palgrave-Macmillan, 2010.

Rosenthal, Debra J. Race Mixture in Nineteenth-Century U.S. and Spanish American Fictions: Gender, Culture, and Nation Building. Chapel Hill: University of North Carolina Press, 2004.

Rothman, Adam. Slave Country: American Expansion and the Origins of the Deep South. Cambridge: Harvard University Press, 2009.

Rothman, Joshua D. Flush Times and Fever Dreams: A Story of Capitalism and Slavery in the Age of Jackson. Athens: University of Georgia Press, 2012.

----. "The Hazards of the Flush Times: Gambling, Mob Violence, and the Anxieties of America's Market Revolution." Journal of American History 95, (2008): 651-677.

Rotundo, Anthony. American Manhood: Transformations in Masculinity from the Revolution to the Modern Era. New York: Basic Books, 1993.

Rousey, Dennis C. "Friends and Foes of Slavery: Foreigners and Northerners in the Old South." Journal of Social History 35, no. 1 (Winter 2001): 373-96.

Rousseau, Peter L. "Jacksonian Monetary Policy, Specie Flows, and the Panic of 1837." The Journal of Economic History 62, no. 2 (June 2002): 457-488.

Ruckel, Ryan. “'A Kind Providence' and 'The Right to Self-Preservation;' How Andrew Jackson, Emersonian Whiggery, and Frontier Calvinism Shaped the Course of American Political Culture." PhD diss., Louisiana State University, 2006.

Ruether, Rosemary Radford. America, Amerikkka: Elect Nation And Imperial Violence. Chicago: Equinox, 2007.

Rugemer, Edward B. "The Southern Response to British Abolitionism: The Maturation of Proslavery Apologetics." The Journal of Southern History 70, No. 2 (May 2004): 221-248.

----- The Problem of Emancipation: The Caribbean Roots of the American Civil War. Baton Rouge: Louisiana State University Press, 2008.

Rutter, Frank. The South American Trade of Baltimore. Baltimore: Johns Hopkins University 1897.

Ryden, David. West Indian Slavery and British Abolition, 1783-1807. Cambridge: Cambridge University Press, 2009. 
Saco, José Antonio. Ideas sobre la incorporación de Cuba en los Estados Unidos, Obras, Vol. III. Havana: Imagen Contemporánea, 2001.

-----. Contra la anexión. Havana: Libreria Cervantes, 1928.

-----. Justa defensa de la Academia Cubana de Literatura contra los violentos ataques que se le han dado en el Diario de la Habana. New Orleans: Mr. St. Romes, 1834. Accessed January 10, 2014. http://nrs.harvard.edu/urn3:FHCL:473516.

----. Paralelo entre la Isla de Cuba y algunas colonias inglesas. Madrid: Oficina de Tomas Jordan, 1837. Accessed January 16, 2014. http://nrs.harvard.edu/urn-3:FHCL:473514.

Sainz, Enrique. La Literatura Cubana de 1700 a 1790, Ciudad de La Habana. Havana: Editorial Letras Cubanas, 1983.

Salvucci, Linda K. "Supply and Demand and the Making of a Market: Philadelphia and Havana, 1780-1830." in Atlantic Port Cities: Economy, Culture and Society in the Atlantic World 1650-1850, edited by Franklin W. Knight and Peggy K. Liss, 40-57. University of Tennessee Press, 1991.

----. “Atlantic Intersections: Early American Commerce and the Rise of the Spanish West Indies (Cuba)." Business History Review 79, no. 4 (Winter 2005): 781-809.

----- "Merchants and Diplomats: Philadelphia’s Early Trade with Cuba." Pennsylvania Legacies 3, no. 2 (November 2003): 6-10.

----. “Anglo American Merchants and Stratagems for Success in Spanish Imperial Markets, 1783-1807.” In The North American Role in the Spanish Imperial Economy, 1764-1819, edited by Jacques A. Barbier and Allan J. Kuethe, 120-150. Manchester: Manchester, 1984.

Salvucci, Linda and Richard Salvucci. "Cuba and the Latin American Terms of Trade: Old Theories, New Evidence.” Journal of Interdisciplinary History, Vol. 31, no. 2 (Autumn 2000): 197-222.

Sampson, Robert. John O'Sullivan and His Times. Kent, Ohio: Kent State University Press, 2003.

Sánchez, Fernando Armario. "La esclavitud en Cuba durante la regencia de Espartero, 1840-1843.” Hispania: Revista Española de Historia 43, no. 153 (1983): 129-53.

Sánchez, Manuel De Paz. “'El Lugareño’ Contra La Esclavocracia: Las Cartas De Gaspar Betancourt Y Cisneros (1803-1866). Revista de Indias 58, no. 214 (1998): 617-639.

----. El Bandolerismo en Cuba, 1800-1933. Tenerife: Centro de la Cultura Popular Canaria, 1993.

Sanders, George. “Northern Lakes and Western Rivers.” Democratic Review 30, no. 163 (January 1852): 13-16.

Sanders, James "Atlantic Republicanism in Nineteenth-Century Colombia: Spanish America's Challenge to the Contours of Atlantic History." Journal of World History 20, no. 1 (March 2009): 131-150.

Sartorius, David. Ever Faithful: Race, Loyalty, and the Ends of Empire in Spanish Cuba. Durham: Duke University Press, 2014.

----. “Uncommon Winds: Race, Passports, and the Legal Culture of Travel in Cuba." Presentation to Boundaries of Bondage, Frontiers of Freedom: Mobility and Slavery, Race, Nation, and Religiosity in the Atlantic World panel of Conference of Latin American History American Historical Association Annual Meeting, January 9, 2011.

----. “My Vassals: Free-Colored Militias in Cuba and the Ends of Spanish Empire.” Journal of Colonialism and 
Colonial History 5, no. 2 (Fall 2004): 1-25.

Savage, John. "Between Colonial Fact and French Law: Slave Poisoners and the Provostial Court in Restoration-Era Martinique." French Historical Studies 29, no. 4 (Fall 2006): 565-594.

Schafer, Daniel. "A Class of People neither Freemen nor Slaves: From Spanish to American Race Relations in Florida, 1821-1861." Journal of Social History 26 (1993): 587-609.

Schafer, Kelleher. Becoming Free, Remaining Free: Manumission and Enslavement in New Orleans, 1846-1862. Baton Rouge: Louisiana State University Press, 2003.

Schaefer, Donald. "Yeomen Farmers and Economic Democracy: A Study of Wealth and Economic Mobility in the Western Tobacco Region, 1850-1860." Explorations in Economic History 15, no. 4 (1978): 421-437.

Schakenbach, Lindsay. "From Discontented Bostonians to Patriotic Industrialists: The Boston Associates and the Transcontinental Treaty, 1790-1825.” New England Quarterly 84, no. 3 (September 2011): 377-401. University Press, 1984.

Schiller, Dan. Objectivity and the News: The Public and the Rise of Commercial Journalism. Philadelphia: University of Pennsylvania Press, 1994.

Schleicher, David. "The Seventeenth Amendment and Federalism in an Age of National Political Parties." Accessed on March 15, 2014. http://www.law.gmu.edu/assets/files/publications/ working_papers/1333 SeventeenthAmendmentandFederalism.pdf.

Schlesinger Jr., Arthur M. The Age of Jackson. Boston: Little \& Brown, 1945.

Schloss, Rebecca. Sweet Liberty: The Final Days of Slavery in Martinique. Philadelphia: University of Pennsylvania, 2009.

Schmidt-Nowara, Christopher. "Wilberforce Spanished: Joseph Blanco White and Spanish Antislavery, 1808-1814." In Slavery and Antislavery in Spain's Atlantic Empire, edited by Josep M. Fradera and Christopher Schmidt-Nowara, 158-170. New York: Berghahn Books, 2013.

-----. Empire and Antislavery: Spain, Cuba, and Puerto Rico, 1833-1874. Pittsburgh: University of Pittsburgh Press, 2009.

----- "Still Continents (and an Island) with Two Histories?" Law and History Review 22, no. 2 (Summer 2004): 377 382

----- "Spanish Cuba: Race and Class in Spanish and Cuban Antislavery Ideology, 1861-1868," Cuban Studies 25, (1995): 101-122.

Schneirov, Matthew. The Dream of a New Social Order: Popular Magazines in America, 1839-1914. New York: Columbia University Press, 1994.

Schoen, Brian. The Fragile Fabric of Union: Cotton, Federal Politics, and the Global Origins of the Civil War. Baltimore: Johns Hopkins University Press, 2009.

Scholnick Robert J. "Extermination and Democracy: O'Sullivan, The Democratic Review, and Empire, 18371840." American Periodicals: A Journal of History, Criticism, and Bibliography 15, no. 2 (2005): 123-141.

Schonhardt-Bailey, Cheryl. "Lessons in Lobbying for Free Trade in $19^{\text {th }}$-Century Britain: To Concentrate or Not." The American Political Science Review 85, no. 1 (March 1991): 37-58.

Schoultz, Lars. Beneath the United States: A History of U.S. Policy Toward Latin America. Cambridge: Harvard University Press, 1998. 
Schroeder, John H. "Major Jack Downing and American Expansionism: Seba Smith's Political Satire, 1847-1856." New England Quarterly 50 (1977): 214-33.

Schroeder, Susan. Cuba: A Handbook of Historical Statistics. Boston: G.K. Hall, 1982.

Schudson, Michael. Discovering the News: A Social History of American Newspapers. New York: Basic Books, 1978.

Schurz, Carl. Henry Clay. Boston: Houghton, 1887.

Schweiger, Beth Barton. The Gospel Working Up: Progress and the Pulpit in Nineteenth-Century Virginia. Oxford University Press, 2000.

Scott, David. Conscripts of Modernity: The Tragedy of Colonial Enlightenment. Durham: Duke University Press, 2004.

Scott, Donald M. "Print and the Public Lecture System, 1840-60." In Printing and Society in Early America edited by William L. Joyce, 278-299. Worcester, MA.: American Antiquarian Society, 1983.

Scott, Nancy N. ed. A Memoir of Hugh Lawson White. Philadelphia: J. B. Lippincott \& Co., 1856.

Scott, Rebecca Jarvis. Slave Emancipation in Cuba: The Transition to Free Labor, 1860-1899. Pittsburgh: University of Pittsburgh Press, 2000.

----.. "Gradual Abolition and the Dynamics of Slave Emancipation in Cuba, 1868-86." The Hispanic American Historical Review 63, no. 3 (August 1983): 449-477.

----. Degrees of Freedom: Louisiana and Cuba after Slavery. Cambridge: Belknap Press, 2005.

-----. "Public Rights and Private Commerce: A Nineteenth-Century Atlantic Creole Itinerary." Current Anthropology 48, no. 2 (April 2007): 237-256.

----. "Explaining Abolition: Contradiction, Adaptation and Challenge in Cuban Slave Society, 18601886." Comparative Studies in Society and History 26 (January 1984): 83-111.

-----. "Paper Thin: Freedom and Re-enslavement in the Diaspora of the Haitian Revolution." Law and History Review 29, no. 4 (November 2011): 1061-1087.

Scott, Rebecca J. and Thomas Holt and Frederick Cooper and Aims McGuinness, eds. Societies After Slavery: A Select Annotated Bibliography of Printed Sources on Cuba, Brazil, British Colonial Africa, South Africa, and the British West Indies. Pittsburgh: University of Pittsburgh Press, 2002.

Scott, Richard. Workers in the Metropolis: Class, Ethnicity and Youth in Antebellum America. Ithaca; Cornell University, 1990.

Scott-Childress, Reynolds J. "Cultural Reconstruction: Nation, Race and the Invention of the American Magazine, 1830-1915.” PhD diss., University of Maryland, 2003.

Scroggs, William O. Filibusters and Financiers: The Story of William Walker and His Associates. New York: MacMillan, 1916.

Sellers, Charles. The Market Revolution: Jacksonian America, 1815-1846. Oxford: Oxford University Press, 1994.

Seward, William. "Welcome to Kossuth: Speeches of William H. Seward, on the Joint Resolution in Honor of Louis Kossuth.” Congressional Speech, December 9, 1851. Accessed May 23, 2013. http://books.google.com/ books? id=h9NpAAAAMAAJ\&source=gbs_navlinks_s. 
Sexton, Jay. The Monroe Doctrine: Empire and Nation in Nineteenth-Century America. New York: Macmillan 2011.

-----. Debtor Diplomacy: Finance and American Foreign Relations in the Civil War Era, 1837-1873. Oxford: Oxford University Press, 2005.

Sheahan, James Washington. The Life of Stephen A. Douglas. New York: Harper, 1860.

Sheridan, R. B. '“Sweet Malefactor;' the Social Costs of Slavery and Sugar in Jamaica and Cuba, 18071854.' Economic History Review 29, 2 (Spring 1976): 236-57.

Sheriff, Carol. The Artificial River: The Erie Canal and the Paradox of Progress, 1817-1862. New York: Hill and Want, 1997.

Sherwood, Marika. After Abolition: Britain and the Slave Trade Since 1807. London: I.B. Tauris, 2007.

Shewmaker, Kenneth. "Daniel Webster and the Politics of Foreign Policy, 1850-1852." Journal of American History, 63 (September 1976): 303-315.

Silbey, Joel. A Respectable Minority: The Democratic Party in the Civil War Era, 1860-1868. New York: W. W. Norton, 1977.

-----. Storm Over Texas: The Annexation Controversy and the Road to the Civil War. New York: Oxford University Press, 2005.

Silverstone, Scott. Divided Union: The Politics of War in the Early American Republic. Ithaca: Cornell University Press, 2004.

Sim, David. "Filibusters, Fenians, and a Contested Neutrality: The Irish Question and U.S. Diplomacy, 1848-1871." American Nineteenth Century History 12, no. 3 (2011): 265-287.

Simmonds, Lorna. “Civil Disturbances in Western Jamaica, 1838-1865.” Jamaican Historical Review 14, (1984): 117.

Simms, Henry. Rise of the Whigs in Virginia, 1824-1840. Richmond: William Byrd Press, 1929.

Singleton, Theresa. "Slavery and Spatial Dialectics On Cuban Coffee Plantations." World Archaeology 33, no. 1 (2001): 98-114.

Sippial, Tiffany A. Prostitution, Modernity, and the Making of the Cuban Republic, 1840-1920. Chapel Hill: University of North Carolina Press, 2013.

Skinner, John. "A Discourse on the Reciprocal Relations of Agriculture and Other Branches of American Industry." The Plough, The Loom, and the Anvil. Accessed on May 23, 2013. https://play.google.com/store/ books/details?id=UFYWAQAAIAAJ\&rdid=book-UFYWAQAAIAAJ \&rdot=1.

Sklodowska, Elzbieta. Espectros Y Espejismos: Haití En El Imaginario Cubano. Madrid: Iberoamericana / Vervuert, 2009.

Skocpol, Theda. Social Revolutions in the Modern World. New York: Cambridge University Press, 1994.

Slatta Richard W. and Jane Lucas de Grummond. Simon Bolivar's Quest for Glory. College Station, TX.: Texas A\&M University, 2003.

Smith, George Winston. “Ante-Bellum Attempts of Northern Business Interested to Redeem the Upper South.” Journal of Southern History 11, no. 2 (May 1945): 177-213. 
Smith, Henry Nash. Virgin Land: The American West as Symbol and Myth. Boston: Harvard University Press, 1950.

Smith, Mark. Mastered by the Clock: Time, Slavery and Freedom in the American South. Chapel Hill: UNC Press, 1997.

Smith, Phillip Matthew. Persistent Borderland: Freedom and Citizenship in Territorial Florida. PhD diss., University of Texas, 2007.

Smith, Robert Freeman. "Twentieth-Century Cuban Historiography." The Hispanic American Historical Review 64, no. 1 (February 1964): 44-73.

Sociedad Economica, Memorias de la Real Sociedad Economica de la Habana. Havana: Sociedad Económica de Amigos del País, 1848. Accessed January 20, 2014. http://books.google.com/books?id=ByEsAA AAYAAJ\&pg=PA3\#v=onepage \&q $\& \mathrm{f}=$ false.

Sommer, Doris. Foundational Fictions: The National Romances of Latin America, 114-137. Berkeley: University of California 1991.

Soto Paz, Rafael. La falsa cubanidad de Saco, Luz y Del Monte. Havana: Editorial Alfa, 1941.

Spear, Jennifer M. Race, Sex, and Social Order in Early New Orleans. Baltimore: JHU Press, 2010.

Spencer, Donald. Louis Kossuth and Young American: A Study of Sectionalism and Foreign Policy 1848-1852. Columbia: University of Missouri Press, 1977.

Sperber, Jonathan. The European Revolutions, 1848-1851. Cambridge: Cambridge University Press, 1994.

Spiller, Robert E. “Emerson’s ‘The Young American.” Clio 1 (October 1971): 37-41.

Stafford, John. The Literary Criticism of Young America. Berkeley: Univ. of California Press, 1952.

Stagg, J. C. A. "George Mathews and John McKee: Revolutionizing East Florida, Mobile, and Pensacola in 1812." The Florida Historical Quarterly 85, no. 3 (Winter, 2007): 269-296.

Stapleton, Edward ed. Some Official Correspondence of George Canning 1821-1827, Vol. 1. London: Longman, Green, \& Co., 1887.

Stauffer, John. The Black Hearts of Men: Radical Abolitionists and the Transformation of Race. Cambridge: Harvard University Press, 2009.

Stein, Barbara H. Edge of Crisis: War and Trade in the Spanish Atlantic, 1789-1808. Baltimore: Johns Hopkins University Press, 2009.

Stephanson, Anders. Manifest Destiny: American Expansion and the Empire of Right. New York: Hill \& Wang, 1995.

Stern, Steve J. "Feudalism, Capitalism, and the World-System in the Perspective of Latin America and the Caribbean." The American Historical Review 93, no. 4 (October 1988): 829-872.

Stewart, Watt. “Argentina and the Monroe Doctrine, 1824-1828.” The American Historical Review 10, no. 1 (Feb. 1930): 26-32.

Stinchcombe, Arthur. Sugar Island Slavery in the Age of Enlightenment: Political Economy of the Caribbean World. Princeton: Princeton University Press, 1995. 
Stirling, James. Letters from the Slave States. London: Parker and Son, 1857. Accessed on March 10, 2014. http://books.google.com/books?id=KB3_5mnSvOsC\&vq=cuba\&pg=PR4\#v=onepage\&q\&f=false.

Stolcke, Verena. Marriage, Class and Colour in Nineteenth Century Cuba: A Study of Racial Attitudes and Sexual Values in a Slave Society. Ann Arbor: University of Michigan, 1989.

Stoler, Ann Laura. "Tense and Tender Ties: The Politics of Comparison in North American History and (Post)Colonial Studies.” The Journal of American History 88, no. 3 (December 2001): 829- 865.

Stout, Joseph Allen. The Liberators; Filibustering Expeditions into Mexico, 1848-1862 and the Last Thrust of Manifest Destiny. New York: Westernlore Press, 1973.

Streeby, Shelley. American Sensations: Class, Empire, and the Production of Popular Culture. Sacramento: University of California Press, 2002.

Strout, Cushing. The American Image of the Old World. New York: Harper and Row, 1963.

Suárez, Reinaldo. "Repercusiones de la Constitucion de Cadiz, Guridi Y Alocercer y la Esclaitud en Cuba." Accessed January 10, 2014. http://www.juridicas.unam.mx/publica /rev/hisder/cont/22/art/art19.htm.

Sullivan, Edward. Rambles and Shambles in North and South American. Boston: Carleton Books, 1870.

Syrett, David. England in the Seven Years' War: A Study in Combined Strategy. London: Navy Records Society, 1970.

Tansey, Richard. "Southern Expansionism: Urban Interests in the Cuban Filibusters." Plantation Society in the Americas 1, (June 1979): 227-251.

Tansill, Charles Callan. The United States and Santo Domingoe, 1798-1873. Baltimore: Johns Hopkins University Press, 1938.

Tawil, Ezra. The Making of Racial Sentiment: Slavery and the Birth of the Frontier Romance. Cambridge: Cambridge University Press, 2008.

Taylor, George Rogers. The Transportation Revolution. New York: Holt, Rinehart and Winston, 1951.

Taylor, John Glanville. The United States and Cuba: Eight Years of Change and Travel. London: R. Bentley, 1851.

Taylor William R. “The Launching of a Commercial Culture: New York City 1860-1930.” In Power, Culture and Place: Essays on New York City, edited by John Hull Mollenkopf, 107-134. New York: Russell Sage Foundation, 1988.

Tebbel, John William and Mary Ellen Zuckerman. The Magazine in America, 1741-1990. Oxford: Oxford University Press, 1991.

Temperley, Harold W.V. The Foreign Policy of Canning 1822-1827. Hamden, CT.: The Shoe String Press, 1925.

----. “Capitalism, Slavery and Ideology:” Past \& Present 75 (May 1977): 94-118.

-----. "The Later American Policy of George Canning.” American Historical Review 11 (Summer 1906): 779-797.

-----. The Foreign Policy of Canning 1822-1827. New York: Frank Cass \& co., 1966.

Thomas, Hugh. Cuba: Or The Pursuit of Freedom. New York: Harper and Row Publishers, 1971. 
Thompson, Todd Nathan. "Modest Proposals: American Satire and Political Change from Franklin to Lincoln." PhD diss., University of Illinois, Chicago, 2008.

Thrasher, John and Gaspar Betancourt. Addresses Delivered At the Celebration of the Third Anniversary in Honor Of The Martyrs For Cuban Freedom At The Mechanics' Institute Hall, New Orleans, Sept. 1, 1854. New Orleans: Sherman, Wharton \& Co. 1854.

Tinajero, Pablo Tornero. Crecimiento Económico y Transformaciones Sociales. Esclavos, Hacendados y Comerciantes En La Cuba Colonial: 1760-1840. Madrid: Ministerio de Trabajo y Seguridad Social, 1996.

-----. "Comerciantes, Hacendados y Política Mercantile en Cuba: La Rivalidad Cadiz-Estados Unidos (1763-1800)." Actas de las IV Jornadas de Andalucía y América 1 (1985): 119-145. Accessed on May 15, 2012. http://hdl.handle.net/10334/414.

Tocqueville, Alexis de. Democracy in America. Accessed May 25, 2012. http://xroads.virginia. edu/ HYPER/DETOC/1_ch03.htm.

Tomlins, Christopher. Freedom Bound: Law, Labor, and Civic Identity in Colonizing English America, 1580-1865. New York: Cambridge University Press, 2010.

Tomich, Dale. Through the Prism of Slavery: Labor, Capital and World Economy. New York: Rowman \& Littlefield Publishers, 2005.

----. "Making the Sugar Frontier, Remaking Slavery: Material Processes, Social Practices and the Cuban Ingenio, 1820-1868." Paper presented to the Cornell University Comparative History Colloquium, Ithaca, New York, March 27, 2006.

----. Slavery in the Circuit of Sugar: Martinique and the World Economy, 1830-1848. Baltimore: Johns Hopkins University Press, 1990.

-----. "World Slavery and Caribbean Capitalism: The Cuban Sugar Industry, 1760-1868." Theory and Society 20 (1991): 297-319.

-----. "The Wealth of Empire: Francisco Arango y Parreño, Political Economy, and the Second Slavery in Cuba," Comparative Studies in Society and History 45, no. 1 (January 2003): 4-28.

-----. "Material Process and Industrial Architecture: Innovation on the Cuban Sugar Frontier, 1818-1857." In Nature, Raw Materials, and Political Economy, edited by Paul Ciccantell, Gay Seidman, and David A. Smith, 287307. Amsterdam: JAI / Elsevier, 2005.

Tomich, Dale and Michael Zeuske, eds. "The Second Slavery: Mass Slavery, World-Economy, and Comparative Microhistories, Part I." Review: A Journal of the Fernand Braudel Center 31, no. 2 (2008): 91-100.

Tompkins, Jane P. Sensational Designs: The Cultural Work of American Fiction, 1790-1860. New York: Oxford University Press, 1985.

Topik, Steven. "The World Coffee Market in the Eighteenth and Nineteenth Centuries, from Colonial To National Regimes." Presented to GEHN Conference, London, England, September 2003.

Torre, Parcero. La Perdida de la Habana y Las Reformas Borbonicas en Cuba: 1760-1773. Castille-Leon, Spain: Junta de Castilla y León, Consejería de Educación y Cultura, 1998.

Torrente, Mariana. Slavery in the Island of Cuba. New York: BiblioBazaar, 2008.

Townsend, John. The Doom of Slavery in the Union: Its Safety Out of It. Charleston: Evans and Cogswell, 1860. 
Accessed March 10, 2014. http://books.google.com/books?id=Tv2zlYJa5sC\&vq=cuba\&pg=PA1\#v $=$ onepage $\& \mathrm{q} \& \mathrm{f}=$ false, 24 .

Tracy, Susan Jean. In The Master's Eye Representations of Women, Blacks, And Poor Whites In Antebellum Southern Literature. Amherst: University of Massachusetts Press, 1995.

Train, George Francis. An American Merchant in Europe, Asia, And Australia: A Series Of Letters From Java, Singapore, China, Bengal, Egypt, The Holy Land, The Crimea And Its Battle Grounds, England, Melbourne, Sydney, Etc, Etc. New York: Putnam \& co, 1857. Accessed on March 10, 2014. http://books.google.com/books?id=i--DWHB7ywC\&pg=PR1\#v=onepage\&q\&f=false.

Trefz, Alexander. "Die USA als Modell einer demokratischen Sklavenrepublik: Exilkubaner und die Annexion Kubas an die Vereinigten Staaten, 1848-1856.” PhD diss., Universität Trier, 2012.

Trescot, William. Position and Course of the South. Accessed March 10, 2014. https://archive.org/details/position courseof00tres.

Trouillot, M.R. "Coffee Planters and Coffee Slaves in the Antilles: The Impact of a Secondary Crop." In Cultivation and Culture: Labor and the Shaping of Slave Life in the Americas, edited by Ira Berlin, 124-137. Charlottesville: University of Virginia Press, 1995.

Tschachler, Heinz. The Monetary Imagination of Edgar Allan Poe: Banking, Currency and Politics in the Writings. Durham: McFarland, 2013.

Tuchinsky, Adam-Max, “'The Bourgeoisie Will Fall and Fall Forever:' The New York Tribune, the 1848 French Revolution and American Social Democratic Discourse." Journal of American History 92, no. 2 (September 2005): 470-97.

Turnbull, David. Travels in the West: Cuba; with Notices of Porto Rico and the Slave Trade. London: Longman, Orme, Brown, Green, and Longmans, 1840.

Turner, Mary Carriel. The Life of Jonathan Baldwin Turner. Urbana: University of Illinois Press, 1961.

Turner, Frederick Jackson. The Frontier in American History. Accessed on March 20, 2014. http://www.gutenberg.org/ebooks/22994.

Turner, James and Paul Bernard. "The 'German Model' and the Graduate School: The University of Michigan and the Origin Myth of the American University." In Language, Religion, Knowledge: Past and Present, edited by James Turner, 69-94. South Bend: Notre Dame University Press, 2003.

Tyrrell, Ian. Transnational Nation: United States History in Global Perspective since 1789. New York: Oxford University Press, 2007.

Ullman, James Todd. "Geographies of Desire: Bayard Taylor and the Romance of Travel in Bourgeois American Culture, 1820-1880.” PhD diss., Rutgers University, 2007.

Un Hacendado, (Cristóbal Mádan). Llamamiento de la isla de Cuba a la nacion Española. New York: Estevan Hallet, 1856.

UNESCO. "World Heritage Convention's Archaeological Landscape of the First Coffee Plantations in the SouthEast of Cuba." Accessed on December 23, 2014. http://whc.unesco.org/en/list/1008/.

University College of London. "Legacies of British Slave-ownership.” Accessed January 17, 2014, http://www.ucl.ac.uk/lbs/.

United States Congress. A Century of Lawmaking for a New Nation: U.S. Congressional Documents and Debates, 
1774-1875, Annals of Congress, Eleventh Congress, Third Session: Journal of the Executive Proceedings of the Senate of the United States of America, Volume 2, (January 11, 1811). Accessed on March 10, 2011. http://memory.loc.gov/cgi-bin/query/D?hlaw:1:./temp/ ammem_qDBX, 183.

Urban, C. Stanley, "Urban New Orleans and the Cuban Question during the Lopez Expeditions of 1849-1851: A Local Study in 'Manifest Destiny.”” MA thesis, LSU Agricultural and Mining College, 1936.

----.. "The Ideology of Southern Imperialism: New Orleans and the Caribbean, 1845-1860." Louisiana Historical Quarterly 39, no. 1 (January 1956): 48-73.

-----. "The Africanization of Cuba Scare, 1853-1855." The Hispanic American Historical Review 37, no. 1 (February 1957): 29-45.

Uribe-Uran, Victor M. "The Birth of a Public Sphere in Latin America During the Age of Revolution." Comparative Studies in Society and History 42, no. 2 (April 2000): 425-45.

Urquhart, D. Annexation of Texas: A Case of War Between England and the United States. London: James Maynard, 1844.

Van Alstyne, Richard W. "American Filibustering and the British Navy: A Caribbean Analogue of Mediterranean Piracy.” The American Journal of International Law 32, no. 1 (January 1938): 138-142.

Van Norman, William C. "Shade Grown Slavery: Life and Labor on Coffee Plantations in Western Cuba, 17901845." PhD diss. University of North Carolina at Chapel Hill, 2005.

Varela, Felix. "Consideraciones Sobre El Estado Actual de la Isla de Cuba.” In Felix Varela: Obras, Vol. II Havana: Editorial Cultura Popular, 2001.

Varon, Elizabeth. Disunion! The Coming of the American Civil War, 1789-1859. Chapel Hill: UNC Press, 2008.

Vera-León, Antonio. “Juan Francisco Manzano: el estilo bárbaro de la nación." Hispamérica: Revista de Literature 22, No. 6 (1991): 3-22.

Veysey, Laurence R. The Emergence of the American University. Chicago: University of Chicago Press, 1965.

Villaverde, Cirilo. Cecilia Valdés, or Angel's Hill: A Novel of Cuban Customs. New York: Oxford University Press, 2005.

Viotti da Costa, Emilia. Crowns of Glory, Tears of Blood: The Demerara Slave Rebellion of 1823. New York: Oxford, 1994.

Vitier, Cintio. Lo cubano el la poesía. Santa Clara: Universidad Central de Las Villas, 1958.

Vitier, Cintio ed. La Literatura en el Papel Periódico de la Havana, 1790-1805. Havana: Editorial Letras Cubanas, 1994).

White, G. Edward. "Reflections on the "Republican Revival": Interdisciplinary Scholarship in the Legal Academy," Yale Journal of Law \& the Humanities, 6, Is. 1 (1994): Article 2.

White, Ashli. Encountering Revolution: Haiti and the Making of the Early Republic. Baltimore: Johns Hopkins University Press, 2010.

Weyland, Kurt. "The Diffusion of Revolution: 1848 in Europe and Latin America.” International Organization 63, no. 3 (2009): 391-423.

Watson, Harry L. "The Common Rights of Mankind": Subsistence, Shad, and Commerce in the Early Republican 
South.” The Journal of American History 83, no. 1 (June 1996): 13-43.

Wright, Gavin. "Economic Democracy' and the Concentration of Agricultural Wealth in the Cotton South, 18501860." Agricultural History 44, no. 1 (January 1970): 63-93.

Wetherington, Mark. Plain Folk's Fight: The Civil War and Reconstruction in Piney Woods Georgia. Chapel Hill: UNC Press, 2005.

Williams, Eric. Capitalism and Slavery. Chapel Hill: University of North Carolina Press, 1944.

Wyatt-Brown, Bertram. Honor and Violence in the Old South. New York: Oxford University Press, 1986.

Widmer, Edward L. Young America: The Flowering of Democracy in New York City. New York: Oxford Univ. Press, 1999.

Way, Peter. Common Labor: Workers and the Digging of American's Canals 1780-1860. Baltimore: Johns Hopkins University Press, 1997.

Williams, George. Sketches of Travel in the Old and New World. London: Walker, Evans \& Cosgwell, 1871.

Wilentz, Sean. Chants Democratic: New York City \& The Rise of the American Working Class, 1788-1850. New York: Oxford University Press, 1984.

Wells, Jonathan Daniel. Origins of the Southern Middle Class, 1800-1861. Chapel Hill: University of North Carolina Press, 2004.

Wright, Gavin. Slavery and American Economic Development. Baton Rouge: Louisiana State University Press, 2006.

Waldstreicher, David. In the Midst of Perpetual Fetes: The Making of American, Nationalism, 1776-1820. Chapel Hill: UNC Press, 1997.

Wurdermann, J.G.L. Notes on Cuba. Boston: Littlefield, 1844.

Williams, George W. Sketches of Travel in the Old and New World London: Walker, Evans \& Cosgwell, 1871.

Williams, Claudette. “Cuban Anti-slavery Narrative through Postcolonial Eyes: Gertrudis Gómez de Avellaneda's Sab.” Bulletin of Latin American Research 27, no. 2 (April 2008): 155-175.

Walker, Daniel E. No, More, No, More: Slavery and Cultural Resistance in Havana and New Orleans. Minneapolis: University of Minnesota Press, 2004.

White, Joseph Blanco. Bosquejo del comercio de esclavos y reflexiónes sobre este tráfico considerado moral, política y cristianamente. Accessed on March 23, 2012. http://books.google.com/books/about/Bosquejo_ del_comercio_de_esclavos_y_refl.html?id=127aAAAAMAAJ.

Wexler, Alice R. "Sex, Race and Character in Nineteenth Century American Accounts of Cuba." Caribbean Studies 18, no. 3/4 (October 1978-January 1979): 115-130.

Williams, Lorna Valerie. The Representation of Slavery in Cuban Fiction. Columbia: University of Missouri, 1994.

Williams, Claudette. “Cuban Anti-slavery Narrative through Postcolonial Eyes: Gertrudis Gómez de Avellaneda's Sab." Bulletin of Latin American Research 27, no. 2 (April 2008): 155-175.

Wallace, Edward. General William Jenkins Worth, Monterey’s Forgotten Hero. Dallas: SMU Press, 1953. 
Webster, Daniel. "The Case of Thrasher." In The Works of Daniel Webster, edited by Edward Everett, 523. Boston: Little, Brown and Company, 1890.

Watson, Harry L. Liberty and Power: The Politics of Jacksonian America. New York: Hill and Wang, 1995.

Widmer, Edward L. Young America: The Flowering of Democracy in New York City. Oxford: Oxford University Press, 2000.

Wilson, Thomas William. An Authentic Narrative of the Piratical Descents upon Cuba Made By Hordes From The United States: Headed By Narciso López, A Native Of South America; To Which Are Added, Some Interesting Letters And Declarations From The Prisoners, With A List Of Their Names \&C. Havana: Self Published, 1851.

Wilentz, Sean. The Rise of American Democracy: Jefferson to Lincoln. New York: W. W. Norton \& Company, 2006.

Wallis, John Joseph, Richard E. Sylla, and Arthur Grinath III. "Sovereign Debt and Repudiation: The EmergingMarket Debt Crisis in the U.S. States, 1839-1843.” 2004 NBER Working Paper. Accessed May 30, 2013. http://www.nber. org/papers/w10753;

Whitman, Walt. "American Futurity." In The Gathering of the Forces Vol. 1, edited by Cleveland Rodgers and John Black, 28. New York: G. P. Putnam's Sons, 1920).

Walters, Ronald. The Antislavery Appeal: American Abolitionism after 1830. Baltimore: JHU Press, 1978.

Ward, A.W. ed. The Cambridge History of British Foreign Policy. New York: Macmillan, 1922.

Weber, Jennifer. Copperheads: The Rise and Fall of Lincoln's Opponents in the North. New York: Oxford University Press, 2008.

Weeks, William Earl. John Quincy Adams \& American Global Empire. Lexington: University Press of Kentucky, 1992.

---“John Quincy Adams's 'Great Gun' and the Rhetoric of American Empire.” Diplomatic History 14, no. 1 (January 1990): 25-42.

Weinberg, Albert. Manifest Destiny: A Study of Nationalist Expansionism in American History. Baltimore: JHU Press, 1935.

Wallis, John Joseph. “What Caused the Crisis of 1839?” NBER Historical Working Paper No. 133, April 2001. Accessed May 30, 2013. http://www.nber.org/ papers/h0133.

Whitaker, Arthur Preston. The United States and the Independence of Latin America, 1800-1830. New York, Russell \& Russell. 1962.

----- "Changing and Unchanging Interpretations of the Enlightenment in Spanish America." Proceedings, American Philosophical Society 114, no. 4 (1970): 257-271.

----- ed. Latin America and the Enlightenment. Ithaca: Cornell University Press, 1961.

Wakefield, Roberta. “Some Factors in Cuba's Foreign Trade.” Economic Geography 13, no. 2 (1937): 109-131.

Ward, J.R. British West Indian Slavery, 1750-1834: The Process of Amelioration. New York: Oxford University Press, 1988.Wilson, Peter Hamish. 1848: The Year of Revolutions. New York: Ashgate, 2006.

White, Laura A. “The United States in the 1850's as Seen by British Consuls.” The Mississippi Valley Historical 
Review 19, no. 4 (March 1933): 509-536.

Williams, Eric “Laissez Faire, Sugar and Slavery.” Political Society Quarterly 58, no. 1 (March 1943): 67-85.

Woodward, Ralph Lee. Spanish Commercial Policy in Louisiana, 1763-1803." Louisiana History: The Journal of the Louisiana Historical Association 44, no. 2 (Spring 2003): 133-164.

Wright, J. Leitch. "British Designs on the Old Southwest: Foreign Intrigue on the Florida Frontier, 1783 1803." The Florida Historical Quarterly 44, no. 4 (April 1966): 265-284.

Yamada, Norihito. “George Canning and the Spanish Questions, September 1822 to March 1823.” The Historical Journal 52, no. 2 (2009): 343-362.

Yun, Lisa. The Coolie Speaks: Chinese Indentured Laborers and African Slaves in Cuba. Philadelphia: Temple University Press, 2008.

Yun, Lisa and Ricardo Laremont. "Chinese Coolies and African Slaves in Cuba, 1847-74." Journal of Asian American Studies 4, no. 2 (June, 2001): 99-122.

Zackodnik, Teresa C. The Mulatta and the Politics of Race. Oxford: University Press of Mississippi, 2004.

Zaforteza, Carlos Alfaro. "The Moderado Party and the Introduction of Steam Power in the Spanish Navy, 18441854." War in History 13 (October 2006): 441-67.

Zanetti, Oscar and Alejandro García. Sugar and Railroads: A Cuban History 1837-1959. Chapel Hill: UNC Press, 1998.

Zeuske, Michael. "Alexander von Humboldt y la comparación de las esclavitudes en las Américas.” Humboldt im Netz 6, no. 11 (2005): 65-89.

----. “Humboldt en Cuba, 1800/1801 y 1804 - Huellas de un enigma." Humboldt im Netz 11, no. 20 (2010): 7-19.

-----. “The Amistad: Ramón Ferrer, Cuba, and the Transatlantic Dimensions of Slaving and Contraband Trade.” In Slavery and Antislavery in Spain's Atlantic Empire, edited by Josep M. Fradera and Christopher Schmidt-Nowara. New York: Bergham Books, 2013.

----- “¡Con López a Cuba! Los voluntarios alemanes en la expedición de Narciso López, 1851-1852.” Ibero-Americana Pragensia, (1994): 65-88.

----. “Alexander von Humboldt in Cuba, 1800-01 and 1804: Traces of an Enigma.” Studies in Travel Writing 15, no. 4 (December 2011): 347-358.

----- "Hidden Markers, Open Secrets: On Naming, Race-Marking, And Race-Making in Cuba.” New West Indian Guide 76, no. 3/4 (2002): 211-241.

Ziegler, V. M. “The Revolt of 'The Ever-faithful Isle:”” The Ten Years' War in Cuba, 1868-1878.” PhD diss., University of California, Santa Barbara, 2007.

Ziesche, Philipp. Cosmopolitan Patriots: Americans in Paris in the Age of Revolution. Charlottesville: University of Virginia Press, 2010.

Zogbauma, Heidi. “The Steam Engine in Cuba's Sugar Industry, 1794-1860.” Journal of Iberian and Latin American Research 8, no. 2 (2002): 37-60.

Zorina, Adelaida. "On the Genesis of Capitalism in Nineteenth-Century Cuba." Latin American Perspectives 2 , no. 4, (1975): 7-20. 